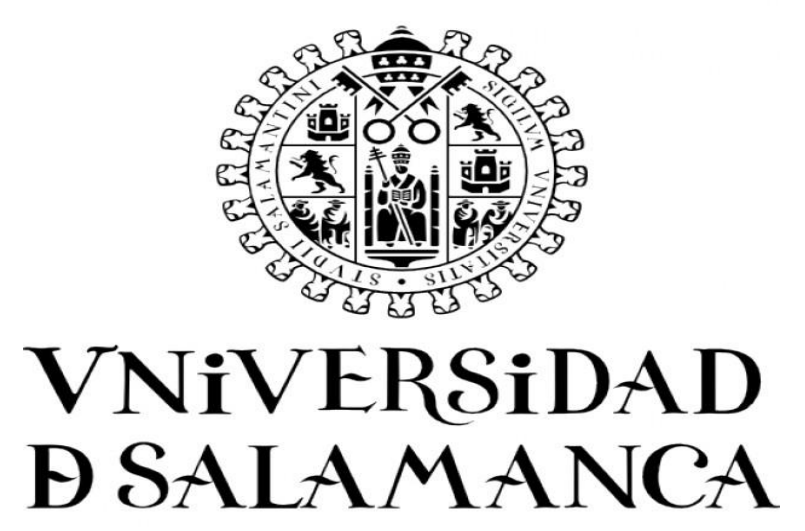

FACULTAD DE PSICOLOGÍA

TESIS DOCTORAL

PERFILES CRIMINALES. UN ESTUDIO DE LA

CONDUCTA CRIMINAL DE LOS ASESINOS EN SERIE

CAROLINA TORRES DELGADO

Director: FRANCISCO JAVIER DE SANTIAGO

HERRERO

Co-Directora: CRISTINA JENARO RÍO

SALAMANCA, 2016 



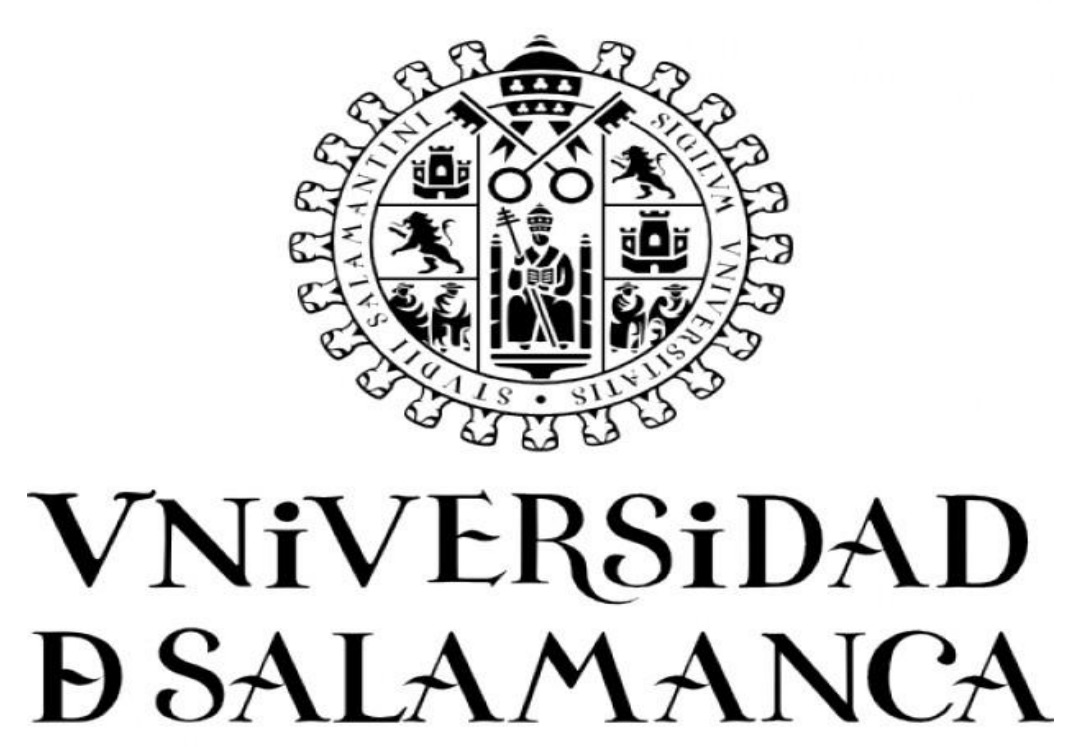

FACULTAD DE PSICOLOGÍA

TESIS DOCTORAL

\section{PERFILES CRIMINALES. UN ESTUDIO DE LA CONDUCTA CRIMINAL DE LOS ASESINOS EN SERIE}

\section{Autora: CAROLINA TORRES DELGADO}

Director: FRANCISCO JAVIER DE SANTIAGO HERRERO

Ayudante Doctor del Departamento de Personalidad, Evaluación y Tratamiento Psicológicos

\section{Co-Directora: CRISTINA JENARO RÍO}

Profesora Titular del Departamento de Personalidad, Evaluación y Tratamiento Psicológicos 

El Dr. Don Francisco Javier de Santiago Herrero, profesor del Departamento de Personalidad, Evaluación y Tratamiento Psicológicos de la Universidad de Salamanca.

\section{CERTIFICA QUE:}

La presente Tesis Doctoral "PERFILES CRIMINALES. UN ESTUDIO DE LA CONDUCTA CRIMINAL DE LOS ASESINOS EN SERIE" reúne, a mi juicio, los méritos suficientes de originalidad y rigor para que la autora pueda optar con ella al título de Doctora.

Y para que así conste, lo firmo en Salamanca a 1 de Abril del 2016

Fdo.: Francisco Javier de Santiago Herrero 



\section{AGRADECIMIENTOS}

En primer lugar quiero agradecer el esfuerzo, sabiduría, empuje y dedicación de mi Director, el Dr. Francisco Javier de Santiago Herrero al que admiro profundamente puesto que no sólo ha constituido un apoyo académico sino también emocional a lo largo de todo el proceso. Asimismo, quiero dar las gracias a la Dra. Cristina Jenaro Río, por su apoyo incondicional.

Deseo expresar también mi agradecimiento a mis padres, Basilio y Carolina y a mi hermano, Javier, por su incansable dedicación, ánimo y motivación ya que nunca dejan que me rinda y constituyen un ejemplo de constancia y trabajo para mí.

Agradecer también a mi futuro marido Alberto, que en todo momento ha estado a mi lado apoyándome, animándome y creyendo en mí, además de ayudarme en todo lo que estuviera de su mano.

Amplío mi agradecimiento a todas aquellas personas que de alguna u otra manera han colaborado para que la presente Tesis Doctoral pudiera desarrollarse de forma óptima, en especial quiero mencionar tanto a María y "su lápiz mágico" como a Inés, ya que sin sus conocimientos el camino recorrido hubiera sido mucho más complicado. También a todos los miembros que conforman la Unidad de Análisis de la Conducta Criminal de la Universidad de Salamanca por su entusiasmo, sabiduría y afán por compartir conocimientos además de la gran ayuda prestada.

Asimismo, expreso mi agradecimiento a todos los miembros de la Asociación Psicoanalítica Kairós, en especial a Alejandra, por esos ratos tan sumamente importantes que me brinda y a María por compartir su amplio conocimiento y entusiasmo en la materia.

Para finalizar, quiero dar las gracias a todas las personas que han colaborado para que esta investigación pudiera llegar a su fin, familia, amigos, compañeros, a todos ellos, muchas gracias. 



\section{ÍNDICE DE CONTENIDOS}

CAPÍTULO 1. DEFINICIÓN Y PERSPECTIVA HISTÓRICA DE LOS

PERFILES CRIMINALES $\ldots \ldots \ldots \ldots \ldots \ldots \ldots \ldots \ldots \ldots \ldots \ldots \ldots \ldots \ldots \ldots \ldots \ldots \ldots \ldots 7$

1.1. DEFINICIÓN DE PERFIL CRIMINOLÓGICO..........................................

1.2. APLICACIÓN Y DESCRIPCIÓN DEL PERFIL CRIMINOLÓGICO....................9

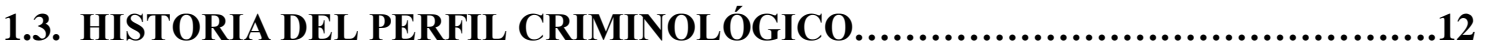

1.3.1. CRIMINALES HISTÓRICOS QUE ORIGINAN LOS PERFILES

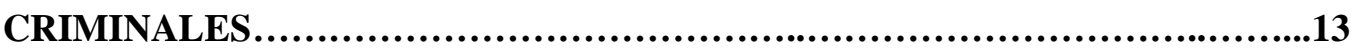

1.3.1.1. JACK EL DESTRIPADOR.............................................13

1.3.1.2. EL BOMBARDERO LOCO...............................................16

1.4. ANTECEDENTES EN EL ESTUDIO DEL PERFIL CRIMINOLÓGICO..................18

1.5. METODOLOGÍAS REFERENCIALES EN LA INVESTIGACIÓN DEL PERFIL

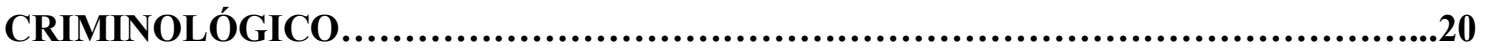

1.5.1. METODOLOGÍA INDUCTIVA................................................21

1.5.2. METODOLOGÍA DEDUCTIVA....................................................26

1.5.3. METODOLOGÍA ABDUCTIVA...................................................27

CAPÍTULO 2. PSICOLOGÍA CRIMINAL_....................................47

2.1. LA PSICOLOGÍA APLICADA AL ÁMBITO JURÍDICO Y DEL DERECHO: RECORRIDO HISTÓRICO......................................................................47

2.2. DELIMITACIÓN TERMINOLÓGICA....................................................54

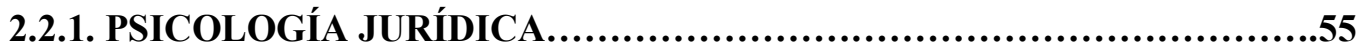

2.2.2. PSICOLOGÍA FORENSE.....................................................56

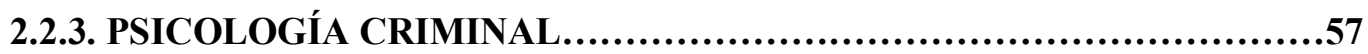


2.2.4. CRIMINOLOGÍA Y CRIMINALÍSTICA................................59

2.3. ÁREAS DE ESTUDIO CRIMINOLÓGICO...................................60

2.4. CONTRIBUCIÓN DE LOS ÁMBITOS DE LA PSICOLOGÍA AL ESTUDIO DE

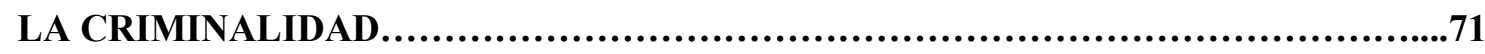

2.4.1. PSICOLOGÍA EVOLUTIVA............................................71

2.4.2. PSICOLOGÍA SOCIAL...............................................72

2.4.3. PSICOLOGÍA BIOLÓGICA.............................................73

2.4.4. PSICOLOGÍA DEL COMPORTAMIENTO.............................75

2.5. TEORÍAS SOCIOLÓGICAS DEL CRIMEN....................................76

2.5.1. ESCUELA DE CHICAGO...........................................76

2.5.2. TEORÍAS ORIGINADAS A RAÍZ DE LA ESCUELA DE CHICAGO......77 2.6. EVALUACIÓN Y DISTRIBUCIÓN DEL DELITO.................................84

2.6.1. ESTADÍSTCIAS OFICIALES........................................84

2.6.2. ENCUESTAS DE VICTIMIZACIÓN...................................85

2.7. ESTUDIOS SOBRE CRIMINALIDAD EN ESPAÑA..........................86

2.8. ESTUDIOS SOBRE CRIMINALIDAD INTERNACIONAL .......................91

CAPÍTULO 3. RECORRIDO HISTÓRICO-CRÍTICO DEL CONCEPTO DE

PSICOPATÍA..............................................................97

3.1. ANTECEDENTES (PRIMERAS PREFIGURACIONES)..........................97

3.1.1. ESBOZO DEL TÉRMINO PSICOPATÍA................................97

3.1.2. PRIMERAS CLASIFICACIONES Y TIPOLOGÍAS DE LA

PSICOPATÍA................................................................102

3.2. DESCRIPCIÓN, DEFINICIÓN Y CRITERIOS DIAGNÓSTICOS DE

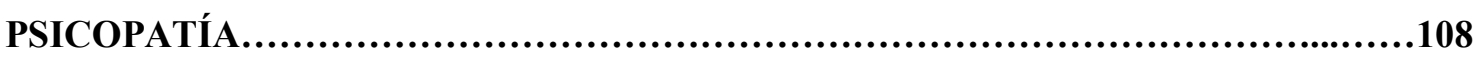


3.2.1. NOSOLOGÍAS ACTUALES................................................115

3.2.1.1. CLASIFICACIÓN APA............................................115

3.2.1.2. CLASIFICACIÓN OMS..........................................117

3.2.1.3. SÍNTESIS DE LAS CARACTERÍSTCIAS DIFERENCIALES

DE LA PSICOPATÍA..................................................118

3.2.1.4. LA ENTREVISTA CON EL PSICÓPATA.......................121

3.2.2. EL MODELO DIMENSIONAL DE BLACKBURN (1996).................123

3.2.3. DIFERENCIA ENTRE PSICÓPATA. TRASTORNO DISOCIAL Y

TRASTORNO ANTISOCIAL ..............................................124

3.2.4. LOS PSICÓPATAS ADAPTADOS INTEGRADOS......................126

3.2.5. PREVALENCIA DE LA PSICOPATÍA................................130

3.3. APORTACIONES PSICOANALÍTICAS AL ESTUDIO DE LA PSICOPATÍA.....130

3.3.1. LAS PSICOPATÍAS Y LAS CONDUCTAS ANTISOCIALES..............135

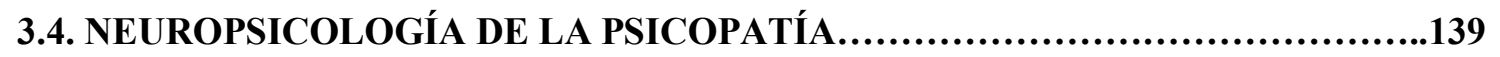

3.4.1. SUSTRATO NEUROLÓGIVO DE LA FUNCIÓN EJECUTIVA: LA CORTEZA PREFRONTAL.................................................139

3.4.2. SÍNDROMES PRINCIPALES DEFINITORIOS EN PSICOPATÍA........141

3.4.2.1. FUNCIÓN EJECUTIVA: SÍNDROME DISEJECUTIVO..........141

3.4.2.2. SÍNDROME PREFRONTAL ORBITAL........................145

3.4.3. OTRAS ESTRUCTURAS ANATÓMICAS IMPLICADAS EN LA

PSICOPATÍA.............................................................147

3.4.4. ASPECTOS HORMONALES Y NEUROQUÍMICOS IMPLICADOS EN

LA PSICOPATÍA.......................................................150

3.4.5. GENÉTICA VS. AMBIENTE.......................................151

3.4.6. INVESTIGACIONES REALIZADAS CON TÉCNICAS DE

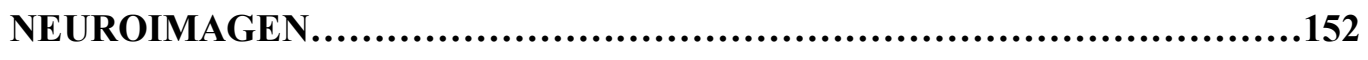

3.4.7. INVESTIGACIONES ACTUALES RESPECTO DE LA ESTRUCTURA

NEURAL DE LA MENTE AMORAL.......................................156 
3.4.8. CASOS FUNDAMENTALES EN EL ESTUDIO NEUROPSICOLÓGICO DE LA PSICOPATÍA..........................................................160

CAPÍTULO 4. ASESINOS EN SERIE.......................................165

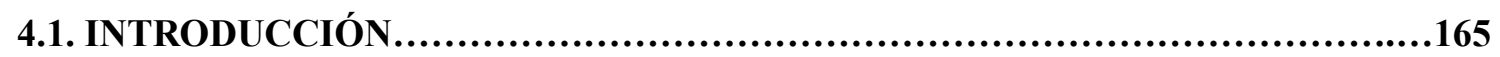

4.2. CONCEPTO DE ASESINO EN SERIE........................................167

4.2.1. ASESINO EN MASA.....................................................167

4.2.2. ASESINO FRENÉTICO................................................169

4.2.3. ASESINO EN SERIE....................................................170

4.3. CARACTERÍSTICAS DE LOS ASESINOS EN SERIE...........................171

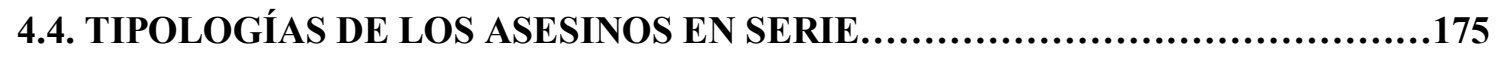

4.5. INFANCIA DE LOS ASESINOS EN SERIE................................183

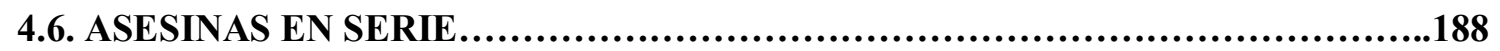

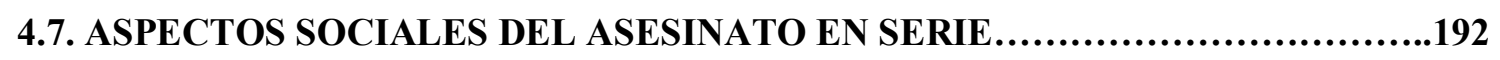

CAPÍTULO 5. MARCO METODOLÓGIVO DEL ESTUDIO SOBRE

ASESINOS EN SERIE...................................................199

5.1. OBJETO DE ESTUDIO Y UNIDAD DE ANÁLISIS..............................199

5.2. TÉCNCIAS DE INVESTIGACIÓN................................................202

5.2.1. REVISIÓN SISTEMÁTICA DE UNA RECOGIDA DE DATOS

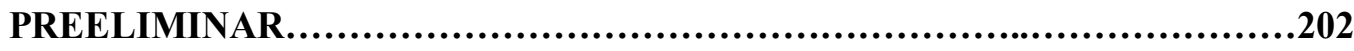

5.2.2. FICHA DE VARIABLES.............................................203

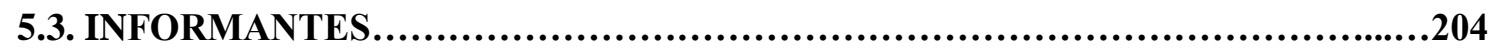

5.3.1. SELECCIÓN DE INFORMANTES Y ACCESO.............................204 
5.3.2. PERFIL DE LOS INFORMANTES....................................205

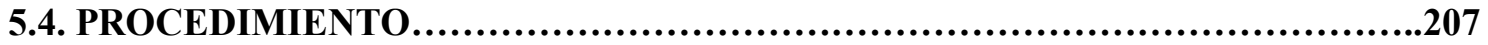

5.4.1. ÁMBITO GEOGRÁFICO...........................................207

5.4.2. PERÍODO CRONOLÓGICO DE INVESTIGACIÓN......................207

CAPÍTULO 6. ESTUDIO COMPARATIVO DE UNA MUESTRA DE ASESINOS EN SERIE QUE ACTUARON ES ESPAÑA Y EN AMÉRICA DEL NORTE....209

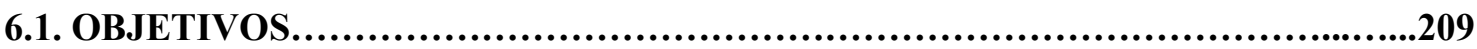

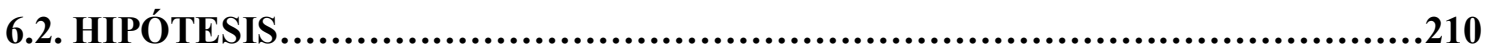

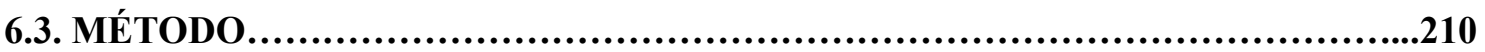

6.3.1. INFORMANTES............................................................210

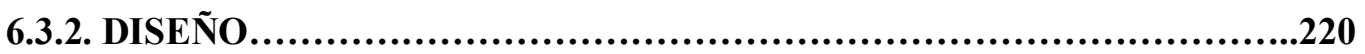

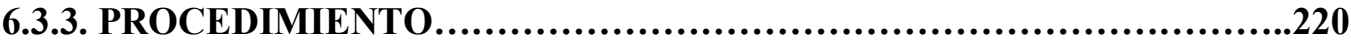

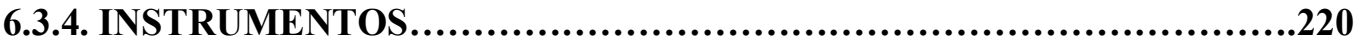

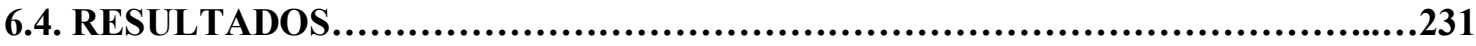

6.4.1. ESTUDIO DESCRIPTIVO DE LA MUESTRA.........................231

6.4.2. ESTUDIO NO PARAMÉTRICO DE LA MUESTRA......................281

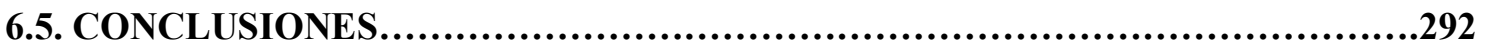

CAPÍTULO 7. ESTUDIO DE UNA MUESTRA INTERNACIONAL DE

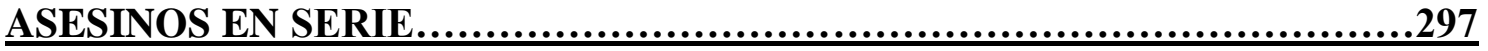

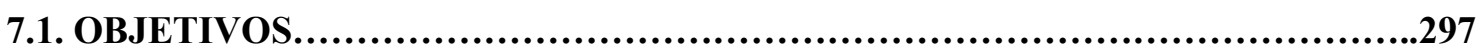

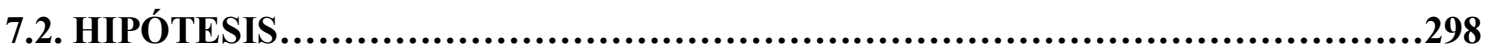

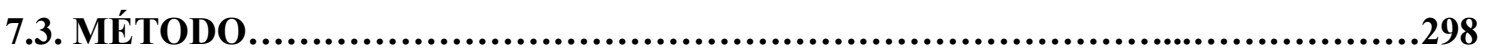


7.3.1. INFORMANTES......................................................298

7.3.2. DISEÑO

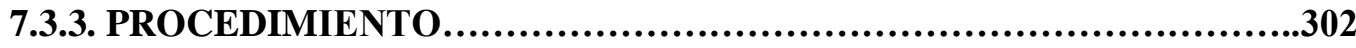

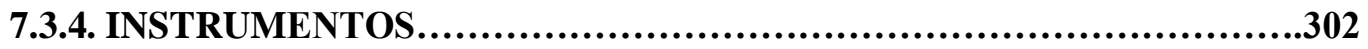

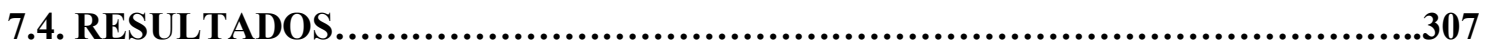

7.4.1. ESTUDIO DESCRIPTIVO DE LA MUESTRA............................307

7.4.2. ESTUDIO NO PARAMÉTRICO.........................................314

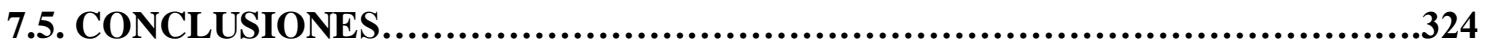

DISCUSIÓN Y CONCLUSIONES FINALES.................................327

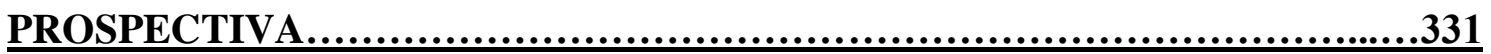

REFERENCIAS BIBLIOGRÁFICAS $\ldots \ldots \ldots \ldots \ldots \ldots \ldots \ldots \ldots \ldots \ldots \ldots \ldots \ldots \ldots \ldots \ldots \ldots . \ldots \ldots 33$

ANEXO 1. GUÍA DE CODIFICACIÓN DE LA UNIDAD DE ANÁLISIS DE LA

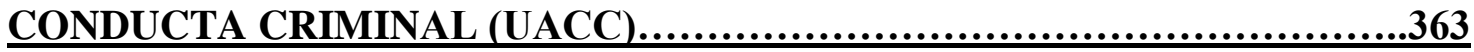

$\underline{\text { ANEXO 2. FICHA DE VARIABLES DEL ESTUDIO COMPARATIVO.........387 }}$

ANEXO 3. FICHA DE VARIABLES DEL ESTUDIO INTERNACIONAL......397 


\section{ÍNDICE DE TABLAS}

TABLA 1. RECOPILACIÓN Y CODIFICACIÓN DE DATOS ...........................................

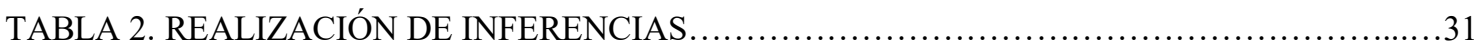

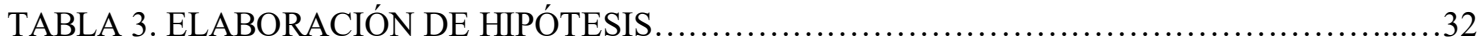

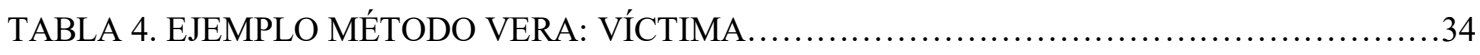

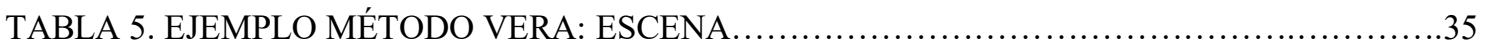

TABLA 6. EJEMPLO MÉTODO VERA: RECONSTRUCCIÓN DEL DELITO............................

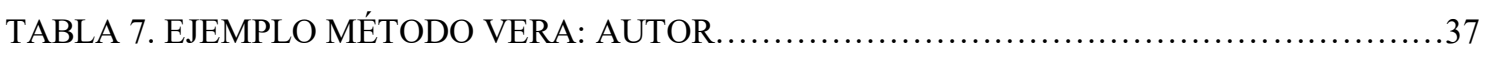

TABLA 8. EJEMPLO MÉTODO VERA: INFERENCIAS VÍCTIMA..................................38

TABLA 9. EJEMPLO MÉTODO VERA: INFERENCIAS ESCENA...................................

TABLA 10. EJEMPLO MÉTODO VERA: INFERENCIAS RECONSTRUCCIÓN DE LOS

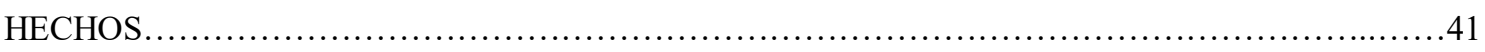

TABLA 11. EJEMPLO MÉTODO VERA: INFERENCIAS AUTOR..................................43

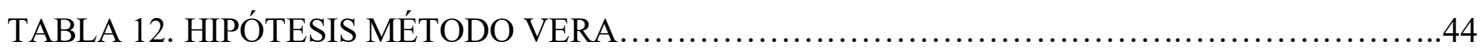

TABLA 13. SUBESPECIALIDADES DE LA PSICOLOGÍA JURÍDICA ..........................56

TABLA 14. FUENTES DE TENSIÓN HABITUALES EN LAS SOCIEDADES

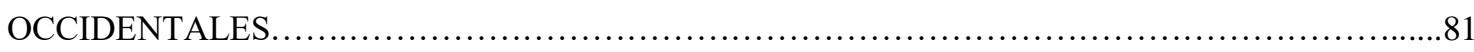

TABLA 15. EVOLUCIÓN DE LAS PERSONAS CONDENADAS ADULTAS (2007-2013)............ 87

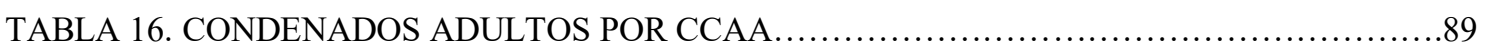

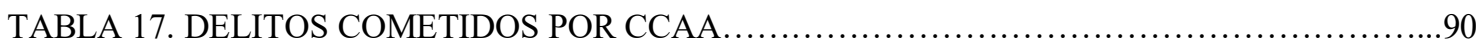

TABLA 18. LAS PERSONALIDADES PSICOPÁTICAS ......................................... 105

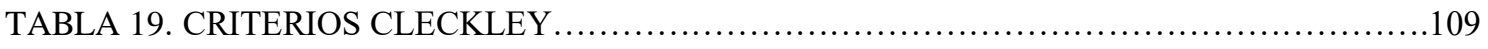

TABLA 20. MODELO DE LOS CUATRO FACTORES DE HARE ................................112

TABLA 21. CRITERIOS DIAGNÓSTICOS DEL TRASTORNO DE PERSONALIDAD

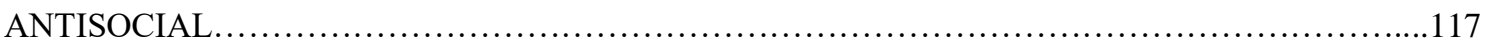

TABLA 22. TRASTORNO DISOCIAL DE LA PERSONALIDAD ...................................118

TABLA 23. TABLA DIFERENCIADORA DE SÍNTOMAS.........................................

TABLA 24. RASGOS DE LIDERAZGO VS. RASGOS PSICOPÁTICOS..............................129 
TABLA 25. SÍNTEIS DE LOS PRINCIPALES HALLAZGOS SOBRE LA BASE NEURAL DE LA CONDUCTA AMORAL

TABLA 26. DIFERENCIACIÓN DE ESCENAS EN CUANTO A CARACTERÍSTCIAS DE LOS SUJETOS

TABLA 27. DIFERENCIACIÓN DE ESCENAS EN CUANTO A LA EVIDENCIA DE PLANIFICACIÓN.

TABLA 28. DIFERENCIACIÓN DE ESCENAS EN CUANTO A LA VIOLENCIA EJERCIDA SOBRE LAS VÍCTIMAS. . 180

TABLA 29. DIFERENCIACIÓN DE ESCENAS EN CUANTO A LA RELACIÓN VÍCTIMAAGRESOR

TABLA 30. ESQUEMA GENERAL DEL PROCESO DE INVESTIGACIÓN .200

TABLA 31. DISTRIBUCIÓN DE FRECUENCIAS DE LA VARIABLE SEXO EN CADA ZONA DE ACTUACIÓN.

TABLA 32. ESTADÍSTICOS DESCRIPTIVOS DE LA VARIABLE AÑO DE NACIMIENTO DE LOS ASESINOS EN SERIE QUE ACTUARON EN ESPÑA.

TABLA 33. ESTADÍSTICOS DESCRIPTIVOS DE LA VARIABLE AÑO DE NACIMIENTO DE LOS ASESINOS EN SERIE QUE ACTUARON EN AMÉRICA DEL NORTE.

TABLA 34. ESTADÍSTICOS DESCRIPTIVOS DE LA VARIABLE EDAD DE INICIO DE LOS ASESINATOS DE LOS ASESINOS EN SERIE QUE ACTUARON EN ESPAÑA.

TABLA 35. ESTADÍSTICOS DESCRIPTIVOS DE LA VARIABLE EDAD DE INICIO DE LOS ASESINATOS DE LOS ASESINOS EN SERIE QUE ACTUARON EN AMÉRICA DEL NORTE

TABLA 36. DISTRIBUCIÓN DE FRECUENCIAS DE LA VARIABLE PERÍODO DE ACTUACIÓN EN CADA ZONA DE ACTUACIÓN

TABLA 37. DISTRIBUCIÓN DE FRECUENCIAS DE LA VARIABLE ESTADO CIVIL EN CADA ZONA DE ACTUACIÓN.

TABLA 38. DISTRIBUCIÓN DE FRECUENCIAS DE LA VARIABLE ORIENTACIÓN SEXUAL EN CADA ZONA DE ACTUACIÓN.

TABLA 39. DISTRIBUCIÓN DE FRECUENCIAS DE LA VARIABLE COMPLEXIÓN EN CADA ZONA DE ACTUACIÓN.

TABLA 40. DISTRIBUCIÓN DE FRECUENCIAS DE LA VARIABLE NIVEL INTELECTUAL EN CADA ZONA DE ACTUACIÓN. 
TABLA 41. DISTRIBUCIÓN DE FRECUENCIAS DE LA VARIABLE RASGOS PSICOPÁTICOS EN CADA ZONA DE ACTUACIÓN.

TABLA 42. DISTRIBUCIÓN DE FRECUENCIAS DE LA VARIABLE IMPLICACIÓN EN LA VIDA SOCIAL EN CADA ZONA DE ACTUACIÓN.

TABLA 43. DISTRIBUCIÓN DE FRECUENCIAS DE LA VARIABLE HABER SUFRIDO ALGÚN TIPO DE MALTRATO EN LA INFANCIA EN CADA ZONA DE ACTUACIÓN.

TABLA 44. DISTRIBUCIÓN DE FRECUENCIAS DE LA VARIABLE HABER SUFRIDO ALGÚN TIPO DE MALTRATO EN LA EDAD ADULTAEN CADA ZONA DE ACTUACIÓN. .236

TABLA 45. DISTRIBUCIÓN DE FRECUENCIAS DE LA VARIABLE PATOLOGÍA MENTAL EN CADA ZONA DE ACTUACIÓN....

TABLA 46. DISTRIBUCIÓN DE FRECUENCIAS DE LA VARIABLE ANTECEDENTES POLICIALES EN CADA ZONA DE ACTUACIÓN

TABLA 47. ESTADÍSTICOS DESCRIPTIVOS DE LA VARIABLE NÚMERO DE CRÍMENES DE LOS ASESINOS EN SERIE QUE ACTUARON EN ESPAÑA.

TABLA 48. ESTADÍSTICOS DESCRIPTIVOS DE LA VARIABLE NÚMERO DE CRÍMENES DE LOS ASESINOS EN SERIE QUE ACTUARON EN AMÉRICA DEL NORTE

TABLA 49. DISTRIBUCIÓN DE FRECUENCIAS DE LA VARIABLE NIVEL DE PLANIFICACIÓN EN CADA ZONA DE ACTUACIÓN.

TABLA 50. DISTRIBUCIÓN DE FRECUENCIAS DE LA VARIABLE MÉTODO DE APROXIMACIÓN EN CADA ZONA DE ACTUACIÓN.

TABLA 51. DISTRIBUCIÓN DE FRECUENCIAS DE LA VARIABLE TIPO DE ARMAS Y UTENSILIOS EMPLEADOS EN CADA ZONA DE ACTUACIÓN.

TABLA 52. DISTRIBUCIÓN DE FRECUENCIAS DE LA VARIABLE FORMA DE CAUSAR LA MUERTE EN CADA ZONA DE ACTUACIÓN.

TABLA 53. DISTRIBUCIÓN DE FRECUENCIAS DE LA VARIABLE INTERACCIÓN VERBAL CON LAS VÍCTIMAS EN CADA ZONA DE ACTUACIÓN

TABLA 54. DISTRIBUCIÓN DE FRECUENCIAS DE LA VARIABLE RELACIONES SEXUALES CON LAS VÍCTIMAS ANTE-MORTEM EN CADA ZONA DE ACTUACIÓN

TABLA 55. DISTRIBUCIÓN DE FRECUENCIAS DE LA VARIABLE RELACIONES SEXUALES CON LAS VÍCTIMAS POST-MORTEM EN CADA ZONA DE ACTUACIÓN 
TABLA 56. DISTRIBUCIÓN DE FRECUENCIAS DE LA VARIABLE PENETRACIÓN EN LAS RELACIONES SEXUALES EN CADA ZONA DE ACTUACIÓN

TABLA 57. DISTRIBUCIÓN DE FRECUENCIAS DE LA VARIABLE CONDUCTAS SÁDICAS Y DE TORTURA EN CADA ZONA DE ACTUACIÓN.

TABLA 58. DISTRIBUCIÓN DE FRECUENCIAS DE LA VARIABLE CANIBALISMO EN

CADA ZONA DE ACTUACIÓN. 251

TABLA 59. DISTRIBUCIÓN DE FRECUENCIAS DE LA VARIABLE MUTILACIÓN EN CADA ZONA DE ACTUACIÓN.

TABLA 60. DISTRIBUCIÓN DE FRECUENCIAS DE LA VARIABLE TOMA DE TROFEOS DE SUS CRÍMENES EN CADA ZONA DE ACTUACIÓN.

TABLA 61. ESTADÍSTICOS DESCRIPTIVOS DE LA VARIABLE NÚMERO DE VÍCTIMAS TOTAL DE LOS ASESINOS SERIALES QUE ACTUARON EN ESPAÑA

TABLA 62. ESTADÍSTICOS DESCRIPTIVOS DE LA VARIABLE NÚMERO DE VÍCTIMAS TOTAL DE LOS ASESINOS SERIALES QUE ACTUARON EN AMÉRICA DEL NORTE. 255

TABLA 63. DISTRIBUCIÓN DE FRECUENCIAS DE LA VARIABLE SELECCIÓN DE LAS VÍCTIMAS EN CADA ZONA DE ACTUACIÓN.

TABLA 64. DISTRIBUCIÓN DE FRECUENCIAS DE LA VARIABLE TIPO I (FBI) EN CADA ZONA DE ACTUACIÓN. .257

TABLA 65. DISTRIBUCIÓN DE FRECUENCIAS DE LA VARIABLE TIPO II (CANTER Y SALFATI) EN CADA ZONA DE ACTUACIÓN.

TABLA 66. DISTRIBUCIÓN DE FRECUENCIAS DE LA VARIABLE TIPO III (HOLMES Y DEBERGUER) EN CADA ZONA DE ACTUACIÓN

TABLA 67. DISTRIBUCIÓN DE FRECUENCIAS DE LA VARIABLE TIPO IV (FOX Y LEVIN) EN CADA ZONA DE ACTUACIÓN....

TABLA 68. DISTRIBUCIÓN DE FRECUENCIAS DE LA VARIABLE TIPO V (CANTER) EN CADA ZONA DE ACTUACIÓN.

TABLA 69. DISTRIBUCIÓN DE FRECUENCIAS DE LA VARIABLE TIPO VI (ROSSMO) EN CADA ZONA DE ACTUACIÓN.

TABLA 70. DISTRIBUCIÓN DE FRECUENCIAS DE LAS VARIABLES HABER SUFRIDO ALGÚN TIPO DE MALTRATO EN LA INFANCIA Y PATOLOGÍA MENTAL EN ASESINOS SERIALES QUE ACTUARON EN AMÉRICA DEL NORTE. 
TABLA 71. DISTRIBUCIÓN DE FRECUENCIAS DE LAS VARIABLES HABER SUFRIDO ALGÚN TIPO DE MALTRATO EN LA INFANCIA Y PATOLOGÍA MENTAL EN ASESINOS SERIALES QUE ACTUARON EN ESPAÑA

TABLA 72. DISTRIBUCIÓN DE FRECUENCIAS DE LAS VARIABLES NIVEL DE PLANIFICACIÓN Y ESTADO CIVIL EN ASESINOS SERIALES QUE ACTUARON EN AMÉRICA DEL NORTE

TABLA 73. DISTRIBUCIÓN DE FRECUENCIAS DE LAS VARIABLES NIVEL DE PLANIFICACIÓN Y ESTADO CIVIL EN ASESINOS SERIALES QUE ACTUARON EN ESPAÑA.

TABLA 74. DISTRIBUCIÓN DE FRECUENCIAS DE LAS VARIABLES NIVEL DE PLANIFICACIÓN Y NIVEL INTELECTUAL EN ASESINOS SERIALES QUE ACTUARON EN AMÉRICA DEL NORTE

TABLA 75. DISTRIBUCIÓN DE FRECUENCIAS DE LAS VARIABLES NIVEL DE PLANIFICACIÓN Y NIVEL INTELECTUAL EN ASESINOS SERIALES QUE ACTUARON EN ESPAÑA

TABLA 76. DISTRIBUCIÓN DE FRECUENCIAS DE LAS VARIABLES INTERACCIÓN VERBAL CON LAS VÍCTIMAS Y FORMA DE CAUSAR LA MUERTE EN ASESINOS SERIALES QUE ACTUARON EN AMÉRICA DEL NORTE. .273

TABLA 77. DISTRIBUCIÓN DE FRECUENCIAS DE LAS VARIABLES INTERACCIÓN VERBAL CON LAS VÍCTIMAS Y FORMA DE CAUSAR LA MUERTE EN ASESINOS SERIALES QUE ACTUARON EN ESPAÑA. .274

TABLA 78. DISTRIBUCIÓN DE FRECUENCIAS DE LAS VARIABLES INTERACCIÓN VERBAL CON LAS VÍCTIMAS Y CONDUCTAS SÁDICAS Y DE TORTURA EN ASESINOS SERIALES QUE ACTUARON EN AMÉRICA DEL NORTE.

TABLA 79. DISTRIBUCIÓN DE FRECUENCIAS DE LAS VARIABLES INTERACCIÓN VERBAL CON LAS VÍCTIMAS Y CONDUCTAS SÁDICAS Y DE TORTURA EN ASESINOS SERIALES QUE ACTUARON EN ESPAÑA

TABLA 80. DISTRIBUCIÓN DE FRECUENCIAS DE LAS VARIABLES CONDUCTAS SÁDICAS Y DE TORTURA Y FORMA DE CAUSAR LA MUERTE EN ASESINOS SERIALES QUE ACTUARON EN AMÉRICA DEL NORTE.

TABLA 81. DISTRIBUCIÓN DE FRECUENCIAS DE LAS VARIABLES CONDUCTAS SÁDICAS Y DE TORTURA Y FORMA DE CAUSAR LA MUERTE EN ASESINOS SERIALES QUE ACTUARON EN ESPAÑA 
TABLA 82. DISTRIBUCIÓN DE FRECUENCIAS DE LAS VARIABLES MUTILACIÓN Y CANIBALISMO EN ASESINOS SERIALES QUE ACTUARON EN AMÉRICA DEL NORTE

TABLA 83. DISTRIBUCIÓN DE FRECUENCIAS DE LAS VARIABLES MUTILACIÓN Y CANIBALISMO EN ASESINOS SERIALES QUE ACTUARON EN ESPAÑA

TABLA 84. DISTRIBUCIÓN DE FRECUENCIAS DE LA VARIABLE NIVEL INTELECTUAL EN CADA ZONA DE ACTUACIÓN

TABLA 85. PRUEBAS CHI CUADRADO DE LA VARIABLE NIVEL INTELECTUAL EN CADA ZONA DE ACTUACIÓN.

TABLA 86. COEFICIENTE DE CORRELACIÓN DE LA VARIABLE NIVEL INTELECTUAL EN CADA ZONA DE ACTUACIÓN.

TABLA 87. DISTRIBUCIÓN DE FRECUENCIAS DE LA VARIABLE PATOLOGÍA MENTAL EN CADA ZONA DE ACTUACIÓN

TABLA 88. PRUEBAS CHI CUADRADO DE LA VARIABLE PATOLOGÍA MENTAL EN CADA ZONA DE ACTUACIÓN.

TABLA 89. COEFICIENTES DE CONTINGENCIA DE LA VARIABLE PATOLOGÍA MENTAL EN CADA ZONA DE ACTUACIÓN

TABLA 90. DISTRIBUCIÓN DE FRECUENCIAS DE LA VARIABLE HABER SUFRIDO ALGÚN TIPO DE MALTRATO EN LA INFANCIA EN CADA ZONA DE ACTUACIÓN.

TABLA 91. PRUEBAS DE CHI CUADRADO DE LA VARIABLE HABER SUFRIDO ALGÚN TIPO DE MALTRATO EN LA INFANCIA EN CADA ZONA DE ACTUACIÓN.

TABLA 92. COEFICIENTES DE CORRELACIÓN DE LA VARIABLE HABER SUFRIDO ALGÚN TIPO DE MALTRATO EN LA INFANCIA EN CADA ZONA DE ACTUACIÓN.

TABLA 93. DISTRIBUCIÓN DE FRECUENCIAS DE LA VARIABLE INTERACCIÓN VERBAL CON LAS VÍCTIMAS EN CADA ZONA DE ACTUACIÓN.

TABLA 94. PRUEBAS CHI CUADRADO DE LA VARIABLE INTERACCIÓN VERBAL

CON LAS VÍCTIMAS EN CADA ZONA DE ACTUACIÓN.

TABLA 95. COEFICIENTE DE CONTINGENCIA DE LA VARIABLE INTERACCIÓN VERBAL CON LAS VÍCTIMAS EN CADA ZONA DE ACTUACIÓN.

TABLA 96. DISTRIBUCIÓN DE FRECUENCIAS DE LA VARIABLE CONDUCTAS SÁDICAS Y DE TORTURA EN CADA ZONA DE ACTUACIÓN 
TABLA 97. PRUEBAS CHI CUADRADO DE LA VARIABLE CONDUCTAS SÁDICAS Y DE TORTURA EN CADA ZONA DE ACTUACIÓN.

TABLA 98. COEFICIENTES DE CONTINGENCIA DE LA VARIABLE CONDUCTAS SÁDICAS Y DE TORTURA EN CADA ZONA DE ACTUACIÓN.

TABLA 99. DISTRIBUCIÓN DE FRECUENCIAS DE LA VARIABLE MUTILACIÓN EN CADA ZONA DE ACTUACIÓN.

TABLA 100. PRUEBAS CHI CUADRADO DE LA VARIABLE MUTILACIÓN EN CADA

ZONA DE ACTUACIÓN.

TABLA 101. COEFICIENTES DE CONTINGENCIA DE LA VARIABLE MUTILACIÓN EN CADA ZONA DE ACTUACIÓN.

TABLA 102. DISTRIBUCIÓN DE FRECUENCIAS DE LA VARIABLE RELACIONES SEXUALES CON LAS VÍCTIMAS POST-MORTEM EN CADA ZONA DE ACTUACIÓN

TABLA 103. PRUEBAS CHI CUADRADO DE LA VARIABLE RELACIONES SEXUALES CON LAS VÍCTIMAS POST-MORTEM EN CADA ZONA DE ACTUACIÓN.

TABLA 104. COEFICIENTES DE CONTINGENCIA DE LA VARIABLE RELACIONES SEXUALES CON LAS VÍCTIMAS POST-MORTEM EN CADA ZONA DE ACTUACIÓN.

TABLA 105. DISTRIBUCIÓN DE FRECUENCIAS DE LA VARIABLE TIPO I (FBI) EN CADA ZONA DE ACTUACIÓN.

TABLA 106. PRUEBAS CHI CUADRADO DE LA VARIABLE TIPO I (FBI) EN CADA ZONA DE ACTUACIÓN

TABLA 107. COEFICIENTE DE CONTINGENCIA DE LA VARIABLE TIPO I (FBI) EN CADA ZONA DE ACTUACIÓN.

TABLA 108. DISTRIBUCIÓN DE FRECUENCIAS DE LA VARIABLE PAÍS DE PROCEDENCIA DE LOS ASESINOS SERIALES. .298

TABLA 109. DISTRIBUCIÓN DE FRECUENCIAS DE LA VARIABLE SEXO DE LOS ASESINOS EN SERIE

TABLA 110. ESTADÍSTICOS DESCRIPTIVOS DE LA VARIABLE EDAD DE INICIO DE LOS ASESINATOS DE LOS ASESINOS EN SERIE.

TABLA 111. DISTRIBUCIÓN DE FRECUENCIAS DE LA VARIABLE RASGOS PSICOPÁTICOS DE LOS ASESINOS EN SERIE. 
TABLA 112. DISTRIBUCIÓN DE FRECUENCIAS DE LA VARIABLE HABER SUFRIDO ALGÚN TIPO DE MALTRATO EN LA INFANCIA DE LOS ASESINOS EN

SERIE 308

TABLA 113. ESTADÍSTICOS DESCRIPTIVOS DE LA VARIABLE NÚMERO DE CRÍMENES DE LOS ASESINOS EN SERIE.

TABLA 114. DISTRIBUCIÓN DE FRECUENCIAS DE LA VARIABLE NIVEL DE PLANIFICACIÓN DE LOS ASESINOS EN SERIE. 310

TABLA 115. DISTRIBUCIÓN DE FRECUENCIAS DE LA VARIABLE FORMA DE CAUSAR LA MUERTE DE LOS ASESINOS EN SERIE.

TABLA 116. DISTRIBUCIÓN DE FRECUENCIAS DE LA VARIABLE RELACIONES SEXUALES CON LAS VÍCTIMAS ANTE-MORTEM DE LOS ASESINOS EN SERIE

TABLA 117. DISTRIBUCIÓN DE FRECUENCIAS DE LA VARIABLE RELACIONES SEXUALES CON LAS VÍCTIMAS POST-MORTEM EN LOS ASESINOS EN SERIE.

TABLA 118. DISTRIBUCIÓN DE FRECUENCIAS DE LA VARIABLE TIPO I (FBI) DE LOS ASESINOS EN SERIE.

TABLA 119. DISTRIBUCIÓN DE FRECUENCIAS DE LAS VARIABLES NIVEL DE PLANIFICACIÓN Y SEXO DE LOS ASESINOS EN SERIE

TABLA 120. PRUEBAS CHI CUADRADO DE LAS VARIABLES NIVEL DE PLANIFICACIÓN Y SEXO DE LOS ASESINOS EN SERIE

TABLA 121. COEFICIENTE DE CONTINGENCIA DE LAS VARIABLES NIVEL DE PLANIFICACIÓN Y SEXO DE LOS ASESINOS EN SERIE

TABLA 122. DISTRIBUCIÓN DE FRECUENCIAS DE LAS VARIABLES RELACIONES

SEXUALES CON LAS VÍCTIMAS

TABLA 123. PRUEBAS CHI CUADRADO DE LAS VARIABLES RELACIONES SEXUALES CON LAS VÍCTIMAS ANTE-MORTEM Y EL SEXO DE LOS ASESINOS EN SERIE

TABLA 124. COEFICIENTES DE CONTINGENCIA DE LAS VARIABLES RELACIONES SEXUALES CON LAS VÍCTIMAS ANTE-MORTEM Y EL SEXO DE LOS ASESINOS

TABLA 125. DISTRIBUCIÓN DE FRECUENCIAS DE LAS VARIABLES HABER SUFRIDO ALGÚN TIPO DE MALTRATO EN LA INFANCIA Y EL CONTINENTE DE PROCEDENCIA DE LOS ASESINOS EN SERIE. 
TABLA 126. PRUEBAS CHI CUADRADO DE LAS VARIABLES HABER SUFRIDO ALGÚN TIPO DE MALTRATO EN LA INFANCIA Y EL CONTINENTE DE PROCEDENCIA DE LOS ASESINOS EN SERIE

TABLA 127. COEFICIENTE DE CONTINGENCIA DE LAS VARIABLES HABER SUFRIDO ALGÚN TIPO DE MALTRATO EN LA INFANCIA Y EL CONTINENTE DE PROCEDENCIA DE LOS ASESINOS EN SERIE

TABLA 128. DISTRIBUCIÓN DE FRECUENCIAS DE LAS VARIABLES HABER SUFRIDO ALGÚN TIPO DE MALTRATO EN LA INFANCIA Y MANTENER RELACIONES SEXUALES CON LAS VÍCTIMAS ANTE-MORTEM DE LOS ASESINOS EN SERIE

TABLA 129. PRUEBAS DE CHI CUADRADO DE LAS VARIABLES HABER SUFRIDO ALGÚN TIPO DE MALTRATO EN LA INFANCIA Y MANTENER RELACIONES SEXUALES CON LAS VÍCTIMAS ANTE-MORTEM DE LOS ASESINOS EN SERIE

TABLA 130. COEFICIENTES DE CONTINGENCIA DE LAS VARIABLES HABER SUFRIDO ALGÚN TIPO DE MALTRATO EN LA INFANCIA Y MANTENER RELACIONES SEXUALES CON LAS VÍCTIMAS ANTE-MORTEM DE LOS ASESINOS EN SERIE

TABLA 131. DISTRIBUCIÓN DE FRECUENCIAS DE LAS VARIABLES NIVEL DE PLANIFICACIÓN Y TIPO I (FBI) DE LOS ASESINOS EN SERIE

TABLA 132. PRUEBAS CHI CUADRADO DE LAS VARIABLES NIVEL DE PLANIFICACIÓN Y TIPO I (FBI) DE LOS ASESINOS EN SERIE

TABLA 133. COEFICIENTE DE CONTINGENCIA DE LAS VARIABLES NIVEL DE PLANIFICACIÓN Y TIPO I (FBI) DE LOS ASESINOS EN SERIE 



\section{ÍNDICE DE FIGURAS}

FIGURA 1: INTEGRACIÓN CONCEPTUAL (DE SANTIAGO, 2015)....

FIGURA 2: PARADOJA DE LOS CÍRCULOS CONCÉNTRICOS

(REDONDO ET AL., 2013).

FIGURA 3: RESPONSABILIDAD DE LAS VÍCTIMAS

(SCHAFER, 1977).

FIGURA 4. CONDENADOS POR SEXO Y GRUPO DE EDAD. AÑO 2013

(INE, 2014) . .88

FIGURA 5. ÍNDICES DE HOMICIDIO DOLOSO, POR SUBREGIÓN, AÑO MÁS RECIENTE DISPONIBLE, DATOS DE LA JUSTICIA PENAL Y DE LA SALUD PÚBLICA. . .92

FIGURA 6. ÍNDICES MEDIOS DE HOMICIDIO DOLOSO DE LOS PAÍSES DE AMÉRICA.

FIGURA 7. ÍNDICES MEDIOS DE HOMICIDIO DOLOSO DE LOS PAÍSES DE ASIA

Y OCEANÍA, 2003-2008 .94

FIGURA 8. ÍNDICES MEDIOS DE HOMICIDIO DOLOSO DE LOS PAÍSES DE EUROPA, 2003-2008.

FIGURA 9: MODELO DE LOS CUATRO FACTORES.

(LÓPEZ ET AL., 2005).

FIGURA 10: DIAGNÓSTICO DE PSICOPATÍA INTEGRADA (HART, COX Y HARE, 1995).

FIGURA 11: MODELO DE JOHN RAY Y J.A.B. RAY (1982) SOBRE PSICOPATÍA Y FUNCIONALIDAD EN LAVIDA

FIGURA 12: FASES DE LOS ASESINOS ORGANIZADOS (GARRIDO, 2008).

FIGURA 13: FANTASÍAS PLATÓN VS. ARISTÓTELES. (DE SANTIAGO-HERRERO, 2014)......187

FIGURA 14. GRÁFICO DE BARRAS AGRUPADAS DE LA VARIABLE SEXO EN

CADA ZONA DE ACTUACIÓN.

FIGURA 15. HISTOGRAMA DE FRECUENCIAS DE LA VARIABLE AÑO DE NACIMIENTO DE LOS ASESINOS EN SERIE QUE ACTUARON EN ESPAÑA.

FIGURA 16. HISTOGRAMA DE FRECUENCIAS DE LA VARIABLE AÑO DE NACIMIENTO DE LOS ASESINOS EN SERIE QUE ACTUARON EN AMÉRICA DEL NORTE. 
FIGURA 17. HISTOGRAMA DE FRECUENCIAS DE LA VARIABLE EDAD INICIO DE LOS ASESINATOS DE LOS ASESINOS SERIALES QUE ACTUARON EN ESPAÑA

FIGURA 18. HISTOGRAMA DE FRECUENCIAS DE LA VARIABLE EDAD INICIO DE LOS ASESINATOS DE LOS ASESINOS SERIALES QUE ACTUARON EN AMÉRICA DEL NORTE

FIGURA 19. GRÁFICO DE BARRAS AGRUPADAS DE LA VARIABLE ESTADO CIVIL EN CADA ZONA DE ACTUACIÓN

FIGURA 20. GRÁFICO DE BARRAS AGRUPADAS DE LA VARIABLE ORIENTACIÓN SEXUAL EN CADA ZONA DE ACTUACIÓN.

FIGURA 21. GRÁFICO DE BARRAS AGRUPADAS DE LA VARIABLE COMPLEXIÓN EN CADA ZONA DE ACTUACIÓN.

FIGURA 22. GRÁFICO DE BARRAS AGRUPADAS DE LA VARIABLE NIVEL

INTELECTUAL EN CADA ZONA DE ACTUACIÓN

FIGURA 23. GRÁFICO DE BARRAS AGRUPADAS DE LA VARIABLE IMPLICACIÓN EN LA VIDA SOCIAL EN CADA ZONA DE ACTUACIÓN.

FIGURA 24. GRÁFICO DE BARRAS AGRUPADAS DE LA VARIABLE HABER SUFRIDO ALGÚN TIPO DE MALTRATO EN LA INFANCIA EN CADA ZONA DE ACTUACIÓN.

FIGURA 25. GRÁFICO DE BARRAS AGRUPADAS DE LA VARIABLE HABER SUFRIDO ALGÚN TIPO DE MALTRATO EN LA EDAD ADULTA EN CADA ZONA DE ACTUACIÓN.

FIGURA 26. GRÁFICO DE BARRAS AGRUPADAS DE LA VARIABLE PATOLOGÍA MENTAL EN CADA ZONA DE ACTUACIÓN

FIGURA 27. GRÁFICO DE BARRAS AGRUPADAS DE LA VARIABLE ANTECEDENTES POLICIALES EN CADA ZONA DE ACTUACIÓN

FIGURA 28. HISTOGRAMA DE FRECUENCIAS DE LA VARIABLE NÚMERO DE CRÍMENES DE LOS ASESINOS EN SERIE QUE ACTUARON EN ESPAÑA

FIGURA 29. HISTOGRAMA DE FRECUENCIAS DE LA VARIABLE NÚMERO DE CRÍMENES DE LOS ASESINOS EN SERIE QUE ACTUARON EN AMÉRICA DEL NORTE .240

FIGURA 30. GRÁFICO DE BARRAS AGRUPADAS DE LA VARIABLE NIVEL DE PLANIFICACIÓN EN CADA ZONA DE ACTUACIÓN 
FIGURA 31. GRÁFICO DE BARRAS AGRUPADAS DE LA VARIABLE INTERACCIÓN VERBAL CON LAS VÍCTIMAS EN CADA ZONA DE ACTUACIÓN.

FIGURA 32. GRÁFICO DE BARRAS AGRUPADAS DE LA VARIABLE RELACIONES SEXUALES CON LAS VÍCTIMAS ANTE-MORTEM EN CADA ZONA DE ACTUACIÓN.

FIGURA 33. GRÁFICO DE BARRAS AGRUPADAS DE LA VARIABLE RELACIONES SEXUALES CON LAS VÍCTIMAS POST-MORTEM EN CADA ZONA DE ACTUACIÓN. .248

FIGURA 34. GRÁFICO DE BARRAS AGRUPADAS DE LA VARIABLE CONDUCTAS SÁDICAS Y DE TORTURA EN CADA ZONA DE ACTUACIÓN.

FIGURA 35. GRÁFICO DE BARRAS AGRUPADAS DE LA VARIABLE CANIBALISMO EN CADA ZONA DE ACTUACIÓN

FIGURA 36. GRÁFICO DE BARRAS AGRUPADAS DE LA VARIABLE MUTILACIÓN EN CADA ZONA DE ACTUACIÓN

FIGURA 37. GRÁFICO DE BARRAS AGRUPADAS DE LA VARIABLE TOMA TROFEOS DE SUS CRÍMENES EN CADA ZONA DE ACTUACIÓN

FIGURA 38. HISTOGRAMA DE FRECUENCIAS DE LA VARIABLE NÚMERO DE VÍCTIMAS TOTAL DE LOS ASESINOS EN SERIE QUE ACTUARON EN ESPAÑA

FIGURA 39. HISTOGRAMA DE FRECUENCIAS DE LA VARIABLE NÚMERO DE VÍCTIMAS TOTAL DE LOS ASESINOS EN SERIE QUE ACTUARON EN AMÉRICA DEL

NORTE

FIGURA 40. GRÁFICO DE BARRAS AGRUPADAS DE LA VARIABLE TIPO I (FBI) EN CADA ZONA DE ACTUACIÓN

FIGURA 41. GRÁFICO DE BARRAS AGRUPADAS DE LA VARIABLE TIPO II (CANTER Y SALFATI) EN CADA ZONA DE ACTUACIÓN

FIGURA 42. GRÁFICO DE BARRAS AGRUPADAS DE LA VARIABLE TIPO III (HOLMES Y DEBERGUER) EN CADA ZONA DE ACTUACIÓN

FIGURA 43. GRÁFICO DE BARRAS AGRUPADAS DE LA VARIABLE TIPO IV (FOX Y LEVIN) EN CADA ZONA DE ACTUACIÓN.

FIGURA 44. GRÁFICO DE BARRAS AGRUPADAS DE LA VARIABLE TIPO V (CANTER) EN CADA ZONA DE ACTUACIÓN.

FIGURA 45. GRÁFICO DE BARRAS AGRUPADAS DE LA VARIABLE TIPO VI (ROSSMO) EN CADA ZONA DE ACTUACIÓN. 
FIGURA 46. GRÁFICO DE BARRAS AGRUPADAS DE LAS VARIABLES HABER SUFRIDO ALGÚN TIPO DE MALTRATO EN LA INFANCIA Y PATOLOGÍA MENTAL EN ASESINOS SERIALES QUE ACTUARON EN AMÉRICA DEL NORTE. 265

FIGURA 47. GRÁFICO DE BARRAS AGRUPADAS DE LAS VARIABLES HABER SUFRIDO ALGÚN TIPO DE MALTRATO EN LA INFANCIA Y PATOLOGÍA MENTAL EN ASESINOS SERIALES QUE ACTUARON EN ESPAÑA .266

FIGURA 48. GRÁFICO DE BARRAS AGRUPADAS DE LAS VARIABLES NIVEL DE PLANIFICACIÓN Y ESTADO CIVIL EN ASESINOS SERIALES QUE ACTUARON EN AMÉRICA DEL NORTE

FIGURA 49. GRÁFICO DE BARRAS AGRUPADAS DE LAS VARIABLES NIVEL DE PLANIFICACIÓN Y ESTADO CIVIL EN ASESINOS SERIALES QUE ACTUARON EN ESPAÑA.

FIGURA 50. GRÁFICO DE BARRAS AGRUPADAS DE LAS VARIABLES NIVEL DE PLANIFICACIÓN Y NIVEL INTELECTUAL EN ASESINOS SERIALES QUE ACTUARON EN AMÉRICA DEL NORTE

FIGURA 51. GRÁFICO DE BARRAS AGRUPADAS DE LAS VARIABLES NIVEL DE PLANIFICACIÓN Y NIVEL INTELECTUAL EN ASESINOS SERIALES QUE ACTUARON EN ESPAÑA

FIGURA 52. GRÁFICO DE BARRAS AGRUPADAS DE LAS VARIABLES INTERACCIÓN VERBAL CON LAS VÍCTIMAS Y CONDUCTAS SÁDICAS Y DE TORTURA EN ASESINOS SERIALES QUE ACTUARON EN AMÉRICA DEL NORTE.

FIGURA 53. GRÁFICO DE BARRAS AGRUPADAS DE LAS VARIABLES INTERACCIÓN VERBAL CON LAS VÍCTIMAS Y CONDUCTAS SÁDICAS Y DE TORTURA EN ASESINOS SERIALES QUE ACTUARON EN ESPAÑA

FIGURA 54. GRÁFICO DE BARRAS AGRUPADAS DE LAS VARIABLES MUTILACIÓN Y CANIBALISMO EN ASESINOS SERIALES QUE ACTUARON EN AMÉRICA DEL

NORTE

FIGURA 55. GRÁFICO DE BARRAS AGRUPADAS DE LAS VARIABLES MUTILACIÓN Y CANIBALISMO EN ASESINOS SERIALES QUE ACTUARON EN ESPAÑA.

FIGURA 56. GRÁFICO DE BARRAS DE LA VARIABLE PAÍS DE PROCEDENCIA DE LOS ASESINOS EN SERIE

FIGURA 57. DIAGRAMA DE SECTORES DE LA VARIABLE SEXO DE LOS ASESINOS EN SERIE 
FIGURA 58. HISTOGRAMA DE FRECUENCIAS DE LA VARIABLE EDAD DE INICIO DE LOS ASESINATOS DE LOS ASESINOS EN SERIE.

FIGURA 59. GRÁFICO DE BARRAS DE LA VARIABLE HABER SUFRIDO ALGÚN TIPO DE MALTRATO EN LA INFANCIA DE LOS ASESINOS EN SERIE.

FIGURA 60. HISTOGRAMA DE FRECUENCIAS DE LA VARIABLE NÚMERO DE

CRÍMENES DE LOS ASESINOS EN SERIE

FIGURA 61. GRÁFICO DE BARRAS DE LA VARIABLE NIVEL DE PLANIFICACIÓN DE LOS ASESINOS EN SERIE.

FIGURA 62. GRÁFICO DE BARRAS DE LA VARIABLE RELACIONES SEXUALES

CON LAS VÍCTIMAS ANTE-MORTEM DE LOS ASESINOS EN SERIE

FIGURA 63. GRÁFICO DE BARRAS DE LA VARIABLE RELACIONES SEXUALES CON LAS

VÍCTIMAS POST-MORTEM EN LOS ASESINOS EN SERIE.

FIGURA 64. GRÁFICO DE BARRAS DE LA VARIABLE TIPO I (FBI) EN LOS ASESINOS EN

SERIE

FIGURA 65. GRÁFICO DE BARRAS AGRUPADAS DE LAS VARIABLES NIVEL DE PLANIFICACIÓN Y SEXO DE L308OS ASESINOS EN SERIE

FIGURA 66. GRÁFICO DE BARRAS AGRUPADAS DE LAS VARIABLES RELACIONES

SEXUALES CON LAS VÍCTIMAS ANTE-MORTEM Y EL SEXO DE LOS ASESINOS

EN SERIE.

FIGURA 67. GRÁFICO DE BARRAS AGRUPADAS DE LAS VARIABLES HABER SUFRIDO ALGÚN TIPO DE MALTRATO EN LA INFANCIA Y EL CONTINENTE DE PROCEDENCIA DE LOS ASESINOS EN SERIE.

FIGURA 68. GRÁFICO DE BARRAS AGRUPADAS DE LAS VARIABLES HABER

SUFRIDO ALGÚN TIPO DE MALTRATO EN LA INFANCIA Y MANTENER

RELACIONES SEXUALES CON LAS VÍCTIMAS ANTE-MORTEM DE LOS

ASESINOS EN SERIE

FIGURA 69. GRÁFICO DE BARRAS AGRUPADAS DE LAS VARIABLES NIVEL DE PLANIFICACIÓN Y TIPO I (FBI) DE LOS ASESINOS EN SERIE. 



\section{PRESENTACIÓN}

La realización de la presente Tesis Doctoral ha respondido a la relativa escasez de investigación, tanto a nivel nacional como en otros países sobre el asesinato serial. Por ello consideramos importante el desarrollo de un estudio comparativo entre España y EEUU a la par que estudiar las características del comportamiento criminal de estos sujetos a nivel internacional.

El tema de los asesinos en serie es un tema tanto apasionante como complicado en su estudio, pues profundizar en el fenómeno produce un gran impacto en el investigador ya que de alguna manera se ve enfrentado cara a cara con el mal.

Siendo conscientes de que solamente un $8 \%$ de la población mundial reside en EEUU y que alrededor de cada cuatro asesinatos seriales ocurren allí (Macía, 2011), creemos esencial profundizar en las características del comportamiento criminal de estos asesinos seriales en comparación con los que actuaron en España, así como en el panorama internacional.

Cuando hablamos de asesino en serie nos estamos refiriendo a un sujeto que mata a dos (Turvey, 2002), tres o más víctimas (Garrido, 2008; Jiménez, 2014), de forma sucesiva y con períodos de enfriamiento - espacio temporal en el que el asesino no mata- entre ellas.

Algunas de las características hasta ahora propuestas para definir al asesino en serie son: que en el período de enfriamiento mantiene una apariencia de normalidad, son fríos emocionalmente, atraídos por la dominación y el poder, no suelen tener vínculo con sus víctimas, presentan una compulsión por matar, no muestran arrepentimiento y tienen afán de protagonismo y grandiosidad. (Edger, 1998)

En este sentido, hasta la actualidad se han identificado y estudiado diversas variables relacionadas con el comportamiento criminal de los asesinos en serie: número de víctimas (Turvey, 2002; Jiménez, 2014), período de enfriamiento (Holmes y Holmes, 2006; Antuña, 2007), sexo (Garrido, 2008), raza (Edger, 1998), formación académica (Garrido, 2008) carácter sexual del asesinato (Turvey, 2008) y características etiológicas (Borras, 2002). Así y teniendo en cuenta las investigaciones previas, para nuestro estudio comparativo seleccionamos 40 variables mediante un análisis interjueces, de las 
143 propuestas inicialmente en la Unidad de Análisis de la Conducta Criminal de la Universidad de Salamanca, así como 13 variables para el estudio internacional. Estas variables han sido divididas en: variables sociodemográficas y físicas, psicológicas, antecedentes de la infancia y la adolescencia, historia de la edad adulta, historial delictivo y de violencia, escena del crimen, modus operandi, ritual llevado a cabo en el crimen, comportamiento geográfico, victimología, y las tipologías de asesinos seriales.

De manera que la presente investigación pretende profundizar en el estudio de estas variables para así aportar nuevos datos sobre el comportamiento criminal de estos sujetos, arrojando mayor luz sobre este fenómeno y sirviendo de ayuda a las Fuerzas de Seguridad desde un enfoque academicista e investigador.

La presente Tesis Doctoral se encuentra organizada en siete capítulos: el primer capítulo dedicado a la definición y marco teórico de los Perfiles Criminales, el segundo centrado en la Psicología Criminal, el tercero correspondiente al recorrido históricocrítico del concepto de Psicopatía, el cuarto dedicado a los asesinos en serie. Por su parte, el quinto capítulo se centra en el marco metodológico de la investigación, el sexto corresponde al estudio comparativo de los asesinos en serie que actuaron en EEUU y los que lo hicieron en España. Finalmente, el séptimo capítulo se corresponde con el estudio de una muestra internacional de asesinos seriales.

Más concretamente, en el capítulo uno, desarrollamos el concepto de Perfil Criminológico y su aplicación. Asimismo explicamos su utilidad y el contexto histórico en el que surgieron, haciendo hincapié en los dos primeros casos que originaron esta técnica. Desarrollamos además las diferentes metodologías existentes en la técnica del Perfil Criminológico -inductiva, deductiva y abductiva- aplicando la metodología abductiva, puesto que es la más novedosa, a un caso real.

El capítulo dos se organiza en torno a la Psicología Criminal, desarrollando en primer lugar el recorrido histórico de la misma. Posteriormente profundizamos en la delimitación terminológica existente entre la Psicología y el Derecho y sus diferentes ramificaciones. Asimismo, son expuestas las diferentes áreas de estudio criminológico: delitos, delincuentes, víctimas y sistemas de control social. Igualmente nos centramos en la contribución de los diferentes ámbitos de la Psicología al estudio de la criminalidad, desarrollando los aportes provenientes de la Psicología Evolutiva, de la Psicología Social, de la Psicología Biológica y por último de la Psicología del 
Comportamiento. Además, profundizamos en las teorías sociológicas existentes sobre el crimen. Asimismo, explicamos la evaluación y distribución del delito y por último ofrecemos diversos estudios sobre la criminalidad en nuestro país y a nivel internacional.

El capítulo tres está dedicado al recorrido histórico-crítico del concepto de Psicopatía, en el que se desarrolla el término Psicopatía, las primeras clasificaciones y tipologías de la misma así como su evolución a lo largo de la historia. Posteriormente, se describen y definen los criterios diagnósticos de la Psicopatía según diferentes autores y las nosologías actuales, así como su diferenciación con otras estructuras psicopatológicas, como son la ansiedad y la esquizofrenia. Además, desarrollamos las características que ha de contener la entrevista con un psicópata así como el concepto de psicópata adaptado integrado. En este capítulo también se ofrecen datos sobre la prevalencia de la Psicopatía. Finalmente, nos centramos además en las explicaciones provenientes desde el Psicoanálisis así como de las ofrecidas por la Neuropsicología y técnicas de neuroimagen

En el capítulo cuatro nos centramos en los asesinos en serie, diferenciándolos de otros tipos de asesinos, como los homicidas en masa o frenéticos. Igualmente desarrollamos el concepto de asesino serial así como las características definitorias del mismo. Presentamos también las diferentes tipologías existentes en torno al asesino en serie, así como explicamos la infancia experimentada por estos sujetos. Dedicamos también un apartado a las mujeres asesinas en serie y sus características y por último nos centramos en los aspectos sociales que rodean al asesino en serie.

El capítulo cinco está dedicado al marco metodológico del estudio sobre asesinos en serie, en el cual se desarrollan: los objetivos específicos de la investigación, el objeto de estudio, el esquema general del proceso de investigación, las diferentes técnicas empleadas (revisión sistemática de una recogida de datos preliminar y la elaboración de la ficha con la que hemos trabajado); la selección, el acceso y el perfil de los informantes; el ámbito geográfico en el que se ha desarrollado y el período cronológico de la misma.

El capítulo sexto se centra en el estudio comparativo de los asesinos seriales que actuaron en EEUU y los que actuaron en España. Nuestros objetivos en este capítulo fueron, en primer lugar, analizar el perfil sociodemográfico de los participantes 
(considerados globalmente y agrupados en función de su zona de actuación). En segundo lugar, hemos analizado qué variables psicológicas influyen en el comportamiento criminal de los asesinos seriales dependiendo de su zona de actuación. Asimismo hemos analizado qué antecedentes de la infancia de los asesinos en serie influyen en el comportamiento criminal en función de su zona de actuación. De modo adicional, hemos pretendido analizar qué variables pertenecientes al ritual de actuación de los asesinos en serie influyen en su comportamiento criminal en función del territorio de actuación, y por último analizar las diferencias existentes en cuanto a la tipología del FBI y la zona de actuación de los asesinos seriales.

En dicho capítulo predecimos que existirá relación entre el nivel intelectual, presencia de patología mental, haber sufrido algún tipo de maltrato en la infancia, el modo de interacción verbal con las víctimas, llevar a cabo conductas sádicas y de tortura con las víctimas así como mutilación, haber llevado a cabo relaciones sexuales con las víctimas post-mortem y en cuanto a la tipología propuesta por el FBI de los asesinos en serie dependiendo de la zona de actuación (EEUU vs. España).

Con la intención de responder a estas preguntas hemos contado con 48 asesinos en serie ( 24 que actuaron en EEUU y 24 que actuaron en España). A todos ellos les hemos aplicado la ficha de 40 variables, proveniente del análisis interjueces realizado por los miembros especialistas de la Unidad de Análisis de la Conducta Criminal de la Universidad de Salamanca. Los resultados y conclusiones que se derivan de los mismos son expuestos con más detalle en dicho capítulo.

El capítulo siete se centra en trece variables que nos han parecido de especial interés a raíz de los resultados obtenidos en el estudio comparativo entre asesinos en serie que actuaron en América del Norte y España, en este caso, en una muestra de 100 asesinos en serie internacionales con el objetivo de alcanzar una información más detallada y contrastada del fenómeno del asesinato serial. Los objetivos de este capítulo son: analizar el perfil sociodemográfico, los rasgos psicopáticos, la influencia de haber sufrido algún tipo de maltrato en la infancia en el comportamiento criminal de los asesinos en serie internacionales, el número de crímenes, qué variables pertenecientes al modus operandi influyen en el comportamiento criminal, qué variables pertenecientes al ritual de actuación influyen en el comportamiento criminal de los asesinos en serie incluidos en este estudio internacional y por último, analizar las diferencias existentes en cuanto a la tipología del FBI en la muestra de asesinos en serie internacional. 
Las preguntas de investigación a las que pretendemos responder en dicho capítulo son: ¿Habrá relación entre el nivel de planificación de los crímenes y el sexo de los asesinos seriales?, ¿Existirá relación entre mantener relaciones sexuales con las víctimas ante-mortem y sexo de los asesinos?, ¿Habrá relación entre haber sufrido algún tipo de maltrato en la infancia y el continente de procedencia?, ¿ influirá el haber padecido algún tipo de maltrato en la infancia con llevar a cabo relaciones sexuales con las víctimas? Y por último ¿hay relación entre la planificación de los crímenes y el tipo al que pertenezcan respecto a la clasificación del FBI?

Para responder a estas preguntas se utilizó la segunda ficha de 13 variables, obtenida de la primera tras un análisis interjueces realizado por los miembros especialistas pertenecientes a la Unidad de Análisis de la Conducta Criminal de la Universidad de Salamanca. Dicha ficha fue aplicada a una muestra de 100 asesinos seriales provenientes de diferentes zonas del mundo. Los resultados y conclusiones derivados de este segundo estudio son desarrollados con detenimiento en el capítulo siete.

La presente Tesis Doctoral finaliza presentando las conclusiones que se derivan de la investigación, las limitaciones y sugerencias para posteriores estudios, así como las referencias bibliográficas y el anexo correspondiente al instrumento utilizado. 


\section{CAPÍTULO I: DEFINICIÓN Y PERSPECTIVA HISTÓRICA DE LOS PERFILES CRIMINALES}

En el presente capítulo se expondrá tanto la definición y utilidad de la técnica del Perfil Criminológico así como las principales metodologías de investigación científica y sus razonamientos.

\subsection{DEFINICIÓN DE PERFIL CRIMINOLÓGICO}

Contamos con diferente terminología para referirnos al término perfil criminológico: Perfil Criminal, Perfil del Delincuente, Perfil del Agresor. Estos términos se relacionan con el modelo de referencia y el ámbito geográfico donde surgen. En general las investigaciones se refieren al Perfil Criminológico desde el modelo europeo occidental y criminal profiling desde el modelo angloamericano. (Alcaraz, 2010).

En EEUU, el término Ofender Profiling o Criminal Profiling -referido al Perfil del Delincuente o Perfil Criminal - surge en los años 70 a través de las investigaciones del FBI e intenta designar una técnica para describir el comportamiento y las principales características del autor de un crimen como referente internacional. (Ressler, 2010).

En España, la Real Academia Española (segunda acepción según la RAE, 22a edición) define el perfil como el "Conjunto de rasgos peculiares que caracterizan a alguien o algo".

En un sentido más amplio, Morales, Muñoz, Santillán, Arenas y Chico, (2007) definen el perfil criminológico como: "descripción, la explicación y la predicción de las características sociodemográficas (edad, sexo, ocupación, etc.), criminológicas (carrera delictiva) y psicológicas (personalidad, patrones conductuales, motivación, patrones de pensamiento, etc.) de las personas que han cometido algún delito" (Morales et al., 2007, p.70).

En general, el término Perfil Criminológico se refiere al conjunto de datos, informaciones y opiniones que el experto realiza respecto al delincuente. (Jiménez, 2012). Además, la utilidad de la técnica del perfil proporciona a los investigadores una información útil y específica respecto al tipo de sujeto que ha llevado a cabo un crimen. 
En esta línea, los conocimientos aportados por la Psicología y la Criminología, son de gran utilidad para la elaboración de Perfiles Criminales y muy especialmente los relacionados con la consistencia comportamental del delincuente a través del tiempo así como el mantenimiento de la evidencia conductual en las acciones, que facilitan una explicación del comportamiento humano delictivo. (Vargas, 2008).

En la actualidad existe un interés cada vez mayor hacia el comportamiento violento y delictivo. De hecho, los organismos internacionales demandan un conocimiento más exhaustivo respecto a las características de los delincuentes, de sus víctimas y de las personas que les rodean. En este sentido, la elaboración de los Perfiles Criminológicos va a permitir la indagación en la conducta delictiva de los diferentes tipos de agresores. En palabras de Arenas, Morales, Muñoz-Delgado, Ponce de León, Santillán (2007):

La explicación y la reducción del comportamiento violento y delictivo son temas de interés para todas las sociedades. Organismos internacionales como las Naciones Unidas y la Organización Mundial de la Salud, llaman la atención sobre la necesidad de conocer más y mejor los diferentes tipos de violencia y de víctimas, así como las características y las circunstancias de los sucesos violentos y de sus autores. Los perfiles criminológicos ofrecen un método útil e interesante para el cumplimiento de estos propósitos, en particular para conocer a los responsables de los hechos violentos. (Arenas et al., 2007, p.69)

La investigación del Perfil Criminológico tiene un carácter multidisciplinar, lo cual conlleva la intervención de numerosos investigadores desde las ciencias del comportamiento, las ciencias sociales-humanas y las ciencias forenses. El objetivo de la investigación sobre Perfiles Criminológicos según López y Gómez (2000) se centra en la reducción del número de sospechosos, en la comprensión y vinculación de diferentes actos de crímenes y a continuar con la investigación de casos no resueltos. En este sentido la investigación criminal se puede entender como la aplicación de diferentes recursos, procedimientos y métodos científicos que ayuden a dilucidar un delito y su perpetrador. (López et al., 2000).

No obstante, en el ámbito occidental el término plantea algunos problemas de interpretación. Este término cambia de nosología según los profesionales implicados en la elaboración del perfil. Para ello nos encontramos con dos términos diferentes: Perfil Criminal (Criminal Profiling) para el perfil elaborado por el psicólogo y Perfil 
Criminológico (Criminology Profiling) para el elaborado conjuntamente por un psicólogo y un criminólogo. Así Garrido (2008) se refiere a que:

Con la expresión perfil criminológico estamos haciendo referencia de un modo explícito a la aportación que un psicólogo o criminólogo hace a las fuerzas policiales para la captura del criminal, y al mismo tiempo ponemos de relieve que en esa tarea el experto ha de emplear los conocimientos que se derivan de la ciencia de la Criminología. (Ibíd, 2008, p.14)

Sin embargo, desde la denominación angloamericana se aplica la nosología del Perfil Criminal (Criminal Profiling) para hacer referencia únicamente a un psicólogo, reduciéndose el campo a una sola figura profesional. (Alcaraz, 2010).

\subsection{APLICACIÓN Y DESCRIPCIÓN DEL PERFIL CRIMINOLÓGICO}

Actualmente, la técnica del Perfil Criminológico se usa para los siguientes casos: asesinato serial, violación y abusos/agresiones sexuales, piromanía, robo con violencia y con fuerza en viviendas. La utilización de la técnica del Perfil Criminológico se aplica y se orienta a los casos seriales ya que en los casos en los que no se produce dicha característica no siempre resulta eficaz. En este sentido, Holmes y Holmes (2002) y Holmes (2009), apuntan que en los crímenes en los cuales los motivos habituales están ausentes, el Perfil Criminológico resulta un instrumento facilitador de la resolución exitosa del caso.

De importancia son los perfiles en los casos de personas con largas carreras delictivas, ya que se ha encontrado que de la totalidad de personas que cometen delitos, es sólo una pequeña parte la que los efectúa de forma violenta y crónica. En este sentido, en investigaciones previas (Farrington, 2005; Moffitt, 2006; Snyder, 1998; Thornberry y Khron, 2003; Wlebush, Baird, Krisberg y Onek, 1995) se ha encontrado que de la totalidad de personas que cometen delitos, los que lo hacen de forma violenta y crónica representa un $15 \%$ de la población carcelaria. Norza et al (2013) destaca la importancia de perfilar a esta población, para una mejor prevención.

De igual forma, la perfilación criminal es eficaz en situaciones en las que se dan repeticiones de comportamiento en las diferentes escenas del crimen, así como cuando el criminal presenta alguna psicopatología. (Douglas, Ressler, Burgess y Hartman, 
1986; Gebert, 1981). De manera que los perfiles han de ser útiles para hallar al responsable en lo que Keppel (1997) ha denominado un continuo de violencia, es decir "en qué lugar se halla el criminal en su secuencia de acciones violentas, con objeto de determinar cuál es la firma del asesino y adónde le puedan llevar sus fuerzas psicológicas". (citado en Garrido, 2008, p.110).

Respecto al objetivo de la técnica, Holmes et al (2002), exponen en este sentido: "la técnica del Perfil Criminológico es un intento elaborado de proporcionar a los equipos de investigación la información específica en torno al individuo que ha cometido un crimen" (Ibíd, 2002, p.13)

De manera que la técnica del Perfil Criminológico va dirigida básicamente a tres cuestiones de la investigación criminal según apunta Alcaraz (2010):

a. Reducir el número de posibles sospechosos, es decir, filtrar posibles autores del hecho aplicando las diferentes técnicas de investigación.

b. Vincular diferentes casos criminales (linkage cases) con características idénticas o razonablemente parecidas.

c. Destacar los casos no resueltos que producen inoperancia a las Fuerzas de Seguridad.

Un Perfil Criminológico contiene además de las características del asesino desconocido varias tareas como son: (Garrido, 2008)

1. Una descripción de la personalidad y características descriptivas del autor desconocido de un crimen o una serie de crímenes.

2. Un estudio sobre dónde puede tener su residencia y/o su base de operaciones para cometer sus delitos.

3. Una valoración sobre la probabilidad de que cometa futuros delitos y su ubicación.

4. Una valoración del caso para proveer al equipo de investigación de nuevas vías de trabajo, por ejemplo, vinculando crímenes diversos en un mismo autor (o diferenciándolos)

5. Consejo especializado acerca de cómo gestionar la relación con los medios en un caso de asesinato o violación serial o de un delito particularmente perverso o violento (por ejemplo, un asesinato múltiple en un solo acto). 
6. Apoyo en la dirección de las entrevistas (interrogatorios) con el (los) posible sospechoso.

De esta manera, la información para poder realizar un Perfil Criminológico abarca cuatro áreas de investigación propuestas por Jiménez (2010):

- La escena del crimen: se pretenden analizar las evidencias forenses halladas en la misma.

- Modus operandi y firma: el análisis de la conducta y comportamiento del criminal así como las motivaciones y necesidades psicológicas que le llevan a realizar el crimen.

- Geografía: cómo se comporta geográficamente el criminal y que características tienen dichas zonas geográficas.

- Victimología: el análisis del comportamiento y características de la víctima ayudan a relacionarlo con rasgos de personalidad y comportamiento del agresor. Igualmente, los diferentes tipos de perfiles, según el mismo autor, nacen de diferentes perspectivas:

- Enfoque psicológico-psicopatológico (evaluación diagnóstica): suele realizarse por profesionales de la salud mental y se basa en la psicopatología criminal.

- Enfoque de análisis de la escena del crimen: es realizado principalmente por los cuerpos de seguridad y se basan en el análisis de la escena del crimen y la información que aporta.

- Enfoque estadístico (investigación académica): realizado principalmente por investigadores y basándose en la metodología inductiva para el análisis de los diferentes elementos de la escena del crimen.

El perfilador debe formar parte de un equipo multidisciplinar, ya que es necesario aunar investigadores provenientes de diferentes disciplinas (Criminología, Psicología, Psiquiatría y Ciencias Forenses) para llegar a evaluar todos los aspectos de un caso con la mayor precisión. Estos equipos deben de trabajar bajo un régimen de grupo evitando los individualismos y coordinados por un investigador jefe, especializado en la técnica. (Norza, Morales, Merchán y Meléndez ,2013). 


\subsection{HISTORIA DEL PERFIL CRIMINOLÓGICO}

El estudio científico de las conductas criminales sitúa el origen dentro de la Criminología en el último tercio del siglo XIX con la escuela Positivista italiana. Sus máximos representantes fueron tres autores: el primero y más significativo fue Lombroso (1856-1909) con su Tratado antropológico experimental del hombre delincuente (1876), y después encontramos a Ferri (1856-1929) y Garófalo (18521934). Todos ellos eran partidarios de un método empírico inductivo basado en la observación del delincuente y de su medio.

Tradicionalmente se creía que los delincuentes no sólo debían tener unas características psicológicas específicas sino que también debían de poseer unos rasgos físicos que les diferenciaran del resto de las personas no criminales. En 1888, en Gran Bretaña, el Dr. George Phillips introduce un método denominado "modelo-herida" en el que relacionaba las heridas que había sufrido la víctima con su agresor. A raíz de estas relaciones se realizaban los primeros perfiles del delincuente.

Cesare Lombroso en 1870, considerado el padre de la Criminología, fue pionero en intentar hacer una clasificación de delincuentes para extraer comparaciones estadísticas. En su obra El hombre delincuente (1876), estudió a 383 reclusos italianos llegando a establecer una de las primeras clasificaciones conocidas sobre delincuentes descritas por Lombroso (2006):

1. Criminales natos: delincuentes muy primitivos, cuya psicología parecería pertenecer a etapas de evolución anteriores. Entre los rasgos físicos característicos de estos asesinos se hallaban los siguientes: cara asimétrica; mandíbula y pómulos grandes; orejas de gran tamaño, o realmente pequeñas, o de forma de asa como las de los chimpancés; dentadura anormal; brazos excesivamente largos; dedos en las manos y pies de más; bolsas en las mejillas; barbilla hundida, o excesivamente larga, o corta y plana, como la de algunos simios.

2. Criminales enfermos: delincuentes que sufrían de enfermedades o deficiencias mentales y físicas.

3. Criminaloides: grupo numeroso de delincuentes que no poseían unas características especiales. No presentaban deficiencias mentales, pero su constitución mental y emocional les predisponía al delito. 
En 1955, Kretschmer realiza un estudio contando con más de 4000 casos y hace la siguiente clasificación:

1. Leptosomático: delgado y alto

2. Atlético: musculoso y fuerte.

3. Pícnico: bajo y gordo.

4. Mixto: contiene características de todas las anteriores.

Según la clasificación, cada tipología estaría relacionada con un tipo de delito concreto. (Kretschmer, 1955, 1997)

No obstante, Jiménez (2010) considera que estas clasificaciones presentaban un elevado componente biologicista por lo que fueron siendo abandonadas por sus carencias científicas y su poca utilidad. Paulatinamente la visión biologicista fue siendo sustituida por una perspectiva más psicológica. En palabras de Pablos (2007):

Que la criminología pertenezca al ámbito de las ciencias empíricas significa, en primer lugar, que su objeto (delito, delincuente, víctima y control social) se inserta en el mundo de lo real, de lo verificable, de lo mesurable, y no en el de los valores. (Ibíd, 2007, p.33)

Respecto al estudio concreto de los crímenes que sirvieron como referencia para la creación del Perfil Criminológico con marcado y evidente carácter social destacan las figuras del investigador George Phillips y el cirujano Thomas Bond quienes fueron partícipes en 1888 en la investigación de los crímenes de Jack el Destripador. (Jiménez, 2015). Así, esta investigación, fue basada en las heridas de las víctimas y a partir de las mismas se pudo inferir la personalidad del asesino teniendo en cuenta el tipo de interacción que llevaba a cabo con las víctimas. (Garrido, 2008).

\subsubsection{Criminales históricos que originan los Perfiles Criminológicos.}

Se considera oportuno la descripción de los casos de Jack el Destripador y del Bombardero Loco, ya que marcaron el origen de lo que hoy conocemos como Perfil Criminológico.

\subsubsection{Jack el Destripador.}

En el caso de Jack el Destripador fue Thomas Bond, un cirujano, el que analizó las heridas que Jack infringía a sus víctimas y a partir de ellas extrajo características 
personales y físicas que darían pistas sobre el posible autor de los crímenes. (Alcaraz, 2010; Norza et ál., 2013).

a. Tipo de Víctimas: En los crímenes de Jack se encuentran algunos aspectos comunes, descritos por Pombo (2008): todas sus víctimas eran trabajadoras sexuales, que aparentemente habían sido asaltadas por la espalda y que la causa de su muerte la había provocado un corte profundo en sus gargantas. No parecía haber rastro de violencia sexual, y en todos los casos menos en uno, hubo mutilación. Con excepción del último crimen, todos los demás fueron cometidos durante la noche y en plena calle, en callejones oscuros del East End londinense.

b. Zona geográfica: La zona en la que llevaba a cabo sus crímenes era de sobra conocida por Jack: Whitechapel, East End, en Londres. Así, Cronwell (2002) describe que el área era de unos cuatrocientos metros cuadrados, compuesta por callejones y salidas, de manera que sabía perfectamente dónde atacar y por dónde escapar.

c. Número de víctimas: en relación al número víctimas, la cifra total es incierta, aunque investigadores como Cronwell (2002) y Jiménez (2015) coinciden en que fueron cinco. Las características que poseían estas víctimas es que eran todas de mediana edad, entre los 25 y 47 años de edad. Todas habían estado casadas en algún momento de sus vidas y en el momento de los crímenes se encontraban solteras o viudas. No tenían hijos y si los tenían los habían abandonado, incluso una de las víctimas de Jack parece ser que estaba embarazada. Todas ellas bebían alcohol y no tenían muy buen nivel de vida, estaban arruinadas.

d. Modus operandi: Respecto al modus operandi Jack atacaba siempre por la noche, se acercaba a ellas mediante la mentira y las engatusaba. Después las atacaba súbitamente cortándoles la garganta, y más tarde escapaba entre los callejones. El que no lo capturaran ni supieran quién era, generaba paranoia y desconfianza en la ciudad, ya que los habitantes pensaban que en cualquier momento podían estar hablando con el asesino.

e. Identidad de las víctimas: A Mary Ann Nichols, de 43 años, le cortó la garganta de oreja a oreja al igual que sus arterias carótidas. Le rebanó el vientre de abajo arriba y se dejaban ver los intestinos. A Annie Chapman, de 47 años, le abrió el abdomen, sacando los intestinos y colocándolos en el hombro de la mujer, 
removiendo también el útero y diferentes partes de la vagina. En el caso de Elizabeth Stride, de 43 años, cortó también la garganta de la mujer pero no llegó a mutilar el cuerpo debido a que alguien pasaba por los alrededores. A Catherine Eddowes, de 43 años también, le desfiguró el rostro rajándole los párpados inferiores. Le extrajo también el riñón izquierdo y los intestinos, que fueron dejados sobre el hombro de la mujer de la misma forma que en Chapman, y otra parte de los órganos fueron dejados sobre el hombro derecho. La manera con la que manejaba el cuchillo denotaba que sabía nociones de cirugía. El último crimen conocido, el de Mary Jane Kelly, de 25 años, fue cometido en un dormitorio, ya que el destripamiento que Jack tenía planeado requería de más tiempo. El rostro de esta chica quedó irreconocible. El abdomen también fue rebanado y los órganos removidos. Los senos, riñones y corazón de la víctima se encontraban sobre la mesa del dormitorio. (Cronwell, 2002; Ressler y Shachtman, 2010).

En general, se aprecia una escalada en la brutalidad y violencia empleada en sus crímenes, pudiendo afirmar que Jack cometía sus crímenes por placer, por sadismo, llevando a cabo un acto parafílico denominado "piquerismo" definido por Safarik y Quiñones (2011) como la búsqueda del incremento de placer, teniendo como mecanismo lesivo el deslizamiento, penetración con el filo y/o punta aguzada idónea, cuyo efecto en el cuerpo humano con cada una de ellas o combinando ambas a la vez es la punción, separación o distensión en la geografía corporal.

Algunas de las cartas que muestra Cullen (1993) en su obra, rezan:

He oído decir que la Policía me anda buscando, pero todavía no he sido apresado. Me río cada vez que presumen de su astucia y afirman estar sobre la pista. La broma respecto a Delantal de Cuero me causó un ataque de hilaridad. Me asquean las rameras y no dejaré de destruirlas hasta que esté satisfecho. El último trabajo fue verdaderamente magnífico. No le di a la mujer tiempo de gritar. Y ahora ¿cómo me podrán atrapar? Me gusta mi trabajo que no abandonaré. Usted no tardará en volver a saber de mí. Había conservado un poco de sangre en una botella de cerveza, para escribirle con ella, pero resulta que está coagulada y no puedo utilizarla. La tinta roja sirve lo mismo ¡Ja, ja, ja! La próxima vez que actúe le cortaré a la dama las orejas y se las enviaré a la Policía como recuerdo. Guarde estar carta hasta mi nuevo trabajo, y luego tírela. Mi cuchillo es estupendo y muy afilado, por lo que deseo trabajar 
inmediatamente, si tengo ocasión. Buena suerte. Sinceramente suyo, Jack el Destripador. (Ibíd, 1993, p.108)

En otra de las cartas decía así: "Sepan que trabajaré en las Minorisas a las doce de la noche, proporcionándoles a las autoridades una buena oportunidad, pero no habrá ningún policía cerca de mí cuando ejecutaré el trabajo" (Cullen, 1993, p.113)

Era evidente que disfrutaba escribiendo al jefe de policía: "Oiga, jefe (...), parece usted muy asustado. Crea que me encantaría producirle varios ataques de nervios, pero no tengo tiempo de jugar con usted a los policías de plomo, aunque espero visitarle cuando no tenga mucho trabajo. Adiós, jefe". (Cullen, 1993, p.162)

Lo cierto es que los crímenes de Jack conmocionaron al mundo y sigue siendo punto de investigación para muchos. El nombre de Jack el Destripador sigue siendo famoso en todo el mundo no sólo por la atrocidad de sus crímenes, sino porque la identidad del mismo sigue siendo un enigma. (Cronwell, 2002).

No obstante, en opinión de Jiménez (2010), el primer Perfil Criminológico tendría sus raíces en el caso del bombardero loco de Nueva York ya que en el caso de Jack el Destripador, el Dr. Brussell considera que Bond realiza un análisis de las heridas, por lo que sería más acercado a un perfil el análisis hecho por Brussell dada su formación y experiencia en Psiquiatría y Psicología criminal considerándolo por tanto, el precedente del Perfil Criminológico.

\subsubsection{El Bombardero Loco.}

En este caso la policía se encontraba perdida ante la innumerable ola de bombardeos que se estaban produciendo por los diferentes puntos de la ciudad desde hacía años. El inspector encargado del caso, Howard Finney, llegado a ese punto, consideró que el autor no podría "estar bien de la cabeza" y decidió consultar con James Brussel, un psiquiatra psicoanalista con marcada experiencia en el ámbito criminal. Se le presentó toda la información que hasta entonces tenían del caso. Brussel analizó minuciosamente dicha información tomándola como si fueran síntomas para llegar a un diagnóstico. Analizó fotografías, el contenido de las cartas y su estructura y los datos aportados por los investigadores. De este análisis tan novedoso dedujo características físicas, sociales y psicológicas que ayudarían sin duda a la captura del autor de los bombardeos. Brussel llegó a dar datos tan exactos como que el autor de los hechos 
vestiría con un chaleco con los botones abrochados, identificándose así al autor de los hechos, George Metesky, quien fue capturado y detenido. El estudio minucioso del caso desde las pistas aportadas por los investigadores del crimen supuso el inicio de una nueva estrategia de trabajo policial que sería de utilidad en futuros crímenes. (Abeijón, 2015).

El perfil que se expone a continuación fue descrito por Jiménez (2012) como se muestra a continuación:

a. Zona geográfica: El primer artefacto hallado fue el 16 de noviembre de 1940 en el edificio de la Consolidated Edison de Manhattan. Era una bomba casera y al lado de la misma había una nota que decía "aquí tenéis, delincuentes del Con. Edison"

b. Modus operandi: Un año más tarde, encontraron otra bomba dentro de un calcetín en la calle 19, cerca de las oficinas de la Con. Edison. La policía de Nueva York estuvo recibiendo cartas firmadas con las iniciales F.P. en las que decía que llevaría ante la justicia a la empresa Con. Edison por sus actos ruines. La alarma social se desató cuando apareció la tercera bomba en la Estación Central y sucesivamente fueron apareciendo en cabinas telefónicas, estaciones de tren y cines. El bombardero loco escribe una carta a la prensa diciendo que no parará hasta que la empresa Con. Edison sea llevada ante los tribunales. No dejaron de aparecer bombas por toda la ciudad y empezaron a llevarse muertes consigo.

c. Análisis conductual del criminal: El encargado del caso, el inspector Howard Finney decide acudir a la ayuda de un psiquiatra freudiano, James Brussel y le enseñó fotos de las bombas, las cartas y toda la documentación recopilada. Brussel analizó el caso como si se tratara de un paciente más, de manera que analizó sus síntomas, sus comportamientos hasta poder establecer un diagnóstico que pudiera ayudar a la policía. Lo primero fue analizar la obsesión con la empresa Con. Edison, lo que le hizo sospechar de un trastorno paranoico. De igual manera hizo un análisis grafológico de las cartas, en las que pudo identificar a una persona ordenada y meticulosa y con buen nivel educativo. Todas las letras eran mayúsculas y con buena caligrafía, exceptuando las "w" que a Brussel le parecían dos pechos. También llegó a la conclusión de que el hecho de rajar los sillones de los cines para introducir las bombas, representaba 
la penetración sexual. Para Brussel, el bombardero habría quedado fijado en la etapa edípica, no tendría muy buenas relaciones con las mujeres y seguramente sería una persona solitaria que viviría con su madre. También apuntó que podría ser eslavo, debido al análisis de las cartas. Y el dato más asombroso fue que advirtió a la policía de que cuando fuera capturado llevaría un traje cruzado y abotonado.

d. Características del autor de los crímenes: Cuando lo capturaron, se encontraron con que vivía solo con sus dos hermanas, le dijeron que se vistiera y se puso un traje cruzado y abotonado. Le preguntaron por las iniciales F.P a lo que el delincuente respondió que se referían a "fair play" (juego limpio). Trabajaba como mecánico en la empresa Con. Edison hasta que un día hubo un escape de gases tóxicos que le provocó graves problemas respiratorios y le despidieron del trabajo. Las denuncias a la empresa fueron ignoradas, así que de esa manera comenzó su venganza.

\subsection{ANTECEDENTES EN EL ESTUDIO DEL PERFIL CRIMINOLÓGICO (CRIMINAL PROFILING)}

El método del Criminal Profiling tiene sus inicios en el ámbito policial. A finales de los años 70, los agentes del FBI Robert K, Ressler, John Douglas y Roy Hazelwood comienzan a analizar el comportamiento de asesinos y violadores seriales, llevando a cabo un estudio con entrevistas a más de 36 asesinos sexuales ( 25 de los cuales eran seriales), tratando de dilucidar las claves de sus modus operandi, sus motivaciones y las circunstancias de sus vidas que podrían haber facilitado sus violentas carreras criminales. (Garrido, 2008).

Abeijón (2005), destaca el hecho de que en 1985, Robert Ressler inicia un estudio en profundidad en el seno del programa VICAP (Programa de Detección del Crimen Violento), en el que se trata de coordinar toda la información recogida por todos los cuerpos de seguridad de Estados Unidos, analizando perfiles psicológicos de los criminales, elementos comunes presentes en los delitos y en los criminales, para así poder obtener datos que permitieran la resolución de casos análogos.

No obstante, Jiménez (2012), apunta que la metodología fue criticada por el escaso número de sujetos estudiados y porque no todos ellos eran agresores seriales. De 
los resultados de dicho estudio se estableció una tipología de agresores principalmente basada en la escena del crimen, diferenciando los llamados "organizados" de los “desorganizados". Los autores tratan de describir cómo sería la escena del crimen de un psicópata (organizado) y la de un psicótico (desorganizado). Con esta tipología, los autores pretendían servir de ayuda a los policías para identificar datos, analizarlos, interpretarlos y así llegar a capturar al autor del crimen.

Desde el punto de vista científico se alega que dicha categorización no tiene fiabilidad ni validez estadísticamente significativa, no obstante sigue siendo de utilidad y sumamente valorada por las fuerzas de seguridad. A este respecto, Ressler (2005) afirma que en sus inicios en la Unidad de Ciencias del Comportamiento: "en aquel entonces, las técnicas de elaboración de Perfiles Criminales eran todavía menos científicas que ahora; era un arte que uno tenía que aprender laboriosamente siendo aprendiz durante muchos años" (Ibíd,2005, p.198).

De manera que Ressler (2005) explica cómo en sus inicios, la elaboración de un Perfil dependía más de la intuición del investigador que de una metodología estadística comprobada y estructurada. Pero en cuanto esta técnica aparece en el mundo académico y de la investigación, genera multitud de críticas por esa falta de criterio científico.

Así mismo, según indica Jiménez (2015), el objetivo que persigue el Perfil Criminológico no es sólo el aporte de una descripción del delincuente en cuanto a sus características psicológicas o criminológicas sino que pretende extraer información de utilidad para proporcionar a los investigadores policiales. Esta información puede incluir características físicas del autor que ayuden a reconocerlo, lugares que frecuenta o de posible actuación, probabilidad de que cometa actos en un futuro e incluso una aproximación al lugar de residencia del delincuente. El Perfil Criminológico entonces no sólo se basa en la descripción de rasgos de la personalidad del criminal sino que consiste en identificar características del mismo en diferentes estratos: a nivel psicológico, social, demográfico, económico, etc.

Jiménez (2015) explica que:

Este enfoque se ha completado añadiendo análisis de tipo criminológico y criminalístico, dando lugar al enfoque de Análisis de la Escena del Crimen, creado por el FBI a través de su unidad de ciencias del comportamiento y que luego se ha extendido a fuerzas policiales de otros países. Dicha metodología 
trabaja sobre la escena, reconstruye el crimen, analizar los informes forenses y de policía científica para inferir características del autor. (Ibíd, 2015, p.72)

Mediante el uso de la técnica del Perfil Criminológico se asientan sus bases como procedimiento de investigación policial, generando una teoría, un proceso formativo y también publicidad con la que se da a conocer. De forma que:

El desarrollo de los Perfiles Criminológicos en el FBI nace de una forma más o menos sistemática con el Proyecto de Investigación de la Personalidad Criminal (PIPC). En él, Ressler y su equipo realizan entrevistas por todas las cárceles de EE.UU. a cientos de criminales. Estas entrevistas se realizan también a personal carcelario, médicos y familiares de los criminales, realizándose posteriormente un análisis estadístico para establecer patrones de comportamiento criminal que puedan usarse en la realización de perfiles. (Jiménez, 2012, p.46)

Desde ese momento, el FBI colabora con los policías de todo el país, proporcionando asesoramiento y realizando perfiles para las investigaciones abiertas. Así lo indican Ressler y Shachtman (2005): "La Unidad de Ciencias del Comportamiento se establece como el equipo que se dedica a este asesoramiento, a la recolección de datos (a través del PIPC) y a la formación de futuros perfiladores" (citado en Jiménez, 2012).

\subsection{METODOLOGÍAS REFERENCIALES EN LA INVESTIGACIÓN DEL PERFIL CRIMINOLÓGICO}

A raíz de las investigaciones llevadas a cabo en los años 70, en las que no se contaba aún con un equipo multidisciplinar especializado en las Ciencias Forenses, surgieron tres vías investigadoras (Inductiva, Deductiva y Abductiva) con el fin de que la realización de un Perfil Criminológico tuviera un mayor rigor científico y contara con un equipo de profesionales en el ámbito.

Por tanto, se puede afirmar que en el caso del "Razonamiento Deductivo", la lógica que se sigue es extraer una conclusión de unas premisas, es decir, aplicar una regla general a un caso en particular. En el caso del "Razonamiento Inductivo" es al contrario, se parte de un caso particular y se pretende extraer una regla general. Se realiza a través de la inferencia. En cuanto a la "Abducción”, se infiere un caso a partir de la regla general y el resultado. (Norza et al.,2013). 
De esta manera, la diferencia entre los tipos de razonamiento es explicada por Soto (2014) de la siguiente manera:

La deducción prueba la necesidad de algo; la inducción muestra que algo es actualmente activo; la abducción simplemente sugiere que algo puede ser. La abducción elabora una hipótesis explicativa, introduce una idea novedosa; la inducción sólo introduce un valor, y la deducción desarrolla consecuencias necesarias a partir de sus premisas. (Soto, 2014,p.50).

\subsubsection{Metodología inductiva}

El interés por el estudio del crimen y en concreto del Perfil Criminológico se ha visto acrecentado dentro del ámbito investigativo y científico, externo al campo de los cuerpos de seguridad. De manera que se han creado diferentes metodologías que aporten mayor fiabilidad y validez. Jiménez (2015) afirma que este enfoque, denominado de Investigación Académica, surge a raíz de las investigaciones de David Canter a mediados de los años noventa en la Universidad de Liverpool, y sustenta sus bases en el análisis estadístico y la metodología inductiva.

Canter (1995) interviene en el campo del Perfil Criminológico, como asesor de un caso de violación serial. Además, es experto en psicología ambiental y con un gran conocimiento en metodología experimental. A partir de su colaboración en este caso, inicia una nueva Metodología Inductiva (más alejada de la llevada a cabo por el FBI), que parte esencialmente de la recogida de datos de crímenes y criminales ya conocidos y su análisis estadístico posterior. El objetivo que perseguía Canter era obtener patrones de conducta y una metodología más estructurada para la elaboración posterior de un Perfil Criminológico.

Para la Metodología Inductiva la escena del crimen resulta crucial en la elaboración del perfil. A partir de ella se relacionan indicios o características que han sido vistas antes en otros crímenes de manera que ayudan a pensar en determinado tipo de persona. Como indica Jiménez (2015), de la comparación de casos resueltos con anterioridad con el caso actual, se extraen características comunes:

Por ejemplo, si en los casos resueltos de agresiones sexuales en serie, casi todos habían sido cometidos por varones y nuestro caso actual es de una agresión sexual, la inferencia que se puede hacer es que es muy probable que el autor de esta agresión también sea varón. (Ibíd, 2015, p.75) 
Por tanto, de todas las variables provenientes de la escena del crimen, las evidencias físicas y psicológicas, la victimología, el comportamiento geográfico del autor, así como características emocionales y motivacionales del mismo, se establecen hipótesis que serán después comprobadas por medio de análisis estadísticos anteriormente recogidos. (Garrido, 2000; Garrido, Stangeland y Redondo, 2006).

Además, esta Metodología Inductiva permite la aplicación de los perfiles también en otros delitos relacionados con terrorismo, piromanía, crimen organizado, entre otros a parte de los asesinatos y violaciones seriales tan necesarios en la actualidad. (Canter, Alison, Alison y Wentink, 2004; Fritzon, Canter y Wilton, 2001).

Esta escuela es denominada Psicología Investigadora. Algunos de los principios teóricos básicos en los que se sustenta son los siguientes (Canter, 1993):

a) Hipótesis de la Consistencia: referida al comportamiento del criminal.

b) Consistencia Interpersonal: referida a las relaciones interpersonales que establece el agresor.

c) Metodología de Escalamiento Multidimensional: referida al análisis estadístico de las características del crimen.

d) El concepto de crimen como narración de una historia personal: referido a la manera en que el criminal relata sus crímenes.

a. Hipótesis de la Consistencia (Canter, 1993)

La hipótesis de la consistencia establece que un criminal se comportará de forma muy parecida a como se comporta en su "vida normal". El comportamiento que lleve a cabo en su día a día aporta rasgos de su personalidad, por lo que la escena del crimen debería aportar rasgos que dieran pistas sobre su comportamiento y personalidad.

En este sentido, la hipótesis de la consistencia delictiva "es quizá la piedra angular sobre la que se sustentan los trabajos de la Psicología Investigadora" (Jiménez, 2012, p.57).

Igualmente, Canter (2003) expone la ecuación en la que se basa la Hipótesis de la Consistencia:

A partir de aquí es posible establecer una ecuación A-R-C, en la que la A son todas las acciones que ocurren y que relatan un crimen. Es necesario establecer qué características del crimen y su escena son las realmente importantes y 
relevantes para tener en cuenta a la hora de examinar el crimen. $\mathrm{C}$ se refiere a las características del delincuente y $\mathrm{R}$ es la relación que se puede establecer entre A y C. (Ibíd,2003, p.160).

\section{b. Consistencia interpersonal}

La consistencia interpersonal hace referencia al autor del delito, el cual se comportará de manera muy similar con la víctima a cómo se comporta con las personas con las que tiene contacto en su día a día. (Canter, 1993).

De esta manera, se aplica "la teoría de las facetas" expuesta por Morales et al. en el año 2007, la cual consiste en la identificación de patrones conductuales (facetas) que se puedan observar o inferir en la escena del crimen y en la información sobre la comisión de un delito. Esta forma de actuación liderada por Canter se centra en la recolección de diferentes patrones de conducta criminal. Estos patrones son:

- Violencia ejercida sobre la víctima: se pueden clasificar a los delincuentes en expresivos o instrumentales. En el caso de los expresivos, la violencia surge de un estado emocional, como resultado de un estado de ira, venganza o frustración. Lo que buscan es hacer daño a la víctima y provocarle sufrimiento. Respecto a los instrumentales, usan la violencia como medio para satisfacer diversas necesidades, como por ejemplo sexuales o económicas. (Goodwin, 2000).

- Conductas de la escena del crimen: se pueden clasificar a los delincuentes en: delincuentes con planificación y delincuentes impulsivos. Los que utilizan la planificación suelen tener una inteligencia alta, son adaptados, socialmente competentes y pueden preparar y planear sus crímenes. En cambio, los impulsivos, no poseen demasiada inteligencia, tienen dificultades de aprendizaje, se dejan llevar y actúan sin ningún tipo de organización. (Safati y Canter, 1999).

- Relación entre delincuente y víctima: es posible clasificar a las víctimas en: víctima objeto, víctima vehículo y víctima persona. (Santillana, Runtti y Mokros, 2004).

En palabras de Canter (1993): 
Cuando la víctima se trata como objeto, hay una falta de sentimiento y empatía con ella, al delincuente no le interesa interactuar, la víctima es poco más que un objeto para ser explorado y jugar con él. (Ibíd, 1993, p.58)

Finalmente, y referente a la relación de poder agresor-víctima, Morales et al. (2007) describen cómo en las ocasiones en las que el criminal ejerce mucho control sobre la víctima, su deseo de poder es especialmente fuerte y se comportará de manera muy violenta con la víctima. Cuando la víctima es tratada a modo de vehículo, el delincuente se comportará con engaños, manipulación y seducción para conseguir algo de la víctima. En los casos en que la víctima es tratada como una persona, el delincuente suele conocer a la víctima y le lleva a establecer interacción y contacto con la misma.

\section{c. Metodología de "Escalamiento Multidimensional"}

Esta metodología es una aportación novedosa para la identificación de tipologías delictivas. Así, Soria y Sáiz (2008) describen que se basa en el análisis estadístico de las características y variables de la escena del crimen, de la víctima, del agresor, etc. El objetivo que persigue es identificar características del delincuente que sean similares a las de otros delincuentes que actúen de forma parecida y que las distingan también de delincuentes que actúen de manera diferente.

Se utiliza el Small Space Analisys (SSA) y el análisis clúster, "ambas metodologías analizan las correlaciones entre las distintas variables y crean grupos de variables que suelen aparecer juntas, diferenciándolas de aquellas que no suelen estar presentes a la vez. A partir de estos datos, los autores pueden elaborar clasificaciones y tipologías con distintas actividades criminales" (Jiménez, 2012, p.59).

El enfoque de Canter (1995) considera la motivación como una de las posibles explicaciones de la conducta criminal, sin embargo critica a su vez que sea la explicación más importante y útil para entender las acciones de una persona. De manera que Canter y Alison (2000) consideran que desde su enfoque, resulta de mayor importancia la conducta observable del agresor que las causas generadoras.

Para Canter (1995), es necesario que el perfilador posea algunas cualidades para el análisis de la escena de un crimen:

a. Capacidad de percibir detalles.

b. Capacidad para percibir patrones de conductas delictivas. 
c. Conocimiento extenso en el poder comparar patrones.

Además, Turvey (2002), añade que es necesario constar de unas habilidades psicológicas específicas para enfrentarse a la difícil tarea de elaborar un perfil. Él sugiere las siguientes:

a. Procurar librarse de deseos y necesidades personales.

b. Aceptar que cualquier conducta y sentimiento puede ser objeto de una fantasía de poder o de sexo.

A la par, Garrido (2008) afirma que "el investigador ha de ser capaz de comprender desde qué ojos está observando el criminal la realidad, de la misma manera que deberá ser posible para él entender a la víctima de un modo plenamente humano, aun a costa de un cierto coste psicológico por su comprensión empática de su sufrimiento" (Ibíd, 2008, p.123).

\section{d. El concepto de crimen como narración de una historia personal}

Keppel y Birnes (1997) afirman que "la víctima, las escenas del crimen y las herramientas o armas empleadas por el asesino son utilizadas como extensiones de sí mismo, como manifestaciones físicas de sus deseos. Dado que el asesino está satisfaciendo sus propias necesidades, no puede si no dejar su tarjeta de visita en la escena del crimen" (Ibíd,1997, p.126).

Garrido (2008) explica el concepto de historia personal propuesto por Canter (2000) para hacer referencia a que cada crimen cometido conforma un capítulo de la historia que escribe el delincuente. Es decir, la narrativa del crimen pone especial atención en lo que el criminal expresa en cada capítulo de la historia del delito que ha realizado, pudiendo así llegar a discernir características y rasgos de la personalidad del asesino para dar con él. A este respecto, este autor refiere que:

Raramente los delitos violentos están al margen de la cólera y la frustración que sienten sus autores, aunque tales sentimientos pueden enmascararse gracias a los hechos realizados por el deseo de evitar la detección, o por la creencia que alberga el asesino de que simplemente, lo que él está haciendo es obtener "simple justicia. (Garrido, 2008, p.124) 
Según Canter (2008), el criminal a través de sus acciones habla de su historia vital, de cómo es su día a día, y los investigadores son los que han de ver en esa historia los datos que interesan para poder capturarlo. Los analistas del comportamiento tratarán de dar con el asesino y ubicarlo en la escena.

\subsubsection{Metodología Deductiva.}

Para realizar el perfil del agresor, Turvey (2000) considera que resulta de mucha utilidad hacer comparaciones con las características de otros comportamientos criminales similares de población conocida (penitenciaria o carcelaria) obtenida mediante el método deductivo.

La Metodología Deductiva se orienta hacia las interpretaciones de la evidencia forense (fotografías de la escena del crimen, autopsia, etc.) de manera que pueda ser posible el realizar inferencias sobre aspectos psicosociales del autor del crimen basadas en un análisis criminalístico, forense y psicológico. (Abeijón, 2006; Giraldo, 2006; Turvey, 1998).

A este respecto, Soria et al (2008) apuntan que:

El proceso deductivo de Perfil Criminal también ha recibido el nombre de "Análisis de la Evidencia del Comportamiento" (Behavior Evidence Analysis) y depende de las habilidades del perfilador para reconocer patrones de comportamiento criminal durante la comisión del crimen, características de la personalidad del criminal y características demográficas, únicamente a partir del análisis de tres tipos de fuentes: la evidencia forense, las características de la escena del crimen y la victimología. (Ibíd, 2008, p.368).

Las herramientas utilizadas por el Método Deductivo para llegar a dilucidar la manera de actuar o modus operandi del agresor son descritas a continuación (Turvey, 1998; López, 2008):

- Evidencia Forense: información extraída del crimen.

- Características de la escena del crimen: como huellas, objetos, etc.

- Victimología: referente a las características que poseen las víctimas y la relación establecida con el agresor.

- Distribución geográfica: referente a las zonas de actuación del agresor. 


\subsubsection{Metodología Abductiva}

El término abducción fue introducido por Aristóteles (384 a. C.- 322 a. C) en su obra "Primeros analíticos" y lo definía como "la inferencia que se realiza cuando es evidente que entre los términos el término medio se predique del primer término, pero no resulta tan evidente que el término medio se derive del último, por muy probable que sea la conclusión" (Soto, 2014, p.51)

Como se explicó anteriormente, la abducción, también denominada "hipótesis" (Peirce, 1906, p.541) se diferencia de la inducción en que propone un argumento novedoso que no se había dado anteriormente (Soto, González y Pérez, 2014). De manera que la deducción viene conformada por los resultados de hipótesis experimentales, la inducción es la prueba experimental y la abducción puede basarse en una hipótesis para predecir hechos.

La abducción se compone de dos pasos tal y como describe Aliseda (1998): seleccionar la información y elaborar hipótesis explicativas. La selección de información se extrae de la escena del crimen, o de la información proporcionada por testigos o víctimas. A través de la interpretación de los datos, se da lugar a la elaboración de hipótesis, a partir de las inferencias que buscan establecer hábitos o regularidades.

Asimismo, Aliseda (1998) explica el proceso abductivo de la siguiente manera:

El proceso cognitivo que integra a la inferencia abductiva con el proceso epistémico puede describirse como sigue: una experiencia novedosa o anómala da lugar a un hecho sorprendente, el cual genera un estado de duda que rompe un hábito de creencia, y así dispara el razonamiento abductivo. Este consiste justamente en explicar el hecho sorprendente y así "apaciguar" el estado de duda. Debe tenerse cuidado con el término anterior de: "apaciguar", pues aunque se puede llegar a una solución plausible, la duda no desaparecerá en tanto una explicación abductiva no necesariamente desemboca en una nueva creencia. La explicación abductiva es simplemente una sugerencia que debe ser puesta a prueba antes de convertirse en creencia. (Ibíd, 1998,p. 4).

La abducción, por tanto, permite extraer mediante ciertos rasgos, los indicios del delito, es decir si es obra del autor del que se sospecha. Igualmente, trata de identificar 
la especie a la que pertenece. Identifica un delito que el mismo autor ha cometido de forma parecida en el pasado. Una vez que se sabe que algo pertenece a una especie concreta, como incluir un delito cometido entre los delitos cometidos por un mismo sujeto, se pueden extraer un gran número de consecuencias acerca de lo que puede esperarse de la inclusión de un acto en una especie de actos. De manera que la abducción se convierte en un proceso en que frente a los indicios del delito, extrae una hipótesis explicativa, el perfil criminológico. Se trata de conectar datos, los delitos, mediante sus semejanzas y diferencias, que puedan llevarnos a una ley general, que sería el Perfil del criminal. Se trata de partir de los hechos, el delito, a la causa, su autor. (Soto, 2014).

Los tres tipos de razonamiento, son los pasos a recorrer en el camino hacia el esclarecimiento del delito. El primer paso sería la abducción por proporcionar una hipótesis en forma de perfil del delincuente, la deducción hará una predicción que será probada mediante la inducción. (Soto, 2014).

El método V.E.R.A. (Víctima, Escenario del Delito, Reconstrucción del Delito y Autor) se asienta en la Metodología Abductiva y como método hipotético utiliza el estudio de caso único. Es un método de reciente creación indicado para la realización del Perfil Criminológico.

\section{EL MÉTODO VERA (Soto, 2014).}

El método V.E.R.A. es una técnica de elaboración de Perfiles Psicológicos de delincuentes violentos que ha sido creada en el año 2014 por Juan Enrique Soto, Inspector Jefe del Cuerpo Nacional de Policía y Jefe de Sección de Análisis de Conducta de la Unidad Central de Inteligencia Criminal del citado Cuerpo, fruto de su experiencia como investigador policial de delitos violentos y como psicólogo.

La técnica aúna los conocimientos actuales sobre el Perfil Criminológico y pretende ser un método objetivo de elaboración de Perfiles Psicológicos durante todo el proceso de elaboración de estos, tanto en la recopilación de los datos y en la realización de inferencias a partir de ellos como en la elaboración de hipótesis que den lugar al perfil final.

El acrónimo VERA lo componen: víctima, escenario del delito, reconstrucción del delito y autor. El objetivo de este método es solventar las carencias que existen de la 
comparación de los casos de criminalidad cometidos con los que sí han sido resueltos. (Soto et al., 2014).

Como se ha indicado anteriormente, el Método VERA es el utilizado por la Metodología Abductiva. Dicho método es fundamentado sobre las siguientes razones propuestas por Soto (2014) a continuación:

1. las situaciones estudiadas son reales, lo que nos permitirá desarrollar una visión de esa realidad, matizada, eso sí, por el contexto en el que tiene lugar y que la condiciona especialmente. El contexto en el caso de los actos delictivos deviene fundamental debido a que no se delinque cuando se quiere sino cuando se puede, cuando las circunstancias que rodean a los personajes que lo ejecutan y sufren, agresor y víctima respectivamente, se componen de tal modo que lo permiten.

2. El proceso de aprendizaje que generan estas investigaciones permitirá el desarrollo de una técnica cuyas conclusiones se irán perfeccionando a medida que se obtengan experiencias concretas y reales gracias a la retroalimentación que proporcionan los investigadores policiales encargados de llevar a buen término cada uno de los casos policiales investigados.

El método VERA es un método de estudio y análisis del comportamiento humano centrado en las relaciones interpersonales. De manera que resulta de importancia obtener información acerca de las emociones, motivaciones, procesos adaptativos y demás procesos cognitivos en relación a la conducta del agresor, útiles para la elaboración de un Perfil. Por lo tanto, es una técnica de gran interés en casos de delitos violentos como asesinatos o agresiones sexuales.

Fases del Método VERA (Soto, 2014).

El método VERA se compone de cuatro fases diferenciadas que Soto (2014) enumera en el siguiente orden:

1. recopilación de datos.

2. Realización inferencias.

3. Elaboración de hipótesis.

4. Redacción y entrega del informe

Dichas fases se desarrollan con mayor profundidad a continuación: 
$1^{o}$. Paso: Recopilación de datos: es la primera fase del método y se basa en la recolección de información que pueda ser relevante obtener sobre el caso investigado. Esta información se distribuye en las cuatro categorías que componen el método: víctima, escena del crimen, reconstrucción y autor.

Soto (2014) pone especial énfasis en que los datos recogidos consten de la mayor objetividad posible, dejando fuera interpretaciones o especulaciones.

Los datos se distribuyen en tablas específicas para cada categoría (víctima, escena del crimen, reconstrucción y autor).

Para el análisis estadístico de todo el material que servirá para la creación del Perfil Criminológico se codificarán los datos obtenidos según la siguiente premisa:

- D: referido a los datos obtenidos.

- V: referido a los datos obtenidos de las víctimas.

- E: referido a los datos obtenidos de la escena del crimen.

- R: referido a los datos obtenidos de la reconstrucción del delito.

- A: referido a los datos obtenidos del autor del crimen.

De manera que cada dato es codificado con la letra D y las iniciales del acrónimo VERA quedando referenciado como DV, DE, DR y DA según sea referido a la víctima, a la escena, a la reconstrucción o al autor, seguida de un número ordinal para facilitar la identificación y localización. Hay que destacar que en cada casilla sólo debe aparecer un dato, para que a la hora de realizar las inferencias sea posible identificar con claridad la información y su origen. (Soto, 2014). Esto queda reflejado en la Tabla 1:

Tabla1: Recopilación y codificación de datos (Soto et al., 2104).

\begin{tabular}{|l|l|}
\hline DATO & VÍCTIMAS \\
\hline D V1 & \\
\hline D V2 & \\
\hline D Vn & \\
\hline DATO & ESCENA DEL DELITO \\
\hline D E1 & \\
\hline D E2 & \\
\hline D En & \\
\hline
\end{tabular}




\begin{tabular}{|l|l|}
\hline DATO & RECONSTRUCCIÓN DEL DELITO \\
\hline D R1 & \\
\hline D R2 & \\
\hline D Rn & \\
\hline DATO & AUTOR \\
\hline D A1 & \\
\hline D A2 & \\
\hline D An & \\
\hline
\end{tabular}

$2^{\circ}$ Paso:Realización de inferencias: esta fase ayuda a realizar inferencias lógicas partiendo de los datos existentes. Se ha de tener en cuenta la interrelación entre los datos, es decir, que cada dato es influido por otros y viceversa, de manera que aunque el análisis se haga dato a dato, no hay que obviar el conjunto de los mismos y la información que proporciona.

$\mathrm{Al}$ igual que en el apartado anterior, las inferencias se codifican con la letra I, y las iniciales de VERA según sea referida a la víctima, a la escena, a la reconstrucción o al autor, seguida de un número ordinal y añadiendo los códigos de la inferencia que proceda para tener claro el origen. Esta codificación de la información queda expuesta en la Tabla 2.

Tabla 2: Realización de inferencias (Soto et al., 2014).

\begin{tabular}{|l|l|l|}
\hline INFERENCIA & VÍCTIMAS & PROCEDE DE \\
\hline I V1 & & \\
\hline I V2 & & \\
\hline I Vn & & \\
\hline INFERENCIA & ESCENA DEL DELITO & PROCEDE DE \\
\hline I E1 & & \\
\hline I E2 & & \\
\hline I En & $\begin{array}{l}\text { RECONSTRUCCIÓN } \\
\text { DEL HECHO }\end{array}$ & PROCEDE DE \\
\hline INFERENCIA & & \\
\hline I R1 & &
\end{tabular}




\begin{tabular}{|l|l|l|}
\hline I R2 & & \\
\hline I Rn & & \\
\hline INFERENCIA & AUTOR & PROCEDE DE \\
\hline I A1 & & \\
\hline I A2 & & \\
\hline I An & & \\
\hline
\end{tabular}

$3^{\circ}$ Paso: Elaboración de hipótesis: las hipótesis se formulan en base a las inferencias de las que proviene de tal forma que permita la identificación de éstas. En esta fase se codifican con la letra $\mathrm{H}$ (hipótesis), seguida del número ordinal que le corresponda y añadiendo los códigos de las inferencias de las que proviene.

Los resultados de estas hipótesis ofrecerán el Perfil Psicológico del posible autor de los hechos.

Tabla 3: Elaboración de hipótesis (Soto et al., 2014).

\begin{tabular}{|l|l|l|}
\hline HIPÓTESIS & & PROCEDE DE \\
\hline $\mathrm{H} 1$ & & \\
\hline $\mathrm{H} 2$ & & \\
\hline $\mathrm{Hn}$ & & \\
\hline
\end{tabular}

$4^{\circ}$ Paso: El perfil psicológico y las sugerencias operativas: en esta última fase y a partir del Perfil Psicológico obtenido, se redacta un informe final que será entregado a las unidades especializadas que lo demanden. En este informe no sólo se incluyen hipótesis, sino que también se recomiendan pautas de actuación para poder actualizar hipótesis o confirmarlas, siempre orientadas a la captura del criminal.

El informe es entregado por escrito, aunque es conveniente que se exponga también de manera verbal para poder resolver todas las dudas que puedan surgir. El informe como apuntan Soto et al., (2014), debe ir firmado, con la fecha de su elaboración y con la hora de su finalización, por el analista que lo elaboró, y deberá explicar sus conclusiones. 
Un mismo autor puede presentar diferentes motivos para cometer diferentes actos o en un mismo acto presentar diversas motivaciones. Por tanto, no hay dos delincuentes iguales. Cada uno es producto de su propia historia personal, de sus experiencias y emociones, de su biología y su psicología, del que configuró sus vicisitudes, las decisiones que tomó, etc. cada delincuente tiene el potencial para crear escenas del delito su modo, así como para satisfacer sus propias necesidades emocionales. Hay indudablemente, similitudes entre diferentes agresores, pero el método VERA establece un perfil psicológico del autor del delito violento que permite a los policías encargados de la investigación restringir las alternativas de búsqueda de sospechosos para una más pronta identificación y detención, con la consiguiente prevención de delitos y sus correspondientes víctimas. (Soto, 2014, p.77).

Por último es necesario tomar en cuenta la aportación de Jiménez (2015) que asevera que a los policías no les sirve que los perfiladores les indiquen ciertos rasgos de personalidad de un sospechoso, o qué trastorno padece, sino que es necesario proporcionales datos operativos, es decir, dónde puede encontrarlo, edad, cómo viste, su trabajo, etc.

Para la mejor comprensión de este novedoso método de realización del Perfil Psicológico del criminal violento, se expone un caso real a continuación.

\section{EJEMPLO DEL MÉTODO VERA APLICADO A UN CASO}

\section{PRESENTACIÓN DEL CASO}

El presente caso está situado geográficamente en la localidad de Santiago de Compostela. La fecha del mismo data del 12 de agosto del año 2009: miércoles a las 23:45 horas de la noche. Cuando la Policía acude al lugar de los hechos, encuentran una mujer de avanzada edad en el sofá del salón de su casa y sin vida. Al llegar los facultativos médicos confirman el fallecimiento de la misma, apreciándose que se ha producido de manera violenta, por lo que avisan a las instituciones correspondientes para iniciar la investigación del crimen. 
De acuerdo a los datos expuestos, se procede a desarrollar el Método V.E.R.A. con el fin de ejemplificar la elaboración de un Perfil Psicológico de un Delincuente Violento.

\section{TÉCNICA DE ELABORACIÓN DEL PERFIL CRIMINOLÓGICO}

Tabla 4: Ejemplo del Método Vera: Víctima

\begin{tabular}{|c|c|}
\hline DATOS & VÍCTIMA \\
\hline VA1 & 70 años \\
\hline VA2 & Mujer \\
\hline VA3 & Viuda \\
\hline VA4 & Bajos recursos económicos \\
\hline VA5 & No tiene estudios ni trabaja \\
\hline VA6 & Vive sola \\
\hline VA7 & Sí \\
\hline VA8 & Estilo de vida pasivo \\
\hline VA9 & Viste con ropa negra \\
\hline VA10 & Personalidad depresiva y con necesidad de atención \\
\hline VA11 & Enfermedad degenerativa: Parkinson \\
\hline VA12 & No tiene antecedentes psiquiátricos \\
\hline VA13 & Existe documentación de su historial médico \\
\hline VA14 & No tiene antecedentes policiales ni judiciales. \\
\hline VA15 & No requiere atención de los Servicios Sociales Municipales. \\
\hline VA16 & Plaza con árboles próximos a su domicilio. \\
\hline VA17 & Presenta riesgo rasgo: persona mayor \\
\hline VA18 & $\begin{array}{l}\text { Pelo de color blanco, ojos oscuros, piel muy blanca, estatura } 1,60 \mathrm{~cm} \\
\text { y obesidad. }\end{array}$ \\
\hline VA19 & Víctima por disponibilidad y accesibilidad \\
\hline VA20 & Intentó resistirse \\
\hline VA21 & Resistencia física \\
\hline VA22 & La víctima no presenta obediencia \\
\hline VA23 & El domicilio se encuentra en un barrio de nivel bajo en una zona no \\
\hline
\end{tabular}




\begin{tabular}{|l|l|}
\hline & conflictiva. \\
\hline VA24 & No hay más víctimas. \\
\hline VA25 & $\begin{array}{l}\text { La víctima se encuentra en el sofá de su casa, tumbada y con la ropa } \\
\text { desabrochada. Presenta varias heridas y está sin vida. }\end{array}$ \\
\hline VA26 & No hay indicios ni nota de suicidio. \\
\hline VA27 & No existen intentos autolíticos previos. \\
\hline VA28 & $\begin{array}{l}\text { Es viuda. } \\
\text { pobres. }\end{array}$ \\
\hline VA29 & $\begin{array}{l}\text { Recopilación de información, VA29 datos sobre la víctima, que } \\
\text { permitirán realizar las pertinentes inferencias para esclarecer ¿Por } \\
\text { qué esa víctima y no otra? }\end{array}$ \\
\hline Van &
\end{tabular}

Tabla 5: Ejemplo del Método Vera: Escena del delito

\begin{tabular}{|l|l|}
\hline \multicolumn{1}{|c|}{ DATOS } & \multicolumn{1}{c|}{ ESCENA DEL DELITO } \\
\hline EA1 & Domicilio \\
\hline EA2 & En el salón \\
\hline EA3 & Escena primaria \\
\hline EA4 & Suele visitar el domicilio la vecina \\
\hline EA5 & Entran por la puerta, que es el único acceso al domicilio \\
\hline EA6 & Es una vivienda unifamiliar \\
\hline EA7 & La víctima reside en la vivienda de forma constante \\
\hline EA8 & Clase social baja. \\
\hline EA9 & No es una zona conflictiva \\
\hline EA10 & No se relaciona con otras escenas \\
\hline EA11 & No existe en la vivienda la privacidad adecuada: casa baja \\
\hline EA12 & Existen huellas lofoscópicas, biológicas y calzado. \\
\hline EA13 & No ha sido seleccionada al azar \\
\hline EA14 & $\begin{array}{l}\text { No existen hallazgos de armas de fuego, blancas u objetos } \\
\text { contundentes. }\end{array}$ \\
\hline EA15 & \\
\hline
\end{tabular}




\begin{tabular}{|l|l|}
\hline EA16 & $\begin{array}{l}\text { La víctima se encontraba en su domicilio. El cadáver fue trasladado } \\
\text { al sofá. Muerte por estrangulación y agresión sexual a la víctima. } \\
\text { Existen signos de resistencia. }\end{array}$ \\
\hline EA17 & $\begin{array}{l}\text { Se ha llegado al domicilio a pie. } \\
\text { permitirá realizar las inferencias para determinar ¿Por qué ese lugar y } \\
\text { no otro? }\end{array}$ \\
\hline Ean
\end{tabular}

Tabla 6: Ejemplo del Método Vera: Reconstrucción del delito

\begin{tabular}{|c|c|}
\hline DATOS & RECONSTRUCCIÓN DEL DELITO \\
\hline RA1 & El método de aproximación ha sido el engaño. \\
\hline RA2 & El método de ataque ha sido fuerza física y dominación. \\
\hline RA3 & El método de control ha sido la agresión sexual y agresión física. \\
\hline RA4 & Hay un agresor principal. \\
\hline RA5 & $\begin{array}{l}\text { Diversas heridas en la víctima en cuello, muñecas, boca y en los } \\
\text { genitales. }\end{array}$ \\
\hline RA6 & $\begin{array}{l}\text { El nivel de planificación es bajo y desordenado. Se lleva una pulsera } \\
\text { de oro de la víctima. }\end{array}$ \\
\hline RA7 & Actúa por la noche y no presenta conciencia forense. \\
\hline RA8 & Amenaza y engaña a la víctima para entrar en el domicilio. \\
\hline RA9 & Comportamiento impulsivo y agresivo. \\
\hline RA10 & Vecina como víctima colateral. \\
\hline RA11 & Durante el último mes, realiza el ataque a la víctima varias veces. \\
\hline RA12 & Los ataques son rápidos \\
\hline RA13 & El día en que se dan los hechos es laboral, miércoles por la noche. \\
\hline RA14 & Sólo una víctima. \\
\hline RA15 & Víctima solitaria. \\
\hline RA16 & No se dan otros ataques por la zona \\
\hline RA17 & Lleva a cabo la agresión hasta lograr sus objetivos. \\
\hline RA18 & El resultado es la muerte de la víctima debido a las agresiones \\
\hline RA19 & El modus operandi no sufre modificaciones. \\
\hline RA20 & El modus operandi es el mismo en todos los ataques \\
\hline
\end{tabular}




\begin{tabular}{|c|c|}
\hline RA21 & Existen lesiones en la víctima. \\
\hline FA1 & Se da conversación con la víctima \\
\hline FA2 & No hay comunicación con la prensa y Policía \\
\hline FA3 & No deja mensajes en la escena del crimen \\
\hline FA4 & Ejerce violencia sobre la víctima: golpes y estrangulación. \\
\hline FA5 & Introducción de objetos en la agresión sexual \\
\hline FA6 & No se da mutilación. \\
\hline FA7 & No se lleva ningún trofeo de la víctima. \\
\hline FA8 & No saca fotografías. \\
\hline FA9 & $\begin{array}{l}\text { Sitúa el cuerpo de la víctima sobre el sofá y pone sus manos en el } \\
\text { regazo. }\end{array}$ \\
\hline FA10 & No existe actividad post-mortem. \\
\hline FA11 & Requiere favores sexuales. \\
\hline FA12 & Necesidad de control y dominación por parte del autor de los hechos \\
\hline RFAn & $\begin{array}{l}\text { Recopilación de información, RA21 datos sobre la reconstrucción de } \\
\text { los hechos, y otros datos FA12 referentes a la firma. Así, estos datos } \\
\text { permitirán realizar las inferencias oportunas para determinar ¿Qué } \\
\text { paso? }\end{array}$ \\
\hline
\end{tabular}

Tabla 7: Ejemplo del Método Vera: Autor

\begin{tabular}{|l|l|}
\hline \multicolumn{1}{|c|}{ DATOS } & \multicolumn{1}{c|}{ AUTOR } \\
\hline DA1 & Es amigo de la víctima \\
\hline DA2 & El acceso al domicilio es fácil \\
\hline DA3 & Suele estar en los alrededores del domicilio. \\
\hline DA4 & $\begin{array}{l}\text { En ocasiones duerme en el domicilio de la víctima, hay artículos } \\
\text { personales suyos. }\end{array}$ \\
\hline DA5 & $\begin{array}{l}\text { La talla del pantalón es una } 40 \text { y presenta manchas de suciedad. El } \\
\text { calzado entre las tallas } 44 . \text { Es un varón adulto de complexión normal } \\
\text { y estatura alta: } 1.85 \text { o } 1.90 \mathrm{~cm} .\end{array}$ \\
\hline
\end{tabular}




\begin{tabular}{|c|c|}
\hline DA6 & Consumidor de alcohol y drogas \\
\hline DA7 & $\begin{array}{l}\text { No ayuda en el hogar de la víctima y existe falta de empatía hacia la } \\
\text { misma. }\end{array}$ \\
\hline DA8 & Es agresivo e impulsivo. Se dan discusiones previas. \\
\hline DA9 & $\begin{array}{l}\text { Deja en el domicilio: un cepillo de dientes, su ropa, calzado y un } \\
\text { cartón de vino tinto. }\end{array}$ \\
\hline DA10 & Acude al domicilio a pie o en bicicleta. \\
\hline DA11 & Usa apodo: El Mani. \\
\hline DA12 & Problemas previos con la Justicia. \\
\hline DA13 & $\begin{array}{l}\text { Se lleva una pulsera de oro de la víctima. No dispone de recursos } \\
\text { económicos. }\end{array}$ \\
\hline DA14 & Frecuenta bares para consumir alcohol o comprarlo. \\
\hline DA15 & No se oculta. \\
\hline DAn & $\begin{array}{l}\text { Recopilación de información, DA15 datos sobre el autor, que } \\
\text { permitirán realizar las oportunas inferencias para dilucidar ¿Qué } \\
\text { sabemos del autor? }\end{array}$ \\
\hline
\end{tabular}

Tabla 8: Ejemplo del Método Vera: Inferencias Víctima

\begin{tabular}{|c|c|c|}
\hline INFERENCIAS & VÍCTIMA & PREOCEDE DE \\
\hline IV1 & $\begin{array}{l}\text { La víctima ha podido } \\
\text { identificada a través de } \\
\text { documentación. }\end{array}$ & $\begin{array}{l}\text { VA1 } \\
\text { VA2 }\end{array}$ \\
\hline IV2 & $\begin{array}{l}\text { La víctima apenas dispone de } \\
\text { recursos económicos. Se deduce de } \\
\text { los extractos bancarios. }\end{array}$ & $\begin{array}{l}\text { VA3 } \\
\text { VA4 } \\
\text { VA5 }\end{array}$ \\
\hline IV3 & $\begin{array}{l}\text { Sólo ella se encuentra empadronada } \\
\text { en su domicilio. }\end{array}$ & VA6 \\
\hline IV4 & $\begin{array}{l}\text { En la autopsia se determina que } \\
\text { existe maltrato físico previo. }\end{array}$ & VA7 \\
\hline IV5 & $\begin{array}{l}\text { Existe } \text { enfermedad } \\
\text { según su historial clínico. No }\end{array}$ & $\begin{array}{l}\text { VA8 } \\
\text { VA9 }\end{array}$ \\
\hline
\end{tabular}




\begin{tabular}{|c|c|c|}
\hline & $\begin{array}{l}\text { obstante, no hay datos de } \\
\text { psicopatología psiquiátrica. Estos } \\
\text { datos son corroborados por } \\
\text { familiares y vecinos además de por } \\
\text { documentos médicos hallados en el } \\
\text { domicilio de la víctima. }\end{array}$ & $\begin{array}{l}\text { VA10 } \\
\text { VA11 } \\
\text { VA12 } \\
\text { VA13 }\end{array}$ \\
\hline IV6 & $\begin{array}{l}\text { No existen datos de mala conducta } \\
\text { en la víctima ni en archivos } \\
\text { policiales ni en los Servicios } \\
\text { Municipales. }\end{array}$ & $\begin{array}{l}\text { VA14 } \\
\text { VA15 }\end{array}$ \\
\hline IV7 & $\begin{array}{l}\text { La víctima pertenece a un grupo de } \\
\text { riesgo por su edad, sexo y condición } \\
\text { física. }\end{array}$ & $\begin{array}{l}\text { VA16 } \\
\text { VA17 } \\
\text { VA18 }\end{array}$ \\
\hline IV8 & $\begin{array}{l}\text { La víctima era accesible y disponible } \\
\text { para el agresor, existió agresión y } \\
\text { ella se defendió hasta que el agresor } \\
\text { acabó con su vida. Es un dato } \\
\text { objetivo por la observación del } \\
\text { cadáver en la escena del crimen y } \\
\text { por la posterior autopsia realizada en } \\
\text { el Instituto Anatómico Forense. }\end{array}$ & $\begin{array}{l}\text { VA19 } \\
\text { VA20 } \\
\text { VA21 } \\
\text { VA22 }\end{array}$ \\
\hline IV9 & $\begin{array}{l}\text { Hubo agresión sexual: se deduce del } \\
\text { estado de su ropa, desabrochada. Se } \\
\text { confirma en la autopsia del cadáver. }\end{array}$ & VA25 \\
\hline IV10 & $\begin{array}{l}\text { Las pocas relaciones interpersonales, } \\
\text { el luto y su soledad son explicadas a } \\
\text { través de los testimonios recogidos y } \\
\text { la observación del estado del } \\
\text { domicilio de la víctima. }\end{array}$ & $\begin{array}{l}\text { VA28 } \\
\text { VA29 }\end{array}$ \\
\hline IVn & $\begin{array}{l}\text { ¿POR QUÉ ESA VÍCTIMA Y NO } \\
\text { OTRA? }\end{array}$ & Van \\
\hline
\end{tabular}


A raíz de los datos, se puede extraer que es una anciana de 70 años, española e identificada, que vive sola y es viuda. Además padece una enfermedad degenerativa, Parkinson. Existen condiciones de insalubridad para las cuales no han intervenido los Servicios Sociales. Pertenece al grupo de riesgo de "la tercera edad" por sus características: avanzada edad, solitaria.

En este sentido, su perfil se acerca a un prototipo de víctima para la delincuencia común. Por lo tanto, teniendo en cuenta la vulnerabilidad de la víctima, el ambiente, los bajos recursos económicos y sus pobres relaciones interpersonales además de sus características demográficas, orientan hacia la respuesta de ¿Por qué ha sido esta víctima y no otra?.

Tabla 9: Ejemplo del Método Vera: Inferencias de la Escena del Delito

\begin{tabular}{|l|l|l|}
\hline INFERENCIAS & \multicolumn{1}{|c|}{ ESCENA DEL DELITO } & PROCEDEN DE \\
\hline IE1 & $\begin{array}{l}\text { El crimen se comete en el domicilio } \\
\text { particular de la víctima. }\end{array}$ & EA1 \\
\hline IE2 & $\begin{array}{l}\text { La escena primaria es el salón. La } \\
\text { agresión sexual se comete en el suelo. }\end{array}$ & EA3 \\
\hline IE3 & $\begin{array}{l}\text { Al domicilio acude la vecina de la } \\
\text { víctima. La entrada es la puerta del } \\
\text { domicilio. El domicilio es una }\end{array}$ & EA6 \\
vivienda unifamiliar de una sola \\
planta.
\end{tabular}




\begin{tabular}{|l|l|l|}
\hline IE6 & $\begin{array}{l}\text { unos de talla } 37 \text { correspondientes a } \\
\text { una mujer y otros de talla } 44 \text { que } \\
\text { corresponde a un varón. }\end{array}$ & \\
\hline Se da un desplazamiento del cadáver & EA16 \\
del suelo al sofá. Además se & \\
encuentran objetos debajo de la & \\
víctima. Tanto las heridas en la & \\
víctima como el estado de su ropa & \\
indican violencia. & $\begin{array}{l}\text { El acceso al domicilio se puede hacer } \\
\text { a pie o en vehículo. La cerradura del } \\
\text { domicilio está en mal estado, lo que } \\
\text { permite un acceso sin problemas. }\end{array}$ & \\
\hline IE7 & $\begin{array}{l}\text { ¿POR QUÉ ESE LUGAR Y NO } \\
\text { OTRO? }\end{array}$ & EAn \\
\hline
\end{tabular}

La noticia llega a la Policía un miércoles a las 23:45 horas, día laborable. La poca seguridad que presenta el domicilio debido a su estado de abandono, permite un acceso fácil para personas ajenas al hogar. La distribución de las habitaciones en el domicilio sitúa como única escena posible del delito el salón.

En este sentido, los datos recopilados indican que existe un gran riesgo en el inmueble y que la escena del delito corresponde al salón. La cerradura en mal estado, el aislamiento y pobres relaciones familiares de la víctima han sido facilitadores para la comisión del delito en ese lugar y no en otro.

Tabla 10: Ejemplo del Método Vera: Inferencias de la reconstrucción de los hechos.

\begin{tabular}{|l|c|l|}
\hline INFERENCIAS & $\begin{array}{c}\text { RECONSTRUCCIÓN DE LOS } \\
\text { HECHOS }\end{array}$ & \multicolumn{1}{|c|}{ PROCEDEN DE } \\
\hline IR1 & El autor utiliza el engaño para acercarse & RA1 \\
& a la víctima y los testimonios acreditan & RA2 \\
& la presencia de otras personas. El estado & RA3 \\
& del cadáver y su vestimenta indica una & \\
& agresión violenta sobre una persona de & \\
\hline
\end{tabular}




\begin{tabular}{|c|c|c|}
\hline & $\begin{array}{l}\text { avanzada edad, con superioridad por } \\
\text { parte del agresor. (Inspección Ocular y } \\
\text { Levantamiento del Cadáver) }\end{array}$ & \\
\hline IR2 & $\begin{array}{l}\text { La víctima presenta heridas en las } \\
\text { muñecas y cuello. El agresor golpea a la } \\
\text { víctima y causa su muerte por el posible } \\
\text { miedo a denuncia. (Observación de la } \\
\text { escena del delito y Autopsia). }\end{array}$ & $\begin{array}{l}\text { RA4 } \\
\text { RA5 }\end{array}$ \\
\hline IR3 & $\begin{array}{l}\text { El nivel de planificación es bajo o nulo } \\
\text { y existe una desorganización general. } \\
\text { Deja en la escena su ropa, zapatos e } \\
\text { indicios biológicos y lofoscópicos. } \\
\text { Además se lleva de la víctima un objeto } \\
\text { que podría ser investigado por la } \\
\text { Policía. No utiliza guantes ni objetos en } \\
\text { la agresión. (Inspección Ocular Técnico } \\
\text { Policial). }\end{array}$ & $\begin{array}{l}\text { RA6 } \\
\text { RA7 }\end{array}$ \\
\hline IR4 & $\begin{array}{l}\text { Debido a que los ataques no duran } \\
\text { mucho tiempo se extrae que existió } \\
\text { agresividad e impulsividad por parte del } \\
\text { autor. Los hechos ocurren durante la } \\
\text { noche, con la luz encendida y cuando la } \\
\text { víctima está sola. (Inspección Ocular y } \\
\text { Técnico Policial). }\end{array}$ & $\begin{array}{l}\text { RA12 } \\
\text { RA13 } \\
\text { RA14 } \\
\text { RA15 }\end{array}$ \\
\hline IR5 & $\begin{array}{l}\text { Agresión sexual y homicidio. (Testigos } \\
\text { que llegan al lugar y Levantamiento del } \\
\text { cadáver). }\end{array}$ & $\begin{array}{l}\text { RA17 } \\
\text { RA18 }\end{array}$ \\
\hline IR6 & $\begin{array}{l}\text { Hay conversaciones con la víctima y } \\
\text { mantienen una relación de amistad } \\
\text { según los testigos que frecuentan la } \\
\text { zona. Se lleva una pulsera de oro de la } \\
\text { víctima. Llama la atención la posición } \\
\text { de las manos de la víctima, con las }\end{array}$ & $\begin{array}{l}\text { FA1 } \\
\text { FA2 } \\
\text { FA3 } \\
\text { FA5 } \\
\text { FA6 }\end{array}$ \\
\hline
\end{tabular}




\begin{tabular}{|l|l|l|}
\hline & $\begin{array}{l}\text { manos una sobre la otra en el regazo. El } \\
\text { agresor ejerce dominio y control sobre } \\
\text { la víctima. }\end{array}$ & FA9 \\
& $\begin{array}{l}\text { FA11 } \\
\text { FA12 }\end{array}$ & F́n \\
\hline IRn & $\begin{array}{l}\text { ¿CÓMO OCURRIÓ LA ACCIÓN } \\
\text { CRIMINAL? }\end{array}$ & RFan \\
\hline
\end{tabular}

Debido al mal estado de la cerradura del domicilio de la víctima, el agresor entró al mismo sin problemas. El hecho se produjo por la noche y con la luz encendida, y fue en un espacio corto de tiempo.

La víctima es hallada sola en el salón, en el que había fruta y un cartón de vino. $\mathrm{El}$ agresor probablemente le sugiere mantener relaciones sexuales, y ante la negativa por parte de la víctima comienzan una discusión en la que se inicia el ataque violento, del que la víctima intenta defenderse, siendo finalmente asesinada.

Finalmente, cambia de lugar el cuerpo de la víctima, del suelo al sofá y deja allí sus objetos personales, abandonando el domicilio de manera apresurada llevándose una pulsera de oro.

Tabla 11: Ejemplo del Método Vera: Inferencias del Autor

\begin{tabular}{|l|l|l|}
\hline INFERENCIAS & \multicolumn{1}{|c|}{ AUTOR } & PROCEDE DE \\
\hline IA1 & $\begin{array}{l}\text { El autor tiene una relación previa de amistad } \\
\text { con la víctima por lo que accede al domicilio } \\
\text { con facilidad (cerradura en mal estado). } \\
\text { (Testimonios de vecinos e Inspección } \\
\text { Técnico Ocular Policial). }\end{array}$ & DA2 \\
\hline IA2 & $\begin{array}{l}\text { Es de la localidad de Santiago de } \\
\text { Compostela. Frecuenta la zona de la víctima } \\
\text { y vive de vender chatarra. Consume alcohol } \\
\text { en los bares del barrio (Pontepedriña). No }\end{array}$ & DA15 \\
\hline IA3 & Duerme de vez en cuando en el domicilio de & DA4 \\
\hline
\end{tabular}




\begin{tabular}{|l|l|l|}
\hline & la víctima. (Testigos). & \\
\hline IA4 & $\begin{array}{l}\text { El autor es varón, viste con ropas sucias. El } \\
\text { vaquero es de la talla } 40 \text { y el calzado talla } \\
\text { del 44, lo que indica una complexión } \\
\text { normal, no obeso y una altura aproximada } \\
\text { de } 1.85 \text { a } 1.90 \text { cm. (Hallazgo Inspección } \\
\text { Ocular Técnico Policial). }\end{array}$ & \\
\hline IA5 & $\begin{array}{l}\text { Consume drogas y alcohol. (Testigos). } \\
\text { IA7 }\end{array}$ & DA6 \\
\hline IA8 & Es violento e impulsivo. & DA14 \\
\hline IA9 & Delincuente (Testigos). & DA8 \\
\hline IA10 & $\begin{array}{l}\text { Pocos recursos económicos. Se lleva de la } \\
\text { víctima una pulsera de oro. (Testimonio de } \\
\text { la sobrina). }\end{array}$ & DA13 \\
\hline IAn & ¿UÉ SABEMOS DEL AUTOR? & DAn \\
\hline
\end{tabular}

El autor se aprovecha de la relación amistosa que mantiene con la víctima para abordarla, accediendo al domicilio. No oculta su rostro ni identidad. Frecuenta la zona y se desplaza en bici o andando. Es consumidor de alcohol y drogas y se dedica a vender chatarra en el barrio de la víctima. Usa pantalones de la talla 40 y viste de manera informal. Su complexión es normal. Utiliza apodo y es agresivo. Se llevó de la víctima una pulsera de oro, por lo que se deduce que posee pocos recursos económicos.

Tabla 12: Hipótesis

\begin{tabular}{|l|l|l|}
\hline HIPÓTESIS & LÍNEAS DE INVESTIGACIÓN & PROCEDEN DE \\
\hline H1 & $\begin{array}{l}\text { El agresor se acerca a los colectivos } \\
\text { marginales y no posee una actividad }\end{array}$ & IV7 \\
& $\begin{array}{l}\text { laboral reglada. Se gana la vida } \\
\text { vendiendo chatarra en el barrio de } \\
\text { Pontepedriña, por lo que se sugiere } \\
\text { rastrear la zona. }\end{array}$ & \\
\hline H2 & El autor es un individuo adulto, entre & IE5 \\
\hline
\end{tabular}




\begin{tabular}{|l|l|l|}
\hline & $\begin{array}{l}55 \text { o } 60 \text { años de complexión normal, } \\
\text { altura entre } 1.85 \text { y } 1.90 \mathrm{~cm} \text {, que viste } \\
\text { de manera informal y con el aseo } \\
\text { descuidado. }\end{array}$ & \\
\hline H3 & $\begin{array}{l}\text { El autor es de la localidad de Santiago } \\
\text { de Compostela y se puede categorizar } \\
\text { como un delincuente común. }\end{array}$ & IR3 \\
\hline
\end{tabular}




\section{CAPÍTULO II: PSICOLOGÍA CRIMINAL}

\subsection{LA PSICOLOGÍA APLICADA AL ÁMBITO JURÍDICO Y DEL DERECHO: RECORRIDO HISTÓRICO}

La Psicología Jurídica se asienta en la relación existente entre Psicología y Derecho. La relación entre estas dos disciplinas, en España ha sido estudiada por Muñoz Savaté (1980) desde tres puntos de vista:

a) "La Psicología del Derecho, que estudia los componentes psicológicos del mismo, analizando las leyes como un producto intencional y propositivo de un consenso colectivo. Aquí entraría el estudio de una serie de temas como la edad de la responsabilidad penal, la segregación racial o la función social del castigo.

b) La Psicología en el Derecho, que estudia las normas jurídicas como estímulos sociales que generan determinadas conductas.

c) La Psicología para el Derecho, que considera la Psicología como una disciplina auxiliar del Derecho, proporcionándole a éste información sobre la conducta humana. Esta perspectiva se identifica, en gran medida, con la Psicología Forense". (Ovejero, 2009, p.19)

Por otra parte, Garrido y Herrero (2006, p.17) afirman que la Ley supone la Psicología como algo de mero sentido común, y a partir de tal supuesto legisla y juzga. Además de considerar que las aportaciones de los psicólogos son de sentido común, estos autores señalan que también son en parte temidas por los juristas, ya que muchas veces contradicen sus afirmaciones. A este respecto apunta Kirby (1978):

Porque los psicólogos que cuestionan algunos de los fundamentos sobre los que la administración de justicia se lleva a cabo han sido mirados generalmente como molestos, irreales o con el prejuicio de ser "académicos". Los psicólogos escudriñan y critican. Son gente difícil que cuestiona cosas establecidas hace mucho tiempo y que han sido reguladas con mucho cuidado. (Ibíd,1978, p.343).

De manera que derivado de las afirmaciones de este autor, se ha hecho eco de la necesidad de grabar en los interrogatorios policiales para evitar las falsas confesiones, qué hacer para no caer en los prejuicios a la hora de dictar sentencias, etc. 
Puesto que la Psicología es la disciplina que estudia la conducta humana y las variables que la regulan, es lógico pensar que será de gran de ayuda en la comprensión de los aspectos relacionados con el delito, el delincuente y las personas implicadas en el marco legal de las conductas delictivas, por lo que no es de extrañar que, desde sus inicios, la Psicología se haya aproximado al marco de la justicia o que los psicólogos fueran requeridos por ello. (Ovejero, 2009, p.22).

En los casos de asesinatos seriales, la aportación del psicólogo va más allá de juzgar al criminal; se bareman multitud de variables como su historia personal, el porqué del comportamiento así como una propuesta de tratamiento del criminal.

Asimismo, King (1984) añade que:

Parece que se han desarrollado y ganado credibilidad, entre algunos, si no la mayoría de los psicólogos en el campo psicolegal, un conjunto de asunciones. Parece que estas son: 1) que los métodos científicos de analizar y probar utilizados por los psicólogos proporcionan instrumentos poderosos para desvelar la verdad sobre algunos aspectos de la conducta a los que prestan su atención; 2) que la verdad desvelada por los psicólogos es, en algún modo, superior y más válida que las verdades tradicionales o de "sentido común" de los abogados, policías y de otros no psicólogos y que no aplican estos métodos; 3) que la verdad desvelada por los psicólogos que utilizan estos métodos tiene validez universal independientemente del contexto social singular en que se desvela esta verdad. (Ibíd, 1984, p.68)

Igualmente, Garrido y Herrero (2006) afirman que en esta lucha entre los ámbitos judicial y psicológico aplicados al estudio del delincuente:

Está en juego, en definitiva, el poder. La Psicología y otras ciencias sociales han sometido a prueba muchos de los supuestos en los que se apoyan las prácticas jurídicas y la misma legislación que los ordena, y los ha hallado inadecuados. Un buen ejemplo son los tribunales del jurado, la credibilidad de los testigos o la constitucionalidad o no de determinadas prácticas siguiendo el espíritu del legislador. Pero, más que disputar la supremacía, habría que buscar la colaboración para obtener una mejor administración de justicia o una justicia mejor. (Ibíd, 2006, p.18)

De manera que para estos autores, la figura del psicólogo en los casos judiciales de asesinatos seriales resulta fundamental. Ya en 1908, El padre de la Psicología 
Jurídica, Hugo Münsterberg en su obra "On the witness stand" (En el estrado del testigo), defiende la presencia del psicólogo en la Sala de Justicia. Münsterberg aboga por los métodos preventivos, en los cuales el psicólogo juega un papel fundamental. De hecho, afirma: "Nadie es criminal de nacimiento (...) Es la sociedad la principal responsable del crimen, por lo que la prevención del crimen es más importante que el tratamiento del crimen" (Münsterberg, 1908, p.232-233). Al contrario del autor, Césare Lombroso (1835-1909) defiende la idea del criminal nato, que se desarrollará más adelante.

Esta idea ya fue precedida por Binet (1900) y Stern (1902) que hicieron sus aportaciones al campo de la Psicología Jurídica.

Binet (1900), hablaba de la sugestión, la cual era entendida por él como "la presión moral que ejerce una persona sobre otra" $(1900$, p.10) a partir de los relatos de niños que contaban como reales y en realidad eran producto de su imaginación.

Por su parte, Stern (1902) en Alemania publica una obra que abogaba por la investigación sobre el testimonio y su exactitud en los juicios: "Zur Psychologie der Aussage (Sobre la Psicología del testigo)"

Ya en 1911, H.Gross en Checoslovaquia publica su obra "Criminal Psychology" obra pionera en el ámbito de la Psicología Judicial que abre paso a la figura del psicólogo en el marco judicial.

En este sentido, Sáiz, Baqués y Sáiz, (2006) afirman que estos trabajos pioneros y antecesores reclamaron la existencia de factores psicológicos sobre los que el psicólogo podía aportar información científica en el marco judicial. Además, afirmaron que el testigo era una persona vulnerable que podía verse sesgada por su percepción y memoria. Asimismo, pusieron el énfasis en la necesidad de control sobre la obtención de las declaraciones, ya que éstas podían alterar el recuerdo inicial y pusieron atención además, en la detección de la mentira.

Los años 20 y 30 fueron característicos por el aumento en el interés de estos campos. A este respecto, Carpintero (2006) destaca que:

Atrayendo a jueces y criminalistas hacia el conocimiento de la Psicología, pero sin que ello redundara en una mayor presencia de los propios psicólogos en el mundo de la justicia (...) La profesionalización, en los EEUU, se consolidó y 
desarrolló después de la II Guerra Mundial, cuando el prestigio de la Psicología Aplicada creció con rapidez tras su eficaz intervención en la guerra, y se ha señalado el nivel de los años setenta como aquel en que la Psicología se consolidó como tal. (Ibíd, 2006, p.65).

\section{SITUACIÓN EN ESPAÑA}

En España la reflexión sobre la imputabilidad de los actos del delincuente es empujada gracias a la implantación del primer Código Penal en 1822. Es a mediados del s. XIX con la tradición más positivista y naturalista cuando aparece la Psicología científica y el empleo de la misma al ámbito judicial. En nuestro país destacan las figuras de Mariano Cubí (1801-1875) y Pere Mata (1811-1877) en España.

Respecto a esta imputabilidad, Mariano Cubí en el año 1836 introduce la Frenología de la mano de Fran Gall (impulsor de dicho postulado teórico a finales del S. XVIII) para aplicarlo al ámbito judicial como atenuante del delito.

Mariano Cubí es considerado el introductor de la frenología en España. La frenología fue un planteamiento teórico desarrollado de la mano de Fran Gall en el s.XIX. A este respecto, Soria et al. (2008) resume las bases de esta teoría como:

La concepción de unas localizaciones cerebrales, con unas tendencias mentales propias a ellas y una derivación de éstas en la forma del cráneo, lo que implica el establecimiento de unas capacidades humanas ligadas a una estructura cerebral. Tal convencimiento deriva en el diagnóstico individual de los humanos mediante la inspección craneal y, por tanto, conlleva la determinación, a través del estudio de protuberancias o hundimientos hallados en el cráneo, de unas características particulares a cada sujeto. (Ibíd,2008, p.5)

A partir de este momento, la Frenología contribuyó de manera destacable en la inclusión de la Psicología con gran peso en la valoración del delito. Según la frenología el aumento excesivo de actividad en ciertos órganos cerebrales estaría relacionado con diferentes delitos. No obstante, la frenología fue punto de duras críticas ya que no presentaba ninguna fiabilidad ni validez estadística, por lo que a finales del S.XIX se vio sustituida por una Medicina más científica.

Otro autor destacable es Mata (1811-1877) que juega un papel notable dentro de la Medicina Legal, organizando los estudios, y después llevándolo al terreno de la Psicología diferenciando las cuestiones relativas al individuo vivo (por ejemplo, 
cuestiones de psicopatología) y al individuo muerto (información desprendida de la autopsia) y, asimismo, las cuestiones referentes a las cosas.

Mata, se centra especialmente en el problema del diagnóstico de la locura, ya que es lo que determina la imputabilidad de los actos delictivos cometidos por el individuo, porque, según Navarro, Pousada y Caparrós (1992), aunque el Código Penal de 1848 los declara exentos de responsabilidad criminal, en la mayoría de casos, las personas con trastornos mentales son tratados como delincuentes, y por consiguiente, condenados.

En España a partir de la Ley de Sanidad (1885) se crea el cuerpo de "Facultativos Forenses" dividida en tres secciones desde 1891:

- Medicina y cirugía: se ocupan de mantener la apropiada salud del individuo.

- Toxicología y Psicología: la Toxicología se ocupa del estudio y los efectos de los productos tóxicos o venenosos sobre el organismo y la Psicología del adecuado mantenimiento de la salud mental del sujeto.

- Medicina mental y Antropología: la primera se ocupa del equilibrio del individuo consigo mismo y con su entorno, y la segunda, hace referencia a la Ciencia que estudia los aspectos físicos y las manifestaciones sociales $\mathrm{y}$ culturales de las comunidades humanas.

Aunque la Psicología esté incluida, no obstante, existe la paradoja de que todavía no hay psicólogos que puedan ejercer en lo forense. Serán los médicos legalistas, psiquiatras o criminólogos los que se ocupen de descifrar qué tipo de factores influyen en la actividad criminal. Este sería entonces el pilar básico para la inclusión del psicólogo en el ámbito jurídico.

Como inicio de la Criminología, es necesario volver a nombrar a Césare Lombroso (1835-1909) y su defensa sobre el criminal nato. Lombroso defendía la idea de que los criminales nacen y que tienen unas características físicas determinadas que los diferencian de los no criminales. Las ideas de Lombroso se asientan en España a finales de los años 80 a partir de dos conferencias: la de Félix de Aramburu, en 1887 y la de Rafael Salillas en 1888 con una conferencia sobre Antropología y Derecho Penal en la que se discutía sobre la locura del criminal y la responsabilidad de éste en caso de cometer un delito. Tanto Salillas como Aramburu se interesan por el estudio del 
ambiente social de los delincuentes de manera científica y con una clara influencia lombrosiana.

Carpintero y Rechea (1995), exponen que Pedro Dorado Montero (1861-1920) al igual que Salillas, estuvo muy influenciado por las ideas krauso-positivistas de Francisco Giner de los Ríos quien comenta que el delincuente es incapaz de llevar la vida por sí mismo y necesita el control de la autoridad. El delincuente no queda ya como responsable de la acción, sino como víctima que necesita ayuda y refuerzo. De manera que Dorado plantea como sustituto de la condena, el tratamiento.

Finalmente, en el s.XX se produce el asentamiento de la Psicología científica en España a través de dos escuelas: la escuela de Brcelona (1930) y la escuela de Madrid (1936).

- La escuela de Barcelona (1930): impulsada por Ramón Turrú Darder y continuada por Pi i Sunyer y Mira defendiendo la necesidad de la Psicología Jurídica.

- La escuela de Madrid (1936): impulsada por Giner de los Ríos y fundada por Simarro, Rodríguez Lafora y Germain. Esta escuela defiende una reforma social a través de la educación.

Por otro lado, la corriente psicoanalítica también tuvo su lugar en España. Las ideas freudianas se asentaron a través de la mano de José Ortega y Gasset, en 1921 destacando las figuras de dos juristas afines a los planteamientos psicoanalíticos: César Camargo Marín (1927) y Luis Jiménez de Asúa (1935).

En este sentido, César Camargo (1927), es el más destacado introductor del pensamiento freudiano en nuestro país tomando al delincuente como un sujeto enfermo; así, destaca que:

El psicoanálisis criminológico debe descubrir el complejo originario causante del crimen. Esta labor le compete al juez, que deberá encauzar y dirigir la libido o potencial del delincuente, transformándola y sublimándola. Estará bajo su tutela y lo vigilará como un médico de cabecera a su enfermo (citado en Soria et al. 2008, p.19).

Por otro lado, Jiménez de Asúa (1935) parte de planteamientos adlerianos, lo que hace que su visión del delito sea la de un fenómeno de inadaptación social forjado 
en el complejo de inferioridad del individuo frente a la sociedad que le envuelve. Este autor hace una clasificación de los criminales en función de la causa del delito y los tratamientos que propone son basados en la eliminación del origen, es decir, de ese complejo de inferioridad y tratar de conseguir la readaptación del criminal. Estas ideas son referenciadas por Mestre (1996), que explica que las ideas de Jiménez de Asúa no defienden la imposición de castigos, sino la creación de procesos pedagógicos y educacionales que eviten el fracaso del individuo en la sociedad.

Otra figura del mundo de la Criminología a resaltar en Quintaliano Saldaña (1878-1938), catedrático de Antropología Criminal y Derecho Penal y Director de la Escuela de Criminología de la Universidad de Madrid el cuál recoge ideas tanto psicoanalíticas como conductistas apuntando a un factor constitucional en el delincuente. De manera que plantea las siguientes ideas respecto a la delincuencia:

1) existe "normalismo", lo que implica que no hay delincuentes, sino personas, dándose un principio de continuidad delincuente-no delincuente, de tal modo que el respetuoso con la Ley puede llegar a ser, en un momento determinado si se dan las circunstancias, un delincuente más. Y 2) "se da el "pancriminalismo", todos somos delincuentes natos. (Soria et al., 2008, p.19)

Ya en los años 40 y 50 la Psicología española está más asentada debido al interés de algunos autores que se ve plasmado en la "Revista de Psicología General y Aplicada". No obstante, se ha considerado la época menos fructífera por parte de la Psicología Jurídica. Así, Garzon (1990) considera que el descenso de las contribuciones de los psicólogos pudo estar motivado por la diversificación de la Psicología en las nuevas áreas de trabajo y por la etapa de reflexión interna que la misma Psicología vivía.

De manera que hasta los años 60, la Psicología Judicial no notará una reactivación. En esta época, los tribunales empiezan a acuciar la figura del psicólogo cualificado como testigo experto sobre cuestiones criminales en las que se debe valorar la responsabilidad del sujeto. En este sentido, es en 1965 cuando se crea el primer gabinete psicológico de la prisión de Madrid y en 1968 se crea la central de observación penitenciaria derivada de la relevancia del papel del psicólogo en el ámbito jurídico.

Este devenir de la Psicología Jurídica en España se ve consolidado finalmente en la década de los 70 con el origen de la Escuela de Barcelona, la cual tuvo una 
importante función generando con ello importantes logros como la creación del primer curso de Psicología Jurídica, promoviendo ciclos de conferencias, edición de revistas pioneras en este campo y el primer libro de Psicología Jurídica: "Introducción a la Psicología Jurídica” (Muñoz, Bayés y Munné, 1980).

De manera que es, finalmente, a partir de los años 80, cuando la Psicología Jurídica se instala en las Universidades y en los Colegios Profesionales de Psicología, creándose diversos grupos de investigación que fomentan y divulgan el conocimiento de la Psicología Jurídica.

En este sentido, haciendo referencia a la consolidación de la Psicología Jurídica en España y derivado de la aprobación de la Ley del divorcio de 1981, Carpintero (2006) apunta que:

Hoy hay un numeroso grupo de psicólogos dedicados a atender las necesidades de los juzgados de familia, nacidos al amparo de la ley del divorcio establecida en 1981; otros muchos dedican su cuidado a los individuos institucionalizados en prisiones y reformatorios; hay una sección de Psicología Jurídica amplia y bien estructurada dentro del Colegio Oficial de Psicólogos; todo ello, en definitiva, muestra que este campo de especialización tiene hoy una solidez notable dentro del horizonte español, y que sus realizaciones y líneas de acción son semejantes a las que cabe hallar en los países de nuestro entorno democrático y cultural. (Ibíd, 2006, p.70).

\subsection{DELIMITACIÓN TERMINOLÓGICA}

La Psicología y el Derecho encuentran su confluencia en el hecho de que ambas disciplinas son ciencias humanas y sociales compartiendo el objetivo de la intervención en la conducta de las personas. En palabras de Munné (1987): "son ciencias llamadas a entenderse como ciencias humanas del comportamiento y sociales" (p.5).

Debido al creciente desarrollo de las relaciones entre la Psicología y el Derecho, se hace necesario especificar la terminología utilizada en estas disciplinas para evitar posibles confusiones. En este sentido, se va a diferenciar entre Psicología Jurídica (que se ocupa del estudio, evaluación, prevención y tratamiento en su caso de los fenómenos psicosociales que influyen en el comportamiento legal de un sujeto), Psicología Forense 
(que engloba todas aquellas actividades que le son requeridas al psicólogo desde la Justicia) y Psicología Criminal (que se encarga de explicar y controlar el delito).

\subsubsection{Psicología Jurídica}

La Psicología Jurídica en España se origina de la mano de Mira (1932) cuando publica su obra "Manual de Psicología Jurídica" en el que define a la misma como: "La psicología jurídica es la psicología aplicada al mejor ejercicio del derecho” (Ibíd, 1932, p.11). En esta línea, Muñoz Sabate (1980) la define como: "los conocimientos psicológicos aplicados a la ciencia jurídica" (p.23).De manera que en ambas definiciones se subraya su carácter de ciencia aplicada.

Por su parte, Clemente (1995), aportando una visión más amplia y centrada en la conducta social normativa, la define como:

Es el estudio del comportamiento de las personas y de los grupos en cuanto que tienen la necesidad de desenvolverse dentro de ambientes regulados jurídicamente, así como de la evolución de dichas regulaciones jurídicas o leyes en cuanto que los grupos sociales se desenvuelven en ellos. (Ibíd, 1995, p. 25).

Además, para Soria (1998) la Psicología Jurídica tiene dos significados: uno más general que abarca todos los campos psicológicos relacionados con la Ley y el Derecho; y otro más específico, que sería la Psicología Judicial, que el autor define como "La aplicación de la Psicología Social que estudia los comportamientos psicosociales de las personas o grupos relacionados, establecidos y controlados por el Derecho en sus diversas vertientes, así como aquellos procesos psicosociales que guían o facilitan los actos y las regulaciones jurídicas" (Ibíd, 1998, p. 4).

Igualmente, Ovejero (2009) aporta una definición de Psicología Judicial describiéndola como: "la rama de la Psicología Jurídica que estudia la influencia que tienen los factores extrajurídicos en las decisiones de los órganos judiciales, sean estos unipersonales o colegiados, sean jueces o jurados, sean profesionales o sean legos" (Ibíd, 2009, p.26).

Este autor dice al respecto de la Psicología Jurídica que generalmente se entiende que es el término del que derivan multitud de subespecialidades, como pueden ser las descritas en la Tabla 13: 
Tabla 13: Subespecialidades de la Psicología Jurídica (Ovejero, 2009).

- Psicología del testimonio

- Psicología judicial

- Psicología Legal

- Psicología Penitenciaria

- Psicología Policial, Psicología Criminal

- Psicología Forense

- Psicología del terrorismo

- Investigación y selección del jurado

- Victimología

- Resolución de conflictos y mediación

- Asesoramiento a Jueces y Abogados

- Psicología Semiótica (documentos)

- Psicología del Juez o Crinología, etc.

\subsubsection{Psicología Forense}

En sus inicios como disciplina, Muñoz Sabate (1980) indica que desde su contexto histórico el auténtico punto de confluencia de la Psicología con el Derecho, era fundamentalmente de tipo probatorio.

Así, Urra (1993) define a la Psicología Forense como:

La ciencia que enseña la aplicación de todas las ramas y saberes de la Psicología ante las preguntas de la Justicia y coopera en todo momento con la Administración de Justicia, actuando en el foro (tribunal), mejorando el ejercicio del Derecho. (Ibíd, 1993, p. 3).

En este sentido, Garzon (1989) y Urra (1993) indican que a nivel práctico la delimitación entre ambas Psicologías se podría explicar como que la Psicología Forense es más aplicada e individual frente a la Psicología Jurídica que es más colectiva y teórica. 
Por tanto, la Psicología Forense es la denominación que ha recibido la vertiente aplicada de la Psicología Jurídica, siendo su función principal la de ofrecer soporte a las administraciones de Justicia.

Más recientemente, Soria (2005) complementa y define la Psicología Forense como:

Aquella rama de la Psicología Jurídica que desarrolla sus conocimientos y aplicaciones con vistas a concluir sus hallazgos en el seno de una sala de justicia con la finalidad de auxiliar al órgano juzgador en su toma de decisión. (Ibíd, 2005, p.33).

Finalmente, para Garrido (2005) lo característico del psicólogo forense es ocuparse de evaluar áreas (en acusados principalmente, pero también en otros actores del proceso, penal o civil) como la capacidad intelectual, la personalidad, la psicopatología, el riesgo de comisión de nuevos delitos o su sinceridad (o manipulación) en su participación para el diagnóstico. Determinadas prestaciones de la Psicología Forense se realizan en contextos bien definidos, como la actividad del psicólogo de prisiones que encaja en los supuestos anteriores o la del psicólogo de los Juzgados de Familia, ocupados en evaluar a los diferentes miembros en aras del bienestar de los niños.

En la práctica cotidiana se entiende por psicólogo forense al perito que acude al foro o tribunal para exponer su informe en base a preguntas previas y contestar según su buen hacer y experiencia a todo lo que tengan a bien solicitar aclaraciones por parte del Juez, Fiscales o Abogados inmersos en el proceso.

\subsubsection{Psicología Criminal}

La Psicología Criminal hace referencia al estudio del comportamiento y los procesos mentales que determinan específicamente la conducta criminal presentando diferentes acepciones: Psicología criminalística, Psicología Aplicada a la función Policial, Psicología Policial, Psicología de la Investigación, etc.

La Psicología Criminal es una subdisciplina de la Psicología Jurídica (Jiménez Serrano, 2005; Garrido y Sobral, 2008; Soria y Saiz, 2010) 
En este sentido, para Blackburn (1993) es una ciencia que se ocupa de explicar el delito y encontrar medidas para su control. Y de entre sus funciones destaca: atender al delincuente, establecer el hecho criminal y prevenir el delito con programas de tratamiento a delincuentes o medidas para hacer menos vulnerables a las víctimas.

En esta misma línea, Dorchs (2002) define Psicología Criminal como una rama aplicada de la Psicología que pone en relación determinadas variables psicológicas con el criterio práctico del atentado contra la norma jurídica.

Para Marchiori (2007) la Psicología Criminal trata de averiguar qué es lo que induce a un sujeto a delinquir, qué significado tiene esa conducta para él y porqué la idea de castigo no le aterroriza y le hace renunciar a su conducta.

Soria y Sáiz (2008) centrándose en la comprensión de la delincuencia, definen la Psicología criminal como:

Aquella vertiente de la Psicología jurídica que agrupando diversas áreas de la misma intenta abordar la comprensión del fenómeno de la delincuencia, sus causas, efectos y tratamiento, con la finalidad de ayudar a su reducción mediante métodos preventivos o interventivos. (Ibíd, 2008, p.29)

Fernández Ballesteros (2010) añaden la preocupación por la seguridad de la ciudadanía y definen la misma como:

El conjunto de principios, métodos y técnicas de la Psicología Científica que, aplicadas al conocimiento del delito en general y del crimen en particular contribuyen a la investigación de los hechos delictivos graves, la identificación de los criminales y la seguridad de los ciudadanos. (Ibíd, 2010, p. 60).

De manera que la Psicología Criminal abracaría los siguientes aspectos desarrollados por Muñoz et al., (2011) y que hacen referencia a:

a) Técnicas de entrevista aplicadas al interrogatorio Policial, con especial atención en casos de detenidos, supuestas víctimas o testigos especialmente vulnerables, discapacitados o con deterioro o trastorno mental, perfilamiento aplicado a la captura de agresores seriales y autopsia psicológica en casos de muerte y/o desapariciones de etiología dudosa.

b) Trabajos con testigos protegidos, apoyo a agentes encubiertos y gestión de colaboradores o informadores. 
Actualmente, González (2015) define la Psicología Criminal como "la aplicación de los conocimientos de la psicología a las tareas policiales operativas; esto es, a la investigación criminal" (Ibíd, 2015,p. 109).

En España la Psicología Criminal todavía está en desarrollo y no cabe el ejercicio de la Psicología Criminalista desde fuera de las instituciones policiales, si bien ya existen autores como Jiménez (2015), que abogan por la figura del asesor policial externo. En la actualidad tanto la Guardia Civil como la Policía Nacional cuentan con unidades propias de análisis de la conducta criminal. Por ejemplo la Guardia Civil creo en 1995 la Sección de Análisis de la Conducta Delictiva (SACD) y en el 2011 el Cuerpo Nacional de Policía una Sección de Análisis de la Conducta (SAC).

Por lo tanto, se trata de una ciencia social aplicada y subespecialidad de la Psicología Jurídica, que busca resolver problemas complejos, utilizando un método, y no actuando de forma aislada ya que es interdisciplinar, apoyándose principalmente en la Biología, la Antropología, la Sociología, La Criminalística, la Victimología y la penología criminológica. Todo ello atendiendo como objeto al delito, al estudio del hecho criminal en sí y a tratar de prevenirlo en la medida de lo posible. (Jiménez, 2015).

\subsubsection{Criminología y Criminalística}

Finalmente, merece hacer mención a dos términos que llevan a confusión en múltiples ocasiones: Criminología y Criminalística.

La Criminología se refiere a la ciencia que se ocupa del estudio del fenómeno criminal con el fin de conocer sus causas y formas de manifestación. Se estudia por lo tanto el crimen y su relación con la especie. Redondo y Garrido (2013) la definen como:

Aquella ciencia que estudia los comportamientos delictivos y las reacciones sociales frente a ellos...el objeto sustantivo de la Criminología es, por tanto, un cruce de camino en el que convergen ciertas conductas humanas, las delictivas, y ciertas reacciones sociales frente a tales conductas. (Ibíd, 2013, p. 47)

Por otro lado, la Criminalística se ocupa del estudio del fenómeno criminal con el fin de determinar en qué forma y quién cometió el delito. De manera que podría decirse que la Criminología se ocupa del "porqué" de los delitos y la Criminalística se ocupa de "cómo se han producido los delitos y quién los ha cometido". 
Por último, se pueden aunar todos los conceptos anteriormente presentados según la Figura 1 propuesta por De Santiago (2015) en el Monográfico sobre Psicopatía y Perfiles Criminales de la Asociación de Psicoterapia Psicoanalítica Kairós.

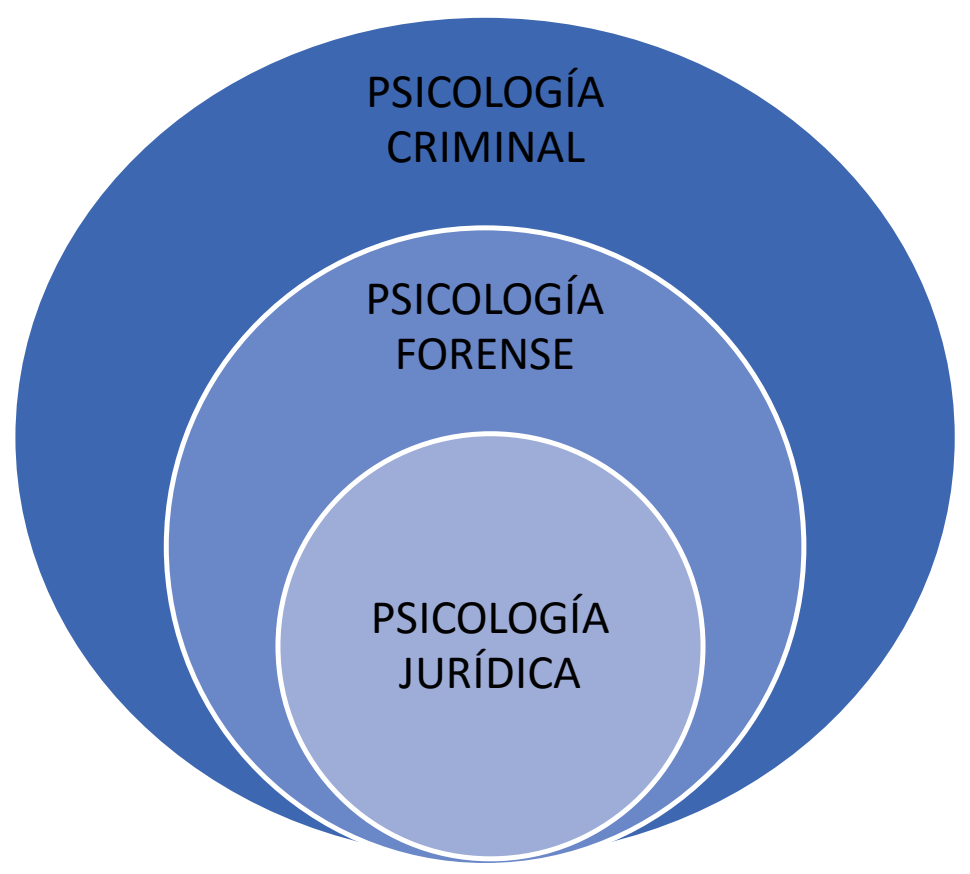

Figura 1: Integración conceptual (De Santiago, 2015)

De manera que al ser círculos concéntricos cada nivel incorpora al otro. Es decir, no se puede llevar a cabo la Psicología Criminal sin tener contacto con la Justicia y la Policía y sin poseer amplios conocimientos teórico-prácticos de las investigaciones y avances de la Psicología Jurídica y de la Psicología General.

\section{3. ÁREAS DE ESTUDIO CRIMINOLÓGICO}

A partir de la definición de Criminología que plantea Sutherland, Cressey y Luckenbill (1992) se explican las áreas de estudio en las que se centra la Criminología: los delitos, los delincuentes, las víctimas y los sistemas de control social.

"el cuerpo de conocimientos relativos a la delincuencia en cuanto fenómeno social, lo que incluiría el análisis del proceso de creación de las leyes, de su quebrantamiento, y, también, de las reacciones sociales que siguen a las infracciones" (citado en Redondo y Garrido, 2013, p.56) 


\section{a. Los delitos}

En cuanto a la definición de delito, Felson (1979) considera de importancia el concepto de interacción, de manera que explica que el delito sería el producto de las interacciones que se dan entre una persona dispuesta a llevarlo a cabo, una víctima u objeto de infracción y un control social.

El artículo 10 del Código Penal español establece que "son delitos o faltas las acciones y omisiones dolosas o imprudentes penadas por la Ley" y el artículo 13 dice así "son delitos graves las infracciones que la Ley castiga con pena grave" y "delitos menores graves las infracciones que la Ley castiga con pena menos grave".

Además, Hagan (1985) diferencia entre delitos "reales" y "socialmente construidos", diferenciación para la cual Walsh (2012) explica tres dimensiones interrelacionadas:

- El grado de "consenso social" sobre la gravedad de cierto delito.

- La gravedad de la "pena" que le está asociada.

- El nivel de "daño" real y directo que se atribuye a la conducta en sí.

En general, se pueden aunar en una sola definición de delito pese a su dificultad, todas las conductas que se consideran como tal. Gottfredson y Hirschi (1990) aportan la siguiente definición de delito: "La utilización de engaño o fuerza para conseguir un objetivo" (citado en Redondo et al., 2013, p.61).

Una de las definiciones más novedosa es la aportada por Felson (2006), el cual considera que: "Un delito es cualquier conducta identificable que un número apreciable de gobiernos ha prohibido específicamente y ha castigado formalmente" (Ibíd, 2006, p.35).

Robiendo y Beaver (2009) centrándose en el concepto de daño, definen los delitos como: "Conductas que son realizadas intencionalmente y que producen algún daño físico o económico a otra persona” (Ibíd, 2009, p.3). Asimismo, estos autores precisan aún más este término y para ello hacen una diferenciación terminológica para evitar confusiones. En este sentido, consideran al "delito" como el acto penado por la Ley y lo diferencian de "delincuencia" como un concepto más amplio, haciendo referencia a conductas que podrían ser 
delitos o conductas prohibidas, y por último, la precisan aún más al distinguir "conducta antisocial" referido a las conductas que no son aceptadas socialmente. Desde la perspectiva clínica este término queda definido por unos criterios diagnósticos en el Manual Diagnóstico y Estadístico de los Trastornos Mentales (DSM-V).

Otro planteamiento para definir el delito a tener en cuenta es el que esboza el modelo del "Interaccionismo Simbólico", el cual expone que la sociedad no castiga siguiendo unos criterios fijos, sino que lo hace teniendo en cuenta las circunstancias contextuales. En este sentido, Becker (1971) expone que:

Desde el planteamiento del interaccionismo simbólico, que se haya conectado en Criminología con las teorías del etiquetado, se señaló que los grupos sociales no definirían y aplicarían las normas punitivas de un modo fijo e inexorable, sino que castigarían las infracciones de forma contingente a determinadas circunstancias. (Ibíd, 1971, citado en Redondo et al., 2013, p.63)

Según la perspectiva anterior, sería la sociedad la que crea la desviación y el delito mediante su propia imposición de normas. Si alguien denuncia una conducta públicamente, es más probable que ésta entre a ser valorada por la sociedad como susceptible de ser castigada o no.

De manera que el delito no puede ser definido desde una única perspectiva, la punitiva, sino que entran en interacción bastantes más elementos. Tal y como apunta Walsh (2012), el Código Penal define los delitos y sus correspondientes castigos dependiendo de factores políticos y teniendo en cuenta su evolución, por lo que no emite una definición estable y definitiva.

En este sentido, Redondo et al. (2013) amplia la paradoja de los círculos concéntricos para explicar los diferentes tipos de delitos en la sociedad. De manera que si se dibujara un círculo, en el centro se encontraría el área I, en la que se reunirían las actividades que son castigadas en casi cualquier sociedad moderna. En esta área se encuentran delitos contra la libertad sexual y delitos de mucha gravedad contra las personas. 
En la zona intermedia del círculo, se encuentra el área II, en la que se sitúan actividades ilícitas, pero que se realizan con frecuencia, como por ejemplo conducir bajo los efectos del alcohol. Se sitúan en esta área los llamados "delitos sin víctimas" como por ejemplo los fraudes a Hacienda.

Finalmente, en el área III, la más alejada del círculo central, se sitúan aquellas actividades que siendo consideradas ilícitas gozan de cierta subjetividad, es decir, existe una falta de consenso para considerarlas sin ninguna duda delitos. Como por ejemplo son aquellas actividades que según la legislación se puedan considerar delito o no, como el aborto. (Véase Figura 2)

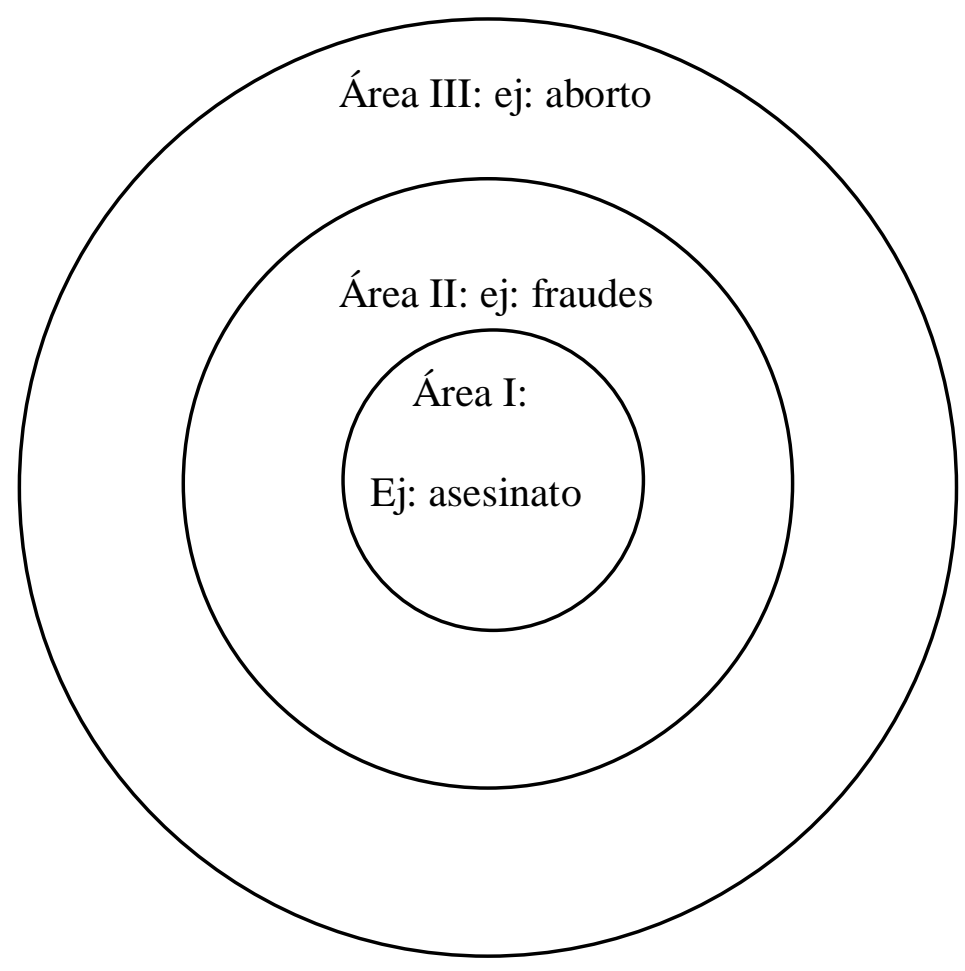

Figura 2: Paradoja de los círculos concéntricos (Redondo et al., 2013)

Por último, según afirma Walsh (2012), en las sociedades existen opiniones contradictorias sobre si penar ciertas conductas o no; esto hace que el sistema Penal vaya cambiando con el tiempo, que se expanda o se retraiga. Es decir, finalmente en la política del castigo las decisiones sobre qué conductas penalizar y cuáles no, van a ser tomadas por el partido político que gobierne en el momento. 


\section{b. Los delincuentes}

Es el área donde existen mayor número investigaciones. Las investigaciones han intentado analizar las influencias biológicas, psicológicas y sociales que existen sobre el comportamiento delictivo. En el área biológica se han hecho diversas investigaciones como las de Damasio en 1994 para dilucidar el desempeño neuropsicológico de los delincuentes. Para ello se han investigado los aspectos hormonales y neuroquímicos, los aspectos genéticos, el ambiente familiar de los delincuentes y se han utilizado técnicas de neuroimagen con el fin de detectar anomalías en el cerebro de los delincuentes. Desde el área psicológica

Illescas y Pueyo (2007), han realizado diferentes investigaciones en las que determinan que la delincuencia es una conducta aprendida, que existen rasgos y características individuales que predisponen al delito, que los delitos constituyen reacciones a vivencias de estrés y tensión, así como que la delincuencia es el resultado de la ruptura de los vínculos sociales, y que el origen y mantenimiento de las conductas delictivas se relacionan con el desarrollo, especialmente durante la infancia y la adolescencia. Con respecto al área social existen diversas investigaciones y teorías como las procedentes de la Escuela de Chicago resaltando a su mayor representante Durkheim (1897) en las que proponen que el delito surge por una ausencia de normas; o las Teorías del Control Social, como por ejemplo la propuesta por Reckless (1961) que afirma que la delincuencia surge de las presiones que reciben los jóvenes para llevar a cabo conductas delictivas y el escaso control de las mismas.

Estas investigaciones se presentarán con mayor profundidad en el capítulo tres. No obstante, Redondo et al. (2013) explican que estas investigaciones han sido basadas sobre muestras de sujetos encarcelados o casos conocidos y que no abarcan a los delincuentes desconocidos como es lógico, por lo que no se pueden extraer conclusiones absolutistas sobre la conducta del criminal.

\section{c. Las víctimas}

Los orígenes de la Victimología se deben a dos autores: Mendelsohn (1940) y Von Henting (1957). 
La primera clasificación de las víctimas basada en el comportamiento de las mismas con el delincuente, la realiza Mendelsohn en 1940 agrupándolas en cinco tipos:

1. Víctimas totalmente inocentes: son aquellas que no han hecho nada para provocar al delincuente, que son ajenas totalmente al criminal.

2. Víctima provocadora: su conducta es considerada provocadora hacia la actividad del delincuente, ya sea con gestos o con palabras.

3. Víctima por ignorancia: aquella que sin ser consciente de ello provoca al criminal.

4. Víctima voluntaria: se considera víctima voluntaria la que colabora con el criminal.

5. Víctima agresora: la cual se divide en dos subtipos:

a. Simuladora: acusa falsamente.

b. Imaginaria: se inventa su discurso de víctima cuando en realidad no ha ocurrido nada.

Además, Von Henting (1957) hace alusión a las colusiones que se establecen entre las "parejas criminales" explicando la relación psicológica que existe entre víctima y criminal, como la relación de dominancia-sumisión; lo que le llevó a poder clasificarlas en base a 11 factores de riesgo: Las personas jóvenes, que por su período de desarrollo son más fáciles de agredir, las mujeres, por ser consideradas socialmente más débiles que el hombre y estar supeditadas a su autoridad y los ancianos, por ser considerados más frágiles debido a la pérdida de capacidades propias de la edad. Las personas discapacitadas, toxicómanas, dementes, alcohólicas, depresivas y los solitarios o abandonados, por tener alteradas sus capacidades cognitivas y en el caso de los solitarios, su condición les hace más vulnerables. Los inmigrantes y minorías, por no estar familiarizados con la cultura en la que viven tanto a nivel lingüístico como social. Los codiciosos, por tener tendencia a inmiscuirse en actividades peligrosas para ganar dinero fácil. Los caprichosos, por tener tendencia a la autosatisfacción y promiscuidad que le pone en situaciones de riesgo. Los torturadores, en el que la víctima puede convertirse en autor del delito y por último los bloqueados, excluidos y agresivos; el bloqueado por su imposibilidad defensiva, el excluido por su aislamiento y el agresivo por la provocación que puede realizar. 
En este sentido, Fattah (2014) teniendo en cuenta las ideas de Von Henting, resalta respecto al efecto motivacional y/o funcionamiento de la víctima sobre el agresor que:

Von Henting insistió en que muchas de las víctimas del crimen contribuyen a su propia victimización, ya sea por incitar o provocar a los criminales o creando o fomentando una situación propicia que pueda dar lugar a la comisión del delito. Otros pioneros en la victimología, que creían firmemente que las víctimas pueden, consciente o inconscientemente jugar un papel causal, describen muchas de las formas que pueden adoptar estas contribuciones: negligencia, descuido, temeridad, imprudencia, y así sucesivamente. Señalaron que el rol de la víctima podría tener un efecto motivacional (atrayendo, despertando, induciendo, incitando, tentando) o funcional (provocando, precipitando, desencadenando, facilitando, participando). (Ibíd, 2014, p.4).

Se han realizado también numerosos estudios sobre los efectos que producen los delitos en las víctimas, así como investigaciones sobre características de las víctimas que puedan dar pistas sobre la conducta del delincuente. Estos estudios han generado una nueva disciplina, denominada "Victimología" que estudia las causas por las que ciertas personas son víctimas de un delito y de cómo las características de la persona y su ambiente influyen en la probabilidad de que sea víctima o no de un delito. (Fattah, 2014).

Este término fue acuñado por Frederick Wertham en 1949. De manera que esta disciplina es de reciente creación. Es en 1950 cuando surge el interés por la víctima como objeto de estudio en un congreso celebrado en Madrid y en 1973 cuando se celebra el primer simposium de Victimología en Jerusalén. (Jiménez, 2012).

La víctima ha sido hasta 1973 la gran olvidada en los estudios criminológicos, más centrados en el delito; incluso también ha sido la olvidada del Derecho Penal, centrado también en castigar al delincuente y olvidándose de los efectos causados en la víctima.

En el campo de la responsabilidad de la víctima y su relación con el agresor, Schafer (1977), a partir de los trabajos de Mendelsohn (1940) y Von 
Henting (1957), hizo un intento clasificatorio proponiendo siete tipos de responsabilidad de parte de la víctima presentados en la Figura 3:
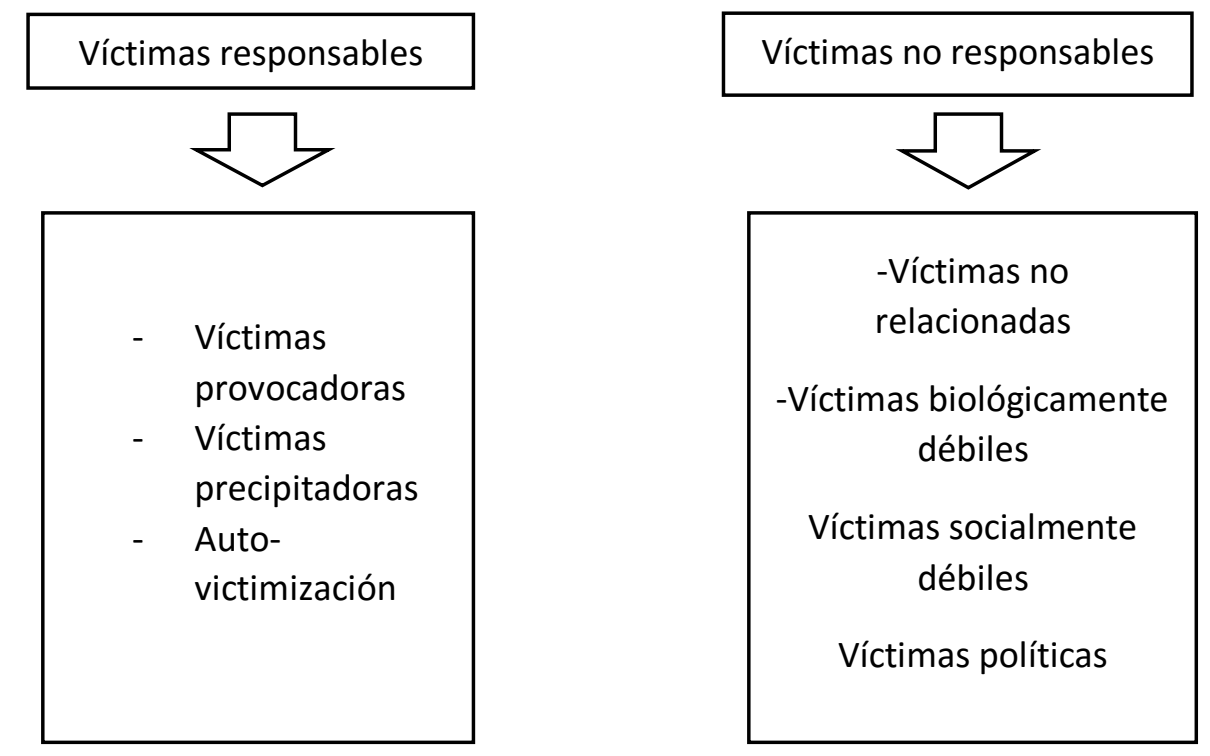

Figura 3: Responsabilidad de las víctimas. (Schafer, 1977).

Desde el intento de explicación de las variaciones en el riesgo de victimización, la diferencia entre grupos y edades, se crean las encuestas de victimización, lo cual da lugar a la creación de modelos teóricos en un intento por explicarlas.

Uno de los primeros modelos teóricos en surgir fue el postulado por Hindelang, Gottfredson y Garófalo (1978) denominado "Modelo de oportunidad basado en el estilo de vida" en el que inciden sobre la importancia que tiene el estilo de vida llevado por una persona sobre el riesgo de una victimización.

Otro es el modelo propuesto por Cohen y Felson en 1979 denominado "Enfoque de la Actividad Rutinaria". Estos autores ponen mayor énfasis en "violaciones predatorias de contacto directo", que son "aquellas que implican contacto físico directo entre al menos un delincuente y al menos una persona $\mathrm{u}$ objeto que ese delincuente intenta tomar o dañar" (Cohen y Felson, 1979, p.589). Para estos autores:

La aparición de este tipo de victimización es el resultado de la convergencia en el espacio y el tiempo de un mínimo de tres elementos: delincuentes motivados, objetivos adecuados, y la ausencia de 
guardianes capaces. Los factores centrales que subyacen en el enfoque de la actividad rutinaria son oportunidad, proximidad/exposición y factores facilitadores. (Fattah, 2014, p.11)

Otros modelos teóricos son el "Modelo de Oportunidad" (Cohen et al., 1981) que aúna los conceptos de los dos anteriores modelos, y el "Modelo Holandés" de Van Dijk y Steinmetz, sin fecha, que propone tres factores como los principales agentes de riesgo para la víctima: la proximidad, el atractivo y la exposición.

Finalmente, y desde las aportaciones de estos autores, es en 1980 cuando se crea la Sociedad Internacional de Victimología.

En este sentido, Henderson (1985) resaltó la existencia de una relación interpersonal bastante estrecha entre víctima y agresor, de manera que algunas víctimas sin saberlo invitan o causan su propia victimización. De esta idea se genera una nueva clasificación: la de las víctimas que provocan el acto delictivo, denominadas víctimas provocadoras o precipitadoras, $\mathrm{y}$ las que inconscientemente tienen la capacidad de ser víctimas, denominadas víctimas propensas. (Ibíd, 1985).

Respecto al desarrollo de la Victimología, Karmen (2007) sugiere que se centra en tres puntos:

- Estudiando los porqués y cómos de la entrada de la víctima en una situación peligrosa.

- Evalúa las interacciones que lleva a cabo la víctima a lo largo de todo el proceso judicial: los policías, las instituciones, etc.

- Evalúa también los efectos restitutivos que se aplican en la víctima, pudiendo cumplir con sus necesidades personales y emocionales.

En este sentido, Jiménez (2012, p.199) opina que debido a la proliferación de esta disciplina, surge diferente terminología que resulta necesario conocer. Para ello, expone los siguientes términos:

- Victimidad: es la predisposición de unas personas para ser víctimas, es decir, el conjunto de factores que predisponen a una persona o grupo a ser víctimas. 
- Victimario: es aquel que produce el daño, sufrimiento o padecimiento de la víctima.

- Víctima: es el ser humano que padece el daño en los bienes jurídicamente protegidos por la normativa penal.

- Victimal: predisposición de un grupo o persona a convertirse en víctima.

- Victimar: hacer objeto a otro u otros de una acción victimante, es decir, convertir a alguien en víctima.

- Factor victimógeno: todo aquello que favorece la victimización.

Por último, dentro de la Victimología se diferencian tres tipos de victimización a los que puede estar expuesta la víctima:

1. Victimización Primaria: “ proceso por el cual una persona sufre, de modo directo o indirecto, daños físicos o psíquicos derivados de un hecho delictivo o acontecimiento traumático" (Jiménez, 2012, p.202)

2. Victimización Secundaria: es la relación de víctima con el sistema judicial. Esto supone una segunda experiencia que puede llegar a ser más traumática que la primera, ya que al enfrentarse a la frialdad de las instituciones la víctima puede llegar a sentir que no se la tiene en cuenta o incluso sentirse acusada.

El término de victimización secundaria fue acuñado por Khüne (1986) para referirse a todas las agresiones psíquicas (no deliberadas pero efectivas) que la víctima recibe en su relación con los profesionales de los servicios sanitarios, policiales o judiciales (interrogatorios, reconstrucción de los hechos, asistencia a juicios, identificaciones de acusados, lentitud y demora de los procesos, etc.) así como los efectos del tratamiento informativo del suceso por parte de los medios de comunicación. (Jiménez, 2012, p.202-203).

3. Victimización Terciaria: se trata del conjunto de costes de la penalización tanto de la propia víctima como de la familia y allegados.

En conclusión, se podría afirmar que muchos de los delitos no serían conocidos de no ser por la víctima, que es la que denuncia los hechos y las que suelen aportar mayor información sobre el delito. Para lo cual, se han 
desarrollado instrumentos de medida con el fin de evaluar el riesgo de sufrir un delito en determinada área social. Para ello se recurre a encuestas de los ciudadanos.

Asimismo, la victimología incluye el estudio de las medidas de protección contra los delitos, entre las que se encontrarían aspectos diversos que van desde las técnicas verbales que las posibles víctimas podrían utilizar para afrontar una situación de acoso sexual hasta medidas antirrobo estrictamente mecánicas. El estudio del coste social y económico de la delincuencia (Serrano Gómez, 1876; Redondo, Garrido y Sánchez-Meca, 1997; Welsh y Farrington, 2011) se suelen vincular también a la victimología. (Redondo et al., 2013, p.67).

\section{d. Los sistemas de control social}

Por último, y para concluir este apartado referido a las diferentes áreas de estudio criminológico, se expone la investigación más reciente (Hikal, 2009) en esta área que diferencia entre control social formal e informal. El formal sería ejercido por las instituciones y el informal sería aquel que es ejercido por las personas (familia, escuela, el trabajo)

El control informal en opinión del autor, suele ser más efectivo contra la delincuencia que el formal, ya que los diferentes estamentos, como la policía y la justicia, se sirven de las personas que les brindan información acerca del delito.

Los sistemas de control social son definidos por Hikal (2009) como el conjunto de normas a los que la sociedad debe obedecer. Este autor resalta la importancia de estos sistemas para la conformidad del individuo a la sociedad. Así, los sistemas de control social quedan definidos en palabras del autor como:

El conjunto de instituciones, estrategias y sanciones sociales, que pretenden promover y garantizar el sometimiento del individuo a los modelos y normas comunitarias. El control social es importante ya que en toda sociedad hay una lucha entre el individuo y la sociedad. La sociedad necesita ejercer su dominio sobre el individuo, así despliega una gama de mecanismos que aseguren la conformidad del individuo a las normas sociales. (Ibíd, 2009, p.4) 


\subsection{CONTRIBUCIÓN DE LOS ÁMBITOS DE LA PSICOLOGÍA AL ESTUDIO DE LA CRIMINALIDAD}

Los diferentes campos de la Psicología han hecho sus aportaciones para una mejor y más profunda comprensión del comportamiento criminal siendo las más relevantes la Psicología evolutiva, Psicología social, Psicología biológica y Psicología del comportamiento.

\subsubsection{Psicología evolutiva}

La estructura personal se va formando desde la infancia con la confluencia de diferentes y variados factores. De manera que la psicología evolutiva muestra la influencia existente entre el desarrollo cognitivo-afectivo del niño y su ambiente. La adolescencia es una época de suma importancia y existen numerosos trabajos sobre su influencia en el comportamiento criminal (Loeber, Farrington y Waschbusch, 1998; Rutter y Giller, 1988; West y Farrington, 1973).

Los estudios de Henggeler (1989) respecto a las relaciones de los adolescentes con los sistemas de control social reflejan que en esta época se producen los primeros encuentros con los mismos, como la policía o la justicia, las relaciones con los grupos de iguales, el acercamiento a las diferentes sustancias como el alcohol y drogas. Esto hace que la adolescencia se convierta en una época crítica para la aparición de las primeras conductas delictivas.

La propia fase de la adolescencia de por sí es difícil, las discrepancias con el entorno familia y la necesidad de buscar nuevas experiencias, llevan al adolescente a una época confusa que merece especial atención. En este sentido, Soria et al., (2008) expone que una constatación universal es la gran cantidad de adolescentes que de forma transitoria transgreden la ley, si bien, abandonan dichas prácticas de forma natural. Es decir, en el adolescente se da una cierta psicopatoplasticidad en cuanto a que conductas delictivas pueden aparecer de forma transitoria y desaparecer de forma súbita o gradual. No obstante otros, los menos, continúan de forma escalonada desde esa adolescencia una carrera delictiva creciente.

En cuanto a la Teoría del Desarrollo de Terrie Moffit (1996), destaca que las personas están influidas por diferentes factores según la etapa de la vida y que las relaciones sociales se modifican influyendo en la conducta delictiva. Sigue criterios 
como la "Fase de la Vida" del delincuente y los "Factores de Riesgo Estadísticos" de la delincuencia. Moffit (1996), especifica que la mayoría de quienes cometen delitos, abandonan su carrera delictiva cuando salen de la adolescencia.

Igualmente, este mismo autor clasifica a los delincuentes en:

a) Delincuentes cuya actividad se limita a la adolescencia. Apostilla que este tipo de delincuencia, llegando el sujeto a la edad de 32 años no presenta diferencias conductuales ni de personalidad con sujetos de la misma edad que no han realizado en ningún momento conductas delictivas.

b) Delincuentes cuya actividad persiste a lo largo de la vida. Para Moffit (1996) la etiopatogenia en estos casos es de naturaleza neuropsicológica, de temperamento y de desarrollo del comportamiento, unido evidentemente a factores ambientales (familia, escuela, barrios, etc) que pueden empeorar esa base constitucional facilitando al mismo tiempo la acumulación de consecuencias negativas.

\subsubsection{Psicología social}

Es la rama que más aportaciones ha hecho al estudio de la criminalidad. Propone varias teorías explicativas:

a) Las actitudes humanas: establecen una relación entre actitud y conducta respecto a un objeto o persona. Como indica Pastor (1988) las actitudes se componen de cogniciones, afectos y conductas es decir, el comportamiento basado en una actitud depende de varios procesos intermedios.

b) Teoría de la Atribución Social (Heider, 1958): esta teoría incide en la idea de que las personas suelen buscar una causa a todas las conductas sociales. La atribución puede hacerse a factores externos, como el contexto, el azar, etc que no dependen de la persona; o a factores internos: implicación, motivación etc, causas pertenecientes a la conducta de la persona.

c) Teoría de la Disonancia Cognitiva: elaborada por Festinger en 1957, propone que el sujeto entra en un estado de tensión al tener que elegir entre dos alternativas de atractivo similar. Una vez tomada la decisión, la persona tomará diversos caminos cognitivos dirigidos a aumentar el atractivo de la decisión tomada y reducir el de la rechazada con el fin de reducir el malestar psicológico producido. Realmente pensamos que lo que hace Festinger es congitivizar el planteamiento psicoanalítico de la de ambivalencia, que no es otro que dos 
fuerzas pulsionales que pujan con la misma intensidad y la cuya resolución del conflicto pasa por el uso de mecanismos de defensa como la racionalización.

d) Estudios de procesos grupales: Estos estudios muestran la diferencia de comportamiento de un individuo al estar en solitario frente a la situación de estar inmerso en un grupo. Los grupos influyen sobre las ideas y las conductas de las personas que los componen. Como ejemplos:

a. La creación de las normas grupales (Sherif, 1936): La interacción dentro de los grupos tiende a crear normas y dichas normas influyen posteriormente sobre los individuos. Así lo demuestra el experimento sobre el efecto autocinético: en un entorno de oscuridad, existe la tendencia a percibir movimiento en un punto luminoso aunque realmente dicho punto permanece inmóvil. Cuando se comparan las percepciones de diversas personas se observa que el criterio de cada uno tiende a converger a un criterio grupal.

b. La tendencia al conformismo (Ash, 1951): se observa la influencia que la mayoría ejerce sobre el individuo aunque esté equivocada. Ante un grupo que se manifiesta unánimemente equivocado, la persona tiende a expresar conformidad en un porcentaje relativamente elevado de ocasiones.

e) Desindividuación social: Este proceso está íntimamente ligado con el anterior. Soria et al., (2008, p.34) define el fenómeno como:

Aquel proceso psicosocial por el que una persona pierde su identidad personal en el seno de un grupo, y en consecuencia, se desindividualiza. Para realizarlo la persona reduce su autoobservación y por consiguiente, también restringe su capacidad de control y los sentimientos de culpa y miedo que conllevan determinados comportamientos en una concreta situación social.

\subsubsection{La psicología biológica}

Los procesos biológicos están interrelacionados con los psicológicos y los sociales, por lo que nadie duda de la unidad bio-psico-social del hombre (Engels, 1977). Las conductas no se dan fuera del cuerpo ni de la sociedad sino que se sustentan sobre una constitución biológica y ninguna explicación coherente del ser humano debería de parcelar su conocimiento a una sola de las perspectivas.

En este sentido, se han seguido varias líneas de investigación: 
a) Estudios genéticos y de adopciones: Intentan comprender la influencia de la herencia genética en la conducta de las personas. Los estudios de adopciones tratan de observar los cambios producidos en niños procedentes de familias sin antecedentes criminales y adoptados por familias que sí los poseen. De manera que así se pueda demostrar si son producidos por factores biológicos o ambientales. Los estudios de gemelos criados en entorno y familias diferentes, muestran precisamente la incidencia de estos factores biológicos. De ellos destaca el realizado por Coninger (1982), que comparó 862 niños adoptados en Suecia. Dividió la muestra entre los que tenían padres criminales y se sospechaba por tanto una predisposición genética de los no criminales, comprobando si las experiencias educativas y ambientales de la familia adoptiva influían en la predisposición criminal. Los resultados revelaron que cuando ambos factores (hereditario y ambiental) eran nocivos, el $40 \%$ de los niños eran criminales frente al $12,1 \%$ cuando sólo estaba presente uno de los dos factores, reafirmando la existencia de una predisposición biológica hacia el crimen.

En esta línea, Mednick y Cabrielli (1984) basándose en los estudios previos de Cloninger (1982) realizan una investigación con una muestra de 14.427 niños adoptados dividiendo a la muestra en cuatro grupos: biológicos delincuentes, biológicos no delincuentes, adoptivos delincuentes y adoptivos no delincuentes. Los hallazgos muestran que si los padres biológicos tenían numerosas condenas, aumentaban las condenas de los hijos adoptados. No obstante, los delitos observados fueron contra la propiedad y no se registraron agresiones violentas.

Una cuestión no obstante, que hay que destacar, es que los genetistas de la conducta como es evidente no son radicales en sus planteamientos, dado que aun privilegiando en sus estudios las bases biológicas de la violencia en ningún momento niegan los factores ambientales dentro de la multifactorialidad del fenómeno.

b) Alteración neurológica: centradas en la relación entre una causa neurológica y el comportamiento criminal. En esta línea destacar estudios como los de Raine (2008) con respecto a las alteraciones 
cerebrales relacionadas con factores de riesgo que incrementan la probabilidad de que se presenten comportamientos antisociales y psicopáticos.

c) Estudios fisiológicos: analizan los cambios biológicos producidos a consecuencia de acontecimientos psicológicos, desde diferentes medidas fisiológicas como el electroencefalograma (EEG), los potenciales relacionados a eventos (PRE), el electroencefalograma (ECG), etc. A este respecto, Williamson; Harpur y Hare (1991) relacionaron la psicopatía con un déficit del procesamiento del lenguaje emocional encontrando que tanto los sujetos no criminales como los criminales no psicópatas respondieron más rápido y acertadamente a palabras emocionales que a las neutras, mostrando por tanto diferencias en los PRE entre los dos tipos de palabras.

\subsubsection{Psicología del comportamiento}

Con la aparición del Conductismo (Watson, 1878; Skinner, 1904), el objeto de estudio se basó en el estudio del comportamiento observable de las personas.

Las bases epistemológicas del conductismo radican en el empirismo, ya que se considera que "el conocimiento es una copia de la realidad". Por otro lado, según esta teoría, el hombre es una "tabula rasa" en la que se van añadiendo conocimientos.

El Conductismo aboga por el empleo de procedimientos únicamente experimentales para estudiar el comportamiento observable (la conducta) y niega toda posibilidad de utilizar los métodos subjetivos como la introspección. Su fundamento teórico está basado en que a un estímulo le corresponde una respuesta, siendo ésta el resultado de la interacción entre el organismo que recibe el estímulo y el medio ambiente. Considera que la observación externa es la única posible para la constitución de una psicología científica.

La teoría de la conducta más relevante para la criminología es la Teoría del Aprendizaje Social (Bandura 1982) en la que se destaca que la agresión se aprende a través de un proceso llamado modelado de comportamiento. Este autor, creía que las personas no heredan tendencias violentas, sino que los individuos, especialmente los niños aprenden las respuestas agresivas de los demás al observar, ya sea personalmente o a través de los medios de comunicación y el medio ambiente. 
El estudio de la conducta observable fue objeto de numerosas críticas y llevó progresivamente a considerar los factores cognitivos como fuente importante de predicción de la conducta elaborándose nuevos métodos de evaluación con fundamentación científica cognitivo-conductual.

En general, desde estas diferentes perspectivas, se observa que la Psicología se ha ocupado de los factores exógenos a la criminalidad (conductuales y cognitivos) como de los factores endógenos e intrapsíquicos (psicología del desarrollo, factores biológicos), entendiendo que ninguno de los Modelos puede explicar por sí solo la conducta criminal.

\subsection{TEORÍAS SOCIOLÓGICAS DEL CRIMEN}

En este apartado se explican los diferentes enfoques sociales existentes respecto a la delincuencia o criminalidad, destacando que dichos enfoques no se centran en el diagnóstico de psicopatía como tal, sino que se manejan desde la perspectiva de que las conductas antisociales se pueden dar en cualquier persona. De manera que no se puede hacer un reduccionismo del aspecto de la psicopatía, por lo que resulta de gran importancia tener en cuenta el aspecto social del mismo.

Así, la Sociología Criminal cuenta con dos enfoques: el europeo, cuyo máximo representante es Durkheim y su Teoría de la Anomia en la que destaca que las conductas antisociales vienen determinadas por una ausencia de normas; y el norteamericano, que surge de la escuela de Chicago y que entre sus representantes destacan Park, Burgess, Mckenzie, Thrasher y Shaw caracterizada por su empirismo y finalidad pragmática.

\subsubsection{Escuela de Chicago}

Es una escuela que ha sido denominada por hacer "sociología de la gran ciudad" (García-Pablos, 2007, p.427) Se interesa por los grupos formados en las grandes ciudades, las minorías conflictivas, comprender el funcionamiento de la ciudad desde dentro. La primera teoría en surgir de la escuela de Chicago es la llamada Teoría Ecológica en la que se explica la ciudad como una unidad ecológica y se establece un 
paralelismo entre el crecimiento de centros urbanos y la criminalidad de los mismos; explica cómo dentro de la gran ciudad existen zonas de delincuencia muy definidas. (Espinoza, 1997).

La teoría ecológica explica este fenómeno criminológico de la gran ciudad acudiendo a los conceptos de desorganización y contagio inherentes a los modernos núcleos urbanos, y sobre todo, invocando el debilitamiento del control social que en éstos tiene lugar. (García-Pablos, 2007, p.429)

Esta idea de "desorganización social" ha sido foco de críticas, tal y como apunta Virgolini (2004), basadas en la idea de que no recoge la realidad de esas partes de la ciudad, sino que se basan en los propios principios de los investigadores. El análisis ecológico, será sustituido a partir de los años 50 por estudios de "área social” y métodos estadísticos multivariados.

\subsubsection{Teorías originadas a raíz de la Escuela de Chicago}

Derivadas de la Escuela de Chicago, surge un grueso de teorías divididas en dos vertientes: por un lado las Teorías de la Tensión, que destacan el papel de la relación medios-fines en la influencia de conductas disruptivas, y por otro, se encuentran las Teorías del control Social que propugnan que con el crecimiento de las ciudades, los vínculos afectivos y lazos familiares se ven alterados, lo que llevaría a un aumento en la inmersión de conductas no aceptadas socialmente.

\section{a. Teorías de la tensión}

Estas teorías se asientan en la idea de que la sociedad promueve que se aspire a ciertas metas, pero no siempre los medios legítimos son los disponibles para alcanzarlas, de ahí que surjan personas que delinquen para alcanzar estos objetivos que de otro modo les sería imposible.

1. Teoría de la Anomia: Durkheim (1897) basa su teoría en la idea de que el delito se comete por una ausencia de normas. De manera que Siegel (2010), Smelser y Warner (1991) exponen que:

Desde un punto de vista etimológico, Durkheim acuñó el neologismo "anomia" a partir de combinar el prefijo griego de negación "a” y el término "nomos" (norma) con esta nueva palabra caracterizó a aquellas situaciones en que se produce una "ausencia de norma" o "desregulación", que serían, según la perspectiva del propio Durkheim y de 
los primeros teóricos de la Escuela de Chicago, el origen principal de la desviación social y el delito. (Citado en Redondo y Garrido, 2013, p.270).

Esta visión fue pronto cuestionada, evolucionando a la idea de que las consideradas "conductas desviadas" en realidad serían reacciones de personas normales ante los problemas sociales que vivían. Otra aportación fue la visión positiva de la delincuencia; queriendo decir con ello que debido a ciertos comportamientos delictivos o cierta criminalidad, el resto de población se uniría delimitando normas, de manera que los actos delictivos serían condenados y servirían como punto de referencia de una conducta inadecuada. (Villavicencio, 1997).

Otro autor representativos de la Teoría de la Anomia (Merton, 1938), expone que "la anomia surge de la discrepancia existente entre las necesidades del hombre y los medios que ofrece una sociedad concreta para satisfacerlas" (citado en Giner, 1993, p.233). Así, este autor, amplía el concepto de anomia, definiéndola como:

Aquel proceso propio de las sociedades modernas, que resultaría del cambio rápido de los valores sociales, sin que dé tiempo a reemplazarlos por otros valores alternativos. Como resultado de ello, los individuos se quedarían sin valores y normas que les sirvan como referentes de su conducta. (Young, 2010; Walsh, 2012, citado en Redondo y Garrido, 2013, p.271).

En este sentido, Merton (1938), apunta la idea de que existe un conflicto medios-fines y que no todas las clases sociales disponen de los medios para alcanzar el "sueño americano" que la sociedad vende (Huertas-Díaz, 2010): "El sueño americano promueve el ideal de que todo el mundo dispone de iguales oportunidades para lograr el éxito. Pero en realidad los grupos minoritarios desfavorecidos y la clase baja no tienen un idéntico acceso a tales oportunidades legítimas" (Akers, 1997, p.120)

Esta teoría de Merton, fue corroborada por Messner y Rosenfeld en 2001. Estos autores explican que el ansiado "sueño americano" tiene 
sus raíces en un capitalismo atroz que ensalza la competencia entre individuos y la obtención exponencial de bienes materiales. Así, se generaría una sociedad en la que "todo vale" en el camino hacia la consecución de objetivos.

2. Teoría de las subculturas: según esta teoría muchos individuos de la clase baja estarían sometidos a una discrepancia entre las aspiraciones sociales y los recursos personales disponibles para su logro. Este desajuste medios-fines les genera estados emocionales de tensión y de disconformidad con las pautas colectivas (Melde y Esbensen, 2011).

En esta línea, las dos aportaciones más destacadas son las de Cohen (1955) y Cloward y Ohlin (1966) en relación a la influencia del conflicto medios-fines sobre las pautas de actuación de las personas.

Cohen (1955) recoge la propuesta de Merton en la que la causa de las tensiones sociales radica en el conflicto medios-fines centrándose en la frustración que genera en los jóvenes la no consecución de los objetivos propuestos. En palabras de Cohen (1955): "La condición crucial para la emergencia de formas culturales nuevas es la existencia en la interacción efectiva con otros de un número de actos con similares problemas de ajuste" (Ibíd, 1955, p.59).

Por otro lado, Cloward y Ohlin (1966), consideran la delincuencia como la actividad dirigida a la consecución de bienes materiales ilegítimos. Su explicación difiere de la Cohen en que consideran la delincuencia como una reacción ante la falta de oportunidades de conseguir unos elevados ingresos económicos mediante actividades o trabajos legítimos. (Howard, Richard y Sparks, 1970).

Finalmente, quienes en tales contextos sociales, no se ubiquen ni el orden social establecido ni en la subcultura delincuencial de la banda, acabarán, según Cloward Ohlin, como sujetos refugiados en actividades marginales tales como el consumo de drogas. (Clemente y Sancha, 1989; Giddens, 2009; citado en Redondo y Garrido, 2013, p.277).

3. Teoría general de la tensión: esta teoría formulada por Agnew en 1992 y la completada en 2006, recoge las ideas fundamentales de Merton, Cohen, Cloward y Ohlin y las amplía explicando que las relaciones 
establecidas con otras personas inmiscuidas en actividades no aprobadas socialmente presentan un carácter negativo.

Según el autor, los jóvenes acuden a la delincuencia por estados emocionales negativos generados por la frustración o la ira, lo que derivaría en una mala relación con su entorno. De esta forma, la tensión era producida por la discrepancia medios-fines.) Existen otras fuentes de tensión además de dicha discrepancia, propuestas por Agnew (1992):

- La imposibilidad de alcanzar objetivos sociales como un mayor status social. Un ejemplo sería la discrepancia entre el esfuerzo invertido en algo y el logro real. Hoy en día podemos comprobar en nuestro propio país como muchos universitarios, muy formados no pueden trabajar de aquello para lo que se han estado formado durante años.

- La tensión derivada de la privación de aquellas gratificaciones que un individuo ya posee o espera poseer, por ejemplo al tener que aceptar un trabajo precario para poder tener un sueldo, y quedar sometido a unos horarios que impiden disfrutar de un tiempo de calidad con la familia.

- La tensión producida cuando una persona es sometida a situaciones negativas o aversivas de las cuales no puede escapar como por ejemplo personas que debido a los pocos recursos económicos viven en barrios conflictivos expuestos a conflictos diarios.

Las fuentes de tensión más habituales de las sociedades occidentales, sobre todo en relación a los jóvenes se exponen en la Tabla 14:

Tabla 14: Fuentes de tensión habituales en las sociedades occidentales (Agnew, 1992; Agnew y Brezina, 1997). 
- Rechazo paterno

- Supervisión/ disciplina errática, excesiva o cruel.

- Abandono o abuso infantil.

- Experiencias negativas en la escuela secundaria.

- Relaciones problemáticas con amigos y compañeros.

- Trabajos marginales.

- Desempleo crónico.

- Problemas de pareja.

- Fracaso en el logro de objetivos deseados (ocio, autonomía, pareja, dinero, bienes...)

- Victimización delictiva

- Residencia en barrios pobres y carentes de servicios

- Carencia de hogar

- Discriminación por raza, género, etc

\section{b. Teorías del control social}

Conforman la segunda línea derivada de la Escuela de Chicago. Estas teorías proponen que debido al crecimiento de las urbes los lazos familiares disminuyen, las relaciones interpersonales en el colegio o barrio se ven afectadas, de manera que el control sobre la conducta de algunas personas se ve disminuido también.

1. Teoría de la Contención de Reckless (1961): afirma que la delincuencia puede ser explicada por dos tipos de factores: las presiones recibidas por los jóvenes para llevar a cabo conductas delictivas y el escaso control para inhibir dichas conductas: "La probabilidad del comportamiento delictivo dependerá del equilibrio que se establezca en el individuo entre las presiones internas y ambientales para el delito y los controles interno y externo contra el delito" (citado en Redondo et al., 2013, p.293)

Reckless afirma que respecto a los controles internos, el factor más importante para prevenir la conducta delictiva es el buen autoconcepto. La falla de esta teoría radica en que no explica por qué unas personas adquieren los controles y otras no. 
2. Teoría de la neutralización y la deriva de Sykes y Matza (1957): esta teoría propone que los jóvenes se encuentran en medio de la conducta adaptada y la inadaptada. Debido a que los valores de estos jóvenes no se han asentado aún con firmeza no sabrán por qué dirección optar. Las técnicas de neutralización adquieren importancia en esta teoría, ya que explican que cuando los jóvenes optan por el camino de la transgresión, pueden recurrir a diferentes mecanismos de neutralización. Sykes y Matza (1957) proponen los siguientes:

- Negación de la responsabilidad y negación del delito (ya sea de ilicitud o del daño causado.

- De la víctima (descalificación).

- Condena/rechazo de aquéllos que condenan la acción

- Apelación a lealtades debidas

- Defensa de la necesidad de la conducta y defensa de un valor

- Negación de la justicia o de la necesidad de la ley

- Argumento de "todo el mundo lo hace" o argumento de "tenía derecho a hacerlo"

3. Teoría del control social o de los vínculos sociales de Hirschi (1969): La idea central que propone esta teoría es que lo que salva a los jóvenes de implicarse en actividades delictivas son los vínculos afectivos establecidos con personas socialmente integradas, de manera que la ruptura con tales vínculos sería lo que les llevaría a delinquir.

Hirschi (1969) además, propone cuatro procesos que facilitarían la inhibición de las conductas antisociales de los jóvenes de tal manera que en la medida en que estos cuatro procesos adquieran fuerza, la probabilidad de implicarse en actividades delictivas será menor: el apego a personas socialmente adaptadas, el compromiso social, la implicación y compromiso en actividades sociales convencionales, como las escolares o las laborales y los valores adaptados socialmente

En palabras del autor:

Una de las evidencias criminológicas mejor documentadas en la investigación, es que los jóvenes delincuentes se hallan menos vinculados a sus padres que los jóvenes no delincuentes. Los vínculos emocionales entre padres e hijos vendrían a ser el vehículo que facilita los procesos de socialización, a través de los cuales 
los hijos reciben las ideas, las expectativas y los valores paternos. (Citado en Redondo et al., 2013, p.300)

4. Teoría del autocontrol de Gottfredson y Hirschi (1990): esta teoría atribuye gran peso a la individualidad, diferenciándose en cuanto a su vulnerabilidad para delinquir, siendo la clave de esta diferenciación el autocontrol. Así, las personas con bajo autocontrol tendrían mayores posibilidades de delinquir que las que cuentan con un alto autocontrol.

Gottfredson y Hirschi (1990) aclaran su idea de bajo autocontrol como:

En síntesis, las personas que carecen de autocontrol tenderán a ser impulsivas, insensibles, físicas (en oposición a mentales), asumidoras de riesgo, imprevisoras y no verbales, y tenderán por tanto a implicarse en actividades delictivas y similares. Como quiera que estos rasgos pueden identificarse con antelación a la edad de responsabilidad delictiva, debido a que existe una considerable tendencia a que estos rasgos aparezcan juntos en las mismas personas, y debido a que los rasgos tienden a persistir a lo largo de la vida, parece razonable considerarlos como un constructo comprensivo y estable de utilidad para la explicación de la delincuencia. (Ibíd, 1990, p.90-91)

Respecto a la etiología del bajo autocontrol demarca su origen previamente a los procesos de crianza y socialización de los niños. Los autores afirman que:

No se conoce grupo social alguno, ya sea delictivo o no, que activamente o intencionalmente intente reducir el autocontrol de sus miembros. La vida social no es mejorada por el bajo autocontrol y sus consecuencias. Por el contrario, la manifestación de estas tendencias socava las relaciones armoniosas de grupo y la capacidad para lograr fines colectivos. Estos hechos niegan explícitamente que la delincuencia sea el producto de la socialización, de la cultura o del aprendizaje positivo de cualquier suerte (Íbid, 1990, p.95-96)

5. Teoría de la acción situacional del delito de Wikström (2004):) Este autor es profesor en el Instituto de Criminología de la Universidad de Cambridge, y aporta una nueva teoría de la delincuencia, denominada "Teoría de la Acción Situacional". Postula que, para poder explicar la conducta delictiva, debe atenderse tanto a factores individuales como contextuales: "el argumento central de la teoría de la acción situacional es que los actos delictivos son el resultado de 
un proceso por el cual el individuo percibe alternativas para la acción y elige (por hábito o por deliberación) qué alternativa seguir" (Wikström, 2004, p.19).

Por tanto, se hace necesario conocer los mecanismos situacionales que ligan a la persona con el escenario del delito. (Wikström, 2006).

\subsection{EVALUACIÓN Y DISTRIBUCIÓN DEL DELITO}

Existen tres tipos de fuentes de datos para el estudio de la distribución del delito: las estadísticas oficiales, que ofrecen datos institucionalizados, las encuestas y los estudios sobre victimización descritos en el apartado anterior.

\subsubsection{Las estadísticas oficiales}

$\mathrm{Al}$ hacer referencia a los datos estadísticos se debe tener en cuenta que existen diferentes conceptos que afectan a la comprensión de las estadísticas:

- Delitos conocidos: son aquellos que han sido cuantificados estadísticamente.

- Cifra negra de criminalidad: aquellos delitos que son desconocidos y por tanto no aparecen en las estadísticas. Esta cifra incluye los delitos cometidos pero que no han sido descubiertos y aquellos para los que no existe una sentencia condenatoria por falta de pruebas.

- La cifra negra se subdivide a su vez en dos más tal y como explican Soria et al. (2008):

- La cifra oscura: aquel volumen de delitos que no aparece en las estadísticas, aun conociéndose al autor, por la falta de denuncia de la víctima.

- La criminalidad oculta: hace referencia al volumen de delitos que no aparecen en las estadísticas oficiales porque la víctima desconoce que el suceso fuera un hecho delictivo.

En el devenir histórico de la frecuencia del delito se observa que en su origen, los estudios sobre la tasa de criminalidad se realizaban con los datos procedentes de las fuentes policiales y judiciales, informatizándose a partir de los años 80 . 
En el período de 1975-1985 se observa una evolución de la criminalidad en forma de campana de Gauss, de manera que a finales de la dictadura se observan niveles bajos de criminalidad. Con la llegada de la democracia a España se observa un aumento de la misma, para posteriormente, a mediados de los años 80, descender de nuevo.

Si bien suele aceptarse, aunque no existe conformación empírica de que el porcentaje varía según los delitos, dicha tasa oscura es menor en los delitos contra la propiedad, aproximadamente un $60 \%$ y mayor en los delitos personales, pudiendo alcanzar según los países el 80\%. (Zauberman, 1985, citado en Soria et al., 2008, p.36).

En resumen, cabe destacar que en nuestro país, se observa un progresivo aumento en la tasa de cifra negra de criminalidad con el tiempo.

A partir de mediados de los años 80, estos datos judiciales y policiales, se abren a otro tipo de fuentes como son las procedentes de las encuestas a la población o a los propios delincuentes.

\subsubsection{Encuestas de victimización}

En los años 70 hubo un cambio de opinión sobre la forma de analizar el acto criminal derivado de dos factores que provocaron dicho cambio: el aumento de la criminalidad real en los años 60 en USA y la problemática percibida por la sociedad en cuanto al aumento de la criminalidad.

Como consecuencia de estos dos factores "El Departamento de Justicia de Estados Unidos creó la President's Comission on Law Enforcement and Administration of Justice, o Comisión Katzenbach, para el estudio de criminalidad y el desarrollo de programas evaluativos y de prevención" (Soria et al., 2008, p.38)

El primer modelo de encuesta de victimización fue elaborado en 1972, por la "National Crime Survey", esta encuesta constaba de tres partes: las encuestas en ciudades, las comerciales (dedicadas a robos y atracos) y el panel de crimen nacional (en la que se entrevistaba repetidas veces a las mismas personas para conocer si habían sido víctimas de algún delito).

De este modelo de encuesta se extrajeron dos conclusiones importantes referidas a la tasa de victimización y a los delitos previos: "La tasa de victimización aparecida fue el doble de la recogida por las estadísticas policiales tradicionales y, segundo, que el 
número de delitos graves era escaso respecto al total de ellos cometidos" (Hidelang, Gottfredson y Garófalo, 1978, citado en Soria et al., 2008, p.38)

En general, las nuevas encuestas desarrolladas coinciden en la multiplicidad de los factores intervinientes: los fenómenos políticos, sociales, culturales, el impacto psicosocial del delito tanto en víctima como en la sociedad.

Por ello actualmente, se acepta que al tratar la criminalidad "debe estudiarse el comportamiento como objeto en sí mismo y no puede abordarse sólo desde una categoría abstracta de base jurídica” (Zanberman, 1985, p.47)

Como complemento a las encuestas se cuenta con métodos de evaluación de la criminalidad complementarios, procedentes de la psicología social, como los delitos confesados por los criminales, los estudios de criminalidad sobre poblaciones concretas o robos cometidos a personas mayores.

No obstante, Zanberman (1985) destaca que de todos los métodos de evaluación citados, las encuestas de victimización son las más potentes, pero dichos métodos han de ser utilizados de forma interactiva, no siendo suficiente la exclusividad de ninguno de ellos.

\subsection{ESTUDIOS SOBRE CRIMINALIDAD EN ESPAÑA}

La primera investigación sobre criminalidad en España fue realizada por Serrano (1986), desde mediados de los años 70 hasta mediados de los 80. Este autor se centra en el delito y su impacto, y sus fuentes son extraídas principalmente de la encuesta de victimización del CSIC, la policía y la Memoria del Tribunal Supremo.

Posteriormente, proliferaron las encuestas de victimización, como la del Centro Superior de Investigaciones Científicas (CSIC) que elabora anualmente una desde 1974. 
Se han recogido los datos más relevantes de las estadísticas oficiales publicadas por el INE (Instituto Nacional De Estadística) el 26 de septiembre de 2014 por ser las más actuales.

Respecto a la población reclusa, las estadísticas indican un descenso de condenados con respecto al año anterior. En 2013 fueron inscritos en el Registro Central de Penados 219.776 personas adultas según las sentencias firmes dictadas y comunicadas. Estos datos hablan de un $0,6 \%$ menos que el pasado año. En cuanto al sexo, en los varones supuso un $1,2 \%$ menos mientras que en las mujeres hubo un aumento del 3,9\%.

En la Tabla 15 se aprecia la evolución de las tasas de condenados desde el año 2013. Se observa que el $88,5 \%$ de los condenados fueron varones y el $11,5 \%$ mujeres. La tasa de personas condenadas por cada 1000 habitantes (de 18 y más años) fue de 5,7.

Tabla 15: Evolución de las personas condenadas adultas (2007-2013). (Instituto Nacional de Estadística).

\section{Evolución de las personas condenadas adultas (2007-2013)}

\begin{tabular}{|c|c|c|c|}
\hline Año & $\begin{array}{c}\text { Total } \\
\text { Condenados }\end{array}$ & Varones & Mujeres \\
\hline 2007 & 160.938 & 147.160 & 13.778 \\
\hline 2008 & 206.396 & 188.215 & 18.181 \\
\hline 2009 & 221.916 & 201.045 & 20.871 \\
\hline 2010 & 215.168 & 193.801 & 21.367 \\
\hline 2011 & 221.590 & 199.073 & 22.517 \\
\hline 2012 & 221.063 & 196.876 & 24.187 \\
\hline 2013 & 219.776 & 194.596 & 25.180 \\
\hline
\end{tabular}

Respecto a la edad, la edad media de las personas condenadas fue de 35,7 años (35,8 en varones y 34,7 en mujeres). Analizando por grupos de edad se observa que el grupo más frecuente es el de 41 a 50 años tanto en varones $(19,8 \%)$ como en mujeres $(18,6 \%)$. (Véase Figura 4). 


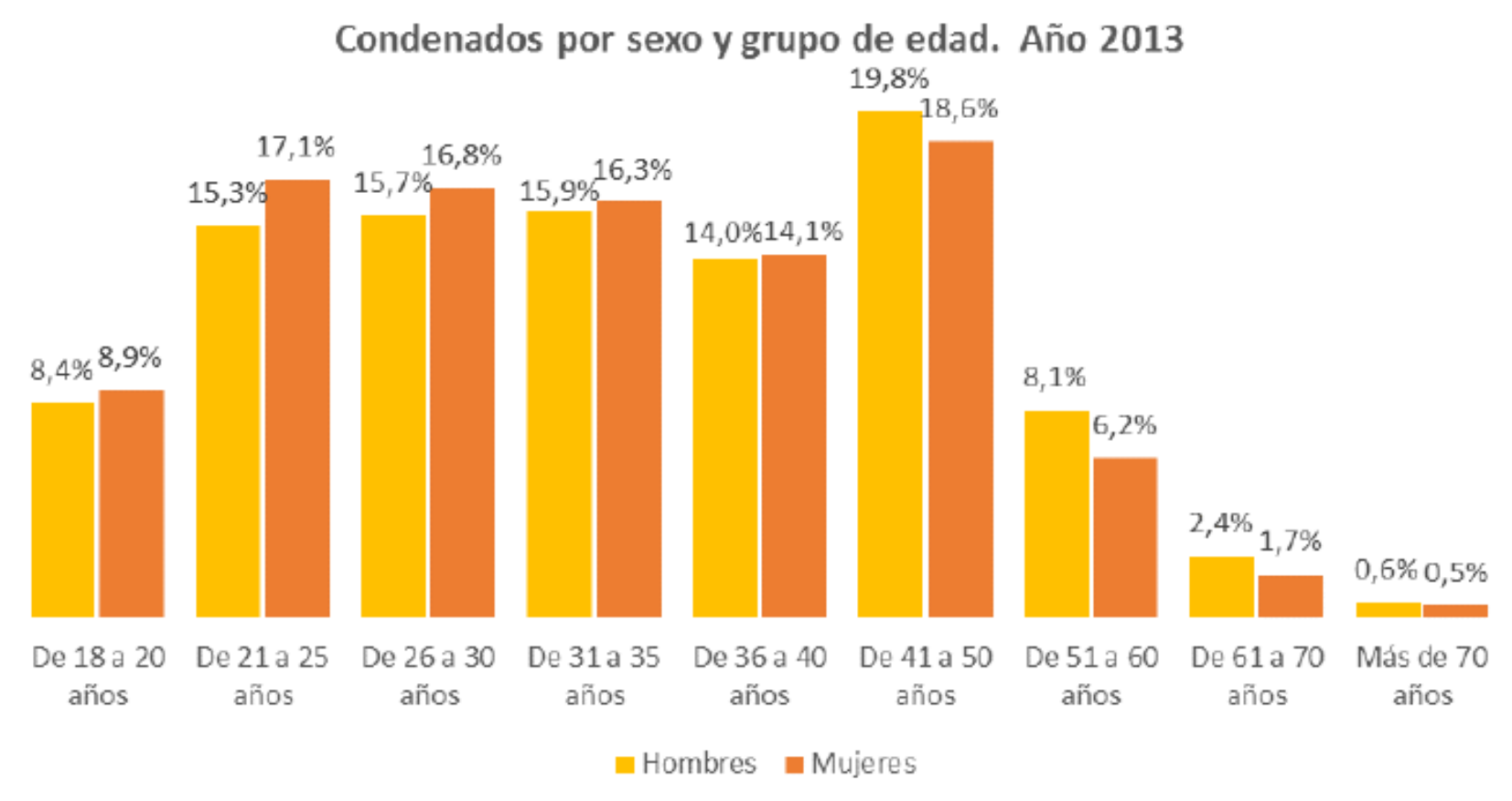

Figura 4. Condenados por sexo y grupo de edad. Año 2013 (INE, 2014)

Según los datos aportados por el Instituto Nacional de Estadística (2014) en el grupo de los extranjeros, los países americanos representan el mayor porcentaje de condenados $(35,2 \%$ del total).

En cuanto al lugar de condena, Andalucía es la comunidad autónoma con mayor porcentaje de condenados, con el 20,0\% del total. En segundo lugar situamos a Cataluña con un 14,6\% y en tercer lugar a la comunidad de Madrid con un 12,5\%.

Ceuta y Melilla presentan las mayores tasas de condenados inscritos por 1000 habitantes (28,3 y 20,6, respectivamente) seguida de la comunidad de Madrid con un 17,0\% y de Andalucía con un 13,5\%. Estos datos quedan referenciados en la Tabla 16: 
Tabla 16: Condenados adultos por CCAA (según lugar de condena).

Condenados adultos por CCAA (según lugar de condena)

Valores absolutos y tasas por 1000 habitantes mayores de 18 años Año 2013

Condenados Tasas

\begin{tabular}{|c|c|c|}
\hline Ceuta & 1.803 & 28,3 \\
\hline Melilla & 1.248 & 20,6 \\
\hline Balears, Illes & 7.094 & 7,8 \\
\hline Murcia, Región de & 8.101 & 7,0 \\
\hline Canarias & 11.756 & 6,8 \\
\hline Comunitat Valenciana & 26.678 & 6,5 \\
\hline Andalucía & 44.033 & 6,5 \\
\hline Total & 219.776 & 5,7 \\
\hline Navarra, Comunidad Foral de & 2.840 & 5,5 \\
\hline Cataluña & 32.120 & 5,3 \\
\hline Extremadura & 4.806 & $\overline{5,3}$ \\
\hline Cantabria & 2.618 & 5,3 \\
\hline Madrid, Comunidad de & 27.374 & 5,3 \\
\hline Rioja, La & 1.338 & 5,1 \\
\hline Asturias, Principado de & 4.702 & 5,1 \\
\hline Galicia & 11.883 & 5,0 \\
\hline Castilla - La Mancha & 8.344 & 4,9 \\
\hline País Vasco & 8.511 & 4,7 \\
\hline Castilla y León & 9.596 & 4,5 \\
\hline Aragón & 4.931 & 4,4 \\
\hline
\end{tabular}

Los datos aportados por el Instituto Nacional de Estadística (2014) referidos a los delitos inscritos en el registro muestran el dato de 275.196 delitos cometidos, lo que habla de una cifra muy similar a la del año anterior con 275.130 delitos.

Con respecto al tipo de delito cometido, según esta misma fuente, los que tuvieron mayor incidencia numérica fueron los delitos contra la seguridad vial, que supusieron un $36,8 \%$ del total, los delitos de lesiones supusieron un $12,3 \%$ y los robos con un $11,1 \%$ del total.

El número medio de delitos por persona condenada fue de 1,3. En cuanto al sexo fue mayor en los varones $(1,3)$ que en las mujeres $(1,2)$ de forma muy similar a lo que ocurrió el año anterior (1,3 en varones frente a un 1,1 en mujeres). Estos datos quedan referenciados en la Tabla 17: 
Tabla 17: Delitos cometidos por CCAA (según lugar de condena). (INE, 2014).

\begin{tabular}{|c|c|c|c|}
\hline & Delitos & Hombres & Mujeres \\
\hline Total & 7,2 & 13,2 & 1,5 \\
\hline Andalucía & 8,1 & 14,8 & 1,7 \\
\hline Aragón & 5,5 & 10,0 & 1,2 \\
\hline Asturias, Principado de & 6,6 & 12,3 & 1,4 \\
\hline Balears, Illes & 9,8 & 17,3 & 2,4 \\
\hline Canarias & 8,2 & 15,0 & 1,6 \\
\hline Cantabria & 6,6 & 12,0 & 1,5 \\
\hline Castilla y León & 5,7 & 10,4 & 1,1 \\
\hline Castilla-La Mancha & 6,1 & 11,1 & 1,1 \\
\hline Cataluña & 6,7 & 12,3 & 1,3 \\
\hline Comunitat Valenciana & 8,3 & 14,8 & 1,9 \\
\hline Extremadura & 6,8 & 12,6 & 1,2 \\
\hline Galicia & 6,5 & 12,4 & 1,2 \\
\hline Madrid, Comunidad de & 6,5 & 12,2 & 1,4 \\
\hline Murcia, Región de & 8,7 & 15,7 & 1,6 \\
\hline Navarra, Comunidad Foral de & 6,5 & 11,9 & 1,2 \\
\hline País Vasco & 6,0 & 11,3 & 1,2 \\
\hline Rioja, La & 6,5 & 11,8 & 1,3 \\
\hline Ceuta & 31,2 & 53,9 & 7,4 \\
\hline Melilla & 22,4 & 40,3 & 3,7 \\
\hline
\end{tabular}

Por último, y debido al lapso temporal en la elaboración de la Tesis Doctoral se ofrecen los datos proporcionados por el Ministerio del Interior, en el balance de criminalidad del primer trimestre de 2015, publicado el 7 de mayo de 2015, el cual señala un descenso de los índices de criminalidad durante el primer trimestre de 2015.

En este balance se muestra que desde enero a marzo de 2015 se han registrado en España un total de 496.133 delitos y faltas, lo que supone un 3,7\% menos con respecto al mismo período del año anterior. La tasa de criminalidad se cuantifica en 44,3 delitos y faltas por cada 1.000 habitantes, de manera que España se convierte en uno de los países más seguros de nuestro entorno.

Esta bajada de delitos y faltas registradas muestra la tendencia descendente que se viene apreciando años atrás, mostrando a España como un referente internacional en la lucha contra la criminalidad. "Cabe señalar que la eficiente utilización de los recursos 
policiales constituye uno de los principales instrumentos para prevenir, combatir y reducir los índices de criminalidad de nuestro país” (Ministerio del Interior, 2015).

Como conclusión, cabe decir que se observa un descenso generalizado con respecto al mismo período del año anterior, siendo la disminución más acusada en lo que respecta a los homicidios dolosos y asesinatos consumados $(-25,0 \%)$, los robos con fuerza en domicilios $(-15,9 \%)$, los robos con violencia e intimidación $(-15,5 \%)$, la delincuencia violenta en general (-14\%) y los robos con fuerza $(-12,2 \%)$.

\subsection{ESTUDIOS SOBRE CRIMINALIDAD INTERNACIONAL}

El término "delincuencia" como se ha recogido a lo largo de este capítulo describe numerosas formas de comportamiento ilegal. En este sentido, las leyes de los diferentes países tienen un baremo prohibitivo diferente y variable.

En el $12^{\circ}$ Congreso de las Naciones Unidas sobre Prevención del Delito y Justicia Penal en Salvador (Brasil) que tuvieron lugar en las fechas del 12 al 19 de abril del año 2010, el Secretario General, Ban Ki-moon apunta que "para elaborar un panorama exacto de la delincuencia en el mundo se requieren estadísticas e investigaciones que revelen la naturaleza y el alcance tanto de la delincuencia convencional como de los delitos organizados, transnacionales o complejos" (Ibíd, 2010, p.5)

Los datos presentados en este congreso relativos a la tendencia de los homicidios en el panorama internacional proceden de las Instituciones de Salud Pública y de las Instituciones Policiales o de Justicia. Los índices medios de homicidio de los países correspondientes al año más reciente disponible, organizados por subregión, se presentan a continuación en la Figura 5: 


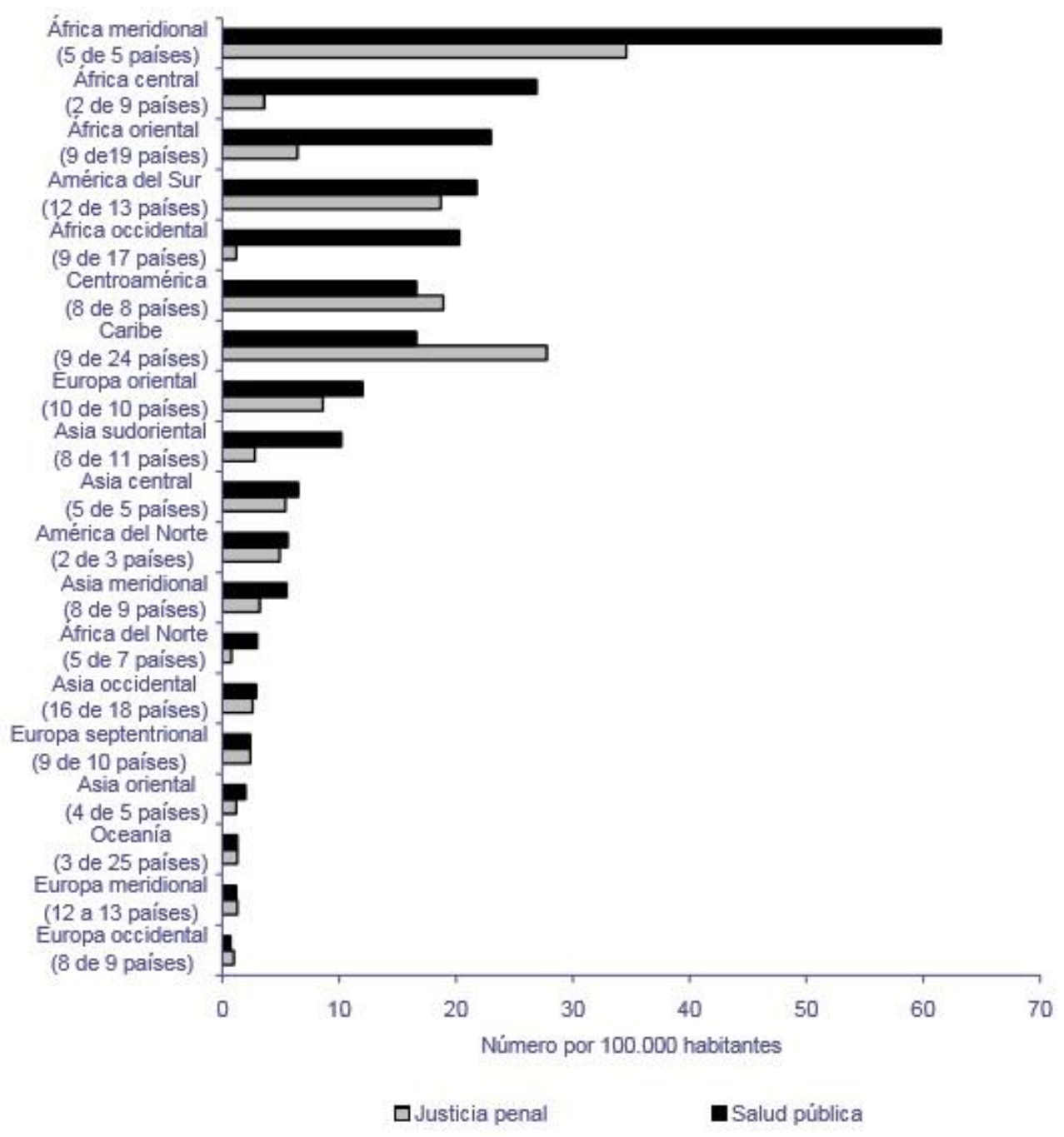

Figura 5. Índices de homicidio doloso, por subregión, año más reciente disponible, datos de la justicia penal y de la salud pública. (12 Congreso de las Naciones Unidas sobre Prevención del Delito y Justicia Penal (2010)).

Según apunta el Secretario General de las Naciones Unidas, los índices que se presentan en la Figura 6 corresponden al promedio de un conjunto limitado de países de cada subregión (144 países en total) respecto de los cuales se dispone de por lo menos un valor de la justicia penal y de la salud pública sobre los homicidios dolosos en el período de 2003 a 2008.

Globalmente, la Figura 7 indica niveles de homicidio relativamente bajos para los países de Europa, Asia y América del Norte. En contraste, los datos arrojan 
índices de homicidio considerablemente más altos para América del Sur, Centroamérica, el Caribe y África meridional. En África central, occidental y oriental las discrepancias de los datos siguen siendo considerables. En estas subregiones se requerirá un trabajo sustantivo en los sistemas de registro de datos administrativos de la justicia penal y la salud pública antes de que puedan hacerse comparaciones válidas con otras subregiones del mundo.

Índices medios de homicidio doloso de los países de América, 2003-2008

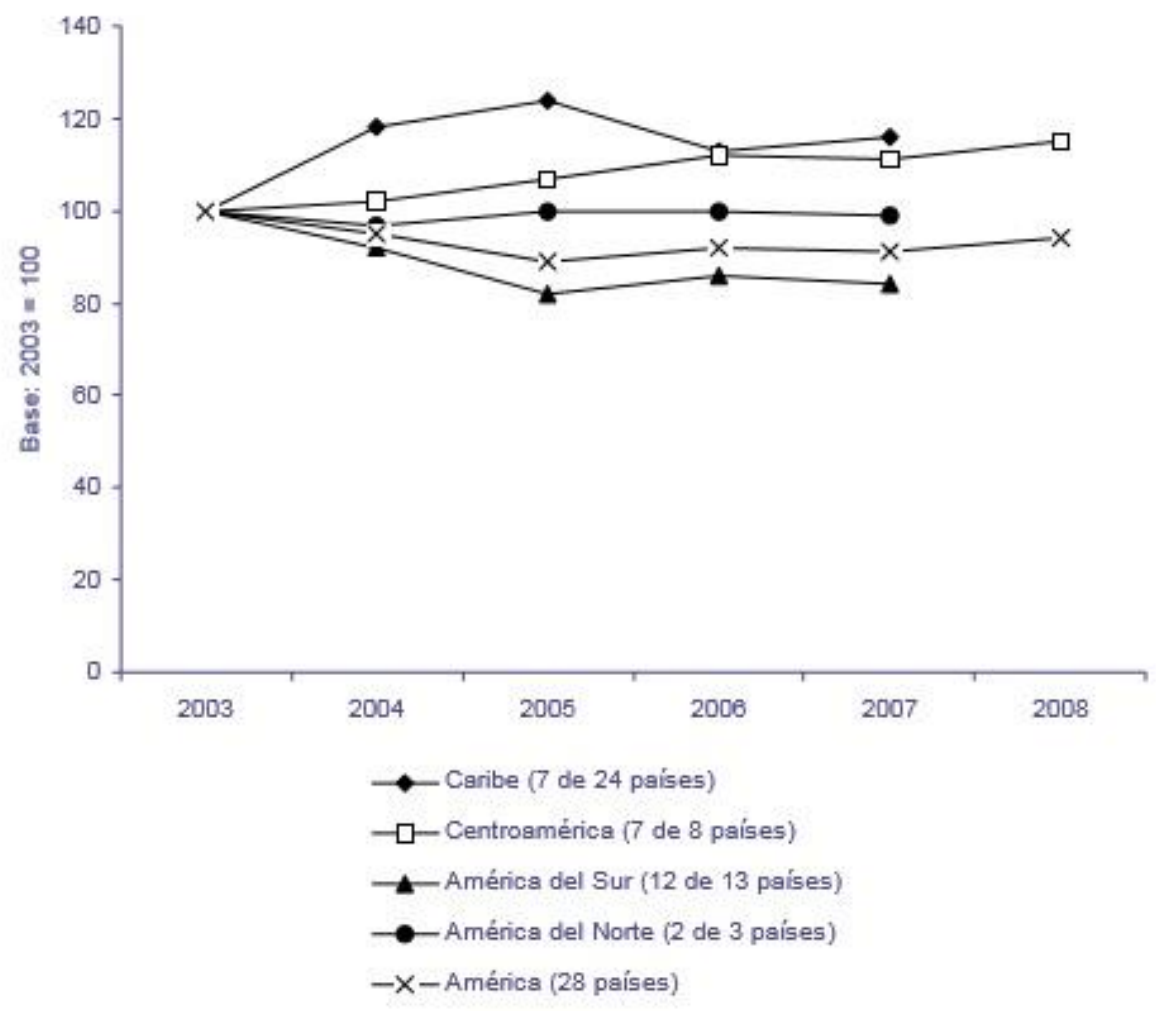

Figura 6. Índices medios de homicidio doloso de los países de América, 2003-2008 
Índices medios de homicidio doloso de los países de Asia y Oceanía, 2003-2008

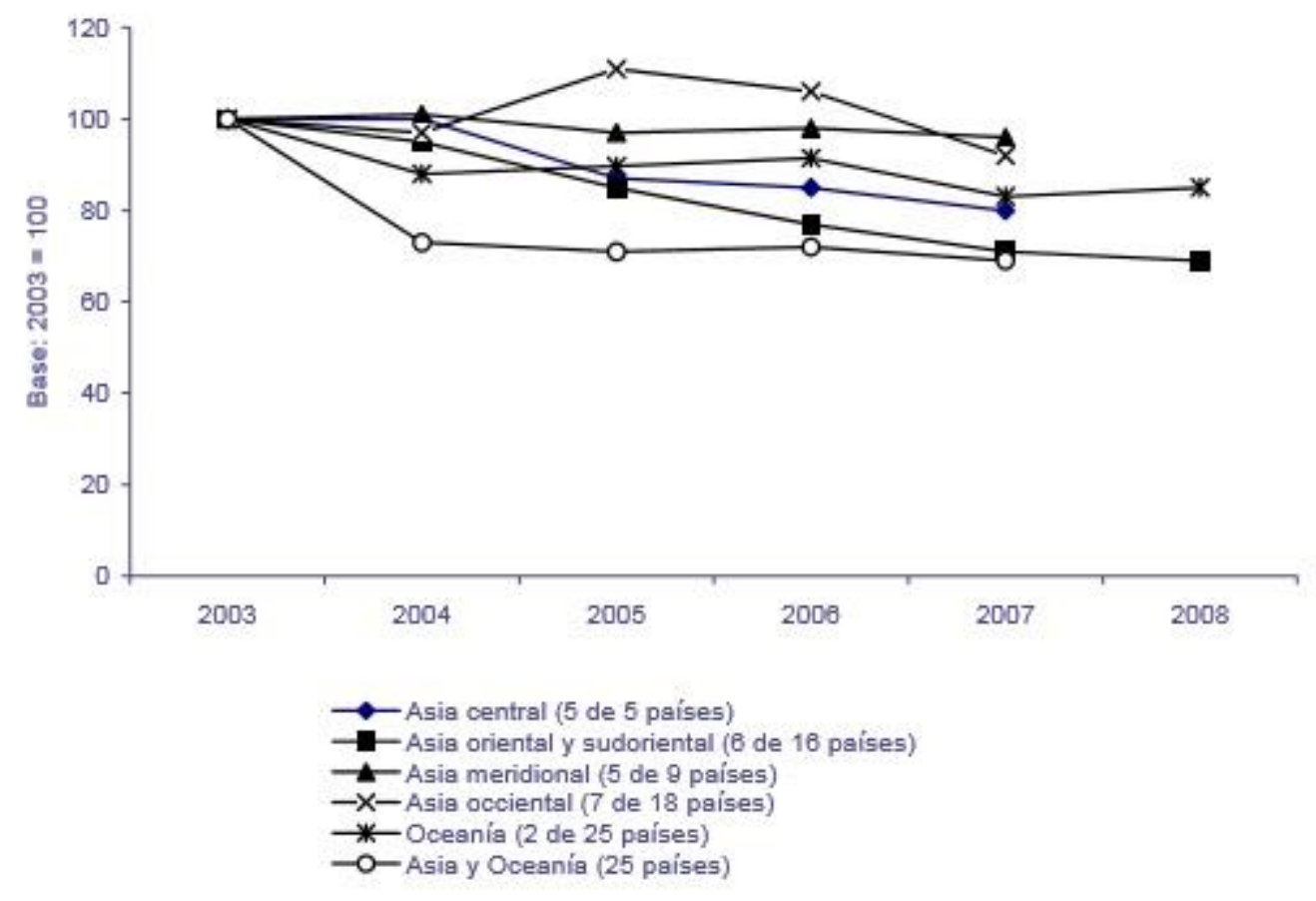

Figura 7. Índices medios de homicidio doloso de los países de Asia y Oceanía, 20032008 


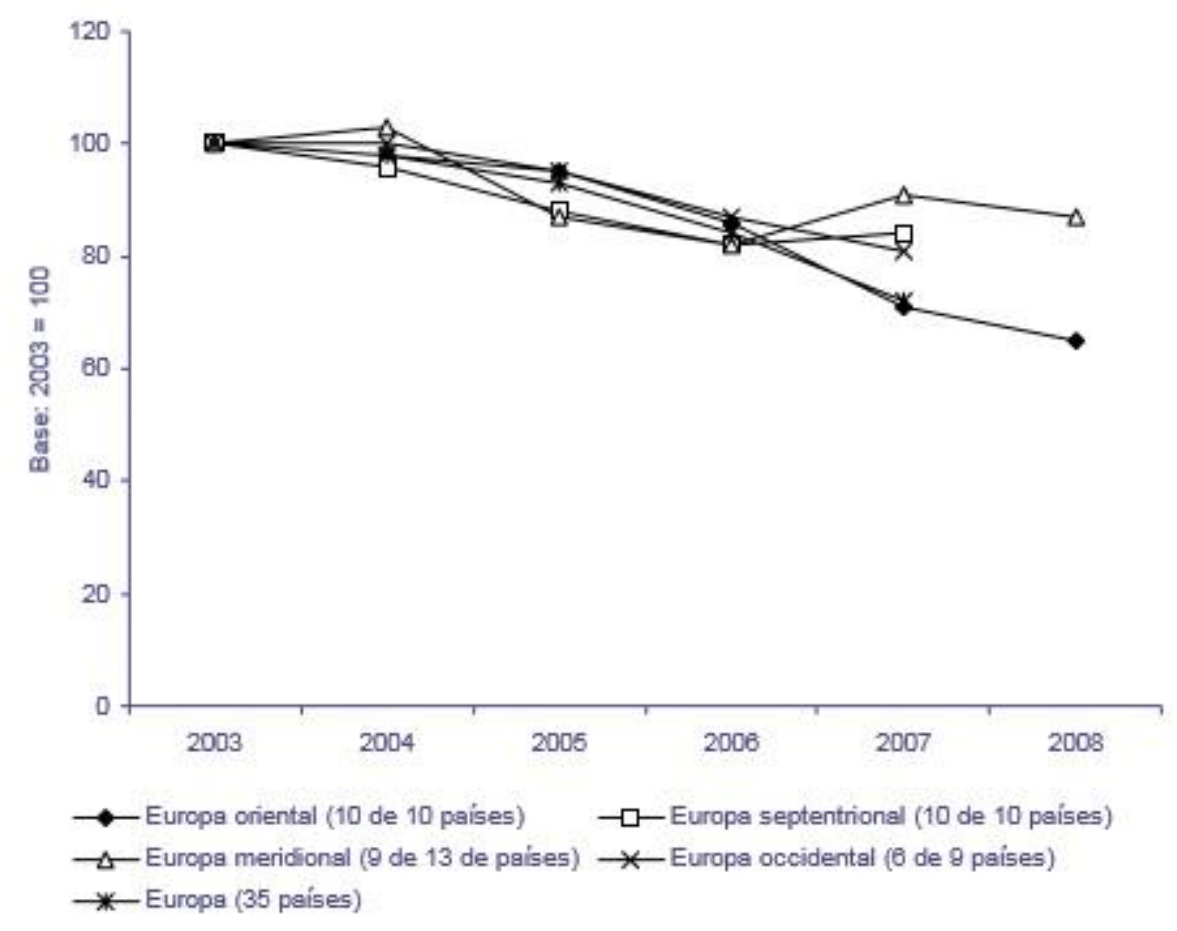

Figura 8. Índices medios de homicidio doloso de los países de Europa, 2003-2008

A nivel regional, los índices medios de homicidio doloso registrados por las Instituciones de Justicia Penal disminuyeron durante el período 2003-2008 en los países de Asia, Oceanía y Europa. En los países de América se mantuvieron casi constantes.

A nivel nacional, algunos países de Centroamérica y el Caribe como Belice, Honduras, Guatemala, Jamaica, Trinidad, Tabago y Venezuela han experimentado grandes aumentos de los índices de homicidio en los últimos años. En contraste, los países de Asia central y Europa oriental y occidental registraron índices en constante disminución durante el período 2003-2008. 


\section{CAPÍTULO III. RECORRIDO HISTÓRICO-CRÍTICO DEL CONCEPTO DE PSICOPATÍA}

\subsection{ANTECEDENTES. (PRIMERAS PREFIGURACIONES)}

En este apartado se va a desarrollar un recorrido histórico del término psicopatía y las definiciones que a lo largo de los años han aportado los diferentes autores que prestaron interés al tema.

\subsubsection{Esbozo del término psicopatía}

El concepto de psicopatía es un término prismático, en el sentido de que al no quedar definido del todo estalla con su luz por múltiples ópticas. Ya apunta Millon (1998) que a lo largo de la historia, la idea del carácter antisocial ha servido para la descripción de numerosos comportamientos que comparten pocas características, a excepción de considerarse socialmente reprobables.

Si se hace un paralelismo con las concepciones históricas de locura se aprecia que ha pasado por las mismas fases. Así existiría un primer momento en el que la interpretación del ser humano ante la locura o el asesinato deshumanizado, es explicada mediante la posesión diabólica, el ocultismo, el triunfo de las fuerzas luciferinas sobre la vida y sobre la bondad de Dios. El segundo momento, vendría a ser el impuesto por la Razón vs. Sinrazón. En este sentido, las “personas de bien”, se siguen planteando si realmente son terrenales determinados comportamientos que serían más típicos de vampiros, licántropos, espíritus malignos... que encuentran su máxima expresión en el placer de "matar por matar" al servicio de la mano izquierda de Satanás o de la falta total de la razón en forma de locura. Pero uno de los problemas, como se irá viendo a la largo de la presente investigación, es que ligar psicopatía con muerte, sangre o asesinato es un error conceptual de primera línea. Pues existen psicópatas que integrados aparentemente en la sociedad nunca cometerán un delito de sangre, y al mismo tiempo delitos de sangre sin psicopatía de por medio.

Descripciones de las características amorales que conforman la personalidad y conducta de estos sujetos ya se encuentran en los escritos de Teofastro (371 a.c.) discípulo en principio de Platón y posteriormente de Aristóteles, que hace referencia al "hombre sin escrúpulos" de la siguiente manera: 
El hombre sin escrúpulos pedirá prestado más dinero a una persona a la que nunca le haya devuelto nada... Cuando vaya a hacer la compra, le recordará al carnicero que éste le ha quedado algo a deber y le pedirá a cambio algo de carne y, si puede, huesos para el caldo. Si la estratagema tiene éxito, mucho mejor; si no, comprará un trozo de tripa y se irá riendo. (citado en Widiger, Corbitt y Millon, 1991, p.63).

A parte de las concepciones morales que en todo momento histórico han existido, las primeras descripciones clínicas que hacen referencia al concepto de psicopatía aparecen durante el siglo XVIII. Sin embargo, primero había que conceptualizar la locura como un trastorno psicológico, de lo que por entonces se llamó facultades morales, como apuntan López y Robles (2005) son alteraciones originadas en el interior del individuo que debían ser tratadas moralmente (moral treatment).

De manera que a lo largo del siglo XVIII y dentro de la tradición británica se le otorga amplia importancia a las facultades morales. Este planteamiento es seguido por el americano Benjamin Rush (1786) quien acuña el término Moral deregement $o$ deprivación moral (innata) para describir un trastorno en el que la razón es conservada al igual que otras facultades intelectuales, siendo alteradas las facultades morales. Y paralelamente similares concepciones son compartidas por los alienistas europeos, principalmente la Escuela francesa de psiquiatría. La figura capital de este movimiento, fue Philippe Pinel (1745-1826) quien orienta su estudio desde tres perspectivas tal y como apunta Álvarez (2008):

1.- Nosológica: ya que Pinel era partidario del uso de las clasificaciones y dio los primeros pasos del discurso alienista perfilando un modelo unitario de patología mental. Propone sustituir el término locura por el de alienación mental.

2.- Interés institucional: ya que fue el creador del "asilo". Al cual se acudía mediante la fuerza o la reclusión rigurosa.

3.- Terapéutico en cuanto al tratamiento moral del enfermo. Pinel buscaba el origen de la locura bajo la premisa de que la imaginación quedaba modificada por la fuerza de las pasiones, y la terapéutica consistía en hacer vencer a toda costa el bien moral con el fin de que se apaciguaran estas pasiones.

En este sentido, quizá lo más importante es que fue quien cuestiona por primera vez la totalidad de la locura, hablando de locuras parciales. Éstas últimas llevan consigo algunos escollos que ineludiblemente hacen cambiar ciertas perspectivas reduccionistas 
de la salud mental, e incluso de las repercusiones legales del sujeto. El planteamiento Pineliano plantea dos problemas fundamentales:

a. La existencia de locuras a medias. Es decir, que la razón y la locura pueden cohabitar en un mismo individuo.

b. La responsabilidad o irresponsabilidad del mismo. En este sentido "la medicina alienista se vio compelida a pronunciarse sobre la responsabilidad penal de algunos monstruos criminales" (cf. p 60)

Embarcado en esta tradición se encontraba Thomas Arnold (1806) quien distingue entre:

- Ideal Insanity: las sensaciones están alteradas y se presentan alucinaciones.

- Notional Insanity: un tipo de locura de conceptos causada por el dominio de las pasiones.

Otra figura, dentro de los alienistas del S. XIX, fue Esquirol (1772-1840), precursor de las nosografías y de la psiquiatría científica iniciada por Philip Pinel. Una de las aportaciones más relevantes, y con mayor repercusión criminológica, fue el de las "Monomanías". Dentro de las mismas concluye que existen diferentes tipos:

a. Las monomanías intelectuales, las manías razonables como las denominaban otros autores. En ellas lo que se produce es que partiendo de una premisa lógica de forma razonante se convierte en cuasidelirante, conservando el resto de su psique con total normalidad.

b. Las monomanías afectivas donde lo que se encuentra ofendida es el área de la voluntad. Esquirol (1847) apunta al respecto: “...el enfermo fuera de las vías ordinarias, es arrastrado a cometer actos que la razón o el sentimiento no determina, que la conciencia reprueba, que la voluntad no tiene fuerza para reprimir: las acciones son involuntarias, instintivas, irresistibles; esto es la monomanía sin delirio o la monomanía instintiva" (Ibíd, 1847, p.292-293)

El famoso médico alienista francés, había clasificado además las monomanías según sus temas preponderantes: erotomanía, monomanía erótica, de embriaguez, pirómana o incendiaria y sobre todo la discutida monomanía homicida, llamada por Foderé (1764-1835) "furor maniaco". 
Dentro de las Monomanías homicidas, el monomaniaco asesino no presenta alteración alguna apreciable de la inteligencia o de las afecciones. Es arrastrado entonces por un instinto ciego, por una cosa indefinible que le empuja al asesinato. Las causas del mismo podrían ser que sujetos normales se vuelven susceptibles e irritables y en un acceso de cólera matan a la persona que les molesta. $\mathrm{O}$ bien los que de forma real o imaginaria consideran que tienen que vengarse de los otros, y por último aquellos que empujados por sus alucinaciones y delirios obedecen a los mismos.

En este sentido, Esquirol (1847) explica que:

He visto un gran número de enajenados que parecían gozar de su inteligencia...todos confesaban que percibían una cosa interior, de la cual no podían darse cuenta, que su cerebro se encontraba embarazado, que experimentaban un cambio inexplicable en el ejercicio de su razón, que este desorden precursor, era anunciado por síntomas físicos de que conservaban un perfecto recuerdo: unos sentían un calor desgarrador, que se encaminaba desde el vientre a su cabeza; otros un ardor quemante acompañado de pulsaciones dentro del cráneo; otros finalmente afirmaban que una ilusión, alucinación o razonamiento falso, les...había determinado a obrar así" (p. 340). "Otros lo hacen por un impulso instintivo (...) obran sin conciencia, sin pasión, sin delirio, sin motivo, por un arrastramiento ciego, instantáneo, independientemente de su voluntad: se encuentran en un acceso de monomanía sin delirio" (...) "La observación demuestra que los individuos afectados de monomanía homicida, tenían un carácter sombrío, melancólico, caprichoso y colérico, o por el contrario se habían distinguido por su dulzura, bondad de las costumbres y hábitos. (Ibíd, 1847,p. 343).

Además, subclasifica las Monomanías en:

a. Los que tienen conciencia de su crimen. Aquí entraríamos, si fuera la pretensión de este estudio, de lleno en el tema de la responsabilidad o irresponsabilidad del "loco" en el dolo jurídico que no es otra cosa que saber lo que se hace y querer hacerlo o no.

b. Los que actúan de forma impulsiva y ciega de forma voluntaria e instintiva. Es decir que no ponen freno a sus instintos no tienen la voluntad de frenarlos.

c. Los que por falta de inteligencia matan o asesinan por imitación. Que vendrían a ser lo que en la actualidad se denomina como "copy cat", es 
decir, sujetos que copian el modus operandi de otros asesinos a los que buscan emular.

d. Los maniacos que por problemas en las funciones y área afectiva y juzgando correctamente las cosas se sienten irresistiblemente obligados a despedazar, destruir y asesinar a sus semejantes. "Lloran su situación y advierten que se libren de su furor" (Esquirol, 1847, p. 339).

En relación a la escena del crimen, una aportación quizá menos conocida de Esquirol es que ya distinguía entre los que manipulan la escena del crimen de forma organizada y los que psicótica o imprudentemente para ellos mismos permanecen en la misma de forma claramente desorganizada. Apunta el autor al respecto:

Hay monomaniacos homicidas que parecen exonerados de aquel sentimiento tan angustioso: están serenos, sin pesares, sin remordimiento y contemplando a sangre fría la víctima, expresando una especie de satisfacción lo más, lejos de huir. Permanecen al lado del cadáver...algunos sin embargo temen el castigo y se sustraen de toda pesquisa ocultando las huellas del crimen...cuando son presos por los agentes de seguridad se apresuran a revelar su acción dando los más pequeños detalles. (Ibíd, 1847,p. 347).

Prefiguraciones, las del psicopatólogo francés, que se adelantan en el tiempo a los postulados por algunas de las modernas tesis investigadoras del FBI entre asesinos psicóticos y asesinos psicópatas.

Respecto a la conducta del psicópata, Benjamin Rush (1812), llamó la atención científica sobre casos similares caracterizados por una lucidez de pensamiento a la par que con comportamientos socialmente inaceptables. Describió a estas personas como poseyentes de una "depravación moral innata en la que probablemente haya una organización original defectuosa en las partes del cuerpo relacionadas con las facultades morales de la mente" (Ibíd, 1812, p.112).

A raíz de estas últimas conceptualizaciones, se desarrollaron una serie de términos como los acuñados por Pritchard (1895): Locura moral o moral insanity. El autor la define como una perversión patológica de sentimientos y afectos estando ausentes las alteraciones del pensamiento como alucinaciones y destacando una tendencia hereditaria en los sentimientos de ira o malicia que presentan estos individuos. Prichard (1935) hizo una importante contribución haciendo alusión a la 
diferencia entre el pronóstico de los rasgos clínicos de larga evolución y los que surgen como respuesta a factores estresantes. En palabras del autor:

Cuando el trastorno está conectado con una fuerte predisposición natural, las expectativas de curación son escasas. Éste es el caso de los trastornos en los que el fenómeno adquiere la forma de un incremento o una exaltación de las peculiaridades naturales del individuo, y éstas pueden identificarse como rasgos destacables de sus hábitos previos. No obstante, si este estado mórbido de la mente ha sido el efecto de alguna causa externa y accidental que puede ser cambiada o el individuo puede ser alejado de esta influencia o se le puede ayudar a defenderse de ella, hay razones para esperar que este trastorno vaya desapareciendo gradualmente. (Ibíd, 1935, p.122).

\subsubsection{Primeras clasificaciones y tipologías de la Psicopatía.}

A raíz de observar el comportamiento de estos individuos, los autores comienzan a tener en cuenta qué factores de tipo constitucional o biológico pueden estar influyendo en el comportamiento psicopáticos de este tipo de sujetos. De este influjo de los factores constitucionales surgen las primeras clasificaciones de psicópatas.

La terminología y la etiología de los fenómenos observados en relación con este tipo de sujetos, no encontraba más que repeticiones consecutivas con ligeros cambios de matices morales hasta que Koch (1891) propone el término inferioridad psicopática constitucional con el que pretende dejar clara una base biológica del trastorno. Así, afirmaba el autor que: "Son siempre psicopáticas las personas que presentan estados y cambios orgánicos que están fuera de la normalidad fisiológica. Surgen de una inferioridad de la constitución cerebral congénita o adquirida” (Ibíd,1891, p.54).

No obstante, probablemente huyendo de explicaciones reduccionistas hablaba ya de tres tipos de psicópatas: el "Psicópata propiamente dicho", "el Psicópata inferior" y el "Psicópata constitucional", como variantes anormales del carácter y la biología. Lo que traducido a nomenclaturas más actuales, lo que hace es establecer la diferencia entre la auténtica psicopatía y la debilidad mental (Caparros, 1981), e inclusive entre psicópatas cuya terapéutica es más esperanzadora y psicópatas biológicamente constreñidos en su anormalidad.

Así, Kraepelin (1896) va a continuar con la obra de Koch introduciendo el término estados psicopáticos para referirse a trastornos constitucionales manifestados en una personalidad enfermiza. Sin embargo, más tarde, el término es sustituido por 
Kraepelin (1904) por el de Personalidades psicopáticas con el que quiere referirse a diferentes formas mórbidas de desarrollo de la personalidad consideradas degenerativas. Por lo tanto, estos individuos no podrían ser considerados enfermos pero tampoco normales ya que su personalidad es anómala. (López et al., 2005). Kraepelin (1904), plantea una tipología de psicópatas: Nerviosos, Neuróticos obsesivos, Excitables (con o sin rasgos histéricos), Impulsivos (aumento de los impulsos normales), Epilepsia afectiva, Impulsivos patológicos, Perversos sexuales (homosexuales, sadistas, masoquistas, fetichistas y exhibicionistas), Discutidores, Extravagantes retorcidos, Mentirosos, Personalidades histéricas, Camorristas y Asociales. Estas tipologías quedan divididas en dos grupos:

- Con disposiciones mórbidas: obsesivos, impulsivos y con desviaciones sexuales.

- Con alteraciones de la personalidad: excitables, inestables, impulsivos, excéntricos, mentirosos, timadores, antisociales y pendencieros.

Pero en el Kraepelin de 1915 aparecen las pretensiones de establecer la posible etiología orgánica de las psicopatías y con ello elevar esta categoría a un problema médico. Ve en las psicopatías formas latentes de psicosis, quizá con ella se refiera a las personalidades límite o borderline, que no acaban de manifestarse y las clasifica en: Excitables, Inestables, fantástico-perversos y mitómanos. O como lo verían los psicoanalistas actuales, que apuntan a que evidentemente hay crímenes delirantes, mientras que en otros casos la propia falta de una construcción delirante en sujetos claramente psicóticos sería la que empuja al crimen, como sería el caso del psicótico asesino y pirómano Wargner de R. Gaupp (Álvarez, 2004).

Por otro lado, desde la perspectiva fenomenológica de Jasper (1913) la psicopatía sería una variación de las condiciones caracteriológicas básicas. Así, las variaciones del carácter tendrían que ver en primer lugar con los temperamentos clásicos: sanguíneo, flemático, eufórico como también con las depresiones subclínicas. Variaciones apoyadas en la voluntad: como los débiles abúlicos y los fuertes de voluntad. Y finalmente las condiciones afectivas e instintivas que es donde llevado a grados extremos sitúa a la psicopatía y los fanatismos. Sobre la psicopatía, moral insana o psicópatas desalmados de K. Schneider (1975), los describe como sujetos apresados en: 
Instintos destructivos con plena insensibilidad para el amor al derecho, a los padres o a los amigos; crueldad natural con algunos impulsos sentimentales aislados singulares (por ejemplo amor a las flores); ausencia de todo instinto de sociabilidad, de todo placer del trabajo, indiferencia ante el porvenir de los otros y el propio; placer en el delito como tal; en todo ello una conciencia inconmovible de energía y de sí mismo; una completa incredulidad y no influenciabilidad... (Ibíd, 1975, p.492).

Listado sintomático, que ya a principios de siglo apunta a las características que en la actualidad son referenciadas y sistematizadas por el Dr. Hare (1980).

En el campo de la influencia social y contemporáneo a Jasper, se encuentra Birnbaum (1914), quien fue el primer autor en sugerir que el término sociopático sería la designación más correcta. El autor afirmaba que el comportamiento antisocial pocas veces surge de rasgos inherentes al carácter, sino que en la mayoría de ocasiones es el contexto y las fuerzas sociales las que inciden en la adquisición de las formas de comportamiento aceptables. Esta línea, como se explicará más adelante fue apoyada por Partidge (1930) y posteriormente por algunas ediciones del DSM.

K. Schneider (1887-1967), influenciado por Jasper, Kraepelin y el psicoanálisis, desarrolla una tipología no sistemática, de las diferentes personalidades psicopáticas. Ésta ofrece la ventaja y el inconveniente de múltiples variaciones y combinaciones. Así, establece diez tipos de psicópatas, en su escrito de 1975 "Las personalidades psicopáticas".

Entre las ventajas de la tipología propuesta por el autor se encuentra su utilidad práctica, además de incluir gradaciones que van desde el simple "rasgo" al "tipo acentuado". Entre los inconvenientes, que no es parsimoniosa en el sentido de extensa y por lo tanto hace falta un manejo fluido de la misma.

En este sentido, Schneider (1975) agrupa las personalidades psicopáticas como se muestran en la Tabla 18: 
Tabla 18: Las personalidades psicopáticas (Schneider, 1975)

1. Psicópatas hipertímicos, activos o pendencieros: $\mathrm{Su}$ estado de ánimo es preponderantemente alegre, vivo, activo, optimista y autosuficiente. No obstante carecen de constancia y de voluntad, por lo que resultan poco fiables. Por ello depositar en ellos la confianza se hace una tarea abocada al fracaso. Una característica importante es que son muy sugestionables y fáciles de influenciar a corto plazo. A este tipo de psicópatas Schneider (1975) los divide en:

a. Hipertímicos irritables, excitados y poco alegres.

b. Hipertímicos amigables y alegres.

2. Psicópatas depresivos: Bajo estado de ánimo, pesimistas, con sentimiento trágico de la vida, plagados de autoreproches y dudas y cuando es más o menos superado este estado se revierte en nuevas preocupaciones o en otra pena. A menudo la salida que les queda es volcarse férreamente en su trabajo, pero con una capacidad sublimatoria mínima, pues en el fondo no se permite satisfacción alguna. Trabaja como un juicio de condenación que busca la dignidad en base a lo que se sufre. Periodos críticos en estos sujetos son los periodos estivales, fines de semana..., es decir, en momentos de inactividad. Dentro de los psicópatas melancólicos se distingue entre:

a. Blandos, tímidos y fáciles de animar

b. Malhumorados, irritables, obstinados e hipercríticos

c. Malvados que gozan haciendo el mal

d. Fanáticos que muestran alegría por las desgracias ajenas dada su visión pesimista del destino.

3. Psicópatas inseguros de sí mismos: Son de carácter más obsesivo, con fuertes sentimientos de culpa que los hacen convertirse en inseguros. El mayor problema es cuando las representaciones y los impulsos obsesivos se convierten en "acting" o acciones irresistibles.

4. Psicópatas fanáticos: Serían más de carácter paranoide. Presentan un narcisismo inflado, sobrevalorado. Dentro de los fanáticos hay que diferenciar:

a. Fanáticos querulantes: $O$ falsos denunciadores, buscan constantemente luchar por su derecho real o imaginario.

b. Fanático idealista: Más cercanos a la megalomanía. Cometen sus atrocidades amparados de ideas altruistas o mesiánicas. 
5. Psicópatas necesitados de estimación: Muy mitómanos y con tendencia a la "pseudología fantástica".

6. Psicópatas lábiles de ánimo: serían aquéllos que presentan una máscara depresiva manifestada en irritabilidad, oscilaciones bruscas del estado de ánimo, tendencia al abuso de alcohol, impulsividad, intentos suicidas y muy manipuladores, que conocen cierta sintomatología psiquiátrica y la manejan en su beneficio representando falsas depresiones con el objetivo de manipular al Otro.

7. Psicópatas explosivos: Cualquier palabra, acto o interpretación les sirve de estímulo disparador de una cólera o ira desmesurada, con el agravante de que luego proyectan sobre el otro la culpa de sus conductas.

8. Psicópatas desalmados: Carencia absoluta de compasión, son frios, torturadores, disfrutan de sus crímenes sin culpa alguna.

9. Psicópatas abúlicos: Muy sugestionables por una figura a la que otorguen poder o idealicen. Suelen ser los compañeros inestables de los verdaderos psicópatas. $\mathrm{Su}$ mayor problema ha sido encontrarse e sobrevalorar al malvado.

10. Psicópatas asténicos o neurasténicos: Viven en una sensación constante de irrealidad, acobardados y con tendencia a dolencias de carácter psicosomático. Carecen de palabras para sus angustias y somatizan todos sus pesares, por ello buscan manejar mediante sus dolencias a todo su entorno, en particular médicos, psicólogos...Sus dolores y estado de ánimo les justifican de cualquier manipulación, pues su dolor les da derecho a casi todo. Otra característica importante es que suelen presentar problemas cognitivos en las áreas de concentración, memoria...

En última instancia, lo que hizo Schneider fue llamar personalidades psicopáticas a las personalidades anormales que actualmente la psiquiatría concibe como trastornos mentales. De esta forma, por ejemplo los psicópatas explosivos, en la nosología de la APA equivalen al Trastorno de la Personalidad Explosivo- Intermitente. (Pozueco, 2010).

Otra de las múltiples aportaciones de Schneider a la psicopatía fue el rechazo del término "antisocial" pues hacía referencia a la etiología social del trastorno y de alguna manera marginaba los aspectos caracteriológicos que a él tanto le interesaban. Como también la incidencia en la comorbilidad de la psicopatía con otros estados 
psicopatológicos como la depresión, la labilidad de ánimo, la pseudología fantástica, etc.

Y por último, sin ser exhaustivos en sus aportaciones, la interpretación que hace Schneider (1975) sobre la presunta mayoría de psicópatas masculinos frente a femeninos es posible que sea debida a cuestiones socioculturales más que de género en sí mismo.

Más adelante, López Ibor (1966), también desde un modelo propiamente médico, entiende que las psicopatías son malformaciones de la personalidad, pero aludiendo a variables más constitucionales y genéticas que psicológicas. Aunque si bien es cierto, que tampoco explica en qué consisten esas "malformaciones de la personalidad".

Desde la biotipología cabe destacar los trabajos de Kretschmer (1888-1964) que busca las correlaciones que pueden existir entre tipos de conformación corporal y las enfermedades mentales, más en particular en la esquizofrenia y en la ciclotimia. Propuso cuatro categorías que se dividen en:

- Atlético: musculoso y fuerte

- Pícnico: bajo y anchos

- Leptosómico: delgado y alto.

- Displásico: que presenta una anomalía en los caracteres sexuales secundarios y en general una estructura somática atípica.

Además, encontró una preponderancia de esquizofrenia en los sujetos leptosómicos y en los atléticos frente a la ciclotima, que se daba principalmente en sujetos pícnicos. A nivel de la criminalidad parece ser que Kretscmer encontró una prevalencia superior en los sujetos leptosomáticos a los que identificaba con la esquizoidia.

En la misma línea se encuentra Sheldon (1954) quien planteaba tres tipos:

- Endomorfo: El sujeto tendría un predominio del sistema vegetativo y tendencia a la obesidad. Flácidos y con formas redondeadas.

- Mesomorfo: Sujetos con predominio de los huesos, los músculos y el tejido conjuntitivo. Este grupo sería el más habitual dentro de la población delincuencial. Bajo la hipótesis de que los delincuentes más violentos poseían un cuerpo de características mesomórficas (atlético o musculoso) se amplió el 
campo de los estudios biológicos (Sheldon, Stevens y Tucker,1940; Gluek y Gluek, 1956).

- Ectomorfo: Predominio de las medidas longitudinales sobre las transversales.

Actualmente existe un consenso en esta variable (Sampson y Laub, 1997) si bien se trata de un factor que no implica ningún grado de predectibilidad de la conducta delictiva, dado, que sí puede ser cierto que la mayoría de la población penitenciaria es mesomórfica, aunque no todos los mesomórficos son tendentes a las conductas antisociales.

\subsection{DESCRIPCIÓN, DEFINICIÓN Y CRITERIOS DIAGNÓSTICOS DE PSICOPATÍA.}

A lo largo de la historia, la psicopatía ha adquirido diferente nosología y descripciones que se explican a continuación. McCord y McCord (1964) describen al psicópata como una persona antisocial, impulsiva y agresiva que carece de sentimiento de culpa a quien le resulta imposible generar vínculos afectivos que perduren en el tiempo. Según estos autores las dos características preponderantes que definirían al psicópata serían la incapacidad para amar y la falta de remordimiento, diferenciándolo así de otras conductas antisociales (agresividad, conductas penadas por ley...).

Posteriormente, Craft (1965), la define también como la ausencia de sentimientos, afecto y amor y la impulsividad, mientras que Foulds (1965) y Buss (1966) la centran en el egocentrismo y la carencia de empatía.

Años más tarde, Cleckley (1976), en su libro "La máscara de la cordura", que se constituye como referente en el estudio de la psicopatía, por primera vez describe la figura del psicópata como una persona escondida tras una máscara con el fin de engañar a los demás. Para este autor, lo definitorio del psicópata es la carencia de emocionalidad que subyace a sus conductas e invade sus esferas personales e interpersonales. Sugiere por lo tanto, algún tipo de "demencia semántica", es decir, que no reaccionan con las emociones apropiadas al contenido verbal expuesto por otros, es decir, "El psicópata se sabe la letra pero no la música" (Johns y Quay, 1962, p.217). 
En esta línea Patrick (1994) destaca que numerosas investigaciones sobre la patología emocional del psicópata que concluyen que la mayoría que este tipo de sujetos presentan un procesamiento no adecuado o anormal en cuanto al material verbal de contenido afectivo.

En este sentido, los criterios considerados por Cleckley (1976) para el diagnóstico de la psicopatía se enumeran a continuación en la Tabla 19:

Tabla 19: Criterios Cleckley (1976)

1. Encanto externo y notable inteligencia.

2. Ausencia de alucinaciones u otros signos de pensamiento irracional.

3. Ausencia de nerviosismo o de manifestaciones psiconeuróticas.

4. Inestabilidad, poca formalidad.

5. Falsedad e insinceridad.

6. Falta de sentimientos, de remordimientos y vergüenza.

7. Conducta antisocial inadecuadamente motivada.

8. Razonamiento insuficiente y falta de capacidad para aprender de la experiencia vivida.

9. Egocentrismo patológico e incapacidad para amar.

10. Pobreza general en las principales relaciones afectivas.

11. Pérdida específica de intuición.

12. Insensibilidad en las relaciones interpersonales generales.

13. Comportamiento fantástico y poco recomendable, con o sin bebida.

14. Amenazas de suicidio raramente llevadas a cabo.

15. Vida sexual impersonal, trivial y pobremente integrada.

16. Fracaso para seguir un plan de vida.

Continuando con el estudio descriptivo de las características de la psicopatía, Andrews y Bonta (1994) buscando la validez de las aportaciones de Cleckley (1936) referidas al concepto más general de psicopatía, lo resumen en cuatro aspectos: 
1. Apariencia externa de normalidad.

2. No presentan alucinaciones ni delirios ni aparecen perturbados.

3. Falta de respuesta al castigo y a las normas o sistemas de control social.

4. La conducta criminal o delictiva no es patognomónica de la psicopatía.

En la línea aportada por Cleckley (1936), Gray y Hutchinson (1964) intentan comprobar el acuerdo en los rasgos definitorios de la psicopatía. Para ello enviaron un cuestionario compuesto por una lista de 29 ítems referidos a las características de la psicopatía a 677 psiquiatras canadienses para que ordenaran de mayor a menor los 10 ítems que considerasen más importantes en el diagnóstico de psicopatía. El resultado de los ítems fue, en este orden:

1. Falta de sentido de la propia responsabilidad.

2. Incapacidad para establecer relaciones interpersonales.

3. Control de impulsos deficiente.

4. Sentido moral deficiente.

5. Actitud crónica o reiteradamente antisocial.

6. Ineficacia de los castigos para hacerles cambiar de conducta.

7. Inmadurez emocional.

8. Incapacidad para experimentar sentimientos de culpa.

9. Egocentrismo.

Asimismo, Hare (1978) a partir de los criterios propuestos por Cleckley (1936) realiza un análisis factorial de los expuestos por éste extrayendo 5 factores:

1. Incapacidad para desarrollar relaciones afectivas con otros, falta de empatía, insensibilidad e indiferencia ante los derechos y sentimientos de los demás, y ausencia de sentimientos de culpa.

2. Estilo de vida inestable con ausencia de planes a largo plazo.

3. Incapacidad de aceptar la responsabilidad de su conducta antisocial.

4. Ausencia de psicopatología.

5. Presencia de controles conductuales débiles e inestables.

Además, de esta investigación crea un instrumento denominado Psychopathy Checklist (PCL) para la investigación en psicopatía que origina dos factores: 
- Factor 1: definido por el egocentrismo, la falta de empatía, la insensibilidad y la falta de remordimiento. Vendría influenciado por la tradición germana anteriormente descrita. Muy estrechamente relacionado con las características que señalaba Cleckley (1936) y con medidas autoinformadas de ansiedad, neuroticismo y emociones negativas.

- Factor 2: comprende la propensión al aburrimiento, la baja tolerancia a la frustración, pobre control conductual y problemas conductuales en la infancia, falta de capacidad para organizar a largo plazo, irresponsabilidad, etc.

Estos factores son afianzados en diversas investigaciones posteriores. (Frick, Lilienfeld, Ellis, Loney y Silverthorn, 1999; Hare, 1991; Harper, Hare y Hakstian, 1989; Patrick, 1994; Verona, Patrick y Joiner, 2001; Schmitt y Newman, 1999).

Sin embargo y a pesar de haber encontrado una buena consistencia y fiabilidad interjueces en la comprobación de la estructura factorial realizada posteriormente por Hare, Harper y Hakstian (1990), se cuenta con propuestas actuales que cuestionan este modelo. Así, Cooke y Michie (2001) proponen un modelo jerarquizado de tres factores:

1. Arrogancia, manipulación interpersonal.

2. Experiencia afectiva deficiente.

3. Impulsividad, conducta irresponsable.

Por otro lado, Hare (2003), propone un modelo de cuatro factores en el que incluyen un nuevo factor de conducta antisocial descrita en la Tabla 20: 
Tabla 20: Modelo de los cuatro factores (Hare, 2003)

\begin{tabular}{|c|c|c|c|}
\hline $\begin{array}{l}\text { Preguntas } \\
\text { interpersonales }\end{array}$ & $\begin{array}{l}\text { Preguntas } \\
\text { afectivas }\end{array}$ & $\begin{array}{ll}\text { Preguntas de } \\
\text { estilo de vida }\end{array}$ & $\begin{array}{l}\text { Preguntas } \\
\text { antisociales }\end{array}$ \\
\hline $\begin{array}{l}\text { Labia, encanto } \\
\text { superficial }\end{array}$ & $\begin{array}{ll}\text { Falta } & \mathrm{de} \\
\text { remordimientos } & \mathrm{o} \\
\text { culpa } & \end{array}$ & $\begin{array}{l}\text { Necesidad de } \\
\text { estímulos/propenso } \\
\text { al aburrimiento }\end{array}$ & $\begin{array}{l}\text { Escaso control de } \\
\text { la conducta }\end{array}$ \\
\hline $\begin{array}{l}\text { Sentido exagerado } \\
\text { de la valía propia }\end{array}$ & $\begin{array}{l}\text { Afecto poco } \\
\text { profundo }\end{array}$ & $\begin{array}{l}\text { Estilo de vida } \\
\text { parasitario }\end{array}$ & $\begin{array}{l}\text { Problemas de } \\
\text { conducta } \\
\text { tempranos }\end{array}$ \\
\hline Mentira patológica & $\begin{array}{l}\text { Insensible } \\
\text { Carece de empatía }\end{array}$ & $\begin{array}{l}\text { Falta de } \\
\text { realistas a largo } \\
\text { plazo }\end{array}$ & $\begin{array}{l}\text { Delincuencia } \\
\text { juvenil }\end{array}$ \\
\hline \multirow[t]{2}{*}{$\begin{array}{l}\text { Astuto, } \\
\text { manipulador }\end{array}$} & $\begin{array}{l}\text { Incapacidad de } \\
\text { aceptar la } \\
\text { irresponsabilidad } \\
\text { por los actos } \\
\text { propios }\end{array}$ & Impulsividad & $\begin{array}{l}\text { Revocación de la } \\
\text { libertad } \\
\text { condicional }\end{array}$ \\
\hline & & Irresponsabilidad & $\begin{array}{l}\text { Versatilidad } \\
\text { criminal }\end{array}$ \\
\hline
\end{tabular}

Este modelo tetrafactorial ha sido estudiado y replicado (Neumann, Kosson, Forth y Hare, 2004; Saleskin, Neuman, Leistico y DiCicco, 2004) comprobando que posee una buena validez externa y estructural.

Otros autores encuentran además una mayor precisión en la predicción de fututas agresiones (Hill et al., 2004), asimismo evalúa relaciones longitudinales entre personalidad estructural y comportamiento antisocial (Vitacco, Newman y Jackson, 2005).

Vitacco et al., (2005) también presentan el modelo de los cuatro factores a partir de la siguiente estructura mostrada en la Figura 9: 


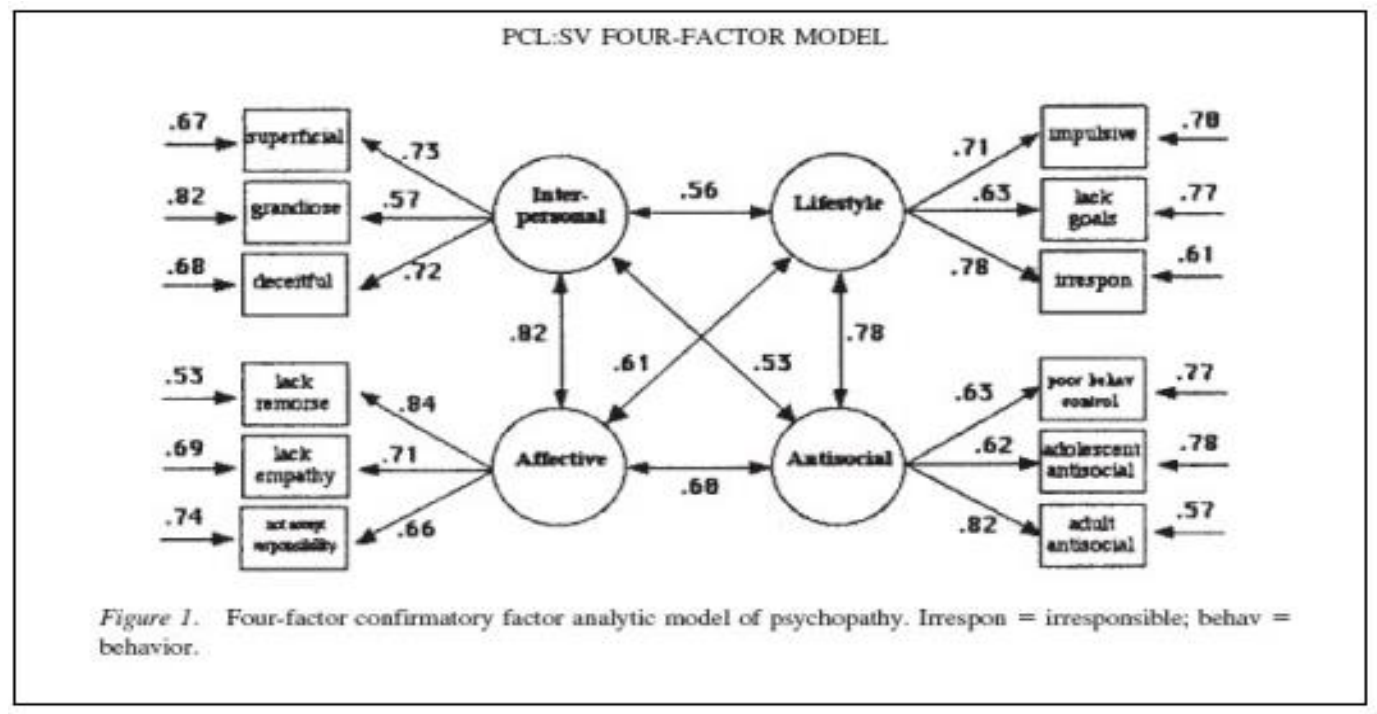

Figura 9: Modelo de los cuatro factores. (López et al., 2005)

Homs (2013), no obstante, aporta algunas críticas que precisan algunos de los ítems de Hare (1980):

1. Si son impulsivos e inconstantes ¿cómo es posible que dominen algunas empresas multinacionales? No se puede ser impulsivo y organizar una red mafiosa, por ejemplo. Por otro lado la impulsividad es un mecanismo de defensa animal que permite adaptación. Si se suprime la impulsividad, el hombre se quedaría sin defensas, amén de que la impulsividad está muy cercana a la creatividad y a la libertad del ser humano.

2. Sobre la sensación grandiosa de autovalía. Cabría decir que la autoestima es un valor importante para el crecimiento y la aceptación personal y no debería considerarse como un factor antisocial.

3. Referente a la necesidad de autoestimulación/aburrimiento. La autoestimulación no es mala y conduce al avance de la cultura. Ej: por esa necesidad se fue a la luna.

4. Sobre las mentiras patológicas. La mentira es más antisocial que psicopática. Todos los comerciales mienten. La mentira forma parte del ser humano, unas veces como negación y otras como adaptación. No podemos convertir la vida en un sincericidio.

5. En torno a la manipulación. No hay una definición consensuada de lo que es o no una manipulación. Ej: manipular es dar para conseguir algo sin fines altruistas. 
6. Falta de empatía, quizá sería más adecuado decir que mantienen una empatía utilitaria.

7. Vida parasitaria. Muchas personas dejan de trabajar por muchas circunstancias (personales, de salud, psicológicas...). Lo parasitario puede ser amoral pero no psicopático. Ej: mujeres de clase social media-alta que antes no trabajaban, hijos de padres muy pudientes, etc.

8. Problemas de conducta tempranos. Todo adolescente es un rebelde. Los adolescentes no quieren que se les comprenda, si algo realmente les ofende es decirle que se les comprende.

9. Falta de metas realistas. En los núcleos de pobreza, las metas son a corto plazo y no por ello son psicópatas.

10. Irresponsabilidad. Podría considerarse un aspecto demasiado subjetivo (para unos una irresponsabilidad puede ser llegar tarde al trabajo mientras que para otros no cuidar de su salud).

A pesar de estas críticas se debe tener presente que el instrumento desarrollado por Hare (PCL-R) además de fiable tiene una alta validez de constructo (Hare, Hart y Harpur 1991; Pastor, 1999). Asimismo, demuestra también su validez predictiva y su aplicación tanto en el ámbito forense como penitenciario. Este instrumento además es fiable para la valoración y relación de la psicopatía con criminalidad, de forma que los sujetos definidos como psicópatas mediante el PCL-R muestran las siguientes características:

a. Comienzan su carrera criminal de forma mucho más precoz y por lo tanto tienen antecedentes de arrestos mucho más tempranos (Harpur y Hare, 1994).

b. Sus delitos son de carácter mucho más violento (Kosson y cols, 1990).

c. Su estancia en prisión es más prolongada y más conflictiva en relación a las conductas de otros reclusos (Hare y McPhersons, 1984)

d. El PCL-R se muestra con un alto grado de predicción de la conducta violenta, siendo el Factor 2 (estilo de vida antisocial) un buen predictor de reincidencia en general, mientras que el Factor 1 (rasgos de personalidad y afectivos), como un buen predictor de la reincidencia violenta (Serin, 1996). Cabría señalar también que la carrera criminal de estos sujetos tiende a disminuir en cuanto a la frecuencia y la severidad con la edad (Hare, Forth y Sctrachan, 1992); si bien esa tendencia a la respuesta violenta y agresiva parece permanecer inalterable a lo largo de sus vidas (Harpur y Hare, 1994). 


\subsubsection{Nosologías actuales}

A continuación se describen los criterios diagnósticos propuestos por las clasificaciones actuales para el diagnóstico de psicopatía.

\subsubsection{Clasificaciones de la APA}

A lo largo de las diferentes ediciones del manual diagnóstico de la APA, las categorías relacionadas con el trastorno psicopático y sus criterios diagnósticos han ido modificándose como describen López et al (2005) a continuación:

a. DSM-I: se usa el término "desorden de la personalidad sociopática, reacción antisocial" para referirse a personas crónicamente antisociales que presentan siempre problemas y no aprenden de la experiencia pasada ni del castigo, así como que no son leales a las personas y no respetan la norma social. Suelen ser sensibles y hedonistas, además de caracterizarse por una marcada inmadurez emocional, falta de responsabilidad y falta de capacidad de enjuiciamiento.

b. DSM-II: se utiliza el término "trastorno antisocial de la personalidad" (TAP), que se caracteriza por rasgos como egocentrismo, insensibilidad, irresponsabilidad, impulsividad, ausencia de sentimiento de culpa y dificultad para aprender de la experiencia pasada.

c. DSM-III: en esta edición se mantiene el mismo término pero los criterios se reelaboran siguiendo las investigaciones de Robbins (1966, 1978), en los que la idea fundamental es que una conducta antisocial en la infancia es predictora de un alto grado de conducta antisocial en la edad adulta. Entre los indicadores de conducta antisocial en la infancia se encuentran actos como el robo, el vandalismo, las conductas violentas, maltrato a los animales, problemas con el alcohol, entre otros. A este respecto, Lynam (1996) hace una relación entre el trastorno por déficit de atención e hiperactividad con la psicopatía.

d. DSM-IV: se mantiene la denominación de "trastornos antisocial de la personalidad" y los cambios que se realizan respecto a la edición anterior son pocos: en la historia previa se señala que deben existir pruebas de un trastorno disocial antes de la edad de 15 años y en cuanto a los rasgos de 
personalidad se añade un primer criterio "un patrón de desprecio y violación de los derechos de los demás que se presenta antes de los 15 años". De manera que se aprecia la necesidad de presentar conductas antisociales en la infancia para poder diagnosticar el trastorno en la edad adulta, así como la presencia de conductas relacionadas con la agresión, el robo y violaciones graves de las normas, ya que de no ser así, el comportamiento antisocial únicamente adulto deberá clasificarse en el Eje I como "otros problemas que pueden ser objeto de atención clínica".

e. DSM-V: en esta última edición el "trastorno antisocial de la personalidad" no sufre cambios respecto a la descripción y criterios pero sí en la ubicación, ya que además de encontrarse en el capítulo "trastornos del control de los impulsos, disruptivos y de conducta" también se encuentra incluido en el capítulo referido a los trastornos de personalidad. (Echeburúa, Salaberría y Cruz-Sáez, 2014).

A continuación, en la Tabla 21 se presentan los criterios diagnósticos para el Trastorno de la personalidad antisocial recogidos en el DM-V: 
Tabla 21: Criterios diagnósticos del Trastorno de Personalidad Antisocial (DSM-V)

Trastorno de la personalidad antisocial

$301.7(\mathrm{~F} 60.2)$

A. Patrón dominante de inatención y vulneración de los derechos de los demás, que se produce desde los 15 años de edad, y que se manifiesta por tres (o más) de los hechos siguientes:

1. Incumplimiento de las normas sociales respecto a los comportamientos legales, que se manifiesta por actuaciones repetidas que son motivo de detención.

2. Engaño, que se manifiesta por mentiras repetidas, utilización de alias o estafa para provecho o placer personal.

3. Impulsividad o fracaso para planear con antelación.

4. Irritabilidad y agresividad, que se manifiesta por peleas o agresiones físicas repetidas.

5. Desatención imprudente de la seguridad propia o de los demás.

6. Irresponsabilidad constante, que se manifiesta por la incapacidad repetida de mantener un comportamiento laboral coherente o cumplir con las obligaciones económicas.

7. Ausencia de remordimiento, que se manifiesta con indiferencia racionalización del hecho de haber herido, maltratado robado a alguien.

B. El individuo tiene como mínimo 18 años.

C. Existen evidencias de la presencia de un trastorno de la conducta con inicio antes de los 15 años.

D. El comportamiento antisocial no se produce exclusivamente en el curso de la esquizofrenia o de un trastorno bipolar.

\subsubsection{Clasificación de la OMS}

La clasificación diagnóstica de la Organización Mundial de la Salud empieza a tener relevancia internacional en el año 1992 con su manual CIE-10. Así, en esta CIE10, la psicopatía queda recogida en la categoría de Trastorno Disocial de la 
Personalidad, y los criterios diagnósticos que plantean son los siguientes, recogidos en la Tabla 22:

Tabla 22: Trastorno disocial de la Personalidad (CIE-10)

Trastorno disocial de la Personalidad (F60.2.)

1. Cruel despreocupación por los sentimientos de los demás y falta de capacidad de empatía.

2. Actitud marcada y persistente de irresponsabilidad, despreocupación por las normas, reglas y obligaciones sociales.

3. Incapacidad para mantener relaciones sociales duraderas.

4. Muy baja tolerancia a la frustración o bajo umbral para descargas de agresividad, dando incluso lugar para sentir culpa y para aprender de la experiencia, en concreto del castigo.

5. Incapacidad para sentir culpa y para aprender de la experiencia, en concreto del castigo.

6. Marcada predisposición a culpar a los demás o a ofrecer racionalizaciones verosímiles del comportamiento conflictivo.

7. Irritabilidad persistente.

\subsubsection{Síntesis de las características diferenciales de la Psicopatía}

A raíz de las descripciones recogidas por autores actuales como Belloch, Sandín, Ramos (2008), Hernández (2010), Hare 1980), Cleckley (1976), Luengo y Carrillo (2008), Clark y Watson (1991), así como por los principales manuales diagnósticos DSM-V y CIE-10 se ha elaborado una tabla diferenciadora de síntomas en la que se pueda observar con claridad los aspectos relevantes y diferenciales de la psicopatía con respecto a la ansiedad y la esquizofrenia ya que en numerosas ocasiones los síntomas pueden llegar a solaparse y llevar a confusión. (Véase Tabla 23): 
Tabla 23: Tabla diferenciadora de síntomas

\begin{tabular}{|c|c|c|c|}
\hline & ANSIEDAD & ESQUIZOFRENIA & PSICOPATÍA \\
\hline Origen (Hernández, 2010) & Causas exógenas & Causas endógenas & Disposición o constitucional \\
\hline Afectos (Hernández, 2010) & Normal/ansioso & Alteración de la realidad & Frío, agresivo, indiferente \\
\hline Intelectualidad & Conservada & Alterada & Conservada \\
\hline $\begin{array}{l}\text { Responsabilidad de sus } \\
\text { acciones (Hare, 1980) }\end{array}$ & $\mathrm{Si}$ & No & No \\
\hline Estabilidad (Cleckley, 1976) & $\mathrm{Si}$ & No & No \\
\hline Culpa (Cleckley, 1976) & $\mathrm{Si}$ & No & No \\
\hline Vergüenza & $\mathrm{Si}$ & No & No \\
\hline Conducta & Adaptada & Inadaptada o variable & inadaptada \\
\hline $\begin{array}{l}\text { Relaciones interpersonales } \\
\text { (Clerkley, 1976) }\end{array}$ & Normales & Alteradas & Pobres \\
\hline Empatía (Hare, 1980) & $\mathrm{Si}$ & No & No \\
\hline Impulsividad (Hare, 1980) & No & $\mathrm{Si}$ & $\mathrm{Si}$ \\
\hline $\begin{array}{l}\text { Sufrimiento emocional (Sandín } \\
\text { y Chorot, 2008) }\end{array}$ & $\mathrm{Si}$ & Embotado & No \\
\hline $\begin{array}{ll}\text { Preocupación } & \text { (Sandín } \quad \text { y } \\
\text { Chorot, 2008) } & \end{array}$ & $\mathrm{Si}$ & No & No \\
\hline Concentración (DSM-V) & Disminuye & Alterada & Buena capacidad \\
\hline Autoestima (Clark y Watson) & Disminuye & Alterada & Alta, exagerada \\
\hline Alucinaciones (DSM-V) & No & $\mathrm{Si}$ & No \\
\hline Delirios (DSM-V) & No & $\mathrm{Si}$ & No \\
\hline $\begin{array}{lrr}\text { Vivencia } \quad \text { del } & \text { tiempo } \\
(\text { Hernández, 2010) } & \end{array}$ & $\begin{array}{l}\text { Pasado negativo y futuro } \\
\text { amenazador }\end{array}$ & $\begin{array}{l}\text { Ruptura en la evolución } \\
\text { biográfica }\end{array}$ & $\begin{array}{l}\text { Vivencia exclusiva del } \\
\text { presente }\end{array}$ \\
\hline $\begin{array}{l}\text { Comunicación interpersonal } \\
\text { (Hernández, 2010) }\end{array}$ & $\begin{array}{l}\text { Posible y normalmente } \\
\text { fácil }\end{array}$ & $\begin{array}{l}\text { Muy difícil (lenguaje } \\
\text { alterado) }\end{array}$ & $\begin{array}{l}\text { Sólo aparentemente vinculada } \\
\text { a sus propios intereses }\end{array}$ \\
\hline
\end{tabular}


No obstante, esta tabla de autores tiene algunos aspectos que pueden resultar revisables respecto a los siguientes apartados expuestos en la Tabla 23:

1. Origen: respecto a la etiología de la ansiedad Vallejo (2002) discrepa con la opinión de Hernández (2010).

a. La ansiedad puede venir causada tanto por factores exógenos como endógenos, ya que puede tener una predisposición genética y estar actuando así, factores biológicos como la hiperactividad del sistema nervioso autónomo y somático. Con relación a los aspectos neurobiológicos se relaciona con una hiperactividad noradrenérgica. Por tanto, no se puede afirmar que su única causa sean los factores exógenos tal y como expone Hernández (2010).

b. De igual modo, con respecto a la esquizofrenia, es simplista afirmar que su única causa sean los factores endógenos. De acuerdo con la teoría psicoanalítica, Dör (1984) apunta a este respecto que debido a una relación simbiótica madre-hijo en la que no se da cabida al padre, y por tanto a la simbolización, el niño/a puede desarrollar una psicosis.

c. Con respecto a la psicopatía, el origen se sitúa tanto en factores exógenos como endógenos. Es decir, existen factores biológicos tal y como apuntan Muñoz y Collado (2004) como la disfunción del lóbulo frontal o una baja actividad de la monoaminooxidasa (MAO) que es un inhibidor de la serotonina además de factores exógenos como la falta de amor materno sufrida por el niño que propicia que se desarrollen rasgos psicopáticos. (Abraham, 1925).

2. Responsabilidad de sus acciones:_Hare (1980) apunta que los psicópatas no tienen responsabilidad en sus acciones, aunque en algunos momentos no sólo aceptan la responsabilidad de sus actos, sino que además la exageran en su beneficio narcisístico. Es decir, se conocen casos en los que no sólo confiesan los crímenes conocidos sino que relatan más crímenes desconocidos por la policía debido a su necesidad narcisista de ser "admirado".

3. Estabilidad: Cleckley (1976) explica que los psicópatas no poseen estabilidad. No obstante, se ha de puntualizar que pueden tener una vida perfectamente estable al margen de sus actividades criminales como en el caso de Joaquín Ferrándiz - el asesino de Castellón-. En numerosas ocasiones, tal y como 
apuntan Caballo y López (2004), los psicópatas son "lobos con piel de cordero", es decir, son personas aparentemente normales, atractivas, de las que nunca se sospecharía los planes que tienen para con sus víctimas.

4. Conducta: siguiendo con el mismo razonamiento, juzgando predominantemente la actividad criminal del psicópata, se observa que su conducta es inadaptada, pero fuera de ésta, su comportamiento puede ser totalmente adaptado.

5. Relaciones interpersonales: Cleckley (1976) apunta que los psicópatas mantienen unas relaciones interpersonales pobres. No obstante, tal y como se viene explicando, su red social puede ser completamente adaptada, puede tener amigos, familia e hijos. No obstante, se ha de puntualizar que las relaciones que mantiene con todas estas personas carecen de calidad empática, es decir, los psicópatas utilizan a las personas para sus fines, los ven como objetos. Por eso, sus relaciones carecen de profundidad, puesto que no son capaces de ponerse en el lugar del otro y tener en cuenta sus necesidades. (Muñoz, Navas y Fernández, 2003).

6. Vivencia del tiempo: Hernández (2010) apunta que viven exclusivamente en el presente. No obstante, Muñoz (2011) comenta que estas personas pueden llegar a ser muy organizadas y planificar crímenes aunque les lleve mucho tiempo. Se basan en su fantasía, y si ésta requiere de un gran lapso temporal para su planificación y que resulte "perfecta" se lo concederán.

\subsubsection{La entrevista con el psicópata}

Para poder llevar a cabo una buena entrevista a un psicópata no sólo se hace necesario manejar perfectamente los criterios diagnósticos y conocer la psicopatología, sino que además un buen entrevistador ha de poseer ciertas características y tener algunos aspectos en cuenta, los cuales se describen a continuación.

La experiencia clínica muestra la entrevista como una pieza clave del diagnóstico con notable implicación legal y policial. Respecto a las características que ha de presentar el entrevistador se enumeran las siguientes:

1. Confianza en sí mismo.

2. Experiencia profesional.

3. Autoridad. 
Respecto al clima de la entrevista se recomienda que sea de respeto y de interés hacia la historia que cuente el entrevistado. De suma importancia es manejar perfectamente la información existente respecto al caso de la persona que se va a entrevistar para evitar posibles sorpresas o contradicciones en el discurso.

Qualey (2008), citado por Jiménez (2015) pone de relieve algunas cuestiones que el psicópata puede manejar en la entrevista tratando con ello de "jugar" con el entrevistador y/o sentirse superior a él:

1. Hablar mucho tiempo sobre sí mismo y durante mucho tiempo con el fin de manejar el ritmo y el tiempo de la entrevista: el hablar en exceso está relacionado con personalidades egocéntricas, pero este egocentrismo puede ser narcisista o histérico de fondo. Si se trata de un narcisista lo que buscará es enaltecer su ego, que se sienta admiración por él, que se le considere muy inteligente. El entrevistador debe estar muy atento de ver que es lo que realmente demanda para de manera muy puntual reforzarle que en algunos aspectos es admirado y se le considera inteligente. Si nos encontramos con un fondo de personalidad histeoride lo que va a intentar es una manipulación transferencial. Es decir, intentará que el entrevistador tenga algún tipo de sentimiento hacia él que por la razón que sea le interese. Actuará de manera similar al narcisista, pero desplegando mucho más teatro sobre lo que cuenta y como rasgo distintivo en alguna ocasión adulará profesionalmente, físicamente, o buscando complicidad temática al entrevistador.

2. Realizar preguntas a los entrevistadores con la finalidad de intercambiar los roles. Se trata de una manera de no sentirse tratado asimétricamente y de en la fantasía ser él el verdadero entrevistador. En algunas ocasiones, de forma demostrativa y seductora, puede utilizar terminología policial, jurídica, psicológica, etc que no le corresponde en un intento por mostrar que él es intelectualmente superior.

3. Realizar respuestas emocionales que provoquen frustración o rabia en los entrevistadores: como echarse a reír cuando comenta una de sus violaciones, bromear sobre aspectos macabros...Resulta de ayuda en algunas ocasiones, mostrar simpatía y admiración, es decir, si el psicópata percibe que la otra persona reconoce su valía es más fácil que colabore. 
4. Negarse a contestar preguntas sencillas: bien para demostrar que quien manda en la entrevista es él, o bien porque intuye que responder a ese dato le puede obligar a responder otros que en principio no quiera.

5. Realizar interrupciones innecesarias: pueden utilizar un lenguaje tangencial intentando demostrar una sensación de soltura y poder total en la entrevista. Se le debe escuchar en esos aspectos lo justo haciéndole percibir que a los entrevistadores les gusta hacer bien su trabajo

6. Tratar de intimidar a los entrevistadores: pueden utilizar gestos desafiantes, miradas fijas, comentarios radicales de sí mismo o de los demás... Se considera conveniente no mostrarle afectividad, pero sí hacerle sentir protagonista de su historia.

7. Cuestionar la competencia de la autoridad de los entrevistadores: es importante no olvidar que el psicópata apenas siente ansiedad ni estrés por ser interrogado, inclusive se puede encontrar a gusto jugando con el entrevistador o simplemente porque en ese momento él es el centro de atención. En este sentido, se hace aconsejable que el entrevistador esté pendiente de su propia ansiedad ya que si no se siente preparado, se aconseja suspender la entrevista.

\subsubsection{El modelo dimensional de Blackburn (1996)}

Las clasificaciones revisadas hasta ahora mantienen una forma de categorizar basada en el modelo médico de enfermedad. Sin embargo, Blackburn (1987) propone un abordaje dimensional a la hora de tratar con los trastornos de personalidad, ya que no se trata de características dicotómicas, sino que se distribuyen a lo largo de un continuo.

Las investigaciones realizadas por Blackburn $(1975,1979,1987,1996)$ queda demostrado que las personas que presentan un desorden psicopático no forman un grupo homogéneo en cuanto a características de personalidad, por lo que no resulta de utilidad el uso de sistemas categoriales.

Blackburn (1979) clasifica a los individuos antisociales basándose en dos factores:

- Beligerancia (psicopatía o agresión antisocial): se compone de características como impulsividad, agresión, hostilidad y falta de sinceridad. En este sentido, mide si las relaciones de una persona se basan en la desconfianza y son expresadas de formas agresivas. 
- Retirada social: se compone de rasgos como timidez, ansiedad, introversión, depresión y evitación de los demás.

En este sentido, Blackburn (1996) afirma que la dimensión que mejor diferencia a los psicópatas de otros criminales es la Beligerancia. A raíz de estas dos dimensiones propuestas por el autor, hace una distinción de cuatro tipos de psicópatas:

1. Psicópatas primarios: alta beligerancia y baja retirada social (son extravertidos y no neuróticos)

2. Psicópatas secundarios: puntuaciones elevadas en beligerancia y alta retirada social (puntúan alto en ansiedad y son retraídos socialmente)

3. No psicópatas controlados: bajo en beligerancia, baja retirada social.

4. No psicópatas inhibidos: bajo en beligerancia y alta retirada social

En la actualidad, según apunta Blackburn $(1992,1993)$ el término psicopatía se usa de tres maneras:

a. Personalidad psicopática como desviación/deterioro personal o social: se equipara con el concepto de personalidad psicopática de Sneider, es decir, como un término referente a cualquier trastorno de la personalidad, como refleja el DSM-III.

b. Personalidad psicopática como desviación/deterioro social: pone el énfasis en la conducta social desviada, lo que ha influido en las categorizaciones diagnósticas ya que el nivel de análisis se circunscribe a la mera conducta.

c. Híbrido: parte de la concepción de Karpman (1941) y propugna el uso de criterios concretos en vez de listas. Exige una división en subtipos del trastorno, ya que considera que la psicopatía no puede ser equiparada a criminalidad, delincuencia o desviación sexual.

\subsubsection{Diferencia entre psicopatía, trastorno disocial y trastorno antisocial.}

Como apunta Cabrera y Fuertes (1997) la diferencia más relevante entre Psicopatía y Trastorno antisocial o las personalidades disociales, estriba en que éstos últimos si son capaces de aprender nuevas normas y diferentes medios de vida, con lo que el repertorio conductual puede variar, y esto precisamente porque en la mayor parte de los casos todo ese elenco sintomatológico es el resultado de una vida marginal, falta de límites, carencias afectivas, académicas, económicas... más que de un auténtico trastorno de la personalidad (cf. p. 341-342). Se ha de tener en cuenta que la mayoría de 
los psicópatas no son delincuentes, por lo que ligar la psicopatía a la delincuencia o al trastorno antisocial es un error muy habitual. En este sentido, Glüeck y Glüeck (1950) demostraron que tan sólo una minoría de delincuentes deberían ser clasificados como psicópatas y que relativamente pocos podrían ser diagnosticados de padecer un trastorno mental de cualquier tipo. En la misma línea, Taylor (1975) advirtió que los delincuentes socializados no están exentos de ansiedad como lo están los psicópatas. Por tanto, confundir a los delincuentes «socializados» con los psicópatas revela un prejuicio, quizás de la clase media, más que un juicio clínico verificable.

No obstante, mientras que en el psicópata la víctima no es más que un objeto que le hace satisfacer sus instintos, el delincuente habitual se haya regido por un flexible código de honor. De alguna manera accede el problema moral, mientras que para el psicópata ese problema está vedado. En esta línea, el proyecto de vida del delincuente se sitúa en vivir al día lo mejor que pueda, y generalmente compartiendo con amigos, el psicópata define su modus vivendi o su proyecto por violar sistemáticamente el bienestar de los demás, "más allá de que tales actos rutinarios quebranten o no la ley" (Redondo y Garrido, 2013 p. 647).

El psicópata suele ser un solitario cuando ataca, o como mucho, se une a otro psicópata más sumiso, mientras que el delincuente habitual es bastante más gregario.

En general, y de lo anteriormente expuesto se puede observar que:

1. El Trastorno Antisocial hace más referencia a la delincuencia

2. Los delincuentes si son capaces de aprender de la experiencia mientras que el psicópata sigue sus impulsos sin tener en cuenta las consecuencias.

3. La mayoría de los psicópatas no son delincuentes

4. Los delincuentes socializados no están exentos de ansiedad.

5. Los proyectos de vida son diferentes en ambos: en el delincuente se define por vivir lo mejor que pueda y en el psicópata el proyecto vital se asienta en perjudicar a los demás.

6. El delincuente es más gregario en sus acciones

7. En muchas investigaciones no se hace esta diferencia lo cual conlleva sesgos importantes, es decir, no es lo mismo recluso penitenciario que psicópata.

Por último, se considera necesario describir una de las personalidades psicopáticas más adaptadas socialmente, que se diferencian del resto por no incurrir tan 
directamente en delitos de sangre contra la sociedad. Estas personalidades se explican a continuación.

\subsubsection{Los psicópatas adaptados integrados}

Este tipo de psicópatas hacen referencia a aquellos sujetos que cumpliendo la mayor parte de los rasgos de psicopatía, no cumplen los que se refiere a conductas delictivas. El Tribunal Supremo Español define la integridad moral como "un atributo de la persona", como ente dotado de dignidad por el solo hecho de serlo, esto es, como sujeto moral, fin en sí mismo, investido de la capacidad para decidir responsablemente sobre el propio comportamiento". Una persona con integridad es una persona en la que se puede confiar por su honradez, honestidad y respeto a los demás, precisamente todo lo contrario de lo que sería una persona psicopática.

Un psicópata es una persona que sólo se interesa por sí mismo, que no considera a sus semejantes como personas, sino como objetos que puede utilizar para sacar adelante sus pretensiones. Cosifica al Otro, y no le concede valor, ni establece con él ningún tipo de raigambre afectiva. No tienen ningún tipo de escrúpulos, por eso en la política y en los grandes cargos directivos existen tantos psicópatas. (Pozueco, 2010) En esta línea, el psiquiatra polaco Łobaczewski (2006), introduce el término de Ponerología que proviene del griego (Ponerós) que designa el mal y (logía) que hace referencia al estudio o conocimiento. Dicho autor estudia cómo los psicópatas influyen en el avance de la injusticia social y sobre cómo se abren paso hacia el poder en todo tipo de Instituciones. Y cuya culminación política, de algunos sujetos de este estilo, es lo que se ha venido a denominar Patocracia:

La patocracia es una enfermedad de grandes movimientos sociales seguidos por sociedades enteras, así como naciones e imperios. Durante el transcurso de la historia de la humanidad, ha afectado a movimientos sociales, políticos y religiosos, al igual que a las ideologías que la acompañan... Y los ha convertido en caricaturas de ellos mismos... Esto ocurrió como resultado de... la participación de agentes patológicos en un proceso patodinámico similar. Esto explica por qué todas las patocracias del mundo son, o han sido, tan similares en sus propiedades esenciales." (Ibíd, 2006, p.22).

En la misma línea, de forma más individual, se podría enfocar el estudio de la psicopatía integrada como el fruto de los pecados capitales, entendido estos no tanto 
como la magnitud o gravedad de la falta sino como que su comisión es el origen de muchas ofensas (Vázquez Tían, 2015). En este sentido, este mismo autor destaca que la lujuria, la soberbia, la avaricia, la envidia, la gula, la ira y la pereza serían actitudes que favorecen la aparición de la psicopatía, ya sea ésta integrada o no.

Si bien la psicopatía femenina es más bien baja comparándola con la de los hombres, Garrido (2004) la sitúa en 1 frente a 7, no obstante no por ello deja de ser menos importante.

Hart, Cox y Hare (1995) destacaron una serie de rasgos de primer y segundo orden de cara al diagnóstico de psicopatía integrada referenciados en la Figura 10:

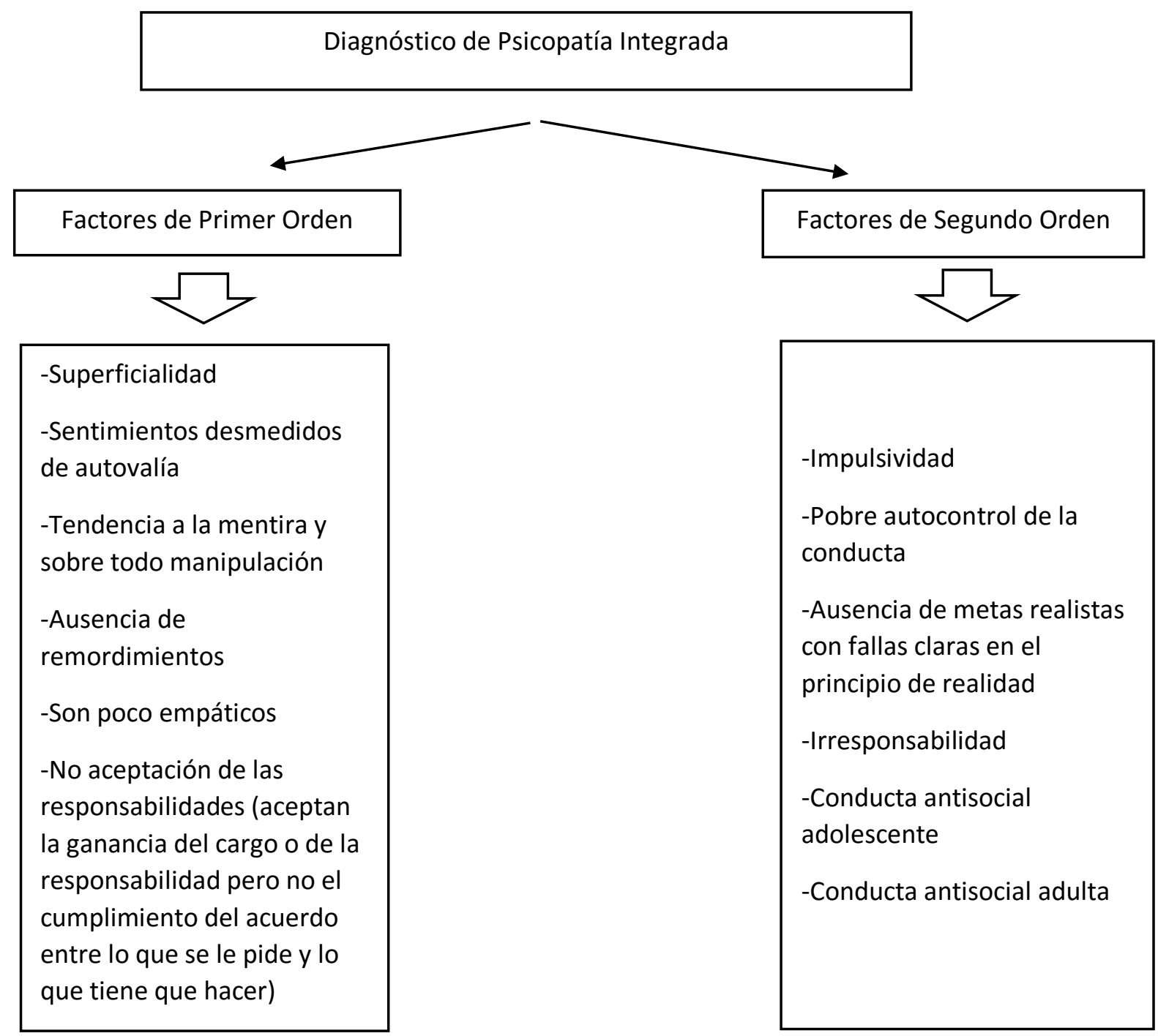

Figura 10: Diagnóstico de psicopatía integrada (Hart, Cox y Hare, 1995) 
Además, Gabbard (2009) hablando de los psicópatas más integrados o de "guante blanco", explica que "encajan perfectamente en una personalidad narcisista, y esta misma personalidad es la que con frecuencia le ha permitido tener éxito, pero ciertos defectos en su conciencia se vuelven eventualmente manifiestos a través de sus conductas antisociales detectadas por otros" (Ibíd, 2009,p. 542). Esta conducta de naturaleza antisocial en estos sujetos puede surgir:

- Por la presión de los iguales

- Por conflicto neurótico (por ejemplo la tendencia a la mentira es típica del neurótico, pues en última instancia si decimos que el diablo entró al mundo por la mentira, el neurótico lo que hace es mentirse a sí mismo (De Santiago, 2005)

- Por pensamiento psicótico: en este aspecto se ha de recordar que dentro de los factores de segundo orden está la ausencia de metas realistas, luego el principio de realidad de una o de otra manera está como poco ligeramente alterado de forma psicótica.

No obstante aunque se va perfilando esta entidad nosológica, la psicopatía integrada todavía se acerca más a características de la clínica con narcisistas y a cuestiones morales y éticas por lo que puede resultar más fácil detectarlos, pero no menos dificultoso el prevenirlo salvo que haya un cambio radical de actitudes en valores, en política y conciencia social.

Es de resaltar la Triada Oscura típica del psicópata integrado (Jones y Paulhus, 2009; Paulhus y Williams, 2002) cuyas características se describen a continuación:

- Psicopatía subclínica: empatía utilitaria del Otro, crueldad, afectos superficiales, pobre sentimientos de culpa.

- Narcisismo: gran sentimiento de importancia personal, se considera un ser especial con privilegios y una actitud explotadora dentro de una imagen desmedida de su Yo.

- Maquiavelismo: manipulador a su favor en todo lo que le interesa, sin tener nunca en cuenta al Otro y sus sentimientos.

Otro aspecto a destacar es la diferenciación entre rasgos psicopáticos y liderazgo. En este sentido, en la empresa Bob Hare y Paul Babiak (citados en Dutton, 2013) desarrollaron el cuestionario el Scan Business y compararon los rasgos psicopáticos con los rasgos de liderazgo. (Véase Tabla 24): 
Tabla 24: Rasgos de liderazgo vs. Rasgos psicopáticos (Bob Hare y Paul Babiak, citados en Dutton, 2013)

Rasgos de liderazgo

1.- Carismático

2.- Confianza en sí mismo

3.- Capacidad de influir

4.- Capacidad de persuasión

5.- Pensamiento visionario

6.- Capacidad para correr riesgos

7.- Orientado a la acción

8.- Capacidad para tomar decisiones difíciles.
Rasgos psicopáticos

1.- Encanto superficial

2.- Fatuidad

3.- Manipulación

4.- Arte del engaño

5.- Inventa historias

6.- Impulsividad

7.- busca emociones

8.- pobreza emocional

En relación al éxito de vida, John Ray (1982) postula la psicopatía en U invertida como modelo que más cuadra en la relación psicopatía y éxito de vida. (Véase Figura 11):

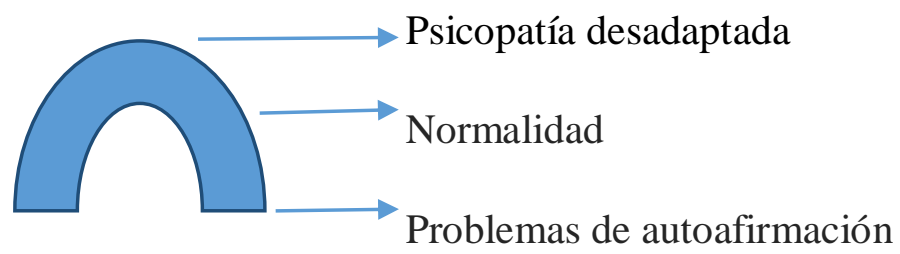

Figura 11: Modelo de John Ray y J.A.B. Ray (1982) sobre psicopatía y funcionalidad en la vida.

Los niveles extremadamente altos y bajos de psicopatía son inadaptados mientras que los intermedios son los más adaptativos, siendo los bajos indicativos de problemas importantes de carácter, melancolía, y depresiones graves y recurrentes. Mientras que los altos darán problemas legales, los bajos de autoafirmación. 


\subsubsection{Prevalencia de la psicopatía}

La Organización Mundial de la Salud (OMS), ofrece una estadística cuanto menos reflexiva. Estima que el $2 \%$ de la población mundial es psicópata, frente a por ejemplo el $1 \%$ de esquizofrenia. Por lo que respecta al género la diferencia es de 3:1 a favor de los hombres. Si se tiene en cuenta que la población mundial en 2007 era de más de 6.000.000.000 de habitantes, de acuerdo con la estadística de la OMS, en el mundo actualmente hay más de 120.000 .000 personas que son psicópatas. Por lo que respecta a España, se presentan distintas cifras. Como significativa se señala la que maneja Garrido (1999) que apunta que en España existen aproximadamente 1.000.000 de psicópatas de los cuales sólo 10.000 cometen hechos delictivos. Las restantes 990.000 personas que son psicópatas y no cometen hechos delictivos -como indica Garrido - se encuentran en todos los estratos de la sociedad española, caracterizándose como personas con un carácter difícil, tal y como ya sugería Schneider (1999).

Según este análisis, los psicópatas tanto integrados como no integrados, pueden pertenecer a cualquier clase social, ser niños, jóvenes, adultos o ancianos al igual que cualquier sexo. En este sentido, Goleman (2006) recuerda que "resulta mucho más habitual y vive entre nosotros, y podemos encontrarlos en las oficinas, las escuelas, los bares y en cualquier recodo de la vida cotidiana" (Ibíd, 2006, p.164). A este respecto conviene reseñar que aun tratándose de un "trastorno", éste no tiene mermada la parte intelectiva del dolo, y muchas veces, quizás las más, tampoco la volitiva. Son personas que, aunque no cometen hechos delictivos, tiene un carácter complejo, carecen de principios y valores morales y, si tienen que hacer sufrir a alguien, lo harán sin dudarlo un momento.

\subsection{APORTACIONES PSICOANALÍTICAS AL ESTUDIO DE LA PSICOPATÍA}

La psicopatía en términos psicoanalíticos se engloba dentro de las perversiones. Normalmente se ha considerado al perverso como una persona maliciosa que no sólo hace mal, sino que quiere y desea hacerlo. El perverso lleva a cabo conductas transgresoras de la norma moral: 
Estas estrategias se ejercen mucho menos con la finalidad de dañar que con la finalidad de gozar. Es justamente este goce el que ejerce indiscutiblemente en el otro un polo de atracción que, a la vez, seduce y fascina pero vuelve tan a menudo las perversiones inadmisibles. De hecho, ese goce no puede ser adquirido más que al precio de la transgresión. (Dor, 1996, p.108).

El perverso además, tiene fantasías muy rígidas debido a que su estructura superyoica sólo deja imaginar relaciones sexuales bastante limitadas. En este sentido, Dor (1996) explica que: "la estructura perversa se caracteriza por una organización psicosexual específica en el sentido de que las vías de realización del deseo que inducen recuerdan siempre al mismo orden" (Ibíd, 1996, p.108)

No obstante, aunque su mundo imaginario sea particularmente pobre, debido a su economía libidinal el perverso se siente empujado a realizar gran parte de sus fantasías de una manera fundamentalmente compulsiva.

Respecto a las características perversas en el neurótico, aunque se puedan identificar, hay que diferenciar un neurótico con una perversión, con un goce perverso, de la persona con verdadera estructura perversa: "Pero desengañémonos, sólo se trata de una perversión soñada; el neurótico no es un perverso sino alguien que sueña con serlo" (Nasio, 1991, p.95)

Añade Nasio (1993):

El neurótico puede vivir fantasmas perversos pero el perverso concreta esos fantasmas sin poder realizarlos. Así, el perverso es aquel que realiza hasta el fracaso humillante el fantasma perverso del neurótico y el perverso goza de verse rebajado de modo degradante, y encuentra su satisfacción en el dolor masoquista" (Ibíd, 1993,p.163-164).

Para poder entender la elección perversa, se ha de entender previamente la problemática fálica. Tal y como afirma Dor (1987), el punto de origen se halla en la identificación pregenital, que no es otra cosa que la identificación fálica en la medida en que esa identificación lo es con el falo materno.

Esta doble vivencia psíquica que asigna a la madre al lugar del Otro, destina al niño por otro lado, a captar la instancia del deseo materno como principal soporte de su propia dimensión identificatoria. El deseo del niño se hará así de buen grado deseo del deseo del Otro vivido en un principio como otro omnipotente y a continuación como otro faltante. Por otra parte, su deseo en una dialéctica donde se identifica él mismo con el 
objeto susceptible de colmar la falta en el Otro. El fundamento de la identificación preedípica en tanto que es identificación fálica, es, por tanto, identificación con el objeto que colma el deseo del Otro. (Dor, 1987, p.90).

Explica Dor (1987), que en un primer momento el niño cree que el falo lo tiene la madre, la ve como una madre omnipotente y todopoderosa. Poco después se dará cuenta que la madre tiene una falta y es él mismo el que la llena, de tal manera que se atribuye el falo a sí mismo. Sin embargo, esta identificación fálica del niño durará poco tiempo debido a la aparición de la figura paterna. La intrusión paterna posibilita un nuevo conocimiento sobre el deseo del Otro, la diferencia sexual y el miedo a la castración. Que aparezca en escena la figura paterna, es lo que posibilita el paso hacia la simbolización de la falta.

El padre, en efecto, no es nunca aprehendido psíquicamente por el niño de otro modo que bajo la forma de esta imagen paterna, es decir, tal como el niño tiene interés en verlo en la economía de su deseo y a través del discurso que la madre pueda dedicarle. Es a la vez polo de las proyecciones significantes de la madre y polo de las proyecciones personales del niño. Por esta razón, la presencia del padre para el niño es siempre más presencia del padre imaginario que del padre real. Asimismo, con esta consistencia ilusoria el padre hace su entrada en la dinámica edípica. Por su parte, el padre simbólico, en tanto interviene de modo estructurante en el complejo de Edipo, no es otro que un padre cuya consistencia se asocia a una investidura puramente significante respecto de la atribución fálica (Dor, 1987, p.91)

No se debe olvidar que para que el padre aparezca en escena, es la madre quien debe permitirlo “(...)convendría ocuparse no únicamente de la manera en que la madre se acomoda a la persona del padre, sino del caso que ella hace de su habla, digamos la palabra, de su autoridad" (Lacan, 1957, citado por Dor, 1987, p.92)

Debido a la aparición de la figura paterna, el niño es cuando se percata de que él no es el falo que completa la falta de la madre. Es en este momento en el que aparece la angustia de la castración que llevará al niño a realizar reacciones defensivas. Las reacciones defensivas que persistan van a delimitar la estructura psíquica del niño.

El sujeto perverso falla en esta última fase, en llevar al padre al registro de lo simbólico: "De alguna manera, la sombra proyectada del padre simbólico es precisamente esa instancia mediadora de la cual el perverso no quiere saber nada, en la 
medida en que le impone tener que reconocer algo del orden de la falta en el Otro" (Íbid, 1987, p.99).

La estructura perversa del niño llega a formarse debido a la ambigüedad creada por una madre seductora y un padre ausente: "La esencia de esta ambigüedad puede sintéticamente circunscribirse en los límites de dos factores predisponentes cuya sinergia captura al niño en la frontera de la dialéctica del ser y el tener. Se trata, por una parte, de la complicidad libidinal de la madre y, por la otra, de la complacencia silenciosa del padre" (Íbid, 1987, p.103)

En este sentido, la madre responde a las necesidades eróticas el niño, manteniendo una relación de complicidad: "lo que me parecía esencial en la relación del perverso con la madre era un lazo de complicidad: de dicha complicidad con una madre seductora (y en caso del perverso no se trata de un puro fantasma de seducción forjado por el sujeto)" (Aulaguier, 2000, p.33)

De esta manera, es lógico pensar que la figura del padre sea vista como intrusiva:

En la complicidad erótica que la madre comparte con el niño, éste puede engañarse sobre la ausencia de mediación paterna respecto del deseo de la madre. Sin embrago, el padre no deja por eso de aparecer como un intruso y tanto más cuanto la madre, sin confirmar en nada el compromiso de su deseo por él, no invalida nunca tampoco la eventualidad de ese deseo respecto del niño.(Dor, 1987, p.104)

El padre no entra en la díada madre-hijo para imponer la ley, y esto es fomentado por la madre, que no le da paso:

Semejante ambigüedad materna no tiene, sin embargo, incidencia determinante sino en la medida en que recibe, como eco, un cierto refuerzo por el lado de la complacencia tácita de un padre; complacencia tácita a dejarse desposeer de buen grado de sus prerrogativas simbólicas delegando su propio habla en el de la madre con todo el equívoco que este mandato supone. (Íbid, 1987, p.104)

Esta situación, de la que son responsables padre y madre lleva a reforzar a la gran madre todopoderosa, a la madre fálica que acompañará para siempre al perverso. Esta imagen de mujer le perseguirá en la búsqueda de "su mujer" encontrándose o bien con la "virgen", la madre fálica impoluta, o bien con la mujer manchada por el deseo, la madre sexuada, la "puta": 
Por un lado, la mujer puede encarnar la madre fálica completamente idealizada. Esa idealización no tiene entonces otra función que la de confirmar, a través de la mujer, protegiendo al perverso de la madre como objeto de deseo. Desde que esta idealización es un proceso de defensa, la mujer es no solamente todopoderosa sino también virgen de todo deseo. Objeto puro y perfecto, el brillo de sus perfecciones la sitúa en el lugar de un objeto fuera del alcance, tan prohibido como imposible. Encarna así el modelo del ideal femenino (...) Por otro lado, la mujer puede igualmente bien metaforizar a la madre repugnante y abyecta; madre sexuada tanto más repugnante cuanto que es, por esta razón, deseosa y deseable a los ojos del padre. Esta mujer/madre no tiene otra salida, para el perverso, que ser prácticamente relegada al rango de puta, es decir, en el lugar de objeto inmundo ofrecido al deseo de todos, puesto que ella no está reservada exclusivamente a los buenos oficios de su deseo propio. Tal es la encarnación femenina que convoca ipso facto al perverso ante el horror mismo de la castración. (Dor, 1987, pp.105-106)

De manera que el perverso hace una transgresión de la ley que él rechaza:

Lo que el perverso viene a demostrar es que ni la castración ni el horror pueden oponerse al goce, que ambos son sus corolarios indispensables, así como la supervivencia de la víctima y esa integridad de su cuerpo siempre recuperada (...) prueban que la castración se anula en el mismo momento en que se cumple (Aulagnier, 2000, p.49)

\section{Respecto al concepto de transgresión, Colina (2006) aporta otra opinión:}

La transgresión, por tanto puede ser perversa o no, extremos que no dependen del tipo de conducta que se practique sino del trato que se ofrezca a quien es llamado a cumplimentar y despertar nuestros deseos. A su vez, la perversión, por su parte, no tiene por qué ser transgresora. De hecho, raramente lo es. El universo perverso es más afín a la repetición que a la novedad. Escapa inicialmente a la ley moral pero permanece rígidamente presa en los límites del deseo. Es repetitiva con este aburrimiento maquinal de lo destructivo y lo sadiano. Repite el abuso y la opresión. La perversión en realidad aunque simule transgredir las leyes, se somete a la peor de todas, que no es otra que el principio de repetición. La transgresión es un desplazamiento estratégico y técnico del deseo y el placer, mientras que la perversión, en cambio, es un concepto de orden puramente moral. (Ibíd, 2006, p.117)

Además explica que: "El perverso no se dedica a incumplir la moral social establecida, sino a vulnerar la moral autónoma de cada persona al no respetar la 
igualdad y el equilibrio. El deseo del perverso se convierte en el derecho sadiano a gozar del otro al margen de su consentimiento" (Íbid, 2006, p.119).

\subsubsection{Las psicopatías y las conductas antisociales}

Freud (1915/1925), en referencia al estudio de la psicopatía, en su texto "Algunos tipos de carácter observados con el trabajo psicoanalítico", describe algunos actos peculiares que no parecían ser propios del carácter de la persona. Así el autor hace referencia a un subgrupo de casos en los que la criminalidad se da a raíz de un sentido de culpa:

El trabajo analítico lleva a la sorprendente conclusión de que tales acciones se producen precisamente porque están prohibidas y, al llevarlas a cabo, la persona disfruta de una sensación de alivio mental. Sufren una sensación aprensiva de culpa, de la que no saben el origen, y, una vez que han cometido la acción prohibida, la opresión se mitiga. (Ibíd,1915/1925, p.342)

Este texto, apoyado al mismo tiempo en su posterior escrito de 1916 Los delincuentes por sentimiento de culpa de S, Freud, fueron los desencadenantes para que otros analistas empezaran a publicar trabajos sobre el tema. Así, Aichhorn (1925/1935) fue el primero en llevar a cabo un examen analítico del comportamiento del delincuente. (Millon, 1998). A este respecto, escribe el autor:

Cuando observamos un comportamiento disocial o síntomas de delincuencia distintos de la delincuencia propiamente dicha, vemos la misma relación que existe entre los síntomas de una enfermedad y la enfermedad misma. Este paralelismo nos lleva a considerar el robo, las escapadas y la vagancia como síntomas de delincuencia, del mismo modo que la fiebre, la inflamación y el dolor son síntomas de enfermedad. Si el médico se limita a tratar los síntomas, no curará necesariamente la enfermedad. Se mantiene la posibilidad de que aparezca una nueva enfermedad, de que síntomas nuevos sustituyan a los viejos...Cuando un proceso psíquico es negado y las energías psíquicas que lo determinan no se pueden descargar, debe encontrarse otra vía para esta descarga, siempre en la línea de la menor resistencia, y puede producirse una nueva forma de delincuencia. (Aichhorn, 1925, p.38).

Abraham (1925) añade que existen patologías que hacen surgir rasgos narcisistas y otras que hacen surgir rasgos antisociales: 
A menudo nos encontramos con los resultados de los primeros mimos, que intensifican las demandas del niño de una forma que nunca podrán ser satisfechas adecuadamente (narcisista). Entre los delincuentes (antisociales) es más probable que la libido siga una evolución diferente en la infancia. Es la ausencia de amor, comparable al sustento psicológico, lo que proporciona un estado previo para el establecimiento de rasgos disociales. Se crea un exceso de aborrecimiento y furia que primero se dirige contra un pequeño grupo de personas y después contra la sociedad en general. (Ibíd, 1925, p.304).

En la misma línea, Reich (1925), explica que el carácter de estas personalidades psicopáticas es debido a que el Superyó no puede expresarse y por lo tanto no puede controlar al Ello frente a las tentaciones instintivas, de manera que se da una libre expresión de los impulsos. En palabras del autor:

Al igual que hemos diferenciado entre los síntomas neuróticos y el carácter neurótico, debemos separar los actos compulsivos, en el sentido de acciones compulsivas incontrolables, del comportamiento general de carácter impulsivo. Mientras el primero parece un cuerpo extraño circunscrito en una personalidad ordenada, y es condenado por ésta, el...individuo impulsivo es...rara vez reconocido como patológico. Las acciones del individuo impulsivo nunca parecen carecer de sentido como ocurre con las acciones del neurótico compulsivo, y están más relacionadas. (Ibíd, 1925, p. 251).

No obstante, no es hasta los trabajos de Alexander (1923, 1930, 1935) cuando se lleva a cabo la primera evaluación de la psicopatía y del comportamiento criminal a través de una perspectiva psicoanalítica. (Millon, 1998). Alexander (1923), propuso cuatro niveles de patología: neurosis, carácter neurótico, psicosis y criminalidad auténtica. Pretendía plasmar la disminución de la acción del Yo para contener los impulsos inconscientes, de manera que los neuróticos presentaban la mayor capacidad y los criminales la mínima. Así, para Alexander, el carácter neurótico era la personalidad subyacente en los psicópatas. En este mismo período, otro autor, Bertmeier (1930) presenta ideas similares:

El carácter neurótico es más audaz y arriesgado que la personalidad neurótica. No permite que la sociedad le intimide en la fantasía y lleva a cabo sus impulsos en la acción real. Mantiene un rencor social contra la civilización y sus restricciones. La vida de estas personas está hecha de indulgencias sociales despreciadas y la subsiguiente búsqueda de castigo. Estas personas sólo cometen crímenes cuando sufren conflictos emocionales, mientras que los verdaderos criminales no experimentan conflicto alguno. (Ibíd, 1930, p.516). 
Wittels (1937) diferencia entre los psicópatas neuróticos (temen sus impulsos bisexuales) y los psicópatas simples (No temen sus impulsos bisexuales). Por otro lado, Karpman (1946) distingue entre psicopatía primaria y secundaria.

- Los primarios serían los que a raíz de déficits constitucionales (predisposición biológica) cometen sus crímenes con una mayor violencia instrumental (no emocional), muestran menos miedo, ansiedad, buena capacidad de reacción al estrés y adecuada dominancia social. Etiológicamente vienen más marcados por la influencia genética.

- Los secundarios son los que acarrean en su historia conflictos emocionales no debidamente resueltos. Entre ellos, malos tratos infantiles, abusos, abandonos, etc .Su violencia es más reactiva y emocional Son sujetos más ansiosos y socialmente más torpes o introvertidos. Presentan más psicopatología franca, ansiedad, depresión, traumas diversos, TDAH. Más tendencia al consumo de drogas y actividades delictivas. La etiología es más de carácter psicosocial.

La importancia de la clasificación de Karpman es doble:

- Por un lado ayuda a establecer un pronóstico terapéutico. Mientras que con los primarios la relación paciente-terapeuta responden de manera nula al tratamiento, los secundarios al poseer sentimientos del estilo de la angustia, culpa, miedo, etc, son más susceptibles al tratamiento.

- Por otro ayuda a la labor preventiva. Una vez vistos los rasgos de personalidad intervenir preventivamente en la línea de que esa psicopatía secundaria no llegue a ser una psicopatía primaria. De hecho parece demostrado, que la psicopatía en general tiene una aparición espontánea entre los 6-11 años y en la adolescencia tardía o primera edad adulta, 16-20 años. Ante la observación de estos síntomas, principalmente problemas de conducta, conviene la intervención temprana.

Pero además Karpman aun sin saberlo contribuye a un tema capital dentro de la psicopatología de la psicopatía y su jurisprudencia, pues de alguna manera distingue entre enfermedad y trastorno.

En la línea de Reich (1925), se encuentra Fenichel (1945) quien diferencia entre la impulsividad antisocial y las compulsiones neuróticas, resaltando también el fracaso del Superyó para controlar los impulsos del Ello. Friedlander amplía esta visión (1945) proponiendo que la estructura psicopática está dominada por el principio del placer y por un Superyó pobremente desarrollado, mientras que Klein (1945) alude a que es 
principalmente la estructuración de un superyó sádico lo que lleva al sujeto a salir del mismo por medio de los "acting". Posteriormente, Bursten (1972) propone como característica principal de los psicópatas la necesidad de engrandecer su autoestima tratando con deprecio a los demás. Así, relata el autor:

Esta conceptualización comienza a ofrecer cierta claridad sobre por qué los sociópatas no parecen aprender de la experiencia; nos fijamos sólo en la experiencia negativa. Con frecuencia, estas personas son bastante brillantes y aprenden. Tienen bastante propensión a evaluar las situaciones sociales. En realidad, su agudeza y su capacidad para desmenuzar una situación son lo que inspira simultáneamente nuestra admiración y nuestra ira. Han aprendido muy bien de la experiencia lo que deben esperar en ciertas situaciones sociales. Además, el comportamiento del sociópata nos desconcierta porque no entendemos su principal propósito. (Ibíd, 1972, p.319).

Shapiro (1965) añade el componente cognitivo a las explicaciones psicoanalíticas: "La falta de planificación es sólo una característica de un estilo cognitivo y de pensamiento, en el que la concentración activa, la capacidad de abstracción, la generalización y la reflexión están seriamente alteradas” (Ibíd, 1965, p.147).

Kernberg $(1970,1984,1989)$ integra las concepciones psicoanalíticas y hace una reconceptualización de la personalidad antisocial. El autor describe los síntomas típicos de la personalidad antisocial de la siguiente manera:

Estos pacientes suelen presentar un trastorno narcisista de la personalidad. Los síntomas típicos de las personalidades narcisistas son, en el área patológica del amor hacia sí mismos: la excesiva autorreferencia y el egocentrismo; la grandiosidad y las características derivadas del exhibicionismo, una actitud de superioridad, imprudencia y ambición excesiva; extremada dependencia de la admiración; superficialidad emocional. Además todos estos pacientes presentan algún grado de patología del Superyó. La patología habitual de las personalidades narcisistas incluye la incapacidad para experimentar melancolía o una tristeza reflexiva; la presencia de cambios de humor importantes y la predominancia de la vergüenza en contraposición a la culpa en la regulación intrapsíquica de su comportamiento social. (Ibíd,1970, p.559).

Dentro de la tradición interpersonal destaca la figura de Learly (1957) resaltando como característica común en las personalidades antisociales la "adaptación a través de la rebelíon”. En esta línea se encuentra Benjamin (1974) afirmando que a las personas antisociales no les importa lo que les ocurra ni a los demás ni a ellos mismos. 
Por otra parte, Millon (1998) recoge como variantes del Trastorno Antisocial de la Personalidad o psicopatías los siguientes:

- El antisocial normal

- El antisocial codicioso

- El antisocial que defiende su reputación

- El antisocial arriesgado

- El antisocial nómada

- El antisocial malevolente.

En este sentido, se encuentra que los autores que más han profundizado en el estudio de la psicopatía han sido Lacan (1957) y su explicación de las perversiones y Kernberg (1989) en cuanto a su estudio de los trastornos de personalidad.

\subsection{NEUROPSICOLOGÍA DE LA PSICOPATÍA}

\subsubsection{Sustrato neurológico de la función ejecutiva: la corteza prefrontal}

La aparición del córtex prefrontal es uno de los desarrollos neuropsicológicos distintivos del cerebro humano. Las funciones dependientes de las áreas frontales se consideran fenómenos consecuentes a la adaptación humana. Los estudios de las relaciones entre la disfunción ejecutiva y los lóbulos frontales comenzaron cuando se intentaba encontrar la relación de los últimos con el comportamiento; se halló una disminución de la ansiedad en aquellos pacientes que habían sido objeto de lobotomías frontales (Moniz, 1937). Estos trabajos iniciales tenían la tendencia de atribuir la regulación, al menos en parte, de las llamadas funciones superiores de los lóbulos frontales; dichas funciones incluyen comportamiento abstracto, ética, planificación, autorregulación y capacidad intelectual (Brickner, 1936). De forma resumida, podría considerarse la capacidad para realizar planes y, en general, la regulación de los impulsos. Pero las funciones frontales también desempeñan un papel comportamental importante en la adaptación de los animales; en los primates con lesión en el córtex prefrontal se muestra una regulación deficiente de las respuestas y una habilidad reducida para organizar programas motores complejos (Pribram, 1973). 
El córtex prefrontal realiza un control supramodular sobre las funciones mentales básicas localizadas en las estructuras basales o retrorolándicas. Este control se lleva a cabo a través de las funciones ejecutivas, que también se distribuyen de manera jerárquica, existiendo una relación interactiva entre ellas (Véase Imagen 1):

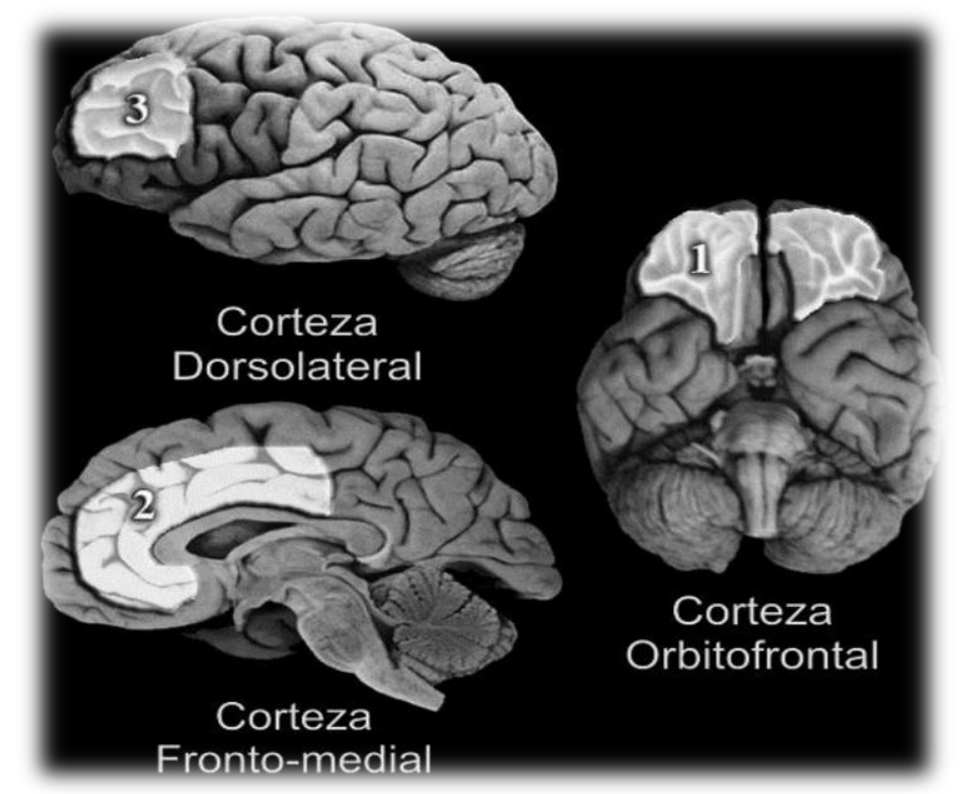

Imagen 1: Las tres divisiones anatómicas de la corteza prefrontal: orbitomedial, dorsolateral y frontomedial. (Tomado de Díaz, K.M., Ostrosky, F., Romero, C. y Pérez, M.L., 2013, p.46)

Fuster (1999) ha defendido la idea de una representación jerárquica en la mediación del lóbulo frontal en la ejecución de las acciones: desde las neuronas motoras, los núcleos motores, el cerebelo, el tálamo, los ganglios basales y el córtex frontal. Al mismo tiempo, ese último también se organizaría jerárquicamente:

a. El córtex motor primario mediaría en la representación y ejecución de movimientos esqueléticos,

b. El córtex premotor actuaría en la programación de los movimientos más complejos, que implican meta y trayectoria,

c. El córtex prefrontal, donde se produce la representación de mayor nivel, actuaría a través de la distribución de redes de neuronas cuya actividad puede verse limitada por la coincidencia temporal de la actividad y el input a través de tres funciones cognitivas básicas: 
- La memoria a corto plazo motora y la preparación para la acción, en el córtex interno o medial. Comprende las áreas de Brodmann 6, 8, 9, 10,24 y 32 .

- La memoria perceptiva a corto plazo, para la retención de la información sensorial relevante, en el córtex dorsolateral. A nivel de la convexidad cerebral, áreas de Brodmann 9, 10 y 46.

- El control inhibitorio de la interferencia para eliminar aquello que es irrelevante, en el córtex orbital o ventral. Abarca las áreas de Brodmann 11, 12, 25, 32 y 47 expuestas en la Imagen 2:

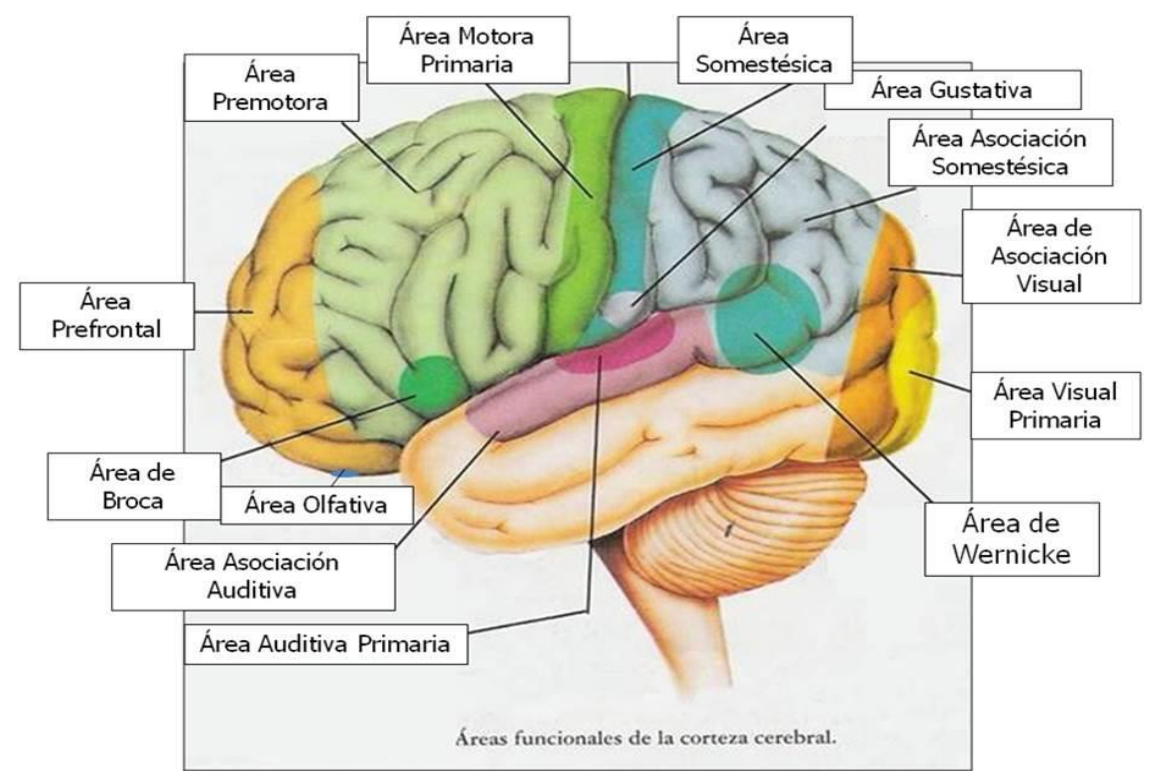

Imagen 2: Corteza prefrontal y las porciones que la constituyen. (Tomado de http://neuropedagogiau2.jimdo.com/area-de-brodman/).

\subsubsection{Síndromes principales definitorios en psicopatía}

Fundamentalmente, la conducta psicopática está definida orgánicamente por dos síndromes neuropsicológicos: Síndrome Disejecutivo y Síndrome Prefrontal orbital, los cuales se explican a continuación.

\subsubsection{Función ejecutiva: Síndrome Disejecutivo.}

La función ejecutiva se puede enmarcar en los lóbulos frontales (región anterior) junto con las áreas prefrontales, así como sus conexiones recíprocas con otras zonas del córtex cerebral y otras estructuras subcorticales, entre ellas los núcleos de la base, el núcleo amigdalino, las estructuras diencefálicas (hipocampo) y el cerebelo. La función 
ejecutiva se ve asociada a zonas cerebrales distintas: la corteza dorsolateral, la corteza orbitofrontal y el córtex cingulado anterior.

El córtex prefrontal es la estructura implicada en la inhibición exitosa de los comportamientos inadecuados. Aquí se encuentran dos tareas principales: la inhibición de respuestas dominantes (pero irrelevantes) y la terminación de una respuesta especialmente cuando un cambio en ella es justificado.

Existen diversas definiciones de la función ejecutiva. Se conceptualiza como un constructo que integra las capacidades implicadas en la formulación de metas, la planificación para su logro y la ejecución de la conducta de una forma eficaz; es decir, integra capacidades como la motivación, la conciencia del sí mismo, la percepción del sujeto y de su relación con el entorno, la capacidad para adoptar una actitud abstracta y tener un pensamiento alternativo, la valoración de diferentes posibilidades y elección de una de ellas, el desarrollo de un marco conceptual que permita dirigir la actividad, la capacidad para iniciar, proseguir y detener secuencias complejas de conducta, la habilidad para controlar, autocorregir y regular el tiempo, así como la intensidad y los aspectos cualitativos de la ejecución (Benson, 1993). Actualmente, se mantiene la idea de la función ejecutiva como un conjunto de factores encargados de organizar y ordenar las funciones superiores.

Para la evaluación de la función ejecutiva se utilizan diferentes pruebas destacando el Test de Clasificación de Tarjetas de Wisconsin (WCST) creado por Henton (1981), que es la prueba más empleada y mide la capacidad de abstracción y la flexibilidad cognitiva a través de un procedimiento de clasificación de tarjetas; los Laberintos de Porteus ( Porteus, 2006), que miden la capacidad de planificación en una tarea de memoria visoespacial; el Test de Fluidez Verbal que mide la amplitud de la fluencia verbal relacionada con el funcionamiento prefrontal izquierdo (Phelps et al., 1997); el Test de Organización Visual incluida en baterías de tests como la Boston process approach (Goodglass, Kaplan y Barresi, 2005), que Hooper (1958) considera que es la prueba más sensible para evaluar el daño de la función visuoperceptiva; la Prueba de fluidez de Diseños (Roff, Light y Evans, 1987), que también mide la fluencia pero en este caso de los aspectos visuomotores. El análisis de la evaluación y programación visuomotora tal y como explican Levin et al. (1991) no está relacionado con la fluidez verbal, por lo que esta prueba se ha tomado como una medida sensible a la actividad prefrontal derecha. Otras pruebas utilizadas son la Prueba de conflicto 
palabra/color o test de Stroop (Golden, 2001) que Bench et al. (1993) consideran que discrimina bien entre personas con daño frontal e individuos normales. La prueba de la Torre de Hanoi (Simon, 1975), evalúa la organización y la programación visoespacial de una secuencia de movimientos, por lo que implica a la memoria operativa. Según las investigaciones de Anderson et al. (1999), en sujetos con daño frontal, este test genera enormes dificultades. Por último cabe mencionar los Subtests de cubos y rompecabezas del WAIS (Wechsler, 1999) ya que para realizar correctamente estas tarea se requiere una atención intacta, planificación, organización, razonamiento abstracto y habilidades constructivas y visuoespaciales. Según los estudios de Goodglass et al. (1979), los individuos con daño prefrontal puntúan bajo en este test.

En general, como apuntan Roussy et al. (2000), estas pruebas así como otros tests sensibles al daño frontal, se han mostrado como buenos predictores de los déficits cerebrales postulados en los psicópatas.

Los correlatos neuropsicológicos de la psicopatía han sido abordados en numerosas investigaciones que sugieren que los problemas de inhibición de los psicópatas están vinculados con daños estructurales o funcionales en la corteza frontal. A continuación se desarrollan las más destacadas.

La mayoría de estudios de caso inciden en la aparición del comportamiento psicopático posteriormente a una lesión orbitofrontal, siendo todos los rasgos que presentan bien documentados y pudiéndose resumir en: comportamiento antisocial e impulsivo, menor empatía, afecto superficial y desinhibición social (Damasio, 1994; Lapierre et al., 1995; Blair, 2004).

Otro trabajo el realizado por Intrator et al. (1997) relacionado con la función frontal, utilizando una tarea de decisión léxica, concluyó que el grupo compuesto por psicópatas drogodependientes (identificados mediante PCL-R) frente al grupo control, obtuvo un flujo sanguíneo cerebral relativo (FSCr) superior en las regiones occipitales y menos en las regiones frontales, temporales y parietales.

En esta misma línea, Dinn y Harris (2000) argumentan que los psicópatas presentan mayor deficiencia en pruebas relacionadas con la disfunción orbitofrontal, que añadido a un déficit en el córtex prefrontal, explicaría las carencias en habilidades de planificación y organización y la incapacidad para pensar en las consecuencias futuras de los actos que presentan los psicópatas. 
Respecto a los estudios realizados mediante electroencefalograma (EEG) y potenciales evocados (PE) destacan los estudios de García y Collado (2004) en los que también se han hallado resultados que relacionan expresiones comportamentales propias del síndrome disejecutivo con los lóbulos frontales. Así, el registro de la actividad espontánea del cerebro de sujetos psicópatas evidencia menor actividad en zonas anteriores (Mednik et al., 1982). En relación a esto, se han encontrado anormalidades en el EEG (56.9\%) en sujetos que han cometido crímenes violentos, las cuales eran eminentemente frontales $(62,2 \%)$. Las conductas psicopáticas se han asociado con gran frecuencia a las ondas frontoparienales $\theta$ (ondas de 4 a $8 \mathrm{~Hz}$ ). Una revisión de estudios con EEG incide en la propuesta de una actividad $\theta$ generalizada excesiva, actividad focal temporal derecha de ondas $\theta$ (entre 6 y $8 \mathrm{~Hz}$ ) y ondas $\beta$ (entre 14 y $16 \mathrm{~Hz}$ ), así como ondas lentas localizadas en el lóbulo temporal.

Más recientemente, las investigaciones de Tremblay et al., (2005) en pruebas cognitivas de lenguaje, percepción y habilidades psicomotoras, parecen demostrar el peor rendimiento de sujetos violentos frente a una muestra control.

Respecto a la integración cognitivoafectiva y la inhibición de respuestas inadecuadas, Acázar-Córcoles et al., (2008) señalan que las regiones prefrontales orbitofrontales, ventromediales y dorsolaterales son las encargadas de la inhibición de las respuestas inadecuadas y del control de la ejecución de las respuestas adecuadas. La primera región implicada en la toma de decisiones de tipo emocional permite el comportamiento adaptativo, mientras que la segunda es la encargada de reflexionar en la toma de decisiones y las acciones que se derivan de ellas. Puede extraerse que la desinhibición comportamental de los psicópatas se relaciona con una disfunción en la corteza frontal ventromedial (integración cognitivoafectiva) y en la corteza frontal dorsolateral (inhibición de la respuesta) o con una comunicación ineficaz entre éstas y otras regiones del cerebro. En cierta forma, podría considerarse que los psicópatas sufren dificultades para conectar las áreas cerebrales cognitivas y emocionales, lo que explicaría la debilidad de los frenos emocionales y su inevitable correlato con la conducta agresiva

Por otra parte, estos mismos autores, dan cuenta de una investigación de Raine et al. (2000), en la cual, sobre una muestra de 21 pacientes psicopáticos se encontró un $11 \%$ de reducción de la sustancia gris de la corteza prefrontal mediante resonancia magnética estructural (RM). En dicha muestra de pacientes no existía ninguna otra 
lesión cerebral. Se postula que las características prototípicas de la conducta psicopática, tales como el pobre condicionamiento al miedo, los problemas de autocontrol y la falta de conciencia así como el bajo arousal podrían ser consecuencias de esta deficiencia estructural prefrontal.

Por último, Alcázar-Córcoles et al., (2010) en una reciente investigación de la neuropsicología de la agresión impulsiva a través de los estudios llevados a cabo con pacientes que sufren daño neurológico, pone en evidencia que daños graves en la materia gris y blanca del córtex prefrontal conllevan expresiones de personalidad pseudopsicopática.

\subsubsection{Síndrome Prefrontal Orbital}

La Corteza Orbitofrontal es la región del lóbulo frontal del cerebro relacionada con el procesamiento cognitivo de la toma de decisiones e incluye las áreas corticales de asociación de Brodmann 10, 11 y 47 relacionadas con los mecanismos de procesamiento de la emoción y de la recompensa. Anatómicamente, la COF se define como la parte de la corteza prefrontal que recibe proyecciones desde los núcleos mediales magnocelulares del tálamo mediodorsal. Su nombre se debe a su posición, ya que se encuentra situada inmediatamente sobre las órbitas en las que se ubican los ojos.

El síndrome prefrontal orbital se caracteriza por la desinhibición de las respuestas impulsivas a los estímulos ambientales y por la presencia de un estado de ánimo elevado. Los pacientes con este daño pueden presentar hiperactividad y parecen tener energía ilimitada, la cual dirigen de forma desorganizada. Además presentan conducta imitativa y de utilización. Estas lesiones están asociadas con el deterioro de la atención, resultante de la interferencia entre las respuestas impulsivas internas y los estímulos externos, más que en el mecanismo primario de control de la atención (de origen dorsolateral). Estos sujetos exhiben despreocupación por las convenciones sociales y éticas, y una falta de preocupación acerca del impacto de su conducta sobre los otros, a lo que Damasio (1994) ha denominado "sociopatía adquirida".

Las lesiones en el área motora suplementaria están asociadas con el deterioro en la iniciación y ejecución del movimiento de extremidades y habla, mientras que las lesiones de los campos visuales frontales (área 8 de Brodmann) están asociadas con 
trastornos en la fijación voluntaria de la mirada. La apatía es común en este tipo de lesiones. Las lesiones en la circunvolución cingulada anterior resultan en hipocinesia o, con grandes lesiones, en acinesia.

El control de la ejecución de las respuestas adecuadas y la inhibición de las respuestas inadecuadas han sido asociadas con la actividad de la corteza prefrontal, especialmente con las regiones ventromedial y dorsolateral. La región prefrontal ventromedial es fundamental en el comportamiento adaptativo desde el punto de vista de la selección natural y en él se incluyen decisiones de tipo emocional, mientras que la región dorsolateral se encuentra más relacionada con reflexionar en la toma de decisiones y las acciones que se derivan de ellas. Con dichas bases neurobiológicas se puede explicar el comportamiento desinhibido de los psicópatas, incluyendo su facilidad para la violencia depredadora, que se encuentra relacionada con una disfunción en la corteza frontal ventromedial (integración congnitivoafectiva) y en la corteza frontal dorsolateral (inhibición de respuestas) y/o con una comunicación ineficaz entre éstas y otras regiones del cerebro (Smith et al., 1992).

Así pues, los estudios de pacientes con daño en la corteza prefrontal, a partir del caso de Phineas Gage que se desarrollará más adelante, sugieren que la corteza prefrontal orbitomedial juega un papel importante en la mediación de algunas conductas relacionadas con la psicopatía. El daño en esta área lleva a una condición determinada de "pseudopsicopatía" o "sociopatía adquirida" (Damasio, 1994) que se caracteriza por la presencia de problemas con la agresión reactiva, la motivación, empatía, planeación y organización, impulsividad, irresponsabilidad, la autorregulación y la inhibición conductual. Estos datos sugieren que algunos aspectos de la psicopatía coinciden con la disfunción de la corteza orbitofrontal y sus zonas adyacentes.

Respecto al funcionamiento cognitivo orbitomedial en psicópatas criminales, la actual investigación de Díaz et al., (2013) muestra resultados reveladores. Así, como muestra tomaron a 63 hombres adultos (20-59 años de edad) divididos en 2 grupos: psicópatas $(\mathrm{n}=30)$ y controles $(\mathrm{n}=33)$. Como instrumentos utilizaron la Escala de Psicopatía Revisada de Hare (PCL-R) para la evaluación de psicopatía, y la Batería Neuropsicológica de Funciones Ejecutivas y Frontales (BANFE) para medir su desempeño orbitomedial. 
Los resultados arrojaron un menor desempeño orbitomedial por parte de los psicópatas cometiendo un mayor número de errores en Stroop. Se encontró una correlación positiva entre el número de errores de mantenimiento y el factor 1 (interpersonal) de psicopatía, así como una correlación positiva entre el porcentaje de cartas de riesgo y el factor 2 (afectivo) de psicopatía.

A modo de conclusión, se determinó que el perfil neuropsicológico orbitomedial de los psicópatas fue significativamente más bajo comparado con el de los controles, especialmente en tareas que involucran procesos de inhibición y de toma de decisiones, apoyando la hipótesis del daño orbitomedial en esta población.

De manera que el presente estudio apoya la teoría del déficit orbitomedial que subyace a la psicopatía, y la probable existencia de una predisposición a la conducta violenta y psicópata. Un elemento importante a tener en cuenta es entender que la psicopatía no es un constructo unitario, y que la comprensión de diferentes componentes que la conforman con un sustrato neurobiológico ayuda a conocer mejor los mecanismos biológicos que subyacen a este tipo de comportamiento (Ibíd, 2013).

\subsubsection{Otras estructuras anatómicas implicadas en la psicopatía.}

Cabe relacionar las alteraciones estructurales y funcionales asociadas a la psicopatía tanto con los déficits en el procesamiento emocional y cognitivo como con el comportamiento impulsivo y antisocial. La combinación de estas disfunciones ha hecho que la psicopatía empiece a entenderse como un trastorno de la capacidad moral humana.

a) Amígdala, Tálamo e Hipotálamo: La estructura amigdalina asociada con el comportamiento agresivo, se trata de una red neural clave para el procesamiento de la información socialmente relevante y funcionan en paralelo con el hipocampo, reconociendo objetos. El daño en este sistema podría verse relacionado en cierto modo con lo que se denomina conducta social inadecuada, que es manifestada frecuentemente por personas violentas. Amígdala, corteza prefrontal e hipocampo están integrados en el sistema límbico, responsable de la expresión de las emociones, al mismo tiempo que el tálamo les envía inputs desde las estructuras subcorticales límbicas hasta la corteza prefrontal. La 
amígdala, el hipocampo, y el tálamo tienen, al mismo tiempo, una gran relevancia en lo que a aprendizaje, atención y memoria se refiere. Así, dificultades en su proceder están relacionadas tanto con la deficiente respuesta de condicionamiento al miedo como a la incapacidad para formular aprendizajes a partir de la experiencia. Esta serie de carencias vienen a definir a los delincuentes que emplean la violencia y son, en suma, una definición comportamental disejecutiva.

A este respecto, los estudios de Yang et al. (2005) afirman que los psicópatas presentan una amígdala un $17 \%$ menor que la del resto de la gente lo que conlleva una comunicación inadecuada con los lóbulos frontales, la parte más moderna del cerebro, y como consecuencia, la ausencia de miedo a cometer actos malvados y la carencia del concepto de moralidad. En esta misma línea, Alcázar-Córcoles (2008), afirman la existencia de una tendencia a una tasa de funcionamiento reducido en las regiones izquierdas de la amígdala, el hipocampo y el tálamo y mayor en las regiones derechas en psicópatas.

b) Respecto al Hipocampo Laakso et al., (2008) encontraron que los psicópatas presentaban un menor tamaño de la parte posterior del hipocampo y un mayor volumen del hipocampo anterior del hemisferio derecho. (Es importante precisar que esta asimetría se ha observado fundamentalmente en psicópatas criminales no exitosos, es decir, que habían sido capturados y condenados.

c) Sustancia Gris: las investigaciones llevadas a cabo por Yang et al,. (2005) informan de un hallazgo complementario, también en psicópatas convictos, según el cual se da una reducción de la sustancia gris en el lóbulo prefrontal. Una anomalía similar detectan investigaciones recientes mediante morfometría basada en vóxels, aunque cabe matizar que dichos estudios extienden este déficit a regiones temporales y límbicas, informando de alteraciones similares en el giro temporal superior derecho. Laakso et al. (2008), utilizando una metodología similar, detectan una atrofia bilateral en el giro postcentral, en la región del polo frontal y en la corteza orbitofrontal de delincuentes violentos recidivantes, una atrofia que se presenta acentuada en los que, además, han sido diagnosticados de psicopatía.

Estos resultados sugieren que las características neuropatológicas relacionadas con la asimetría hipocampal y con la reducción de sustancia gris 
prefrontal se hallan relacionadas con el escaso condicionamiento del miedo asociado al riesgo, con la desregulación emocional y con el déficit en el control de impulsos, lo que explica que este tipo de personas sean menos sensibles a las claves situacionales que predicen el peligro y actúen de forma precipitada, incrementando el riesgo de tener problemas con la ley (Gao et al., 2009). De hecho, ciertos psicópatas violentos sumamente escurridizos (como algunos asesinos en serie) presentan una función prefrontal más que óptima, lo que les permite planear con fría minuciosidad sus crímenes, evitando ser detectados y arrestados.

d) Cuerpo Estriado: Las investigaciones de Barkataki et al., (2006) han informado de una reducción en el volumen del cuerpo estriado en psicópatas. Dado que el estriado forma parte del llamado sistema de recompensa, parece que las anomalías estructurales y funcionales halladas en estos núcleos podrían ayudar a explicar el placer que pueden sentir los psicópatas ante el sufrimiento ajeno. (Véase Imagen 3):

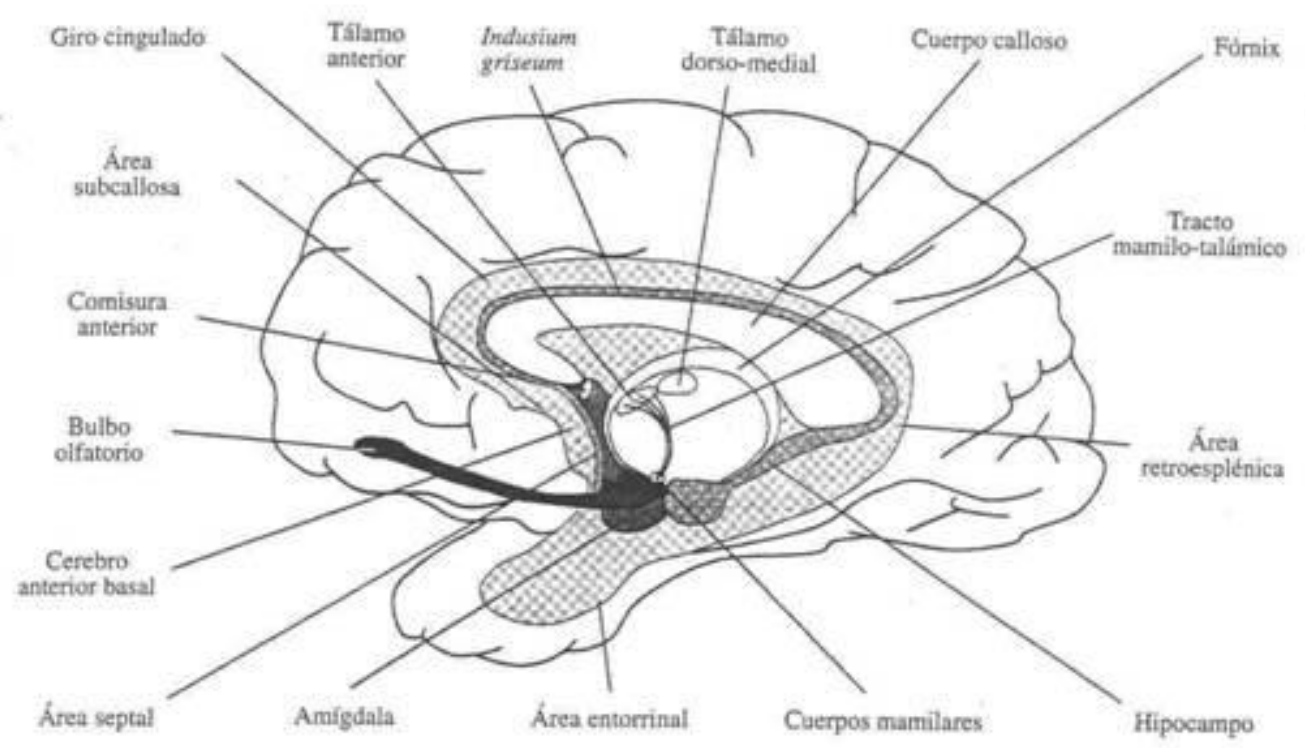

Imagen 3: Sistema límbico. (Tomada de http://www.waece.org/cd_morelia2006/ponencias/serrano.htm) 


\subsubsection{Aspectos hormonales y neuroquímicos implicados en la psicopatía}

Los estudios de Damasio (1994), Soderstrom (2003), Blair (2004) y Van Honk y Schutter (2006) han informado de que las hormonas testosterona, prolactina, foliculoestimulante, luteinizante, corticotropina, alfamelanocito-estimulante, betaendorfinas, arginina-vasopresina y corticosterona se asocian a la psicopatía ya que afectan al comportamiento agresivo a través de mecanismos mediados por la serotonina $(5-\mathrm{HT})$.

De manera que de entre estas investigaciones destaca El modelo del Triple Balance de la Emoción propuesto por Van Honk y Schutter en 2006 en el que se explica el papel del cortisol y la testosterona en la psicopatía. Este modelo lo conforman otros cuatro submodelos explicados a continuación.

a) El modelo de bajo temor de Lykken (1957), que propone que los psicópatas muestran menos evitación pasiva, lo cual es resultado del pobre condicionamiento aversivo.

b) La hipótesis del marcador somático de Damasio (1994), que es un modelo de aprendizaje emocional que ocurre después de que sensaciones (marcadores somáticos) con valencia inconsciente son asociadas a ciertos estímulos o situaciones.

c) El modelo de psicopatía de desequilibrio motivacional (BIS-BAS) de Arnett (1997). De manera que se infiere un aprendizaje emocional defectuoso en la psicopatía: las tendencias motivacionales de aproximación (BAS) o evitación (BIS) pueden ser vistas como marcadores somáticos. Cuando estos están fuera de equilibrio por la influencia del cortisol y la testosterona, el aprendizaje emocional se altera.

d) El modelo de mecanismo de inhibición de la violencia de Blair (2004), según el cual las expresiones de temor y tristeza son claves que activan un mecanismo de inhibición de la violencia y hacen que el individuo frene las acciones que puedan infligir daño al otro. En los psicópatas, entonces, este mecanismo parece estar defectuoso (incluyendo la interacción entre la amígdala y la corteza orbitofrontal).

A partir de la integración de esos cuatro modelos, El Modelo de Triple Balance de la Emoción distingue tres desequilibrios del procesamiento emocional en los 
psicópatas, mediados por la testosterona y el cortisol. Esencialmente, este es un modelo con dos niveles:

1. El subcortical para el procesamiento motivacional básico.

2. El cortical para el procesamiento cognitivo y la percepción consciente de las emociones. Ambos niveles, así como la comunicación entre ellos, pueden estar desequilibrados.

\subsubsection{Genética Vs. Ambiente.}

La psicopatía presenta una etiología multifactorial dado que en la manifestación de los rasgos psicopáticos resultan fundamentales, aparte de los posibles factores genéticos, la experiencia temprana de cada individuo y el contexto familiar, educativo y sociocultural. (Raine y Glenn, 2009).

En relación al estudio de los factores que parecen predisponer genéticamente a la psicopatía, destacan las investigaciones que se han basado en el estudio de las conductas psicopáticas en gemelos univitelinos. La contribución genética a este tipo de comportamiento oscila entre el 33\% (Rhee y Waldman, 2002) y el 69\% (Fu et al., 2002). Otros investigadores sugieren que una compleja interacción entre factores genéticos y ambientales resulta clave en la predicción del desarrollo de psicopatía (Raine, 2008): cuando se hallan presentes factores genéticos y ambientales la probabilidad de que se manifiesten rasgos psicopáticos aumenta exponencialmente.

Se cuenta con líneas de investigación alternativas que han examinado los polimorfismos de determinados genes para dar con la predisposición genética al comportamiento violento, centrándose especialmente en los genes que regulan los niveles de serotonina, un neurotransmisor cuya disponibilidad sináptica correlaciona negativamente con la impulsividad, la falta de control conductual y la agresividad. Destacan los trabajos de Seo et al. (2008) sobre el polimorfismo del gen que codifica la monoaminoxidasa (MAO-A), una enzima que degrada la serotonina: según parece, los niños maltratados que desarrollan conductas violentas tienden a tener la variante del gen que produce una menor actividad de la (MAO-A).

Respecto a los estudios de influencia del ambiente familiar, Raine et al. (2003) dividieron una muestra de asesinos en dos grupos: asesinos que provenían de hogares 
relativamente funcionales, contando con una muestra de 12 asesinos; y otro grupo de 26 asesinos que provenían de hogares relativamente disfuncionales.

En este estudio de Raine et al., (2003) se registran como factores de riesgo psicosociales: el maltrato físico, el abuso sexual, el abandono infantil, la adopción, los conflictos familiares graves, los hogares rotos y los padres relacionados con el mundo del crimen.

Se ha observado que cuando las personas adultas, con una buena capacidad de autocontrol, sufren lesiones en esta área cerebral, acaban presentando deficiencias emocionales y de la personalidad que recuerdan al comportamiento psicopático criminal o lo que Damasio et al. (1994) han denominado "sociopatía adquirida". De manera que si el delincuente muy violento tiene un entorno familiar disfuncional, entonces lo más probable es que el origen de su violencia esté determinado por ese mal ambiente. Por otro lado, si el delincuente proviene de una familia funcional, entonces lo más probable es que no sean factores ambientales, sino deficiencias biológicas las causantes de su comportamiento biológico.

\subsubsection{Investigaciones realizadas con técnicas de neuroimagen.}

La aplicación de la neuroimagen a la investigación de las bases neurobiológicas de la psicopatía ha hecho posible la detección de diversas anomalías en el funcionamiento del cerebro del psicópata.

Se cuenta con investigaciones de elevado interés centradas en el estudio específico de las disfunciones neurales asociadas a los distintos rasgos psicopáticos, que Hare (1991) agrupa en dos grandes factores: afectivo-interpersonal e impulsivoantisocial. En síntesis, estos estudios apuntan a un déficit en el funcionamiento cerebral altamente localizado en la región fronto-límbico-temporal observado claramente mediante las técnicas de neuroimagen.

Más específicamente, las alteraciones detectadas en la región temporal media (muy particularmente en la amígdala y en el hipocampo) se relacionan con los rasgos psicopáticos que se asocian a un pobre procesamiento emocional, es decir, con los agrupados en el factor 1 (afectivo-interpersonal) de Hare (1991), tales como la superficialidad, la falta de empatía, la ausencia de sentimiento de culpa y de remordimiento, la frialdad emocional, el comportamiento amoral o la despreocupación 
por los actos que puedan dañar a los demás, etc. A este respecto cabe citar el estudio reciente de Glenn et al. (2009) que demuestra que los psicópatas presentan una menor activación de la amígdala a la hora de emitir juicios morales con un importante componente emocional. La amígdala resulta crucial en la asociación estímulo-respuestaconsecuencia, muy relevante en el proceso de socialización, dado que así se aprende a evitar las acciones que pueden resultar dañinas para los demás y/o que son socialmente indeseables.

Por otro lado, numerosos estudios han observado que los psicópatas presentan una respuesta reducida en la corteza orbitofrontal durante el condicionamiento del miedo (Birbaumer et al., 2005) y durante la participación en el dilema del prisionero reiterado o iterativo (Rilling et al., 2007), un juego interactivo en el que el máximo beneficio para los implicados se halla en la colaboración, pese a incentivarse la traición al otro. En la versión reiterada, se juega repetidamente, por lo que cada jugador puede castigar al otro por una traición anterior. Así, entre otras funciones, la corteza ventromedial/orbitofrontal juega un papel relevante en el proceso de integración del conocimiento moral con las claves emocionales, en la comprensión del estado emocional de los demás y en la inhibición de los impulsos antisociales, mecanismos claves para la cooperación, la lealtad y el compromiso.

Respecto a los estudios de Resonancia Magnética Funcional (fMRI), destacan las investigaciones llevadas a cabo por Kiehl et al., (2006) que utilizaron una tarea semántica y esta técnica, encontrando que los psicópatas presentaban una activación anómala en el giro temporal superior, la corteza prefrontal ventromedial, la corteza temporal media y la parte anterior del giro cingulado. Según los autores, dichas anomalías se relacionan con un déficit en el procesamiento de los estímulos abstractos. (Véase Imagen 4): 

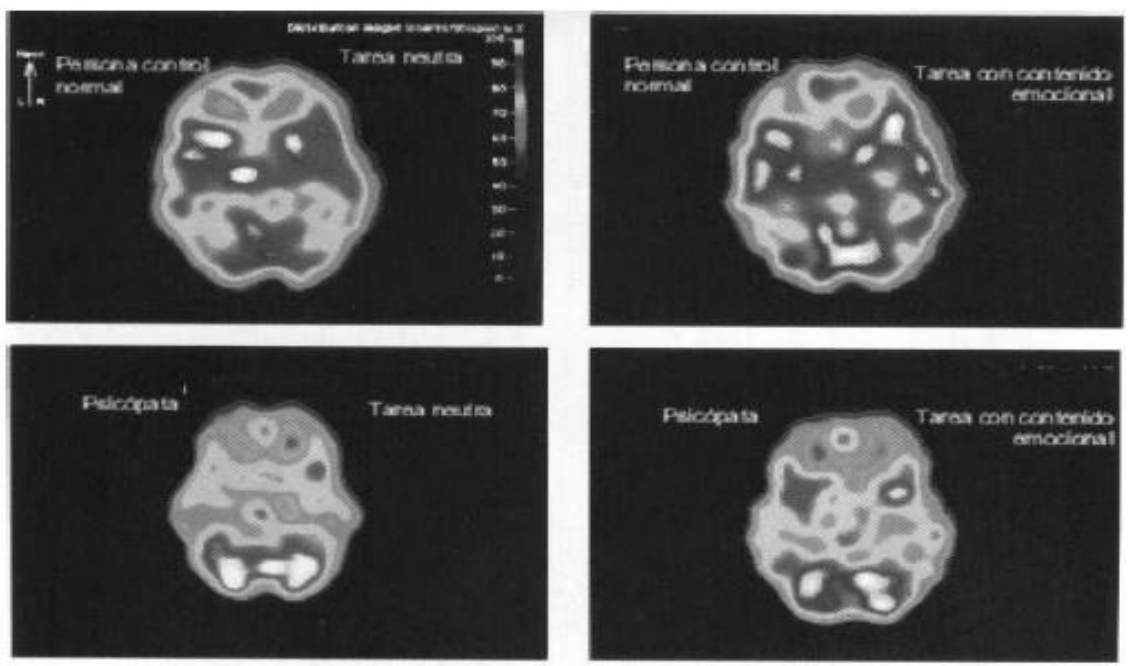

Imagen 4: Deficiencias prefrontales de tipo estructural en psicópatas (paneles inferiores) y no psicópatas (paneles superiores). (Tomado de Raine, 2011 p. 69)

Otros estudios que han utilizado la misma técnica, son los llevados a cabo por Gao et al. (2009) en los que se han utilizado imágenes y estímulos afectivos. Los hallazgos de los autores informan de alteraciones relacionadas con disfunciones en el procesamiento de la información emocional que se localizan básicamente en la corteza prefrontal dorsolateral, la corteza prefrontal ventromedial, las regiones anterior y posterior del cíngulo cingulado, la amígdala, el hipocampo, el giro parahipocampal y el giro temporal anterior derecho). Estos resultados son congruentes con la evidencia clínica que atribuye a la psicopatía diversas carencias en la respuesta emocional y en la empatía (Cleckley, 1936). (Véase Imagen 5): 


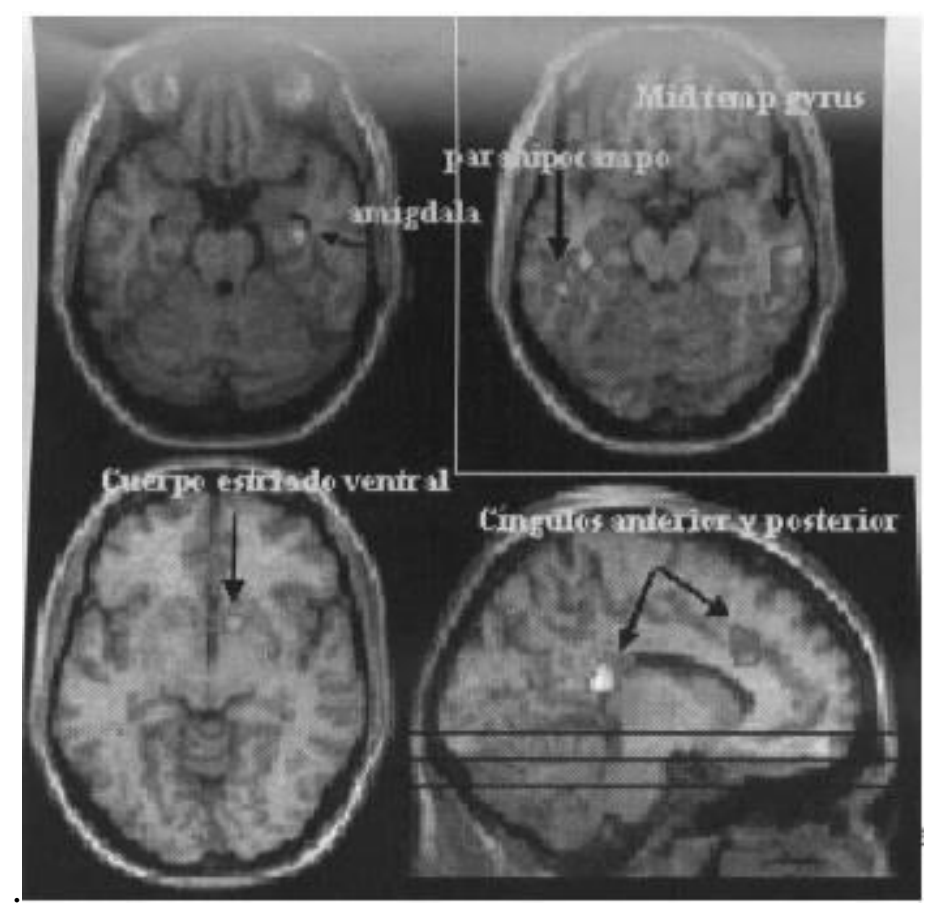

Imagen 5: Disfunciones en el procesamiento de la información emocional: amígdala, giro temporal anterior derecho, parahipocampo, cuerpo estriado ventral, cíngulos anterior y posterior. (Tomado de Raine, 2011 p. 70)

Por último, cabe destacar los estudios realizados mediante las técnicas de Tomografía de Emisión de Positrones (TEP) y la Tomografía Computarizada de Emisión de Fotones (TCEF). Entre estas investigaciones se encuentran las realizadas por Volkow et al. (1995), que aplicando la TEP a personas que se hallaban en situación de reposo y con los ojos abiertos, observaron que el metabolismo de la glucosa era menor de lo normal en regiones prefrontales y temporales mediales.

Utilizando esta misma técnica, destacan los estudios de Seidenwurn et al., (1996) que aplicando la TEP a personas en la misma situación que el anterior estudio, descubrieron una reducción significativa del metabolismo de la glucosa en el lóbulo temporal medial en el caso de siete agresores violentos, que habían sido remitidos para su examen. En esta misma línea, Goyer et al. (2004), mediante Tomografía de Emisión de Positrones (TEP) aplicada a personas con activación auditiva, mostraron que los actos impulsivos de corte agresivo crecían a medida que bajaba la cantidad de glucosa en la corteza frontal.

Entre las investigaciones realizadas mediante Tomografía Computarizada de Emisión de Fotones (TCEF), destacan las de Kuruoglu et al. (1996) que aplicando una 
Tomografía Computarizada de Emisión de Fotones (TCEF) a personas en situación de reposo, revelaron un flujo sanguíneo cerebral muy reducido en la región frontal. Igualmente, Seidenwurn et al. (1996) aplicando la TCEF, mostraron que ocho psicópatas presentaban un flujo sanguíneo mayor en ambas regiones frontotemporales, mientras procesaban palabras con contenido emocional, en comparación con 9 personas que no eran psicópatas.

Estos 5 estudios apoyan la idea de Raine et al. (1994) de que la psicopatía está conectada con la baja actividad de las regiones frontales y temporales y, en particular, de las primeras.

\subsubsection{Investigaciones actuales respecto de la estructura neural de la mente amoral}

El paradigma de la Neurociencia Social aporta datos novedosos que sugieren que la psicopatía impide experimentar las emociones y fenómenos afectivos que suelen guiar el comportamiento moral humano. En este sentido, el cerebro del psicópata presenta anomalías tanto en las regiones neurales que procesan las emociones morales, como en las áreas directamente implicadas en el proceso de toma de decisiones que se halla en la raíz de la moralidad humana.

A continuación se detalla en la Tabla 25 los recientes estudios que abordan el estudio del cerebro "anormal" del psicópata: 
Tabla 25: Síntesis sobre los principales hallazgos sobre la base neural de la conducta amoral.

\begin{tabular}{|c|c|c|c|c|}
\hline \multicolumn{2}{|c|}{ Psicopatía: disfunciones neurales relacionadas con el "cerebro amoral" } \\
\hline Referencia & $\begin{array}{c}\text { Técnica de } \\
\text { neuroimagen }\end{array}$ & Tarea & $\begin{array}{c}\text { Hallazgos } \\
\text { principales }\end{array}$ & Implicaciones \\
\hline Müller et al., 2003 fMRI & $\begin{array}{c}\text { Presentación de } \\
\text { imágenes } \\
\text { emocionales (IAPS) }\end{array}$ & $\begin{array}{c}\text { Activación incrementada en } \\
\text { la región orbitofrontal lateral } \\
\text { y reducida en la corteza } \\
\text { prefrontal medial derecha y } \\
\text { en la región temporal }\end{array}$ & $\begin{array}{c}\text { Déficits en el } \\
\text { procesamiento emocional } \\
\text { (¿falta de integración de } \\
\text { las claves emocionales en } \\
\text { las decisiones morales?) }\end{array}$ \\
\hline Kiehl et al., 2004 & fMRI & $\begin{array}{c}\text { Decisión léxica. } \\
\text { Identificación de } \\
\text { palabras reales }\end{array}$ & $\begin{array}{c}\text { Disfunción en la activación } \\
\text { del giro temporal anterior } \\
\text { derecho }\end{array}$ & $\begin{array}{c}\text { Dificultad del hemisferio } \\
\text { derecho en el } \\
\text { procesamiento abstracto, } \\
\text { quectaría a la empatía, la } \\
\text { culpa, el remordimiento, el } \\
\text { amor, el comportamiento } \\
\text { moral, etc. }\end{array}$ \\
\hline
\end{tabular}

\begin{tabular}{|c|c|c|c|c|}
\hline $\begin{array}{l}\text { Birbaumer et al., } \\
2005\end{array}$ & fMRI & $\begin{array}{c}\text { Condicionamiento } \\
\text { del miedo mediante } \\
\text { un paradigma } \\
\text { pauloviano }\end{array}$ & $\begin{array}{c}\text { Disfunción en la corteza } \\
\text { orbitofrontal }\end{array}$ & $\begin{array}{l}\text { Dificultades de aprendizaje } \\
\text { del temor a las } \\
\text { consecuencias de ciertos } \\
\text { actos. Pobre respuesta al } \\
\text { castigo }\end{array}$ \\
\hline Gordon, 2004 & fMRI & $\begin{array}{l}\text { Tarea de } \\
\text { reconocimiento que } \\
\text { implicaba bien } \\
\text { atender a la } \\
\text { información } \\
\text { afectiva, bien a la } \\
\text { identidad del } \\
\text { estímulo. }\end{array}$ & $\begin{array}{c}\text { Menor activación de la } \\
\text { amígdala y mayor } \\
\text { activación de la corteza } \\
\text { prefrontal dorsolateral en la } \\
\text { tarea de reconocimiento } \\
\text { emocional }\end{array}$ & $\begin{array}{c}\text { Déficit en el procesamiento } \\
\text { emocional y compensación } \\
\text { de la disfunción límbico- } \\
\text { prefrontal con la } \\
\text { supraactivación de áreas } \\
\text { implicadas en las } \\
\text { decisiones "racionales" }\end{array}$ \\
\hline Rilling et al., 2007 & fMRI & $\begin{array}{c}\text { Dilema del } \\
\text { prisionero iterativo: } \\
\text { juego relacionado } \\
\text { con la } \\
\text { cooperación'no } \\
\text { cooperación con un } \\
\text { compañero }\end{array}$ & $\begin{array}{c}\text { Menor activación } \\
\text { amigdalina ante la traición } \\
\text { del otro, menor activación } \\
\text { orbitofrontal ante la decisión } \\
\text { de cooperar. Mayor } \\
\text { activación dorsolateral y de } \\
\text { la parte rostral del giro } \\
\text { cingulado anterior ante la } \\
\text { decisión de cooperar que } \\
\text { ante la de no cooperar }\end{array}$ & $\begin{array}{l}\text { Tendencia del psicópata a } \\
\text { la traición, al egocentrismo } \\
\text { y a defraudar al otro, que } \\
\text { sólo puede compensarse } \\
\text { con un esfuerzo cognitivo }\end{array}$ \\
\hline
\end{tabular}




\begin{tabular}{|c|c|c|c|c|}
\hline Rilling et al., 2007 & fMRI & $\begin{array}{c}\text { Dilema del } \\
\text { prisionero iterativo: } \\
\text { juego relacionado } \\
\text { con la } \\
\text { cooperaciórnno } \\
\text { cooperación con un } \\
\text { companero }\end{array}$ & $\begin{array}{c}\text { Menor activación } \\
\text { amigdalina ante la traición } \\
\text { del otro, menor activación } \\
\text { orbitofrontal ante la decisión } \\
\text { de cooperar. Mayor } \\
\text { activación dorsolateral y de } \\
\text { la parte rostral del giro } \\
\text { cingulado anterior ante la } \\
\text { decisión de cooperar que } \\
\text { ante la de no cooperar }\end{array}$ & $\begin{array}{l}\text { Tendencia del psicópata a } \\
\text { la traición, al egocentrismo } \\
\text { y a defraudar al otro, que } \\
\text { sólo puede compensarse } \\
\text { con un esfuerzo cognitivo }\end{array}$ \\
\hline $\begin{array}{l}\text { Oliveira-Souza et al., } \\
\qquad 2008\end{array}$ & $\begin{array}{c}\text { Morfometria } \\
\text { optimizada } \\
\text { basada en } \\
\text { vóxels }\end{array}$ & - & $\begin{array}{l}\text { Reducción de la materia } \\
\text { gris en las cortezas } \\
\text { frontopolar, orbitofrontal y } \\
\text { temporal anterior }\end{array}$ & $\begin{array}{l}\text { Base neural de los } \\
\text { sintomas asociados al } \\
\text { factor interpersonal- } \\
\text { afectivo de la psicopatia. } \\
\text { Papel crucial de la red } \\
\text { frontotemporal en la } \\
\text { empatia y la sensibilidad } \\
\text { moral }\end{array}$ \\
\hline $\begin{array}{l}\text { Glenn, Raine y } \\
\text { Schug, } 2009\end{array}$ & fMRI & Dilemas morales & $\begin{array}{c}\text { Menor activación de la } \\
\text { amigdala al tomar } \\
\text { decisiones morales con } \\
\text { contenido emocional. Los } \\
\text { suejtos con mayor } \\
\text { puntuación en el factor } \\
\text { interpersonal presentan } \\
\text { activación reducida en la } \\
\text { corteza prefrontal medial, el } \\
\text { cingulado posterior y el giro } \\
\text { angular }\end{array}$ & $\begin{array}{l}\text { La disfunción amigdalina } \\
\text { parece central para } \\
\text { explicar los diversos } \\
\text { rasgos psicopáticos. } \\
\text { Disfunciones de los } \\
\text { procesos sociales } \\
\text { complejos necesarios para } \\
\text { el comportamiento moral }\end{array}$ \\
\hline
\end{tabular}

En conjunto, los resultados expuestos en la Tabla 30 apuntan:

1. Que la psicopatía cursa con un déficit generalizado en el condicionamiento aversivo, lo que se relaciona con la menor ansiedad que sienten los psicópatas al anticipar las consecuencias de sus actos y, a la vez, con la dificultad en modificar su comportamiento a partir de medidas punitivas (de ahí, por ejemplo, el alto grado de reincidencia de los psicópatas violentos).

2. Los resultados revisados (especialmente los relacionados con la disfunción amigdalina y la orbitofrontal), demuestran una falta de respuesta afectiva ante el distrés ajeno, lo que favorecería al engaño y la manipulación, la insensibilidad ante el dolor de los demás, los actos impulsivos, las decisiones irresponsables, la falta de sentimiento de culpa o de remordimiento, las conductas de agresión 
instrumental y la disminución del miedo a los posibles costes de su forma de actuar, alterando el juicio del o que resulta moralmente aceptable.

3. Finalmente, los psicópatas invierten más recursos cognitivos en el procesamiento de la información con contenido afectivo (tal vez para compensar sus carencias en la decodificación emocional), o bien tienen tendencia a racionalizar lo emocional, lo que explicaría la frialdad que les caracteriza.

No obstante, una aproximación integral respecto a los rasgos psicopáticos debería contemplar también las disfunciones neurales que se relacionan, no sólo con la insensibilidad al sufrimiento ajeno, sino con el placer que puede generar a los psicópatas dicho sufrimiento. Las investigaciones realizadas son todavía escasas, pero los datos de algunos trabajos pioneros resultan congruentes con la hipótesis de que, en el origen de la agresión instrumental típica de la psicopatía, se hallan una serie de alteraciones cerebrales que provocan el placer que sienten ciertos psicópatas al infringir sufrimiento al prójimo y que anatómicamente se encuentran en el cuerpo estriado. De este modo, el logro de esa vivencia de elevado valor hedónico sería un potente incentivo que impulsaría los actos que provocan dolor -físico o emocional- a los demás, y, por ende, propiciaría la conducta psicópata (Decety et al., 2009).

En general, los resultados obtenidos hasta la fecha demuestran que existen diferencias significativas entre el cerebro de los sujetos afectados de psicopatía y el de los individuos que no padecen dicho desorden, particularmente en las áreas que se hallan involucradas en las decisiones y la conducta moral emocionalmente inspiradas (Müller et al., 2003; Birbaumer et al., 2005; Gordon, 2004; Rilling et al., 2007; Glenn, Raine y Schug, 2009). De la consistencia en los resultados de los estudios anteriormente citados, destaca el papel de la amígdala y la corteza ventromedial/orbitofrontal en la asociación de zonas cerebrales específicas y la conducta del psicópata.

Por una parte, la disfunción de este sistema, que interviene en la generación del miedo y la culpa, del remordimiento y de la empatía, podría explicar por qué los psicópatas apenas se inmutan al perjudicar a los demás en beneficio propio y por qué responden muy pobremente tanto al castigo como al refuerzo, lo que dificulta sin duda alguna su socialización. Complementariamente, la sobreactivación observada en algunos núcleos relacionados con el Sistema de Recompensa explicaría, además, por qué pueden llegar a sentir un placer intenso al causar daño ajeno. 
Por tanto, al concebir la psicopatía como una alteración moral (producto de un cerebro amoral o, según algunos, inmoral) se asume que ese déficit radica en una serie de disfunciones en el procesamiento de las emociones que guían la moralidad. Esa concepción sentimentalista de la moral fue defendida en sus inicios por filósofos como Hume (1739-1740).

Para explicar por qué el comportamiento moral se basa, al menos en parte, en las emociones resulta esencial el concepto de empatía. Esa puede ser, tal vez, la carencia fundamental del psicópata: pese a saber si su conducta es moralmente aceptable o no, ese conocimiento le deja emocionalmente indiferente, es decir, no le importa romper la norma porque, pese a conocerla, esa transgresión no le resulta emocionalmente aversiva. El reciente trabajo de Cima y Raine (2009), sugiere que esta podría ser una de las claves del comportamiento psicopático.

A continuación se exponen dos hitos que marcaron el inicio de las investigaciones neuropsicológicas en el estudio de la psicopatía.

\subsubsection{Casos fundamentales en el estudio neuropsicológico de la psicopatía.}

El accidente de Phineas Gage y su legado a la neuropsicología del estudio del área prefrontal

Una vez expuestas las investigaciones referentes a la neuroanatomía de la psicopatía, se considera relevante la presentación de dos casos reales que avalan el compendio de resultados expuestos anteriormente.

El caso de Phineas Gage marcó el origen de las investigaciones en torno a la relación entre el lóbulo frontal y los comportamientos psicopáticos (Fernández Guinea et al., 2003). Gage es, a no dudar, uno de los pacientes más famosos de la historia de la neurología en general y la neuropsicología en particular. Una cita ineludible para cualquier texto que trate de poner en relación aspectos como el comportamiento, pensamiento o la forma de sociabilizar con regiones cerebrales y las alteraciones en éstas, evidenciando una base biológica.

El 13 de septiembre de 1848, Phineas Gage, de 26 años de edad, trabajaba de capataz en la construcción de una línea estadounidense de ferrocarril. Una de sus funciones era colocar cargas explosivas en agujeros taladrados en la roca. Para ello 
llenaba el agujero de pólvora, colocaba un detonador, y finalmente lo tapaba con arena y aplastaba la arena con una pesada barra de metal. Ese día Phineas en un descuido olvidó echar arena antes de presionar con la barra, por lo que al hacerlo hubo una chispa que hizo que explotase la pólvora. Esta explosión a su vez provocó que la barra de metal saliese disparada atravesando el cráneo de Gage, más concretamente atravesando la región cigomática izquierda, destrozando la porción posterior de la órbita ipsilateral y parte del lóbulo frontal contralateral derecho, saliendo por el vértex craneal, con tal fuerza que incluso se desplazó casi 25 metros más allá hasta que llegó al suelo llevando consigo una cantidad considerable de sangre y tejido cerebral (Muci-Mendoza, 2007) (Véase Imagen 6):

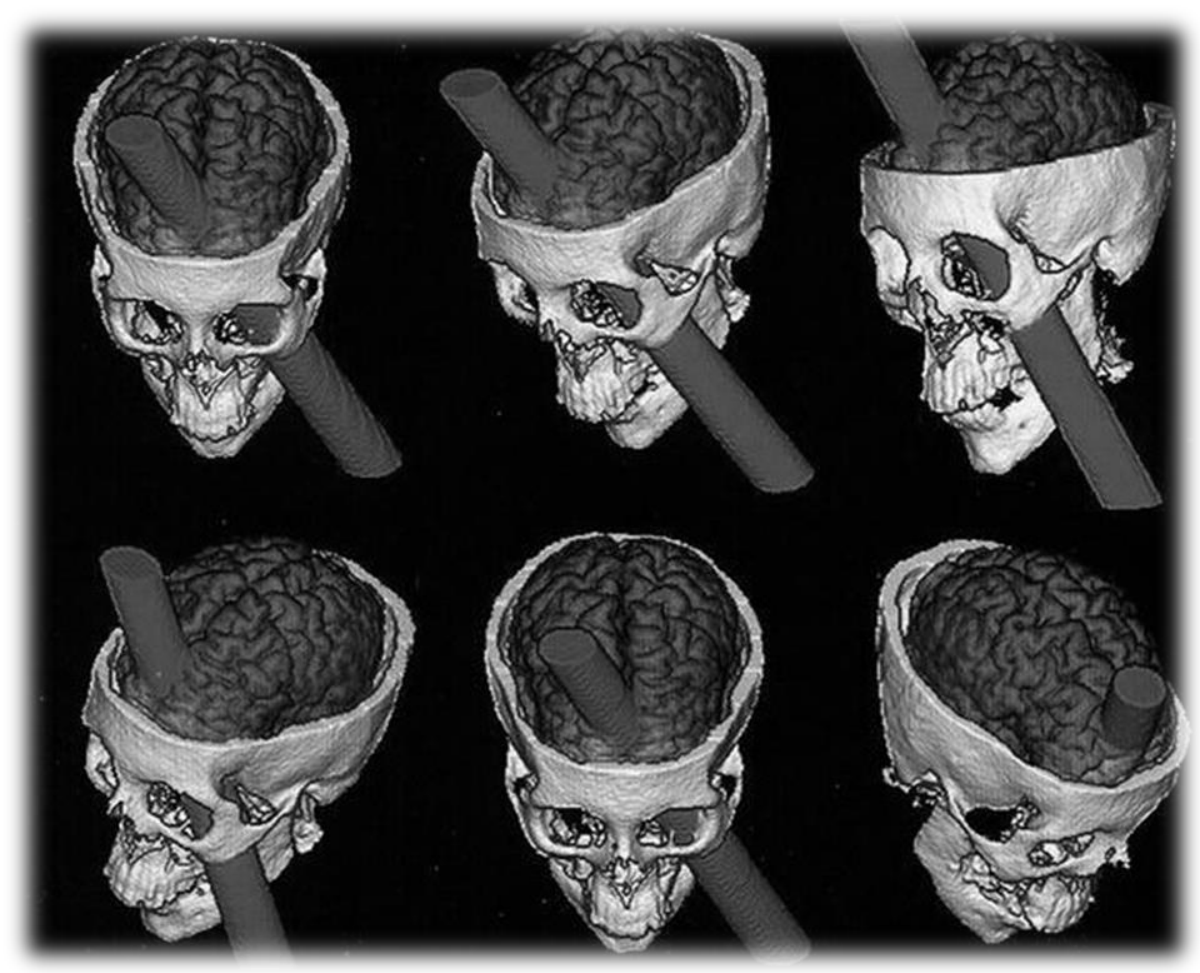

Imagen 6: Reconstrucción de la lesión cerebral de Phineas Gage. (Tomado dehttps://escuelaconcerebro.wordpress.com/2011/11/28/el-error-de-descartes/)

Gage no sólo sobrevivió al accidente, sino que se mantuvo consciente en todo momento. Después del terrible accidente lo llevaron en una carreta a varios kilómetros hasta la consulta del doctor Harlow, uno de los médicos del pueblo, que fue quien dejó constancia de su evolución, ya que Gage seguía consciente mientras lo llevaban.

Sobrevivir a una explosión y a una herida como esa con la rudimentaria medicina de la época y seguir siendo capaz de andar y hablar racionalmente es 
realmente asombroso. No menos singular es que dos meses después el doctor Harlow consideraría que Gage estaba completamente recuperado, dándole el alta. Gage sobrevivió al fatídico accidente de milagro, pero a un alto precio.

Tras pasar la fase aguda, la personalidad de Phineas se tornó irresponsable, irreverente, blasfema, impaciente, impulsiva, indiferente ante las emociones y reacciones de los demás e incapaz de planificar acciones futuras, además de egoísta, hostil, manipuladora, obstinada, caprichosa, dada a la bebida y desinhibida, todos ellos rasgos bien distintos a los que le caracterizaban antes del accidente cuando era una persona responsable, competente, equilibrada, sensata, jovial y amigable. La investigación reciente ha demostrado que la zona afectada por el infortunio fue fundamentalmente la región ventromedial/orbitofrontal (Damasio, 1994).

Después de la catástrofe Phineas perdió su trabajo en el ferrocarril. Era incapaz de mantener uno por mucho tiempo, ya que los abandonaba o lo despedían por sus continuas reyertas con sus compañeros. Su salud se estaba deteriorando y murió con 38 años tras una serie de crisis epilépticas.

El caso Gage está considerado como una de las primeras pruebas científicas que sugieren que una lesión del lóbulo frontal puede alterar aspectos de la personalidad, la emoción y la interacción social. Antes de este caso y bastante tiempo después, los lóbulos frontales se consideraban estructuras silentes sin función y sin relación alguna con el comportamiento humano (Véase Imagen 7):

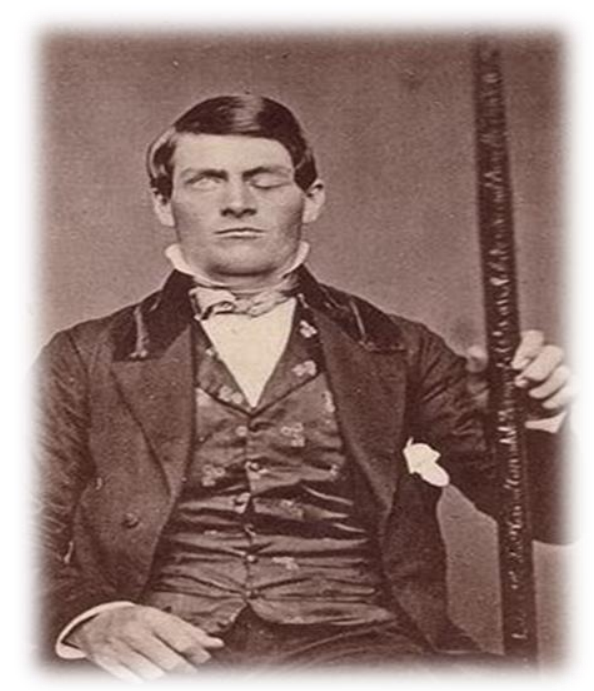

Imagen 7: Phineas Gage tras el accidente con la barra que atravesó su cráneo. (Tomado de https://es.wikipedia.org/wiki/Phineas_Gage) 
El neurólogo Antonio Damasio (1994) estudió en profundidad el caso de Phineas Gage aludiendo a la existente relación entre los lóbulos frontales, la emoción y la toma de decisiones en su teoría del marcador somático.

Este caso también es un pilar básico en el concepto de las funciones ejecutivas, siendo las vinculadas a las capacidades implicadas en la formulación de metas, planificación de las actividades para llevarlas a cabo y ejecución de las conductas de forma eficaz.

En definitiva, el caso Phineas es juzgado como una de las mejores descripciones del desorden psicopático del comportamiento relacionado con una lesión traumática del córtex prefrontal, donde la correlación anatomoclínica ha sido intentada empleando diversas concepciones y métodos a la usanza de los diversos momentos históricos (García-Molina, 2008).

\section{El caso Elliot y su legado a la neuropsicología del estudio del cerebro emocional y la}

\section{conducta}

El Dr. Antonio Damasio (1994) investigó un caso parecido al de Phineas Gage. Un paciente llamado Elliot tenía un tumor del tamaño de una naranja pequeña, situado en el lóbulo frontal, donde la zona más dañada fue la ventromedial/orbitofrontal. La cirugía lo eliminó por completo. Aunque la operación resultó un éxito, la gente que lo conocía decía que Elliot ya no era el de antes, y que había sufrido un drástico cambio de personalidad.

El problema de Elliot mostraba una pauta desconcertante. Intelectualmente era tan brillante como siempre, pero utilizaba muy mal su tiempo, se disipaba en detalles sin importancia y parecía haber perdido toda noción de sus prioridades. Damasio (1994) quedó sorprendido al notar que en el repertorio mental de Elliot faltaba un elemento: aunque su lógica, su memoria, su atención y las demás habilidades cognitivas no presentaban ningún problema, Elliot era prácticamente inconsciente de sus sentimientos con respecto a lo que le había sucedido. Lo más sorprendente era que podía narrar los trágicos acontecimientos de su vida con absoluta imparcialidad, como si fuera un observador de las pérdidas y fracasos de su pasado, sin mostrar la más mínima nota de arrepentimiento o tristeza, frustración o ira por la injusticia de la vida. 
El prestigioso neurólogo llegó a la conclusión de que la fuente de la inconsciencia emocional de Elliot era la eliminación, junto con el tumor cerebral, de una parte de los lóbulos prefrontales. En efecto, la cirugía había cortado las conexiones entre los centros inferiores del cerebro emocional (amígdala y circuitos relacionados) y la capacidad pensante de la neocorteza. El pensamiento de Elliot se había vuelto igual al de un ordenador, capaz de dar todos los pasos anteriores a la toma de decisión, pero incapaz de asignar valores a distintas posibilidades.

Con una sintomatología muy similar a la de Gage, destacando la frialdad emocional y la incapacidad de tomar decisiones adecuadas en el ámbito personal y social, este estudio resultó altamente revelador para establecer la naturaleza de la conexión entre los lóbulos frontales, principalmente en su región ventromedial, con la experimentación de emociones y sentimientos. 


\section{CAPÍTULO IV: ASESINOS EN SERIE}

\subsection{INTRODUCCIÓN}

El concepto de maldad ha variado en cuanto al objeto a lo largo de los años. Los romanos entendían que la maldad residía en los esclavos o personas provenientes de los llamados pueblos bárbaros. Ya el historiador Suetonio, citado por Otin (2013), en sus escritos "De vita Caesarum" nos ilustra con descripciones que en la actualidad podríamos denominar como de asesinos en serie. Con la llegada de la Iglesia Católica y la tradición judeo-cristiana, el mal residía en el demonio como para diversas culturas en las que encuentran el origen del mal en algo divino ajeno a su responsabilidad. Como la representación del diablo en la tierra se hace por medio de las debilidades del hombre, ya en el año 380 d.c., Evagrio Póntico, monje anacoreta, estudió las ocho tentaciones que llevaban al alma a su destrucción en la tierra y a su condena divina. Él mismo, concluye que las desastrosas inflexiones tenían su origen en la lujuria, la avaricia, la gula, la acedia, la ira, la soberbia, la vanagloria y la tristeza. No obstante las reflexiones del monje no se elevan a oficiales en cuanto a la Iglesia Católica hasta la llegada en el S. VI del Papa San Gregorio Magno, finalmente, en el S. XIII con la figura del Filósofo y Teólogo Santo Tomás (1225-1274) se asienta la definitiva lista de pecados capitales donde se sustituye la vanagloria por la soberbia y la tristeza por la pereza. Conviene destacar, no obstante, como señala Vázquez (2015) que la referencia del término capital no se refiere tanto a la gravedad del pecado, sino que él mismo en sí es origen y fuente de un sin límite de ofensas a Dios y a los hombres. Dice textualmente Santo Tomás: "Un vicio capital es aquel que tiene un fin excesivamente deseable, de manera tal que en su deseo, un hombre comete muchos pecados, todos los cuales se dice son originados en aquel vicio como su fuente principal” (Santo Tomás, II, 153:4, citado por Vázquez, 2015 p. 16). La lista, ya con Santo Tomás queda cerrada de la siguiente manera: lujuria, soberbia, avaricia, envidia, gula, ira y pereza.

Con la llegada de la Teoría de la Evolución, el hombre ya no es un heredero directo de Dios sino que proviene de sus congéneres simios. Es entonces, durante el siglo XIX cuando Charles Darwin (1809-1882) presenta al hombre como un ser con la posibilidad transgeneracional de ser como un animal primario, violento y no tan civilizado. El debate ya no se centra en lo divino y lo terrenal sino en lo instintivo como 
animal predeterminado o lo aprendido como animal domesticado por el entorno. Las influencias Culturalistas vs. Instintivistas, es decir, Lorenz vs. S. Freud.

En referencia a esta parte oscura del ser humano, la violencia contra el Otro o contra sí mismo -derivado de cualquiera de dichos pecados capitales- se destacan por ser más inhumanos los asesinos en serie. Aunque los conocemos como tal desde finales de los años 60, su existencia es anterior. Los casos de hombres lobo, los vampiros, las brujas o sectas satánicas la mayor parte de las veces no son más que versiones mitificadas y popularizadas de lo que hoy conocemos como asesinos en serie.

El Dr. Frankenstein surge de la unión de diferentes partes de cadáveres, como hacen algunos asesinos en serie de la actualidad al manipular los cuerpos de las víctimas (en esta línea estaría por ejemplo el llamado “carnicero de Milwaukee” Jeffrey Dahmer) que tras su detención en el verano de 1991, se encontraron con todo tipo de macabros trofeos y pruebas de tortura y canibalismo). En el Dr. Jekyll y Mr. Hyde, encontramos las dos caras del psicópata, en el que por un lado puede llevar una vida de los más sociable y normal y por otro es un bárbaro asesino. Pero si hay algo que realmente al ser humano le da pavor y terror, no es otra cosa que la de no entender por qué se mata sin motivo.

Se entiende por asesinar matar de forma involuntaria e ilegal a otro ser humano, sin embargo, si hay asesinatos en los que podemos encontrar razones básicas, tales como la muerte como resultado de una riña, ganancia monetaria, celos, etc, que de alguna forma nos permiten comprender el motivo del asesinato, en el caso de los seriales, las motivaciones son distintas, no pudiendo ser considerados como normales. (Antuña y Rodríguez, 2007, p.19).

Se pueden comprender, aunque con dificultades por entender, los asesinatos pasionales, por lucro, venganzas, los movidos por los pecados capitales, aunque evidentemente esa comprensión no se convierte, aunque lo aclaren, en ningún caso en justificación. Por ello, el asesino que mata a un desconocido y sin ningún beneficio personal más allá de la satisfacción de sus más profundas perversiones activa todas las alarmas del miedo tanto en el individuo como en la sociedad. En este capítulo, nos proponemos aportar un poco de luz a este fenómeno tan complejo como es el de aparentemente "matar simplemente por matar y disfrutar haciéndolo". 


\subsection{CONCEPTO DE ASESINO EN SERIE}

El asesino en serie en realidad es un subtipo de asesino múltiple. En este sentido, cabe definir primeramente qué se entiende por asesino múltiple. Así, Abrahamsen (1976) describe al asesino múltiple como aquél que mata a una pluralidad de personas. Además, propone diez características de los mismos que se describen a continuación:

1. Deseos de venganza y fantasías de realizar hazañas grandiosas.

2. Soledad, retraimiento, desconfianza, subestimación propia, causadas por experiencias traumáticas sufridas en la infancia.

3. Situación familiar sexualmente sobreestimulante.

4. Errores ortográficos o verbales en relación a trastornos emocionales surgidos en la infancia.

5. Tendencia a cambios de identidad, imagen propia confusa.

6. Incapacidad para tolerar la frustración, poca capacidad de canalizar impulsos hostiles de forma constructiva.

7. Egocentrismo, dependencia y dificultades para aceptar la autoridad.

8. Tendencias suicidas acompañadas de depresión.

9. La víctima es percibida defectuosamente e incorpora y refleja la propia imagen del criminal.

10. Antecedentes delictivos, amenazas de homicidio. (Ibíd, 1976, p.43)

Dentro de los asesinos múltiples se diferencian tres subtipos: asesino en masa, asesino frenético y finalmente asesino en serie.

\subsubsection{Asesinos en masa}

Jiménez (2014) describe al asesino en masa como:

Un asesino que mata a cuatro o más víctimas en un mismo momento temporal y lugar. No existe período de enfriamiento porque los asesinatos se producen de forma sucesiva o con muy poco espacio de tiempo entre ellos. El lugar no tiene que ser el mismo espacio donde se concentran todas las víctimas, sino que puede haber desplazamiento por la zona sin que implique viaje o alejarse excesivamente del punto donde comienza los asesinatos. (Ibíd, 2014, p.5).

Como ejemplo de este tipo de asesino cabe citar el caso del noruego Anders Behring Breivik que el 22 de julio de 2011 cometió una de las peores masacres 
realizadas por un solo asesino en la historia. Su ataque tuvo dos fases: primero colocó una bomba en el centro de Oslo y pasadas unas horas se dirigió al islote de Uteya, donde se celebraba una concentración juvenil del partido laboralista. Se hace pasar por policía para congregar a la gente y avisarles de que había una bomba en Oslo y una vez reunidos comienza a disparar indiscriminadamente sobre ellos. El resultado final fueron 77 muertos y 96 heridos.

Igualmente, los asesinos en masa pueden dividirse en varias tipologías (Rappaport, 1988):

1. Pseudo-comandos: suelen ser jóvenes que viven obsesionados con las armas y que generalmente acaban suicidándose.

2. Incendiarios, bombarderos y envenenadores: presentan un alto grado de planificación con el fin de poder escapar.

3. Aniquiladores familiares: suelen ser varones de mediana edad, alcohólicos que matan a su mujer, hijos, mascotas, padres, en definitiva, familiares o personas cercanas.

Posteriormente, Holmes y Holmes (1992) sugieren las siguientes categorías:

1. Discípulos: suelen formar parte de algún grupo religioso o de culto y son ordenados a matar.

2. Empleado disgustado: como resultado de un despido de trabajo decide vengarse como el citado caso del bombardero loco de Nueva York.

Abellán (2010) destaca que la mayoría de estos casos de alguna forma advierten, incluso algunos hablan abiertamente de sus proyectos de destrucción. Lo que apunta el citado autor, es que en algunos casos la personalidad de estos sujetos ya era observada por profesores, psiquiatras, psicólogos, asistentes sociales, etc. Pone de ejemplo al surcoreano Cho Seung Hui que se paseó abiertamente por el campus de la Universidad con dos pistolas matando indiscriminadamente, y de alguna manera todo el mundo conocía de sus rarezas. En este sentido Abellán (2010), considera oportuno la prevención primaria de la psicopatía, ofreciendo las garantías oportunas para que no supusiese en sí misma un estigma. Dado que estas situaciones muchas veces implican un fracaso de varias instituciones sociales, como la educativa, salud mental, protección social, etc. 


\subsubsection{Asesinos frenéticos}

El asesino frenético es el asesino que mata a dos o más personas consecutivamente y en dos o más lugares diferentes. El tiempo entre asesinatos no es debido a un período de enfriamiento, sino que es el lapso de tiempo que transcurre para encontrar una nueva víctima. En este caso "se requiere movilidad geográfica del asesino. Se podría decir que el asesino no deja de matar, no habría individualización de cada víctima, es parte de una serie consecutiva de asesinatos" (Jiménez, 2014, p.6). Ejemplo paradigmático de este tipo de asesinos frenéticos es el de la pareja de raza negra constituida por John Allen Muhammad y Lee Boyd Malvo, denominados "Los francotiradores de Washington D.C.”. Durante el mes octubre de 2002 matan a 10 personas y dejaron heridas a otras 3 tras realizar 21 disparos. En un principio nadie sospechaba que podría tratarse de francotiradores debido a que no quedaba nunca identificado desde donde mataban y a la par desaparecían sin dejar el más mínimo rastro. Se comprobó una vez resuelto el caso que el modus operandi era manipular el maletero del coche desde donde disparaban dejando un agujero por donde introducir un rifle con silenciador. Así, con el arma apoyada para ganar en precisión, disparaban para posteriormente diluirse perfectamente en el tráfico como otro coche más que circula por la carretera. Al parecer uno de los motivos para sus asesinatos era una especie de revolución contra la raza blanca considerada opresora y marcadamente racista.

En relación a los asesinatos grupales, Garrido (2008) apunta que "contrariamente a la creencia popular, los homicidas de grupo no suelen siempre atacar a extraños que tuvieron la desgracia de estar en "el sitio equivocado en el momento equivocado", sino que en un 50\% de los casos entre los afectados de la masacre están familiares, amigos o compañeros de estudio o de trabajo del homicida" (Ibíd, 2008, p.85)

Los factores que pueden contribuir a la hora de llevar a cabo un homicidio de grupo son descritos por Fox y Levin (en Petherick, 2006) y se presentan a continuación:

- La frustración: incapacidad para afrontar los problemas, que le puede llevar a una depresión permanente.

- Externalización de la responsabilidad: no encuentra la responsabilidad de los sucesos en sí mismo sino en los demás, lo que generará un odio hacia otras personas. 
- Una pérdida catastrófica: una ruptura o la pérdida de un familiar querido puede ser el desencadenante para que empiece a matar.

- Contagio: puede surgir de un fenómeno de imitación como por ejemplo los casos de colegios o institutos.

- Aislamiento social: muchos de estos asesinos se ven solos y aislados, lo que aumenta su frustración y la agresividad hacia los demás.

En general, se puede comprobar que surgen de la ira no resuelta.

\subsubsection{Asesinos en serie}

El término asesino en serie, fue acuñado por Robert Ressler en la década de los 70. En sus clases recuerda cómo las series de aventura que veía de pequeño le dejaban con la intriga hasta el siguiente capítulo, lo que le recordó a la insatisfacción que sienten los asesinos en serie al comprobar que el asesinato cometido no es tan perfecto como habían diseñado en su fantasía, lo que les lleva a matar "próximamente" para mejorarlo.

En lo referente a la explicación de la conducta del asesino en serie, existen tres ámbitos o niveles de explicación: biológico, psicológico y social.

Desde la biología el fenómeno de los asesinos en serie se ha investigado con el fin de hallar un error o cisma en el cerebro de los mismos. De manera que desde lo observable en las estructuras anatómicas se pueda explicar el comportamiento deleznable, tal y como se presentó en el capítulo tres.

Desde la psicología se ha seguido la vía de la psicopatología, el psicoanálisis, los factores de riesgo asociados a infancias traumáticas, el sadismo, las fantasías compulsivas, y un sinfín de variables intentando dar explicación al comportamiento criminal con algún trastorno: de la conducta, del aprendizaje, de la personalidad, etc, que pudiera dilucidar cómo una persona llega a convertirse en asesino serial. Pero, evidentemente con la prudencia de que estos modelos clínicos tienen sus limitaciones. En este aspecto ya nos apunta Urra (1997) que "la psicología junto al contexto social explican la criminalidad. La psicopatología sólo en algunos casos” (Ibíd, 1997, p. 258).

Y por último desde el enfoque sociológico se ha abordado el fenómeno desde dos vertientes: la legal y la resocializadora. Desde el enfoque legal se intenta vislumbrar si el asesino es un enfermo mental o no, apoyado en el concepto jurídico del Dolo - 
saber y querer-. Y desde la segunda vertiente se plantean programas de reeducación con el fin de reinsertar a estos sujetos.

\subsection{CARACTERÍSTICAS DE LOS ASESINOS EN SERIE}

Se cuenta con diferentes autores que han intentado aunar las características definitorias del asesino serial.

Steven Egger (1988), criminólogo estadounidense, explica que para considerar a un sujeto asesino en serie debe contar con varias características numeradas a continuación:

1. Que cometa de 3 a 5 asesinatos con un intervalo temporal no superior a seis meses.

2. Crímenes y modus operandi similar.

3. En ese período de tiempo de no actuación el sujeto mantiene una apariencia de normalidad, que dificulta su captura.

4. Son características la frialdad emocional, su crueldad y el afán de poder y dominación.

5. No suele tener un vínculo con sus víctimas.

6. En la infancia de estas personas se pueden detectar malos tratos, abusos, familias desestructuradas o fanatismos religiosos.

7. Pueden conservar objetos de sus víctimas como fetiches, no siendo el motivo material.

8. Cada víctima supone un logro más, que pronto pasa y comienza la compulsión de matar nuevamente.

9. Prefieren víctimas vulnerables.

10. Presentan falta de arrepentimiento y no tienen ningún sentimiento de culpa o vergüenza.

11. En muchas ocasiones, se sabe que en su infancia les gustaba torturar animales.

12. Tienen atracción por las autoridades.

13. Afán de protagonismo y grandiosidad.

En esta definición existen aspectos cuestionables: como por ejemplo la no existencia de vínculo entre asesino y víctima (punto 5). En este sentido, Hickey (1997) observa que de los asesinos seriales únicamente el $61 \%$ mataron a desconocidos, mientras que el resto lo hicieron con personas conocidas e incluso familiares. 
En relación a la motivación, la mayoría de los asesinos ocasionales, matan por razones explicables como el dinero, poder, venganza, celos, etc siendo el azar la causa que más queda impune por no ser descubiertos (Wentzl, Potter, Laviana y Kelly, 2011), salvo que lo repita de forma constante. A modo de ejemplo Ted Bundy mató al menos a 36 personas antes de ser atrapado, Jeffrey Dahmer a 17, Richard Ramirez a 14, Wayne Willimans al menos a 24, John Wayne Gacy, Luis Alfredo Garavito cerca de 200 y ninguno de ellos tenía motivación aparente.

Respecto al número de víctimas requeridas para categorizarlo como asesino serial, ha ido variando según los diferentes autores, desde 2 hasta 10 víctimas (Jiménez, 2014). De manera que el FBI proponía dos o más crímenes separados y llevados a cabo por la misma persona. Pero a partir de 1998, el FBI cambia de criterio exigiendo un mínimo de tres homicidios. Sin embargo, existen autores como Brent Turvey (2002), que considera que con dos homicidios es suficiente para categorizar a alguien como asesino en serie.

En relación al período de enfriamiento, es decir, el "espacio temporal en el que el asesino no mata, aunque eso no quiere decir que no esté planeando seguir haciéndolo" (Jiménez, 2014, p.5) hay diferentes opiniones. Ressler, Burgess, D’Agostino y Douglas (1984) opinan que dicho período puede ser de días o meses. Holmes y Holmes (2006) opinan que el período entre un asesinato y otro ha de ser de 30 días. Sin embargo, Antuña y Rodríguez (2007) explican que se encuentran casos en los que un asesino considerado "en serie" comete crímenes en el mismo día, por lo tanto, no tendría tanto valor la variable tiempo, sino "considerar los asesinatos como acontecimientos discretos que ocurren a lo largo de un período de tiempo" (Antuña et al., 2007, p.23). Sobre estos lapsos temporales se ha de tener mucha precaución. El caso de Dennis Rader (BTK) - el asesino más veterano de los Estados Unidos - mostró que dicho lapso temporal puede ser muy amplio. Este asesino, cometió su primer crimen en enero de 1974 y fue detenido posteriormente el 25 de febrero de 2005. Se le determinó culpable de 10 cargos, pero tuvo periodos de enfriamiento de hasta 13 años; si bien hay constancia de que en estos periodos no dejaba de buscar víctimas, observando, siguiendo, vigilando, etc, pero sin pasar al acto.

Al igual que Edger (1988), Garrido en el 2008 plantea las siguientes características del asesino en serie entendidas más como tendencias que como afirmaciones rotundas: 
- Hombres de raza blanca, en torno a los 30 años (el 58\% está entre los 20 y 29 años).

- Actúan en solitario.

- Formación académica secundaria.

- Víctimas mujeres, un poco mayores, a las que no conocían previamente.

- Asesinan por razones de gratificación sexual. (Ibíd, 2008, p.78)

En lo referente a la raza blanca como predominante en los asesinos en serie, si bien los datos criminológicos dan pruebas a favor de esta hipótesis, no se debe nunca descartar a priori que esto sea siempre así. En este sentido, cabe destacar el caso de Coral Eugene Watts, que se cree que dio muerte a cerca de 80 mujeres a las cuales acuchillaba, asfixiaba o ahorcaba de forma "refinada" las mañanas de domingo.

En cuanto a su actuación en solitario, lo usual es que actúen de forma individual, no obstante tampoco se puede dejar de lado una gran cantidad de parejas asesinas que actúan conjuntamente. Por ejemplo, en la década de los 60 la pareja Caril Ann Fugate y Charles Starkweather (que asesinaron a 11 personas); Myra Hindley y Ian Brad, que secuestraban, violaban, torturaban y mataban a niños de entre 10 y 17 años, y a los cuales grababan y fotografiaban en sus juegos sádicos. $\mathrm{O}$ a Rosemary Letts y Fred West que llevaban a su casa a jóvenes ofreciéndolas trabajo como niñeras para secuestrarlas, violarlas, torturarlas de las formas más sádicas, matarlas y cortarlas en pedazos para, finalmente, enterrarlas en el patio de su casa. En total mataron entre 11 y 13 jóvenes, 2 de ellas sus propias hijas y la primera mujer de Fred.

Respecto a la formación académica, igualmente se encuentra que no es siempre baja, pues el caso de Harold Shipman, apodado "Doctor muerte", médico inglés con formación académica muy avanzada quien en 1993 fundó su propia clínica se le atribuye el asesinato de 250 pacientes (oficialmente se han comprobado 15). En el caso opuesto, asesinos seriales como Manuel Delgado Villegas (alias el arropiero) son completamente analfabetos.

Sobre la edad de la víctima, Garrido (2008) afirma que es completamente aleatoria, debido a que cada franja de edad tiene un riesgo específico para las motivaciones de cada asesino serial. Así como ejemplo, se encuentra el caso de José 
Antonio Rodríguez Vega (alias el Mataviejas) que acabó con la vida de al menos 16 ancianas de edades comprendidas entre los 70 y los 93 años, en su Santander natal, o Luis Alfredo Garavito que mató y violó a niños de entre 6 y 14 años, y si bien la cifra es incierta puntualmente se encuentra judicializado por 172 homicidios, con un fallo condenatorio de 138, según las datos aportados por Valencia Laharenas (2010). O el mismo Andrei Chikatilo (alias el carnicero de Rostov). Este asesino en serie ruso mataba a niños, chicas y mujeres, a menudo mendigos y prostitutas. Si bien tenía una predilección por los niños, las víctimas podían ser de todas las edades y sexo.

Y por último, en cuanto a que asesinen por razones de carácter sexual, este puede ser uno de los motivos principales, tanto a nivel consciente como inconsciente, pero ni mucho menos se puede decir que un asesino serial es un asesino sexual debido a que muchos lo hacen por sentir la sensación de poder, por rabia, ira, frustración no debidamente canalizada y por una multiplicidad de motivos. En este sentido, se debe tener en cuenta el Principio de Motivación Dinámica propuesto por Turvey (2008) según el cual, en una agresión o agresiones siempre influyen una amplia gama de factores desencadenantes. Por lo que resulta. en la mayoría de los casos, un reduccionismo y una necesidad de atomizar el conocimiento lo que lleve erróneamente a la búsqueda de un único motivo.

Borras (2002) de sus investigaciones etiológicas concluye que los asesinos en serie suelen darse asociados a alguna de las siguientes características, en las cuales se irá profundizando a lo largo de este capítulo:

a.- Maltrato infantil en la infancia

b.- Presencia de psicopatía o trastorno antisocial

c.- Padecer algún tipo de psicosis, preferentemente paranoide

d.- Presentar una o varias parafilias, especialmente gerontofilia, paidofilia, sadismo y necrofilia.

Otras situaciones asociadas serían: "alcoholismo, experiencias precoces con la muerte (especialmente el fallecimiento temprano de algún progenitor); experiencias sexuales inusuales y precoces (abuso sexual, incesto, etc), defectos o minusvalías físicas -reales o autopercibidas- , institucionalismo en la crianza, abandono o sobreprotección infantil, mala relación con los profesores” (Ibíd, 2002, p.226-227). 
A modo de conclusión, cabe decir que para poder diferenciar los asesinos en serie de los otros dos subtipos, existen dos criterios básicos a tener en cuenta, éstos son el lugar en el que se cometen los crímenes (si en el mismo sitio o en diferentes lugares) y el tiempo que transcurre entre los mismos (período de enfriamiento).

De manera que con el afán de zanjar las discusiones sobre qué se debe entender o no por asesino en serie, en el Simposio de S. Agustín, Texas, 2005 se adoptó la siguiente definición: "El homicidio de dos o más víctimas por el (los) mismo (s) delincuente (s), en eventos separados". ${ }^{1}$

Actualmente, Jiménez (2014) define al asesino en serie como un "asesino que mata tres o más víctimas de forma sucesiva y con períodos de "enfriamiento" entre ellas. La característica principal de esta tipología es la existencia de un período de enfriamiento y una individualización de los crímenes en cuanto a que cada víctima puede verse por separado en momento y lugar" (Ibíd, 2014, p.5).

\subsection{TIPOLOGÍAS DE LOS ASESINOS EN SERIE}

A continuación, se van a explicar las diferentes tipologías y sus características propuestas en las investigaciones relacionadas con el modus operandi, la interacción con la víctima, la motivación, el comportamiento geográfico, etc. profundizadas por cada autor.

Las primeras investigaciones centradas en la motivación de los asesinos en serie, son las realizadas por el Centro Nacional para el Análisis del Crimen Violento (NCAVC) y la Academia del FBI en Quántico, Virginia, las cuales proponen dos tipos de asesinos seriales: el que lo realiza por diversión, que no suelen presentar período de enfriamiento y el motivo suele ser económico o la búsqueda de sensaciones, y el clásico, que suele tener una motivación sádico/sexual.

Posteriormente, Dietz (1986) los divide en psicopático sexual sádico, que asesina y tortura por puro placer, el asesino que mata por diversión, los miembros del crimen organizado como la mafia, bandas, etc. que buscan dinero o ganar territorios, los envenenadores que cuidan a otras personas y asfixiadores (ej: enfermeras que matan a

\footnotetext{
${ }^{1}$ (Tomado de: http:// www. fbi. Gov/stats-services/publications/serial-murder)
} 
las personas que cuidan) y los supuestamente psicóticos que matan como resultado de un estado delirante.

Igualmente, Skrapec (en Sanmartín y Raine, 2002) muestra desde la metodología fenomenológica cuáles son las motivaciones de los asesinos en serie para matar. Éstas son:

1. Venganza-justificación: todos los asesinos estudiados por Skrapec se consideraban ellos mismos como víctimas, por lo que sus crímenes los justificaban por haber sufrido algún tipo de maltrato en sus vidas y era esa ira lo que les hacía matar.

Otro de los resultados de su estudio era que estos asesinos seriales empatizaban cognitivamente con sus víctimas, pero no emocionalmente, es decir, comprendían el daño que les estaban causando, pero no eran capaces de sentir nada por ellas.

Este motivo podría estar relacionado con la necesidad de seguridad de la teoría de Maslow (1943). El asesino en serie necesita recuperar la seguridad de su supervivencia, si hay alguien que lo intenta dañar o lo ha dañado, él se defiende, ataca como instinto básico para sobrevivir. En este caso, la necesidad está distorsionada y llevada al extremo. Para este tipo de agresores todas las víctimas son potenciales enemigos. Su seguridad es quebradiza y usa la violencia para restituirla y para vengarla, sus actos tienen el objetivo de reparar el mal que se le ha hecho dentro de unos criterios propios de justicia y moral. Asesinar para ellos es protegerse. (Jiménez, 2014, p.10)

2. Control y poder: esta es otra de las motivaciones que apareció en el estudio. La necesidad de control y poder nace de sus fantasías de grandiosidad en la que controlan todo y tienen más poder que nadie. El asesinato de alguien le proporcionaba ese placer, aunque fuera momentáneo de hacer realidad la fantasía.

Esa motivación está claramente recogida en la teoría de McClelland (1989), cuando habla de motivación de poder. Este tipo de agresores tienen realmente baja autoestima y complejos de inferioridad que les hacen sentirse insignificantes. Para escapar de esta sensación elaboran unas fantasías en las que alcanzan una superioridad infinita, el poder divino de controlar la vida y la muerte. (Jiménez, 2014, p.10) 
3. Sentirse vivos: en el estudio los asesinos en serie afirmaron que asesinar les hacía sentirse vivos entendido como una súbita euforia, un alto nivel de ira que cuando la descargaban por medio de asesinatos les producía una sensación de placer y calma. Todo esto era seguido más tarde por un estado de nerviosismo y miedo que se iba acrecentando con el tiempo. Para eliminar estos sentimientos recurrían a sustancias o a sus fantasías. Este tipo de motivación se relaciona muy estrechamente con las últimas necesidades de la pirámide de Maslow, es decir, las necesidades de estima y autorrealización. En relación a la estima, los asesinos seriales buscan la fama, el reconocimiento público como seres superiores. En cuanto a la necesidad de autorrealización, intentan como hemos descrito, realizar sus fantasías por medio de los asesinatos, sin embargo, siempre les llevará a una frustración porque nunca consiguen hacerlo como imaginan en su fantasía.

La clasificación más actual asentada en la motivación es la aportada por Fox y Levin (en Petherick, 2006):

a. Emocionales: buscan experimentar sensaciones fuertes. Existen dos subtipos:

a. Sádico: se excita con el dolor de la víctima.

b. Dominante: se excita con la sensación de poder.

b. Misionarios: creen que deben cumplir una misión. También tienen dos subtipos:

a. Reformista: no presenta alucinaciones.

b. Visionario: sí presenta alucinaciones.

c. Por conveniencia: buscan un beneficio de sus víctimas:

a. El que saca provecho: ej: asesinos a sueldo.

b. El protector: mata para no dejar testigos.

Holmes y de Burger (1985) aportan una tipología basada en la clasificación Organizado vs. Desorganizado atendiendo a la distinción de transitoriedad geográfica, diferenciando entre asesinos geográficamente estables (mega stat) en los que el lugar de residencia y el lugar en el que lleva a cabo los crímenes no distan demasiado y geográficamente transeúntes (megamóviles), que viajan grandes distancias en busca de la víctima perfecta. 
Posteriormente, estos mismos autores en 1988 clasifican a los asesinos seriales en:

a. Visionario: psicótico con alucinaciones auditivas que le ordenan que mate. Un asesino visionario: Tendrá muy poco control de la escena siendo esta generalmente caótica, dejará mucha evidencia física inclusive el arma, no trasladará el cuerpo de la víctima o lo hará de forma muy torpe y no suelen ser sujetos que escojan el estrangulamiento como forma de matar.

b. Misionario: en este caso en vez de alucinaciones, lo que elabora es una idea delirante de matar a determinadas personas; se cree un salvador. Un asesino misionario actuará con un elevado control de la escena y seleccionará a sus víctimas metódicamente.

c. Hedonista: mata por el placer que le proporciona el acto de matar. Un asesino hedonista controla la escena, pero ésta no es caótica. Dejará evidencias de tortura incluyendo armas para la misma y trasladará el cuerpo que suele esconder con precaución y astucia. Realizará sexo aberrante (inclusive necrofilia, penetración de objetos etc) y recurrirá frecuentemente al estrangulamiento.

d. Dominante: busca la sensación de poder y control. Un asesino dominante controla la escena y no deja evidencias, es posible que torture y por lo demás actuará de forma muy similar al hedonista, con la diferencia principal de que éste no deja evidencias fácilmente. Para Otín (2013) “cuando se amañan pistas o se escenifican en una serie de crímenes podemos estar seguros que estamos en frente a un asesino organizado, que busca y se orienta por el poder y el control y que evidencia que no quiere ser capturado y que quiere seguir matando" (Ibíd, 2013, p. 188).

No obstante, la clasificación más destacable es la planteada por Ressler, Burgess y Douglas en 1988 basada en la clasificación de "organizado vs. desorganizado" asentada en el análisis de la escena del crimen tal y como se expone en las Tablas 26, 27, 28 y 29 : 
Tabla 26: Con respecto a las características de los sujetos (Schelinger, 2000 y Morales, 2003, citado en Garrido, 2008)

\begin{tabular}{|c|c|}
\hline ESCENAS ORGANIZADAS & ESCENAS DESORGANIZADAS \\
\hline Metódicos y controlados & Impulsivos \\
\hline Competentes social y sexualmente & Incompetentes social y sexualmente \\
\hline Inteligencia media o superior & Poco inteligentes \\
\hline Cuentan con habilidades para trabajar & Inhábiles para el trabajo \\
\hline $\begin{array}{l}\text { Mayor probabilidad de vivir acompañados de } \\
\text { una mujer o estar casados }\end{array}$ & Viven solos o con algún familiar \\
\hline $\begin{array}{l}\text { Buscan información relacionada con sus } \\
\text { crímenes en los medios de comunicación y } \\
\text { están al tanto de la investigación }\end{array}$ & $\begin{array}{l}\text { No hacen esfuerzos por mantenerse } \\
\text { informados de la investigación de sus } \\
\text { delitos }\end{array}$ \\
\hline Desafían a la policía & $\begin{array}{l}\text { No es frecuente que desafíen a la } \\
\text { policía }\end{array}$ \\
\hline \multicolumn{2}{|l|}{ Motivados por el control y el dominio } \\
\hline $\begin{array}{l}\text { Es probable que antes de cometer sus delitos } \\
\text { hayan tenido que enfrentar algún evento } \\
\text { estresante }\end{array}$ & $\begin{array}{l}\text { Los motivos más frecuentes son la } \\
\text { enfermedad mental y la gratificación } \\
\text { sexual }\end{array}$ \\
\hline $\begin{array}{l}\text { Presentan una historia de conflictos con la } \\
\text { autoridad }\end{array}$ & $\begin{array}{l}\text { Historia de tratamiento psiquiátrico e } \\
\text { intentos de suicidio }\end{array}$ \\
\hline Personalidad antisocial o psicopática & $\begin{array}{l}\text { Personalidad } \\
\text { esquizofrenia }\end{array}$ \\
\hline
\end{tabular}


Tabla 27: La evidencia de planificación (Schelinger, 2000 y Morales, 2003, citado en Garrido, 2008)

\begin{tabular}{|l|l|}
\hline ESCENAS ORGANIZADAS & ESCENAS DESORGANIZADAS \\
\hline Planifican cuidadosamente sus crímenes & No planean sus ataques \\
\hline $\begin{array}{l}\text { Seleccionan previamente el arma que } \\
\text { usarán en el delito y se la llevan consigo } \\
\text { después del crimen }\end{array}$ & $\begin{array}{l}\text { No seleccionan previamente el arma (son } \\
\text { producto de la oportunidad) y suelen } \\
\text { dejarla en la escena del delito }\end{array}$ \\
\hline $\begin{array}{l}\text { Hacen esfuerzos por ocultar la evidencia, } \\
\text { mueven el cadáver o intentan ocultarlo }\end{array}$ & $\begin{array}{l}\text { No se preocupan por ocultar la evidencia, } \\
\text { no intentan ocultar el cadáver }\end{array}$ \\
\hline $\begin{array}{l}\text { Recorren grandes distancias para cometer } \\
\text { sus delitos }\end{array}$ & $\begin{array}{l}\text { Cometen los delitos cerca de donde viven } \\
\text { o trabajan }\end{array}$ \\
\hline
\end{tabular}

Tabla 28: En relación con la violencia ejercida sobre las víctimas (Schelinger, 2000 y Morales, 2003, citado en Garrido, 2008)

\begin{tabular}{|l|l|}
\hline ESCENAS ORGANIZADAS & ESCENAS DESORGANIZADAS \\
\hline $\begin{array}{l}\text { Mantienen control sobre su comportamiento } \\
\text { agresivo }\end{array}$ & Son incapaces de mantener el control \\
\hline $\begin{array}{l}\text { Hay mayor probabilidad de que violen y } \\
\text { torturen a sus víctimas antes de morir }\end{array}$ & $\begin{array}{l}\text { Cometen actos extremos de violencia, } \\
\text { mutilan y tienen actos sexuales post- } \\
\text { mortem con sus víctimas }\end{array}$ \\
\hline Asesinan a sus víctimas lentamente & $\begin{array}{l}\text { Asesinan de manera rápida, matan } \\
\text { instantáneamente }\end{array}$ \\
\hline
\end{tabular}


Tabla 29: Relación agresor-víctima (Schelinger, 2000 y Morales, 2003, citado en Garrido, 2008)

\begin{tabular}{|c|c|}
\hline ESCENA ORGANIZADA & ESCENA DESORGANIZADA \\
\hline $\begin{array}{l}\text { Eligen cuidadosamente a sus víctimas ya que } \\
\text { tienen un significado especial para él }\end{array}$ & $\begin{array}{l}\text { La elección de sus víctimas es } \\
\text { aleatoria, no tienen un significado } \\
\text { especial para el agresor }\end{array}$ \\
\hline La víctima suele ser desconocida & La víctima suele ser conocida \\
\hline $\begin{array}{l}\text { Hay interacción con la víctima para } \\
\text { aproximarse a ella, utiliza alguna estrategia } \\
\text { verbal como engaño }\end{array}$ & $\begin{array}{l}\text { No media interacción con la víctima, es } \\
\text { muy probable que se acerquen por } \\
\text { detrás y que haya una mínima } \\
\text { interacción }\end{array}$ \\
\hline $\begin{array}{l}\text { Intentan controlar a la víctima durante el } \\
\text { asalto }\end{array}$ & No intentan controlar a la víctima \\
\hline $\begin{array}{l}\text { La víctima tiene un significado (por sus } \\
\text { características personales) para el agresor }\end{array}$ & $\begin{array}{l}\text { Despersonalizan a la víctima y la tratan } \\
\text { como un objeto }\end{array}$ \\
\hline
\end{tabular}

Tal y como se expone en el capítulo 3, se puede observar desde estas características que, los asesinos organizados suelen ser psicópatas y los desorganizados, psicóticos.

En general, en los actos cometidos por asesinos organizados teniendo en cuenta que planifican cada movimiento, Garrido (2008) diferencia una serie de fases expuestas en la Figura 12: 
Etapa 1: elige a sus víctimas haciendo caso a sus fantasías. Utiliza sus recursos para atraerlas y aprovecha los momentos de mayor vulnerabilidad de la víctima. actúa en un radio geográfico amplio y suele moverse en sus propios medios de transporte para dificultar su captura

Etapa 2: el asesino en serie organizado suele excitarse con la emoción de la persecución y torturando a sus víctimas. Le gusta llevar el control y hacerlo notar. Normalmente lleva todo planeado: el día de la muerte, las armas que utilizará, etc

Etapa 3: va variando el modus operandi en cada homicidio para dificultar su captura.

Etapa 4: disfruta confundiendo a las autoridades por lo que pueden hacer llamadas falsas y así afirmarse en su inteligencia.

Figura 12: Fases de los asesinos organizados (Garrido, 2008)

Más tarde, Hickey (1991) elabora otra tipología basada en la localización del crimen, distinguiendo entre asesinos viajeros, que se desplazan geográficamente y conforman el $28 \%$ de los asesinatos en serie; los locales, que permanecen en una zona geográfica concreta (45\%) y finalmente los que asesinan en lugares específicos, que utilizan su casa o el lugar de trabajo $(27 \%)$.

Posteriormente, Kim Rossmo (1995) aporta mayor información respecto a las víctimas y la geografía diferenciando entre el asesino cazador, que busca a las víctimas en las proximidades de su vivienda, el cazador furtivo que las busca en un área concreta diferente a donde reside, el pescador que busca a la víctima en lugares rutinarios como el trabajo, eligiendo el momento idóneo y por último el denominado trampero que usa el engaño y demás trucos para llevar a la víctima donde él quiera y allí cometer el delito. 
Igualmente, Canter y Salfati (1999) incluyen en su clasificación la interacción que se da entre la víctima y el agresor distinguiendo los tipos que se describen a continuación:

a. Instrumental-cognitivo: es un asesino planificador, premeditado, que quiere conseguir un objetivo. No suele dejar evidencias objetivas en el crimen ya que es un asesino con un alto grado de conciencia forense que aumenta progresivamente con su experiencia.

b. Expresivo-impulsivo: este tipo de asesino se mueve por las emociones, ya sean de ira o de venganza. Suele ser un ataque repentino y provoca mucho daño en la víctima. sus crímenes son fruto de una furia desmesurada y nada planificados.

c. Instrumental-oportunista: también presenta intencionalidad y espera obtener algún beneficio de la víctima. La elección de la víctima en este caso no es planificada. Las armas usadas suelen ser de oportunidad. Estos crímenes suelen estar relacionados con robos o agresiones sexuales.

\section{5. INFANCIA DE LOS ASESINOS EN SERIE}

Ressler (2010), destaca que los dos factores más relevantes que generan un asesino en serie son los paternofiliales, explicando que "En la infancia de muchos asesinos en serie se reproduce el esquema de la figura paterna ausente y de una madre fría o distante" (Ibíd, 2010, p.280)

Respecto a las relaciones interfamiliares de los asesinos en serie suelen ser disruptivas. Así, un gran número de asesinos en serie proceden de familias de clase media aparentemente normales pero que en realidad tienen muchos problemas en la intimidad: los padres abusan del alcohol o drogas, están implicados en actividades que no son legales, tienen antecedentes psiquiátricos, etc. Y la mayoría de ellos han abusado o maltratado a sus hijos.

Es cierto que la mayoría de estos individuos han sufrido traumas terribles como abusos en la infancia por parte de los padres y otros familiares, pero no quiere decir que exista una relación causal, es decir, no todos los niños que han sufrido malos tratos o abusos sexuales se convierten en psicópatas o asesinos. "los expertos saben de sobra 
que los abusos físicos y psicológicos no son una causa directa que provoca que una persona comience a matar en un futuro pero sí es un factor clave para empezar a comprender los motivos que le llevan a hacerlo" (Abeijón, 1005, p.53)

El papel que juega la madre en la vida de una persona es fundamental. (Dor, 1987). La falta de cariño por parte de la madre, desencadena en el niño diversos trastornos del comportamiento y una acusada falta de empatía debido al retraimiento. La madre suele seguir o bien el patrón de madre extremadamente sobreprotectora o todo lo contrario, una madre fría que no proporciona ni un ápice de amor a sus hijos, sin embargo, al padre lo suelen culpar de "borracho", "maltratador" o figura ausente. La unión de estos factores predispone significativamente a la conducta criminal.

Bourgoin (1993) lo sintetiza de la siguiente manera: "En su conjunto, el sujeto fue un niño desatendido o víctima de abusos, que pasó por un gran número de conflictos durante su infancia sin que fuera capaz de erigir y utilizar sistemas de defensa adecuados" (Ibíd, 1993, citado en Abeijón 2005, p.57). Dichas situaciones de tensión prolongadas en el tiempo, llevan al niño a un aislamiento social, percibiendo el mundo externo como territorio hostil. De manera que según este autor, "Ese individuo posee una pobre opinión de sí mismo y rechaza una sociedad que según cree, lo ha echado de lado y en un momento dado se expresará por medio de actos antisociales que pueden conducirle al asesinato tratando de vengarse de la sociedad y de castigar a los que se encuentran a gusto en ella" (Ibíd, 1993, citado en Abeijón, 2005. p.57).

No obstante, en la historia del crimen encontramos también figuras cuya infancia en principio ha sido de todo menos traumática, al menos a nivel externo. (De Santiago, 2008). Ejemplo de ello sería Mark James Robert Esexx cuya adaptación infanto-juvenil tanto a nivel familiar, escolar, entre iguales y socioeconómica es palpable hasta que determinadas situaciones ambientales relacionadas con el racismo en el ejército americano le convierten en un asesino en serie que acabó abatido a tiros por los Cuerpos de Seguridad de Nueva Orleans, después de un largo asedio.

Se considera abuso a un menor "cualquier clase de placer sexual con el niño sin que necesariamente exista contacto físico" (Abeijón, 2005, p.58). Dentro de lo que se considera abuso, se enmarca la violación, los tocamientos, la exposición de un menor a órganos sexuales, la seducción por parte de un adulto, la masturbación o la realización del acto sexual. En la mayoría de casos los agresores son familiares, por lo que dificulta 
la detección de los casos. Son considerados malos tratos de igual forma la falta de cuidados y abandono físico del niño. Los que aparecen de forma más oculta y causan mayor daño son los malos tratos emocionales, ya que son sufridos en silencio. (Echeburúa y Corral, 2006). Son sufridos en forma de humillaciones, insultos, discusiones de los progenitores en presencia de los menores, amenazas, etc. que desembocan en diferentes trastornos en el niño: miedos, fobias, inseguridades, ansiedad, agresividad, et.

Estos daños emocionales, son difíciles de detectar y no suelen salir a la luz hasta la adolescencia o más tarde, edad en la que muchos de estos niños se han convertido en "sus padres", es decir, en personas agresivas y abusivas que pueden llegar a maltratar de igual forma sus hijos. A este respecto, Gil (1994) expone que "Algunos niños se identifican con el agresor (que puede maltratarlos a ellos o al cónyuge además de a las mascotas) y se convierten ellos mismos en agresores" (Ibíd, 1994, p.20).

Siguiendo a Queron (2011) se pueden identificar unos rasgos comunes en niños y adolescentes que presentan violencia escolar, de las cuales destaca:

a) Se sienten inferiores y criticados.

b) Presentan comportamientos violentos/agresivos de diferentes maneras y no en un episodio aislado.

c) Son rechazados repetidamente, lo que contribuye al incremento progresivo de su agresividad.

d) Niños aislados mientras sufren daño emocional.

e) Los adultos no presentaron la suficiente atención a signos de alarma (como el maltrato a animales, ya que no se consideró a los animales como víctimas sino como una propiedad). Hay jóvenes que cometen actos de crueldad hacia animales como síntomas de una psicopatología y, a veces acompañados de una historia familiar problemática.

Además de estas características, Querón (2011) incluye en su “perfill” algunas de las siguientes características:

a) Diagnóstico de trastorno de conducta.

b) Falta de cuidados y/o malos tratos (abuso físico, sexual o emocional, no atención médica, etc).

c) Violación de las normas sociales y los derechos humanos y animales básicos. 
d) Perpetrar actos criminales violentos o no, incluyendo los relativos a la propiedad.

e) Baja autoestima y elevada susceptibilidad a la presión de otras personas.

f) Poco control de la agresividad física y la ira.

g) Rechazo real o percibido erróneamente y sentimiento de ser criticados y/o perseguidos.

h) Falta de control de impulsos.

i) Sentimiento de falta de poder e inferioridad.

j) Capacidad no adecuada de relacionarse socialmente en la mayoría de los ámbitos.

k) Exceso o falta de apego.

1) Falta de apoyo e inoculación de valores básicos por parte de los padres.

Los asesinos en serie que han padecido malos tratos se vengarán de los mismos, pero esta vez como agresores en sus crímenes, por eso "La manera de matar suele ser de contacto directo con la víctima. Estrangulan, golpean, degüellan, y casi nunca utilizan un arma de fuego" (Abeijón, 2005, p.61).

Ressler, Burgess y Douglas (1988) exponen que "tras esta fallida infancia, el individuo crece acompañado por sus fantasías de dominación y control, no experimentando simpatía ni remordimiento por los demás, ya que toda persona es reducida a un nuevo símbolo que puede ser manipulado de acuerdo a la fantasía de turno" (citado en Antuña y Rodríguez, 2007, pp.33-34).

Las fantasías, a pesar de su constante presencia en el ser humano, son un fenómeno al que le ha dedicado escaso interés desde la psicología académica (Kinsey y cols, 1948; 1953). Generalmente es un campo al que se le ha considerado como poco heurístico y más próximo a la literatura erótica que a un campo de estudio científico interesado en la comprensión del fenómeno (Leitenberg y Henning, 1995). Sin embargo, es un tema ya abordado por los clásicos. Así, para Platón el lugar de las fantasías no sería otro que el de ser una facultad intermedia entre el sentir y el pensar, esquema que completa Aristóteles (De anima, III, 3; De memoria et reminiscencia 449 y ss: Retórica, 1370) cuando apuntala que la fantasía es una facultad intermedia, dado que participa de las dos facultades, antes comentadas. Es decir, que sintiendo por las percepciones y pensando con el sentido común se construyen las fantasías. (Véase Figura 13): 


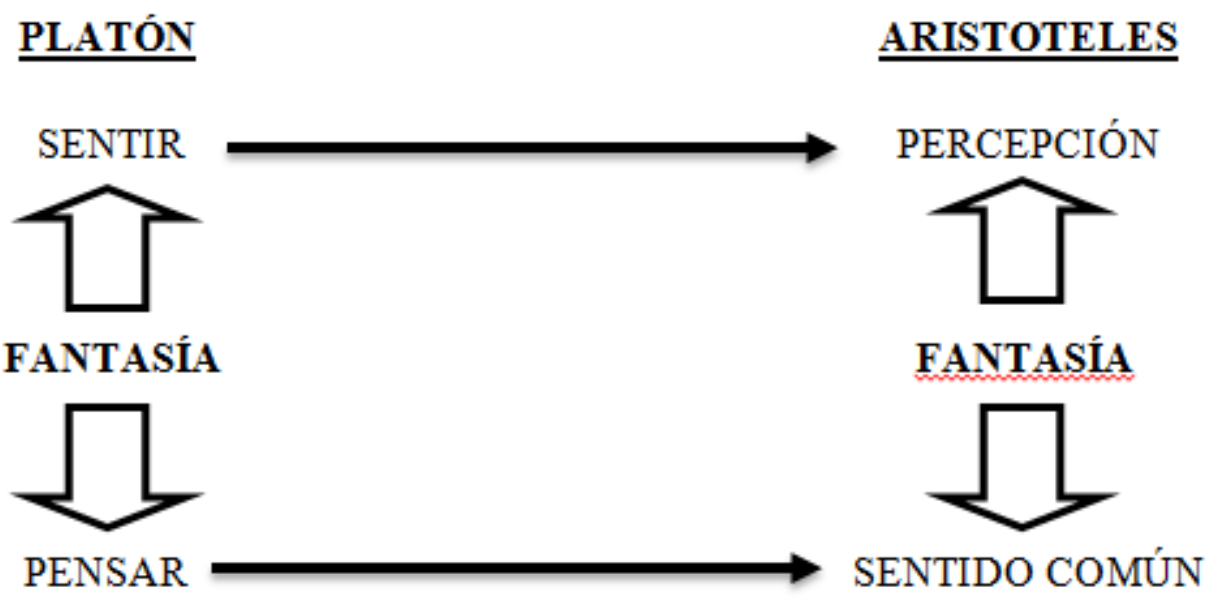

Figura 13: Fantasías Platón vs. Aristóteles. (De Santiago-Herrero, 2014)

La fantasía sería, por tanto, la facultad intermedia entre el sentido común (o percepción) y el intelecto (o pensamiento), en tanto que participa de los dos (Serés, G. 1994 p. 210). Fantasear es una actividad básica del psiquismo humano. Permite trascender la realidad inmediata y crear mundos imaginarios (Stumm, Pritz y Quintana, 2009) y desde un punto de vista psico-criminológico, en cuanto a los asesinos en serie, es frecuente señalar como una de las variables más relevantes la presencia de fantasías violentas desde la infancia que culminan llevándolas a la práctica por medio del crimen (Kessler \& Schachtman, 2005).

Una de las conductas disruptivas más importantes sería el maltrato animal, además de la piromanía y la enuresis. Así, "Se estima que el $60 \%$ de los criminales padecen incontinencia urinaria aún llegada la adolescencia” (Abeijón, 2005, p.34). De tal forma que la violencia hacia los animales podría tener un valor predictivo de violencia hacia humanos (ya sea como asesinatos en serie o como asesinatos en masa...) (Querol, 2011, p.1).

En este sentido, algunos de los asesinos en serie más conocidos reconocieron esta práctica, (Jeffrey Dahmer, Alberto De Salvo, David Berkowitz, etc), datos corroborados por el estudio realizado por el FBI en 1970 sobre 36 asesinos múltiples, en el que el $46 \%$ reconocieron haber matado animales en su adolescencia.

White y Shapiro, en 1994, comentan que:

Los niños reciben desde temprana edad contacto con imágenes de animales (e incluso, la mayoría de ellos conviven con una o varias mascotas). De éstos aprenden a ser 
responsables, a desarrollar empatía, afecto incondicional y muchos adquieren su autoestima como consecuencia de su relación con su animal de compañía. Desafortunadamente, en familias problemáticas, los niños pueden aprender que los animales pueden ser maltratados e incluso que la conducta agresiva es aceptable hacia humanos. (White et al., 1994, p.22).

Por último, respecto a las características conductuales del asesino en serie, se considera importante dedicar un apartado a la conducta particular de la mujer asesina en serie.

\subsection{ASESINAS EN SERIE}

Las asesinas seriales representan el $11 \%$ del conjunto de asesinos en serie y suelen ser menos agresivas o violentas que los varones, pero sin embargo debido a su forma de asesinar han sido consideradas más peligrosas. La mayoría de estudios se han centrado en la figura masculina del asesino en serie por conformar la mayoría de esta población delictiva. Esta puede ser la razón por lo que se ha dejado olvidada la figura de la asesina en serie. (Abeijón, 2005).

Los primeros estudios llevados a cabo sobre asesinas en serie ya trataban de buscar una explicación a la conducta criminal de las mismas y diferenciarla de la llevada a cabo por los hombres.

Así, en referencia a las características innatas de las asesinas seriales, Lombroso y Ferrero en "The female ofender" (1903-1920), afirmaban que la delincuencia femenina "es algo inherente en las mujeres que no habían evolucionado apropiadamente hacia mujeres femeninas, delicadas y con moral" (López, 2013, p.3). Argumentaban en base a las características craneales de éstas mujeres, que no correspondían a la época, y se caracterizaban por una predisposición a la frialdad, pasividad psicológica e inmovilidad fisiológica.

Almeda, (2003) comenta que "Lombroso y Ferrero señalaron que son doblemente prejuiciosas comparadas con los hombres y que su doble infracción de las leyes comporta que a las mujeres criminales se las pueda considerar como un “monstruo” (Ibíd, 2003, citado en López, 2013, p.4). 
Respecto a las explicaciones más psicológicas de la conducta criminal de estas mujeres, Pollack (1950) afirma la existencia de causas psicológicas para explicar por qué estas mujeres son inherentemente mentirosas. Su argumento radica en la explicación de que los hombres no pueden esconder sus deseos sexuales ya que tienen erecciones; sin embargo, las mujeres pueden mentir en este contexto y si se dan circunstancias como trabajos domésticos, como enfermeras y profesoras, pueden delinquir sin ser descubiertas. Más aún, Pollack (1950) afirmaba que las mujeres recibían un trato más favorable por parte de la justicia debido a las armas de seducción que éstas utilizaban.

Posteriormente, Adler (1975) en su libro "Sister in crime" consideraba a las mujeres igual de violentas y propensas a la delincuencia que los hombres. Por otro lado, en el libro "Women and Crime" de J.R. Simon (1975) queda patente cómo las mujeres atentan más contra la propiedad y cometen un menor número de delitos violentos. Sin embargo, Steffensmeir (1980) en su artículo "Trends in female delinquency" critica a los dos autores anteriores afirmando que aunque las mujeres cometan más delitos, la diferencia con los hombres sigue siendo amplia.

Teniendo en cuenta el tipo de crímenes y el móvil del mismo se generan varios tipos:

a) Viudas negras: matan por un beneficio mayormente económico. En el caso de las "envenenadoras" el asesinato es frío y calculado, buscando una ganancia económica como cobrar una herencia. Suelen ser mujeres psicópatas mayores de 30 años que son plenamente conscientes de sus actos. La media de víctimas ronda las 6 u 8 en un período de tiempo de 10 años. Los productos utilizados para llevar a cabo el envenenamiento son fáciles de encontrar en tiendas: insecticidas, raticidas, lejías, etc. Ej: La vampira de Barcelona, Enriqueta Marti.

b) Los ángeles de la muerte: suelen ser enfermeras o cuidadoras que matan a sus pacientes debido al poder que les hace sentir. Suelen comenzar su carrera criminal en torno a los 20 años, en su trabajo como enfermeras, cuidadoras, etc. de manera que el crimen puede ser fácilmente disimulado. Ej: Jane Toppan, que administraba una mezcla letal a sus pacientes y se tumbaba a su lado mientras morían.

Son personas discretas y volcadas profundamente en su trabajo, que nunca protestan a la hora de asumir determinadas funciones que otras enfermeras 
tratan de evitar, como es el cuidado de personas mayores dependientes. Como grandes manipuladoras que son, se muestran extremadamente cercanas a estas personas, manteniendo una relación muy calurosa tanto con el paciente como con sus familiares. (Abeijón, 2005, p.128)

Suelen ser personas solitarias y manipulan a la víctima de manera que se conviertan en indispensables para ella. "Fingen ser almas caritativas y sacrificadas por el bienestar de los demás" (Íbid, 2005, p.129).

c) Infanticidas: matan a sus propios hijos, la razón suele ser la venganza. Respecto a este tipo de asesinas se puede nombrar el caso del "Síndrome de Munchausen por poderes" consistente en una forma de abuso infantil en el que la madre provoca en el niño síntomas de enfermedad para someterlo a infinidad de pruebas médicas. Las agresiones pueden llegar incluso a causarle la muerte. La mayor parte de las veces, estas mujeres han sufrido malos tratos en la infancia y presentan problemas de pareja. Son personas muy manipuladoras. Ej: Jeanne Weber, quien mató a sus hijos y sobrinos estrangulándolos.

d) Depredadoras: similares al perfil de asesino en serie varón, matan por alguna fantasía y a partir de un trauma del pasado. La fantasía creada por las llamadas “depredadoras" consiste en provocar el mayor dolor posible y ejercer el control absoluto sobre su víctima. Estas mujeres se asemejan a los asesinos en serie varones en que sus fantasías son proyectadas en el cuerpo de las víctimas y no tienen sentimientos de culpa. Tienden a actuar también con público, y al no llegar a culminar su fantasía siguen torturando a su víctima con el fin de hacerla realidad. Ej: Ailen Wuornoss, mujer politraumatizada en la infancia que acabó con la vida de siete hombres.

A ellas también les excita el hecho de planear el crimen y despistar a la policía, además que suele ser más difícil capturarlas debido a su meticulosidad.

El criminólogo Hickey (1997) realizó un estudio de 62 asesinas que estaban cumpliendo condena y llegó a las siguientes conclusiones: la gran mayoría había actuado con algún cómplice masculino, son personas que presentan una conducta antisocial y labilidad emocional, sin embargo, carecen de esa impulsividad característica de los asesinos en serie varones. Suelen tener una media de edad de 33 años y el número de víctimas aproximado suele ser entre 7 y 9. 
Las motivaciones que les lleva a matar son en primer lugar el dinero, la venganza, el poder y por último la dominación sexual. El $80 \%$ de ellas opta por matar a gente que conocen, debido a su mayor vulnerabilidad. Así, "El paso al acto de un homicida se produce de manera diferente que en los hombres: raramente actuarán de manera impulsiva. Dependiendo del móvil del crimen, fijan una determinada víctima y crean una fantasía alrededor que será largamente madurada hasta que consideran que es perfecta" (Abeijón, 2005, p.100)

A diferencia de los hombres, las mujeres que han sufrido traumas en la infancia no exteriorizan la ira sino que la interiorizan y tiende a culparse a ella misma castigándose de formas demoledoras tales como el abuso de sustancias o la prostitución; de ahí que las mujeres asesinas en serie sean las menos, y sean casos concretos.

En la asesina en serie no existe la fantasía sexual que existe en el hombre, sino que pretenden causar dolor y tortura de una manera paulatina. Respecto a la psicología de estas mujeres, es bastante similar a la de los asesinos en serie varones: suelen ser ambiciosos, no tienen empatía y les gusta tener el control, sentir que manejan todo. Los hombres cometen un mayor número de crímenes, pero ellas son más perfeccionistas. Son menos violentas y es muy raro encontrar algún caso con carácter sexual. Suelen usar métodos menos llamativos, menos sangrientos. No suelen utilizar armas de fuego o blancas, prefieren el silencioso veneno. (López, 2005).

En relación a las causas de sus asesinatos, se ha hablado también de las presiones sociales que recaen sobre la mujer. Además de los abusos o malos tratos sufridos en la infancia que afectarían a su manera de estar en el mundo y su conducta, el querer llegar a alcanzar el estereotipo impuesto de mujer perfecta puede llegar a ser fatal. En muchos lugares, como pueblos pequeños, las mujeres que no se han casado y tenido hijos a cierta edad son estigmatizadas, y su es el caso de ser una madre soltera, esto se acrecienta, por lo que una mujer con factores predisponentes para un comportamiento digamos conflictivo, puede llegar a culpar inconscientemente a su hijo de ese rechazo social al que se ve sometida. (Martín, 2013). 


\section{7. ASPECTOS SOCIALES DEL ASESINATO EN SERIE}

Desde esta perspectiva, Leyton (1984) propone que el fenómeno del asesino múltiple - donde se incluye el asesino en serie- ni se produce de forma fortuita sino que responde a tensiones y alteraciones específicas en la comunidad humana, por lo que el énfasis de la etiología de estas conductas asesinas lo debemos buscar no solo en el individuo sino también en la sociedad. En esta línea argumenta que: "El asesino múltiple no surge al azar a lo largo de la historia. Surge en unos momentos concretos de la evolución social, durante unos periodos de tensión particular” (Ibíd, 1984, p. 377). Ya en este sentido el psicoanalista francés, Lagache (1950) advertía que: “...solo en el marco de las relaciones del individuo y los grupos se puede tratar de explicar la formación de la personalidad del criminal y la génesis de su conducta” (Ibíd, 1950, p.12-13).

Del estudio del Leyton (1984), se concluyen que existen diferencias específicas tanto en el modus operandi, la clase social del asesino y en las victimología a lo largo de la historia. Es decir, no existe un continuo en cuanto a la forma de proceder y el tipo de víctima elegida, porque las circunstancias históricas y las tensiones de clases en cada momento son particulares.

De esta forma, este autor, históricamente delimita unos periodos que considera esenciales.

1.- Periodo preindustrial: Los famosos asesinos múltiples de la etapa preindustrial, mataban simplemente por lucro, eran asaltantes de caminos, personas que se querían beneficiar de herencias, etc. Esto es una constante mundial que aún se mantiene dependiendo de estado de desarrollo de cada país. Pero los más famosos de este periodo eran precisamente lo contrario a unos pobres desfavorecidos por una sociedad que les impulsa al delito. Se trataba de aristócratas que satisfacían sus bajos instintos con siervos y campesinos. Más aún si situamos este periodo preindustrial en torno a los $\mathrm{S}$. XIII y XV en el cual el modelo feudalista comienza a hacer aguas y los campesinos de forma más organizada empezaban a ser molestos para la cúpula de los integrantes máximos del sistema feudal. La solución que encontraron de forma desmedida algunos aristócratas para mantener lo que en su momento era el orden social no podía ser otra que la de férreamente reprimir la inminente guerra de clases. En este contexto surgen unas de las figuras más aterradoras y feroces de la historia, como sería el caso de la 
Condesa húngara Erzebet Bathory o el Barón de Gilles de Rais. En lo que respecta a la "Condesa sangrienta", como se le apodó se estima que mató cerca de 616 mujeres, a las que desangraba y se bañaba en su sangre como método infalible para conservar su juventud, no sin antes haberlas sometido a toda práctica de torturas. A tal punto llegó su sadismo de carácter lésbico que en las cercanías de su castillo hubo una importante despoblación de mujeres (Doval, 2012) y en lo que se refiere al Barón Gilles de Rais ${ }^{2}$, se trataba principalmente de un asesino de niños, cerca de 300, apoyado por siniestros cómplices del estilo de alquimistas, brujos, videntes, etc, y en cuyos asesinatos veía que realizaba aquello que según él todos los seres humanos desean. En este sentido sería la figura precursora de la pretendida filosofía de Donatien Alphonse François, más conocido como el Marqués de Sade, al cual como apunta Marina (1995), leerlo puede resultar apasionante pero no así, vivirlo. Tal y como apunta Leyton (1984) "No puede ser mera coincidencia que los únicos asesinos múltiples de la era preindustrial que mataran por matar y de los que tenemos noticias fiables, fueran miembros de ese orden amenazado (Ibíd, 1984, p. 354).

2.- Periodo industrial: (finales del S. XVIII), época en la que irrumpen en la comunidad las diversas y nuevas clases sociales. El campesino comienza a ser propietario de su producción, lo que le hace ser más protagonista de su estilo de vida e ideología personal. En el S. XIX se produce una revolución mecánica y un nuevo orden económico. Los pueblos comienzan a desaparecer para centrarse en las grandes urbes. Las ideologías de los nuevos burgueses llevaban consigo la idea de que el no progreso o el estancamiento en determinados empleos o subempleos se debía no tanto a una cuestión social sino individual. El que no progresaba no era porque había un poder aristocrático que lo oprimiera, sino que simplemente se trataba de un perdedor, un sujeto sin habilidades para vender o comercializar su propio producto y vida. Estas desproporciones generaban en algunos sujetos humillación, inseguridad y desigualdad (Leyton, 1985, p.357) y conducen a otro nuevo tipo de asesinos seriales, asentados también en una clase acomodada, pero de tipo medio. Era normal encontrarse entre los asesinos múltiples de esta época a profesores, médicos, funcionarios, que precisamente servían a la nueva burguesía los que elegían a sus víctimas entre las clases sociales más

\footnotetext{
2 Personaje emblemático conocido como "Barba azul", debido a su negra barba con tintes azulados Comenzó a matar cuando tenía 15 años, pero debido a su condición social fue eludiendo a la justicia. Como dato histórico es que comenzó a matar con tan solo 15 años y aún en la actualidad se discute si estamos delante de un psicópata o de un psicótico.
} 
desfavorecidas, como prostitutas, criados, niños en riesgo social, etc. Parecía como si realmente lo que buscaban era hacer desaparecer del sistema a aquellos que consideraban perdedores, amorales o que ensuciaban el nuevo ambiente social. Baste recordar los crímenes del anónimo Jack el Destripador, al que apuntan desde diversos frentes como un aristócrata londinense o un asentado peluquero de la clase media. También en Londres Joseph Philippe, en la década de 1860, que estrangulaba y degollaba meretrices y el Dr. Thomas Cream que en torno a 1981 se dedicó a envenenarlas. En tierras francesas el famoso caso Wagner de 1913, que tras la paranoia de que se descubriera un periodo de homosexualidad activa antes de su matrimonio y con ello desprestigiar su esforzada posición social comenzó una serie de asesinatos e incendios de forma frenética en la localidad en la que residía.

Otra constante de esta era industrial era la rabia que sentían los estratos inferiores de la sociedad ante la exclusión de la misma. Caso paradigmático en este sentido sería el de Carl Panzram, que violaba, mataba y destruía las propiedades de cualquier víctima de oportunidad que se cruzara en su camino. El mismo Pazram, antes de su ejecución reconoció 21 asesinatos, miles de robos de todos los estilos, incendios y cometer sodomía con más de mil varones, al mismo tiempo que señalaba su ausencia de arrepentimiento y el odio tan arraigado que tenía a la sociedad de la cual se sentía totalmente excluido.

3.- Periodo moderno: Leyton (1984), señala como posteriormente a la Segunda Guerra Mundial, durante dos décadas, se vivió un periodo de tranquilidad asesina. El sector industrial crecía y tenían oportunidades toda clase de personas, tanto de la clase media como de clases marginales y poco cualificadas. La sociedad avanzaba unida socialmente hacia una mejora que no excluía ningún estrato social. Sin embargo, a partir de los años 60 se produce una proliferación de los asesinos en serie y en masa que no ha parado de crecer hasta el momento actual. Las empresas que antes estaban en expansión comienzan una progresiva reducción de personal. Sujetos que habían soñado en alcanzar la igualdad ven truncados sus aspiraciones al ser precisamente los menos cualificados los primeros en ser despedidos. Se produce entonces un fenómenos curioso, desde el punto de vista de Leyton (1984), si bien en la era preindustrial era el aristócrata el que satisfacía sus bajas pulsiones, ahora en la modernidad son sujetos de clase social media-baja los que arremetían contra las jóvenes universitarias, consumidores de grandes almacenes y víctimas de urbanizaciones más bien acomodadas, lo que evidencia 
que el individuo excluido deposita ahora su rabia y agresividad hacia los sujetos que simbolizan su destierro social. Por ejemplo: David Berkowitz, conocido como el Hijo de Sam, cuyas víctimas las encontraba en las atractivas jóvenes de un barrio de Queens, que era un segmento muy por encima de él en la jerarquía social; posteriormente subió el nivel buscando víctimas de otro barrio aún más burgués. Reconoció una vez detenido haber asesinado a seis personas y haber herido a otras siete en el curso de ocho tiroteos sucedidos en Nueva York entre 1976 y 1977 (Doval, 2012). Una de las causas que encontraron sus investigadores fue precisamente una reivindicación de venganza ante las injusticias sociales y la privación de identidad que le abrumaba (Leyton, 1984). Hijo ilegítimo, empleado de correos, criado en un barrio obrero, se convierte con sus asesinatos en una figura famosa al que biógrafos, psicólogos, televisiones, etc de todo el mundo visitan en su encarcelamiento en la penitenciaria de máxima seguridad de Attica en Nueva York.

Alrededor de 2 de cada 4 asesinatos en serie acontecen en EEUU, estando California y Florida encabezando las estadísticas de actos delictivos.

Con respecto al resto del mundo las mayores tasas de asesinatos seriales ocurren en las ciudades con un mayor grado de desarrollo y más pobladas; éstas son: Inglaterra, Francia y Alemania, que suman un $68 \%$ de los asesinatos seriales, quedando el $32 \%$ restante repartido en otras.

En cuanto a los datos de individuos, Macía (2011, p.19) aporta los siguientes:

1. Del total de asesinatos seriales en el mundo un $90 \%$ son hombres.

2. Un $65 \%$ de las víctimas son mujeres.

3. Un $89 \%$ de las víctimas son personas de raza blanca.

4. Del total de los asesinos, un $86 \%$ son heterosexuales.

5. Respecto a la edad vemos que:

a. Un $36 \%$ comienza su carrera criminal en la adolescencia.

b. Se calcula que el $44 \%$ comienza entre los 20 y 30 años.

c. El $21 \%$ comienza a los 30 años.

d. El 6\% restante corresponde a contados asesinos seriales que son de muy elevada edad (seguramente con cierta incidencia de la demencia senil o lesiones frontales) o psicópatas infantiles sin estructura familiar ni social. 
Este mismo autor, (2011, op.cit) propone 4 repercusiones que provoca el asesinato serial:

1. La magnitud de la alarma social: los asesinos seriales son personas "desconocidas" que hace que cualquier persona pueda ser un temido agresor. Esta "invisibilidad" del agresor crea una alarma social.

2. La indeterminación de las víctimas: las víctimas son elegidas muchas veces de manera aleatoria, o son personas vulnerables, por lo que de igual manera que el desconocimiento del agresor crea un miedo en la sociedad.

3. El terror como "herramienta criminal": el asesino actúa con una agresividad y sadismo extremos. Necesitan dominar y sentir el poder, lo que les lleva a torturar a sus víctimas hasta la muerte.

4. La soledad del criminal: una vez cometido el crimen los agresores vuelven a su vida "normal", a esa insatisfacción por no haber realizado del todo su fantasía, lo que le llevará a panificar otro crimen.

Para Godwin y Rosen (2006) el típico asesino americano tiene una media de 8 víctimas. La edad de las víctimas suele ser muy similar en cada asesino, y la edad del mismo ronda entre los 18 y 50 años, destacando que sólo el $3 \%$ mata a adolescentes. Nosotros reseñamos que independientemente de si mata o no adolescentes todos matan a víctimas relativamente fáciles, no hemos encontrado ningún asesino en serie que mate policías, miembros de seguridad o militares

Los estudios de Leyton (1984) se centran en la sociedad americana, si bien también toma en cuenta la Unión Soviética con asesinos seriales como Andrei Chikatilo (alias el carnicero de Rostov). Este asesino en serie ruso mataba a niños, chicas y mujeres, a menudo mendigos y prostitutas teniendo predilección por los niños. En cuanto los niños, su víctima más joven fue de siete años y el mayor de 16. Respecto a los adultos, la víctima de mayor edad fue una vagabunda alcohólica de 44 años. El asesino utilizaba como método de aproximación a sus víctimas el engaño, generalmente a los menores les decía que les iba a mostrar un cachorro, un aparato de vídeo o unos sellos. Cometía sus asesinatos principalmente en la región de Rostov, donde vivía Chikatilo, así como en otras regiones como la de Moscú. El primer contacto que establecía con sus víctimas lo solía hacer en las estaciones de tren. Muchos de sus asesinatos los cometió en las zonas de bosque (por lo que también se ale apodó el asesino de los bosques) que protegían las vías del ferrocarril de las nevadas. Chikatilo 
utilizaba un cuchillo y en los cuerpos de sus víctimas se encontraban hasta 60 puñaladas. Sacaba los ojos de sus víctimas porque no podía soportar su mirada. A algunos de ellos los violaba. En algunos casos les hacía cortes y luego les mordía las orejas, los genitales y los pechos, e incluso llegó a extraer un corazón. En una ocasión, tras matar a una estudiante húngara y mutilarla, recogió algunas partes de su cuerpo envueltas en la ropa de la víctima y con todo ello se dirigió a celebrar el cumpleaños de su padre desde la más aparente normalidad.

Centrándonos en la cultura americana, aunque evidentemente aplicable a otras sociedades y siguiendo al autor citado se encuentran una serie de variables sociales que explicarían parte del fenómeno del asesino serial.

a.- Cultura de la violencia: Que implica que la violencia está legitimizada en forma de autoafirmación, que inclusive es noble y hábil y que el más mínimo agravio puede ser pagado con sangre. Esta cultura aparece de forma patente o sublimada en el cine, internet, TV y en la posesión legal de armas.

b- Cultura del miedo: desde pequeños a los niños americanos se les enseña a protegerse de cualquier evento exterior, ya sea prepararse para una guerra atómica o regalarle en sus primeros cumpleaños armas de autodefensa con la cual practican de forma lúdica y ociosa en familia. El empleo de la violencia es en muchas ocasiones convertido en una digna reclamación moral que unida a la enorme tolerancia sobre las armas favorece que determinados sujetos se lancen a una lucha en masa, frenética o serial con bastante facilidad. Al mismo tiempo la violencia se construye sobre la premisa de su virilidad, como una actitud de hombría deseable en el imago masculino, si bien no en el salvajismo al menos en la certeza de una autodefensa férrea e industrializada.

c.- Cultura del individualismo competitivo: El sistema industrial priva de identidad al sujeto. La valía de una persona depende de su competitividad en el mercado y del cómo gerencia esa competitividad. Todo el mundo debe ser emprendedor en el sueño americano. El ideal del Yo se aleja estratosféricamente del Yo real de muchos sujetos. Esta ambición narcisista apunta hacia la consecución de imposibles y muchos sujetos con tendencias a la descarga agresiva descontrolada, comienzan a racionalizar una especie de salida más digna al conflicto. Los mismos asesinos seriales compiten entre ellos sobre quién ha matado más. Por otro lado, no hay asesino americano que no tenga un libro escrito o una película, luego a la par que se rompe con el opresor, se alcanza la 
fama. . En enero de 1978, Dennis Rader (BTK) había escrito “¿A cuántas tengo que matar para salir en los periódicos o para que este país me preste atención?’. Algunas mujeres le pidieron matrimonio y le enviaban dinero a la penitenciaria. Al final había acabado con el mismo "halo romántico" de asesinos en serie como Ted Bundy y J.Wayne Gracy, que se habían casado con admiradoras mientras estaban en prisión (Wenzl, Potter, Laviana y Kelly, 2011). Tristemente Cancy Sigal (citado en Leyton 1984, p. 386) afirmaba que "En Estados Unidos los asesinos son más valorados y ciertamente más admirados que sus víctimas”. 


\section{CAPÍTULO V: MARCO METODOLÓGICO DEL ESTUDIO SOBRE ASESINOS EN SERIE.}

El presente capítulo tiene como objetivo general ofrecer el marco metodológico de la investigación. Para ello, se estructuran las fases de la investigación, desde la planificación del estudio hasta la elaboración final del trabajo.

\subsection{OBJETO DE ESTUDIO Y UNIDAD DE ANÁLISIS}

En la presente Tesis Doctoral se pretende profundizar en el estudio de los asesinos en serie. Nuestra motivación ha sido conocer qué variables influyen en el comportamiento criminal de los asesinos en serie. Para poder ahondar en el conocimiento del tema, se han estudiado diferentes muestras de población: una muestra de asesinos seriales que actuaron en España, una muestra de asesinos en serie que actuaron en América del Norte y una muestra general internacional.

La metodología empleada ha sido la cualitativa, llevándose a cabo mediante criterios establecidos por los investigadores en base a la literatura.

Para llevar a cabo la presente investigación, se comenzaron ordenando los tiempos y fases del estudio. Seguidamente, se realizó una revisión de la literatura existente sobre el tema para crear el marco teórico y de esta manera, trabajar sobre una base teórica sólida sobre la que poder contrastar posteriormente nuestra investigación. El marco teórico ha sido confeccionado desde el principio del estudio y a lo largo de la parte metodológica, teniendo en cuenta que las publicaciones se actualizan constantemente. La búsqueda bibliográfica ha sido tanto física como virtual, utilizando para ello las bibliotecas de la Universidad de Salamanca y de la Universidad Pontificia de Salamanca. 
Tabla 30. Esquema general del proceso de investigación

\section{Fase 1. Definición del problema}

\begin{tabular}{|l|l|}
\hline Organización espacio-temporal de la investigación & $\begin{array}{l}\text { Durante esta primera fase realizamos la planificación } \\
\text { general del estudio, es decir, concretamos dónde y en } \\
\text { cuánto tiempo aproximado se iba a llevar a cabo la } \\
\text { investigación. }\end{array}$ \\
\hline Formulación teórica & $\begin{array}{l}\text { Realizamos un análisis exhaustivo de las } \\
\text { investigaciones similares y de aquéllas que aportaran } \\
\text { información relevante para así, crear una base teórica } \\
\text { sólida de información sobre la cual poder construir y } \\
\text { comparar nuestra investigación. }\end{array}$ \\
\hline
\end{tabular}

Fase 2. Elaboración del instrumento

\begin{tabular}{|l|l|}
\hline Elaboración de la ficha de variables & $\begin{array}{l}\text { Esta ficha fue elaborada a partir de la literatura } \\
\text { eligiendo las variables más relevantes en la explicación } \\
\text { del comportamiento criminal de un asesino en serie. }\end{array}$ \\
\hline Análisis interjueces & $\begin{array}{l}\text { Dicha ficha, fue sometida posteriormente a una } \\
\text { valoración interjueces por especialistas en la materia } \\
\text { pertenecientes a la Unidad de Análisis de la Conducta } \\
\text { Criminal de la Universidad de Salamanca para evaluar } \\
\text { el grado de acuerdo y desacuerdo en las variables } \\
\text { selecionadas. Durante el mismo proceso, se llevó a } \\
\text { cabo una segunda prueba interjueces con el fin de } \\
\text { seleccionar 13 variables que se utilizaron para hacer el } \\
\text { estudio internacional. }\end{array}$ \\
\hline
\end{tabular}

Fase 3. Recogida de datos

\begin{tabular}{|l|l|}
\hline Estudio comparativo & $\begin{array}{l}\text { La tercera etapa de la investigación se centró en la } \\
\text { búsqueda de la muestra de asesinos en serie que } \\
\text { actuaron en España y en EEUU. } \\
\text { Para esta búsqueda se utilizaron fuentes tanto físicas } \\
\text { como virtuales, en la Universidad de Salamanca y la } \\
\text { Universidad Pontificia de Salamanca, así como } \\
\text { contactando con investigadores de renombre en el } \\
\text { tema. Además en esta fase, se aplicó la ficha de } \\
\text { variables realizada a cada asesino de la muestra para así } \\
\text { obtener los datos cualitativos y poder llevar a cabo el } \\
\text { estudio. }\end{array}$ \\
\hline Estudio internacional & $\begin{array}{l}\text { Asimismo se hizo una búsqueda de asesinos en serie } \\
\text { internacional utilizando de nuevo fuentes físicas, } \\
\text { virtuales de la Universidad de Salamanca y de la } \\
\text { Universidad Pontificia de Salamanca, así como } \\
\text { información cedida por profesionales especialistas en la } \\
\text { materia. En esta fase se aplicó de nuevo la ficha de } \\
\text { variables a la muestra de asesinos en serie } \\
\text { internacional. }\end{array}$ \\
\hline
\end{tabular}

Fase 4. Sistematización y elaboración del documento final

\begin{tabular}{|l|l|}
\hline Análisis de los datos e interpretación & $\begin{array}{l}\text { Esta fase estuvo dedicada al análisis y clasificación de } \\
\text { la información obtenida en las fases anteriores. Una vez } \\
\text { hallados los resultados, finalizamos la fase con la } \\
\text { interpretación de los mismos. }\end{array}$ \\
\hline Síntesis y redacción de los resultados & $\begin{array}{l}\text { Esta última fase se basa en la composición, redacción y } \\
\text { discusión de la información obtenida en las etapas } \\
\text { anteriores. }\end{array}$ \\
\hline
\end{tabular}


En la etapa de elaboración del marco teórico, se hizo una revisión exhaustiva de la información disponible sobre los Perfiles Criminales y los asesinos en serie, de manera que se dilucidaran las variables a estudiar en este sentido. Tal y como apunta Hernández Sampieri (2010), la revisión de la literatura consiste en revelar, examinar y conseguir la bibliografía y otros materiales que sean de utilidad para el objeto de estudio, de donde se tiene que extraer y reunir la información relevante y necesaria que concierne a nuestro objeto de investigación. La revisión de la literatura es un proceso caracterizado por profundizar en el conocimiento existente y disponible ligado a nuestro planteamiento del problema. A su vez, es un producto de uno mayor: el reporte de la investigación (Yedigis y Winbach, 2005, citado en Hernández y Sampieri, 2010). De esta forma, una vez formulada la base teórica se procedió a llevar a cabo la siguiente etapa.

Esta segunda etapa se caracteriza por la realización de la ficha de variables con la que se ha trabajado sobre la muestra de asesinos en serie. Esta ficha fue elaborada a partir de la literatura consultada tanto en base física como virtual, eligiendo las variables más relevantes en la explicación del comportamiento criminal de un asesino en serie. Dicha ficha, fue sometida posteriormente a una valoración interjueces para evaluar el grado de acuerdo y desacuerdo en las variables seleccionadas. Durante el mismo proceso, se llevó a cabo una segunda prueba interjueces con el fin de seleccionar 13 variables que se utilizaron para hacer el estudio internacional.

La tercera etapa de la investigación se centró en la búsqueda de la muestra de asesinos en serie. Se ha de señalar, que respecto a los que actuaron en España sólo encontramos 24 asesinos en serie, lo cual limitó la muestra de asesinos en serie que actuaron en América del Norte, ya que en esta población existen muchos más casos. De manera que se establecieron las dos muestras de asesinos seriales, los que actuaron en España y los que actuaron en América del Norte, para posteriormente poder realizar el estudio comparativo entre las mismas. Asimismo se hizo una búsqueda de asesinos en serie internacional. Para esta búsqueda se utilizaron fuentes tanto físicas como virtuales, en la Universidad de Salamanca y la Universidad Pontificia de Salamanca, así como contactando con investigadores de renombre en el tema. Además en esta fase, se aplicó la ficha de variables realizada a cada asesino de la muestra para así obtener los datos cualitativos y poder llevar a cabo el estudio. 
La cuarta fase estuvo dedicada a la sistematización y elaboración del proyecto final. En este sentido, se organizó toda la información recopilada de los datos cualitativos para después poder llevar a cabo los análisis estadísticos, la interpretación y conceptualización de la información, intentando realizar así, las conclusiones. En la última etapa, de síntesis y redacción de los resultados, se contrastó toda la información y se elaboró la discusión correspondiente. El objetivo de esta etapa fue dar sentido a los datos, redactar los resultados, contrastarlos con estudios previos, etc.

\section{2. TÉCNICAS DE INVESTIGACIÓN}

\subsubsection{Revisión sistemática de una recogida de datos preliminar.}

Para la recogida de datos preliminar sobre asesinos en serie se utilizó un cuestionario criminológico sobre los mismos a nivel mundial en 2015, aunque dicho proceso supuso cuatro meses de trabajo y fue desarrollado de febrero a mayo de este mismo año, en la que participaron 250 alumnos del Grado de Criminología de la Universidad de Salamanca. La recogida de datos consistió en que cada uno de los alumnos debía cumplimentar una ficha de 143 variables relacionadas con características aplicables a asesinos seriales, elaborada previamente por los miembros integrantes de la Unidad de Análisis de la Conducta Criminal de la Universidad (UACC) de Salamanca, en la cual a cada alumno se le asignó un asesino en serie con el fin de que completara la ficha de variables en base a fuentes documentales de alto nivel científico para su posterior análisis.

Para que la ficha de variables se completase de una forma adecuada y correcta, se les proporcionó a los alumnos una guía de codificación desarrollada también por los miembros de la UACC. Este manual se elaboró con el propósito de definir y delimitar los términos y criterios que conforman la ficha de variables con la finalidad de que fuese cumplimentada en todos los casos en base a un mismo patrón de respuestas. (Véase Anexo 1) 


\subsubsection{Ficha de variables.}

Partiendo de la recogida de datos preliminar, se constituyó el instrumento de medida utilizado para esta investigación, realizado a partir de la literatura consultada teniendo en cuenta las variables más relevantes que pueden influir en el comportamiento de los agresores y las analizadas en la recogida de datos previa y sometida después a una valoración interjueces. Este grupo está formado por un equipo multidisciplinar especialistas en la materia. El conjunto de especialistas lo conforman: 7 Psicólogos expertos en diferentes modelos clínicos como Terapia Familiar y de Pareja, Mediación y Orientación Familiar, Psicoanálisis, Psicología General Sanitaria y Metodología de la Investigación, como al mismo tiempo en Psicología Jurídico-Forense; 4 Criminólogos, 1 Informático, 1 Abogado y diversos miembros de los Cuerpos de Seguridad del Estado; pertenecientes a la Unidad de Análisis de la Conducta Criminal de la Universidad de Salamanca dirigida por el Doctor Francisco Javier de Santiago Herrero y codirigida por Luis Miguel Sánchez Gil. Las 40 variables que finalmente fueron seleccionadas, (veáse Anexo 2) se escogieron teniendo en cuenta el número de acuerdos y desacuerdos sobre la relevancia de las mismas en este estudio con una validez de 0,823. Dentro de este mismo proceso, se realizó una segunda prueba interjueces para seleccionar las 13 variables que se utilizaron para confeccionar la ficha para el estudio de la muestra de asesinos en serie internacional. (Véase Anexo 3). El resto de variables manejadas no fueron incluidas en la ficha final debido al elevado número de desacuerdos entre los especialistas. De manera que una vez realizada la ficha de variables se aplicaría a la muestra de asesinos en serie cuya zona de actuación fue España así como a la muestra de asesinos seriales que actuaron en América del Norte y finalmente a la muestra de asesinos en serie internacional.

Del mismo modo que se empleó la guía de codificación elaborada por los distintos miembros de la UACC para la correcta cumplimentación de la ficha de variables de la recogida de datos preliminar, fue utilizada para la presente investigación.

En este cuestionario se exponen en primer lugar las instrucciones, incluidas en la guía de codificación. En ellas se explica el funcionamiento del formato de respuesta, en el que han de tenerse en cuenta diversos aspectos:

- La no codificación de una variable significa el desconocimiento de los datos sobre la misma. 
- En caso de información de dudosa credibilidad o datos enfrentados sobre los que no se puede dilucidar, con algo de certeza, la codificación de una variable, deberá optar por su no cumplimentación. Es decir, se opta por el desconocimiento de los datos antes que por la codificación errónea.

- Las variables no señaladas explícitamente como de respuesta múltiple, se entienden, automáticamente, como de respuesta única (p. ej. sexo).

- En las variables de elección múltiple, se seleccionaran todas aquellas opciones que concurran en el caso analizado (p. ej. tipo de arma), aunque no sea posible que lo hagan de forma simultánea (p. ej. estado civil) pero sí a lo largo del periodo homicida en cuestión.

- Cuando en una variable nominal abierta se presenten múltiples respuestas, estas se anotaran separadas por punto y coma (p. ej. nombre).

Una vez comprendidas y entendidas las pautas expuestas anteriormente, se procedió a la recopilación de información sobre la muestra de asesinos en serie seleccionada. Para ello se recurrió a sentencias judiciales, bibliografía con elevado rigor científico, consultas con las Fuerzas de Seguridad del Estado, así como con personal docente e investigador expertos en la materia de estudio. Tras la recogida de información bibliográfica se procedió a la cumplimentación de las fichas de variables correspondientes a cada asesino en serie pertenecientes a la muestra.

\subsection{INFORMANTES}

\subsubsection{Selección de informantes y acceso.}

Según León y Montero (2003), los individuos elegidos para la muestra de una investigación deben cumplir tres características: representatividad, idoneidad y accesibilidad.

Los participantes resultan representativos si se asemejan al resto de población objeto de estudio, de los que los mismos conforman un subconjunto. Esta característica va a permitir generalizar los resultados a poblaciones que reúnan las mismas características, aunque se encuentren en contextos distintos.

La idoneidad hace referencia a la adecuación de los participantes al fenómeno que se pretende investigar. Y por último, la accesibilidad se refiere al nivel de dificultad 
para encontrar participantes y tener en cuenta las limitaciones espacio-temporales del estudio.

Para Hernández Sampieri et al. (2010), al seleccionar una muestra se pretende que la misma represente de manera fidedigna al conjunto de la población. En nuestro caso, hemos tenido en cuenta esta información para nuestra investigación. Así, los subconjuntos de sujetos estuvieron determinados por la zona de actuación en la que llevaron a cabo los asesinatos.

\subsubsection{Perfil de los informantes.}

\section{a. Estudio Comparativo.}

El perfil de los sujetos que componen la muestra, se ha establecido en función de la zona de actuación donde realizaron los asesinatos. Hemos recogido un total de 48 cuestionarios correspondientes cada uno de ellos a un asesino serial para la primera parte de la investigación, es decir, el estudio comparativo entre asesinos en serie que actuaron en España y asesinos en serie que actuaron en América del Norte. La muestra se compone de 48 asesinos en serie, 24 cuya zona de actuación fue España y 24 cuya zona de actuación fue América del Norte. En relación a los 24 asesinos en serie que actuaron en España, 17 son varones y 7 son mujeres. Asimismo, de los 24 asesinos seriales cuya zona de actuación fue América del Norte, 22 son hombres y 2 son mujeres.

La media de edad de inicio de los asesinatos del total de asesinos seriales incluidos en la muestra del primer estudio es de 31 años, siendo la mínima 12 y la máxima de 50 años. En cuanto a los asesinos seriales que actuaron en España, la media de edad de inicio de los asesinatos se sitúa en aproximadamente 32 años, siendo la mínima 12 y la máxima de 50 años. Por otro lado, la media de edad de inicio de los asesinatos de los sujetos que actuaron en América del Norte es de aproximadamente 30 años, siendo la mínima 14 y la máxima de 48 años.

Respecto al estado civil de los sujetos que forman la muestra, un 42,6\% (20 casos) del total de la muestra analizada son solteros, de los cuales un 25,5\% (12 casos) actuaron en España y un 17\% (8 casos) actuaron en América del Norte. Además, un 42,6\% (20 casos) de los sujetos casados, un 23,4\% (11 casos) actuaron en América del 
Norte frente a un 19,1\% (9 casos) que lo hicieron en España. Finalmente, de los sujetos incluidos en la muestra, tan sólo un 14,9\% (7 casos) estaban separados o divorciados.

Centrándonos en la orientación sexual de los individuos, un 83,0\% (39 casos) del total de la muestra son heterosexuales, de los cuales un 46,8\% (22 casos) actuaron en España y un 36,2\% (17 casos) lo hicieron en América del Norte. Además, el 10,6\% ( 5 casos) del total de asesinos en serie incluidos en la muestra son bisexuales, siendo un 8,5\% (4 casos) asesinos que actuaron en América del Norte y un 2,1\% (1 caso) que actuó en España. Por último, tan sólo un 6,4\% (3 casos) del total de la muestra son homosexuales.

\section{b. Estudio Internacional.}

La muestra de este estudio internacional está formada por 100 asesinos en serie procedentes de diferentes zonas geográficas a nivel mundial. Para el estudio de la misma, se han recogido 100 cuestionarios, cada uno de ellos pertenecientes a un asesino serial.

En relación al sexo de los mismos, un 85\% (85 casos) de los asesinos en serie incluidos en la muestra son hombres y un 15\% (15 casos) son mujeres.

La media de edad de inicio de los asesinatos del total de asesinos seriales incluidos en la muestra del segundo estudio es de 31 años, siendo la mínima 9 y la máxima de 55 años.

En cuanto a la zona de procedencia de los asesinos seriales incluidos en este estudio, 36 son de Europa del Oeste, 5 son de Europa del Oeste, 1 es de Asia Oriental, 3 son de Asia Occidental, 39 son norteamericanos, 12 son sudamericanos y 4 son canadienses. 


\subsection{PROCEDIMIENTO}

\subsection{1. Ámbito geográfico.}

Nuestra investigación se ha llevado a cabo en un área geográfica concreta: Salamanca (España). La investigación tuvo como lugares centrales las Facultades de Derecho y Psicología de la Universidad de Salamanca, así como la Universidad Pontificia de Salamanca. En estos lugares se llevaron a cabo las fases del planteamiento del problema, planificación de la investigación, análisis de datos y su consiguiente interpretación, así como la redacción y discusión de resultados.

\subsubsection{Período cronológico de la investigación.}

La investigación se ha desarrollado en un período total de un año, comenzando en abril de 2015 y finalizando en mayo de 2016.

La primera etapa de planificación de la investigación fue llevada a cabo en abril de 2015. De mayo a septiembre de 2015 se desarrolló el marco teórico, por lo que leímos y sintetizamos numerosos artículos y libros referentes al objeto de estudio. El cuestionario criminológico final fue realizado en los meses de septiembre y octubre de 2015 y los datos referentes a los asesinos en serie que componen la muestra fueron recogidos en esos mismos meses. La cumplimentación de las fichas de cada asesino en serie pertenecientes tanto a la muestra del estudio comparativo como al estudio internacional, fue realizada en el mes de octubre. A inicios de noviembre de este mismo año, procedimos con el análisis de datos, empezando en un primer lugar con el análisis descriptivo de los mismos, para continuar posteriormente con el análisis inferencial que daría respuesta a las hipótesis planteadas previamente para el desarrollo de estas investigaciones, llevando a cabo en un primer lugar el análisis de datos del primer estudio comparativo y posteriormente el análisis del estudio internacional. Una vez analizados los datos, comenzamos con su interpretación y discusión, finalizando esta fase a principios de febrero de 2016. A la par, fuimos trabajando el marco teórico de la investigación. Finalizada esta etapa, llevamos a discusión la interpretación de los datos y su obligada conexión con el resto de información y datos sobre el tema. Esta fase llegó a su término a principios de marzo de 2016. Por último, redactamos las conclusiones del estudio y su discusión, revisamos que todas las citas estuvieran 
referenciadas en la bibliografía, estudiamos en profundidad la investigación y llevamos a cabo las correcciones necesarias. Esta revisión final fue llevada a cabo en abril de 2016. 


\section{CAPÍTULO VI: ESTUDIO COMPARATIVO DE UNA MUESTRA DE ASESINOS EN SERIE QUE ACTUARON EN ESPAÑA Y EN AMÉRICA DEL NORTE.}

Como hemos expuesto en capítulos precedentes, de la amplia revisión bibliográfica efectuada, se desprende que existen una serie de variables asociadas a la conducta de los asesinos en serie, así como el tipo de arma empleada, la selección de las víctimas, antecedentes de maltrato en la infancia, patología mental, estado civil...

De manera que en un intento de determinar el grado en que las variables expuestas previamente encuentran apoyo empírico en la presente Tesis Doctoral, son varios los objetivos que nos planteamos en este estudio tal y como indicamos a continuación.

\subsection{OBJETIVOS}

(1) Analizar el perfil sociodemográfico de los participantes, considerados globalmente y agrupados en función de su zona de actuación.

(2) Analizar qué variables psicológicas influyen en el comportamiento criminal de los asesinos seriales dependiendo de su zona de actuación.

(3) Analizar qué antecedentes de la infancia de los asesinos en serie influyen en el comportamiento criminal en función de su zona de actuación.

(4) Analizar qué variables pertenecientes al ritual de actuación de los asesinos en serie influyen en su comportamiento criminal en función de su zona de actuación.

(5) Analizar las diferencias existentes en cuanto a la tipología del FBI y la zona de actuación de los asesinos seriales. 


\subsection{HIPÓTESIS}

(1) Comprobar la relación entre el nivel intelectual de los asesinos en serie y la zona de actuación.

(2) Comprobar la relación entre presentar patología mental y la zona de actuación de los asesinos seriales.

(3) Comprobar la relación entre haber sufrido algún tipo de maltrato en la infancia y la zona de actuación.

(4) Comprobar la relación entre el modo de interacción verbal con las víctimas y la zona de actuación.

(5) Comprobar la relación entre haber llevado a cabo conductas sádicas y de tortura con las víctimas según la zona de actuación.

(6) Comprobar la relación entre haber llevado a cabo conductas de mutilación con las víctimas y la zona de actuación.

(7) Comprobar la relación entre haber llevado a cabo relaciones sexuales con las víctimas post-mortem y la zona de actuación.

(8) Comprobar la relación entre la clasificación Tipo I (FBI) y la zona de actuación.

\subsection{MÉTODO}

\subsubsection{Informantes}

La muestra perteneciente a este estudio está formada por 48 asesinos en serie. Esta muestra está dividida en 24 asesinos seriales que actuaron en España y 24 asesinos en serie que actuaron en América del Norte.

En relación al sexo de los participantes, se extrae que el 81,2\% (39 casos) de los asesinos en serie incluidos en la muestra son hombres, de los cuales un 45,8\% (22 casos) actuaron en América del Norte y un 35,4\% (17 casos) lo hicieron en España. De lo mismo, se observa que tan sólo un 18,8\% (9 casos) de los casos incluidos son mujeres, de las cuales 7 (14,6\%) tuvieron su zona de actuación en España y 2 (4,2\%) 
actuaron en América del Norte. Estos resultados aparecen representados en la Tabla 31 y Figura 14.

Tabla 31. Distribución de frecuencias de la variable sexo en cada zona de actuación.

\begin{tabular}{|c|c|c|c|c|c|}
\hline & & & \multicolumn{2}{|c|}{ Zona de Actuación } & \multirow[b]{3}{*}{ Total } \\
\hline & & & & Térica del & \\
\hline & & & España & Norte & \\
\hline \multirow[t]{4}{*}{ Sexo } & Hombre & Recuento & 17 & 22 & 39 \\
\hline & & $\%$ del total & $35,4 \%$ & $45,8 \%$ & $81,3 \%$ \\
\hline & Mujer & Recuento & 7 & 2 & 9 \\
\hline & & $\%$ del total & $14,6 \%$ & $4,2 \%$ & $18,8 \%$ \\
\hline \multirow[t]{2}{*}{ Total } & & Recuento & 24 & 24 & 48 \\
\hline & & $\%$ del total & $50,0 \%$ & $50,0 \%$ & $100,0 \%$ \\
\hline
\end{tabular}

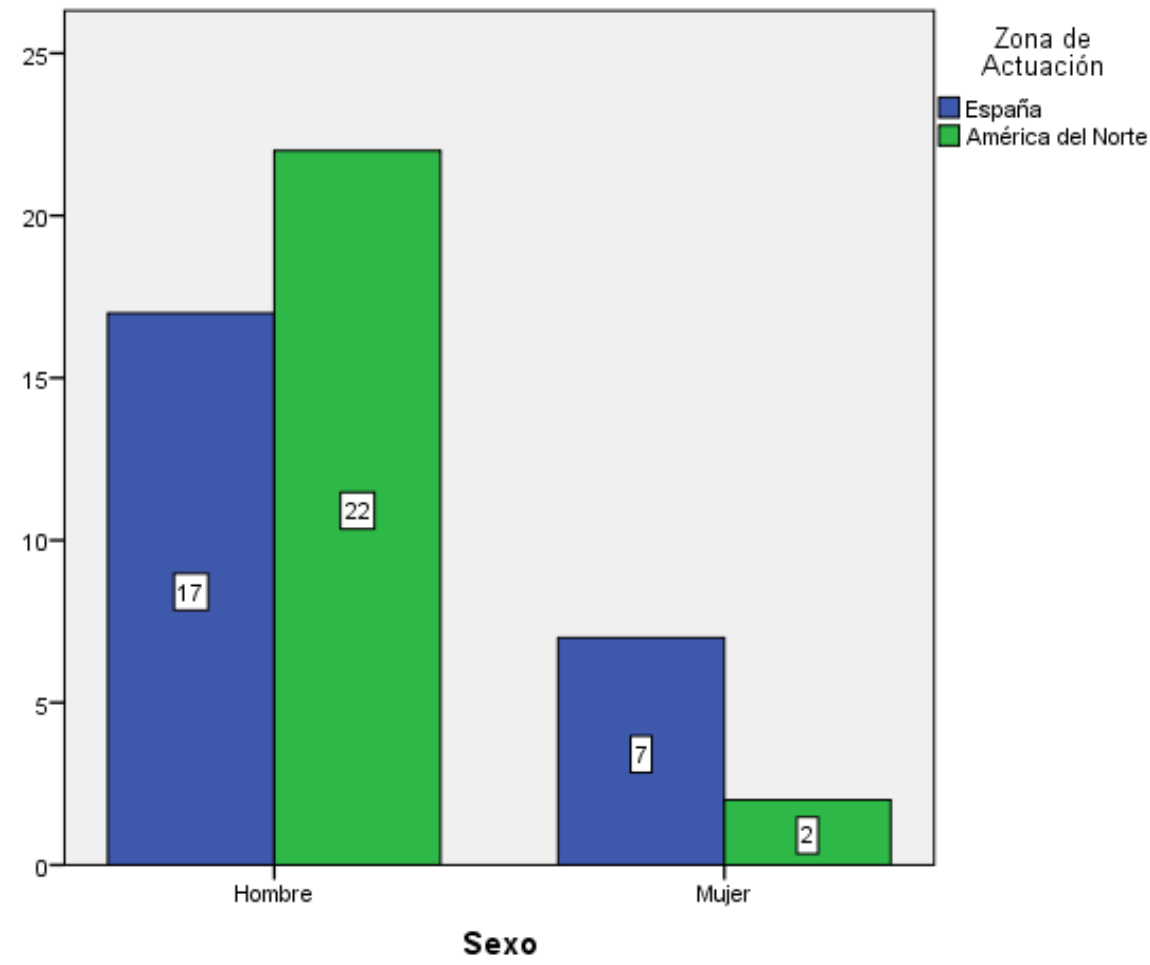

Figura 14. Gráfico de barras agrupadas de la variable sexo en cada zona de actuación.

En cuanto al año de nacimiento, en esta muestra de 24 asesinos en serie cuya zona de actuación es España, el año de nacimiento de los mismos no se aproxima a una distribución normal (asimétrica, As= -2,869 y leptocúrtica $K=10,376$ ). El año medio de nacimiento ha sido aproximadamente en 1953 (mediana 1958) con una desviación típica de 23,794 tal y como se observa en la Tabla 32 y Figura 15. 
Tabla 32. Estadísticos descriptivos de la variable año de nacimiento de los asesinos en serie que actuaron en España.

\begin{tabular}{|c|c|c|}
\hline \multirow[t]{2}{*}{$\bar{N}$} & Válidos & 24 \\
\hline & Perdidos & 0 \\
\hline \multicolumn{2}{|c|}{ Media } & 1953,42 \\
\hline \multicolumn{2}{|c|}{ Error típ. de la media } & 4,857 \\
\hline \multicolumn{2}{|c|}{ Mediana } & 1958,00 \\
\hline \multicolumn{2}{|c|}{ Moda } & 1965 \\
\hline \multicolumn{2}{|c|}{ Desv. típ. } & 23,794 \\
\hline \multicolumn{2}{|c|}{ Varianza } & 566,167 \\
\hline \multicolumn{2}{|c|}{ Asimetría } & $-2,869$ \\
\hline \multicolumn{2}{|c|}{ Error típ. de asimetría } & ,472 \\
\hline \multicolumn{2}{|c|}{ Curtosis } & 10,376 \\
\hline \multicolumn{2}{|c|}{ Error típ. de curtosis } & ,918 \\
\hline
\end{tabular}

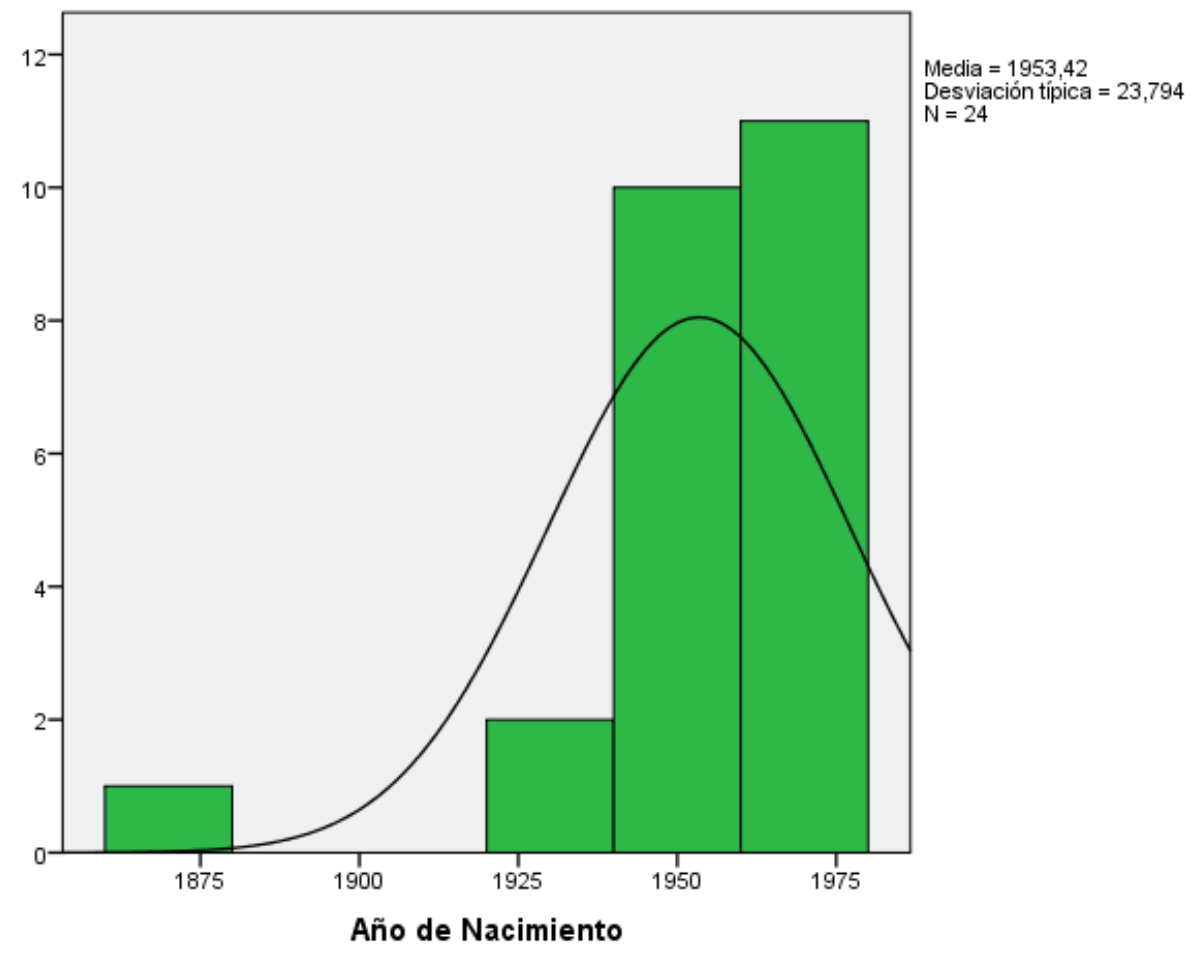

Figura 15. Histograma de frecuencias de la variable año de nacimiento de los asesinos en serie que actuaron en España. 
En esta muestra de 24 asesinos en serie cuya zona de actuación es América del Norte, el año de nacimiento de los mismos no se aproxima a una distribución normal (asimétrica, As= $-1,833$ y leptocúrtica $\mathrm{K}=3,709$ ). El año medio de nacimiento ha sido aproximadamente en 1940 (mediana 1946) con una desviación típica de 21,407 tal y como se observa en la Tabla 33 y en la Figura 16.

Tabla 33. Estadísticos descriptivos de la variable año de nacimiento de los asesinos en serie que actuaron en América del Norte.

\begin{tabular}{|c|c|c|}
\hline \multirow[t]{2}{*}{$\mathrm{N}$} & Válidos & 24 \\
\hline & Perdidos & 0 \\
\hline \multicolumn{2}{|c|}{ Media } & 1940,08 \\
\hline \multicolumn{2}{|c|}{ Error típ. de la media } & 4,370 \\
\hline \multicolumn{2}{|c|}{ Mediana } & 1946,00 \\
\hline \multicolumn{2}{|c|}{ Moda } & $1943^{\mathrm{a}}$ \\
\hline \multicolumn{2}{|c|}{ Desv. típ. } & 21,407 \\
\hline \multicolumn{2}{|c|}{ Varianza } & 458,254 \\
\hline \multicolumn{2}{|c|}{ Asimetría } & $-1,833$ \\
\hline \multicolumn{2}{|c|}{ Error típ. de asimetría } &, 472 \\
\hline \multicolumn{2}{|c|}{ Curtosis } & 3,709 \\
\hline \multicolumn{2}{|c|}{ Error típ. de curtosis } &, 918 \\
\hline
\end{tabular}

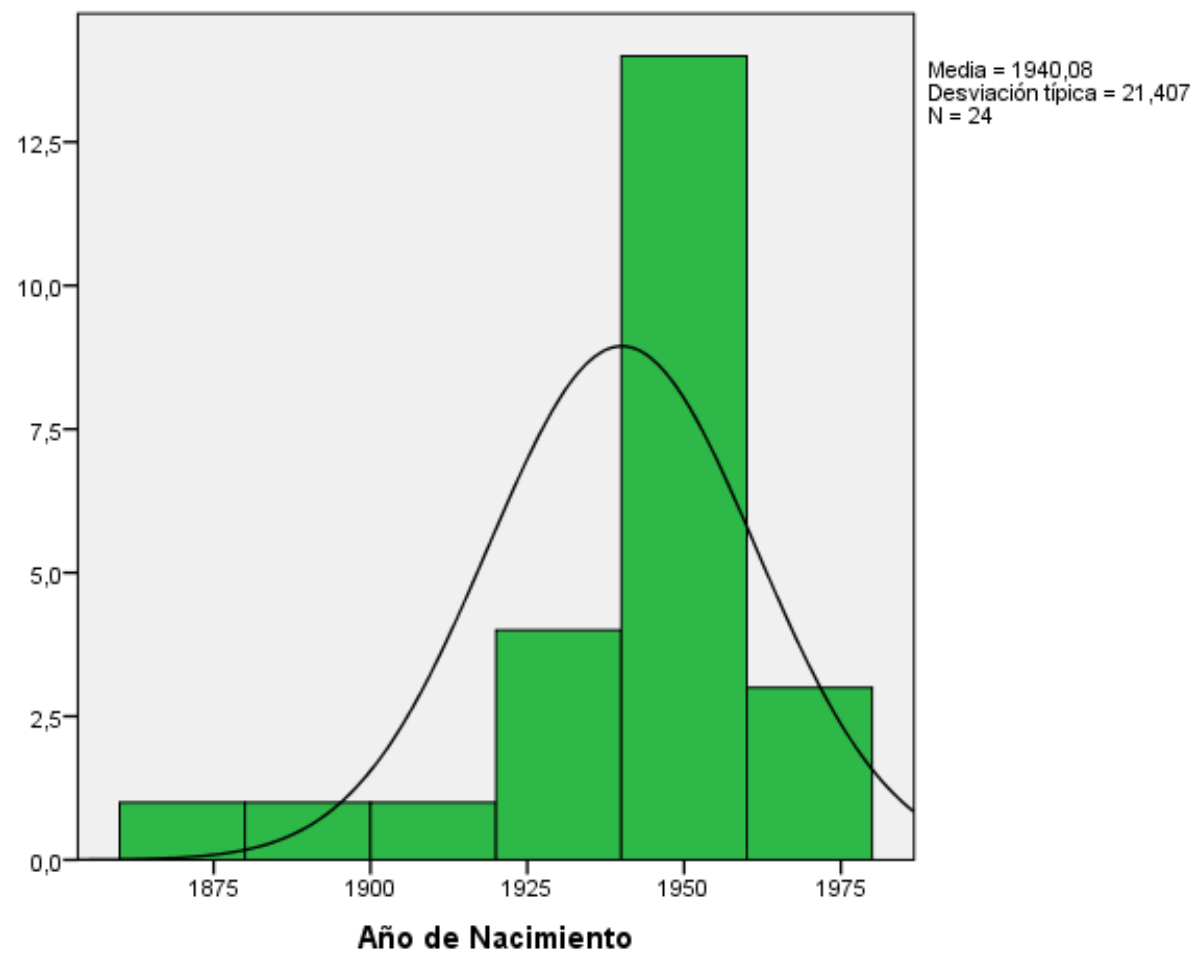

Figura 16. Histograma de frecuencias de la variable año de nacimiento de los asesinos en serie que actuaron en América del Norte. 
Con respecto a la edad de inicio de los asesinatos, en esta muestra de 24 asesinos en serie cuya zona de actuación es España, la edad de inicio de los asesinatos se aproxima a una distribución normal (simétrica, As= -0,219 y mesocúrtica $\mathrm{K}=0,023$ ). La edad media de inicio de los asesinatos ha sido aproximadamente 32 años (mediana 33) con una desviación típica de 8,744 como se observa en la Tabla 34 y Figura 17.

Tabla 34. Estadísticos descriptivos de la variable edad inicio de los asesinatos de los asesinos seriales que actuaron en España.

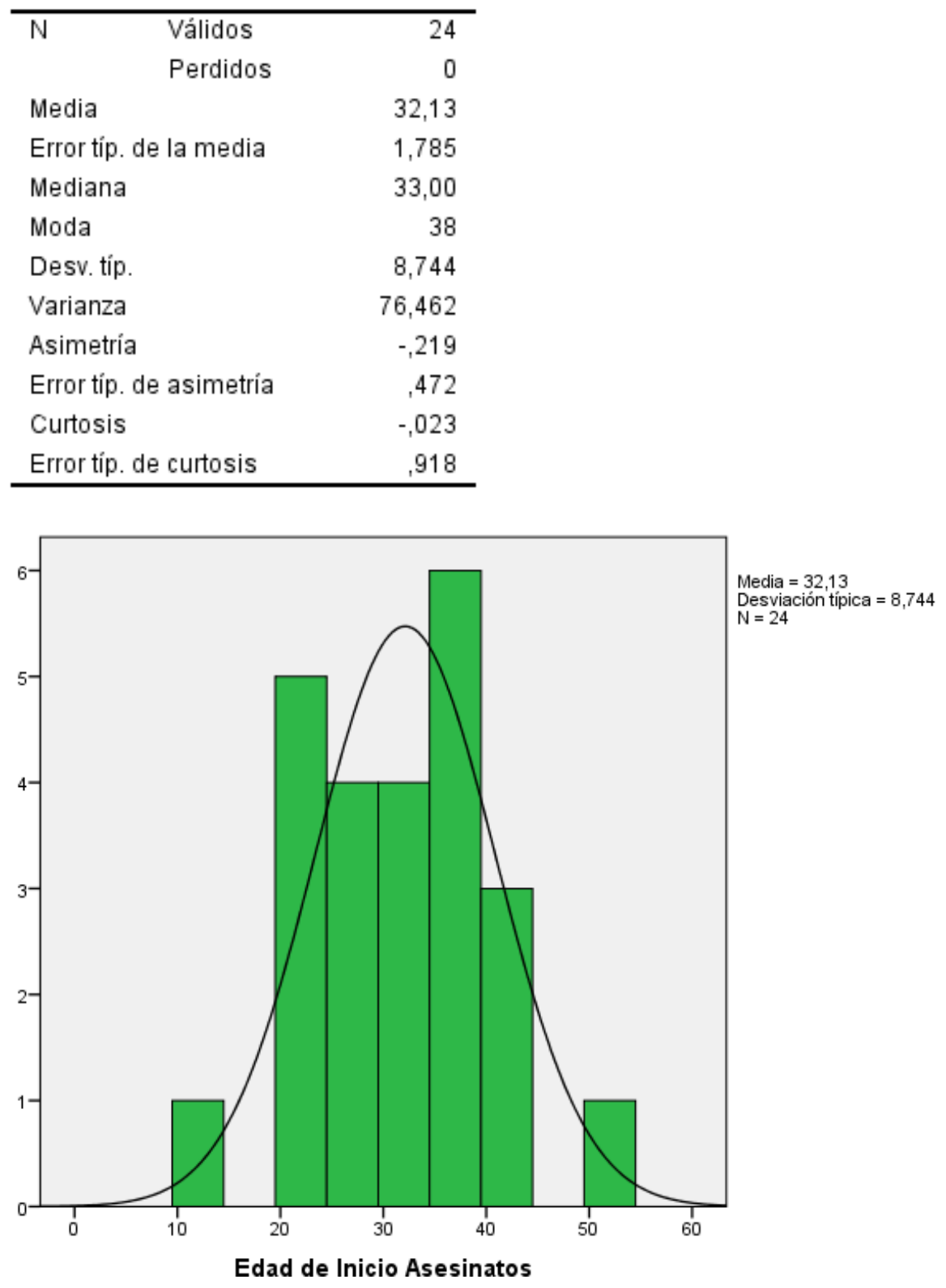

Figura 17. Histograma de frecuencias de la variable edad inicio de los asesinatos de los asesinos seriales que actuaron en España. 
En esta muestra de 24 asesinos en serie cuya zona de actuación es América del Norte, la edad de inicio de los asesinatos se aproxima a una distribución normal ( imétrica, As=0,119 y mesocúrtica $\mathrm{K}=0,234$ ). La edad media de inicio de los asesinatos ha sido aproximadamente 30 años (mediana 29) con una desviación típica de 8,295 como se puede observar en la Tabla 35 y Figura 18.

Tabla 35. Estadísticos descriptivos de la variable edad inicio de los asesinatos de los asesinos seriales que actuaron en América del Norte.

\begin{tabular}{lr}
\hline$N$ & $\begin{array}{c}\text { Válidos } \\
\text { Perdidos }\end{array}$ \\
Media & 0 \\
Error típ. de la media & 1,693 \\
Mediana & 29,80 \\
Moda & $29^{\mathrm{a}}$ \\
Desv. típ. & 8,295 \\
Varianza & 68,810 \\
Asimetría &, 119 \\
Error típ. de asimetría &, 472 \\
Curtosis &, 234 \\
Error típ. de curtosis &, 918 \\
\hline
\end{tabular}

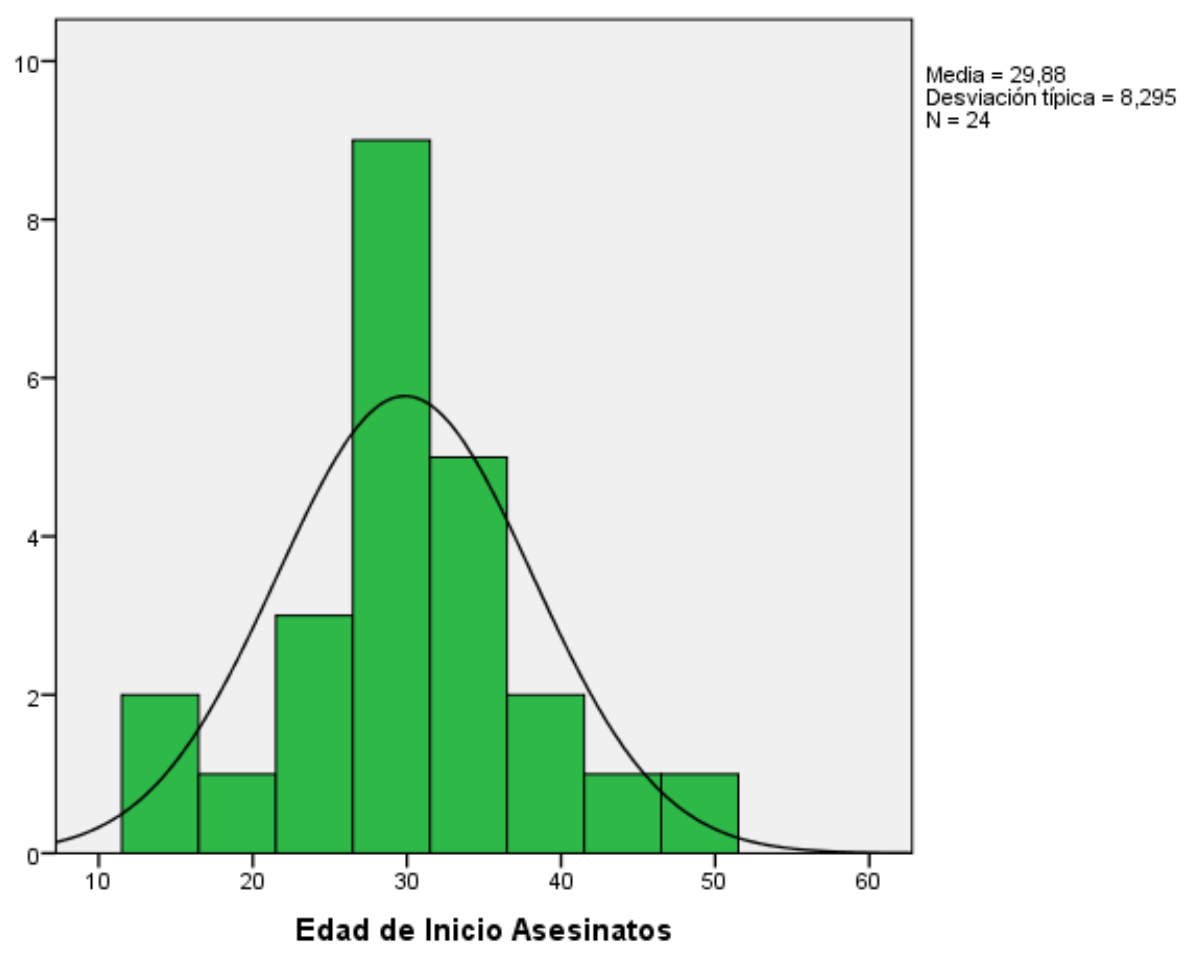

Figura 18. Histograma de frecuencias de la variable edad inicio de los asesinatos de los asesinos seriales que actuaron en América del Norte. 
En cuanto al período de actuación de los asesinos en serie pertenecientes a este estudio, se observa que de los 24 sujetos (50\%) incluidos en la muestra cuya zona de actuación fue América del Norte. 11 casos (22,9\%) actuaron en el período de 1970-1980 y 7 sujetos $(14,6 \%)$ lo hicieron entre 1980-1990.

Por otro lado, de los 24 asesinos en serie (50\%) incluidos en la muestra cuya zona de actuación fue España, 10 sujetos (20,8\%) lo hicieron entre 1990-2000 y 9 de ellos (18,8\%) actuaron en el período del 2000-2010. Estos datos pueden observarse en la Tabla 36.

Tabla 36. Distribución de frecuencias de la variable período de actuación en cada zona de actuación.

\begin{tabular}{|c|c|c|c|c|c|}
\hline & & & \multicolumn{2}{|c|}{ Zona de Actuación } & \multirow[b]{2}{*}{ Total } \\
\hline & & & España & América del Norte & \\
\hline \multirow[t]{20}{*}{ Período de Actuación ${ }^{a}$} & $1900-1910$ & Recuento & 0 & 1 & 1 \\
\hline & & $\%$ del total & $0,0 \%$ & $2,1 \%$ & $2,1 \%$ \\
\hline & $1910-1920$ & Recuento & 1 & 1 & 2 \\
\hline & & $\%$ del total & $2,1 \%$ & $2,1 \%$ & $4,2 \%$ \\
\hline & $1930-1940$ & Recuento & 0 & 1 & 1 \\
\hline & & $\%$ del total & $0,0 \%$ & $2,1 \%$ & $2,1 \%$ \\
\hline & $1950-1960$ & Recuento & 2 & 2 & 4 \\
\hline & & $\%$ del total & $4,2 \%$ & $4,2 \%$ & $8,3 \%$ \\
\hline & $1960-1970$ & Recuento & 2 & 5 & 7 \\
\hline & & $\%$ del total & $4,2 \%$ & $10,4 \%$ & $14,6 \%$ \\
\hline & $1970-1980$ & Recuento & 3 & 11 & 14 \\
\hline & & $\%$ del total & $6,3 \%$ & $22,9 \%$ & $29,2 \%$ \\
\hline & $1980-1990$ & Recuento & 6 & 7 & 13 \\
\hline & & $\%$ del total & $12,5 \%$ & $14,6 \%$ & $27,1 \%$ \\
\hline & $1990-2000$ & Recuento & 10 & 4 & 14 \\
\hline & & $\%$ del total & $20,8 \%$ & $8,3 \%$ & $29,2 \%$ \\
\hline & $2000-2010$ & Recuento & 9 & 0 & 9 \\
\hline & & $\%$ del total & $18,8 \%$ & $0,0 \%$ & $18,8 \%$ \\
\hline & $2010-2020$ & Recuento & 2 & 0 & 2 \\
\hline & & $\%$ del total & $4,2 \%$ & $0,0 \%$ & $4,2 \%$ \\
\hline \multirow[t]{2}{*}{ Total } & & Recuento & 24 & 24 & 48 \\
\hline & & $\%$ del total & $50,0 \%$ & $50,0 \%$ & $100,0 \%$ \\
\hline
\end{tabular}

Los porcentajes y los totales se basan en los encuestados.

a. Agrupación

En lo referente al estado civil de los asesinos en serie incluidos en este estudio, se extrae que un $42,6 \%$ (20 casos) del total de la muestra analizada son solteros, de los 
cuales un 25,5\% (12 casos) actuaron en España y un 17\% (8 casos) actuaron en América del Norte.

De lo mismo se observa que también un 42,6\% (20 casos) de los sujetos son casados, de los cuales un 23,4\% (11 casos) actuaron en América del Norte frente a un $19,1 \%$ (9 casos) que lo hicieron en España.

De los sujetos incluidos en la muestra, tan sólo un 14,9\% (7 casos) estaban separados o divorciados tal y como se observa en la Tabla 37 y Figura 19.

Tabla 37. Distribución de frecuencias de la variable estado civil en cada zona de actuación.

\begin{tabular}{|c|c|c|c|c|c|}
\hline & & & \multicolumn{2}{|c|}{ Zona de Actuación } & \multirow[b]{2}{*}{ Total } \\
\hline & & & España & América del Norte & \\
\hline \multirow[t]{6}{*}{ Estado Civil } & Soltero & Recuento & 12 & 8 & 20 \\
\hline & & $\%$ del total & $25,5 \%$ & $17,0 \%$ & $42,6 \%$ \\
\hline & Casado & Recuento & 9 & 11 & 20 \\
\hline & & $\%$ del total & $19,1 \%$ & $23,4 \%$ & $42,6 \%$ \\
\hline & Separado-Divorciado & Recuento & 3 & 4 & 7 \\
\hline & & $\%$ del total & $6,4 \%$ & $8,5 \%$ & $14,9 \%$ \\
\hline \multirow[t]{2}{*}{ Total } & & Recuento & 24 & 23 & 47 \\
\hline & & $\%$ del total & $51,1 \%$ & $48,9 \%$ & $100,0 \%$ \\
\hline
\end{tabular}

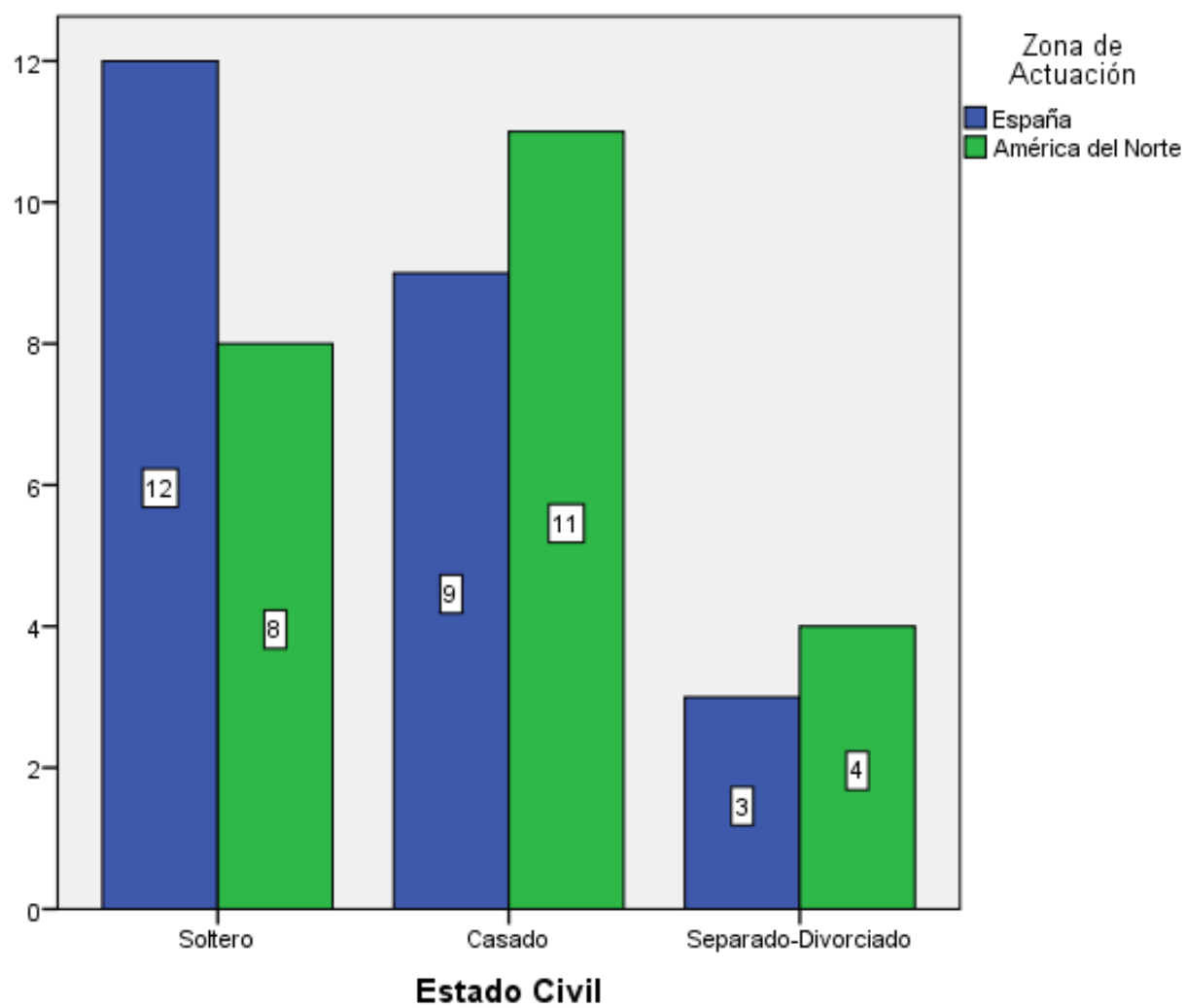

Figura 19. Gráfico de barras agrupadas de la variable estado civil en cada zona de actuación. 
En lo referente a la orientación sexual, se extrae que un 83,0\% (39 casos) del total de la muestra son heterosexuales, de los cuales un 46,8\% (22 casos) actuaron en España y un 36,2\% (17 casos) lo hicieron en América del Norte.

Además, se observa que el 10,6\% (5 casos) del total de asesinos en serie incluidos en la muestra son bisexuales, siendo un 8,5\% (4 casos) los asesinos que actuaron en América del Norte y un 2,1\% (1 caso) que actuó en España. Por último, tan sólo un 6,4\% (3 casos) del total de la muestra son homosexuales. (Tabla 38 y Figura 20)

Tabla 38. Distribución de frecuencias de la variable orientación sexual en cada zona de actuación.

\begin{tabular}{|c|c|c|c|c|c|}
\hline & & & \multicolumn{2}{|c|}{ Zona de Actuación } & \multirow[b]{2}{*}{ Total } \\
\hline & & & España & América del Norte & \\
\hline \multirow[t]{6}{*}{ Orientación Sexual } & Heterosexual & Recuento & 22 & 17 & 39 \\
\hline & & $\%$ del total & $46,8 \%$ & $36,2 \%$ & $83,0 \%$ \\
\hline & Homosexual & Recuento & 1 & 2 & 3 \\
\hline & & $\%$ del total & $2,1 \%$ & $4,3 \%$ & $6,4 \%$ \\
\hline & Bisexual & Recuento & 1 & 4 & 5 \\
\hline & & $\%$ del total & $2,1 \%$ & $8,5 \%$ & $10,6 \%$ \\
\hline \multirow[t]{2}{*}{ Total } & & Recuento & 24 & 23 & 47 \\
\hline & & $\%$ del total & $51,1 \%$ & $48,9 \%$ & $100,0 \%$ \\
\hline
\end{tabular}

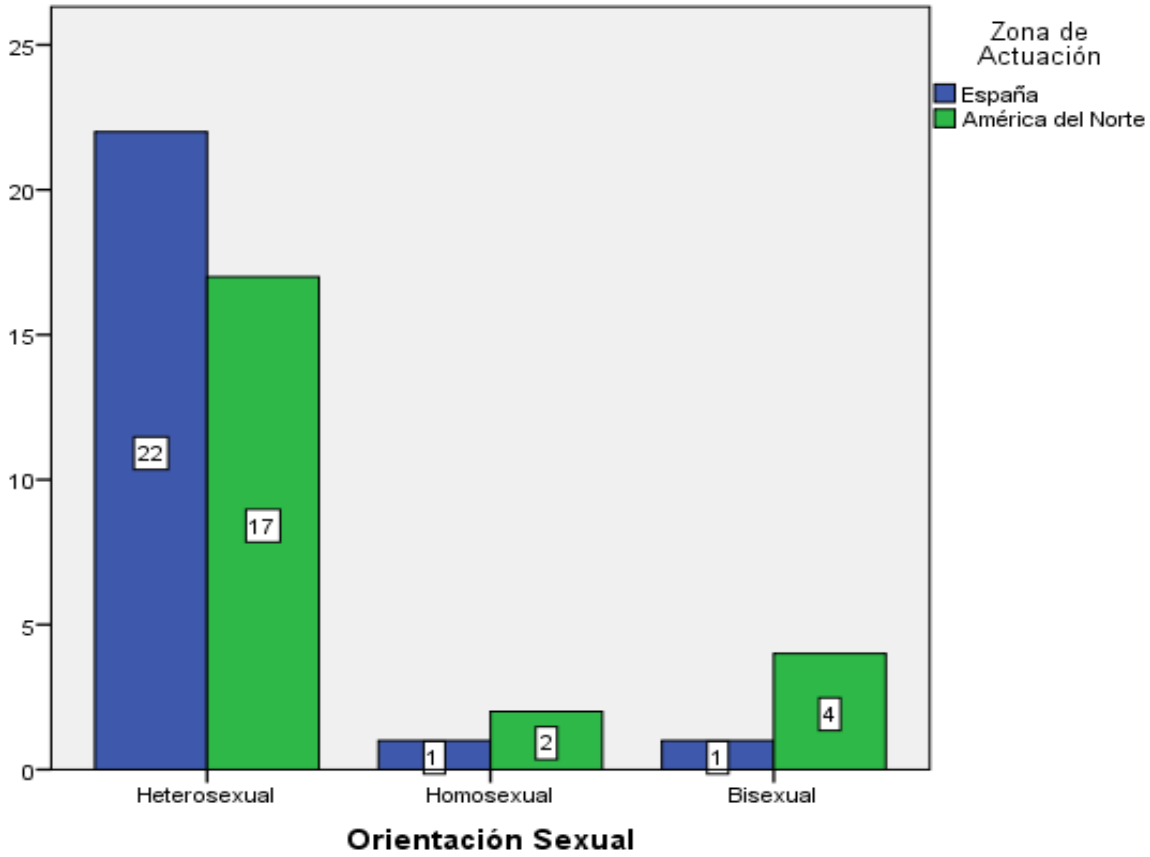

Figura 20. Gráfico de barras agrupadas de la variable orientación sexual en cada zona de actuación. 
En cuanto a la complexión de los asesinos en serie pertenecientes a este estudio, un 43,8\% (21 casos) de los mismos tienen una complexión fuerte-atlética, frente a un 39,6 (19 casos) que son delgados y tan solo un 16,7\% (8 casos) son obesos.

De los 8 sujetos que tienen una complexión obesa, 6 de ellos $(12,5 \%)$ tienen su zona de actuación en España. Estos datos se observan en la Tabla 39 y Figura 21.

Tabla 39. Distribución de frecuencias de la variable complexión en cada zona de actuación.

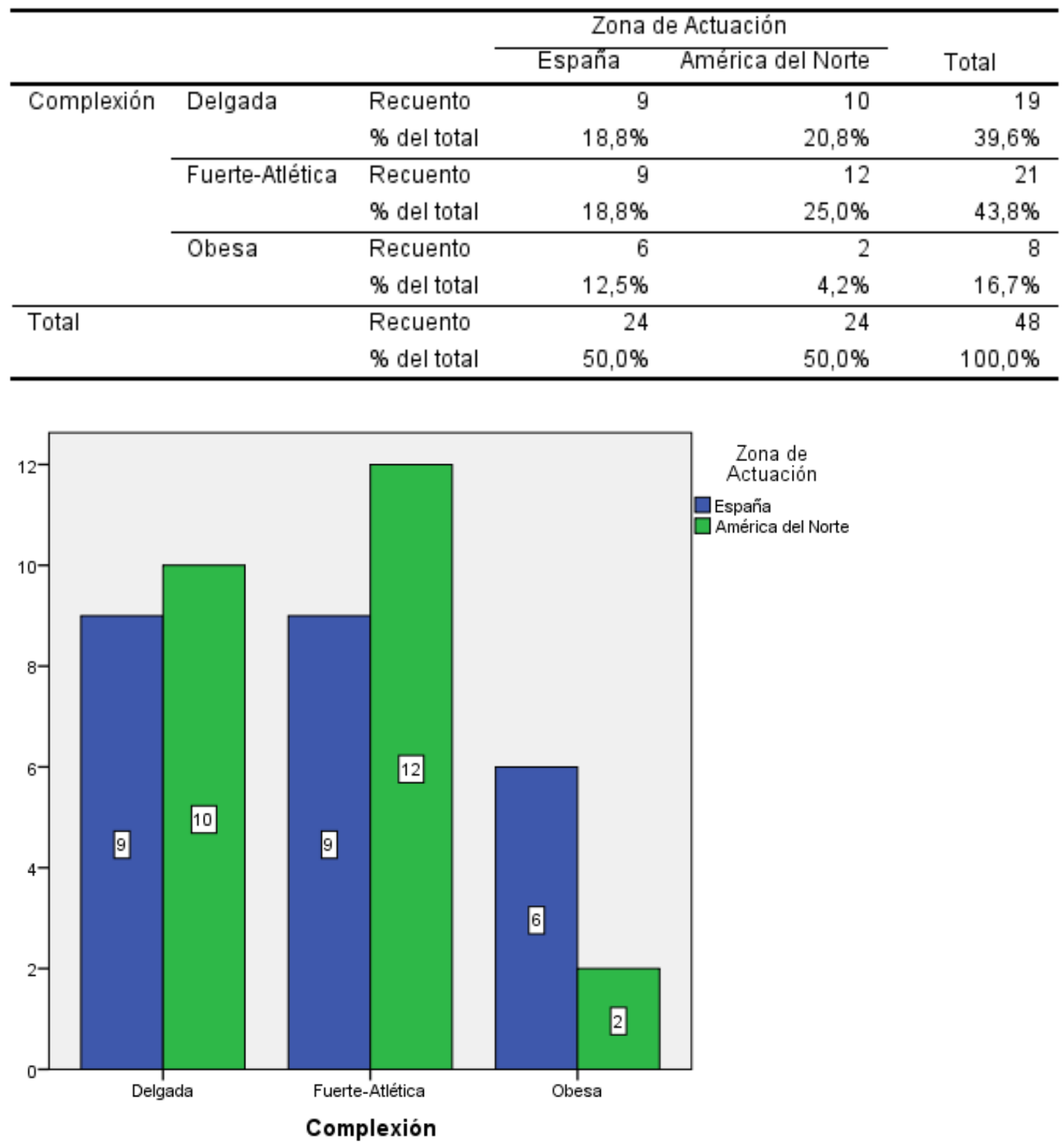

Figura 21. Gráfico de barras agrupadas de la variable complexión en cada zona de actuación. 


\subsubsection{Diseño.}

Para llevar a cabo este estudio, hemos empleado una metodología de la investigación correlacional, ya que el propósito de este estudio es observar la existencia de una correlación entre dos o más variables que no pueden ser analizadas experimentalmente. En este caso, hemos construido un instrumento de medición que contempla las variables a estudiar y cuyo posterior análisis estadístico de los datos nos permitirá obtener una certeza de la verdad o la falsedad de nuestras hipótesis. Consiste en la búsqueda de algún tipo de relación entre dos variables, y en qué medida la variación de una de las variables afecta a la otra, sin llegar a conocer cuál de ellas puede ser causa o efecto. La información que se recoja sobre las variables involucradas en la relación comprobará o no esa relación, en cuanto a su magnitud, dirección y naturaleza.

\subsubsection{Procedimiento.}

Los datos de la muestra de los asesinos en serie, fueron recogidos de la información obtenida a través de bibliografía científica, bases de datos (Infocop, Psycinfo) y el contacto con profesionales especialistas en la materia. Una vez recopilados los datos se procedió a la elaboración de la ficha final que utilizaríamos como instrumento en nuestra investigación. La información detallada del proceso de recogida de datos cualitativa se encuentra en el capítulo anterior (Marco Metodológico) por lo que, para evitar la reiteración de este proceso, omitiremos la descripción en este apartado.

\subsubsection{Instrumentos.}

Hemos partido de un instrumento de 40 variables que supone la versión reducida de la primera ficha que constaba de 143 variables creada por los miembros integrantes de la Unidad de Análisis de la Conducta Criminal de la Universidad de Salamanca.

En nuestro instrumento de 40 variables, hemos seleccionado las mismas por su relevancia en la literatura y después de haber realizado un análisis interjueces con numerosos especialistas en la materia. (Véase Anexo 2). 
Las variables seleccionadas han sido agrupadas en varias dimensiones que hemos denominado:

1. Variables sociodemográficas y físicas: Grupo de variables que comprende aquellas relativas a aspectos identificativos del sujeto y de su esfera familiar y social.

a. Nombre (nominal abierta). Debe ser tenido en cuenta que, especialmente en el caso de asesinos norteamericanos, no es extraño que el individuo tenga dos nombres. Deben ser reflejados todos los nombres que se conozcan del sujeto, separados por comas.

b. Apellidos (nominal abierta). Hay que considerar que, en muchos casos, el asesino puede tener un solo apellido. Deben ser reflejados todos los apellidos que se conozcan del sujeto, separados por comas.

c. Sexo (nominal cerrada). En su determinación se atenderá al sexo biológico del individuo, es decir, al que manifiestan sus órganos sexuales.

d. Complexión (ordinal cerrada). Constitución física de una persona, pudiéndose distinguir entre:

- Delgada: si es un individuo leptosómico.

- Fuerte/atlética: si el sujeto es musculoso o mesomórfico.

- Obesa: si es un sujeto pícnico.

e. Año de nacimiento (ordinal cerrada). El año será recogido en el formato "AAAA" (p. ej. 1989 codifica a un sujeto que nace en el año 1989).

f. Edad inicio asesinatos (numérica abierta). Hace referencia a la edad del agresor en el momento en que realiza el primer asesinato. Por tanto, no tiene que corresponder, necesariamente, con la edad en la que se inicia en la delincuencia, ya que pudo cometer otro tipo de delitos con anterioridad.

g. Periodo de actuación (numérica cerrada) (elección múltiple). Etapa/s durante la que el agresor desarrolló su actividad homicida.

h. Lugar de nacimiento (nominal abierta). Denominación del municipio o ciudad en el que nace el sujeto. 
i. País de procedencia (nominal cerrada). Lugar de nacimiento.

j. Estado civil (nominal cerrada) (elección múltiple). En caso de que varíe durante su periodo de actuación la codificación será múltiple.

k. Orientación sexual (nominal cerrada). En base al sexo biológico del individuo vendrá determinada por sus relaciones sexuales.

2. Variables psicológicas: Grupo de variables que recogen datos que el agresor manifiesta en el periodo de actuación homicida (incluyendo tanto los actos criminales en todas sus fases, como el posterior enfriamiento emocional). Queda excluida de este grupo la información relativa a otros periodos temporales, ocupándose de ella los grupos de "antecedentes en la infancia y adolescencia" e "historial edad adulta".

a. Nivel intelectual (ordinal cerrada). Inferido a través de su conducta o extraído de datos objetivos sobre el mismo.

- Bajo: si de sus actos se deducen signos de oligofrenia, su diagnóstico o un nivel inferior a la media.

- Medio: comprende a todos aquellos sujetos que se encuentran dentro de la franja media.

- Alto: cuando de su conducta se infiere que el individuo puede ser tener superdotación o un nivel superior a la media.

b. Rasgos psicopáticos (nominal cerrada) (elección múltiple). Deberán ser extraídos a través de las conductas manifestadas por el sujeto o informes realizados por profesionales de la Psiquiatría o la Psicología. Los rasgos son los siguientes:

- Falta de empatía: incapacidad de ponerse en el lugar de los demás, sobre todo emocionalmente.

- Manipulación/mentira: uso de recursos ajenos a la verdad, así como distorsión de la realidad para conseguir sus fines o por el mero placer de hacerlo.

- Versatilidad criminal: realización de varios actos delictivos de distinta índole. 
- Falta de responsabilidad: despreocupación por las obligaciones y los compromisos sociales, laborales, familiares y/o culturales.

- Encanto superficial: capacidad para generar en los demás una valoración positiva sobre su persona.

- Egocentrismo y elevada autovalía: elevado nivel de narcisismo y arrogancia. Fe ciega en sus capacidades y la superación de obstáculos.

- Impulsividad: incapacidad para regular la respuesta conductual y tener una actitud reflexiva.

- Falta de culpa: ausencia de preocupación por los efectos de sus actos en los demás.

- Estilo de vida parasitario: dependencia económica y/o material buscada y provocada respecto a terceras personas de las cuales se aprovecha,

- Promiscuidad sexual: establecimiento de relaciones sexuales polígamas.

- Superficialidad afectiva: imposibilidad de experimentar emociones fuertes, intensas y profundas.

c. Implicación en la vida social (ordinal cerrada). Será inferida de sus hábitos y la práctica de sus relaciones sociales, tanto por el número de las mismas como por el tiempo que invierte en ellas.

- Baja: si apenas mantiene relaciones sociales o estas son muy escasas y poco activas.

- Media: cuando el sujeto se relaciona con otros miembros de la sociedad de forma normal.

- Alta: comprende aquellos supuestos en los que el individuo destaca por una gran actividad social, con un gran número de lazos de amistad, compañerismo, etc.

3. Antecedentes infancia y adolescencia: Conjunto de variables que agrupan características y circunstancias relacionadas con los primeros años de vida del 
agresor, a fin de unificar posiciones se entenderá aproximadamente como final de esta etapa y comienzo de la edad adulta los 18 años.

a. Algún tipo de maltrato (nominal cerrada): hace referencia a haber sufrido algún tipo de maltrato ya sea físico o psicológico en la infancia.

4. Historia edad adulta: Conjunto de variables que recogen aspectos relativos a la vida adulta del sujeto, entendiéndose como punto de partida de la misma aproximadamente los 18 años y excluyendo el periodo homicida.

a. Algún tipo de maltrato (nominal cerrada): hace referencia a haber sufrido algún tipo de maltrato ya sea físico o psicológico en la edad adulta.

b. Patología mental (nominal cerrada): puede ser inferida a partir de su conducta o porque haya un diagnóstico sobre la misma.

5. Historial delictivo y de violencia: Grupo de variables relacionadas con las actividades violentas y criminales del agresor.

a. Antecedentes policiales (nominal cerrada). Historial de sanciones policiales (aunque no hayan llegado a considerarse de tipo penal). En cualquier caso, los antecedentes penales deben ser considerados también policiales, pero no necesariamente a la inversa.

6. Escena: Conjunto de variables que recogen características y elementos relacionados con los escenarios del crimen. Para ello, cabe precisar que entendemos por escena del crimen, de acuerdo con Turvey (2008), el «escenario donde el agresor y la víctima interactúan y donde, según el principio de transferencia de Locard, algo de cada uno de los actores se transferirá al otro 
dejando una huella que debe ser observada, recogida y analizada» (en Jiménez Serrano, 2010, p. 59).

a. Número de crímenes (numérica abierta). Hace referencia al número de actos (separados por un periodo de enfriamiento emocional). Es decir, recoge los sucesos y no las víctimas derivadas de los mismos, ya que, de un mismo acto, pueden resultar varias víctimas. En esta variable, serán contabilizados tanto los asesinatos/homicidios consumados como las tentativas.

7. Modus Operandi: grupo de variables que reúnen elementos relativos al Modus Operandi del agresor, entendido como el "conjunto de actos estrictamente necesarios para perpetrar el delito y obtener éxito en su comisión” (Soto, 2014, p.58).

a. Nivel de planificación (ordinal cerrada). Referida a la proyección que el agresor tiene sobre el acto criminal y que se reflejará en todas las fases del crimen, a partir de las cuales debe ser inferida.

b. Método de aproximación (nominal cerrada) (elección múltiple). Establecido por Turvey (2008) (en Jiménez Serrano, 2010), distinguiéndose entre:

- Explícito: el agresor se acerca a la víctima con la intención clara y manifiesta de efectuar el ataque, siendo esta consciente de ello y teniendo, de este modo, un breve tiempo de reacción.

- Súbito: el agresor toma contacto con la víctima y, sin dilación, efectúa el ataque.

- Sorpresa: el criminal sorprende a la víctima en un momento en que esta es vulnerable, bien porque está centrada en la ejecución de una tarea, bien porque está distraída, dormida, etc.

- Encubierto: el criminal se aproxima a la víctima sin manifestar ningún tipo actitud hostil de la que pueda inferirse una agresión $\mathrm{y}$, solamente, cuando esta puede ser efectiva realiza el ataque. 
- Engaño: el agresor se gana la confianza de la víctima empleando tretas.

- Se desconoce: no hay datos sobre cómo se produce la aproximación del agresor a la víctima.

c. Tipo de armas y utensilios empleados (nominal cerrada) (elección múltiple). Si concurre el uso de estos instrumentos se distingue entre:

- Armas contundentes: objetos de tipo romo (piedras, bastón, etc.).

- Armas blancas: cualquier instrumento punzante, cortante, cortopunzante o corto-contundente.

- Armas de fuego: comprende tanto armas cortas (revólveres y pistolas) como armas largas (escopetas, rifles, etc.).

- Instrumentos de inmovilización: cualquier objeto que sirva para privar a la víctima de libertad de movimientos. Los más típicos son los grilletes, las cuerdas, las bridas, etc.

- Mordazas: instrumentos que, colocados en la boca, impiden la articulación verbal de la víctima.

- Otros: cualquier otra arma o instrumento empleado que no corresponda a las categorías anteriormente reseñadas.

d. Forma de causar la muerte (nominal cerrada) (elección múltiple). Se refiere al modo en que el agresor acaba con la vida de la víctima, a pesar de que puedan concurrir múltiples lesiones en esta variable solo deben ser contempladas aquellas que condujeron a la muerte de las víctimas.

- Por contusión: tipo de lesión física no penetrante sobre un cuerpo humano o animal causada por la acción de objetos rotundos, que actúan sobre el organismo por intermedio de una fuerza más o menos considerable.

- Estrangulación: acción de apretar el cuello para comprimir las arterias carótidas o la tráquea causando la muerte.

- Con arma blanca: forma de causar la muerte mediante un cuchillo u objeto puntiagudo similar a éste.

- Intoxicación: forma de causar la muerte a través de la acción de sustancias nocivas para el organismo. 
- Con arma de fuego: forma de causar la muerte utilizando cualquier arma de fuego, como por ejemplo una pistola, escopeta, etc.

- Otra: cualquier otra forma de causar la muerte.

- Se desconoce: no hay datos sobre la forma de causar la muerte.

8. Ritual: Grupo de variables referidas a aquellos aspectos de ritual, entendiendo este como el «patrón distintivo de conductas del agresor que le son características y que satisfacen necesidades psicológicas y emocionales» (Soto, 2014, p. 62).

a. Interacción verbal con las víctimas (nominal cerrada). Relativa a si el agresor habla o no con sus víctimas. En caso de existir la interacción verbal puede catalogarse como agresiva, si emplea violencia verbal, o no agresiva, si no concurre violencia verbal, pudiendo concurrir ambas.

b. Relaciones sexuales con las víctimas ante-mortem (nominal cerrada). Existe en aquellos casos en que el agresor, antes de causar la muerte a la víctima, práctica sexo con ella.

c. Relaciones sexuales con las víctimas post-mortem (nominal cerrada). Concurre en los hechos en que el criminal, tras asesinar a la víctima, práctica sexo con ella.

d. Penetración en las relaciones sexuales (nominal cerrada) (elección múltiple). Precisa si, en el caso de concurrir relaciones sexuales, hay o no penetración y el tipo de esta.

e. Conductas sádicas y de tortura (nominal cerrada). Concurren en los supuestos en que el agresor pretende provocar un gran sufrimiento en la víctima o víctimas, sufrimiento que trata alargar en el tiempo y a través del cual obtiene placer. Para ello el criminal inflige dolor y causa lesiones en la víctima sin que estas lleguen a provocarle un fallecimiento rápido. 
f. Canibalismo (nominal cerrada). Antropofagia. Se produce cuando el individuo ingiere, al menos, alguna parte del cuerpo de sus víctimas (cocinada o cruda).

g. Mutilación (nominal cerrada). Descuartizamiento de la víctima o de alguno de sus miembros con una finalidad distinta a las del modus operandi.

h. Toma "trofeos" de sus crímenes (nominal cerrada). Objetos que el individuo sustrae de las víctimas o de los escenarios del crimen y que, frecuentemente, emplea a posteriori para recordar o revivir la experiencia homicida.

\section{Comportamiento geográfico.}

a. Zona de actuación (nominal cerrada). Continente o zona en que el criminal ha desarrollado su ciclo asesino.

b. País/es de actuación (nominal abierta). Estado/s en los que el agresor ha actuado. Puede darse la circunstancia de que su acción sea trasnacional.

10. Victimología: Conjunto de variables relativas a las víctimas del agresor, tanto a la de sus hechos consumados como a las de sus tentativas, siempre y cuando sean hechos probados.

a. Número víctimas total (numérica abierta). Engloba el número de víctimas de sus tentativas y de sus hechos consumados.

b. Selección de las víctimas (nominal cerrada) (elección múltiple). Para su concreción se emplea la clasificación de Turvey (2008) que precisa que «en la selección de la víctima influyen 6 factores:

- Posibilidad: se refiere a la accesibilidad de la víctima para el criminal.

- Localización: se refiere al lugar donde se encuentra la víctima. 
- Vulnerabilidad: la percepción de la posibilidad de ataque a la víctima sin que el criminal pueda sufrir daños o con peligro.

- Relaciones: la víctima es elegida por la relación que existe con el criminal.

- Simbolismo: la víctima es seleccionada porque tiene un significado para el criminal.

- Fantasía: la víctima es elegida porque puede satisfacer una particular fantasía del criminal.

11. Tipologías: referidas en Jiménez (2012).

a. Tipo 1 (FBI) (nominal cerrada).

- Organizado: agresión planeada, víctima extraña, personaliza a la víctima, controla la conversación, controla la escena del crimen, hace sumisa a la víctima, usa métodos de control, muchos actos agresivos, traslada el cadáver, usa armas, deja pocos indicios en la escena.

- Desorganizado: agresión espontánea, víctima conocida, despersonaliza a la víctima, no habla con la víctima o muy poco, la escena del crimen es caótica, violencia súbita, no usa métodos de control, realiza sexo después de la muerte, no traslada el cadáver, no usa armas o son de oportunidad, hay muchos indicios en la escena.

- Mixto: no predomina ningún conjunto de características propias de una u otra categoría.

b. Tipo 2 (Canter y Salfati, 1999) (nominal cerrada).

- Instrumental-cognitivo: racional, intencionado, planificador. Su asesinato tiene intencionalidad y persigue un objetivo. Suele planear sus crímenes y no suele haber muchas evidencias forenses debido a la experiencia delictiva del agresor.

- Instrumental-oportunista: también presente la intencionalidad, que obedece a la obtención de algún beneficio con su víctima. La elección de la víctima es oportunista, por estar en un lugar y momento propicios para el agresor. El arma suele ser de oportunidad o las propias manos. Crímenes relacionados con robos o agresiones sexuales. 
- Expresivo-impulsivo: actúa como respuesta a un estado emocional intenso. Su crimen es el resultado de la ira o la venganza contra la víctima. El ataque suele producirse de forma repentina, con un ataque fulgurante y explosivo que provoca mucho daño y heridas en la víctima. Sus crímenes no son fríos ni planificados, sino arrebatos de furia contra un tipo concreto de víctima que tiene un significado para el asesino.

c. Tipo 3 (Holmes y DeBerguer, 1988) (nominal cerrada).

- Visionario: es un psicótico que tiene alucinaciones auditivas que le incitan a matar.

- Misionario: no tiene alucinaciones. Elabora una idea delirante en la que tiene la misión de acabar con un determinado colectivo (p. ej. prostitutas, drogadictos, vagabundos...). Se cree un salvador, un redentor.

- Hedonista: mata por el puro placer que le produce acabar con la vida de otra persona.

- Dominante: mata por la sensación de poder que le produce tener en sus manos la vida y la muerte de otra persona. Busca la sensación de poder y control.

d. Tipo 4 (Fox y Levin, en Petherick, 2006) (nominal cerrada).

- Emocional: se mueve por la sensación de experimentar sensaciones fuertes.

○ Sádico: se excita con el dolor de la víctima.

○ Dominante: necesita experimentar la sensación de dominación y control sobre la víctima.

- Misionario: cree que tiene una misión que cumplir con sus asesinatos.

○ Reformista: no tiene alucinaciones.

○ Visionario: sí las tiene.

- Por conveniencia: consigue un beneficio con sus víctimas.

- Saca provecho (p. ej. sicario, asesino a sueldo).

○ Protector: asesina para eliminar testigos y protegerse. 
e. Tipo 5 (Canter, 2005) (nominal cerrada).

- Merodeador: avalan la hipótesis del círculo. Agresores que viajan desde su base o puto de anclaje hasta el lugar del crimen para posteriormente regresar a la base.

- Viajero: no viven dentro del círculo. Viajan desde su base hacia otro lugar y es aquí donde establecen una zona de acción donde cometen sus crímenes.

f. Tipo 6 (Rossmo, 1995) (nominal cerrada) (elección múltiple).

- Cazador: busca a sus víctimas en los alrededores de donde vive.

- Cazador furtivo: actúa en un área específica que es distinta a donde vive.

- Pescador: actúa en su zona de actividad rutinaria, donde trabaja, se divierte... buscando la víctima y la situación oportuna.

- Trampero: usa artimañas y situaciones para llevar a la víctima a su punto de anclaje, y es allí donde comete el delito.

\subsection{RESULTADOS}

\subsubsection{Estudio Descriptivo de la Muestra}

En primer lugar, dentro de la dimensión denominada "variables psicológicas" se ha procedido a realizar el análisis descriptivo de las variables nivel intelectual, rasgos psicopáticos e implicación en la vida social de los asesinos en serie que conforman este estudio.

Tal y como se muestra en la Tabla 40 y Figura 22, en relación al nivel intelectual de los asesinos en serie incluidos en la muestra, un 59,6\% (28 casos) tienen un nivel intelectual medio.

Con respecto al 27,7\% (13 casos) que poseen un nivel intelectual alto, un 21,3\% (10 casos) pertenece a asesinos en serie que ubicaron su zona de actuación en América del Norte, frente a un 6,4\% (3 casos) que actuaron en España.

De los asesinos en serie incluidos en la muestra, sólo un 12,8\% (6 casos) tienen un nivel intelectual bajo, de los cuales un 8,5\% (4 casos) actuaron en España. 
Tabla 40. Distribución de frecuencias de la variable nivel intelectual en cada zona de actuación.

\begin{tabular}{llrrrr}
\hline & & \multicolumn{2}{c}{ Zona de Actuación } & \\
\cline { 3 - 5 } Nivel Intelectual & & & España & América del Norte & Total \\
\cline { 3 - 5 } & & Recuento & 4 & 2 & 6 \\
& Medio & Recuento & 16 & $4,3 \%$ & $12,8 \%$ \\
\cline { 2 - 5 } & & \% del total & $34,0 \%$ & 12 & 28 \\
& Alto & Recuento & 3 & $25,5 \%$ & $59,6 \%$ \\
\hline Total & \% del total & $6,4 \%$ & 10 & 13 \\
& & Recuento & 23 & $21,3 \%$ & $27,7 \%$ \\
\hline & \% del total & $48,9 \%$ & $51,1 \%$ & $100,0 \%$ \\
\hline
\end{tabular}

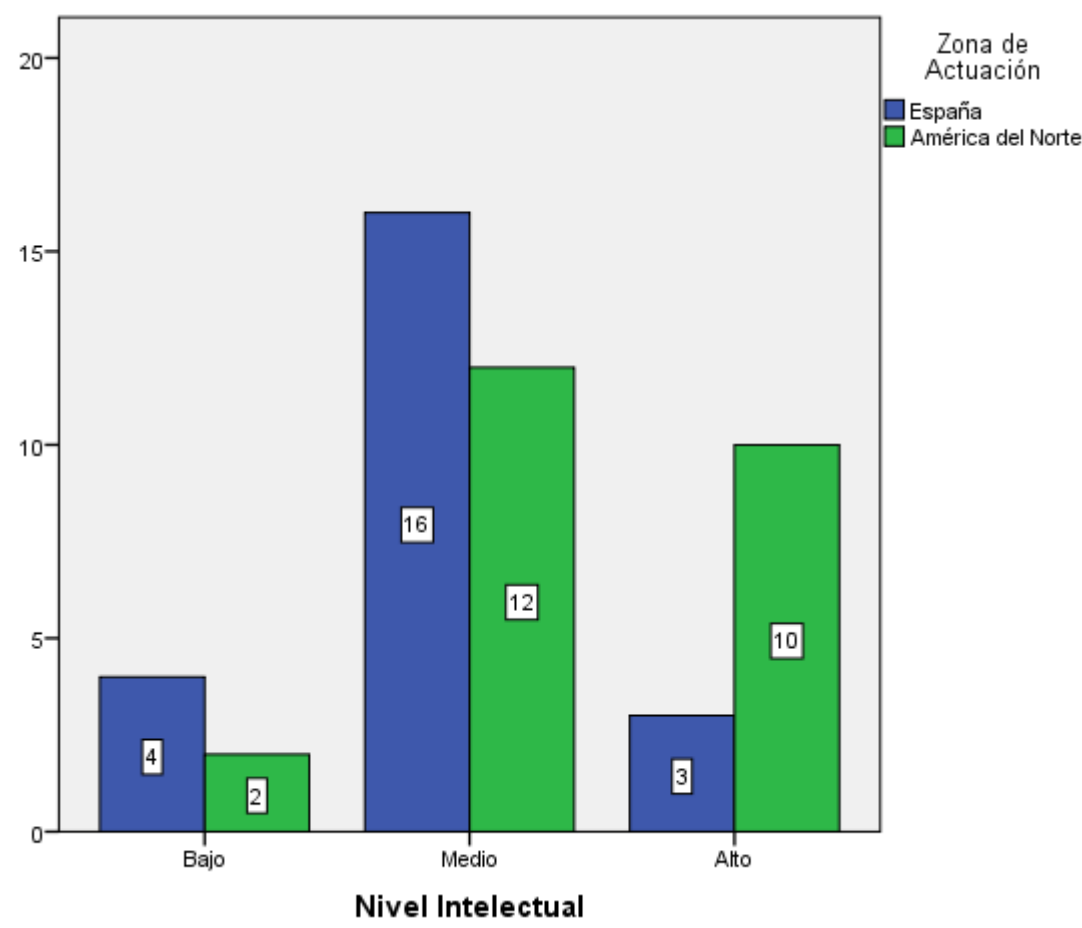

Figura 22. Gráfico de barras agrupadas de la variable nivel intelectual en cada zona de actuación.

En relación a los rasgos psicopáticos que presentan los asesinos seriales que conforman esta investigación, se extrae que un 87,5\% (42 casos) del total de la muestra analizada presentaron falta de empatía, un 66,7\% (32 casos) utilizaron la manipulaciónmentira y un mismo porcentaje presentaron falta de culpa como rasgos psicopáticos. 
Por otro lado, tan sólo un 14,6\% (7 casos) del total de asesinos incluidos en este estudio tuvieron un estilo de vida parasitario y un mismo porcentaje de casos presentaron superficialidad afectiva.

Con respecto a la zona de actuación no se aprecian grandes diferencias en cuanto a los rasgos psicopáticos presentados, puesto que el número de casos de los mismos es muy similar. Estos datos quedan representados en la Tabla 41.

Tabla 41. Distribución de frecuencias de la variable rasgos psicopáticos en cada zona de actuación.

\begin{tabular}{|c|c|c|c|c|c|}
\hline & & & \multicolumn{2}{|c|}{ Zona de Actuación } & \multirow[b]{2}{*}{ Total } \\
\hline & & & España & América del Norte & \\
\hline \multirow[t]{22}{*}{ Rasgos Psicopáticos ${ }^{a}$} & Sí - Falta de Empatía & Recuento & 22 & 20 & 42 \\
\hline & & $\%$ del total & $45,8 \%$ & $41,7 \%$ & $87,5 \%$ \\
\hline & Sí - Manipulación Mentira & Recuento & 18 & 14 & 32 \\
\hline & & $\%$ del total & $37,5 \%$ & $29,2 \%$ & $66,7 \%$ \\
\hline & Sí - Versatilidad Criminal & Recuento & 6 & 9 & 15 \\
\hline & & $\%$ del total & $12,5 \%$ & $18,8 \%$ & $31,3 \%$ \\
\hline & Sí - Falta de Responsabilidad & Recuento & 7 & 5 & 12 \\
\hline & & $\%$ del total & $14,6 \%$ & $10,4 \%$ & $25,0 \%$ \\
\hline & Sí - Encanto Superficial & Recuento & 10 & 11 & 21 \\
\hline & & $\%$ del total & $20,8 \%$ & $22,9 \%$ & $43,8 \%$ \\
\hline & Sí - Egocentrismo y Elevada & Recuento & 6 & 5 & 11 \\
\hline & Autovalía & $\%$ del total & $12,5 \%$ & $10,4 \%$ & $22,9 \%$ \\
\hline & Sí - Impulsividad & Recuento & 11 & 6 & 17 \\
\hline & & $\%$ del total & $22,9 \%$ & $12,5 \%$ & $35,4 \%$ \\
\hline & Sí - Falta de Culpa & Recuento & 15 & 17 & 32 \\
\hline & & $\%$ del total & $31,3 \%$ & $35,4 \%$ & $66,7 \%$ \\
\hline & Sí - Estilo de Vida Parasitario & Recuento & 3 & 4 & 7 \\
\hline & & $\%$ del total & $6,3 \%$ & $8,3 \%$ & $14,6 \%$ \\
\hline & Sí - Promiscuidad Sexual & Recuento & 9 & 9 & 18 \\
\hline & & $\%$ del total & $18,8 \%$ & $18,8 \%$ & $37,5 \%$ \\
\hline & Sí - Superficialidad Afectiva & Recuento & 4 & 3 & 7 \\
\hline & & $\%$ del total & $8,3 \%$ & $6,3 \%$ & $14,6 \%$ \\
\hline \multirow{2}{*}{\multicolumn{2}{|c|}{ Total }} & Recuento & 24 & 24 & 48 \\
\hline & & $\%$ del total & $50,0 \%$ & $50,0 \%$ & $100,0 \%$ \\
\hline
\end{tabular}

En cuanto a la implicación en la vida social de los asesinos seriales que han sido incluidos en este estudio, se extrae que un 37,5\% (18 casos) tienen una implicación en la vida social baja, un 33,3\% (16 casos) una implicación media y un 29,2\% (14 casos) una implicación alta; no observándose grandes diferencias entre las zonas de actuación de los distintos sujetos. Estos datos quedan representados en la Tabla 42 y Figura 23. 
Tabla 42. Distribución de frecuencias de la variable implicación en la vida social en cada zona de actuación.

\begin{tabular}{lllrrr}
\hline & & & \multicolumn{2}{c}{ Zona de Actuación } & \\
\cline { 3 - 5 } & & & España & América del Norte & \multicolumn{1}{c}{ Total } \\
\hline \multirow{2}{*}{ VP Implicación Vida Social } & Baja & Recuento & 9 & 9 & 18 \\
& & \% del total & $18,8 \%$ & $18,8 \%$ & $37,5 \%$ \\
\cline { 2 - 5 } & Media & Recuento & 7 & 9 & 16 \\
& & \% del total & $14,6 \%$ & $18,8 \%$ & $33,3 \%$ \\
\cline { 2 - 5 } & Alta & Recuento & 8 & 6 & 14 \\
& & \% del total & $16,7 \%$ & $12,5 \%$ & $29,2 \%$ \\
\hline Total & & Recuento & 24 & 24 & 48 \\
& & \% del total & $50,0 \%$ & $50,0 \%$ & $100,0 \%$ \\
\hline
\end{tabular}

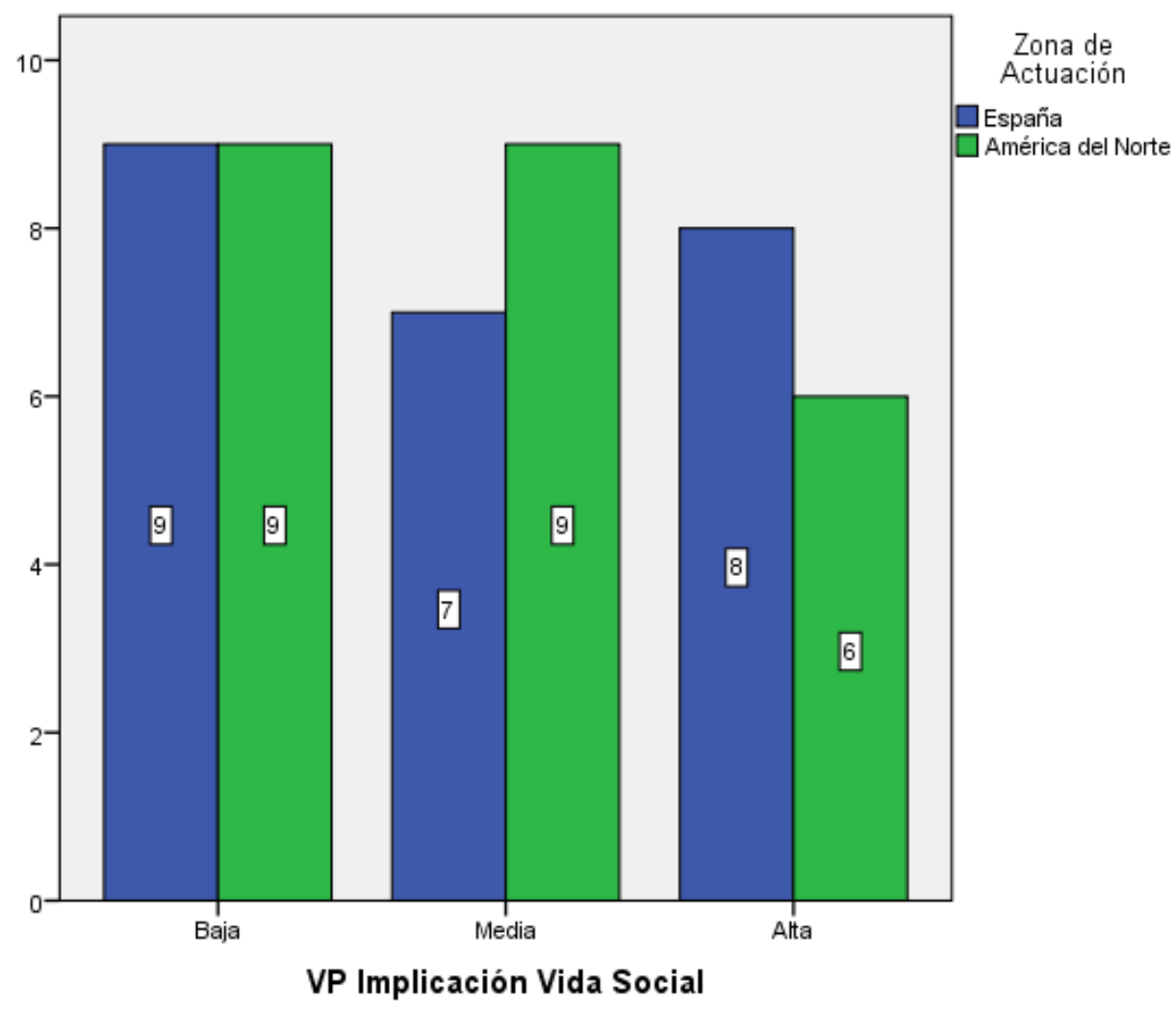

Figura 23. Gráfico de barras agrupadas de la variable implicación en la vida social en cada zona de actuación.

Dentro de la dimensión "antecedentes en la infancia y la adolescencia", se analizó la variable haber sufrido algún tipo de maltrato en la infancia. En relación a esta variable, se aprecia que un 39,6\% (19 casos) de asesinos en serie cuya zona de actuación es España no recibieron algún tipo de maltrato en la infancia, frente a un 
18,8\% (9 casos) de asesinos en serie que actuaron en América del Norte medidos en la misma variable de un total de 48 casos.

Además, del 47,7\% (20 casos) de asesinos en serie que sí recibieron algún tipo de maltrato en la infancia, un 31,2\% (15 casos) tuvieron su zona de actuación en América del Norte. Podemos observar estos datos en la Tabla 43 y Figura 24.

Tabla 43. Distribución de frecuencias de la variable haber sufrido algún tipo de maltrato en la infancia en cada zona de actuación.

\begin{tabular}{llrrrr}
\hline & & \multicolumn{2}{c}{ Zona de Actuación } & \multirow{2}{*}{ Total } \\
\cline { 3 - 4 } & & & España & América del Norte & \multicolumn{2}{c}{ Totar } \\
\hline Al Algún Tipo de Maltrato & No & Recuento & 19 & 9 & 28 \\
& & \% del total & $39,6 \%$ & $18,8 \%$ & $58,3 \%$ \\
\cline { 2 - 5 } & Sí & Recuento & 5 & 15 & 20 \\
& & \% del total & $10,4 \%$ & $31,3 \%$ & $41,7 \%$ \\
\hline Total & & Recuento & 24 & 24 & 48 \\
& & \% del total & $50,0 \%$ & $50,0 \%$ & $100,0 \%$ \\
\hline
\end{tabular}

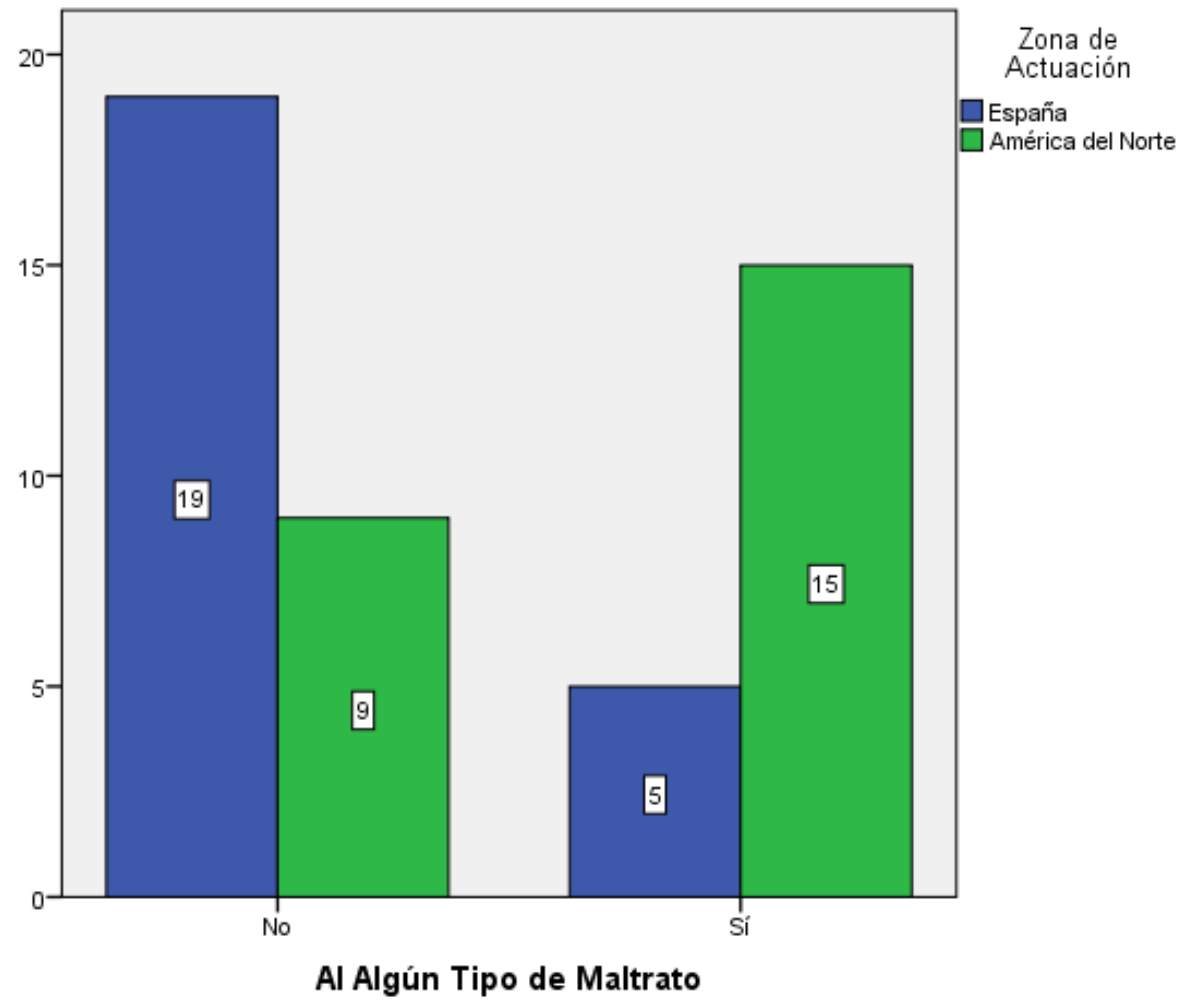

Figura 24. Gráfico de barras agrupadas de la variable haber sufrido algún tipo de maltrato en la infancia en cada zona de actuación. 
En cuanto a la dimensión "historia de la edad adulta", se analizaron las variables haber sufrido algún tipo de maltrato y patología mental.

Con respecto a haber sufrido algún tipo de maltrato en la edad adulta, del 81,3\% (39 casos) de sujetos que no han sufrido algún tipo de maltrato en la edad adulta, 21 de ellos actuaron en España y los 18 restantes actuaron en América del Norte.

Tan solo un 6,3\% (3 casos) que si han tenido algún tipo de maltrato en la edad adulta actuaron en España; de un total de 9 casos que han sido incluidos en la muestra que recibieron algún tipo de maltrato en la adultez. La distribución de frecuencias queda representada en la Tabla 44 y Figura 25.

Tabla 44. Distribución de frecuencias de la variable haber sufrido algún tipo de maltrato en la edad adulta en cada zona de actuación.

\begin{tabular}{llrrrr}
\hline & & & \multicolumn{2}{c}{ Zona de Actuación } & \\
\cline { 4 - 5 } & & & España & América del Norte & \multicolumn{2}{c}{ Total } \\
\hline A Algún Tipo de Maltrato & No & Recuento & 21 & 18 & 39 \\
& & \% del total & $43,8 \%$ & $37,5 \%$ & $81,3 \%$ \\
\cline { 2 - 4 } & Sí & Recuento & 3 & 6 & 9 \\
& & \% del total & $6,3 \%$ & $12,5 \%$ & $18,8 \%$ \\
\hline Total & & Recuento & 24 & 24 & 48 \\
& & \% del total & $50,0 \%$ & $50,0 \%$ & $100,0 \%$ \\
\hline
\end{tabular}

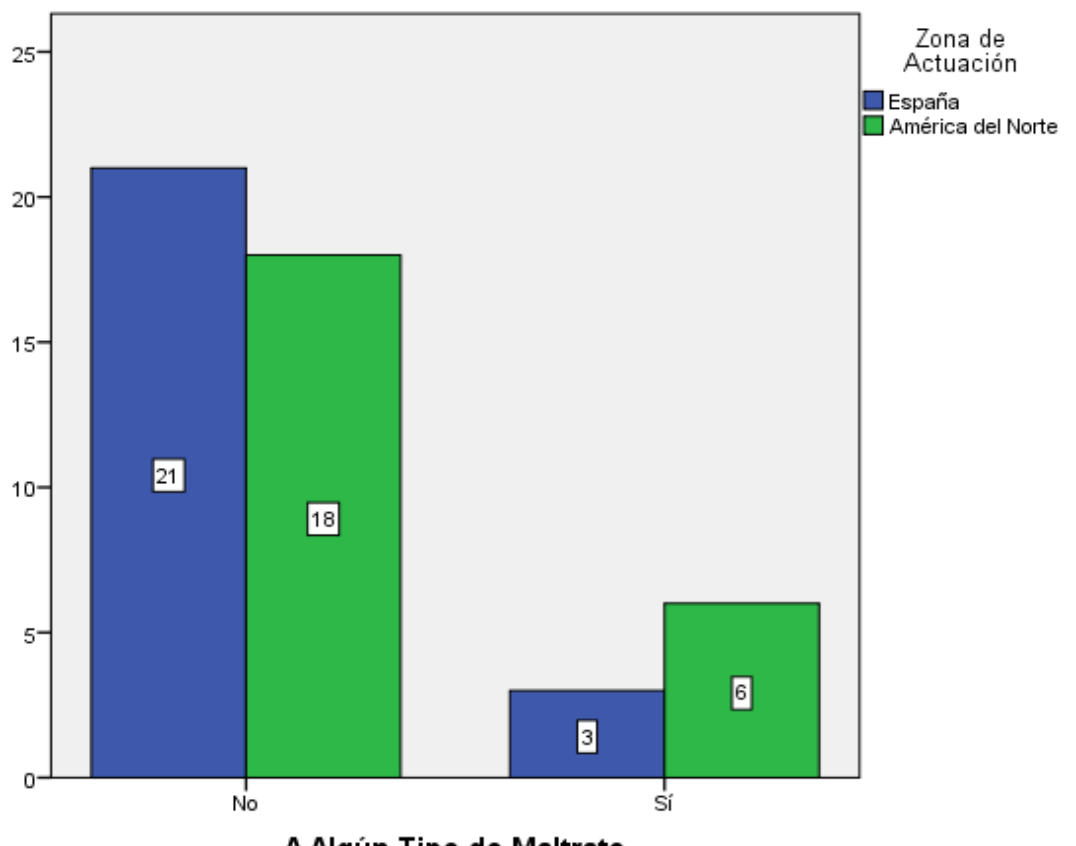

Figura 25. Gráfico de barras agrupadas de la variable haber sufrido algún tipo de maltrato en la edad adulta en cada zona de actuación. 
En relación a padecer algún tipo de patología mental en la edad adulta (Tabla 45 y Figura 26), se extrae que un 66,7\% (32 casos) del total de la muestra analizada no presenta patología mental, de los cuales un 39,6\% (19 casos) tuvieron su zona de actuación en España y un 27,1\% (13 casos) actuaron en América del Norte.

Por otro lado, un 33,3\% (16 casos) del total de asesinos en serie incluidos en la muestra presentan patología mental, de los cuales un 22,9 \% (11 casos) actuaron en América del Norte frente a un 10,4\% (5 casos) que actuaron en España.

Tabla 45. Distribución de frecuencias de la variable patología mental en cada zona de actuación.

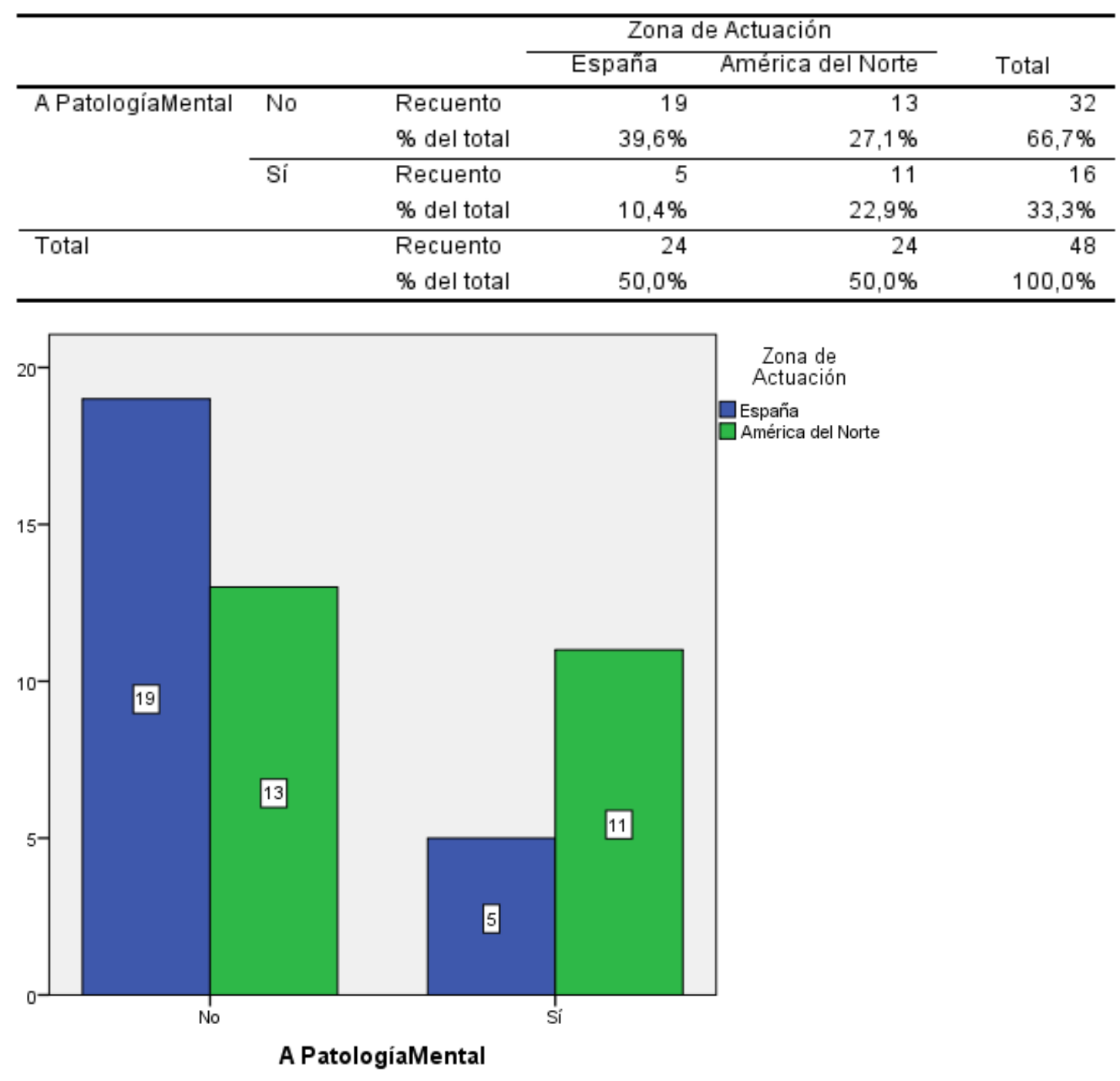

Figura 26. Gráfico de barras agrupadas de la variable patología mental en cada zona de actuación. 
Dentro de la dimensión "historial delictivo y de violencia", se analizó la variable antecedentes policiales. En lo referente a esta variable, es decir, a los antecedentes policiales de los asesinos seriales que conforman este estudio, se puede extraer que de los 46 casos analizados un 58,7\% (27 casos) sí tuvieron antecedentes policiales, de los cuales un 30,4\% (14 casos) su zona de actuación fue América del Norte y un 28,3\% (13 casos) fue España.

Por consiguiente, un 41,3\% (19 casos) no tuvieron antecedentes policiales, de los cuales un 21,7\% (10 casos) actuaron en España y un 19,6\% (9 casos) actuaron en América del Norte. Podemos observar los datos en la Tabla 46 y Figura 27.

Tabla 46. Distribución de frecuencias de la variable antecedentes policiales en cada zona de actuación.

\begin{tabular}{|c|c|c|c|c|c|}
\hline & & & \multicolumn{2}{|c|}{ Zona de Actuación } & \multirow[b]{2}{*}{ Total } \\
\hline & & & España & América del Norte & \\
\hline \multirow[t]{4}{*}{ Antecedentes Policiales } & No & Recuento & 10 & 9 & $\overline{19}$ \\
\hline & & $\%$ del total & $21,7 \%$ & $19,6 \%$ & $41,3 \%$ \\
\hline & Sí & Recuento & 13 & 14 & 27 \\
\hline & & $\%$ del total & $28,3 \%$ & $30,4 \%$ & $58,7 \%$ \\
\hline \multirow[t]{2}{*}{ Total } & & Recuento & 23 & 23 & $\overline{46}$ \\
\hline & & $\%$ del total & $50,0 \%$ & $50,0 \%$ & $100,0 \%$ \\
\hline
\end{tabular}

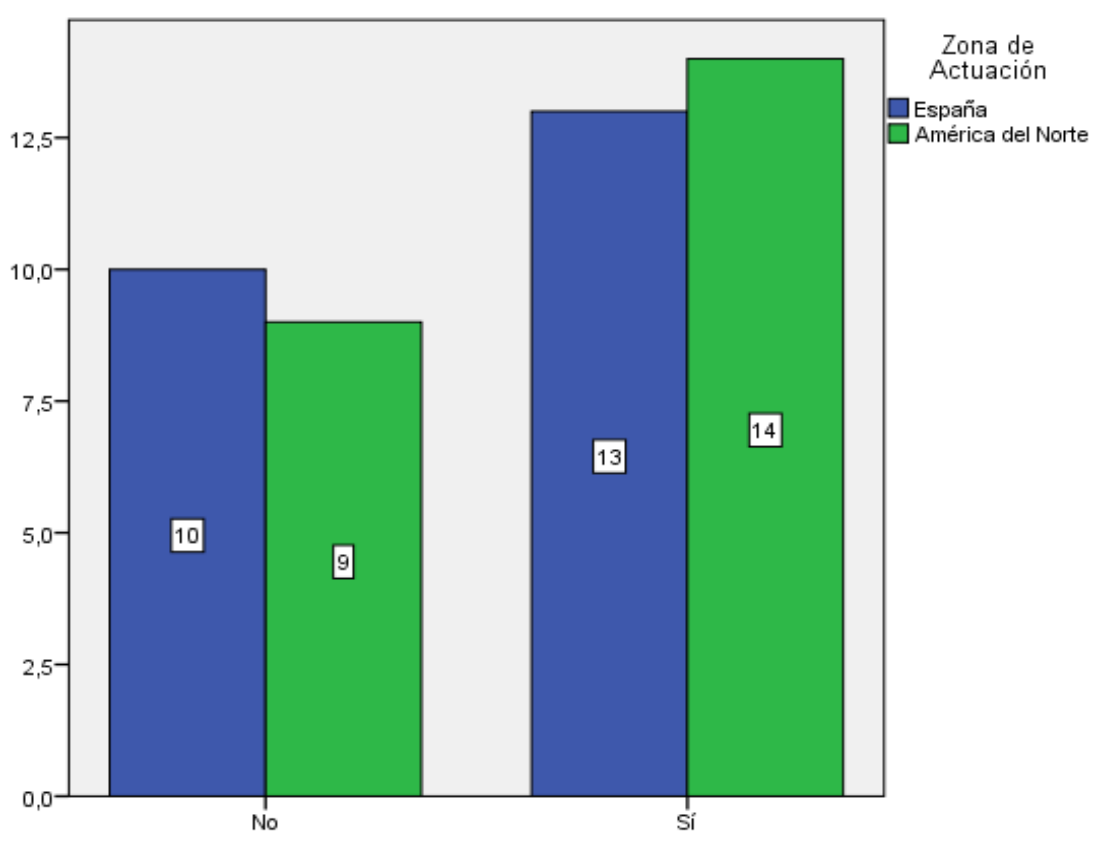

Antecedentes Policiales

Figura 27. Gráfico de barras agrupadas de la variable antecedentes policiales en cada zona de actuación. 
En cuanto a la dimensión "escena", se ha analizado la variable número de crímenes. En relación a esta variable, formada por esta muestra de 24 asesinos en serie cuya zona de actuación fue España, el número de crímenes no se aproxima a una distribución normal (asimétrica, As= 3,794 y leptocúrtica $\mathrm{K}=16,106$ ). La media del número de crímenes cometidos por estos sujetos ha sido aproximadamente 7 crímenes (mediana 4) con una desviación típica de 9,488 tal y como se muestra en la Tabla 47 y Figura 28.

Tabla 47. Estadísticos descriptivos de la variable número de crímenes de los asesinos seriales que actuaron en España.

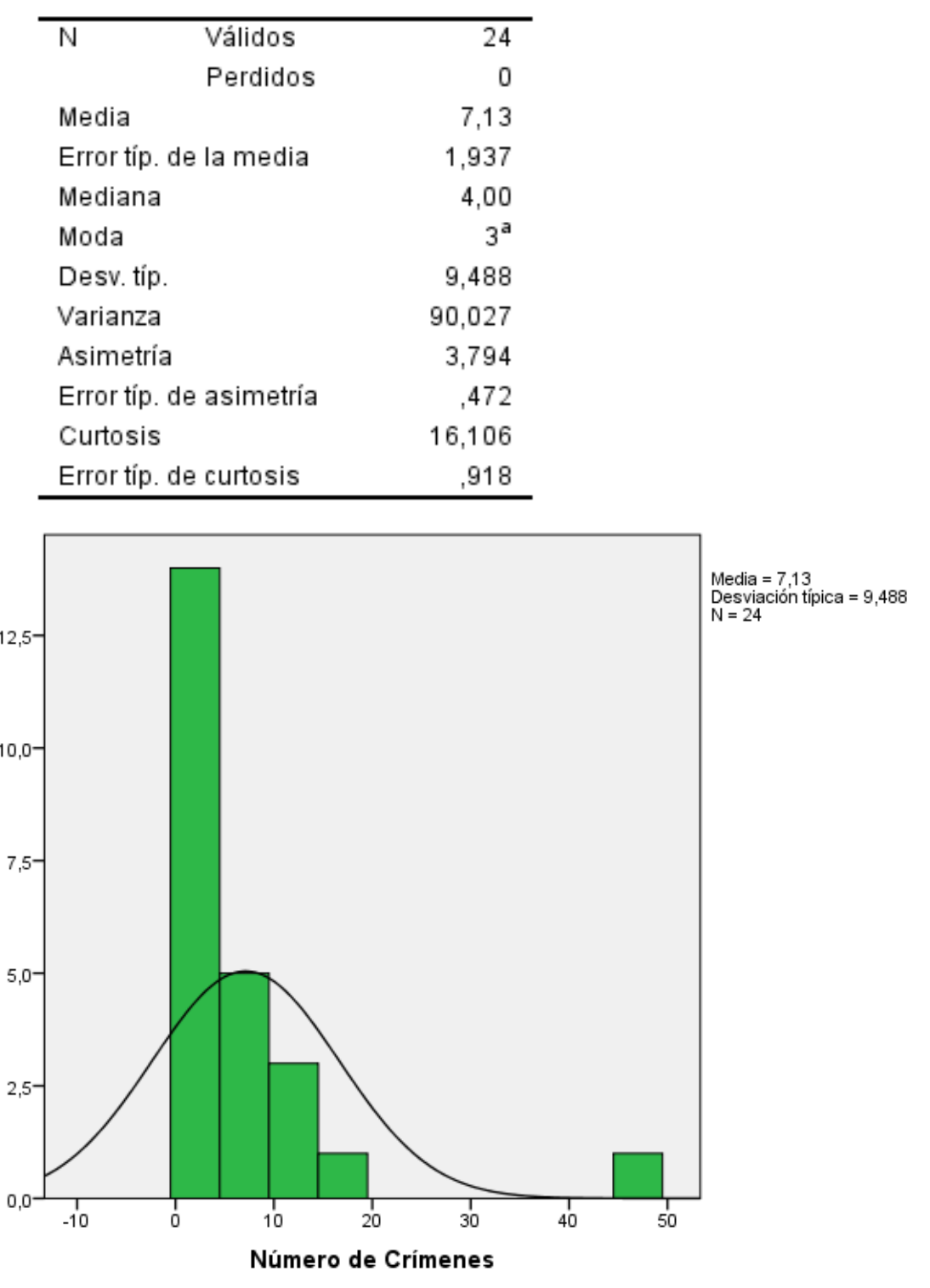

Figura 28. Histograma de frecuencias de la variable número de crímenes de los asesinos en serie que actuaron en España. 
En la muestra de 24 asesinos en serie cuya zona de actuación fue América del Norte, el número de crímenes no se aproxima a una distribución normal (asimétrica, $\mathrm{As}=1,945$ y leptocúrtica $\mathrm{K}=3,594)$. La media del número de crímenes cometidos por estos sujetos ha sido aproximadamente 12 crímenes (mediana 9) con una desviación típica de 11,513 tal y como se observa en la Tabla 48 y Figura 29.

Tabla 48. Estadísticos descriptivos de la variable número de crímenes de los asesinos seriales que actuaron en América del Norte.

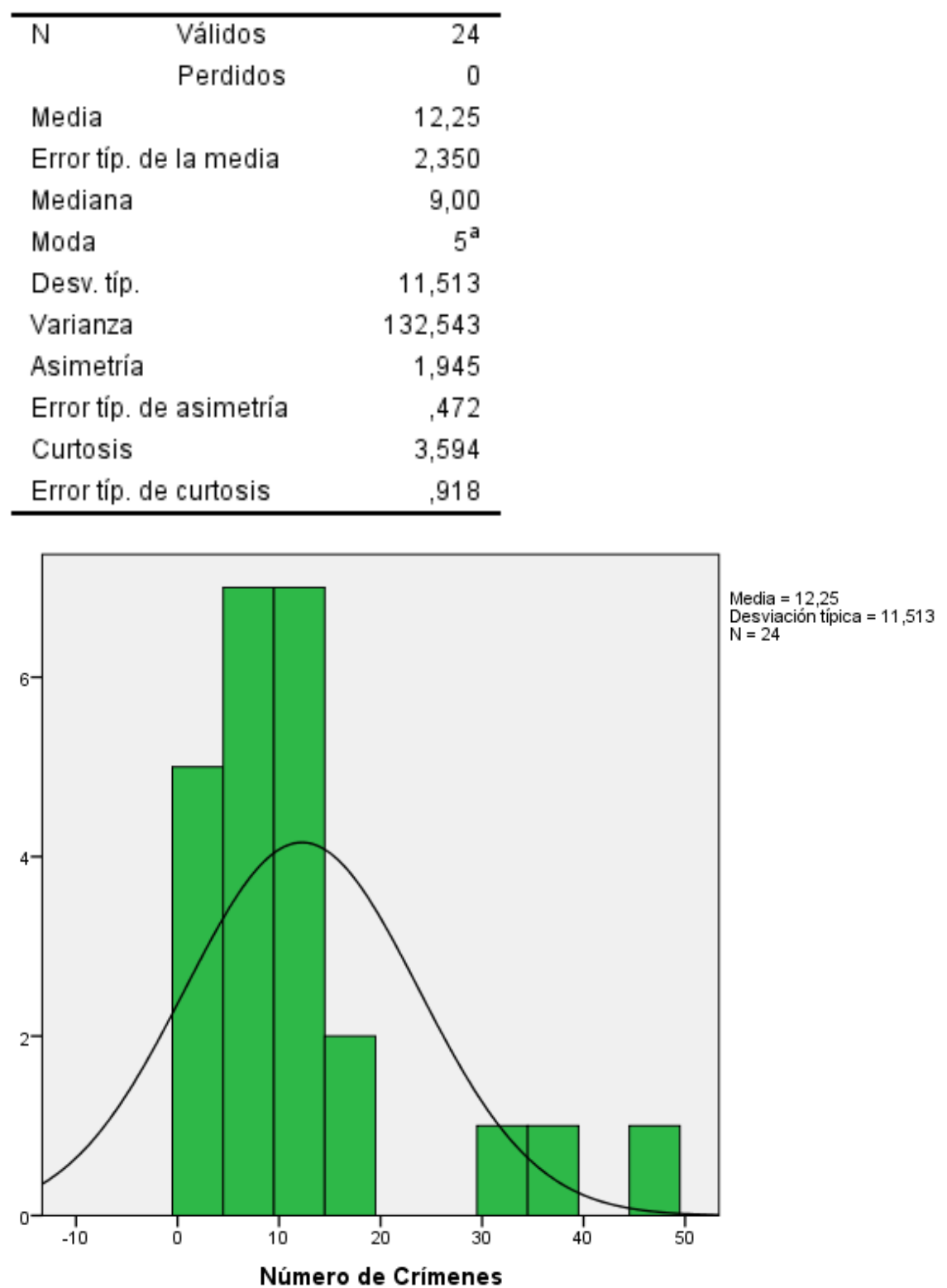

Figura 29. Histograma de frecuencias de la variable número de crímenes de los asesinos en serie que actuaron en América del Norte. 
Dentro de la dimensión "modus operandi" se han analizado las variables nivel de planificación, método de aproximación, tipo de armas y utensilios empleados y forma de causar la muerte.

En cuanto al nivel de planificación de los asesinos en serie que han sido incluidos en el estudio, se observa que un 33,3\% (16 casos) del total de la muestra analizada tuvieron un nivel de planificación alto al igual que los que tuvieron un nivel de planificación medio. Por otro lado, un 27,1\% (13 casos) presentaron un nivel de planificación bajo.

De los 24 asesinos en serie incluidos en la muestra que actuaron en España, un 20,8\% (10 casos) tuvieron un nivel de planificación alto.

De los casos incluidos en la muestra, tan sólo un 6,3\% (3 casos) tuvieron un nivel de planificación nulo, de los cuales un 4,2\% (2 casos) actuaron en América del Norte y un 2,1\% (1 caso) actuó en España. Estos datos quedan representados en la Tabla 49 y Figura 30.

Tabla 49. Distribución de frecuencias de la variable nivel de planificación en cada zona de actuación.

\begin{tabular}{lllrrr}
\hline & & & \multicolumn{2}{c}{ Zona de Actuación } & \\
\cline { 3 - 5 } & & & España & América del Norte & Total \\
\hline Nivel de Planificación & Nulo & Recuento & 1 & 2 & 3 \\
& & \% del total & $2,1 \%$ & $4,2 \%$ & $6,3 \%$ \\
\cline { 2 - 5 } & Bajo & Recuento & 6 & 7 & 13 \\
& & \% del total & $12,5 \%$ & $14,6 \%$ & $27,1 \%$ \\
\cline { 2 - 5 } & Medio & Recuento & 7 & 9 & 16 \\
& & \% del total & $14,6 \%$ & $18,8 \%$ & $33,3 \%$ \\
\cline { 2 - 5 } & Alto & Recuento & 10 & 6 & 16 \\
& & \% del total & $20,8 \%$ & $12,5 \%$ & $33,3 \%$ \\
\hline Total & & Recuento & 24 & 24 & 48 \\
& & \% del total & $50,0 \%$ & $50,0 \%$ & $100,0 \%$ \\
\hline
\end{tabular}




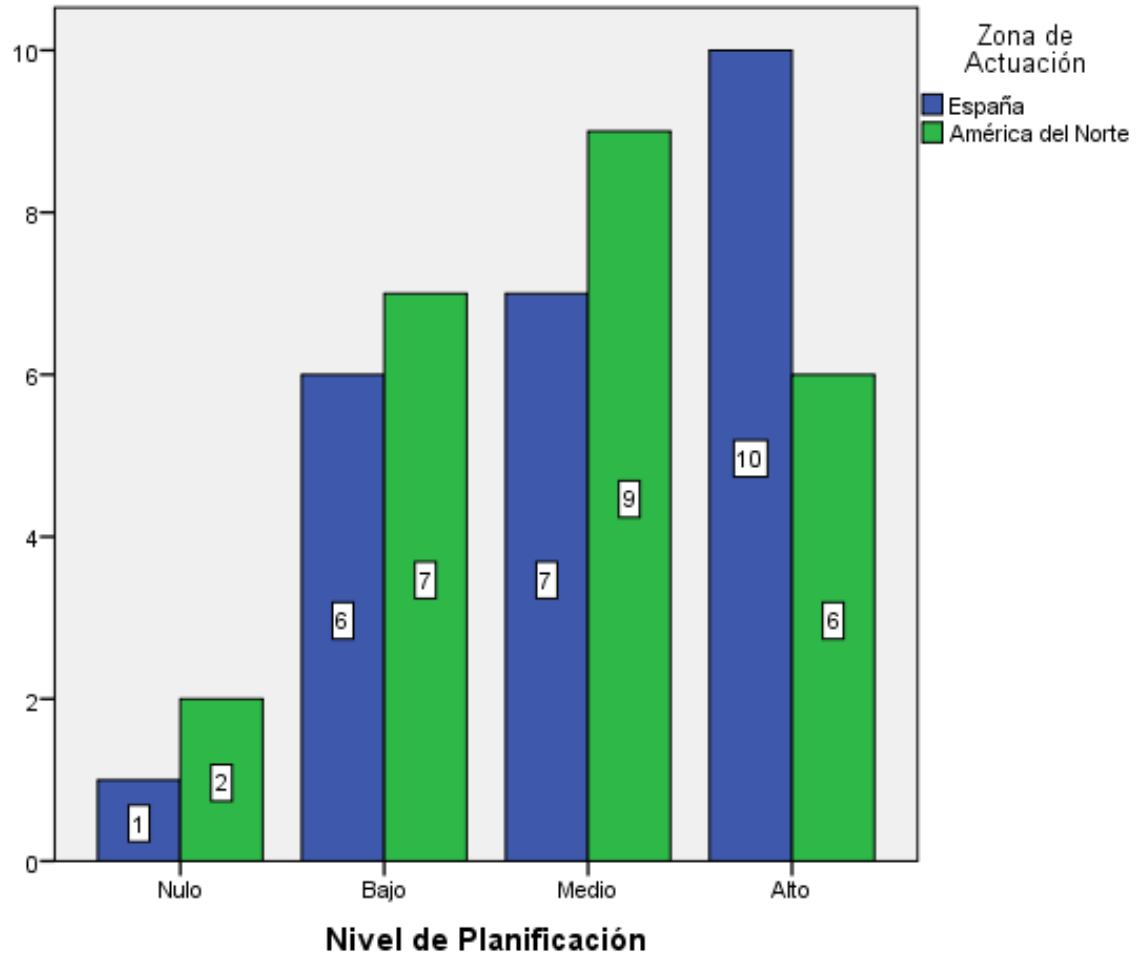

Figura 30. Gráfico de barras agrupadas de la variable nivel de planificación en cada zona de actuación.

En cuanto al método de aproximación hacia las víctimas empleado por los asesinos en serie que forman la muestra de este estudio, se extrae que el 53,2\% (25 casos) de los asesinos en serie emplearon un método de aproximación mediante el engaño.

Además, un 23,4\% (11 casos) emplearon la sorpresa como método de aproximación y un 19,1\% (9 casos) lo hicieron de forma encubierta.

Del total de sujetos incluidos en la muestra, 8 sujetos (17\%) tuvieron un método de aproximación explícito, de los cuales $5(10,6 \%)$ actuaron en América del Norte y 3 $(6,4 \%)$ lo hicieron en España.

Por último, sólo un 10,6\% (5 casos) tuvieron un método de aproximación súbito, de los cuales un 6,4\% ( 3 casos) actuaron en España frente a un 4,3\% ( 2 casos) que lo hicieron en América del Norte. Se puede observar lo indicado en la Tabla 50. 
Tabla 50. Distribución de frecuencias de la variable método de aproximación en cada zona de actuación.

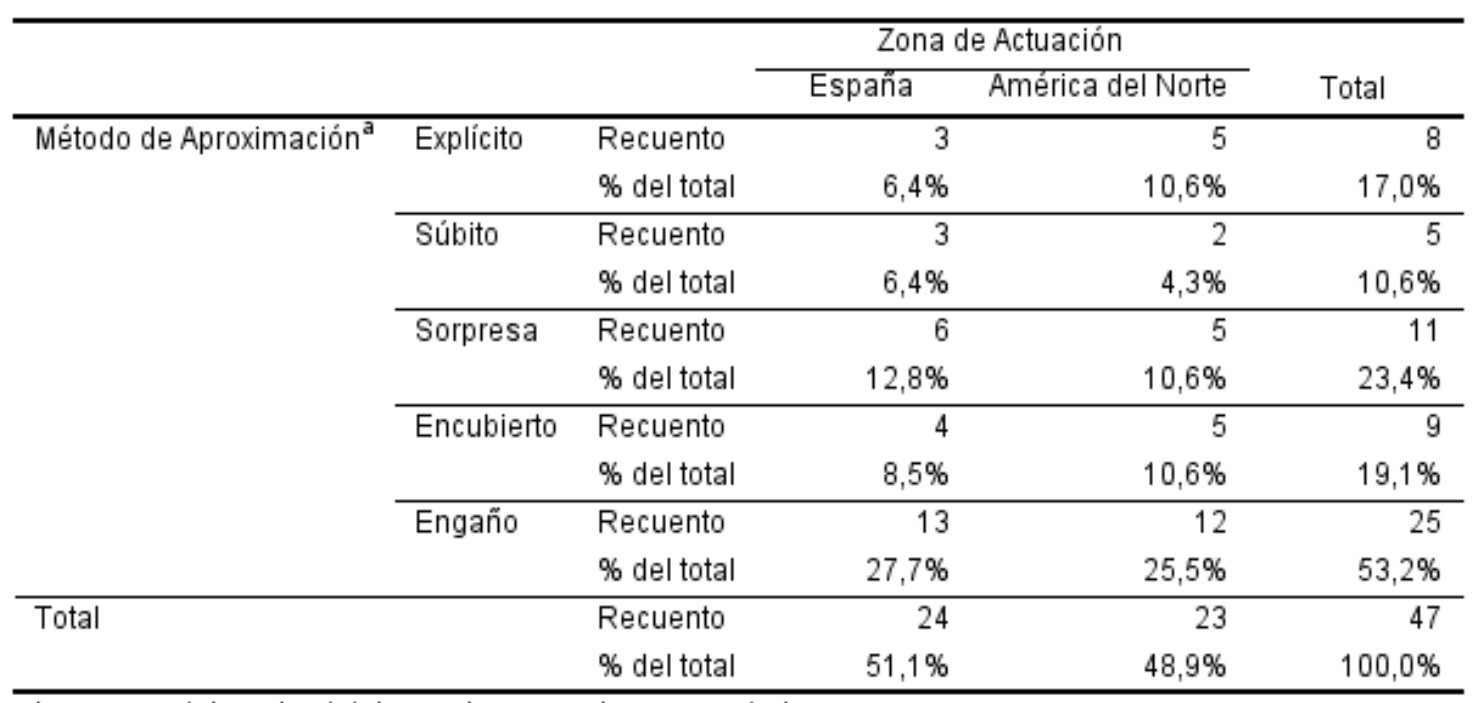

Los porcentajes y los totales se basan en los encuestados.

a. Agrupación

En lo relacionado con el tipo de armas y utensilios empleados con las víctimas de los asesinos en serie que han sido incluidos en esta investigación, se extrae que un 46,8\% (22 casos) del total de asesinos en serie incluidos en la muestra empleó armas blancas y un 34\% (16 casos) empleó armas contundentes con las víctimas, dándose el mismo número de casos independientemente de la zona de actuación.

Por otro lado, un 36,2\% (17 casos) del total de la muestra utilizó armas de fuego, de los cuales un 29,8\% (14 casos) tuvo como zona de actuación América del Norte.

Igualmente, un 19,1\% (9 casos) de los asesinos incluidos emplearon sustancias nocivas, de los cuales un 12,8\% (6 casos) actuaron en España.

Solamente un 2,1\% (1 caso) del total de asesinos no empleó ningún tipo de arma, siendo España la zona de actuación de dicho asesino. Estos datos quedan representados en la Tabla 51. 
Tabla 51. Distribución de frecuencias de la variable tipo de armas y utensilios empleados en cada zona de actuación.

\begin{tabular}{|c|c|c|c|c|c|}
\hline & & & \multicolumn{2}{|c|}{ Zona de Actuación } & \multirow[b]{2}{*}{ Total } \\
\hline & & & Espan̉a & América del Norte & \\
\hline \multirow[t]{14}{*}{ Tipo de Armas ${ }^{a}$} & \multirow[t]{2}{*}{ No Emplea } & Recuento & 1 & 0 & $\overline{1}$ \\
\hline & & $\%$ del total & $2,1 \%$ & $0,0 \%$ & $2,1 \%$ \\
\hline & \multirow[t]{2}{*}{ Sí - Emplea Armas Contundentes } & Recuento & 8 & 8 & 16 \\
\hline & & $\%$ del total & $17,0 \%$ & $17,0 \%$ & $34,0 \%$ \\
\hline & \multirow[t]{2}{*}{ Sí - Emplea Armas Blancas } & Recuento & 11 & 11 & 22 \\
\hline & & $\%$ del total & $23,4 \%$ & $23,4 \%$ & $46,8 \%$ \\
\hline & \multirow[t]{2}{*}{ Sí - Emplea Armas de Fuego } & Recuento & 3 & 14 & 17 \\
\hline & & $\%$ del total & $6,4 \%$ & $29,8 \%$ & $36,2 \%$ \\
\hline & \multirow{2}{*}{$\begin{array}{l}\text { Sí - Emplea Instrumentos de } \\
\text { Inmovilización }\end{array}$} & Recuento & 9 & 12 & 21 \\
\hline & & $\%$ del total & $19,1 \%$ & $25,5 \%$ & $44,7 \%$ \\
\hline & \multirow[t]{2}{*}{ Sí - Emplea Mordazas } & Recuento & 4 & 3 & 7 \\
\hline & & $\%$ del total & $8,5 \%$ & $6,4 \%$ & $14,9 \%$ \\
\hline & \multirow[t]{2}{*}{ Sí - Emplea Sustancias Nocivas } & Recuento & 6 & 3 & 9 \\
\hline & & $\%$ del total & $12,8 \%$ & $6,4 \%$ & $19,1 \%$ \\
\hline \multirow{2}{*}{\multicolumn{2}{|c|}{ Total }} & Recuento & 24 & 23 & 47 \\
\hline & & $\%$ del total & $51,1 \%$ & $48,9 \%$ & $100,0 \%$ \\
\hline
\end{tabular}

En cuanto a la forma de causar la muerte a las víctimas (Tabla 52), se muestra que un 42,6\% (20 casos) utilizaron la estrangulación como forma de causar la muerte, de los cuales un 23,4\% (11 casos) actuaron en España, frente a un 19,1\% (9 casos) que lo hicieron en América del Norte.

Además, un 38,3\% (18 casos) emplearon arma blanca, un 25,5\% (12 casos) causaron la muerte por contusión y un 10,6\% (5 casos) utilizaron otra forma de causar la muerte.

De los 11 sujetos $(25,5 \%)$ que causaron la muerte con arma de fuego, un $19,1 \%$ (9 casos) actuaron en América del Norte y un 6,4\% (3 casos) lo hicieron en España.

De los sujetos incluidos en la muestra, sólo un 12,8\% (6 casos) utilizaron la intoxicación como forma de causar la muerte; de los cuales un 10,6\% (5 casos) lo hicieron en España frente a un 2,1\% (1 caso) que actuó en América del Norte. 
Tabla 52. Distribución de frecuencias de la variable forma de causar la muerte en cada zona de actuación.

\begin{tabular}{|c|c|c|c|c|c|}
\hline & & & \multicolumn{2}{|c|}{ Zona de Actuación } & \multirow[b]{2}{*}{ Total } \\
\hline & & & España & América del Norte & \\
\hline \multirow[t]{12}{*}{ Forma de Causar la Muerte ${ }^{a}$} & Por Contusión & Recuento & 5 & 7 & $\overline{12}$ \\
\hline & & $\%$ del total & $10,6 \%$ & $14,9 \%$ & $25,5 \%$ \\
\hline & Estrangulación & Recuento & 11 & 9 & 20 \\
\hline & & $\%$ del total & $23,4 \%$ & $19,1 \%$ & $42,6 \%$ \\
\hline & Con Arma Blanca & Recuento & 8 & 10 & 18 \\
\hline & & $\%$ del total & $17,0 \%$ & $21,3 \%$ & $38,3 \%$ \\
\hline & Intoxicación & Recuento & 5 & 1 & 6 \\
\hline & & $\%$ del total & $10,6 \%$ & $2,1 \%$ & $12,8 \%$ \\
\hline & Con Arma de Fuego & Recuento & 3 & 9 & 12 \\
\hline & & $\%$ del total & $6,4 \%$ & $19,1 \%$ & $25,5 \%$ \\
\hline & Otra & Recuento & 3 & 2 & 5 \\
\hline & & $\%$ del total & $6,4 \%$ & $4,3 \%$ & $10,6 \%$ \\
\hline \multirow[t]{2}{*}{ Total } & & Recuento & 24 & 23 & 47 \\
\hline & & $\%$ del total & $51,1 \%$ & $48,9 \%$ & $100,0 \%$ \\
\hline
\end{tabular}

Los porcentajes y los totales se basan en los encuestados a. Agrupación

En referencia a la dimensión "ritual", han sido analizadas las variables interacción verbal con las víctimas, relaciones sexuales con las víctimas ante-mortem, relaciones sexuales con las víctimas post-mortem, penetración en las relaciones sexuales, conductas sádicas y de tortura, canibalismo, mutilación y toma trofeos de sus crímenes.

En lo relacionado a la interacción verbal con las víctimas (Tabla 53 y Figura 31), se observa que un 54,5\% (24 casos) del total de la muestra sí tienen interacción verbal con las víctimas de forma no agresiva, de los cuales un 34,1\% (15 casos) actuaron en España y un 20,5\% (9 casos) lo hicieron en América del Norte.

De lo mismo, se extrae que un 40,9\% (18 casos) mantuvieron una interacción verbal con las víctimas de forma agresiva, de los cuales un 29,5\% (13 casos) actuaron en América del Norte y un 11,4\% (5 casos) lo hicieron en España.

Por último, de un total de 44 sujetos analizados en estas variables, tan sólo un 4,5\% (2 casos) no tuvieron interacción verbal con las víctimas. 
Tabla 53. Distribución de frecuencias de la variable interacción verbal con las víctimas en cada zona de actuación.

\begin{tabular}{|c|c|c|c|c|c|}
\hline & & & \multicolumn{2}{|c|}{ Zona de Actuación } & \multirow[b]{2}{*}{ Total } \\
\hline & & & España & América del Norte & \\
\hline \multirow[t]{6}{*}{ Interacción Verbal con las Víctimas } & No & Recuento & 1 & 1 & $\overline{2}$ \\
\hline & & $\%$ del total & $2,3 \%$ & $2,3 \%$ & $4,5 \%$ \\
\hline & Sí - Agresiva & Recuento & 5 & 13 & 18 \\
\hline & & $\%$ del total & $11,4 \%$ & $29,5 \%$ & $40,9 \%$ \\
\hline & Sí - No Agresiva & Recuento & 15 & 9 & 24 \\
\hline & & $\%$ del total & $34,1 \%$ & $20,5 \%$ & $54,5 \%$ \\
\hline \multirow[t]{2}{*}{ Total } & & Recuento & 21 & 23 & 44 \\
\hline & & $\%$ del total & $47,7 \%$ & $52,3 \%$ & $100,0 \%$ \\
\hline
\end{tabular}

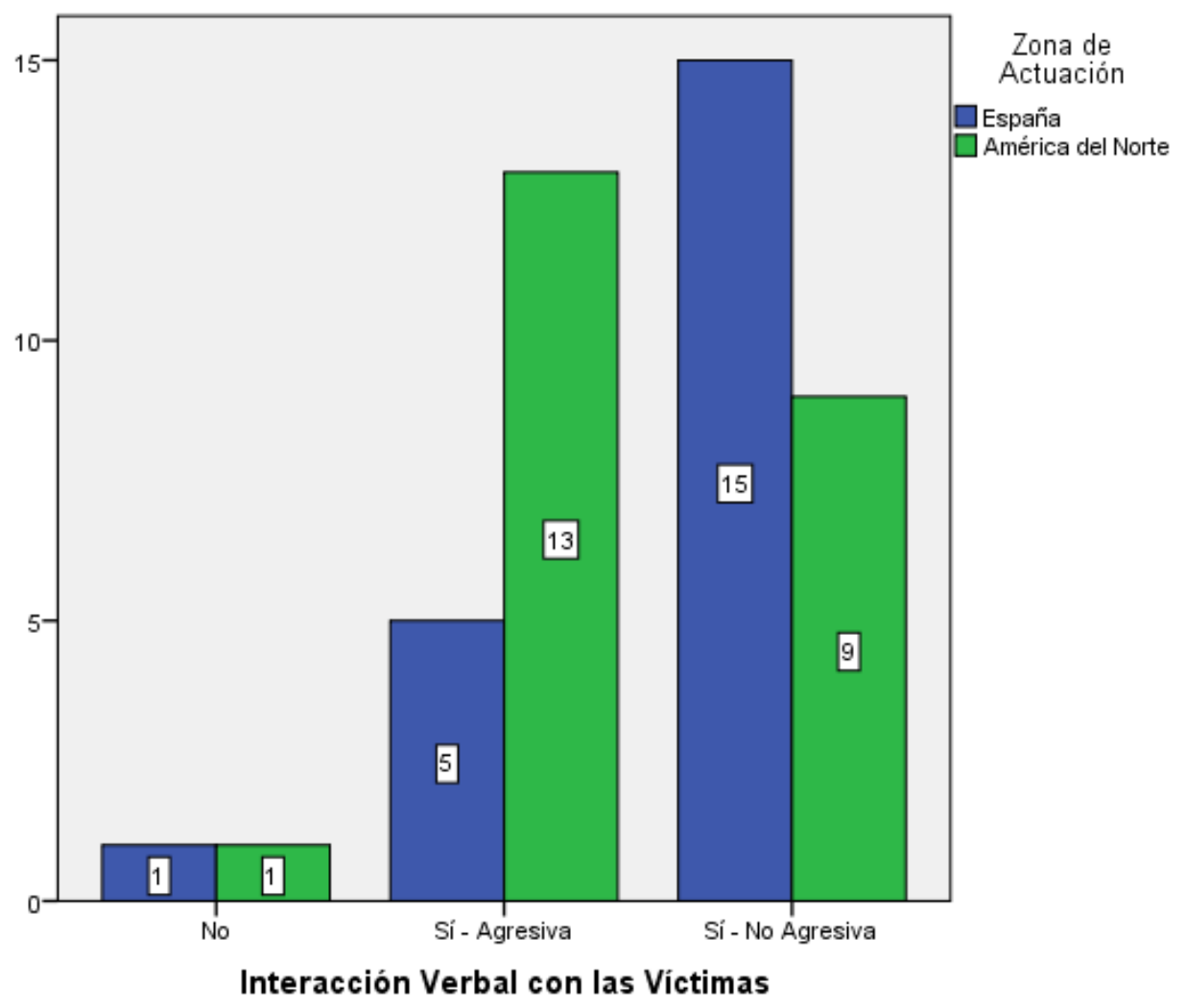

Figura 31. Gráfico de barras agrupadas de la variable interacción verbal con las víctimas en cada zona de actuación.

En cuanto al mantenimiento de relaciones sexuales con las víctimas antemortem, se observa que un 51,1\% (24 casos) del total de la muestra sí tuvieron relaciones sexuales con las víctimas ante-mortem, de los cuales un 29,8\% (14 casos) actuaron en América del Norte frente a un 21,3\% (10 casos) que actuaron en España. 
Por otro lado, un 48,9\% (23 casos) del total de asesinos en serie incluidos en la muestra no tuvieron relaciones sexuales con las víctimas ante-mortem, de los cuales un 29,8\% (14 casos) actuaron en España y un 19,1\% (9 casos) lo hicieron en América del Norte. Podemos observar lo indicado en la Tabla 54 y Figura 32.

Tabla 54. Distribución de frecuencias de la variable relaciones sexuales con las víctimas antemortem en cada zona de actuación.

\begin{tabular}{llrrrr}
\hline & & & \multicolumn{2}{c}{ Zona de Actuación } & \\
\cline { 4 - 5 } & & & España & América del Norte & \multicolumn{2}{c}{ Total } \\
\hline Relaciones Sexuales con las & No & Recuento & 14 & 9 & 23 \\
Víctimas Ante-Mortem & & \% del total & $29,8 \%$ & $19,1 \%$ & $48,9 \%$ \\
\cline { 3 - 4 } & Sí & Recuento & 10 & 14 & 24 \\
& & \% del total & $21,3 \%$ & $29,8 \%$ & $51,1 \%$ \\
\hline Total & & Recuento & 24 & 23 & 47 \\
& & \% del total & $51,1 \%$ & $48,9 \%$ & $100,0 \%$ \\
\hline
\end{tabular}

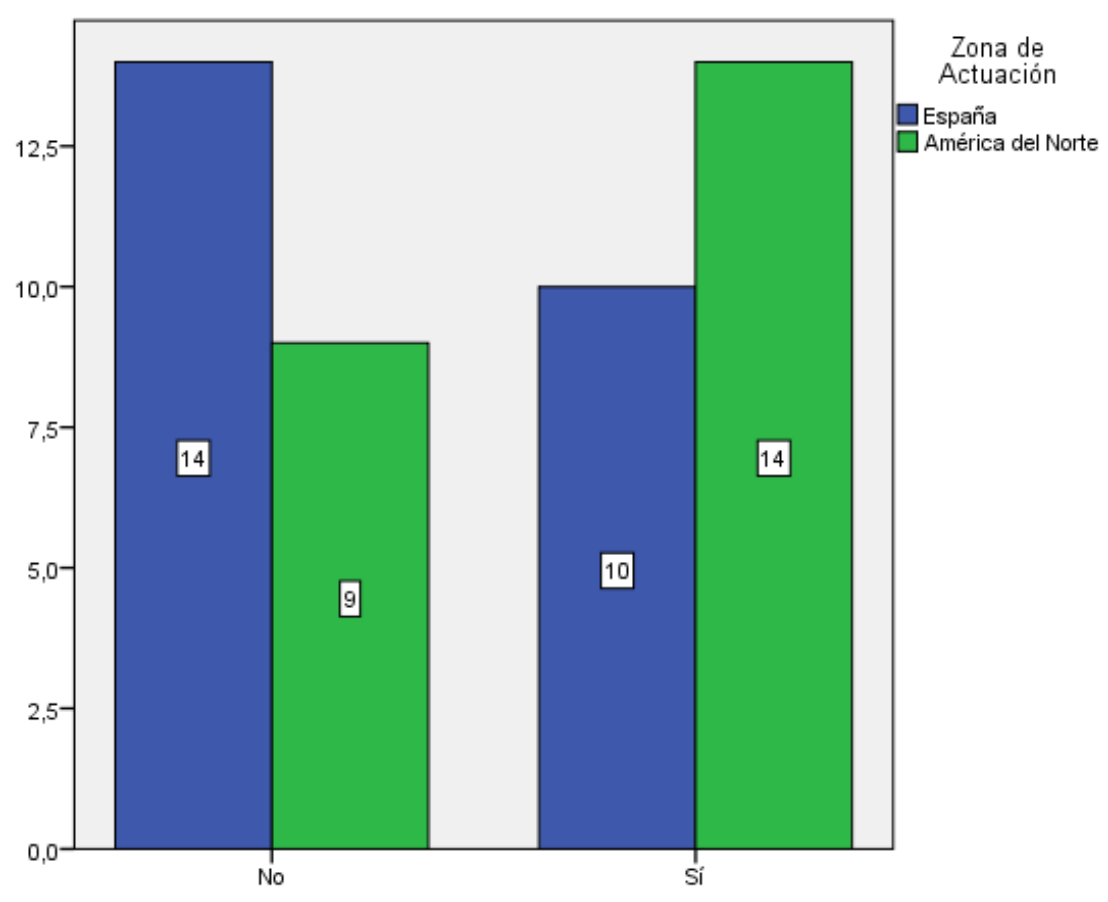

Relaciones Sexuales con las Víctimas Ante-Mortem

Figura 32. Gráfico de barras agrupadas de la variable relaciones sexuales con las víctimas antemortem en cada zona de actuación.

En relación al mantenimiento de relaciones sexuales con las víctimas postmortem, se extrae que un 65,9\% (27 casos) del total de la muestra no tuvieron 
relaciones sexuales con las víctimas post-mortem, de los cuales un 43,9\% (18 casos) tuvieron su zona de actuación en España frente a un 22\% (9 casos) que actuaron en América del Norte.

Además, se observa que el 34,1\% (14 casos) de los asesinos sí tuvieron relaciones sexuales con las víctimas post-mortem, de los cuales un 22\% (9 casos) actuaron en América del Norte y un 12,2\% (5 casos) lo hicieron en España. (Tabla 55 y Figura 33).

Tabla 55. Distribución de frecuencias de la variable relaciones sexuales con las víctimas postmortem en cada zona de actuación.

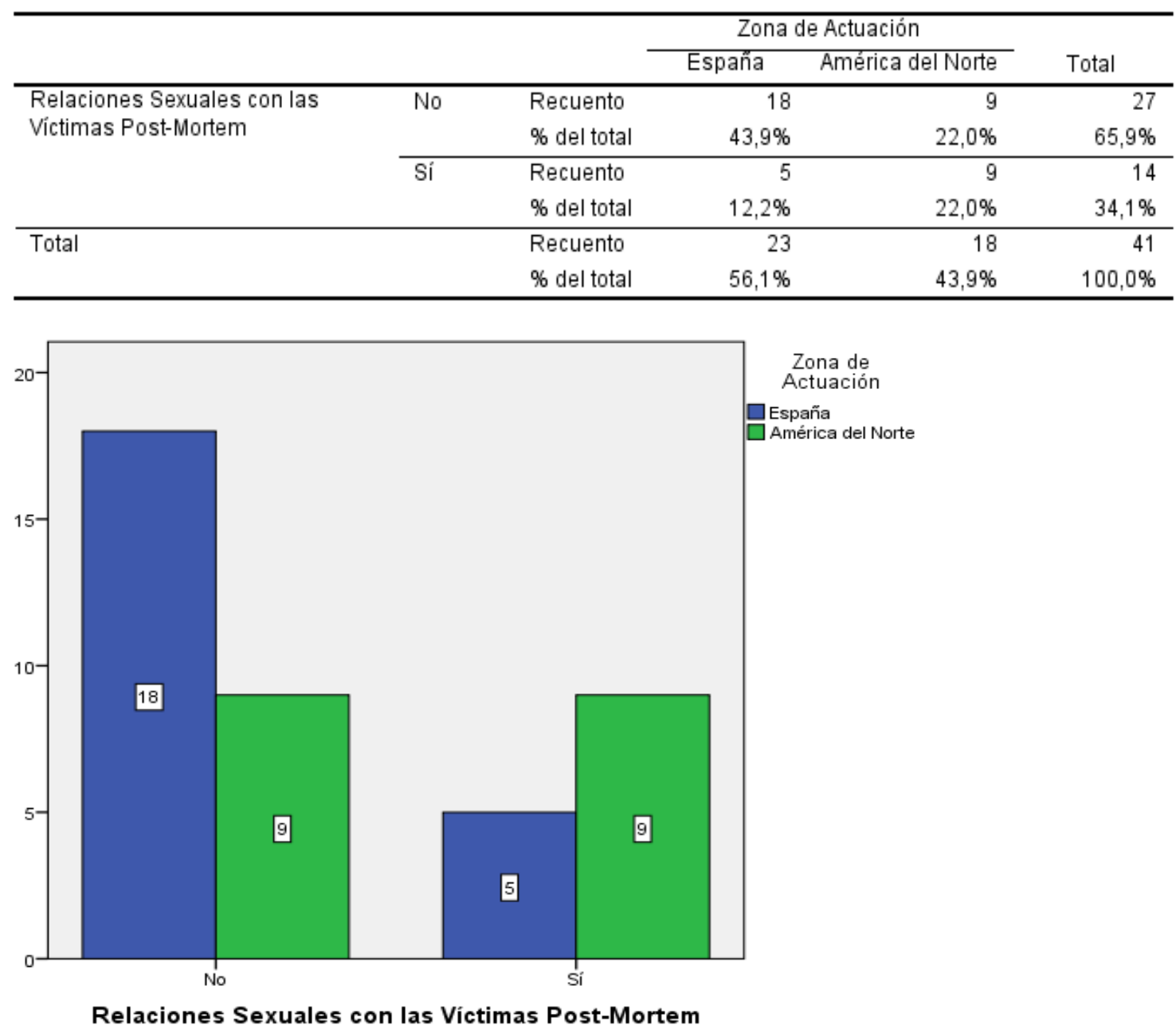

Figura 33. Gráfico de barras agrupadas de la variable relaciones sexuales con las víctimas postmortem en cada zona de actuación. 
En cuanto al tipo de penetración que emplearon con las víctimas (Tabla 56), se extrae que un $50 \%$ (22 casos) del total de la muestra analizada no tuvieron penetración en las relaciones sexuales, de los cuales un 31,8\% (14 casos) actuaron en España y un 18,2\% (8 casos) actuaron en América del Norte.

Por otro lado, un 43,2\% (19 casos) del total sí tuvieron penetración vaginal en las relaciones sexuales y un 22,7\% (10 casos) sí la tuvieron de forma bucal.

Por último, tan sólo un 15,9\% (7 casos) del total de asesinos en serie emplearon la penetración de forma anal, de los cuales un 13,6\% (6 casos) tuvieron su zona de actuación en América del Norte frente a un 2,3\% (1 caso) que actuó en España.

Tabla 56. Distribución de frecuencias de la variable penetración en las relaciones sexuales en cada zona de actuación.

\begin{tabular}{|c|c|c|c|c|c|}
\hline & & & \multicolumn{2}{|c|}{ Zona de Actuación } & \multirow[b]{2}{*}{ Total } \\
\hline & & & España & América del Norte & \\
\hline \multirow{8}{*}{$\begin{array}{l}\text { Penetración en las Relaciones } \\
\text { Sexuales }^{\text {a }}\end{array}$} & No & Recuento & 14 & 8 & 22 \\
\hline & & $\%$ del total & $31,8 \%$ & $18,2 \%$ & $50,0 \%$ \\
\hline & Sí-Bucal & Recuento & 3 & 7 & 10 \\
\hline & & $\%$ del total & $6,8 \%$ & $15,9 \%$ & $22,7 \%$ \\
\hline & Sí - Vaginal & Recuento & 7 & 12 & 19 \\
\hline & & $\%$ del total & $15,9 \%$ & $27,3 \%$ & $43,2 \%$ \\
\hline & Sí - Anal & Recuento & 1 & 6 & 7 \\
\hline & & $\%$ del total & $2,3 \%$ & $13,6 \%$ & $15,9 \%$ \\
\hline \multirow[t]{2}{*}{ Total } & & Recuento & 22 & 22 & 44 \\
\hline & & $\%$ del total & $50,0 \%$ & $50,0 \%$ & $100,0 \%$ \\
\hline
\end{tabular}

Los porcentajes y los totales se basan en los encuestados.

a. Agrupación

En cuanto a la práctica de conductas sádicas y de tortura con las víctimas, se observa que de los 23 asesinos en serie que actuaron en América del Norte (50\% de los casos), un 36,6\% (15 casos) sí practicaron conductas sádicas y de tortura, frente a un $17,4 \%$ ( 8 casos) que no emplearon dicha práctica.

De lo mismo se puede extraer que de los 23 asesinos en serie que actuaron en España (50\% de los casos), un 30,4\% (14 casos) no practicaron conductas sádicas y de tortura, frente a un 19,6\% (9 casos) que sí lo hicieron. Podemos observar lo indicado en la Tabla 57 y Figura 34. 
Tabla 57. Distribución de frecuencias de la variable conductas sádicas y de tortura en cada zona de actuación.

\begin{tabular}{llrrrr}
\hline & & \multicolumn{2}{c}{ Zona de Actuación } & \multicolumn{2}{c}{} \\
\cline { 3 - 4 } & & & España & América del Norte & \multicolumn{1}{l}{ Total } \\
\hline Conductas Sádicas y de Tortura & No & Recuento & 14 & 8 & 22 \\
& & \% del total & $30,4 \%$ & $17,4 \%$ & $47,8 \%$ \\
\cline { 2 - 5 } & Sí & Recuento & 9 & 15 & 24 \\
& & \% del total & $19,6 \%$ & $32,6 \%$ & $52,2 \%$ \\
\hline Total & Recuento & 23 & 23 & 46 \\
& & \% del total & $50,0 \%$ & $50,0 \%$ & $100,0 \%$ \\
\hline
\end{tabular}

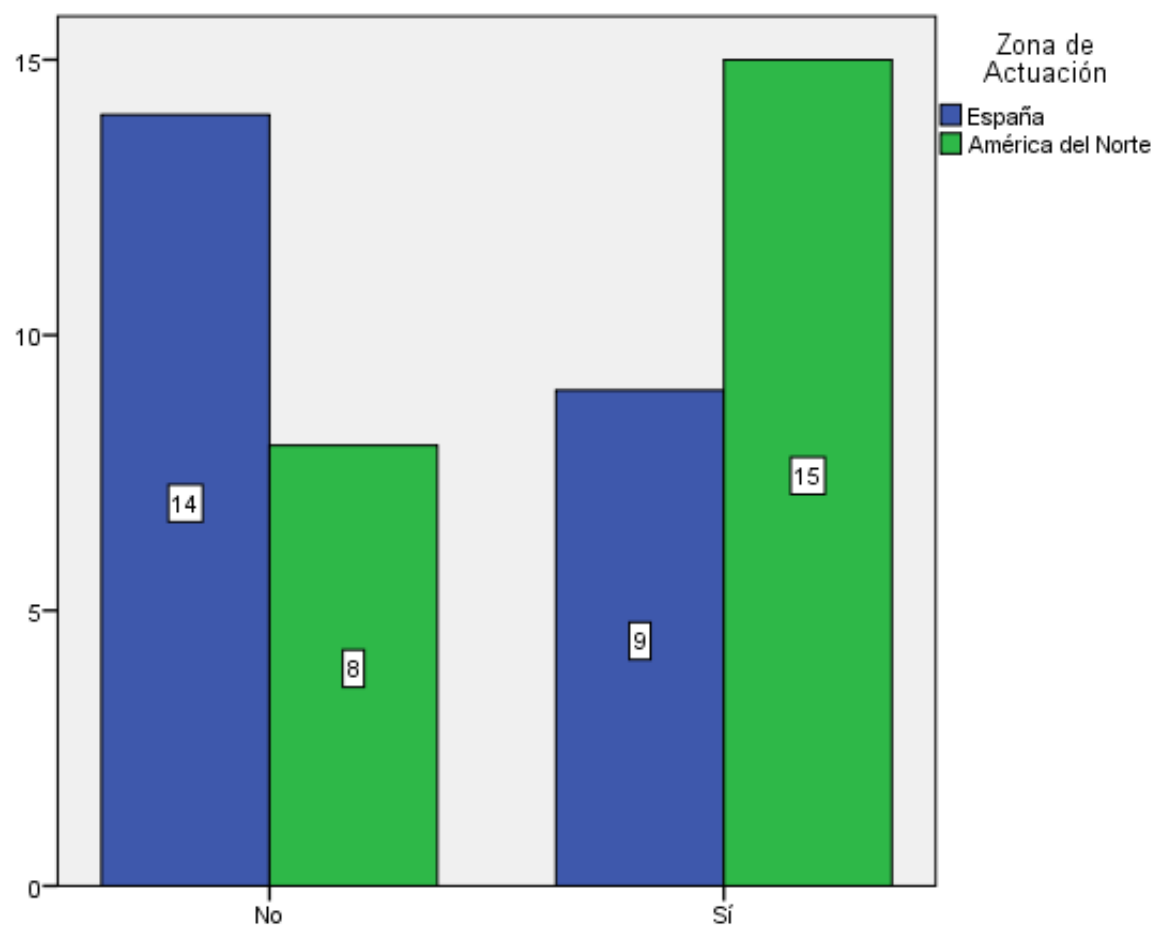

Conductas Sádicas y de Tortura

Figura 34. Gráfico de barras agrupadas de la variable conductas sádicas y de tortura en cada zona de actuación.

En lo referente a la práctica de conductas caníbales (Tabla 58 y Figura 35), se observa que el 87,5\% (42 casos) no han llevado a cabo conductas caníbales.

De los sujetos incluidos en la muestra, tan sólo un 12,5\% (6 casos) han practicado canibalismo, siendo la zona de actuación de 5 de ellos $(10,4 \%)$ América del Norte. 
Tabla 58. Distribución de frecuencias de la variable canibalismo en cada zona de actuación.

\begin{tabular}{llrrrr}
\hline & & \multicolumn{2}{c}{ Zona de Actuación } & \\
\cline { 3 - 4 } & & & España & América del Norte & Total \\
\hline Canibalismo & No & Recuento & 23 & 19 & 42 \\
& & \% del total & $47,9 \%$ & $39,6 \%$ & $87,5 \%$ \\
\cline { 2 - 5 } & Sí & Recuento & 1 & 5 & 6 \\
& \% del total & $2,1 \%$ & $10,4 \%$ & $12,5 \%$ \\
\hline Total & Recuento & 24 & 24 & 48 \\
& & \% del total & $50,0 \%$ & $50,0 \%$ & $100,0 \%$ \\
\hline
\end{tabular}

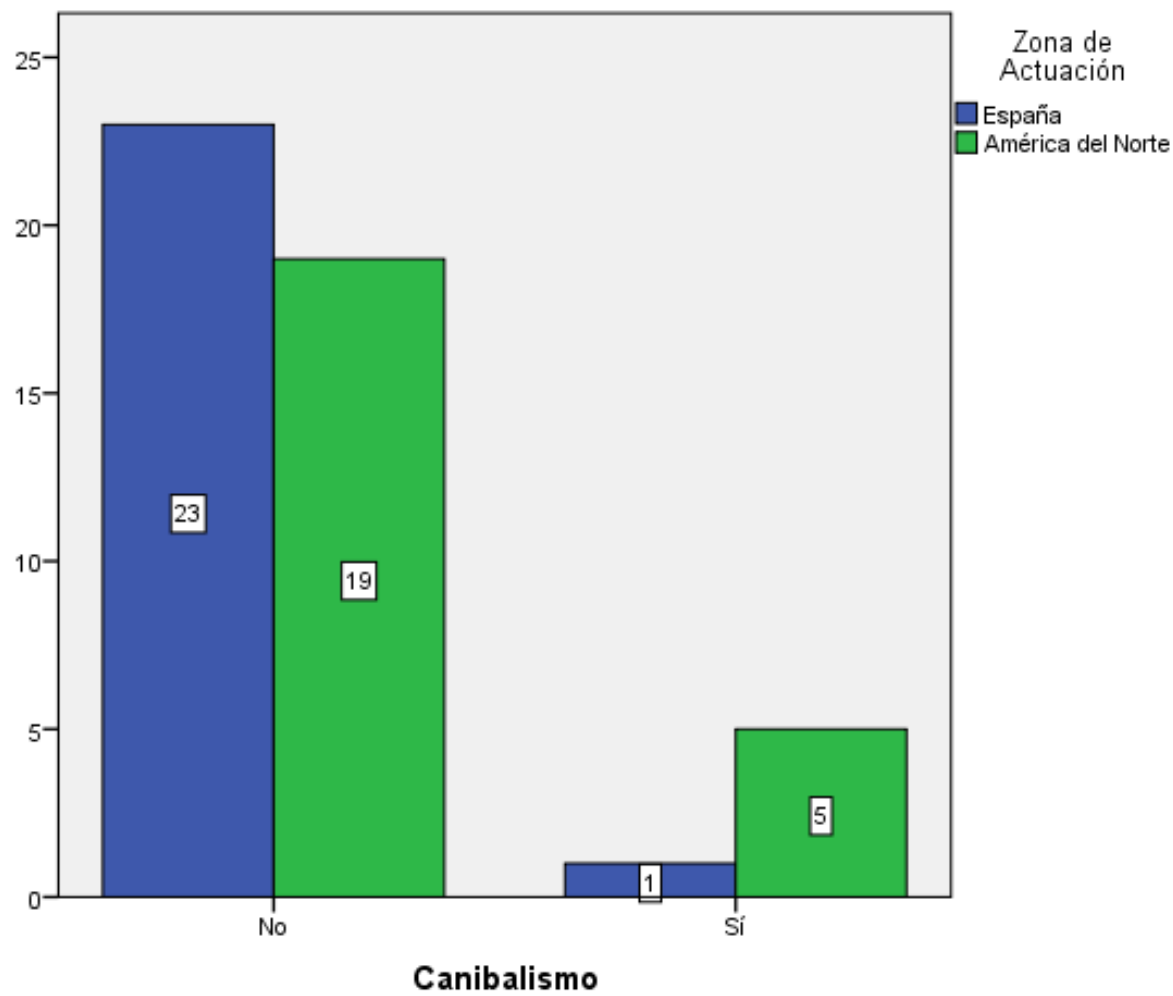

Figura 35. Gráfico de barras agrupadas de la variable canibalismo en cada zona de actuación.

En lo relacionado con haber llevado a cabo la mutilación con las víctimas (Tabla 59 y Figura 36), se extrae que un 64,6\% (31 casos) del total de la muestra no llevan a cabo mutilación, de los cuales un 41,7\% (20 casos) actuaron en España y un 22,9\% (11 casos) actuaron en América del Norte.

Además, un 31,3\% (17 casos) del total de asesinos en serie sí llevaron a cabo mutilación, un 22,9\% (13 casos) lo hicieron en América del Norte y tan sólo un 8,3\% (4 casos) lo hicieron en España. 
Tabla 59. Distribución de frecuencias de la variable mutilación en cada zona de actuación.

\begin{tabular}{llrrrr}
\hline & & \multicolumn{2}{c}{ Zona de Actuación } & \multicolumn{2}{c}{} \\
\cline { 3 - 5 } & & & España & América del Norte & \multicolumn{2}{c}{ Total } \\
\hline Mutilación & No & Recuento & 20 & 11 & 31 \\
& & \% del total & $41,7 \%$ & $22,9 \%$ & $64,6 \%$ \\
\cline { 2 - 5 } & Sí & Recuento & 4 & 13 & 17 \\
& & \% del total & $8,3 \%$ & $27,1 \%$ & $35,4 \%$ \\
\hline Total & Recuento & 24 & 24 & 48 \\
& & \% del total & $50,0 \%$ & $50,0 \%$ & $100,0 \%$ \\
\hline
\end{tabular}

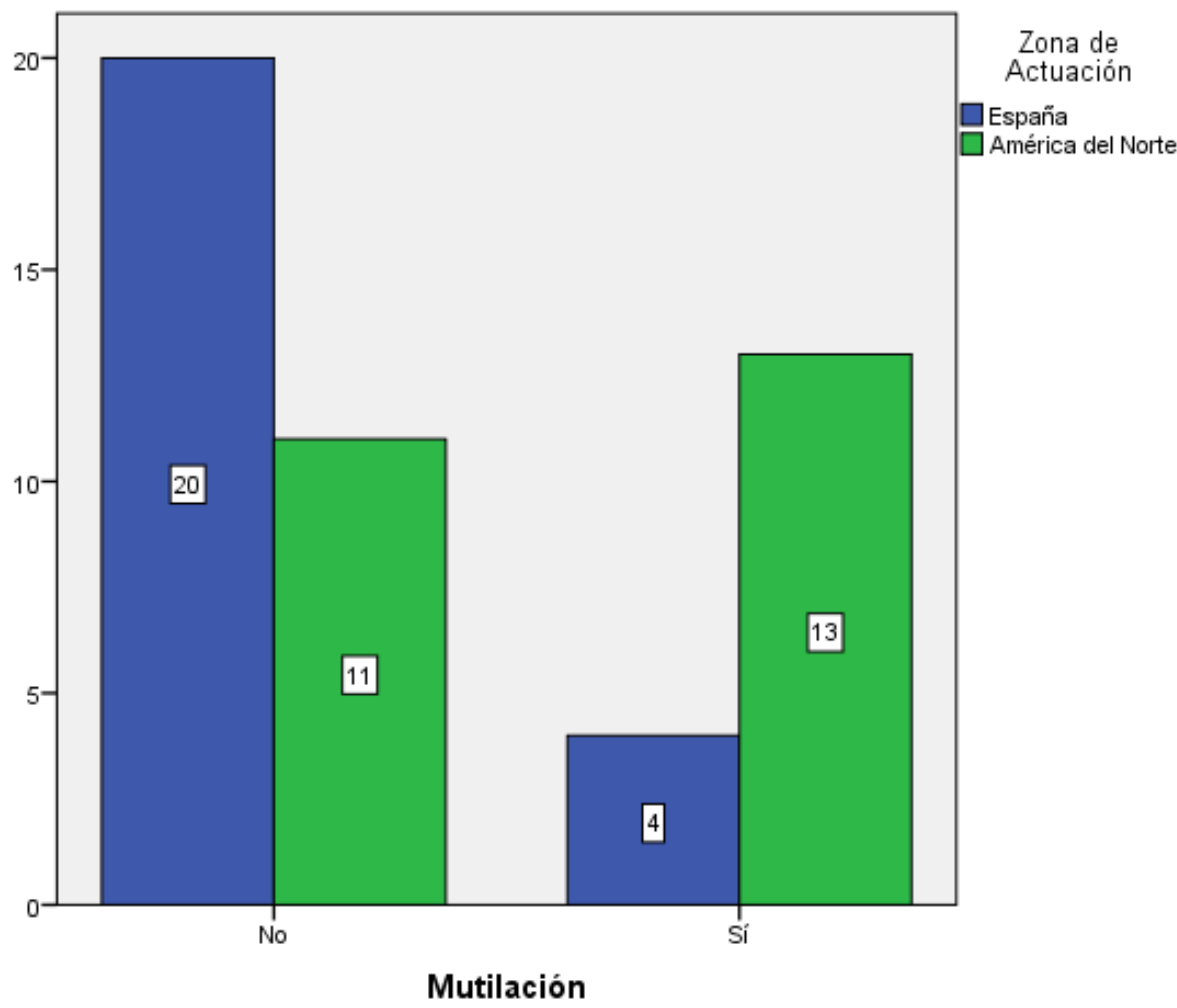

Figura 36. Gráfico de barras agrupadas de la variable mutilación en cada zona de actuación.

En cuanto a la toma de trofeos de sus crímenes, se observa que un $66,7 \%$ (32 casos) del total de asesinos incluidos en la muestra no tomaron trofeos de sus crímenes, siendo el mismo número de sujetos (16 casos) independientemente de la zona de actuación. 
Además, se observa que el 33,3\% restante (16 casos) sí tomaron trofeos de sus crímenes, repartiéndose el mismo porcentaje 16,7\% (8 casos) entre las dos zonas de actuación. Estos datos quedan representados en la Tabla 60 y Figura 37.

Tabla 60. Distribución de frecuencias de la variable toma de trofeos de sus crímenes en cada zona de actuación.

\begin{tabular}{llrrrr}
\hline & & & \multicolumn{2}{c}{ Zona de Actuación } & \multirow{2}{*}{ Total } \\
\cline { 3 - 4 } & & & España & América del Norte & \multicolumn{1}{c}{ Totar } \\
\hline Toma Trofeos de sus Crímenes & No & Recuento & 16 & 16 & 32 \\
& & \% del total & $33,3 \%$ & $33,3 \%$ & $66,7 \%$ \\
\cline { 2 - 5 } & Sí & Recuento & 8 & 8 & 16 \\
& & \% del total & $16,7 \%$ & $16,7 \%$ & $33,3 \%$ \\
\hline Total & & Recuento & 24 & 24 & 48 \\
& & \% del total & $50,0 \%$ & $50,0 \%$ & $100,0 \%$ \\
\hline
\end{tabular}

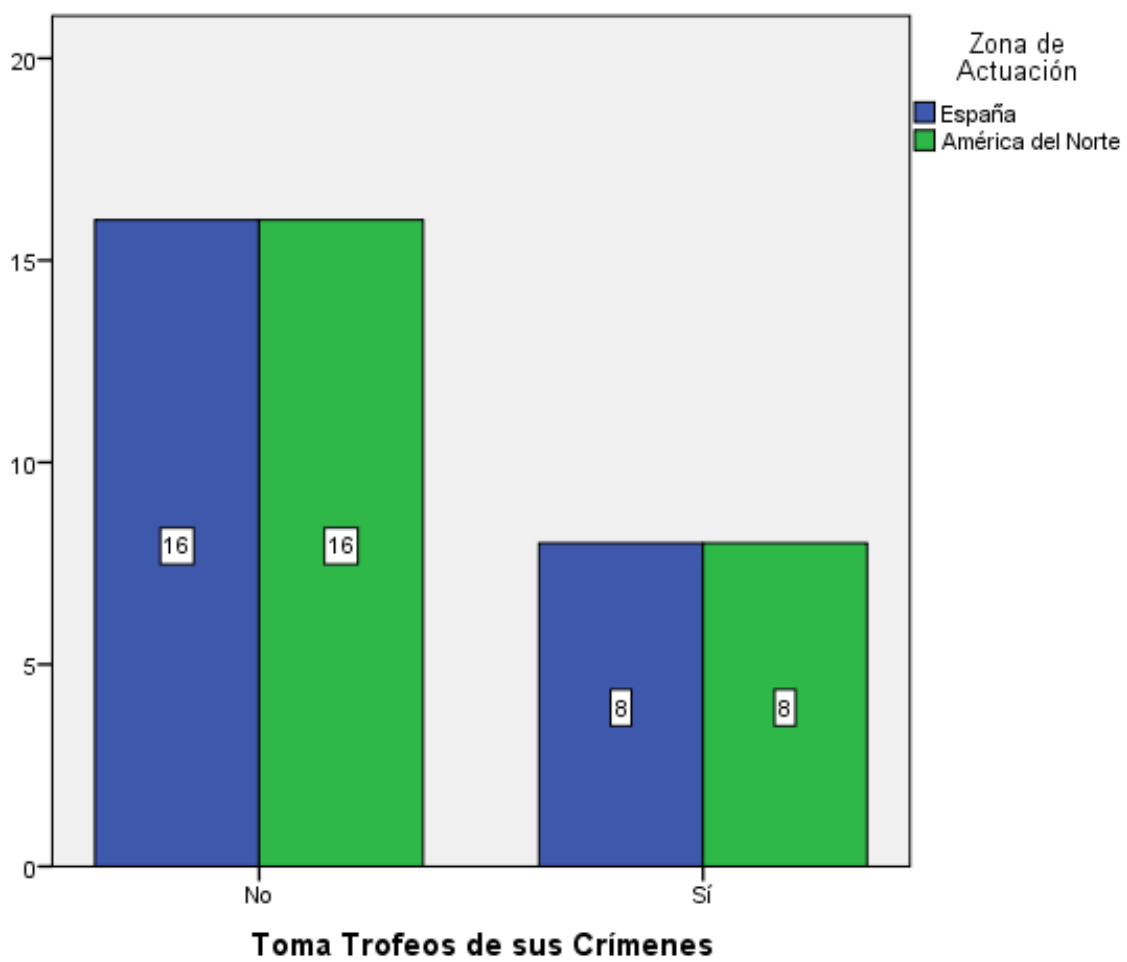

Figura 37. Gráfico de barras agrupadas de la variable toma trofeos de sus crímenes en cada zona de actuación.

En relación a la dimensión "victimología", se han analizado las variables número de víctimas total y selección de las víctimas. 
En cuanto al número de víctimas total, en esta muestra de 24 asesinos en serie cuya zona de actuación fue España, el número de víctimas total no se aproxima a una distribución normal (asimétrica, As= 2,701 y leptocúrtica $\mathrm{K}=8,189$ ). La media del número de víctimas total ha sido aproximadamente de 9 (mediana 4) con una desviación típica de 10,504 tal y como se observa en la Tabla 61 y Figura 38.

Tabla 61. Estadísticos descriptivos de la variable número de víctimas total de los asesinos seriales que actuaron en España.

\begin{tabular}{lr}
\hline$N$ & Válidos \\
Media & Perdidos \\
Error típ. de la media & 9,08 \\
Mediana & 2,144 \\
Moda & 4,00 \\
Desv. típ. & 4 \\
Varianza & 10,504 \\
Asimetría & 110,341 \\
Error típ. de asimetría & 2,701 \\
Curtosis &, 472 \\
Error típ. de curtosis & 8,189 \\
\hline
\end{tabular}

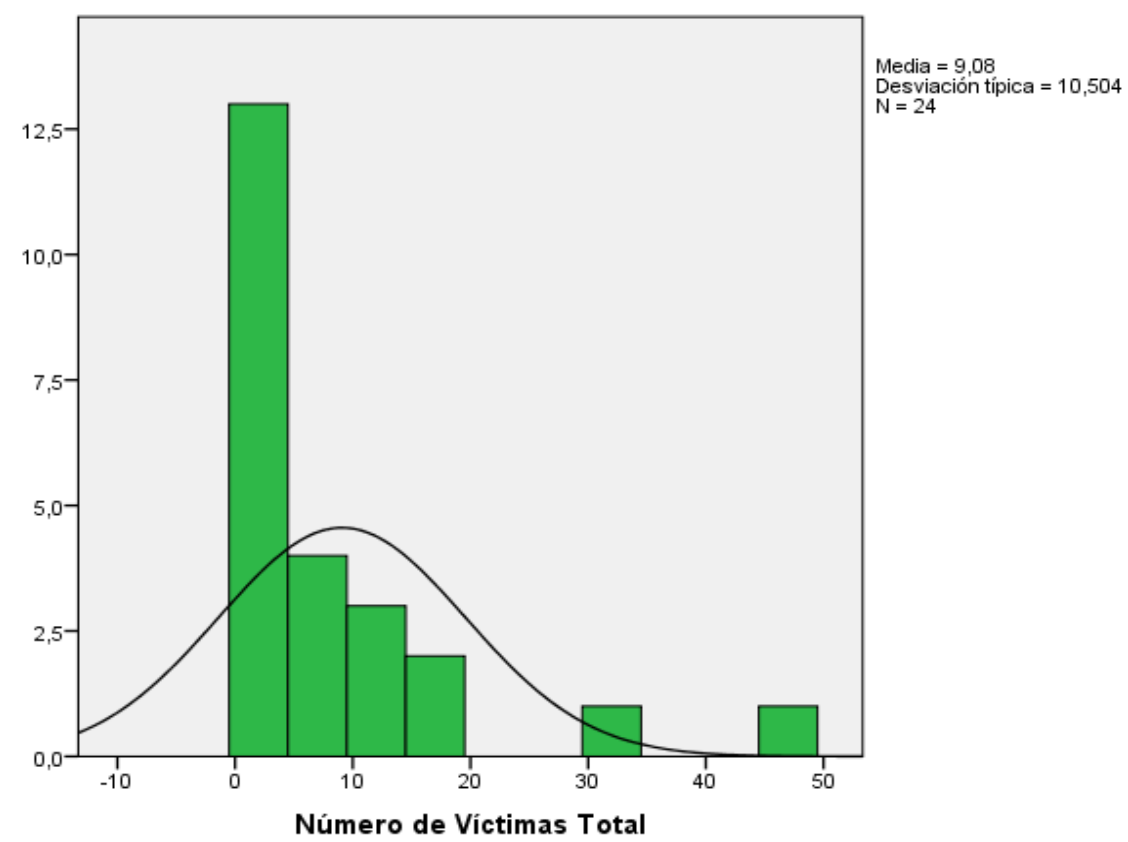

Figura 38. Histograma de frecuencias de la variable número de víctimas total de los asesinos en serie que actuaron en España. 
En la muestra de 24 asesinos en serie cuya zona de actuación fue América del Norte, el número de víctimas total no se aproxima a una distribución normal (asimétrica, As=1,848 y leptocúrtica $\mathrm{K}=3,073$ ). La media del número de víctimas total ha sido aproximadamente de 13 (mediana 10) con una desviación típica de 11,564 (Tabla 62 y Figura 39).

Tabla 62. Estadísticos descriptivos de la variable número de víctimas total de los asesinos seriales que actuaron en América del Norte.

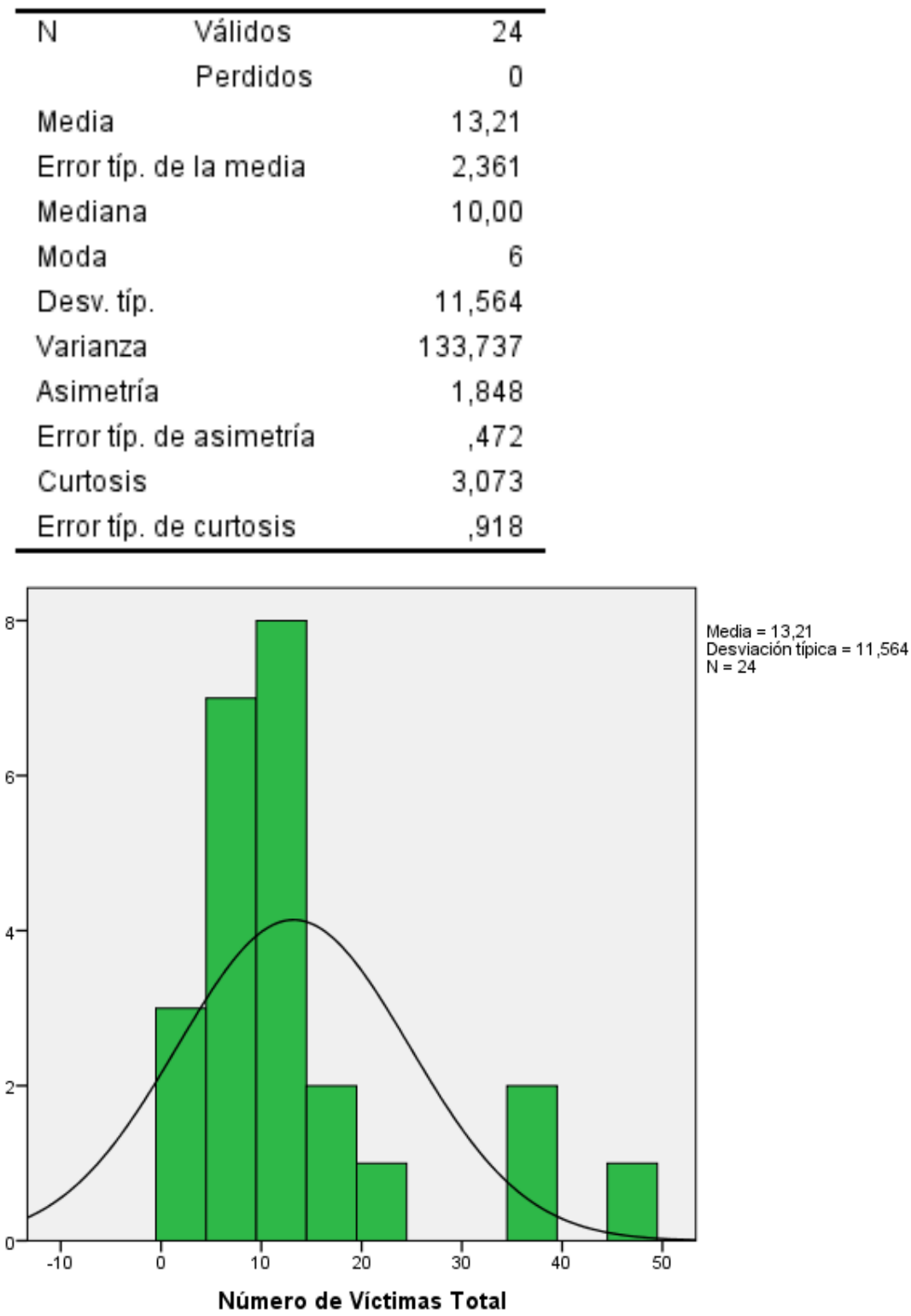

Figura 39. Histograma de frecuencias de la variable número de víctimas total de los asesinos en serie que actuaron en América del Norte. 
En cuanto al modo de selección de las víctimas, se extrae que el 58,3\% (28 casos) del total de asesinos incluidos en la muestra seleccionan a sus víctimas por posibilidad, siendo el mismo porcentaje 29,2\% (14 casos) independientemente de la zona de actuación; mientras que un 41,7\% (20 casos) del total de la muestra las seleccionan por vulnerabilidad.

Por otro lado, 17 sujetos $(35,4 \%)$ del total de 48 asesinos seleccionan a sus víctimas por localización, 10 sujetos $(20,8 \%)$ lo hacen mediante relaciones y 5 de ellos $(10,4 \%)$ lo hacen por fantasía.

Por último, tan sólo un 6,2\% (3 casos) de los sujetos que forman parte de la muestra del total de 48 asesinos en serie seleccionan a sus víctimas por simbolismo, de los cuales un 4,2\% ( 2 casos) tuvieron su zona de actuación en América del Norte y un 2,1\% ( 1 caso) actuó en España. Podemos observar lo indicado en la Tabla 63.

Tabla 63. Distribución de frecuencias de la variable selección de las víctimas en cada zona de actuación.

\begin{tabular}{|c|c|c|c|c|c|}
\hline & & & \multicolumn{2}{|c|}{ Zona de Actuación } & \multirow[b]{2}{*}{ Total } \\
\hline & & & España & América del Norte & \\
\hline \multirow[t]{12}{*}{ Selección de las Víctimas ${ }^{a}$} & Posibilidad & Recuento & 14 & 14 & 28 \\
\hline & & $\%$ del total & $29,2 \%$ & $29,2 \%$ & $58,3 \%$ \\
\hline & Localización & Recuento & 7 & 10 & 17 \\
\hline & & $\%$ del total & $14,6 \%$ & $20,8 \%$ & $35,4 \%$ \\
\hline & Vulnerabilidad & Recuento & 9 & 11 & 20 \\
\hline & & $\%$ del total & $18,8 \%$ & $22,9 \%$ & $41,7 \%$ \\
\hline & Relaciones & Recuento & 6 & 4 & 10 \\
\hline & & $\%$ del total & $12,5 \%$ & $8,3 \%$ & $20,8 \%$ \\
\hline & Simbolismo & Recuento & 1 & 2 & 3 \\
\hline & & $\%$ del total & $2,1 \%$ & $4,2 \%$ & $6,3 \%$ \\
\hline & Fantasía & Recuento & 2 & 3 & 5 \\
\hline & & $\%$ del total & $4,2 \%$ & $6,3 \%$ & $10,4 \%$ \\
\hline \multirow[t]{2}{*}{ Total } & & Recuento & 24 & 24 & 48 \\
\hline & & $\%$ del total & $50,0 \%$ & $50,0 \%$ & $100,0 \%$ \\
\hline
\end{tabular}

Los porcentajes y los totales se basan en los encuestados.

a. Agrupación

En relación a la dimensión "tipologías", se han analizado las variables Tipo I (FBI), tipo II (Canter y Salfati), tipo III (Holmes y DeBerguer), tipo IV (Fox y Levin), tipo V (Canter) y tipo VI (Rossmo). 
En cuanto a la tipología del FBI (Tipo I), se extrae que el 45,8\% (22 casos) del total de la muestra analizada son asesinos de tipo "organizado", de los cuales un $31,2 \%$ (15 casos) actuaron en España y un 14,6\% (7 casos) lo hicieron en América del Norte.

Del mismo modo, un 14,6\% (7 casos) del total de asesinos en serie son de tipo "desorganizado", de los cuales un 8,3\% (4 casos) tuvieron su zona de actuación en América del Norte y un 6,2\% (3 casos) actuaron en España.

Por último, un 39,6\% (19 casos) del total de la muestra son asesinos con una organización de tipo "mixto", de los cuales un 27,1\% (13 casos) actuaron en América del Norte frente a un 12,5\% (6 casos) que lo hicieron en España. (Tabla 64 y Figura 40).

Tabla 64. Distribución de frecuencias de la variable tipo I (FBI) en cada zona de actuación.

\begin{tabular}{llrrrr}
\hline & & \multicolumn{2}{c}{ Zona de Actuación } & \\
\cline { 3 - 4 } & & & España & América del Norte & \multicolumn{2}{c}{ Total } \\
\hline Tipo 1 (FBI) & Organizado & Recuento & 15 & 7 & 22 \\
& & \% del total & $31,3 \%$ & $14,6 \%$ & $45,8 \%$ \\
\cline { 2 - 5 } & Desorganizado & Recuento & 3 & 4 & 7 \\
& & \% del total & $6,3 \%$ & $8,3 \%$ & $14,6 \%$ \\
\cline { 2 - 5 } & Mixto & Recuento & 6 & 13 & 19 \\
& & \% del total & $12,5 \%$ & $27,1 \%$ & $39,6 \%$ \\
\hline Total & Recuento & 24 & 24 & 48 \\
& & \% del total & $50,0 \%$ & $50,0 \%$ & $100,0 \%$ \\
\hline
\end{tabular}

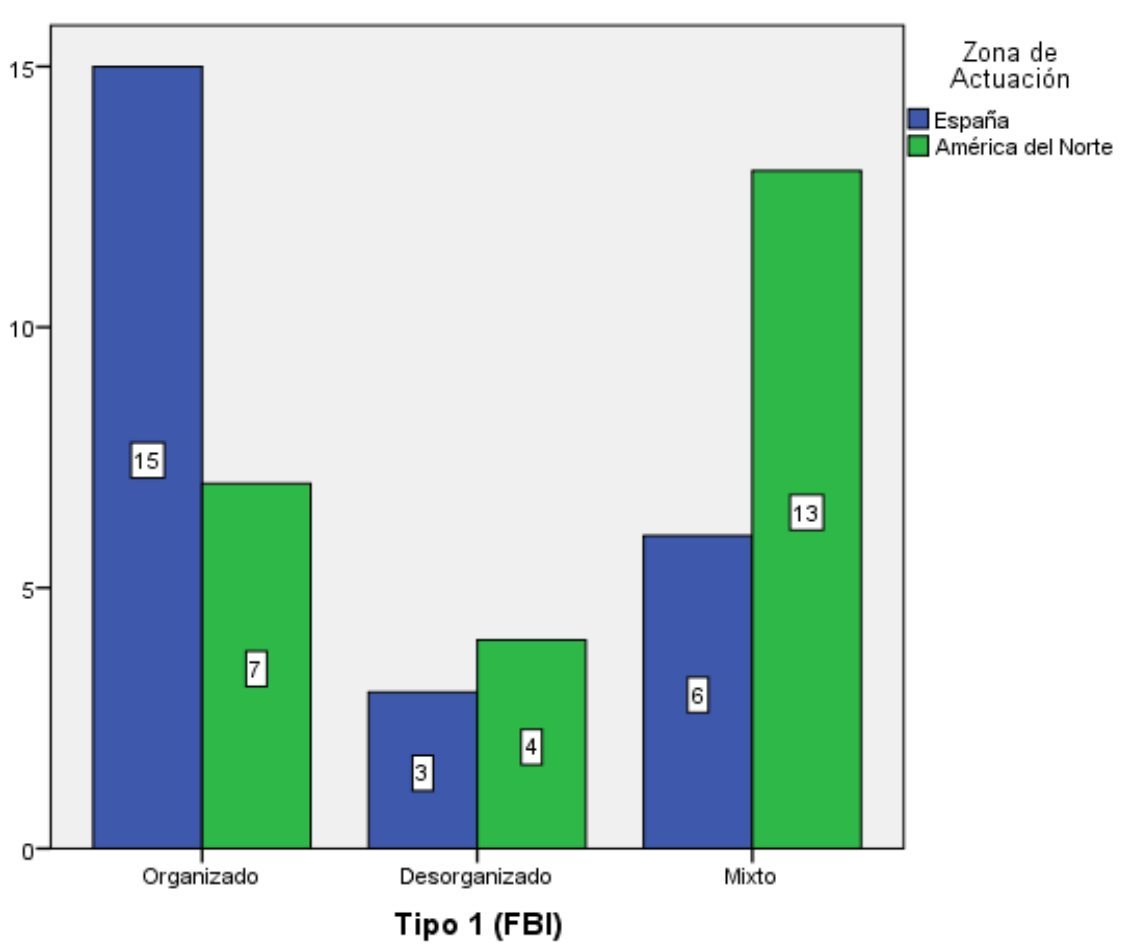

Figura 40. Gráfico de barras agrupadas de la variable tipo I (FBI) en cada zona de actuación. 
En relación a la tipología de Canter y Salfati, (Tipo II) (Tabla 65 y Figura 41), se extrae que un 60,4\% (29 casos) del total de asesinos en serie incluidos en la muestra son de tipo "instrumental-oportunista", de los cuales un 31,2\% (15 casos) actuaron en España frente a un 29,2\% (14 casos) que lo hicieron en América del Norte.

De lo mismo, se observa que un 37,5\% (18 casos) del total de la muestra son de tipo "instrumental-cognitivo", de los cuales un 18,8\% (9 casos) actuaron en América del Norte, siendo el mismo número de casos los asesinos en serie de este tipo que actuaron en España.

Por último, tan sólo 1 caso $(2,1 \%)$ de los incluidos en la muestra es de tipo "expresivo-impulsivo", siendo su zona de actuación América del Norte.

Tabla 65. Distribución de frecuencias de la variable tipo II (Canter y Salfati) en cada zona de actuación.

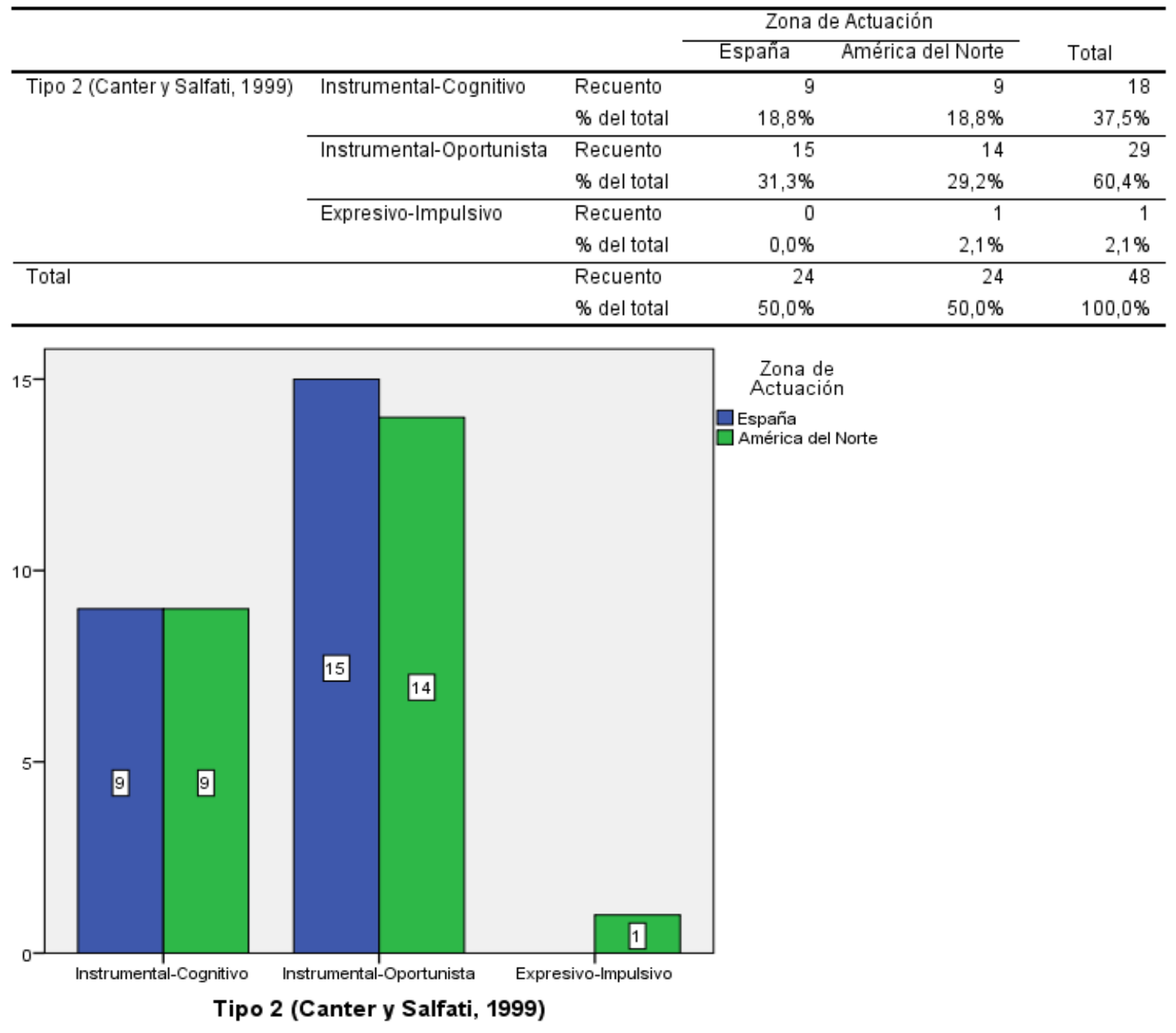

Figura 41. Gráfico de barras agrupadas de la variable tipo II (Canter y Salfati) en cada zona de actuación. 
En cuanto a la tipología de Holmes y DeBerguer, (Tipo III), se extrae que un 47,9\% (23 casos) del total de la muestra analizada es de tipo "dominante", de los cuales un 35,4\% (17 casos) actuaron en España frente a un 12,5\% (6 casos) que actuaron en América del Norte; mientras que un 31,2\% (15 casos) del total de asesinos en serie son de tipo "hedonista", de los cuales un 20,8\% (10 casos) tuvieron su zona de actuación en América del Norte frente a un 10,4\% (5 casos) que actuaron en España.

Por otro lado, un 12,5\% (6 casos) del total son de tipo "misionario", de los cuales 5 sujetos $(10,4 \%)$ actuaron en América del Norte; mientras que tan sólo un 8,3\% (4 casos) son de tipo "visionario", de los cuales 3 asesinos tuvieron su zona de actuación en América del Norte. Podemos observar lo indicado en la Tabla 66 y Figura 42 .

Tabla 66. Distribución de frecuencias de la variable tipo III (Holmes y DeBerguer) en cada zona de actuación.

\begin{tabular}{|c|c|c|c|c|c|}
\hline & & & \multicolumn{2}{|c|}{ Zona de Actuación } & \multirow[b]{2}{*}{ Total } \\
\hline & & & España & América del Norte & \\
\hline \multirow[t]{8}{*}{ Tipo 3 (Holmes y DeBerguer, 1988) } & Visionario & Recuento & 1 & 3 & 4 \\
\hline & & $\%$ del total & $2,1 \%$ & $6,3 \%$ & $8,3 \%$ \\
\hline & Misionario & Recuento & 1 & 5 & 6 \\
\hline & & $\%$ del total & $2,1 \%$ & $10,4 \%$ & $12,5 \%$ \\
\hline & Hedonista & Recuento & 5 & 10 & 15 \\
\hline & & $\%$ del total & $10,4 \%$ & $20,8 \%$ & $31,3 \%$ \\
\hline & Dominante & Recuento & 17 & 6 & 23 \\
\hline & & $\%$ del total & $35,4 \%$ & $12,5 \%$ & $47,9 \%$ \\
\hline \multirow[t]{2}{*}{ Total } & & Recuento & 24 & 24 & 48 \\
\hline & & $\%$ del total & $50,0 \%$ & $50,0 \%$ & $100,0 \%$ \\
\hline
\end{tabular}




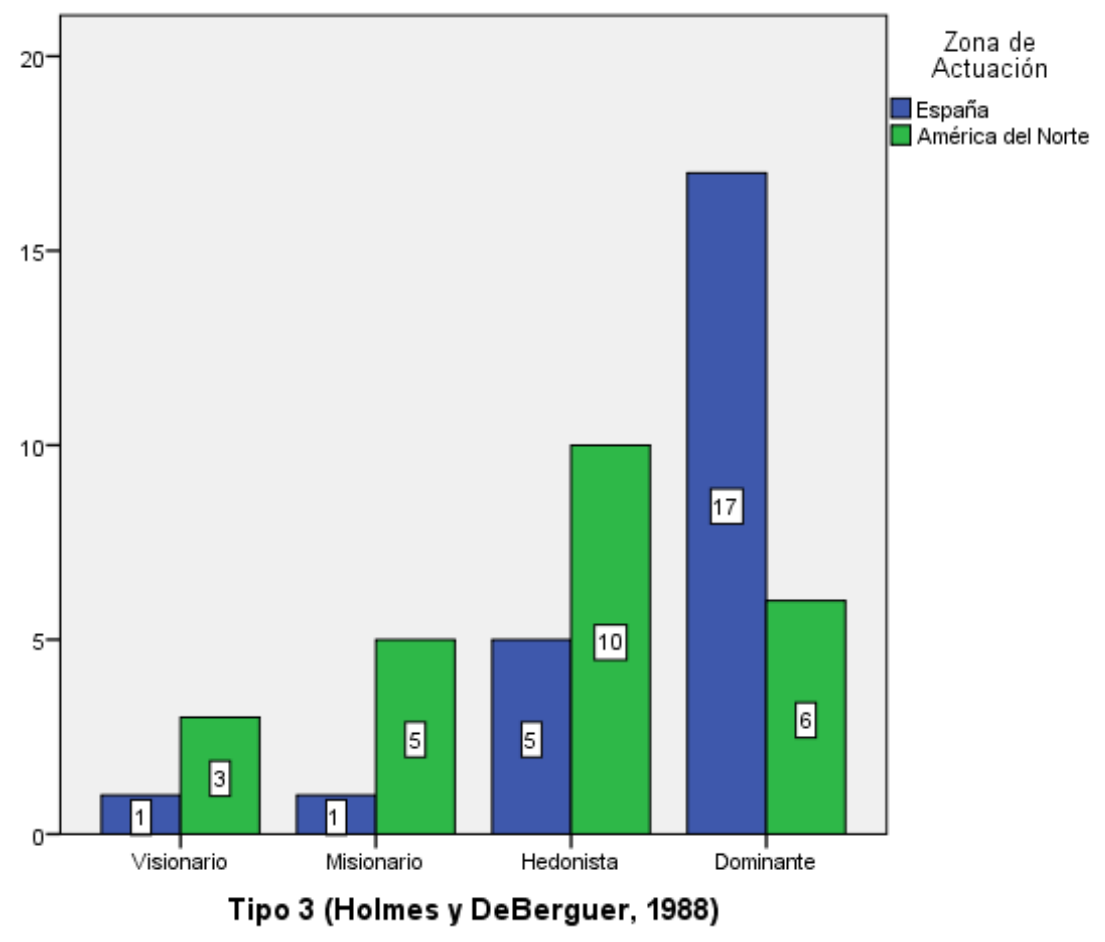

Figura 42. Gráfico de barras agrupadas de la variable tipo III (Holmes y DeBerguer) en cada zona de actuación.

En cuanto a la tipología de Fox y Levin, (Tipo IV), se extrae que un 33,3\% (16 casos) del total de asesinos en serie incluidos en la muestra son de tipo "emocionaldominante"; siendo el mismo porcentaje para los que son "emocional-sádico" de los cuales un 20,8\% (10 casos) actuaron en América del Norte y un 12,5\% (6 casos) lo hicieron en España.

De lo mismo se observa que un 18,8\% (9 casos) del total de la muestra son de tipo "por conveniencia sacan provecho", de los cuales todos tuvieron su zona de actuación en España, no encontrándose, por lo tanto, asesinos en serie de este tipo que actuasen en América del Norte.

Además, un 12,5\% (6 casos) de los incluidos en este estudio son de tipo "misionario-visionario", de los cuales tan sólo un caso $(2,1 \%)$ actuó en España.

Por otro lado, solamente un caso de los incluidos en la muestra es de tipo "misionario-reformista", siendo su zona de actuación América del Norte. Estos datos quedan representados en la Tabla 67 y Figura 43. 
Tabla 67. Distribución de frecuencias de la variable tipo IV (Fox y Levin) en cada zona de actuación.

\begin{tabular}{|c|c|c|c|c|c|}
\hline & & & \multicolumn{2}{|c|}{ Zona de Actuación } & \multirow[b]{2}{*}{ Total } \\
\hline & & & España & América del Norte & \\
\hline \multirow[t]{10}{*}{ Tipo 4 (Fox y Levin) } & Emocional-Sádico & Recuento & 6 & 10 & $\overline{16}$ \\
\hline & & $\%$ del total & $12,5 \%$ & $20,8 \%$ & $33,3 \%$ \\
\hline & Emocional-Dominante & Recuento & 8 & 8 & 16 \\
\hline & & $\%$ del total & $16,7 \%$ & $16,7 \%$ & $33,3 \%$ \\
\hline & Misionario-Reformista & Recuento & 0 & 1 & 1 \\
\hline & & $\%$ del total & $0,0 \%$ & $2,1 \%$ & $2,1 \%$ \\
\hline & Misionario-Visionario & Recuento & 1 & 5 & 6 \\
\hline & & $\%$ del total & $2,1 \%$ & $10,4 \%$ & $12,5 \%$ \\
\hline & Por Conveniencia-Sacan Provecho & Recuento & 9 & 0 & 9 \\
\hline & & $\%$ del total & $18,8 \%$ & $0,0 \%$ & $18,8 \%$ \\
\hline \multirow[t]{2}{*}{ Total } & & Recuento & 24 & 24 & 48 \\
\hline & & $\%$ del total & $50,0 \%$ & $50,0 \%$ & $100,0 \%$ \\
\hline
\end{tabular}

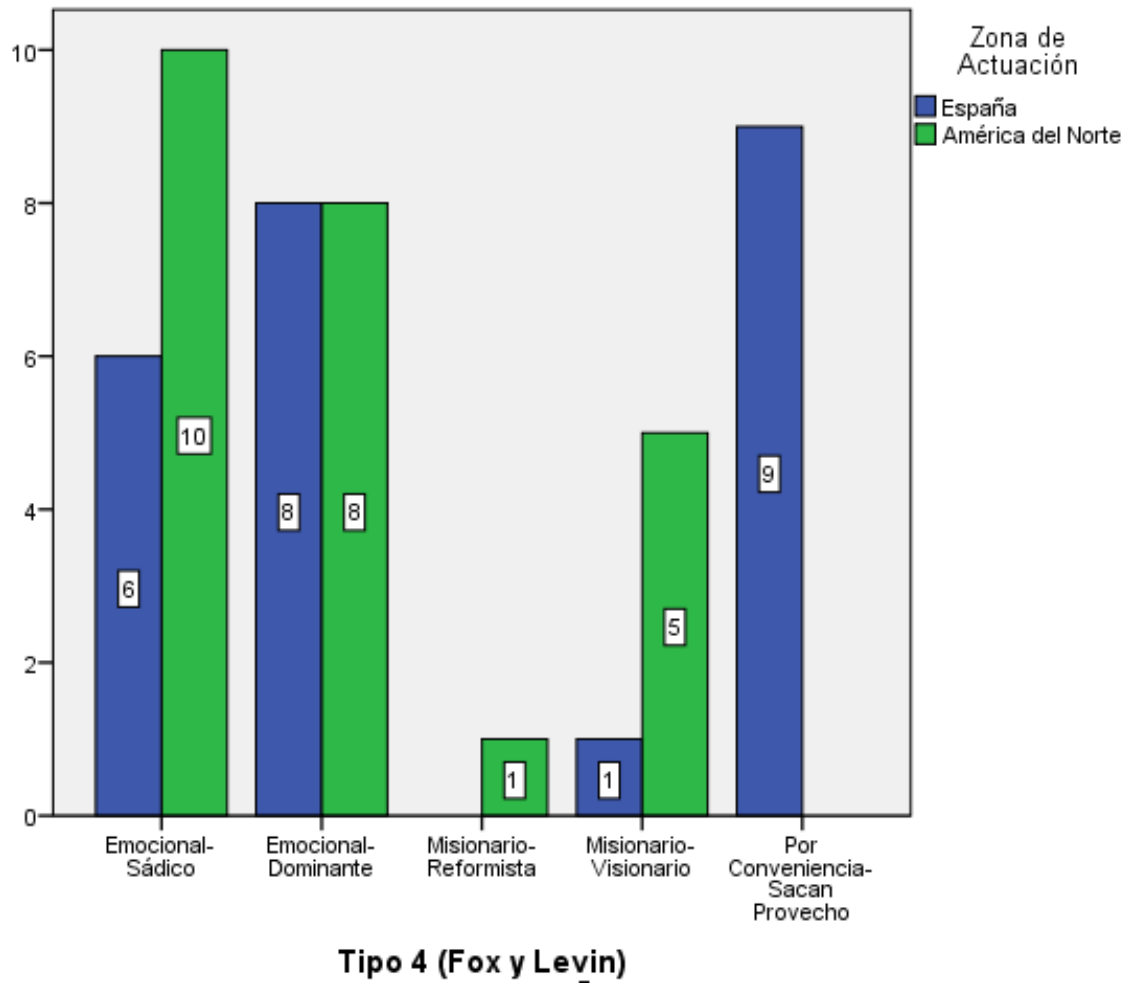

Figura 43. Gráfico de barras agrupadas de la variable tipo IV (Fox y Levin) en cada zona de actuación. 
En relación a la tipología de Canter, (Tipo V), se observa que el 79,2\% (38 casos) de los asesinos en serie incluidos en el estudio son de tipo "merodeador", de los cuales un 43,8\% (21 casos) actuaron en España frente a un 35,4\% (17 casos) que lo hicieron en América del Norte.

De lo mismo, se extrae que un 20,8\% (10 casos) del total de asesinos en serie de la muestra son de tipo "viajero", de los cuales un 14,6\% (7 casos) tuvieron su zona de actuación en América del Norte y un 6,2\% (3 casos) actuaron en España. Podemos observar lo indicado en la Tabla 68 y la Figura 44.

Tabla 68. Distribución de frecuencias de la variable tipo V (Canter) en cada zona de actuación.

\begin{tabular}{llrrrr}
\hline & & \multicolumn{2}{c}{ Zona de Actuación } & \multicolumn{1}{c}{} \\
\cline { 3 - 5 } & & & España & América del Norte & \multicolumn{1}{c}{ Total } \\
\hline Tip0 5 (Canter, 2005) & Merodeador & Recuento & 21 & 17 & 38 \\
& & \% del total & $43,8 \%$ & $35,4 \%$ & $79,2 \%$ \\
\cline { 2 - 5 } & Viajero & Recuento & 3 & 7 & 10 \\
& & \% del total & $6,3 \%$ & $14,6 \%$ & $20,8 \%$ \\
\hline Total & Recuento & 24 & 24 & 48 \\
& & \% del total & $50,0 \%$ & $50,0 \%$ & $100,0 \%$ \\
\hline
\end{tabular}

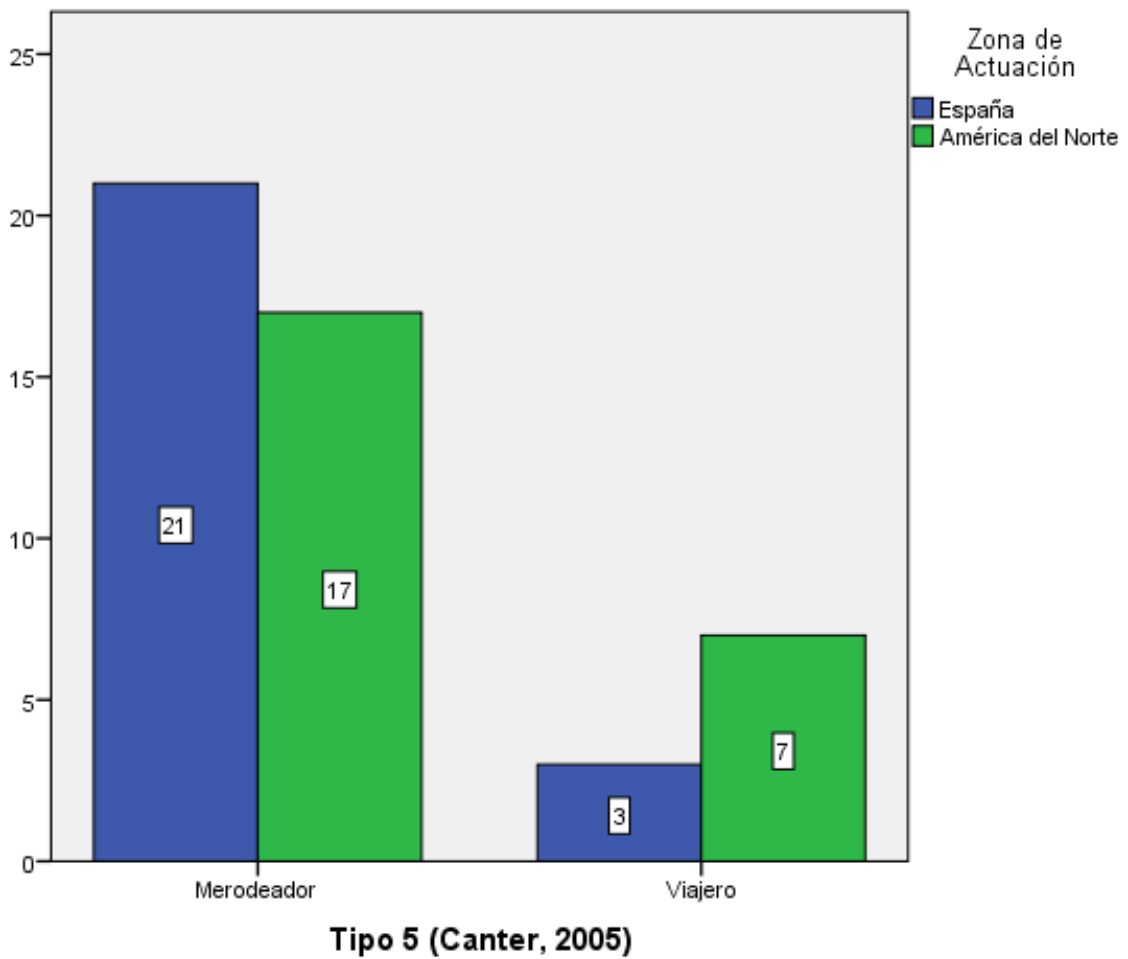

Figura 44. Gráfico de barras agrupadas de la variable tipo V (Canter) en cada zona de actuación. 
En cuanto a la tipología de Rossmo, (Tipo VI) (Tabla 69 y Figura 45), se extrae que el 50\% (24 casos) del total de asesinos en serie son de tipo "pescador", de los cuales un 35,4\% (17 casos) actuaron en España frente a un 14,6\% (7 casos) que lo hicieron en América del Norte.

De lo mismo se observa que un 22,9\% (11 casos) del total de la muestra son de tipo "cazador" y un 18,8\% (9 casos) del total fueron de tipo "cazador-furtivo".

Por último, tan sólo 4 sujetos $(8,3 \%)$ de los incluidos en la muestra fueron de tipo “trampero", siendo la zona de actuación de todos ellos América del Norte.

Tabla 69. Distribución de frecuencias de la variable tipo VI (Rossmo) en cada zona de actuación.

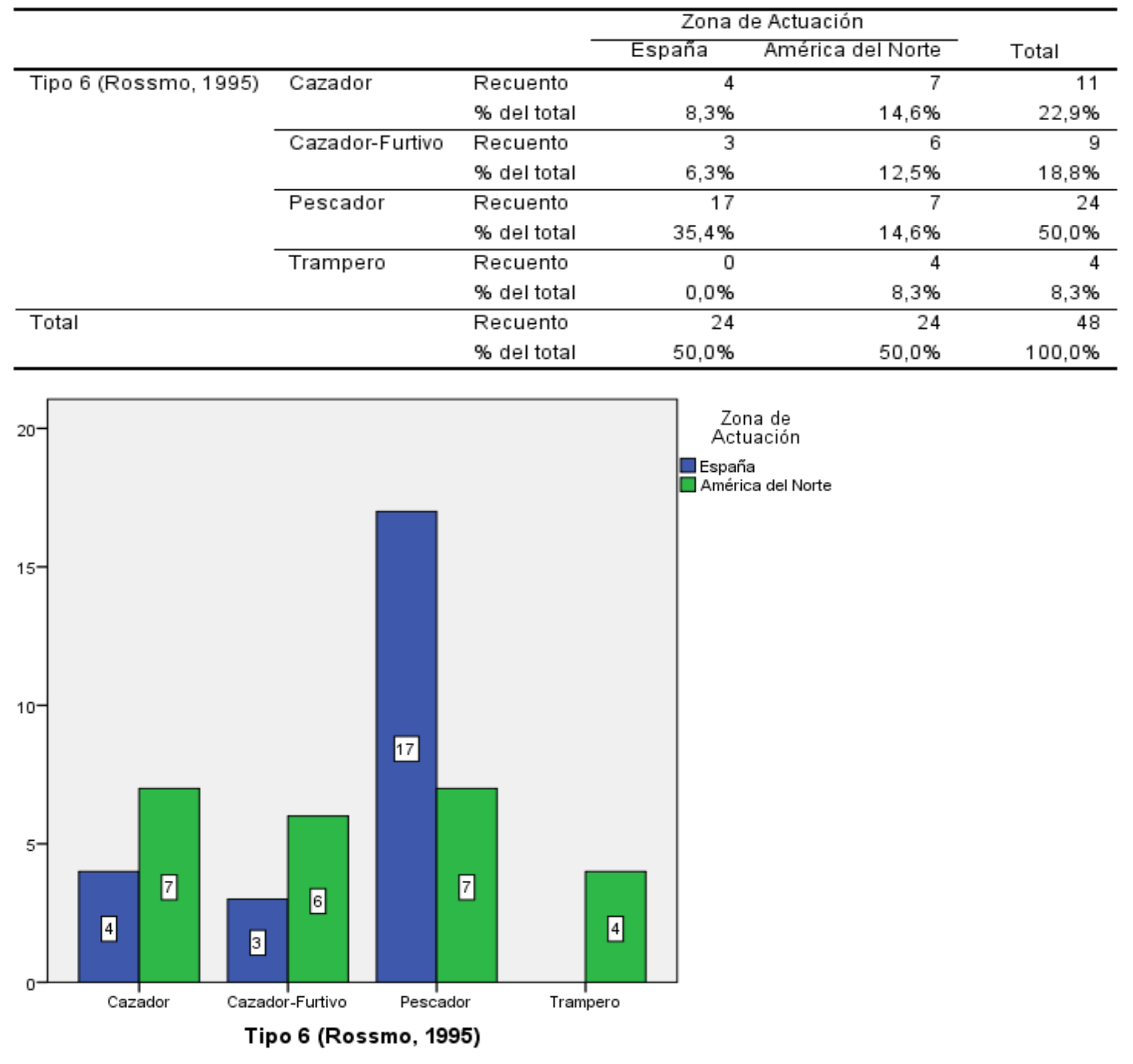

Figura 45. Gráfico de barras agrupadas de la variable tipo VI (Rossmo) en cada zona de actuación. 
Una vez realizado el análisis descriptivo de las diferentes variables de estudio propuestas para esta investigación según la zona de actuación de los asesinos en serie pertenecientes a esta muestra, hemos procedido a analizar en profundidad la distribución de las frecuencias resultantes del cruce de distintas variables categóricas en tablas cruzadas dependiendo de la zona de actuación de los asesinos seriales.

En primer lugar, se han elegido las variables haber sufrido algún tipo de maltrato en la infancia y padecer alguna patología mental.

Con respecto a haber sufrido algún tipo de maltrato en la infancia y además padecer alguna patología mental, se extrae que el 62,5\% (15 casos) de los asesinos en serie incluidos en la muestra cuya zona de actuación fue América del Norte sí tuvieron algún tipo de maltrato en la infancia, de los cuales un 41,7\% (10 casos) presentan patología mental.

De lo mismo, se observa que un 37,5\% (9 casos) de los sujetos que actuaron en América del Norte no tuvieron algún tipo de maltrato en la infancia, de los cuales un $33,3 \%$ (8 casos) no presentan patología mental. Podemos observar lo indicado en la Tabla 70 y la Figura 46.

Tabla 70. Distribución de frecuencias de las variables haber sufrido algún tipo de maltrato en la infancia y patología mental en asesinos seriales que actuaron en América del Norte.

\begin{tabular}{|c|c|c|c|c|c|}
\hline & & & \multicolumn{2}{|c|}{ A Patologiamental } & \multirow[b]{2}{*}{ Total } \\
\hline & & & No & Sí & \\
\hline \multirow[t]{4}{*}{ Al Algún Tipo de Maltrato } & No & Recuento & 8 & 1 & 9 \\
\hline & & $\%$ del total & $33,3 \%$ & $4,2 \%$ & $37,5 \%$ \\
\hline & Sí & Recuento & 5 & 10 & 15 \\
\hline & & $\%$ del total & $20,8 \%$ & $41,7 \%$ & $62,5 \%$ \\
\hline \multirow[t]{2}{*}{ Total } & & Recuento & 13 & 11 & 24 \\
\hline & & $\%$ del total & $54,2 \%$ & $45,8 \%$ & $100,0 \%$ \\
\hline
\end{tabular}




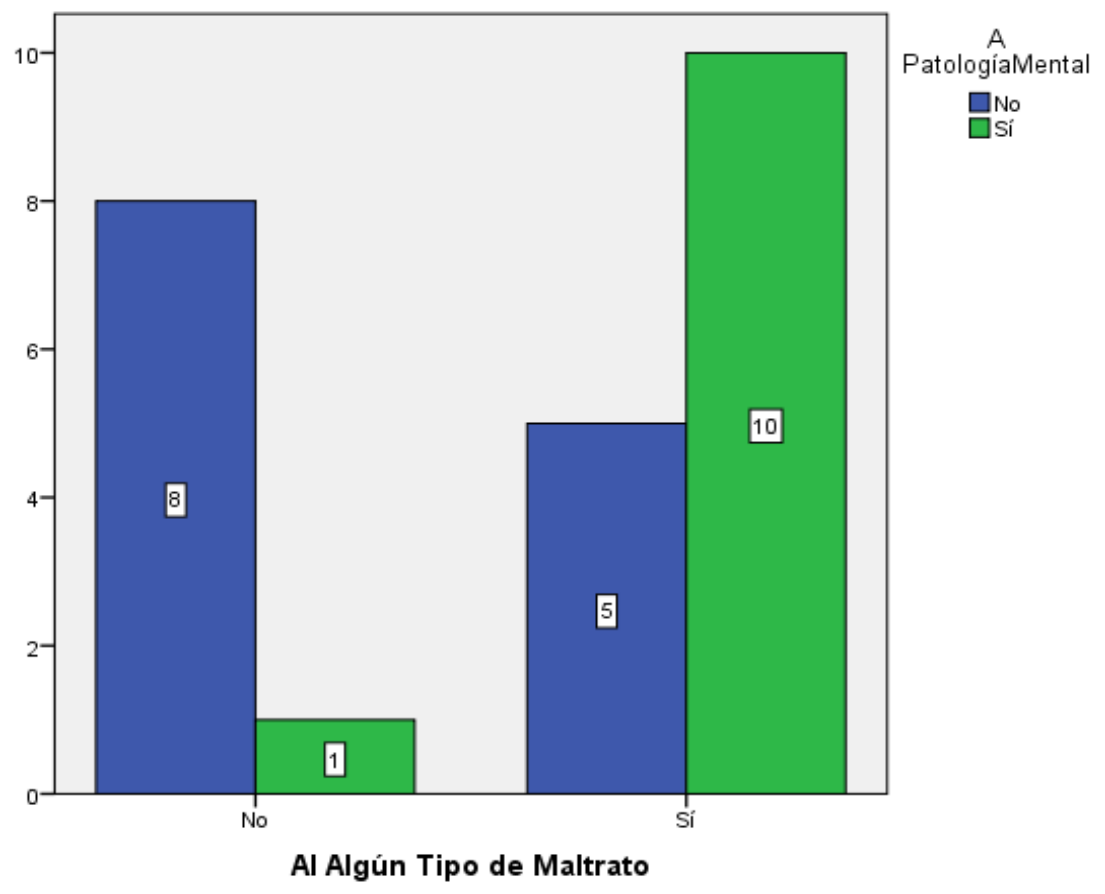

Figura 46. Gráfico de barras agrupadas de las variables haber sufrido algún tipo de maltrato en la infancia y patología mental en asesinos seriales que actuaron en América del Norte.

Con respecto a haber sufrido algún tipo de maltrato en la infancia y además padecer alguna patología mental, se observa que un 79,2\% (19 casos) del total de asesinos en serie incluidos en la muestra cuya zona de actuación fue España no tuvieron algún tipo de maltrato en la infancia, de los cuales un 70,8 (17 casos) no presentan patología mental frente a un 8,3\% (2 casos) que sí la presentan.

De lo mismo, se extrae que un 20,8\% (5 casos) de los asesinos en serie que actuaron en España sí tuvieron algún tipo de maltrato en la infancia, de los cuales un $12,5 \%$ ( 3 casos) presentan patología mental frente a un 8,3\% (2 casos) que no la presentan tal y como se observa en la Tabla 71 y la Figura 47. 
Tabla 71. Distribución de frecuencias de las variables haber sufrido algún tipo de maltrato en la infancia y patología mental en asesinos seriales que actuaron en España.

\begin{tabular}{|c|c|c|c|c|c|}
\hline & & & \multicolumn{2}{|c|}{ A PatologíaMental } & \multirow[b]{2}{*}{ Total } \\
\hline & & & No & Sí & \\
\hline \multirow[t]{4}{*}{ Al Algún Tipo de Maltrato } & No & Recuento & 17 & 2 & 19 \\
\hline & & $\%$ del total & $70,8 \%$ & $8,3 \%$ & $79,2 \%$ \\
\hline & Sí & Recuento & 2 & 3 & 5 \\
\hline & & $\%$ del total & $8,3 \%$ & $12,5 \%$ & $20,8 \%$ \\
\hline \multirow[t]{2}{*}{ Total } & & Recuento & 19 & 5 & 24 \\
\hline & & $\%$ del total & $79,2 \%$ & $20,8 \%$ & $100,0 \%$ \\
\hline
\end{tabular}

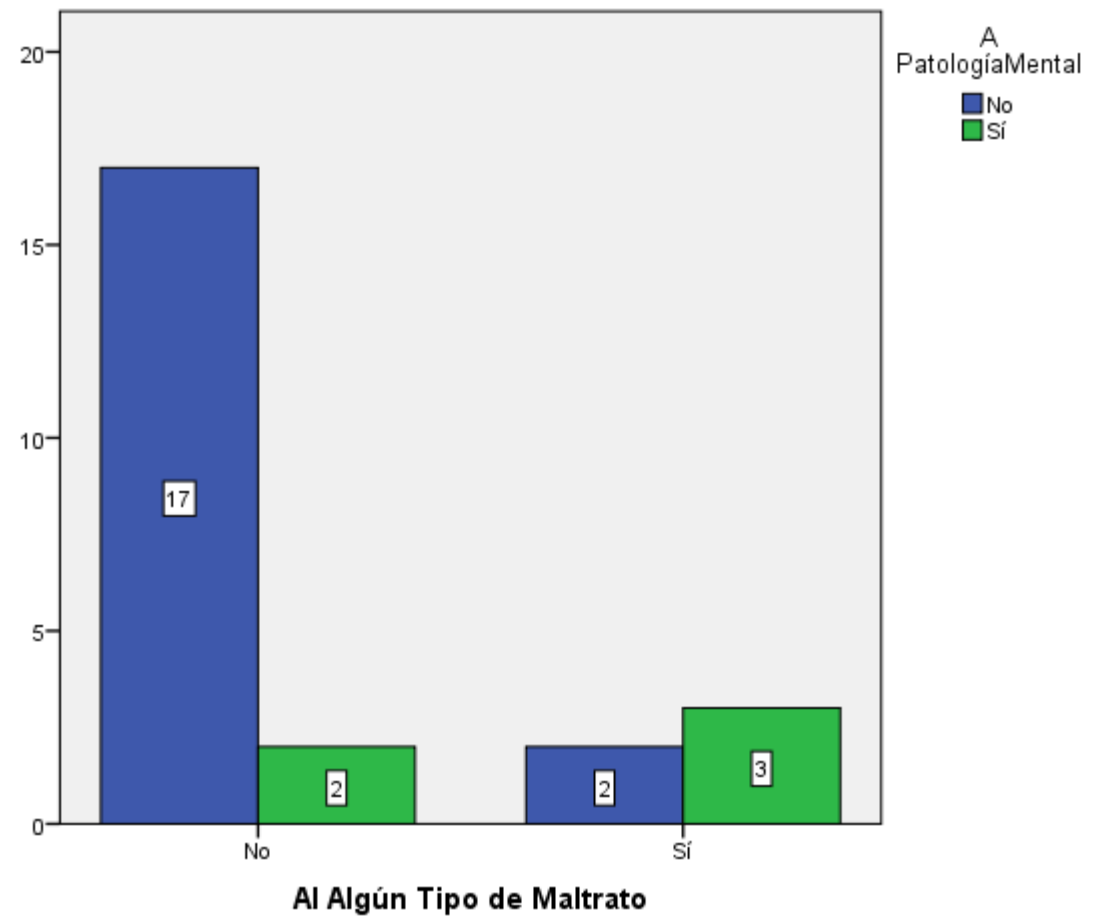

Figura 47. Gráfico de barras agrupadas de las variables haber sufrido algún tipo de maltrato en la infancia y patología mental en asesinos seriales que actuaron en España.

Las siguientes variables a analizar son el nivel de planificación y el estado civil de los asesinos seriales.

En relación al nivel de planificación y el estado civil, el 47,8\% (11 casos) de los asesinos en serie incluidos en la muestra que actuaron en América del Norte estaban casados, de los cuales un 30,4\% (7 casos) tienen un nivel de planificación medio. 
De lo mismo, se observa que el $34,8 \%$ (8 casos) de los asesinos cuya zona de actuación fue América del Norte estaban solteros, de los cuales un 13\% (3 casos) tuvieron un nivel de planificación alto y un mismo porcentaje de sujetos lo tuvieron bajo.

Además, tan sólo 4 sujetos $(17,4 \%)$ de los asesinos que actuaron en América del Norte estaban separados o divorciados, de los cuales 2 de ellos $(8,7 \%)$ tuvieron un nivel de planificación bajo.

Por último, sólo un 8,7\% ( 2 casos) del total de 24 asesinos en serie que actuaron en América del Norte tuvieron un nivel de planificación nulo. Estos datos quedan representados en la Tabla 72 y la Figura 48.

Tabla 72. Distribución de frecuencias de las variables nivel de planificación y estado civil en asesinos seriales que actuaron en América del Norte.

\begin{tabular}{|c|c|c|c|c|c|c|}
\hline & & & \multicolumn{3}{|c|}{ Estado Civil } & \multirow[b]{2}{*}{ Total } \\
\hline & & & Soltero & Casado & $\begin{array}{l}\text { Separado- } \\
\text { Divorciado }\end{array}$ & \\
\hline \multirow[t]{8}{*}{ Nivel de Planificación } & Nulo & Recuento & 1 & 0 & 1 & 2 \\
\hline & & $\%$ del total & $4,3 \%$ & $0,0 \%$ & $4,3 \%$ & $8,7 \%$ \\
\hline & Bajo & Recuento & 3 & 2 & 2 & 7 \\
\hline & & $\%$ del total & $13,0 \%$ & $8,7 \%$ & $8,7 \%$ & $30,4 \%$ \\
\hline & Medio & Recuento & 1 & 7 & 0 & 8 \\
\hline & & $\%$ del total & $4,3 \%$ & $30,4 \%$ & $0,0 \%$ & $34,8 \%$ \\
\hline & Alto & Recuento & 3 & 2 & 1 & 6 \\
\hline & & $\%$ del total & $13,0 \%$ & $8,7 \%$ & $4,3 \%$ & $26,1 \%$ \\
\hline \multirow[t]{2}{*}{ Total } & & Recuento & 8 & 11 & 4 & 23 \\
\hline & & $\%$ del total & $34,8 \%$ & $47,8 \%$ & $17,4 \%$ & $100,0 \%$ \\
\hline
\end{tabular}




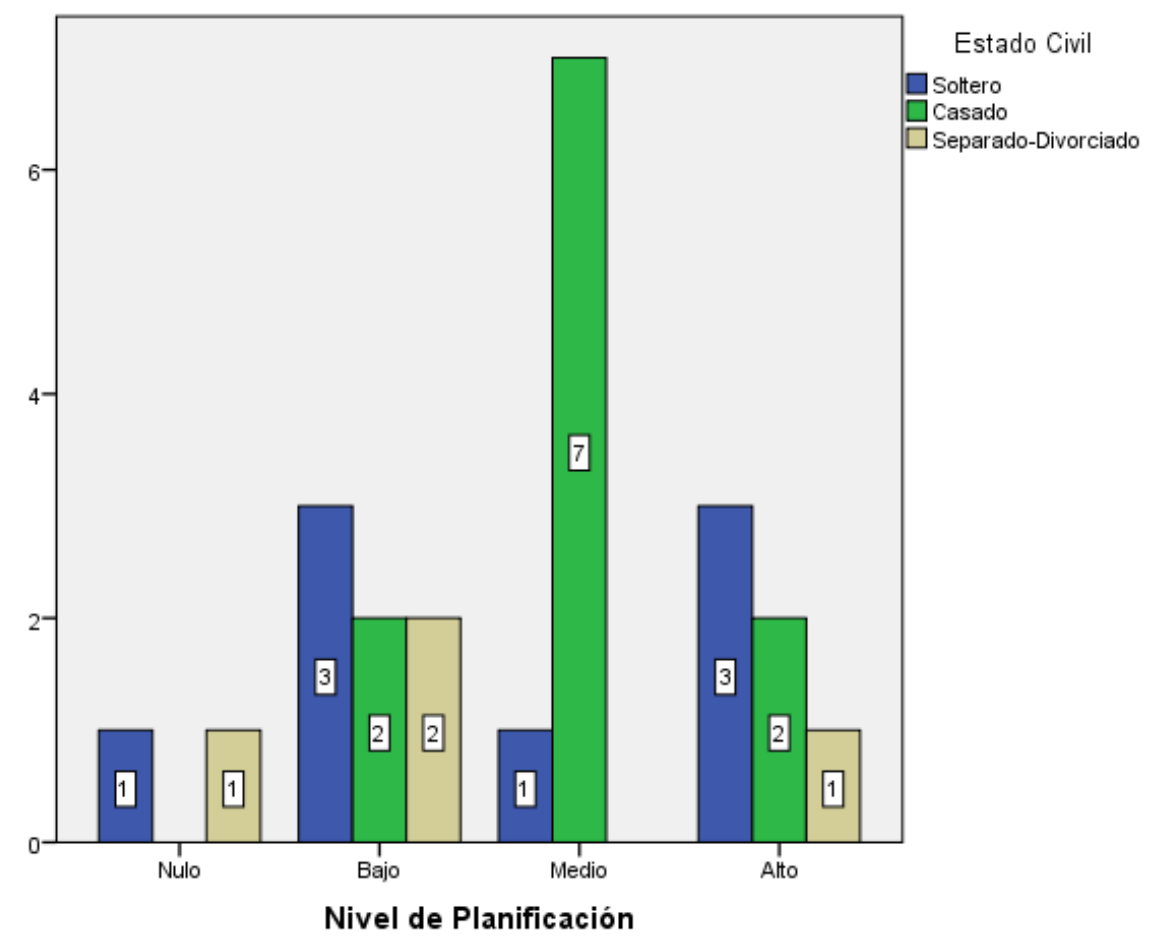

Figura 48. Gráfico de barras agrupadas de las variables nivel de planificación y estado civil en asesinos seriales que actuaron en América del Norte.

En cuanto al nivel de planificación y el estado civil, se observa que el 50\% (12 casos) del total de 24 asesinos en serie que actuaron en España estaban solteros, de los cuales el 20,8\% (5 casos) tuvieron un nivel de planificación alto y sólo un 4,2\% (1 caso) tuvo un nivel de planificación nulo.

De lo mismo, se extrae que el 37,5\% (9 casos) del total de la muestra de asesinos cuya zona de actuación fue España estaban casados, de los cuales el 16,7\% (4 casos) tuvieron un nivel de planificación medio, un 8,3\% (2 casos) lo tuvo bajo y ninguno de ellos tuvo un nivel de planificación nulo.

Por último, tan sólo 3 sujetos $(12,5 \%)$ del total de la muestra de asesinos que actuaron en España estaban separados o divorciados, de los cuales 2 asesinos $(8,3 \%)$ tuvieron un nivel de planificación alto y un asesino en serie (4,2\%) lo tuvo bajo. Se puede observar lo indicado en la Tabla 73 y la Figura 49. 
Tabla 73. Distribución de frecuencias de las variables nivel de planificación y estado civil en asesinos seriales que actuaron en España.

\begin{tabular}{|c|c|c|c|c|c|c|}
\hline & & & \multicolumn{3}{|c|}{ Estado Civil } & \multirow[b]{2}{*}{ Total } \\
\hline & & & Soltero & Casado & $\begin{array}{l}\text { Separado- } \\
\text { Divorciado }\end{array}$ & \\
\hline \multirow[t]{8}{*}{ Nivel de Planificación } & Nulo & Recuento & 1 & 0 & 0 & 1 \\
\hline & & $\%$ del total & $4,2 \%$ & $0,0 \%$ & $0,0 \%$ & $4,2 \%$ \\
\hline & Bajo & Recuento & 3 & 2 & 1 & 6 \\
\hline & & $\%$ del total & $12,5 \%$ & $8,3 \%$ & $4,2 \%$ & $25,0 \%$ \\
\hline & Medio & Recuento & 3 & 4 & 0 & 7 \\
\hline & & $\%$ del total & $12,5 \%$ & $16,7 \%$ & $0,0 \%$ & $29,2 \%$ \\
\hline & Alto & Recuento & 5 & 3 & 2 & 10 \\
\hline & & $\%$ del total & $20,8 \%$ & $12,5 \%$ & $8,3 \%$ & $41,7 \%$ \\
\hline \multirow[t]{2}{*}{ Total } & & Recuento & 12 & 9 & 3 & 24 \\
\hline & & $\%$ del total & $50,0 \%$ & $37,5 \%$ & $12,5 \%$ & $100,0 \%$ \\
\hline
\end{tabular}

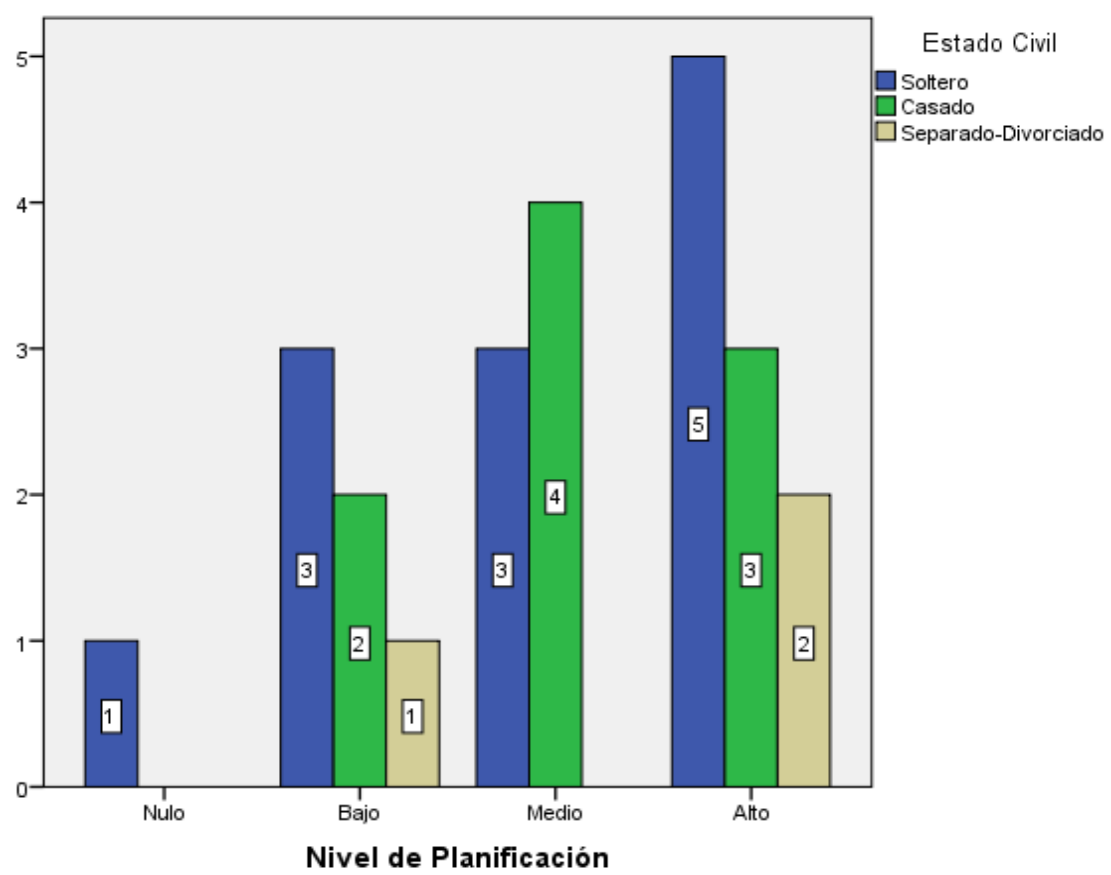

Figura 49. Gráfico de barras agrupadas de las variables nivel de planificación y estado civil en asesinos seriales que actuaron en España.

En tercer lugar, se procedió al análisis de las variables nivel de planificación y nivel intelectual de los asesinos seriales.

En relación al nivel de planificación y el nivel intelectual, se extrae que un 25\% (6 casos) de los asesinos en serie que actuaron en América del Norte que tiene un nivel de planificación alto, un 20,8\% (5 casos) tienen un nivel intelectual alto. 
De lo mismo, se observa que 9 sujetos $(37,5 \%)$ que tienen un nivel de planificación medio, 6 asesinos en serie (25\%) tienen un nivel intelectual medio y 3 sujetos lo tienen alto.

Además, un 29,2\% (7 casos) de los asesinos en serie cuya zona de actuación es América del Norte que tuvieron un nivel de planificación bajo, un 20,8\% (5 casos) tienen un nivel intelectual medio.

Por último, tan sólo 2 de los asesinos en serie $(8,3 \%)$ que actuaron en América del Norte que tienen un nivel de planificación nulo han sido incluidos en la muestra, de los cuales uno de ellos $(4,2 \%)$ tiene un nivel intelectual bajo y otro $(4,2 \%)$ lo tiene medio. Estos datos pueden observarse en la Tabla 74 y la Figura 50.

Tabla 74. Distribución de frecuencias de las variables nivel de planificación y nivel intelectual en asesinos seriales que actuaron en América del Norte.

\begin{tabular}{|c|c|c|c|c|c|c|}
\hline & & & \multicolumn{3}{|c|}{ Nivel Intelectual } & \multirow[b]{2}{*}{ Total } \\
\hline & & & Bajo & Medio & Alto & \\
\hline \multirow[t]{8}{*}{ Nivel de Planificación } & Nulo & Recuento & 1 & $\overline{1}$ & 0 & 2 \\
\hline & & $\%$ del total & $4,2 \%$ & $4,2 \%$ & $0,0 \%$ & $8,3 \%$ \\
\hline & Bajo & Recuento & 0 & 5 & 2 & 7 \\
\hline & & $\%$ del total & $0,0 \%$ & $20,8 \%$ & $8,3 \%$ & $29,2 \%$ \\
\hline & Medio & Recuento & 0 & 6 & 3 & 9 \\
\hline & & $\%$ del total & $0,0 \%$ & $25,0 \%$ & $12,5 \%$ & $37,5 \%$ \\
\hline & Alto & Recuento & 1 & 0 & 5 & 6 \\
\hline & & $\%$ del total & $4,2 \%$ & $0,0 \%$ & $20,8 \%$ & $25,0 \%$ \\
\hline \multirow[t]{2}{*}{ Total } & & Recuento & 2 & 12 & 10 & 24 \\
\hline & & $\%$ del total & $8,3 \%$ & $50,0 \%$ & $41,7 \%$ & $100,0 \%$ \\
\hline
\end{tabular}




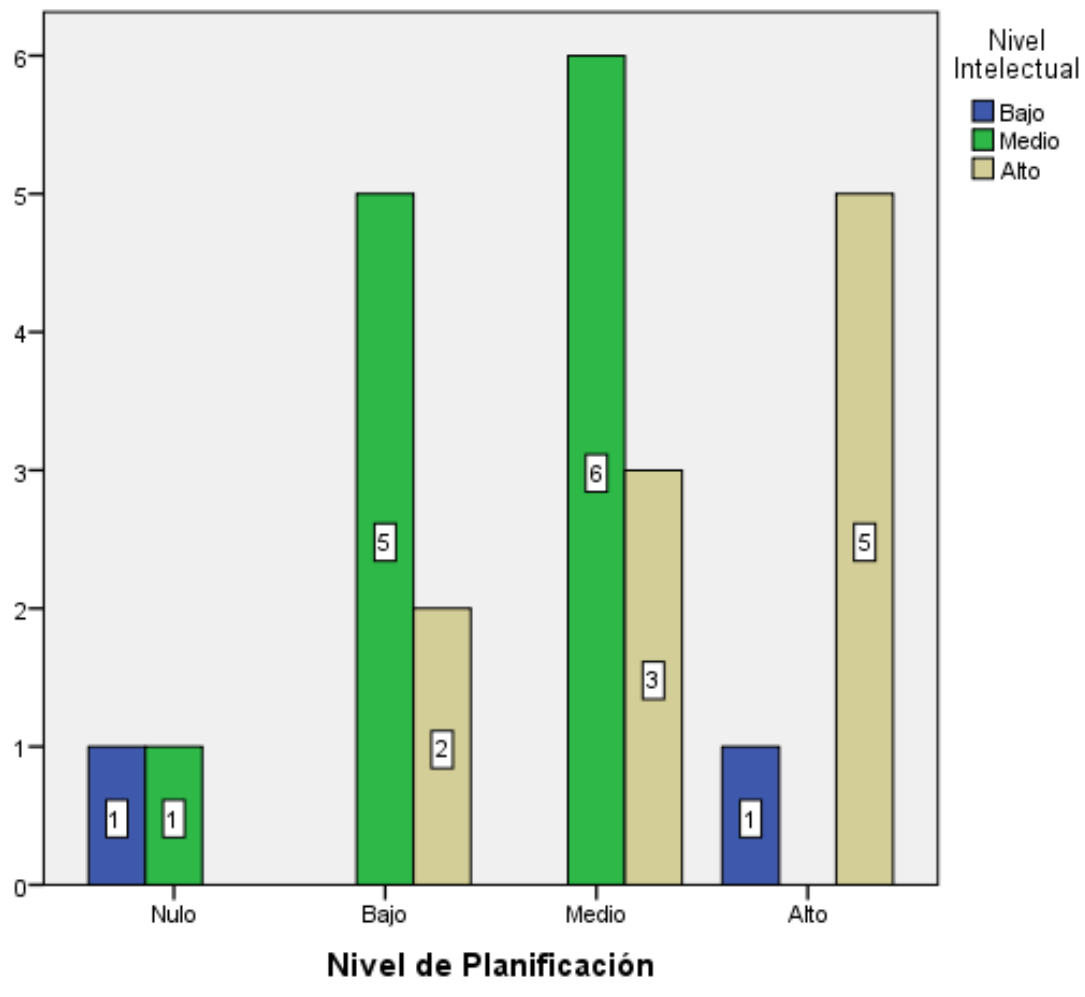

Figura 50. Gráfico de barras agrupadas de las variables nivel de planificación y nivel intelectual en asesinos seriales que actuaron en América del Norte.

En cuanto al nivel de planificación y el nivel intelectual, se observa que un 43,5\% (10 casos) del total de 23 asesinos en serie que actuaron en España que tuvieron un nivel de planificación alto, un 30,4\% (7 casos) tienen un nivel intelectual medio.

De lo mismo se extrae que 7 asesinos en serie $(30,4 \%)$ cuya zona de actuación es España tuvieron un nivel de planificación medio de los cuales 5 de ellos $(21,7 \%)$ tienen un nivel intelectual medio.

Además, se observa que un 21,7\% (5 casos) de los asesinos que tuvieron un nivel de planificación bajo, un 17,4\% (4 casos) tenían un nivel intelectual medio frente a un $4,3 \%$ (1 caso) que lo tiene bajo.

De los 23 asesinos en serie que actuaron en España incluidos en la muestra, tan sólo un 4,3\% (1 caso) tuvo un nivel de planificación nulo, teniendo además un nivel intelectual bajo. Podemos observar lo indicado en la Tabla 75 y la Figura 51. 
Tabla 75. Distribución de frecuencias de las variables nivel de planificación y nivel intelectual en asesinos seriales que actuaron en España.

\begin{tabular}{|c|c|c|c|c|c|c|}
\hline & & & \multicolumn{3}{|c|}{ Nivel Intelectual } & \multirow[b]{2}{*}{ Total } \\
\hline & & & Bajo & Medio & Alto & \\
\hline \multirow[t]{8}{*}{ Nivel de Planificación } & Nulo & Recuento & 1 & 0 & 0 & 1 \\
\hline & & $\%$ del total & $4,3 \%$ & $0,0 \%$ & $0,0 \%$ & $4,3 \%$ \\
\hline & Bajo & Recuento & 1 & 4 & 0 & 5 \\
\hline & & $\%$ del total & $4,3 \%$ & $17,4 \%$ & $0,0 \%$ & $21,7 \%$ \\
\hline & Medio & Recuento & 1 & 5 & 1 & 7 \\
\hline & & $\%$ del total & $4,3 \%$ & $21,7 \%$ & $4,3 \%$ & $30,4 \%$ \\
\hline & Alto & Recuento & 1 & 7 & 2 & 10 \\
\hline & & $\%$ del total & $4,3 \%$ & $30,4 \%$ & $8,7 \%$ & $43,5 \%$ \\
\hline \multirow[t]{2}{*}{ Total } & & Recuento & 4 & 16 & 3 & 23 \\
\hline & & $\%$ del total & $17,4 \%$ & $69,6 \%$ & $13,0 \%$ & $100,0 \%$ \\
\hline
\end{tabular}

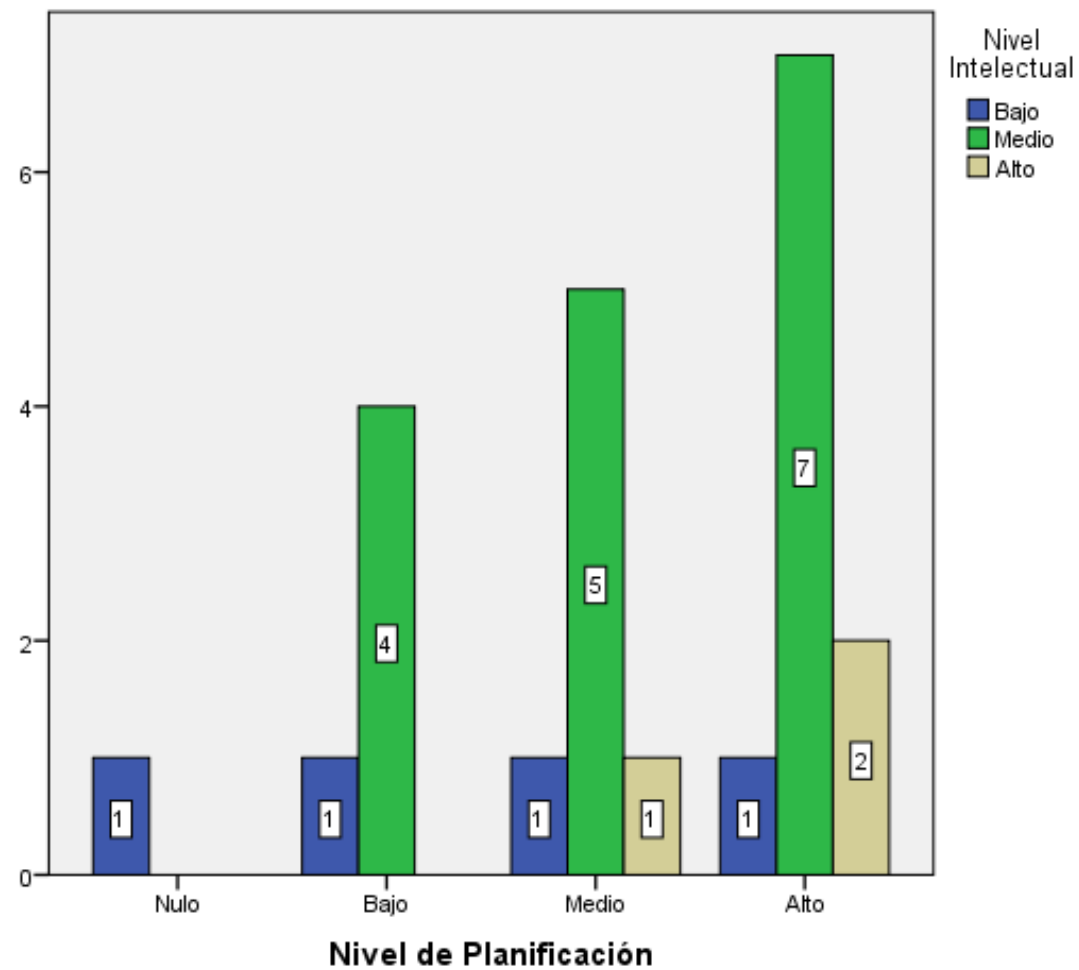

Figura 51. Gráfico de barras agrupadas de las variables nivel de planificación y nivel intelectual en asesinos seriales que actuaron en España.

En cuarto lugar, se procedió con el análisis de las variables interacción verbal con las víctimas y forma de causar la muerte. 
En relación a la interacción verbal con las víctimas y la forma de causar la muerte, se observa que de los asesinos en serie que actuaron en América del Norte, un $45,5 \%$ (10 casos) causaron la muerte con arma blanca, de los cuales un 22,7\% (5 casos) tuvieron una forma de interacción con las víctimas de forma agresiva y un 4,5\% (1 caso) no tuvo interacción verbal con las mismas.

De lo mismo, se extrae que un 40,9\% (9 casos) causaron la muerte por estrangulación, de los cuales un 31,8\% (7 casos) tuvieron una interacción con las víctimas de forma no agresiva.

Además, un 36,4\% (8 casos) causaron la muerte con arma de fuego, de los cuales un $18,2 \%$ ( 4 casos) tuvieron una interacción con las víctimas de forma agresiva y un $13,6 \%$ ( 3 casos) la tuvieron de forma no agresiva.

De los 7 sujetos $(31,8 \%)$ que causaron la muerte por contusión, un 22,7\% (5 casos) tuvieron una interacción con las víctimas de forma agresiva.

Por último, el único sujeto que causó la muerte por intoxicación, mantuvo una interacción verbal con las víctimas de forma no agresiva. Estos datos quedan representados en la Tabla 76.

Tabla 76. Distribución de frecuencias de las variables interacción verbal con las víctimas y forma de causar la muerte en asesinos seriales que actuaron en América del Norte.

\begin{tabular}{|c|c|c|c|c|c|c|}
\hline & & & \multicolumn{3}{|c|}{ Interacción Verbal con las Víctimas } & \multirow[b]{2}{*}{ Total } \\
\hline & & & No & Sí - Agresiva & Sí - No Agresiva & \\
\hline \multirow[t]{12}{*}{ Forma de Causar la Muerte ${ }^{a}$} & Por Contusión & Recuento & 0 & 5 & 2 & 7 \\
\hline & & $\%$ del total & $0,0 \%$ & $22,7 \%$ & $9,1 \%$ & $31,8 \%$ \\
\hline & Estrangulación & Recuento & 0 & 7 & 2 & 9 \\
\hline & & $\%$ del total & $0,0 \%$ & $31,8 \%$ & $9,1 \%$ & $40,9 \%$ \\
\hline & Con Arma Blanca & Recuento & 1 & 5 & 4 & 10 \\
\hline & & $\%$ del total & $4,5 \%$ & $22,7 \%$ & $18,2 \%$ & $45,5 \%$ \\
\hline & Intoxicación & Recuento & 0 & 0 & 1 & 1 \\
\hline & & $\%$ del total & $0,0 \%$ & $0,0 \%$ & $4,5 \%$ & $4,5 \%$ \\
\hline & Con Arma de Fuego & Recuento & 1 & 4 & 3 & 8 \\
\hline & & $\%$ del total & $4,5 \%$ & $18,2 \%$ & $13,6 \%$ & $36,4 \%$ \\
\hline & Otra & Recuento & 0 & 1 & 1 & 2 \\
\hline & & $\%$ del total & $0,0 \%$ & $4,5 \%$ & $4,5 \%$ & $9,1 \%$ \\
\hline \multirow[t]{2}{*}{ Total } & & Recuento & 1 & 13 & 8 & 22 \\
\hline & & $\%$ del total & $4,5 \%$ & $59,1 \%$ & $36,4 \%$ & $100,0 \%$ \\
\hline
\end{tabular}


En relación a la interacción verbal con las víctimas y la forma de causar la muerte, se observa que los asesinos seriales que actuaron en España un 42,9\% (9 casos) causaron la muerte por estrangulación de los cuales un 23,8\% (5 casos) tuvieron una interacción verbal con las víctimas de forma no agresiva y un 14,3\% (3 casos) la tuvieron de forma agresiva.

De lo mismo, se extrae que un $28,6 \%$ (6 casos) causaron la muerte con arma blanca, de los cuales un 19\% (4 casos) tuvieron una interacción verbal con las víctimas de forma no agresiva.

Además, un 23,8\% (5 casos) causaron la muerte por intoxicación, de los cuales todos ellos tuvieron una interacción con las víctimas de forma no agresiva.

Por último, el 9,5\% (2 casos) que causaron la muerte a las víctimas con arma de fuego, un caso $(4,8 \%)$ tuvo una interacción verbal con las víctimas de forma agresiva y otro caso $(4,8 \%)$ la tuvo de forma no agresiva. Podemos observar lo indicado en la Tabla 77.

Tabla 77. Distribución de frecuencias de las variables interacción verbal con las víctimas y forma de causar la muerte en asesinos seriales que actuaron en España.

\begin{tabular}{|c|c|c|c|c|c|c|}
\hline & & & \multicolumn{3}{|c|}{ Interacción Verbal con las Víctimas } & \multirow[b]{2}{*}{ Total } \\
\hline & & & No & Sí - Agresiva & Sí - No Agresiva & \\
\hline \multirow[t]{12}{*}{ Forma de Causar la Muerte ${ }^{a}$} & Por Contusión & Recuento & 0 & 2 & 2 & 4 \\
\hline & & $\%$ del total & $0,0 \%$ & $9,5 \%$ & $9,5 \%$ & $19,0 \%$ \\
\hline & Estrangulación & Recuento & 1 & 3 & 5 & 9 \\
\hline & & $\%$ del total & $4,8 \%$ & $14,3 \%$ & $23,8 \%$ & $42,9 \%$ \\
\hline & Con Arma Blanca & Recuento & 1 & 1 & 4 & 6 \\
\hline & & $\%$ del total & $4,8 \%$ & $4,8 \%$ & $19,0 \%$ & $28,6 \%$ \\
\hline & Intoxicación & Recuento & 0 & 0 & 5 & 5 \\
\hline & & $\%$ del total & $0,0 \%$ & $0,0 \%$ & $23,8 \%$ & $23,8 \%$ \\
\hline & Con Arma de Fuego & Recuento & 0 & 1 & 1 & 2 \\
\hline & & $\%$ del total & $0,0 \%$ & $4,8 \%$ & $4,8 \%$ & $9,5 \%$ \\
\hline & Otra & Recuento & 0 & 1 & 2 & 3 \\
\hline & & $\%$ del total & $0,0 \%$ & $4,8 \%$ & $9,5 \%$ & $14,3 \%$ \\
\hline \multirow[t]{2}{*}{ Total } & & Recuento & 1 & 5 & 15 & 21 \\
\hline & & $\%$ del total & $4,8 \%$ & $23,8 \%$ & $71,4 \%$ & $100,0 \%$ \\
\hline
\end{tabular}

Las siguientes variables que han sido analizadas son interacción verbal con las víctimas y conductas sádicas y de tortura. (Tabla 78 y Figura 52) 
En relación a la interacción verbal con las víctimas y la práctica de conductas sádicas, se extrae que el 68,2\% (15 casos) del total de asesinos en serie incluidos en la muestra que actuaron en América del Norte no realizan conductas sádicas y de tortura, de los cuales un 45,5\% (10 casos) tuvieron una interacción verbal con las víctimas de forma agresiva frente a un 4,5\% (1 caso) que no tuvo interacción verbal con las mismas.

Por consiguiente, un $31,8 \%$ (7 casos) del total de la muestra cuya zona de actuación fue América del Norte realizó conductas sádicas y de tortura, de los cuales un $18,2 \%$ (4 casos) tuvo una interacción verbal con las víctimas de forma no agresiva frente a un 13,6\% (3 casos) que la tuvo de forma agresiva.

Tabla 78. Distribución de frecuencias de las variables interacción verbal con las víctimas y conductas sádicas y de tortura en asesinos seriales que actuaron en América del Norte.

\begin{tabular}{|c|c|c|c|c|c|}
\hline & & & \multicolumn{2}{|c|}{ Conductas Sádicas y de Tortura } & \multirow[b]{2}{*}{ Total } \\
\hline & & & No & Sí & \\
\hline \multirow[t]{6}{*}{ Interacción Verbal con las Víctimas } & No & Recuento & 0 & $\overline{1}$ & $\overline{1}$ \\
\hline & & $\%$ del total & $0,0 \%$ & $4,5 \%$ & $4,5 \%$ \\
\hline & Sí - Agresiva & Recuento & 3 & 10 & 13 \\
\hline & & $\%$ del total & $13,6 \%$ & $45,5 \%$ & $59,1 \%$ \\
\hline & Sí - No Agresiva & Recuento & 4 & 4 & 8 \\
\hline & & $\%$ del total & $18,2 \%$ & $18,2 \%$ & $36,4 \%$ \\
\hline \multirow[t]{2}{*}{ Total } & & Recuento & 7 & 15 & 22 \\
\hline & & $\%$ del total & $31,8 \%$ & $68,2 \%$ & $100,0 \%$ \\
\hline
\end{tabular}

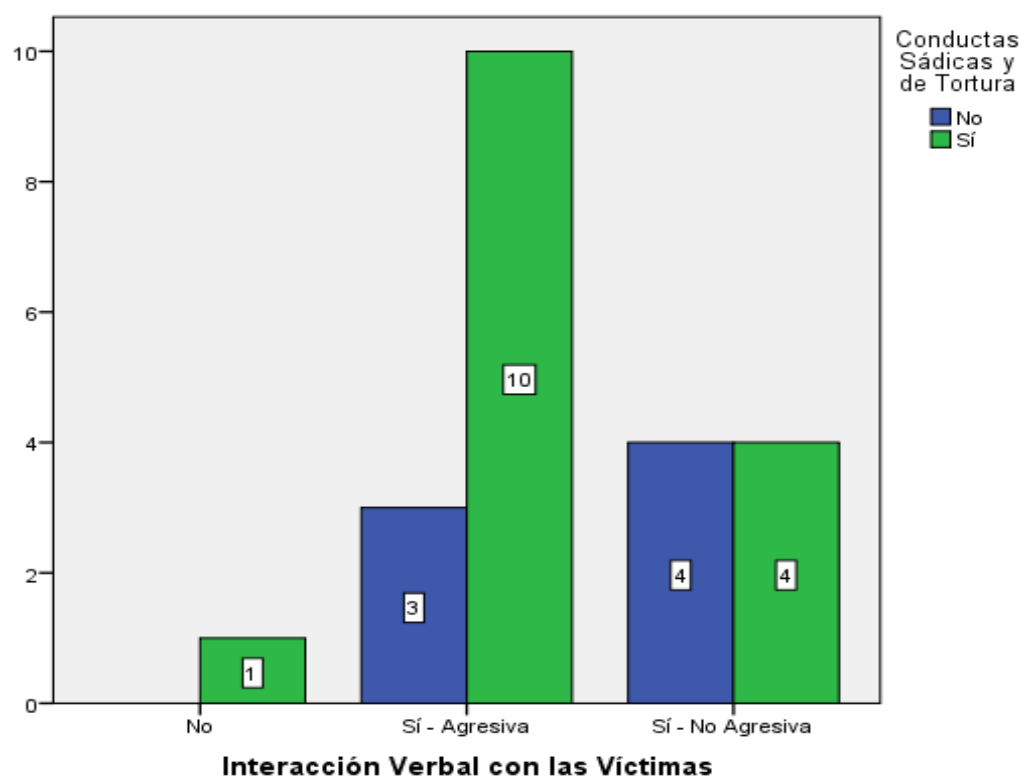

Figura 52. Gráfico de barras agrupadas de las variables interacción verbal con las víctimas y conductas sádicas y de tortura en asesinos seriales que actuaron en América del Norte. 
En cuanto a la interacción verbal con las víctimas y la práctica de conductas sádicas (Tabla 79 y Figura 53), se observa que un 66,7\% (14 casos) del total de asesinos en serie que actuaron en España no realizaron conductas sádicas o de tortura, de los cuales un 47,6\% (10 casos) tuvieron una interacción verbal con las víctimas de forma no agresiva, frente a un 4,8\% (1 caso) que no mantuvo interacción verbal con las mismas.

De lo mismo, se extrae que un 33,3\% (7 casos) sí realizaron conductas sádicas o de tortura, de los cuales un 23,8\% (5 casos) tuvieron una interacción verbal con las víctimas de forma no agresiva, frente a un 9,5\% ( 2 casos) que la tuvieron de forma agresiva.

Tabla 79. Distribución de frecuencias de las variables interacción verbal con las víctimas y conductas sádicas y de tortura en asesinos seriales que actuaron en España.

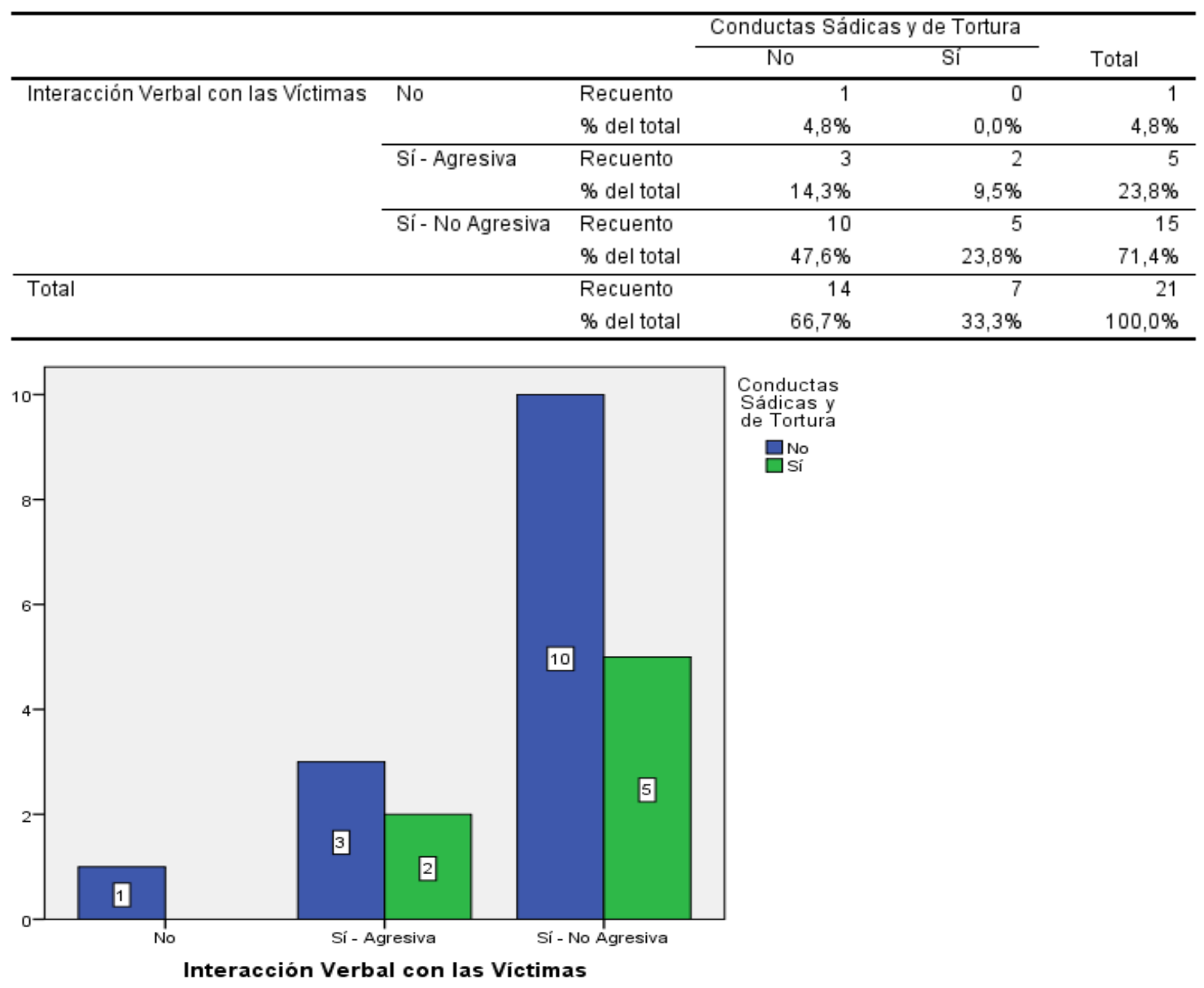

Figura 53. Gráfico de barras agrupadas de las variables interacción verbal con las víctimas y conductas sádicas y de tortura en asesinos seriales que actuaron en España. 
En sexto lugar, se analizaron las variables conductas sádicas y de tortura y forma de causar la muerte de los asesinos seriales que conforman este estudio.

En cuanto a la relación de la práctica de conductas sádicas y de tortura y la forma de causar la muerte, de los asesinos seriales cuya zona de actuación fue América del Norte un 43,5\% (10 casos) causaron la muerte con arma blanca, de los cuales un 30,4\% (7 casos) sí llevaron a cabo conductas sádicas y de tortura con las víctimas.

De lo mismo, se extrae que un $39,1 \%$ ( 9 casos) causaron la muerte por estrangulación de los cuales un 34,8\% (8 casos) llevaron a cabo conductas sádicas y de tortura con las víctimas. Un mismo porcentaje de casos, un 39,1\% (9 casos) causaron la muerte con arma de fuego, de los cuales un $21,7 \%$ (5 casos) no llevaron este tipo de conductas.

Además, un 30,4\% (7 casos) causaron la muerte a las víctimas por contusión, de los cuales un $26,1 \%$ (6 casos) sí llevaron a cabo conductas sádicas y de tortura con las mismas.

Finalmente, el único caso que causó la muerte por intoxicación, no llevó a cabo este tipo de conductas con las víctimas. Podemos observar lo indicado en la Tabla 80.

Tabla 80. Distribución de frecuencias de las variables conductas sádicas y de tortura y forma de causar la muerte en asesinos seriales que actuaron en América del Norte.

\begin{tabular}{|c|c|c|c|c|c|}
\hline & & & \multicolumn{2}{|c|}{ Conductas Sádicas y de Tortura } & \multirow[b]{2}{*}{ Total } \\
\hline & & & No & Sí & \\
\hline \multirow[t]{12}{*}{ Forma de Causar la Muerte $^{a}$} & Por Contusión & Recuento & 1 & 6 & 7 \\
\hline & & $\%$ del total & $4,3 \%$ & $26,1 \%$ & $30,4 \%$ \\
\hline & Estrangulación & Recuento & 1 & 8 & 9 \\
\hline & & $\%$ del total & $4,3 \%$ & $34,8 \%$ & $39,1 \%$ \\
\hline & Con Arma Blanca & Recuento & 3 & 7 & 10 \\
\hline & & $\%$ del total & $13,0 \%$ & $30,4 \%$ & $43,5 \%$ \\
\hline & Intoxicación & Recuento & 1 & 0 & 1 \\
\hline & & $\%$ del total & $4,3 \%$ & $0,0 \%$ & $4,3 \%$ \\
\hline & Con Arma de Fuego & Recuento & 5 & 4 & 9 \\
\hline & & $\%$ del total & $21,7 \%$ & $17,4 \%$ & $39,1 \%$ \\
\hline & Otra & Recuento & 0 & 2 & 2 \\
\hline & & $\%$ del total & $0,0 \%$ & $8,7 \%$ & $8,7 \%$ \\
\hline \multirow[t]{2}{*}{ Total } & & Recuento & 8 & 15 & 23 \\
\hline & & $\%$ del total & $34,8 \%$ & $65,2 \%$ & $100,0 \%$ \\
\hline
\end{tabular}


En cuanto a la relación de la práctica de conductas sádicas y de tortura y la forma de causar la muerte (Tabla 81), se observa que de los asesinos en serie cuya zona de actuación fue España un 43,5\% (10 casos) causaron la muerte por estrangulación, de los cuales un 30,4\% (7 casos) no llevaron a cabo conductas sádicas y de tortura con las víctimas.

De lo mismo, se extrae que un 34,8\% (8 casos) causaron la muerte a las víctimas con arma blanca, siendo el mismo porcentaje de casos, un 17,4\% (4 casos), aquellos que no llevaron a cabo conductas sádicas y de tortura y los que sí llevaron a cabo este tipo de conductas.

Además, un 21,7\% (5 casos) causaron la muerte por intoxicación y un mismo porcentaje de casos por contusión. Entre los asesinos seriales que actuaron en España y que causaron la muerte por intoxicación, un 17,4\% (4 casos) no llevaron a cabo conductas sádicas y de tortura con las víctimas; y aquellos que la causaron por contusión, un $8,7 \%$ ( 2 casos) sí llevaron a cabo este tipo de conductas.

Por último, un 8,7\% (2 casos) causaron la muerte con arma de fuego, de los cuales todos ellos no llevaron a cabo conductas sádicas y de tortura con las víctimas.

Tabla 81. Distribución de frecuencias de las variables conductas sádicas y de tortura y forma de causar la muerte en asesinos seriales que actuaron en España.

\begin{tabular}{|c|c|c|c|c|c|}
\hline & & & \multicolumn{2}{|c|}{ Conductas Sádicas y de Tortura } & \multirow[b]{2}{*}{ Total } \\
\hline & & & No & Sí & \\
\hline \multirow[t]{12}{*}{ Forma de Causar la Muerte ${ }^{a}$} & Por Contusión & Recuento & 3 & 2 & 5 \\
\hline & & $\%$ del total & $13,0 \%$ & $8,7 \%$ & $21,7 \%$ \\
\hline & Estrangulación & Recuento & 7 & 3 & 10 \\
\hline & & $\%$ del total & $30,4 \%$ & $13,0 \%$ & $43,5 \%$ \\
\hline & Con Arma Blanca & Recuento & 4 & 4 & 8 \\
\hline & & $\%$ del total & $17,4 \%$ & $17,4 \%$ & $34,8 \%$ \\
\hline & Intoxicación & Recuento & 4 & 1 & 5 \\
\hline & & $\%$ del total & $17,4 \%$ & $4,3 \%$ & $21,7 \%$ \\
\hline & Con Arma de Fuego & Recuento & 2 & 0 & 2 \\
\hline & & $\%$ del total & $8,7 \%$ & $0,0 \%$ & $8,7 \%$ \\
\hline & Otra & Recuento & 1 & 2 & 3 \\
\hline & & $\%$ del total & $4,3 \%$ & $8,7 \%$ & $13,0 \%$ \\
\hline \multirow[t]{2}{*}{ Total } & & Recuento & 14 & 9 & 23 \\
\hline & & $\%$ del total & $60,9 \%$ & $39,1 \%$ & $100,0 \%$ \\
\hline
\end{tabular}


Por último, se analizaron las variables mutilación y canibalismo de los asesinos seriales que forman la muestra de esta investigación.

En relación al empleo de la mutilación y llevar a cabo canibalismo, se extrae que un 79,2\% (19 casos) del total de asesinos en serie incluidos en la muestra cuya zona de actuación fue América del Norte no llevaron a cabo conductas caníbales, de los cuales un 45,8\% (11 casos) sí emplearon la mutilación frente a un 33,3\% (8 casos) que no la emplearon.

De lo mismo, se observa que un 20,8\% (5 casos) del total de la muestra que actuó en América del Norte sí llevaron a cabo conductas caníbales, de los cuales todos ellos emplearon la mutilación con sus víctimas. Se puede observar lo indicado en la Tabla 82 y la Figura 54.

Tabla 82. Distribución de frecuencias de las variables mutilación y canibalismo en asesinos seriales que actuaron en América del Norte.

\begin{tabular}{llrrrr}
\hline & & \multicolumn{3}{c}{ Mutilación } & \multicolumn{1}{c}{ Total } \\
\cline { 3 - 5 } & & & No & Sí & 19 \\
\hline Canibalismo & No & Recuento & 11 & 8 & $79,2 \%$ \\
\cline { 3 - 5 } & & \% del total & $45,8 \%$ & $33,3 \%$ & 5 \\
& Si & Recuento & 0 & 5 & $20,8 \%$ \\
\hline Total & \% del total & $0,0 \%$ & $20,8 \%$ & 24 \\
& & Recuento & 11 & 13 & $100,0 \%$ \\
\hline
\end{tabular}




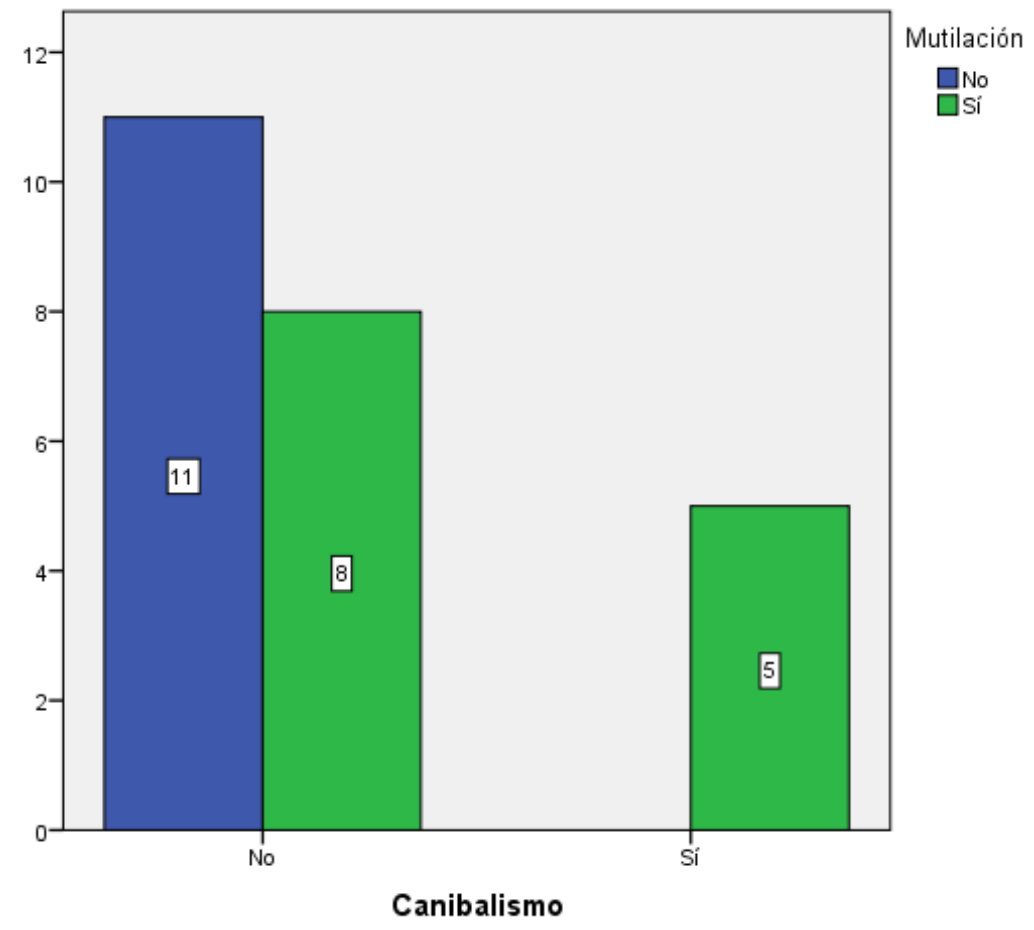

Figura 54. Gráfico de barras agrupadas de las variables mutilación y canibalismo en asesinos seriales que actuaron en América del Norte.

En relación al empleo de la mutilación y llevar a cabo canibalismo, se extrae que un $95,8 \%$ (23 casos) del total de asesinos en serie incluidos en la muestra cuya zona de actuación fue España no llevan a cabo conductas caníbales, de los cuales un 83,3\% (20 casos) no emplearon la mutilación con sus víctimas frente a un 12,5\% (3 casos) que sí lo hicieron.

De lo mismo, se observa que tan sólo un 4,2\% (1 caso) del total de sujetos que actuaron en España sí llevó a cabo conductas caníbales, empleando además la mutilación con sus víctimas. Estos datos quedan representados en la Tabla 83 y la Figura 55. 
Tabla 83. Distribución de frecuencias de las variables mutilación y canibalismo en asesinos seriales que actuaron en España.

\begin{tabular}{lllrrr}
\hline & & \multicolumn{3}{c}{ Mutilación } & \multicolumn{1}{c}{ Total } \\
\cline { 3 - 5 } & & & No & \multicolumn{1}{c}{ Si } & \\
\hline Canibalismo & No & Recuento & 20 & 3 & 23 \\
& & \% del total & $83,3 \%$ & $12,5 \%$ & $95,8 \%$ \\
\cline { 2 - 5 } & Si & Recuento & 0 & 1 & 1 \\
& \% del total & $0,0 \%$ & $4,2 \%$ & $4,2 \%$ \\
\hline Total & Recuento & 20 & 4 & 24 \\
& & \% del total & $83,3 \%$ & $16,7 \%$ & $100,0 \%$ \\
\hline
\end{tabular}

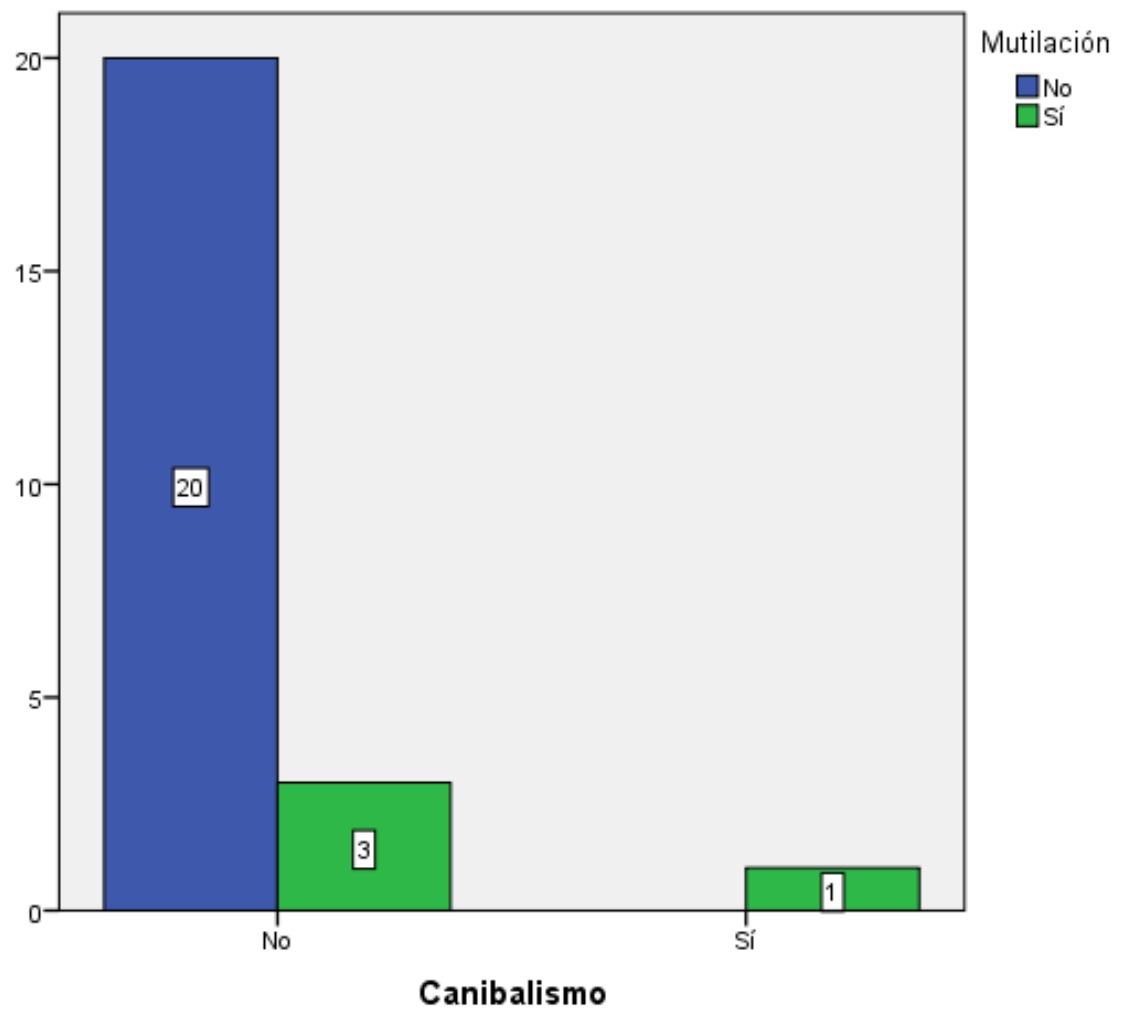

Figura 55. Gráfico de barras agrupadas de las variables mutilación y canibalismo en asesinos seriales que actuaron en España.

\subsubsection{Estudio No Paramétrico de la Muestra}

En primer lugar, en la muestra de 47 asesinos seriales que han sido incluidos en este estudio, 23 sujetos $(48,9 \%)$ tuvieron como zona de actuación España, de los cuales un $34 \%$ tenían un coeficiente intelectual medio, un 8,5\% tenían un coeficiente intelectual bajo y un 6,4\% lo tenían alto. Entre los $24(51,1 \%)$ asesinos en serie cuya zona de actuación fue América del Norte, un 25,5\% tenían un coeficiente intelectual 
medio, un 21,3\% tenían un coeficiente intelectual alto y un 4,3\% lo tenían bajo. Con $\mathrm{p}<, 10$ se observó una correlación estadísticamente significativa $\left(\mathrm{G}^{2}=5,208 ; \mathrm{gl}=2 ; \mathrm{n}=47\right.$; p<0,074) que apoya la suposición inicial de que sí existe relación entre el nivel de coeficiente intelectual y la zona de actuación de los asesinos en serie; siendo el tamaño del efecto moderado $(C=, 310)$. Según el análisis de los residuos tipificados corregidos, se puede indicar que es probable que los asesinos en serie que hayan actuado en América del Norte tengan un nivel intelectual alto. Se puede observar lo indicado en la Tabla 84,85 y 86 .

Tabla 84. Distribución de frecuencias de la variable nivel intelectual en cada zona de actuación.

\begin{tabular}{|c|c|c|c|c|c|}
\hline & & & \multicolumn{2}{|c|}{ Zona de Actuación } & \multirow[b]{2}{*}{ Total } \\
\hline & & & España & América del Norte & \\
\hline \multirow[t]{12}{*}{ Nivel Intelectual } & Bajo & Recuento & 4 & 2 & 6 \\
\hline & & Recuento esperado & 2,9 & 3,1 & 6,0 \\
\hline & & $\%$ del total & $8,5 \%$ & $4,3 \%$ & $12,8 \%$ \\
\hline & & Residuo corregido &, 9 &,- 9 & \\
\hline & Medio & Recuento & 16 & 12 & 28 \\
\hline & & Recuento esperado & 13,7 & 14,3 & 28,0 \\
\hline & & $\%$ del total & $34,0 \%$ & $25,5 \%$ & $59,6 \%$ \\
\hline & & Residuo corregido & 1,4 & $-1,4$ & \\
\hline & Alto & Recuento & 3 & 10 & 13 \\
\hline & & Recuento esperado & 6,4 & 6,6 & 13,0 \\
\hline & & $\%$ del total & $6,4 \%$ & $21,3 \%$ & $27,7 \%$ \\
\hline & & Residuo corregido & $-2,2$ & 2,2 & \\
\hline \multirow[t]{3}{*}{ Total } & & Recuento & 23 & 24 & 47 \\
\hline & & Recuento esperado & 23,0 & 24,0 & 47,0 \\
\hline & & $\%$ del total & $48,9 \%$ & $51,1 \%$ & $100,0 \%$ \\
\hline
\end{tabular}

Tabla 85. Pruebas Chi Cuadrado de la variable nivel intelectual en cada zona de actuación.

\begin{tabular}{lrrr}
\hline & Valor & gl & \multicolumn{2}{c}{$\begin{array}{c}\text { Significación } \\
\text { asintótica (bilateral) }\end{array}$} \\
\hline Chi-cuadrado de Pearson & $4,988^{\mathrm{a}}$ & 2 &, 083 \\
Razón de verosimilitud & 5,208 & 2 &, 074 \\
Asociación lineal por lineal & 4,272 & 1 &, 039 \\
N de casos válidos & 47 & & \\
\hline
\end{tabular}

Tabla 86. Coeficiente de correlación de la variable nivel intelectual en cada zona de actuación.

\begin{tabular}{lrrr}
\hline & & Valor & \multicolumn{2}{c}{$\begin{array}{c}\text { Significación } \\
\text { aproximada }\end{array}$} \\
\hline Nominal por Nominal & Coeficiente de contingencia &, 310 &, 083 \\
N de casos válidos & 47 & \\
\hline
\end{tabular}


En segundo lugar, en la muestra de 48 asesinos en serie que conforman esta investigación, 24 de ellos (50\%) tuvieron como zona de actuación España, de los cuales un 39,6\% no padecían ningún tipo de patología mental, frente a un 10,4\% que sí la padecían. Entre los 24 (50\%) asesinos seriales que actuaron en América del Norte, un $27,1 \%$ no padecían ningún tipo de patología mental, frente a un 22,9\% que sí la padecían. Con $\mathrm{p}<, 10$ se observó una correlación estadísticamente significativa $\left(\chi^{2}=3,375 ; g l=1 ; n=48 ; p<0,066\right)$ que apoya la suposición inicial de que sí existe relación entre padecer o no patología mental y la zona de actuación de los asesinos en serie; siendo el tamaño del efecto moderado $(\varphi$ y V=,265). Según el análisis de los residuos tipificados corregidos, se puede indicar que es probable que exista una tendencia a que los asesinos en serie que hayan actuado en España no presenten ningún tipo de patología mental, mientras que aquellos que hayan actuado en América del Norte sí padezcan algún tipo de patología mental. (Tabla 87, 88 y 89).

Tabla 87. Distribución de frecuencias de la variable patología mental en cada zona de actuación.

\begin{tabular}{|c|c|c|c|c|c|}
\hline & & & \multicolumn{2}{|c|}{ Zona de Actuación } & \multirow[b]{2}{*}{ Total } \\
\hline & & & España & América del Norte & \\
\hline \multirow[t]{6}{*}{ A PatologíaMental } & No & Recuento & 19 & 13 & 32 \\
\hline & & $\%$ del total & $39,6 \%$ & $27,1 \%$ & $66,7 \%$ \\
\hline & & Residuos corregidos & 1,8 & $-1,8$ & \\
\hline & Sí & Recuento & 5 & 11 & 16 \\
\hline & & $\%$ del total & $10,4 \%$ & $22,9 \%$ & $33,3 \%$ \\
\hline & & Residuos corregidos & $-1,8$ & 1,8 & \\
\hline \multirow[t]{2}{*}{ Total } & & Recuento & 24 & 24 & 48 \\
\hline & & $\%$ del total & $50,0 \%$ & $50,0 \%$ & $100,0 \%$ \\
\hline
\end{tabular}

Tabla 88. Pruebas Chi Cuadrado de la variable patología mental en cada zona de actuación.

\begin{tabular}{|c|c|c|c|c|c|}
\hline & Valor & $g \mid$ & $\begin{array}{l}\text { Sig. asintótica } \\
\text { (bilateral) }\end{array}$ & $\begin{array}{c}\text { Sig. exacta } \\
\text { (bilateral) }\end{array}$ & $\begin{array}{l}\text { Sig. exacta } \\
\text { (unilateral) }\end{array}$ \\
\hline Chi-cuadrado de Pearson & $3,375^{\mathrm{a}}$ & 1 & 066 & & \\
\hline Corrección por continuidad ${ }^{b}$ & 2,344 & 1 &, 126 & & \\
\hline Razón de verosimilitudes & 3,438 & 1 &, 064 & & \\
\hline Estadístico exacto de Fisher & & & &, 125 &, 062 \\
\hline Asociación lineal por lineal & 3,305 & 1 &, 069 & & \\
\hline $\mathrm{N}$ de casos válidos & 48 & & & & \\
\hline
\end{tabular}


Tabla 89. Coeficientes de contingencia de la variable patología mental en cada zona de actuación.

\begin{tabular}{llrr}
\hline & & \multicolumn{1}{c}{ Valor } & Sig. aproximada \\
\hline Nominal por nominal & Phi &, 265 &, 066 \\
& V de Cramer &, 265 &, 066 \\
N de casos válidos & & 48 & \\
\hline
\end{tabular}

En tercer lugar, en la muestra de 48 asesinos en serie incluidos en este estudio, 24 tuvieron como zona de actuación América del Norte, de los cuales un 62,5\% de ellos sufrieron algún tipo de maltrato en la infancia. Entre los 24 asesinos seriales que actuaron en España, un 79,2\% no sufrió algún tipo de maltrato en la infancia, por lo que solamente un 20,8\% sí experimentaron algún tipo de maltrato en la infancia. Con p<,05 se observó una correlación estadísticamente significativa $\left(\chi^{2}=8,571 ; \mathrm{gl}=1 ; \mathrm{n}=48\right.$; p<0,003) que apoya la suposición inicial de que sí existe relación entre haber sufrido algún tipo de maltrato en la infancia y la zona de actuación de los asesinos en serie; siendo el tamaño del efecto moderado $(\varphi$ y V=,423). Según el análisis de los residuos tipificados corregidos, se puede indicar que es probable que los asesinos en serie que hayan actuado en América del Norte hayan sufrido algún tipo de maltrato, mientras que aquellos que hayan actuado en España no lo hayan sufrido. (Tabla 90, 91 y 92).

Tabla 90. Distribución de frecuencias de la variable haber sufrido algún tipo de maltrato en la infancia en cada zona de actuación.

\begin{tabular}{|c|c|c|c|c|c|}
\hline & & & \multicolumn{2}{|c|}{ Zona de Actuación } & \multirow[b]{2}{*}{ Total } \\
\hline & & & España & América del Norte & \\
\hline \multirow[t]{8}{*}{ Al Algún Tipo de Maltrato } & No & Recuento & 19 & 9 & 28 \\
\hline & & Recuento esperado & 14,0 & 14,0 & 28,0 \\
\hline & & $\%$ del total & $39,6 \%$ & $18,8 \%$ & $58,3 \%$ \\
\hline & & Residuo corregido & 2,9 & $-2,9$ & \\
\hline & Sí & Recuento & 5 & 15 & 20 \\
\hline & & Recuento esperado & 10,0 & 10,0 & 20,0 \\
\hline & & $\%$ del total & $10,4 \%$ & $31,3 \%$ & $41,7 \%$ \\
\hline & & Residuo corregido & $-2,9$ & 2,9 & \\
\hline \multirow{3}{*}{\multicolumn{2}{|c|}{ Total }} & Recuento & 24 & 24 & 48 \\
\hline & & Recuento esperado & 24,0 & 24,0 & 48,0 \\
\hline & & $\%$ del total & $50,0 \%$ & $50,0 \%$ & $100,0 \%$ \\
\hline
\end{tabular}


Tabla 91. Pruebas de Chi Cuadrado de la variable haber sufrido algún tipo de maltrato en la infancia en cada zona de actuación.

\begin{tabular}{|c|c|c|c|c|c|}
\hline & Valor & $\mathrm{gl}$ & $\begin{array}{l}\text { Sig. asintótica } \\
\text { (bilateral) }\end{array}$ & $\begin{array}{c}\text { Sig. exacta } \\
\text { (bilateral) }\end{array}$ & $\begin{array}{l}\text { Sig. exacta } \\
\text { (unilateral) }\end{array}$ \\
\hline Chi-cuadrado de Pearson & $8,571^{\text {a }}$ & 1 &, 003 & & \\
\hline Corrección por continuidad $^{b}$ & 6,943 & 1 &, 008 & & \\
\hline Razón de verosimilitudes & 8,884 & 1 &, 003 & & \\
\hline Estadístico exacto de Fisher & & & &, 008 &, 004 \\
\hline Asociación lineal por lineal & 8,393 & 1 &, 004 & & \\
\hline $\mathrm{N}$ de casos válidos & 48 & & & & \\
\hline
\end{tabular}

Tabla 92. Coeficientes de correlación de la variable haber sufrido algún tipo de maltrato en la infancia en cada zona de actuación.

\begin{tabular}{llrr}
\hline & & \multicolumn{1}{c}{ Valor } & Sig. aproximada \\
\hline Nominal por nominal & Phi &, 423 &, 003 \\
& V de Cramer &, 423 &, 003 \\
N de casos válidos & & 48 & \\
\hline
\end{tabular}

En cuarto lugar, en la muestra de 44 asesinos en serie incluidos en este estudio, $21(47,7 \%)$ tuvieron como zona de actuación España, de los cuales un 34,1\% sí mantuvieron interacción verbal con las víctimas de forma no agresiva, un 11,4\% sí la mantuvieron de forma agresiva y un 2,3\% no mantuvo ningún tipo de interacción verbal con las víctimas. Entre los 23 (52,3\%) asesinos en serie que actuaron en América del Norte, un 29,5\% sí mantuvieron interacción verbal con las víctimas de forma agresiva, un $20,5 \%$ sí la mantuvieron de forma no agresiva y un 2,3\% no mantuvo ningún tipo de interacción verbal con las mismas. Con $\mathrm{p}<, 10$ se observó una correlación estadísticamente significativa $\left(\mathrm{G}^{2}=5,108 ; \mathrm{gl}=2 ; \mathrm{n}=44 ; \mathrm{p}<0,078\right)$ que apoya la suposición inicial de que sí existe relación entre el tipo de interacción verbal con las víctimas y la zona de actuación de los asesinos en serie; siendo el tamaño del efecto moderado $(\mathrm{C}=, 319)$. Según el análisis de los residuos tipificados corregidos, se puede indicar que es probable que los asesinos en serie que hayan actuado en España tengan una 
interacción verbal con las víctimas de forma no agresiva, mientras que aquellos que hayan actuado en América del Norte la tengan de una forma agresiva. (Tabla 93, 94 y 95).

Tabla 93. Distribución de frecuencias de la variable interacción verbal con las víctimas en cada zona de actuación.

\begin{tabular}{|c|c|c|c|c|c|}
\hline & & & \multicolumn{2}{|c|}{ Zona de Actuación } & \multirow[b]{2}{*}{ Total } \\
\hline & & & España & América del Norte & \\
\hline \multirow[t]{9}{*}{ Interacción Verbal con las Víctimas } & No & Recuento & 1 & 1 & 2 \\
\hline & & $\%$ del total & $2,3 \%$ & $2,3 \%$ & $4,5 \%$ \\
\hline & & Residuos corregidos & 1 &,- 1 & \\
\hline & Sí - Agresiva & Recuento & 5 & 13 & 18 \\
\hline & & $\%$ del total & $11,4 \%$ & $29,5 \%$ & $40,9 \%$ \\
\hline & & Residuos corregidos & $-2,2$ & 2,2 & \\
\hline & Sí - No Agresiva & Recuento & 15 & 9 & 24 \\
\hline & & $\%$ del total & $34,1 \%$ & $20,5 \%$ & $54,5 \%$ \\
\hline & & Residuos corregidos & 2,1 & $-2,1$ & \\
\hline \multirow[t]{2}{*}{ Total } & & Recuento & 21 & 23 & 44 \\
\hline & & $\%$ del total & $47,7 \%$ & $52,3 \%$ & $100,0 \%$ \\
\hline
\end{tabular}

Tabla 94. Pruebas Chi Cuadrado de la variable interacción verbal con las víctimas en cada zona de actuación.

\begin{tabular}{lrrr}
\hline & Valor & gl & \multicolumn{2}{c}{$\begin{array}{c}\text { Sig. asintótica } \\
\text { (bilateral) }\end{array}$} \\
\hline Chi-cuadrado de Pearson & $4,975^{\text {a }}$ & 2 &, 083 \\
Razón de verosimilitudes & 5,108 & 2 &, 078 \\
Asociación lineal por lineal & 3,199 & 1 &, 074 \\
N de casos válidos & 44 & & \\
\hline
\end{tabular}


Tabla 95. Coeficiente de contingencia de la variable interacción verbal con las víctimas en cada zona de actuación.

\begin{tabular}{lrrr}
\hline & & Valor & Sig. aproximada \\
\hline Nominal por nominal & Coeficiente de contingencia &, 319 &, 083 \\
$N$ de casos válidos & 44 & \\
\hline
\end{tabular}

En quinto lugar, en la muestra de 46 asesinos en serie que han sido incluidos en este estudio, 23 (50\%) tuvieron como zona de actuación España, de los cuales un 30,4\% no llevaron a cabo conductas sádicas y de tortura con sus víctimas, frente a un 19,6\% que sí las llevaron a cabo. Entre los $23(50 \%)$ asesinos en serie que actuaron en América del Norte, un 32,6\% sí emplearon conductas sádicas y de tortura con las víctimas, frente a un $17,4 \%$ que no las emplearon. Con $\mathrm{p}<, 10$ se observó una correlación estadísticamente significativa $\left(\chi^{2}=3,136 ; \mathrm{gl}=1 ; \mathrm{n}=46 ; \mathrm{p}<0,077\right)$ que apoya la suposición inicial de que sí existe relación entre el empleo de conductas sádicas y de tortura con las víctimas y la zona de actuación de los asesinos seriales; siendo el tamaño del efecto moderado $(\varphi$ y V=,261). Según el análisis de los residuos tipificados corregidos, se puede indicar que es probable que exista una tendencia a que los asesinos en serie que hayan actuado en España no lleven a cabo conductas sádicas y tortura mientras que los asesinos en serie que hayan actuado en América del Norte sí lleven a cabo este tipo de conductas. Estos datos se observan en las Tablas 96, 97 y 98.

Tabla 96. Distribución de frecuencias de la variable conductas sádicas y de tortura en cada zona de actuación.

\begin{tabular}{|c|c|c|c|c|c|}
\hline & & & \multicolumn{2}{|c|}{ Zona de Actuación } & \multirow[b]{2}{*}{ Total } \\
\hline & & & España & América del Norte & \\
\hline \multirow[t]{6}{*}{ Conductas Sádicas y de Tortura } & No & Recuento & 14 & 8 & 22 \\
\hline & & $\%$ del total & $30,4 \%$ & $17,4 \%$ & $47,8 \%$ \\
\hline & & Residuos corregidos & 1,8 & $-1,8$ & \\
\hline & Sí & Recuento & 9 & 15 & 24 \\
\hline & & $\%$ del total & $19,6 \%$ & $32,6 \%$ & $52,2 \%$ \\
\hline & & Residuos corregidos & $-1,8$ & 1,8 & \\
\hline \multirow[t]{2}{*}{ Total } & & Recuento & 23 & 23 & 46 \\
\hline & & $\%$ del total & $50,0 \%$ & $50,0 \%$ & $100,0 \%$ \\
\hline
\end{tabular}


Tabla 97. Pruebas Chi Cuadrado de la variable conductas sádicas y de tortura en cada zona de actuación.

\begin{tabular}{lccccc}
\hline & Valor & gl & $\begin{array}{c}\text { Sig. asintótica } \\
\text { (bilateral) }\end{array}$ & $\begin{array}{c}\text { Sig. exacta } \\
\text { (bilateral) }\end{array}$ & $\begin{array}{c}\text { Sig. exacta } \\
\text { (unilateral) }\end{array}$ \\
\hline Chi-cuadrado de Pearson & $3,136^{\text {a }}$ & 1 &, 077 & & \\
Corrección por continuidad & 2,178 & 1 &, 140 & & \\
Razón de verosimilitudes & 3,173 & 1 &, 075 & & \\
Estadístico exacto de Fisher & & & &, 139 & \\
Asociación lineal por lineal & 3,068 & 1 &, 080 & & \\
$\mathrm{~N}$ de casos válidos & 46 & & & & \\
\hline
\end{tabular}

Tabla 98. Coeficientes de contingencia de la variable conductas sádicas y de tortura en cada zona de actuación.

\begin{tabular}{llrr}
\hline & & Valor & Sig. aproximada \\
\hline Nominal por nominal & Phi &, 261 &, 077 \\
& V de Cramer &, 261 &, 077 \\
N de casos válidos & & 46 & \\
\hline
\end{tabular}

En sexto lugar, en la muestra de 48 asesinos en serie incluidos en esta investigación, 24 tuvieron como zona de actuación España y un 83,3\% de ellos no llevaron a cabo la mutilación con sus víctimas, por lo que un 16,7\% sí llevaron a cabo esta conducta. Entre los 24 asesinos seriales que actuaron en América del Norte, un 54,2\% sí emplea la mutilación, por lo que un 45,8\% no ponen en práctica este tipo de conducta con sus víctimas. Con $\mathrm{p}<, 05$ se observó una correlación estadísticamente significativa $\left(\chi^{2}=7,378 ; g l=1 ; n=48 ; \mathrm{p}<, 007\right)$ que apoya la suposición inicial de que sí existe relación entre llevar a cabo conductas de mutilación y la zona de actuación de los asesinos en serie; siendo el tamaño del efecto moderado ( $\varphi$ y V=,392). Según el análisis de los residuos tipificados corregidos, se puede decir que es probable que los asesinos en serie que hayan actuado en España no lleven a cabo conductas de mutilación, mientras que los asesinos seriales cuya zona de actuación haya sido América del Norte sí lleven a cabo dicha conducta. (Tabla 99, 100 y 101). 
Tabla 99. Distribución de frecuencias de la variable mutilación en cada zona de actuación.

\begin{tabular}{llrrrr}
\hline & & \multicolumn{2}{c}{ Zona de Actuación } & \\
\cline { 3 - 4 } & & España & América del Norte & Total \\
\hline Mutilación & No & Recuento & 20 & 11 & 31 \\
& & Recuento esperado & 15,5 & 15,5 & 31,0 \\
& & \% del total & $41,7 \%$ & $22,9 \%$ & $64,6 \%$ \\
& & 2,7 & $-2,7$ & \\
\cline { 3 - 4 } & Residuo corregido & 4 & 13 & 17 \\
& Si & Recuento & 8,5 & 8,5 & 17,0 \\
& Recuento esperado & $8,3 \%$ & $27,1 \%$ & $35,4 \%$ \\
& \% del total & $-2,7$ & 2,7 & \\
\hline Total & Residuo corregido & 24 & 24 & 48 \\
& Recuento & 24,0 & 24,0 & 48,0 \\
& Recuento esperado & $50,0 \%$ & $50,0 \%$ & $100,0 \%$ \\
\hline
\end{tabular}

Tabla 100. Pruebas Chi Cuadrado de la variable mutilación en cada zona de actuación.

\begin{tabular}{|c|c|c|c|c|c|}
\hline & Valor & gl & $\begin{array}{c}\text { Significación } \\
\text { asintótica (bilateral) }\end{array}$ & $\begin{array}{l}\text { Significación exacta } \\
\text { (bilateral) }\end{array}$ & $\begin{array}{l}\text { Significación exacta } \\
\text { (unilateral) }\end{array}$ \\
\hline Chi-cuadrado de Pearson & $7,378^{\mathrm{a}}$ & 1 & .007 & & \\
\hline Corrección de continuidad ${ }^{b}$ & 5,829 & 1 &, 016 & & \\
\hline Razón de verosimilitud & 7,668 & 1 &, 006 & & \\
\hline Prueba exacta de Fisher & & & &, 015 & ,007 \\
\hline Asociación lineal por lineal & 7,224 & 1 & ,007 & & \\
\hline $\mathrm{N}$ de casos válidos & 48 & & & & \\
\hline
\end{tabular}

Tabla 101. Coeficientes de contingencia de la variable mutilación en cada zona de actuación.

\begin{tabular}{llrr}
\hline & & Valor & \multicolumn{2}{c}{$\begin{array}{c}\text { Significación } \\
\text { aproximada }\end{array}$} \\
\hline Nominal por Nominal & Phi &, 392 &, 007 \\
& V de Cramer &, 392 &, 007 \\
N de casos válidos & & 48 & \\
\hline
\end{tabular}

En séptimo lugar, en la muestra de 41 asesinos en serie que conforman la muestra de este estudio, $23(56,1 \%)$ tuvieron como zona de actuación España de los 
cuales un 43,9\% no mantuvieron relaciones con las víctimas post-mortem, frente a un 12,2\% que sí las mantuvieron. Entre los $18(43,9 \%)$ asesinos seriales cuya zona de actuación fue América del Norte, un $22 \%$ sí mantuvieron relaciones sexuales con las víctimas post-mortem, frente a un mismo porcentaje de casos que no las mantuvieron. Con $\mathrm{p}<, 10$ se observó una correlación estadísticamente significativa $\left(\chi^{2}=3,586 ; \mathrm{gl}=1\right.$; $\mathrm{n}=41 ; \mathrm{p}<0,058)$ que apoya la suposición inicial de que sí existe relación entre mantener o no relaciones sexuales con las víctimas post-mortem y la zona de actuación de los asesinos en serie; siendo el tamaño del efecto moderado ( $\varphi$ y V=,296). Según el análisis de los residuos tipificados corregidos, se puede indicar que es probable que los asesinos en serie que hayan actuado en España no mantengan relaciones sexuales con las víctimas post-mortem, mientras que los asesinos seriales que hayan actuado en América del Norte sí las mantengan. (Tabla 102, 103 y 104).

Tabla 102. Distribución de frecuencias de la variable relaciones sexuales con las víctimas postmortem en cada zona de actuación.

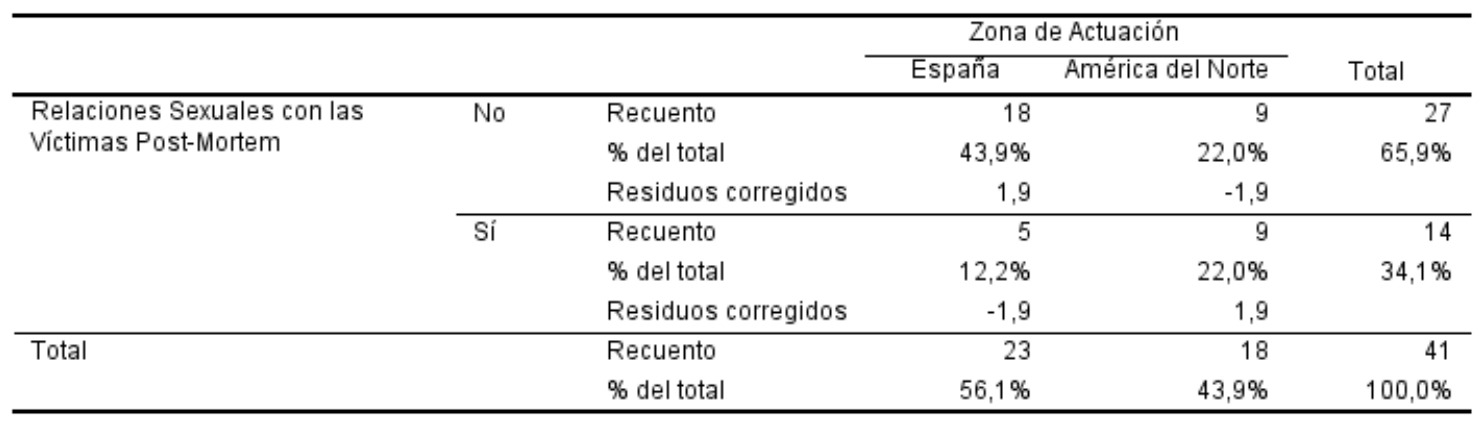

Tabla 103. Pruebas Chi Cuadrado de la variable relaciones sexuales con las víctimas postmortem en cada zona de actuación.

\begin{tabular}{|c|c|c|c|c|c|}
\hline & Valor & $\mathrm{gl}$ & $\begin{array}{l}\text { Sig. asintótica } \\
\text { (bilateral) }\end{array}$ & $\begin{array}{c}\text { Sig. exacta } \\
\text { (bilateral) }\end{array}$ & $\begin{array}{l}\text { Sig. exacta } \\
\text { (unilateral) }\end{array}$ \\
\hline Chi-cuadrado de Pearson & $3,586^{\mathrm{a}}$ & 1 & 058 & & \\
\hline Corrección por continuidad $^{\mathrm{b}}$ & 2,440 & 1 &, 118 & & \\
\hline Razón de verosimilitudes & 3,606 & 1 &, 058 & & \\
\hline Estadístico exacto de Fisher & & & &, 097 & 059 \\
\hline Asociación lineal por lineal & 3,499 & 1 &, 061 & & \\
\hline $\mathrm{N}$ de casos válidos & 41 & & & & \\
\hline
\end{tabular}


Tabla 104. Coeficientes de contingencia de la variable relaciones sexuales con las víctimas post-mortem en cada zona de actuación.

\begin{tabular}{llrr}
\hline & & Valor & Sig. aproximada \\
\hline Nominal por nominal & Phi &, 296 &, 058 \\
& V de Cramer &, 296 &, 058 \\
N de casos válidos & & 41 & \\
\hline
\end{tabular}

Por último, en la muestra de 48 asesinos en serie que conforman la muestra de este estudio, 24 (50\%) actuaron en España de los cuales un 31,2\% son de tipo organizado, un $12,5 \%$ son de tipo mixto y un $6,2 \%$ son de tipo desorganizado. Entre los $24(50 \%)$ cuya zona de actuación fue América del Norte, un $27,1 \%$ son de tipo mixto, un $14,6 \%$ son de tipo organizado y un $8,3 \%$ son de tipo desorganizado. Con $p<, 10$ se observó una correlación estadísticamente significativa $\left(G^{2}=5,761 ; g l=2 ; n=48 ; p<0,056\right)$ que apoya la suposición inicial de que sí existe relación entre las tipologías pertenecientes a la clasificación del FBI y la zona de actuación de los asesinos en serie; siendo el tamaño del efecto moderado $(\mathrm{C}=, 324)$. Según el análisis de los residuos tipificados corregidos, se puede indicar que es probable que los asesinos en serie que hayan actuado en España sean de tipo organizado, mientras que los asesinos seriales que lo hayan hecho en América del Norte sean de tipo mixto. (Tabla 105, 106 y 107).

Tabla 105. Distribución de frecuencias de la variable tipo I (FBI) en cada zona de actuación.

\begin{tabular}{llrrrr}
\hline & & \multicolumn{2}{c}{ Zona de Actuación } & \\
\cline { 3 - 4 } & & & España & América del Norte & \multicolumn{2}{c}{ Total } \\
\hline Tip0 1 (FBl) & Organizado & Recuento & 15 & 7 & 22 \\
& & \% del total & $31,3 \%$ & $14,6 \%$ & $45,8 \%$ \\
& & Residuos corregidos & 2,3 & $-2,3$ & \\
\cline { 3 - 5 } & Desorganizado & Recuento & 3 & 4 & 7 \\
& & \% del total & $6,3 \%$ & $8,3 \%$ & $14,6 \%$ \\
& Residuos corregidos &,- 4 & 13 & 19 \\
& Mixto & Recuento & 6 & $27,1 \%$ & $39,6 \%$ \\
& & \% del total & $12,5 \%$ & 2,1 & \\
\hline Total & Residuos corregidos & $-2,1$ & 24 & 48 \\
& & Recuento & 24 & $50,0 \%$ & $100,0 \%$ \\
\hline
\end{tabular}


Tabla 106. Pruebas Chi Cuadrado de la variable tipo I (FBI) en cada zona de actuación.

\begin{tabular}{lrrr}
\hline & Valor & gl & \multicolumn{2}{c}{$\begin{array}{c}\text { Sig. asintótica } \\
\text { (bilateral) }\end{array}$} \\
\hline Chi-cuadrado de Pearson & $5,631^{\text {a }}$ & 2 &, 060 \\
Razón de verosimilitudes & 5,761 & 2 &, 056 \\
Asociación lineal por lineal & 5,398 & 1 &, 020 \\
N de casos válidos & 48 & & \\
\hline
\end{tabular}

Tabla 107. Coeficiente de contingencia de la variable tipo I (FBI) en cada zona de actuación.

\begin{tabular}{lrrr}
\hline & Valor & Sig. aproximada \\
\hline Nominal por nominal & Coeficiente de contingencia &, 324 &, 060 \\
$N$ de casos válidos & \multicolumn{2}{c}{48} & \\
\hline
\end{tabular}

\subsection{Conclusiones.}

A lo largo del presente capítulo nos hemos centrado en analizar qué variables influyen en el comportamiento criminal de los asesinos en serie dependiendo de su zona de actuación, cómo influyen esas variables y conocer las diferencias existentes de dichas variables en relación a la zona de actuación de los asesinos seriales, en este caso, España y América del Norte.

A la luz de los resultados obtenidos en este capítulo, podemos confirmar la primera hipótesis, según la cual existe relación entre las variables nivel intelectual y la zona de actuación de los asesinos en serie pertenecientes a la muestra. Se observó que el nivel intelectual de los asesinos en serie que actuaron en América del Norte fue mayor que el de los asesinos seriales cuya zona de actuación fue España; por lo que es más probable que la zona de actuación de un asesino en serie que tenga un coeficiente intelectual alto sea América del Norte en vez de España.

Podemos confirmar también la segunda hipótesis, según la cual existe relación entre presentar patología mental y la zona de actuación de los asesinos seriales que componen la muestra. Se ha observado que un mayor porcentaje de asesinos en serie que actuaron en América del Norte presentaron patología mental, del mismo modo que se ha observado que un mayor porcentaje de asesinos en serie que actuaron en España 
no presentaron patología mental. Por lo tanto, existirá una tendencia a que los asesinos seriales cuya zona de actuación sea América del Norte presenten algún tipo de patología mental; así como los que sitúen su zona de actuación en España no la presenten.

Confirmamos también la tercera hipótesis, según la cual existe relación entre haber sufrido algún tipo de maltrato en la infancia y la zona de actuación de los asesinos en serie que pertenecen a la muestra. Se ha observado que un mayor porcentaje de asesinos en serie cuya zona de actuación fue América del Norte han sufrido algún tipo de maltrato en la infancia, del mismo modo que se ha observado que un mayor porcentaje de asesinos en serie que actuaron en España no han sufrido algún tipo de maltrato en la infancia. Por lo tanto, es más probable que los asesinos en serie que actúen en América del Norte hayan sufrido algún tipo de maltrato en la infancia; así como los que sitúen su zona de actuación en España no hayan sufrido algún tipo de maltrato en la infancia. En este sentido, no se aceptaría la hipótesis de Pincus (2000), que asegura que la psicopatía es consecuencia del maltrato infantil prolongado, ya que cambia de forma permanente la anatomía y el funcionamiento del cerebro. En caso de que fuera así el funcionamiento del cerebro afectado estaría distorsionado en ambas poblaciones. No obstante, numerosos autores (Ochotorena y Arruabarrena, 1996, 2007; Borja y Ostrosky-Solis, 2009; Craparo, Schimmenti y. Caretti, 2013) afirman que el maltrato en la infancia si favorece la aparición de psicopatía asesina.

Hemos confirmado la cuarta hipótesis, que plantea relación entre el modo de interacción verbal con las víctimas y la zona de actuación de los asesinos seriales que componen la muestra. Se ha observado que un mayor porcentaje de asesinos en serie que actuaron en América del Norte llevan a cabo una interacción verbal con las víctimas de forma agresiva, del mismo modo que se ha observado que un mayor porcentaje de asesinos en serie que actuaron en España llevaron a cabo dicha interacción de manera no agresiva. Por lo tanto, es probable que los asesinos en serie que actúen en América del Norte lleven a cabo una interacción verbal con las víctimas de forma agresiva, en comparación con los que actúen en España que la llevarán a cabo de una forma no agresiva.

Podemos confirmar también la quinta hipótesis, según la cual existe relación entre haber llevado a cabo conductas sádicas y de tortura y la zona de actuación de los asesinos en serie pertenecientes a la muestra. Se ha observado que un mayor porcentaje 
de asesinos en serie cuya zona de actuación fue América del Norte han llevado a cabo conductas sádicas y de tortura con las víctimas, del mismo modo que se ha observado un mayor porcentaje de asesinos seriales que actuaron en España, no han llevado a cabo conductas sádicas y de tortura con sus víctimas. Por lo tanto, existe una tendencia a que los asesinos en serie que actúen en América del Norte lleven a cabo conductas sádicas y de tortura con sus víctimas, en comparación a los que sitúen su zona de actuación en España, que no las llevarán a cabo.

Hemos confirmado la sexta hipótesis, según la cual existe relación entre haber llevado a cabo conductas de mutilación con las víctimas y la zona de actuación de los asesinos en serie que conforman la muestra. Se ha observado que un mayor porcentaje de asesinos seriales cuya zona de actuación fue América del Norte han llevado a cabo conductas de mutilación con las víctimas, del mismo modo que se ha observado que un mayor porcentaje de asesinos seriales que actuaron en España no han llevado a cabo dichas conductas con sus víctimas. Por lo tanto, es más probable que los asesinos en serie que actúen en América del Norte lleven a cabo conductas de mutilación con las víctimas, mientras que los asesinos en serie que actúen en España no lleven a cabo este tipo de conductas con las víctimas.

Estos resultados apoyan las investigaciones de Leyton (1984) en las que sugiere que en EEUU impera una cultura de la violencia, del miedo, ya que desde temprana edad se enseña a las personas a protegerse del exterior y que el empleo de la violencia se utiliza como reclamación moral, además de ser enormemente tolerada. Además, según las investigaciones del citado autor, en EEUU prima un individualismo competitivo que les lleva a hacer todo lo posible para poder alcanzar el sueño americano.

Confirmamos además la séptima hipótesis que planteaba que existe relación entre haber llevado a cabo relaciones sexuales con las víctimas post-mortem y la zona de actuación de los asesinos en serie pertenecientes a la muestra. Se ha observado que un mayor porcentaje de asesinos en serie cuya zona de actuación fue América del Norte han mantenido relaciones sexuales con las víctimas post-mortem, del mismo modo que se ha observado que un mayor porcentaje de asesinos en serie seriales que actuaron en España no han mantenido relaciones sexuales con las víctimas post-mortem. Por lo tanto, es probable que los asesinos en serie que actúen en América del Norte mantengan 
este tipo de relaciones sexuales con las víctimas, mientras que los asesinos seriales que actúen en España no las mantengan.

Por último, confirmamos también la octava hipótesis según la cual existe relación entre la clasificación del FBI (organizado, desorganizado y mixto) y la zona de actuación de los asesinos seriales que componen la muestra. Se ha observado que un mayor porcentaje de asesinos en serie cuya zona de actuación fue España son de tipo organizado, del mismo modo que se ha observado un mayor porcentaje de asesinos seriales que actuaron en América del Norte son de tipo mixto. Por lo tanto, es probable que los asesinos en serie que actúen en España sean de tipo organizado, mientras que los asesinos seriales que actúen en América del Norte sean de tipo mixto. 


\section{CAPÍTULO VII: ESTUDIO DE UNA MUESTRA INTERNACIONAL DE ASESINOS EN SERIE.}

En el capítulo anterior hemos analizado e interpretado los datos recogidos en el cuestionario sobre asesinos en serie citado con anterioridad. En este capítulo nos vamos a centrar en trece variables que nos han parecido de especial interés a raíz de los resultados obtenidos en el estudio comparativo entre asesinos en serie que actuaron en América del Norte y España, en este caso, en una muestra de 100 asesinos en serie internacionales con el objetivo de alcanzar una información más detallada y contrastada del fenómeno del asesinato serial.

\subsection{OBJETIVOS}

(1) Analizar el perfil sociodemográfico de los asesinos en serie internacionales.

(2) Analizar los rasgos psicopáticos de los asesinos seriales en una muestra internacional.

(3) Analizar la influencia de haber sufrido algún tipo de maltrato en la infancia en el comportamiento criminal de los asesinos seriales internacionales.

(4) Analizar la escena del crimen de los asesinos en serie de una muestra internacional.

(5) Analizar qué variables pertenecientes al modus operandi influyen en el comportamiento criminal de los asesinos en serie internacionales que conforman la muestra.

(6) Analizar qué variables pertenecientes al ritual de actuación influyen en el comportamiento criminal de los asesinos en serie incluidos en este estudio internacional.

(7) Analizar las diferencias existentes en cuanto a la tipología del FBI en la muestra de asesinos en serie internacional. 


\subsection{HIPÓTESIS}

(1) Comprobar la relación entre el nivel de planificación de los asesinos en serie y el sexo de los mismos.

(2) Comprobar la relación entre haber mantenido relaciones sexuales con las víctimas ante-mortem y el sexo de los asesinos seriales.

(3) Comprobar la relación entre haber sufrido algún tipo de maltrato en la infancia y el continente de procedencia de los asesinos en serie.

(4) Comprobar la relación entre haber mantenido relaciones sexuales con las víctimas y haber sufrido algún tipo de maltrato en la infancia.

(5) Comprobar la relación entre el nivel de planificación de los asesinos en serie y la clasificación del FBI.

\subsection{MÉTODO}

\subsubsection{Informantes}

La muestra está compuesta por 100 asesinos en serie. De estas 100 personas, 36 asesinos seriales son de Europa del Oeste, 5 son de Europa del Eeste, 1 es de Asia Oriental, 3 son de Asia Occidental, 39 son norteamericanos, 12 son sudamericanos y 4 son canadienses tal y como se observa en la Tabla 108 y la Figura 56.

Tabla 108. Distribución de frecuencias de la variable país de procedencia de los asesinos seriales.

\begin{tabular}{llrrrr}
\hline & Frecuencia & Porcentaje & Porcentaje válido & \multicolumn{2}{c}{$\begin{array}{c}\text { Porcentaje } \\
\text { acumulado }\end{array}$} \\
\hline Válido & Europa Oeste & 36 & 36,0 & 36,0 & 36,0 \\
& Europa Este & 5 & 5,0 & 5,0 & 41,0 \\
& Asia Oriental & 1 & 1,0 & 1,0 & 42,0 \\
& Asia Occidental & 3 & 3,0 & 3,0 & 45,0 \\
& América del Norte & 39 & 39,0 & 39,0 & 84,0 \\
& América del Sur & 12 & 12,0 & 12,0 & 96,0 \\
Canadá & 4 & 4,0 & 4,0 & 100,0 \\
Total & 100 & 100,0 & 100,0 & \\
\hline
\end{tabular}




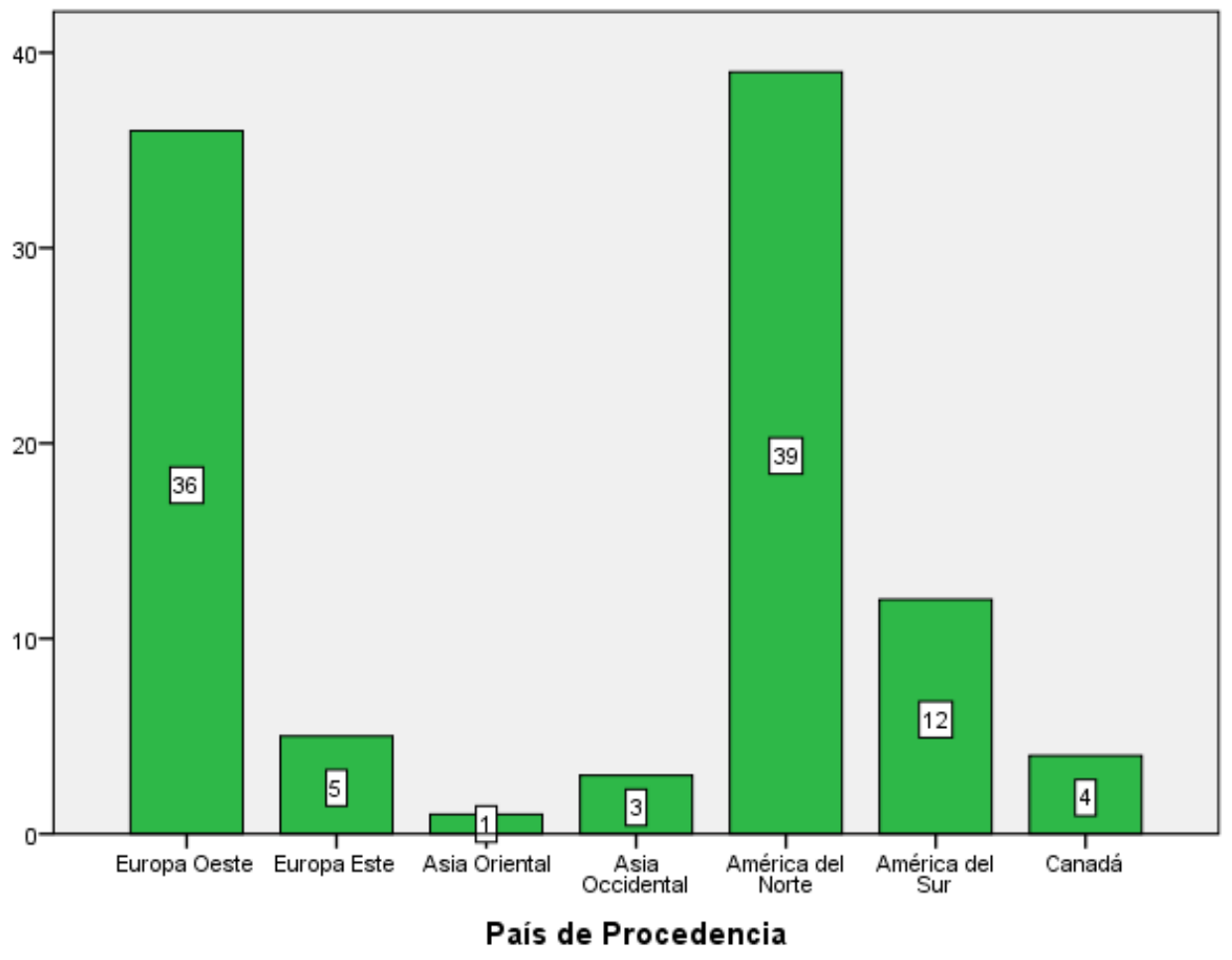

Figura 56. Gráfico de barras de la variable país de procedencia de los asesinos en serie.

En relación al sexo de los participantes se extrae que, un $85 \%$ (85 casos) de los asesinos en serie incluidos en la muestra son hombres y un 15\% (15 casos) son mujeres, como se observa en la Tabla 109 y la Figura 57.

Tabla 109. Distribución de frecuencias de la variable sexo de los asesinos en serie.

\begin{tabular}{llrrrr}
\hline & & Frecuencia & Porcentaje & Porcentaje válido & \multicolumn{2}{c}{$\begin{array}{c}\text { Porcentaje } \\
\text { acumulado }\end{array}$} \\
\hline Válido & Hombre & 85 & 85,0 & 85,0 & 85,0 \\
& Mujer & 15 & 15,0 & 15,0 & 100,0 \\
& Total & 100 & 100,0 & 100,0 & \\
\hline
\end{tabular}




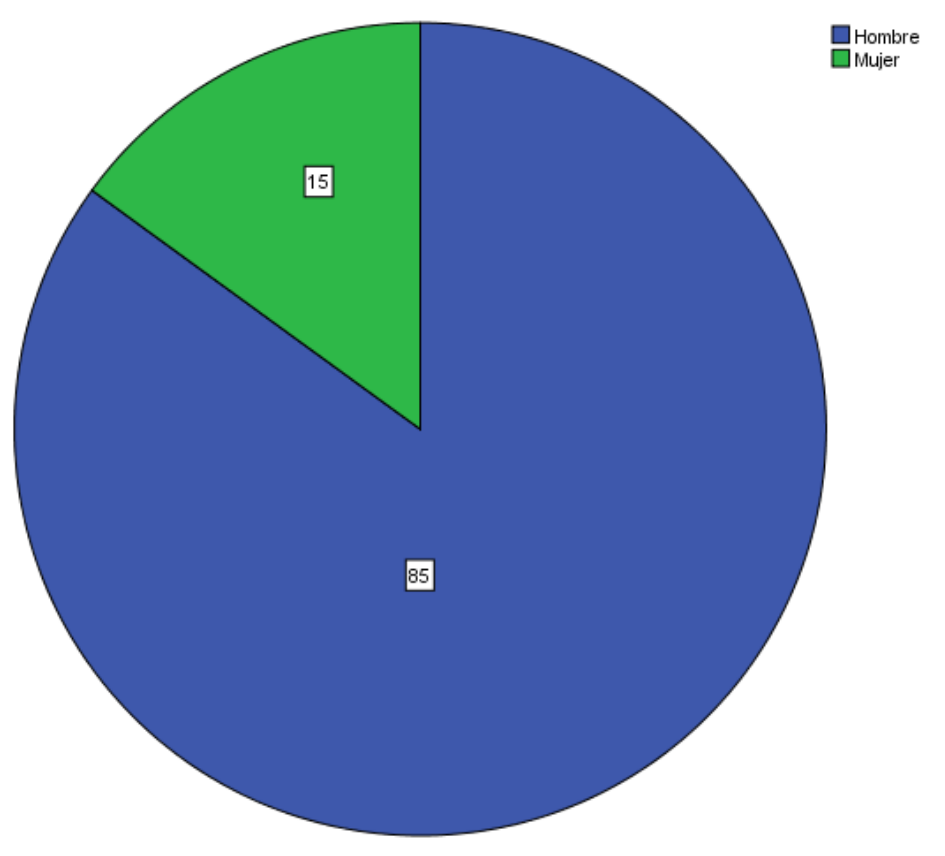

Figura 57. Diagrama de sectores de la variable sexo de los asesinos en serie.

En cuanto a la variable edad de inicio de los asesinatos, se observa que ésta se aproxima a una distribución normal (simétrica, As= 0,014 y mesocúrtica $\mathrm{K}=-0,024)$. La edad media de inicio de los asesinatos ha sido aproximadamente de 31 años (mediana 31) con una desviación típica de 9,331; siendo la edad mínima de inicio de los asesinatos 9 años y la edad máxima 55 años tal y como se observa en la Tabla 110 y Figura 58.

Tabla 110. Estadísticos descriptivos de la variable edad de inicio de los asesinatos de los asesinos en serie.

\begin{tabular}{|c|c|c|}
\hline \multirow[t]{2}{*}{$N$} & Válido & 100 \\
\hline & Perdidos & 0 \\
\hline \multicolumn{2}{|c|}{ Media } & 31,29 \\
\hline \multicolumn{2}{|c|}{ Mediana } & 31,00 \\
\hline \multicolumn{2}{|c|}{ Moda } & 33 \\
\hline \multicolumn{2}{|c|}{ Desviación estándar } & 9,331 \\
\hline \multicolumn{2}{|c|}{ Varianza } & 87,077 \\
\hline \multicolumn{2}{|c|}{ Asimetría } &, 014 \\
\hline \multicolumn{2}{|c|}{ Error estándar de asimetría } &, 241 \\
\hline \multicolumn{2}{|c|}{ Curtosis } &,- 024 \\
\hline \multicolumn{2}{|c|}{ Error estándar de curtosis } & ,478 \\
\hline \multicolumn{2}{|c|}{ Mínimo } & 9 \\
\hline \multicolumn{2}{|c|}{ Máximo } & 55 \\
\hline
\end{tabular}




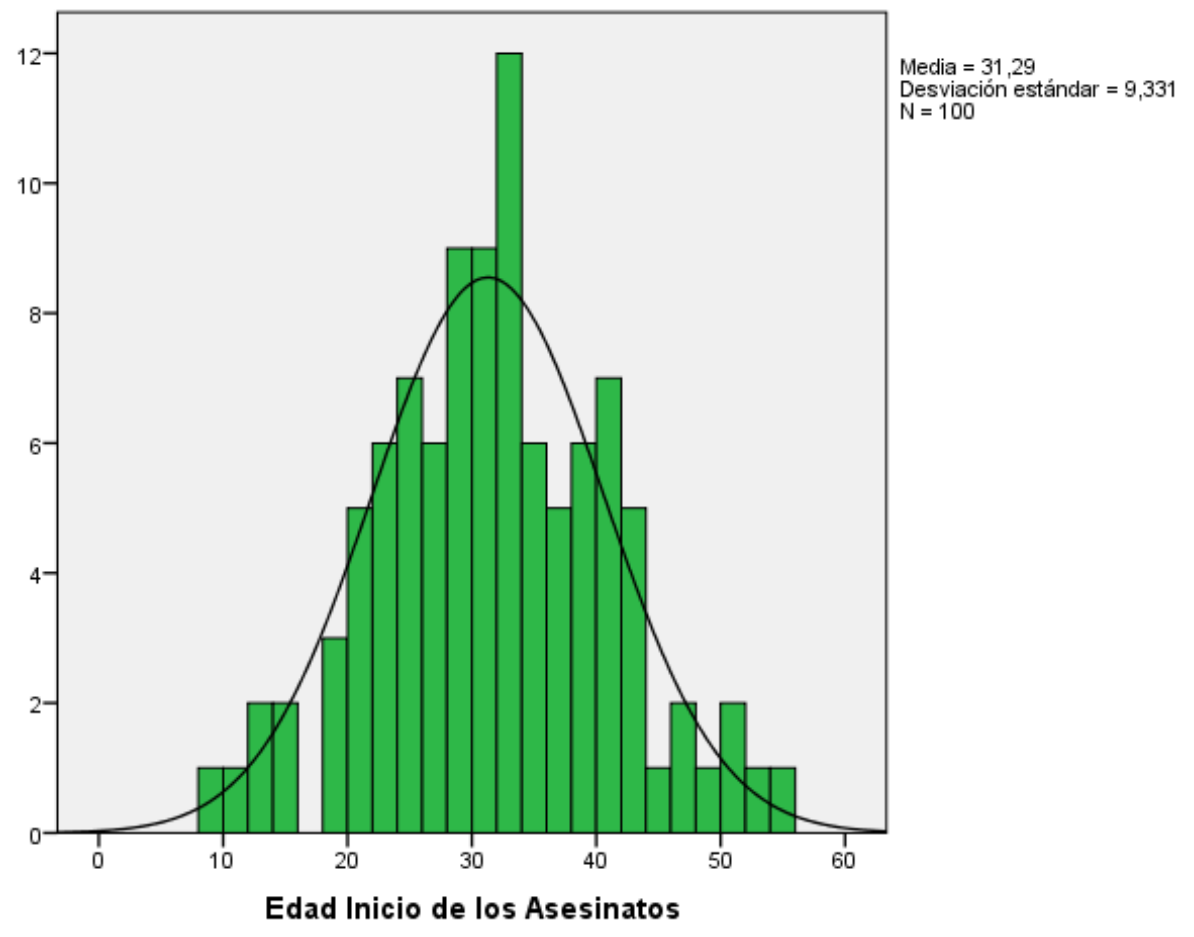

Figura 58. Histograma de frecuencias de la variable edad de inicio de los asesinatos de los asesinos en serie.

\subsubsection{Diseño}

Para llevar a cabo este estudio, hemos empleado una metodología de la investigación correlacional, ya que el propósito de este estudio es observar la existencia de una correlación entre dos o más variables que no pueden ser analizadas experimentalmente. En este caso, hemos construido un instrumento de medición que contemplan las variables a estudiar y cuyo posterior análisis estadístico de los datos nos permitirá obtener una certeza de la verdad o la falsedad de nuestras hipótesis. Consiste en la búsqueda de algún tipo de relación entre dos variables, y en qué medida la variación de una de las variables afecta a la otra, sin llegar a conocer cuál de ellas puede ser causa o efecto. La información que se recoja sobre las variables involucradas en la relación comprobará o no esa relación, en cuando a su magnitud, dirección y naturaleza. 


\subsubsection{Procedimiento}

Los datos fueron recogidos de asesinos en serie provenientes de todas las partes del mundo a través de bibliografía de riguroso carácter científico, así como de la información facilitada por especialistas en la materia. La recogida de datos supuso un mes de trabajo y fue realizada en octubre de 2015. La información detallada del proceso de recogida de datos se encuentra desarrollada en el capítulo cinco, por lo que, en aras de no ser repetitivos, omitiremos la descripción en este apartado.

\subsubsection{Instrumentos}

Hemos partido de un instrumento compuesto por 13 variables, adaptación a su vez y versión reducida del instrumento utilizado para el estudio comparativo (ficha de variables realizada por los miembros pertenecientes a la Unidad de Análisis de la Conducta Criminal de la Universidad de Salamanca). (Véase Anexo 3).

En este instrumento las variables manejadas han sido:

1. Variables sociodemográficas y físicas: Grupo de variables que comprende aquellas relativas a aspectos identificativos del sujeto y de su esfera familiar y social.

a. Nombre (nominal abierta). Debe ser tenido en cuenta que, especialmente en el caso de asesinos norteamericanos, no es extraño que el individuo tenga dos nombres. Deben ser reflejados todos los nombres que se conozcan del sujeto, separados por comas.

b. Sexo (nominal cerrada). En su determinación se atenderá al sexo biológico del individuo, es decir, al que manifiestan sus órganos sexuales.

c. Edad inicio asesinatos (numérica abierta). Hace referencia a la edad del agresor en el momento en que realiza el primer asesinato. Por tanto, no tiene que corresponder, necesariamente, con la edad en la que se inicia en la delincuencia, ya que pudo cometer otro tipo de delitos con anterioridad.

d. Zona de procedencia (nominal cerrada). Denominación del país en el que nace el sujeto. 
e. Continente de procedencia (nominal cerrada). Denominación del continente en el que nace el sujeto.

2. Variables psicológicas: Grupo de variables que recogen datos que el agresor manifiesta en el periodo de actuación homicida (incluyendo tanto los actos criminales en todas sus fases, como el posterior enfriamiento emocional). Queda excluida de este grupo la información relativa a otros periodos temporales, ocupándose de ella los grupos de "antecedentes en la infancia y adolescencia" e "historial edad adulta".

a. Rasgos psicopáticos (nominal cerrada) (elección múltiple). Deberán ser extraídos a través de las conductas manifestadas por el sujeto o informes realizados por profesionales de la Psiquiatría o la Psicología. Los rasgos son los siguientes:

- Falta de empatía: incapacidad de ponerse en el lugar de los demás, sobre todo emocionalmente.

- Manipulación/mentira: uso de recursos ajenos a la verdad, así como distorsión de la realidad para conseguir sus fines o por el mero placer de hacerlo.

- Versatilidad criminal: realización de varios actos delictivos de distinta índole.

- Falta de responsabilidad: despreocupación por las obligaciones y los compromisos sociales, laborales, familiares y/o culturales.

- Encanto superficial: capacidad para generar en los demás una valoración positiva sobre su persona.

- Egocentrismo y elevada autovalía: elevado nivel de narcisismo y arrogancia. Fe ciega en sus capacidades y la superación de obstáculos.

- Impulsividad: incapacidad para regular la respuesta conductual y tener una actitud reflexiva.

- Falta de culpa: ausencia de preocupación por los efectos de sus actos en los demás. 
- Estilo de vida parasitario: dependencia económica y/o material buscada y provocada respecto a terceras personas de las cuales se aprovecha,

- Promiscuidad sexual: establecimiento de relaciones sexuales polígamas.

- Superficialidad afectiva: imposibilidad de experimentar emociones fuertes, intensas y profundas.

3. Antecedentes infancia y adolescencia: Conjunto de variables que agrupan características y circunstancias relacionadas con los primeros años de vida del agresor, a fin de unificar posiciones se entenderá aproximadamente como final de esta etapa y comienzo de la edad adulta los 18 años.

a. Algún tipo de maltrato (nominal cerrada): hace referencia a haber sufrido algún tipo de maltrato ya sea físico o psicológico en la infancia.

4. Escena: Conjunto de variables que recogen características y elementos relacionados con los escenarios del crimen. Para ello, cabe precisar que entendemos por escena del crimen, de acuerdo con Turvey (2008), el «escenario donde el agresor y la víctima interactúan y donde, según el principio de transferencia de Locard, algo de cada uno de los actores se transferirá al otro dejando una huella que debe ser observada, recogida y analizada» (en Jiménez Serrano, 2010, p. 59).

a. Número de crímenes (numérica abierta). Hace referencia al número de actos (separados por un periodo de enfriamiento emocional). Es decir, recoge los sucesos y no las víctimas derivadas de los mismos, ya que, de un mismo acto, pueden resultar varias víctimas. En esta variable, serán contabilizados tanto los asesinatos/homicidios consumados como las tentativas. 
5. Modus Operandi: grupo de variables que reúnen elementos relativos al Modus Operandi del agresor, entendido como el "conjunto de actos estrictamente necesarios para perpetrar el delito y obtener éxito en su comisión” (Soto, 2014, p.58).

a. Nivel de planificación (ordinal cerrada). Referida a la proyección que el agresor tiene sobre el acto criminal y que se reflejará en todas las fases del crimen, a partir de las cuales debe ser inferida.

b. Forma de causar la muerte (nominal cerrada) (elección múltiple). Se refiere al modo en que el agresor acaba con la vida de la víctima, a pesar de que puedan concurrir múltiples lesiones en esta variable solo deben ser contempladas aquellas que condujeron a la muerte de las víctimas.

- Por contusión: tipo de lesión física no penetrante sobre un cuerpo humano o animal causada por la acción de objetos rotundos, que actúan sobre el organismo por intermedio de una fuerza más o menos considerable.

- Estrangulación: acción de apretar el cuello para comprimir las arterias carótidas o la tráquea causando la muerte.

- Con arma blanca: forma de causar la muerte mediante un cuchillo u objeto puntiagudo similar a éste.

- Intoxicación: forma de causar la muerte a través de la acción de sustancias nocivas para el organismo.

- Con arma de fuego: forma de causar la muerte utilizando cualquier arma de fuego, como por ejemplo una pistola, escopeta, etc.

- Otra: cualquier otra forma de causar la muerte.

- Se desconoce: no hay datos sobre la forma de causar la muerte.

6. Ritual: Grupo de variables referidas a aquellos aspectos de ritual, entendiendo este como el «patrón distintivo de conductas del agresor que le son 
características y que satisfacen necesidades psicológicas y emocionales» (Soto, 2014, p. 62).

a. Relaciones sexuales con las víctimas ante-mortem (nominal cerrada). Existe en aquellos casos en que el agresor, antes de causar la muerte a la víctima, práctica sexo con ella.

b. Relaciones sexuales con las víctimas post-mortem (nominal cerrada). Concurre en los hechos en que el criminal, tras asesinar a la víctima, práctica sexo con ella.

7. Tipologías: referidas en Jiménez (2012).

a. Tipo 1 (FBI) (nominal cerrada).

- Organizado: agresión planeada, víctima extraña, personaliza a la víctima, controla la conversación, controla la escena del crimen, hace sumisa a la víctima, usa métodos de control, muchos actos agresivos, traslada el cadáver, usa armas, deja pocos indicios en la escena.

- Desorganizado: agresión espontánea, víctima conocida, despersonaliza a la víctima, no habla con la víctima o muy poco, la escena del crimen es caótica, violencia súbita, no usa métodos de control, realiza sexo después de la muerte, no traslada el cadáver, no usa armas o son de oportunidad, hay muchos indicios en la escena.

- Mixto: no predomina ningún conjunto de características propias de una u otra categoría. 


\subsection{RESULTADOS}

\subsubsection{Estudio descriptivo de la muestra}

Dentro de la dimensión "variables psicológicas", se analizó la variable rasgos psicopáticos de los asesinos seriales (Tabla 111).

En relación a esta variable se puede observar que un 21,1\% de los asesinos en serie incluidos en el estudio presentaron falta de empatía, un 15,3\% presentaron manipulación mentira, un mismo porcentaje de casos presentó falta de culpa, un 9\% encanto superficial y tan sólo un $2,7 \%$ de los asesinos seriales presentaros superficialidad afectiva; como rasgos psicopáticos más destacados.

Tabla 111. Distribución de frecuencias de la variable rasgos psicopáticos de los asesinos en serie.

\begin{tabular}{|c|c|c|c|c|}
\hline & & \multicolumn{2}{|c|}{ Respuestas } & \multirow{2}{*}{$\begin{array}{c}\text { Porcentaje de } \\
\text { casos }\end{array}$} \\
\hline & & $\mathrm{N}$ & Porcentaje & \\
\hline \multirow[t]{11}{*}{ Rasgos Psicopáticos ${ }^{a}$} & Falta de Empatía & 87 & $21,1 \%$ & $87,0 \%$ \\
\hline & Manipulación Mentira & 63 & $15,3 \%$ & $63,0 \%$ \\
\hline & Versatilidad Criminal & 24 & $5,8 \%$ & $24,0 \%$ \\
\hline & Falta de Responsabilidad & 26 & $6,3 \%$ & $26,0 \%$ \\
\hline & Encanto Superficial & 37 & $9,0 \%$ & $37,0 \%$ \\
\hline & Egocentrismo y Elevada Autovalía & 25 & $6,1 \%$ & $25,0 \%$ \\
\hline & Impulsividad & 34 & $8,2 \%$ & $34,0 \%$ \\
\hline & Falta de Culpa & 63 & $15,3 \%$ & $63,0 \%$ \\
\hline & Estilo de Vida Parasitario & 13 & $3,1 \%$ & $13,0 \%$ \\
\hline & Promiscuidad Sexual & 30 & $7,3 \%$ & $30,0 \%$ \\
\hline & Superficialidad Afectiva & 11 & $2,7 \%$ & $11,0 \%$ \\
\hline Total & & 413 & $100,0 \%$ & $413,0 \%$ \\
\hline
\end{tabular}

Dentro de la dimensión "antecedentes en la infancia y la adolescencia", se analizó variable haber sufrido algún tipo de maltrato en la infancia.

En relación a esta variable se puede observar que el 57\% (57 casos) de los asesinos en serie incluidos en la muestra no han sufrido algún tipo de maltrato en la infancia, y un 43\% (43 casos) sí lo han padecido tal y como se observa en la Tabla 112 y la Figura 59. 
Tabla 112. Distribución de frecuencias de la variable haber sufrido algún tipo de maltrato en la infancia de los asesinos en serie.

\begin{tabular}{llrrrr}
\hline & & Frecuencia & Porcentaje & Porcentaje válido & \multicolumn{2}{c}{$\begin{array}{c}\text { Porcentaje } \\
\text { acumulado }\end{array}$} \\
\hline Válido & No & 57 & 57,0 & 57,0 & 57,0 \\
& Sí & 43 & 43,0 & 43,0 & 100,0 \\
& Total & 100 & 100,0 & 100,0 & \\
\hline
\end{tabular}

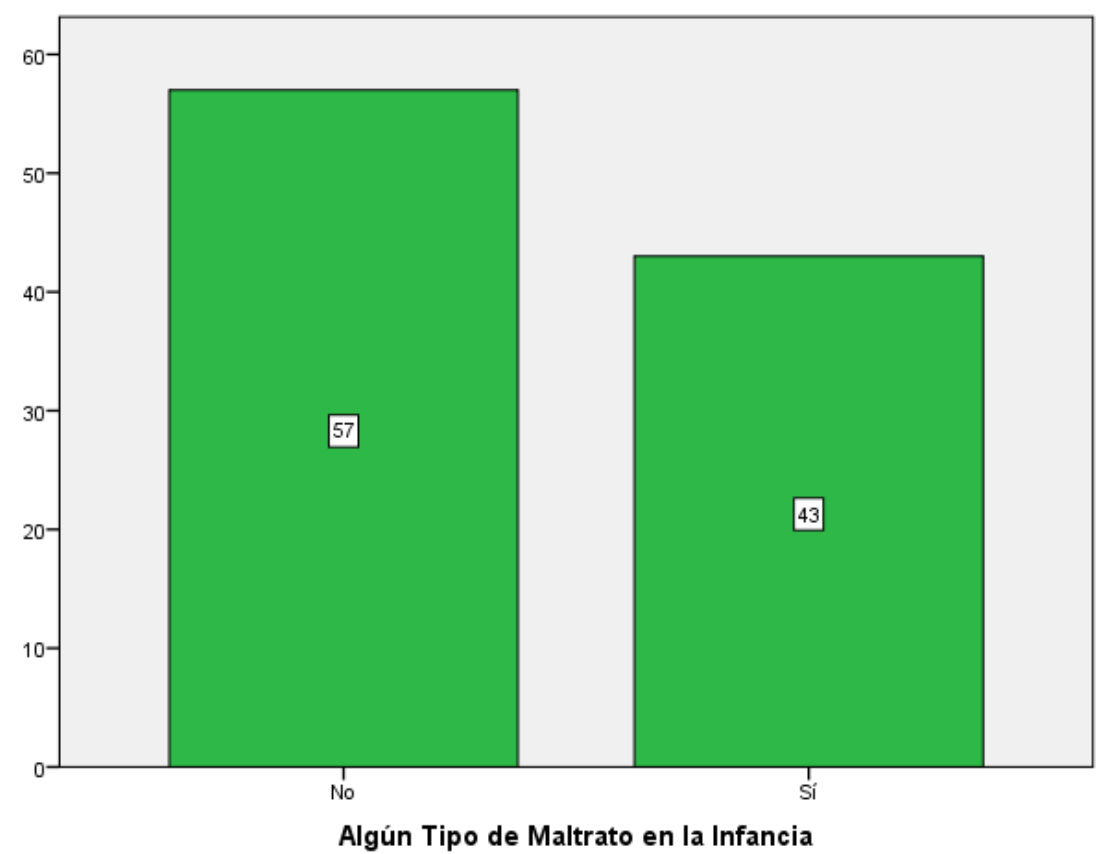

Figura 59. Gráfico de barras de la variable haber sufrido algún tipo de maltrato en la infancia de los asesinos en serie.

En cuanto a la dimensión "escena", se ha analizado la variable número de crímenes (Tabla 113 y Figura 60).

En la muestra de 100 asesinos seriales que ha sido incluida en este estudio, el número de crímenes presenta una marcada asimetría (asimétrica, As= 4,075 y leptocúrtica $\mathrm{K}=17,988)$. El número medio de crímenes cometidos ha sido aproximadamente de 26 crímenes (mediana 11) con una desviación típica de 50,791; siendo el menor número de crímenes cometidos 2 y el mayor 300. 
Tabla 113. Estadísticos descriptivos de la variable número de crímenes de los asesinos en serie.

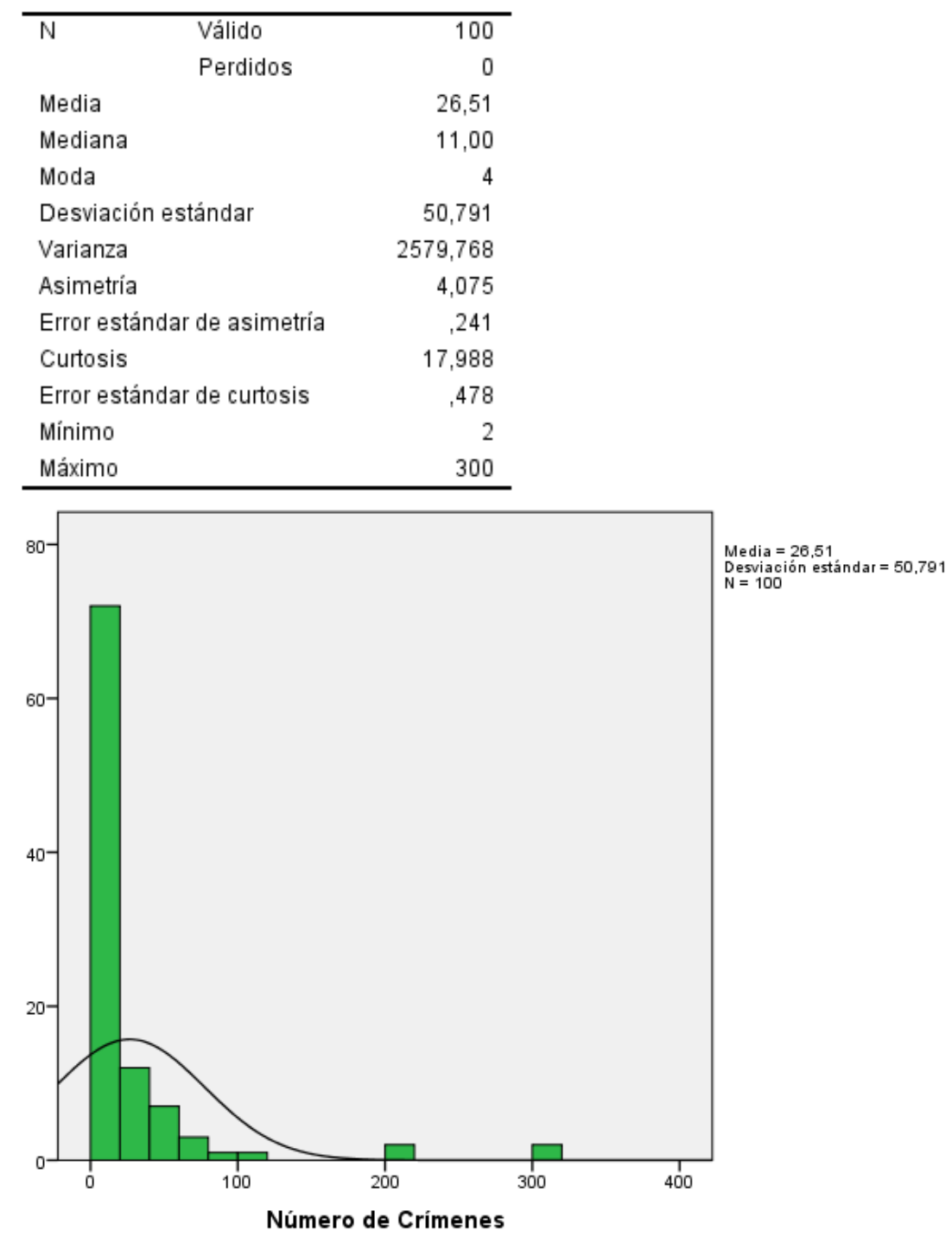

Figura 60. Histograma de frecuencias de la variable número de crímenes de los asesinos en serie.

Dentro de la dimensión "modus operandi", se han analizado las variables nivel de planificación y forma de causar la muerte.

En relación a la variable nivel de planificación, se ha observado que el 4\% (4 casos) del total de asesinos en serie que forman la muestra tienen un nivel de planificación nulo, un 25\% (25 casos) lo tienen bajo, un 40\% (40 casos) tienen un nivel de planificación medio y un $31 \%$ (31 casos) lo tienen alto tal y como se observa en la Tabla 114 y la Figura 61. 
Tabla 114. Distribución de frecuencias de la variable nivel de planificación de los asesinos en serie.

\begin{tabular}{llrrrr}
\hline & & Frecuencia & Porcentaje & Porcentaje válido & \multicolumn{2}{c}{$\begin{array}{c}\text { Porcentaje } \\
\text { acumulado }\end{array}$} \\
\hline Válido & Nulo & 4 & 4,0 & 4,0 & 4,0 \\
& Bajo & 25 & 25,0 & 25,0 & 29,0 \\
& Medio & 40 & 40,0 & 40,0 & 69,0 \\
& Alto & 31 & 31,0 & 31,0 & 100,0 \\
& Total & 100 & 100,0 & 100,0 & \\
\hline
\end{tabular}

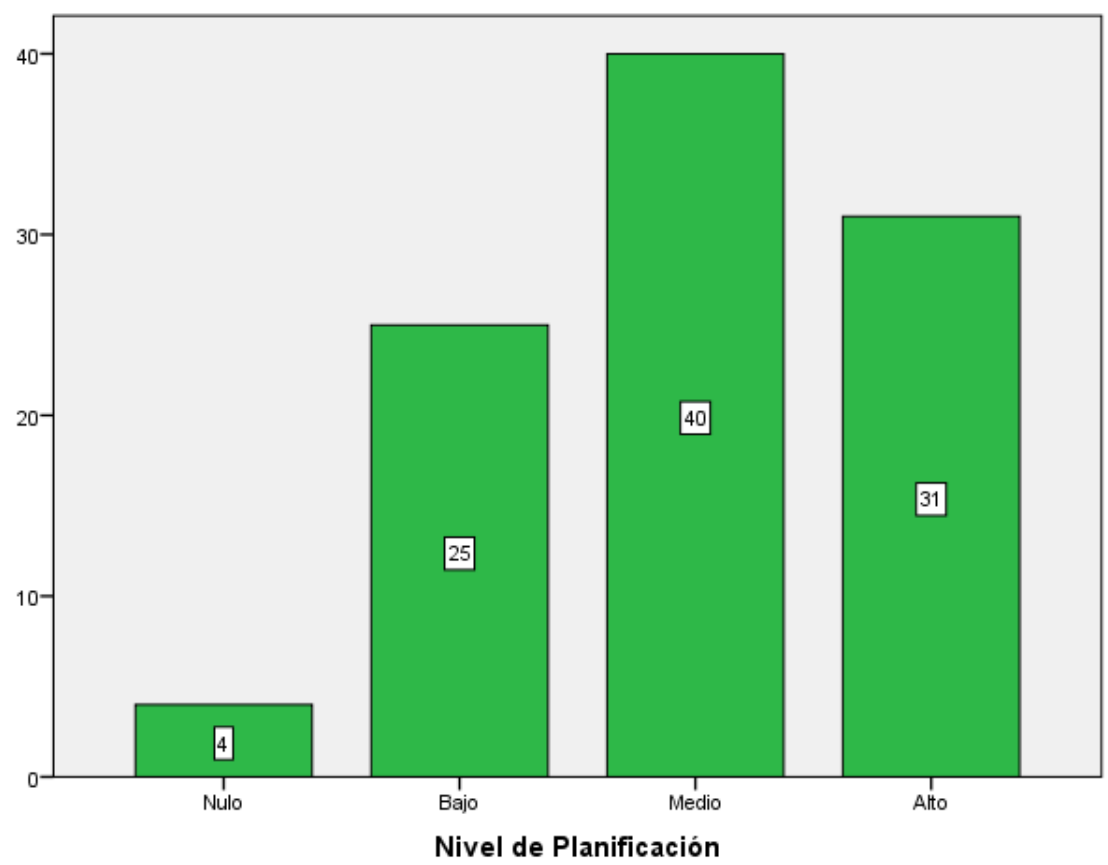

Figura 61. Gráfico de barras de la variable nivel de planificación de los asesinos en serie.

En cuanto a la variable forma de causar la muerte (Tabla 115), se ha observado que un $24,7 \%$ de los asesinos seriales que conforman este estudio causaron la muerte por estrangulación, un mismo porcentaje de casos lo hicieron con arma blanca, un 18,4\% causaron la muerte a las víctimas por contusión, un 13,3\% lo hicieron con arma de fuego, un 10,8\% por intoxicación y un 7,6\% causaron la muerte a las víctimas de otra forma diferente a las anteriores. 
Tabla 115. Distribución de frecuencias de la variable forma de causar la muerte de los asesinos en serie.

\begin{tabular}{clrrrr}
\hline & & \multicolumn{2}{c}{ Respuestas } & \multicolumn{2}{c}{$\begin{array}{c}\text { Porcentaje de } \\
\text { casos }\end{array}$} \\
\cline { 3 - 4 } Forma de Causar la Muerte $^{\text {a }}$ & Desconocido & 1 & $0,6 \%$ & $1,0 \%$ \\
& Por Contusión & 29 & $18,4 \%$ & $29,0 \%$ \\
& Estrangulación & 39 & $24,7 \%$ & $39,0 \%$ \\
& Con Arma Blanca & 39 & $24,7 \%$ & $39,0 \%$ \\
& Intoxicación & 17 & $10,8 \%$ & $17,0 \%$ \\
& Con Arma de Fuego & 21 & $13,3 \%$ & $21,0 \%$ \\
Total & Otra & 12 & $7,6 \%$ & $12,0 \%$ \\
a. Grupo & 158 & $100,0 \%$ & $158,0 \%$ \\
\hline
\end{tabular}

En referencia a la dimensión "ritual", han sido analizadas las variables relaciones sexuales con las víctimas ante-mortem y relaciones sexuales con las víctimas post-mortem.

En cuanto a la variable haber mantenido relaciones sexuales con las víctimas ante-mortem, se ha encontrado que un 50\% (50 casos) de los asesinos seriales incluidos en esta investigación han mantenido relaciones sexuales con las víctimas ante-mortem y el 50\% (50 casos) restante no las mantuvo. Se puede observar lo indicado en la Tabla 116 y la Figura 62.

Tabla 116. Distribución de frecuencias de la variable relaciones sexuales con las víctimas antemortem de los asesinos en serie.

\begin{tabular}{rrrrrr}
\hline & & Frecuencia & Porcentaje & Porcentaje válido & \multicolumn{2}{c}{$\begin{array}{l}\text { Porcentaje } \\
\text { acumulado }\end{array}$} \\
\hline Válido & No & 50 & 50,0 & 50,0 & 50,0 \\
& Sí & 50 & 50,0 & 50,0 & 100,0 \\
& Total & 100 & 100,0 & 100,0 & \\
\hline
\end{tabular}




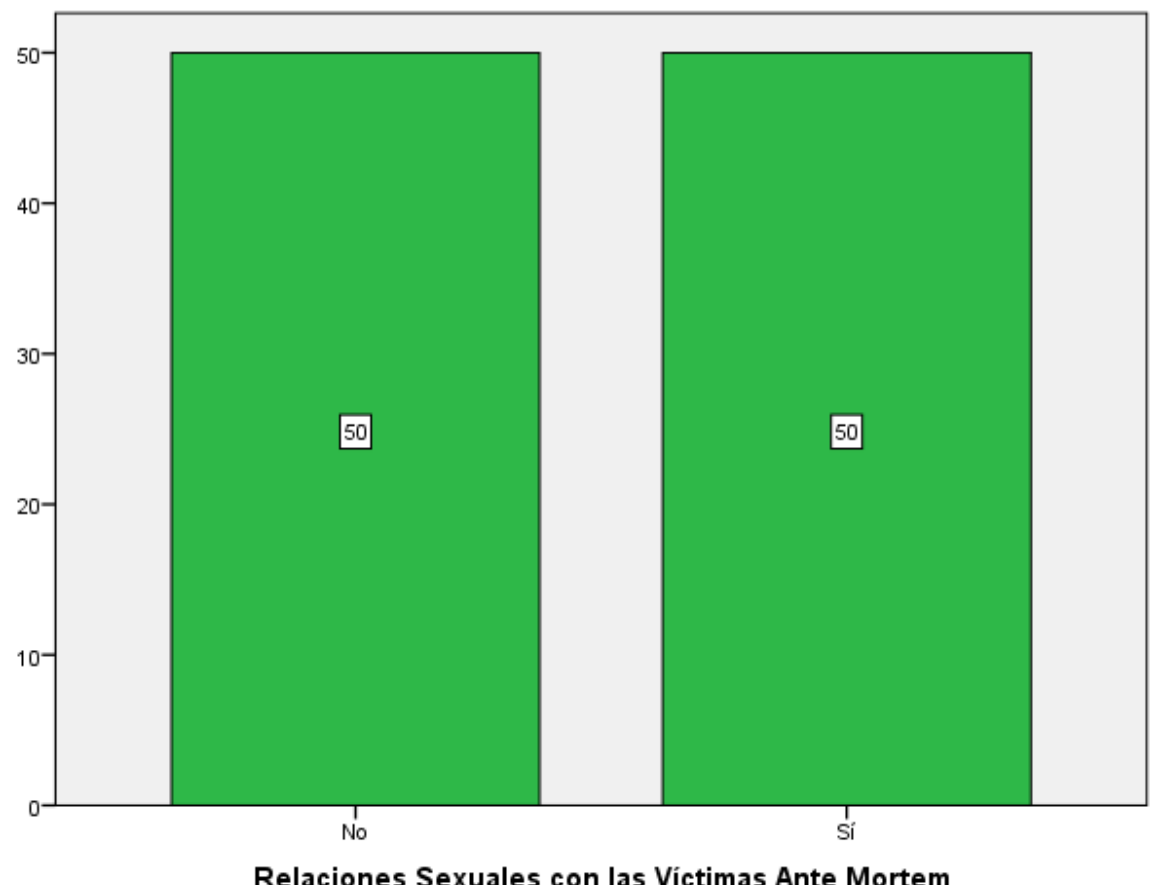

Figura 62. Gráfico de barras de la variable relaciones sexuales con las víctimas ante-mortem de los asesinos en serie.

En relación a la variable haber mantenido relaciones sexuales con las víctimas post-mortem, se ha encontrado que el $78 \%$ (78 casos) de los asesinos en serie que conforman la muestra no han tenido relaciones sexuales con las víctimas post-mortem, y un 22\% (22 casos) sí las han mantenido tal y como se observa en la Tabla 117 y la Figura 63.

Tabla 117. Distribución de frecuencias de la variable relaciones sexuales con las víctimas postmortem en los asesinos en serie.

\begin{tabular}{llrrrr}
\hline & & Frecuencia & Porcentaje & Porcentaje válido & \multicolumn{2}{c}{$\begin{array}{c}\text { Porcentaje } \\
\text { acumulado }\end{array}$} \\
\hline Válido & No & 78 & 78,0 & 78,0 & 78,0 \\
& Sí & 22 & 22,0 & 22,0 & 100,0 \\
& Total & 100 & 100,0 & 100,0 & \\
\hline
\end{tabular}




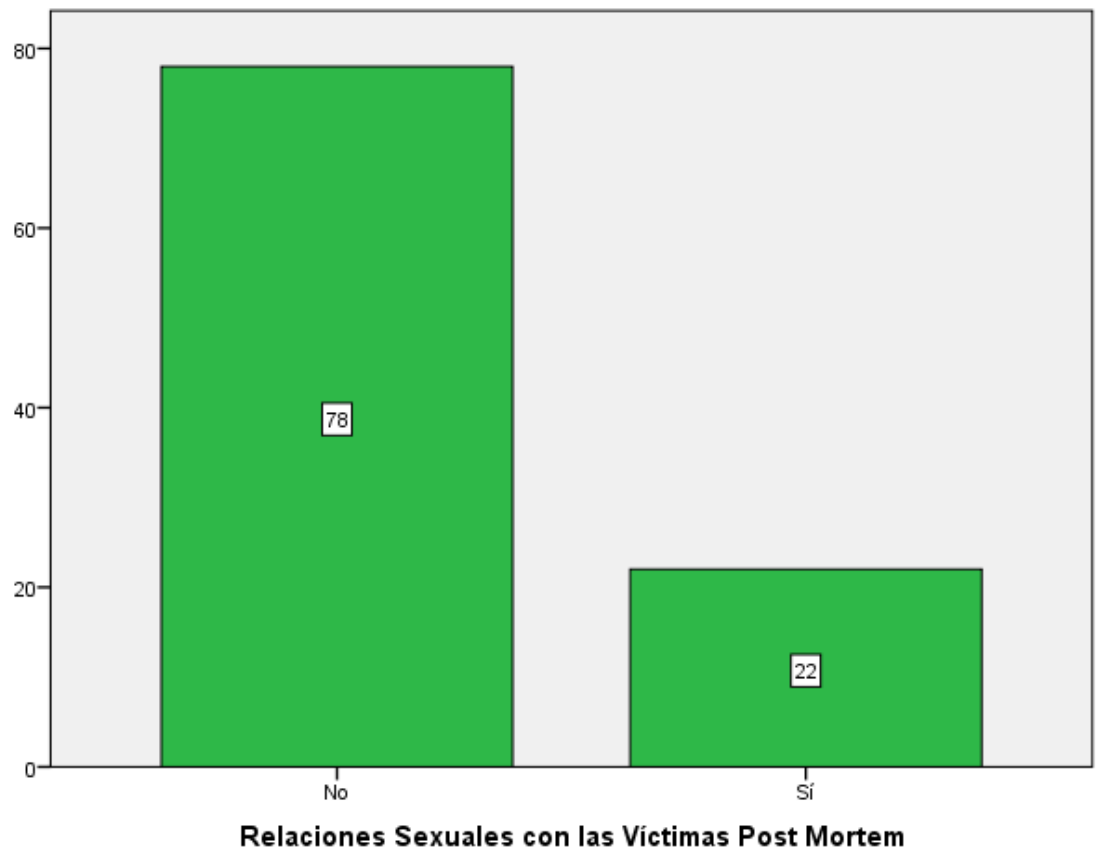

Figura 63. Gráfico de barras de la variable relaciones sexuales con las víctimas post-mortem en los asesinos en serie.

En relación a la dimensión "tipologías", se ha analizado la variable Tipo I (FBI) de los asesinos en serie que conformar el estudio.

En lo referente a la tipología propuesta por el FBI, se ha encontrado que el $49 \%$ (49 casos) de los asesinos en serie incluidos en la muestra son de tipo organizado, un $14 \%$ (14 casos) lo son de tipo desorganizado y un $37 \%$ (37 casos) son de tipo mixto. Se puede observar lo indicado en la Tabla 118 y la Figura 64.

Tabla 118. Distribución de frecuencias de la variable tipo I (FBI) de los asesinos en serie.

\begin{tabular}{llrrrr}
\hline & Frecuencia & Porcentaje & Porcentaje válido & $\begin{array}{c}\text { Porcentaje } \\
\text { acumulado }\end{array}$ \\
\hline Válido & Organizado & 49 & 49,0 & 49,0 & 49,0 \\
& Desorganizado & 14 & 14,0 & 14,0 & 63,0 \\
& Mixto & 37 & 37,0 & 37,0 & 100,0 \\
& Total & 100 & 100,0 & 100,0 & \\
\hline
\end{tabular}




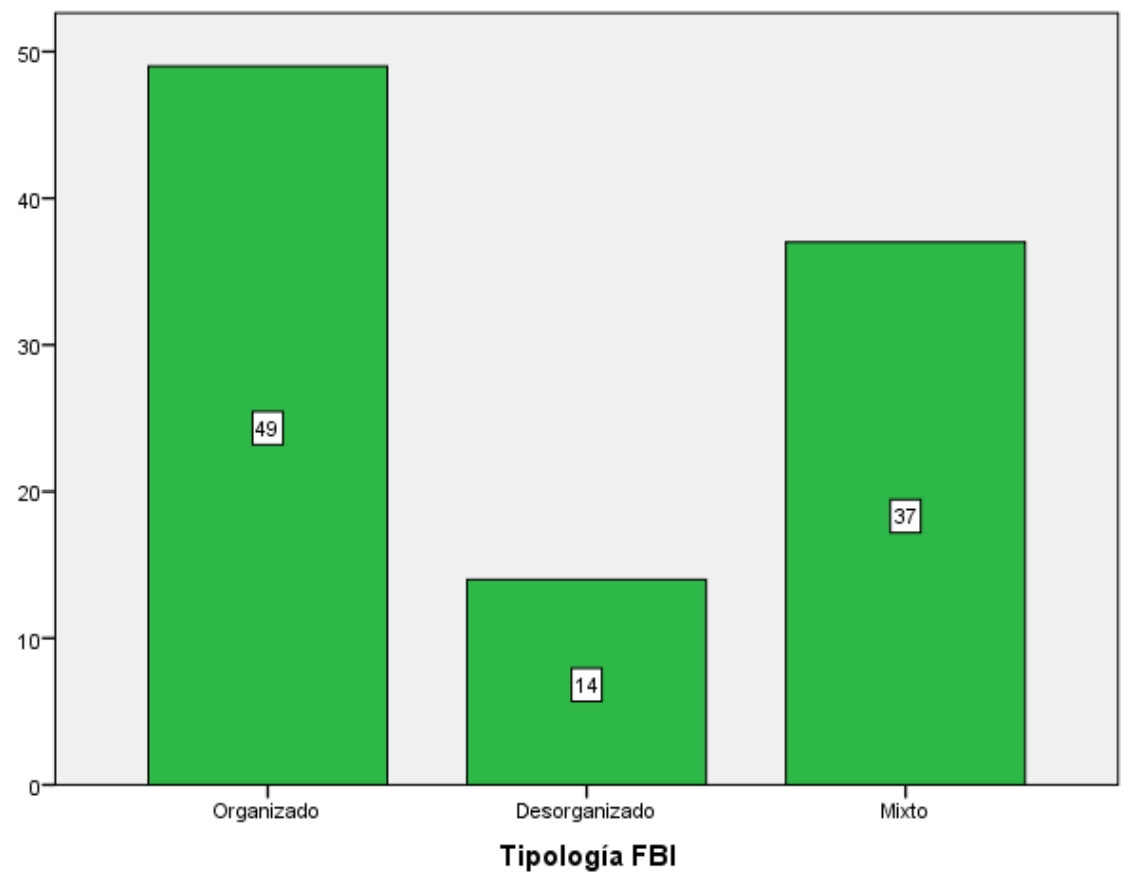

Figura 64. Gráfico de barras de la variable tipo I (FBI) en los asesinos en serie.

\subsubsection{Estudio no paramétrico}

En primer lugar, en la muestra de 100 asesinos seriales incluidos en la muestra de este estudio, 85 fueron hombres, un $4 \%$ (4 casos) de los mismos tuvieron un nivel de planificación nulo, un 24\% (24 casos) lo tuvieron bajo, un 35\% (35 casos) lo tuvieron medio y un 22\% (22 casos) tuvieron un nivel de planificación alto. Del total de la muestra, 15 fueron mujeres, de las cuales un 1\% ( 1 caso) tuvo un nivel de planificación bajo, un 5\% (5 casos) lo tuvo medio y un $9 \%$ (9 casos) tuvo un nivel de planificación alto. Con $\mathrm{p}<, 05$ se observó una correlación estadísticamente significativa $\left(\mathrm{G}^{2}=8,652\right.$; $\mathrm{gl}=3 ; \mathrm{n}=100 ; \mathrm{p}<, 034)$ que apoya la suposición inicial de que sí existe relación entre el nivel de planificación dependiendo y el sexo de los asesinos en serie; siendo el tamaño del efecto moderado $(C=, 273)$. Según el análisis de los residuos tipificados corregidos, se puede indicar que es probable haya una tendencia a que los asesinos en serie que sean hombres tengan un nivel de planificación medio- bajo, mientras que es probable que los asesinos en serie que sean mujeres tengan un nivel de planificación alto. Podemos observar lo indicado en la Tabla 119, 120 y 121 y la Figura 65. 
Tabla 119. Distribución de frecuencias de las variables nivel de planificación y sexo de los asesinos en serie.

\begin{tabular}{llrrrr}
\hline & & \multicolumn{2}{c}{ Sexo } & \multicolumn{2}{c}{} \\
\cline { 3 - 4 } & & & Hombre & Mujer & Total \\
\hline Nivel de Planificación & Nulo & Recuento & 4 & 0 & 4 \\
& & \% del total & $4,0 \%$ & $0,0 \%$ & $4,0 \%$ \\
& Residuo corregido &, 9 &,- 9 & \\
\cline { 2 - 5 } & Bajo & Recuento & 24 & 1 & 25 \\
& \% del total & $24,0 \%$ & $1,0 \%$ & $25,0 \%$ \\
& Residuo corregido & 1,8 & $-1,8$ & \\
\cline { 2 - 5 } & Medio & Recuento & 35 & 5 & 40 \\
& & \% del total & $35,0 \%$ & $5,0 \%$ & $40,0 \%$ \\
& Residuo corregido &, 6 &,- 6 & \\
\cline { 2 - 5 } & Alto & Recuento & 22 & 9 & 31 \\
& & \% del total & $22,0 \%$ & $9,0 \%$ & $31,0 \%$ \\
& Residuo corregido & $-2,6$ & 2,6 & \\
\hline Total & Recuento & 85 & 15 & 100 \\
& & \% del total & $85,0 \%$ & $15,0 \%$ & $100,0 \%$ \\
\hline
\end{tabular}

Tabla 120. Pruebas Chi Cuadrado de las variables nivel de planificación y sexo de los asesinos en serie.

\begin{tabular}{lrrr}
\hline & Valor & gl & \multicolumn{2}{c}{$\begin{array}{c}\text { Significación } \\
\text { asintótica (bilateral) }\end{array}$} \\
\hline Chi-cuadrado de Pearson & $8,062^{\text {a }}$ & 3 &, 045 \\
Razón de verosimilitud & 8,652 & 3 &, 034 \\
Asociación lineal por lineal & 7,433 & 1 &, 006 \\
N de casos válidos & 100 & & \\
\hline
\end{tabular}

Tabla 121. Coeficiente de contingencia de las variables nivel de planificación y sexo de los asesinos en serie.

\begin{tabular}{lccc}
\hline & Valor & \multicolumn{2}{c}{$\begin{array}{c}\text { Significación } \\
\text { aproximada }\end{array}$} \\
\hline Nominal por Nominal & Coeficiente de contingencia &, 273 &, 045 \\
N de casos válidos & 100 & \\
\hline
\end{tabular}




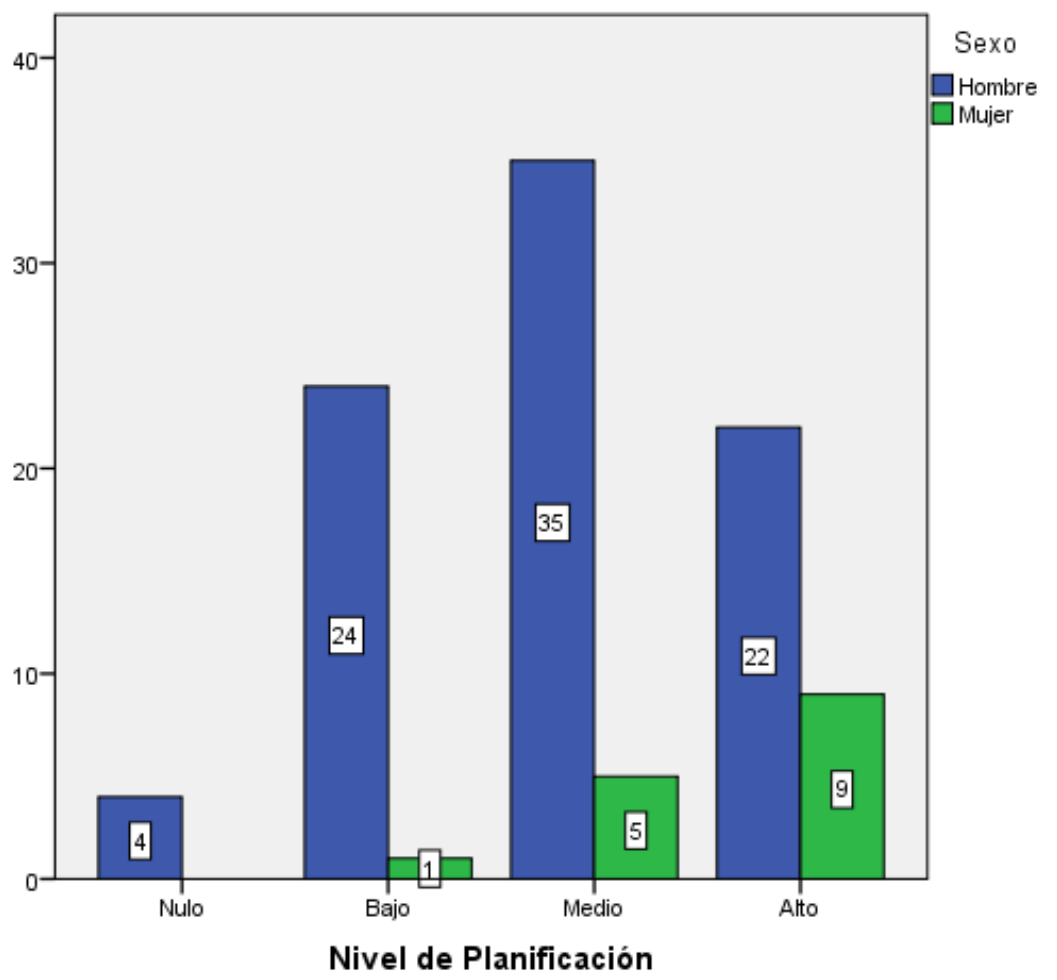

Figura 65. Gráfico de barras agrupadas de las variables nivel de planificación y sexo de los asesinos en serie.

En segundo lugar, en la muestra de 100 asesinos en serie que han sido incluidos en esta investigación, 85 fueron hombres, de los cuales un 37\% (37 casos) no mantuvo relaciones sexuales con las víctimas ante-mortem, frente a un 48\% (48 casos) que sí las mantuvo. De total de la muestra, 15 fueron mujeres, de las cuales un 13\% (13 casos) no mantuvo relaciones sexuales con las víctimas ante-mortem, frente a un 2\% ( 2 casos) que sí las mantuvo. Con $\mathrm{p}<, 05$ se observó una correlación estadísticamente significativa $\left(\chi^{2}=9,490 ; \mathrm{gl}=1 ; \mathrm{n}=100 ; \mathrm{p}<, 002\right)$ que apoya la suposición inicial de que sí existe relación entre mantener relaciones sexuales ante-mortem y el sexo de los asesinos en serie; siendo el tamaño del efecto moderado $(\varphi$ y V=,308). Según el análisis de los residuos tipificados corregidos, se puede indicar que es probable que los asesinos en serie que sean hombres hayan mantenido relaciones sexuales con las víctimas ante-mortem, mientras que es probable que los asesinos en serie que sean mujeres no las hayan mantenido. Se puede observar lo indicado en las Tablas 122, 123 y 124 y la Figura 66. 
Tabla 122. Distribución de frecuencias de las variables relaciones sexuales con las víctimas ante-mortem y el sexo de los asesinos en serie.

\begin{tabular}{|c|c|c|c|c|c|}
\hline & & & \multicolumn{2}{|c|}{ Sexo } & \multirow[b]{2}{*}{ Total } \\
\hline & & & Hombre & Mujer & \\
\hline \multirow{6}{*}{$\begin{array}{l}\text { Relaciones Sexuales con las } \\
\text { Victimas Ante Mortem }\end{array}$} & No & Recuento & 37 & 13 & 50 \\
\hline & & $\%$ del total & $37,0 \%$ & $13,0 \%$ & $50,0 \%$ \\
\hline & & Residuo corregido & $-3,1$ & 3,1 & \\
\hline & Sí & Recuento & 48 & 2 & 50 \\
\hline & & $\%$ del total & $48,0 \%$ & $2,0 \%$ & $50,0 \%$ \\
\hline & & Residuo corregido & 3,1 & $-3,1$ & \\
\hline \multirow[t]{2}{*}{ Total } & & Recuento & 85 & 15 & 100 \\
\hline & & $\%$ del total & $85,0 \%$ & $15,0 \%$ & $100,0 \%$ \\
\hline
\end{tabular}

Tabla 123. Pruebas Chi Cuadrado de las variables relaciones sexuales con las víctimas antemortem y el sexo de los asesinos en serie.

\begin{tabular}{|c|c|c|c|c|c|}
\hline & Valor & $\mathrm{gl}$ & $\begin{array}{c}\text { Significación } \\
\text { asintótica (bilateral) }\end{array}$ & $\begin{array}{c}\text { Significación exacta } \\
\text { (bilateral) }\end{array}$ & $\begin{array}{l}\text { Significación exacta } \\
\text { (unilateral) }\end{array}$ \\
\hline Chi-cuadrado de Pearson & $9,490^{\text {a }}$ & 1 &, 002 & & \\
\hline Corrección de continuidad $^{\mathrm{b}}$ & 7,843 & 1 &, 005 & & \\
\hline Razón de verosimilitud & 10,442 & 1 &, 001 & & \\
\hline Prueba exacta de Fisher & & & &, 004 &, 002 \\
\hline Asociación lineal por lineal & 9,395 & 1 &, 002 & & \\
\hline $\mathrm{N}$ de casos válidos & 100 & & & & \\
\hline
\end{tabular}

Tabla 124. Coeficientes de contingencia de las variables relaciones sexuales con las víctimas ante-mortem y el sexo de los asesinos en serie.

\begin{tabular}{llrr}
\hline & & Valor & $\begin{array}{c}\text { Significación } \\
\text { aproximada }\end{array}$ \\
\hline Nominal por Nominal & Phi &,- 308 &, 002 \\
& $\vee$ de Cramer &, 308 &, 002 \\
N de casos válidos & & 100 & \\
\hline
\end{tabular}




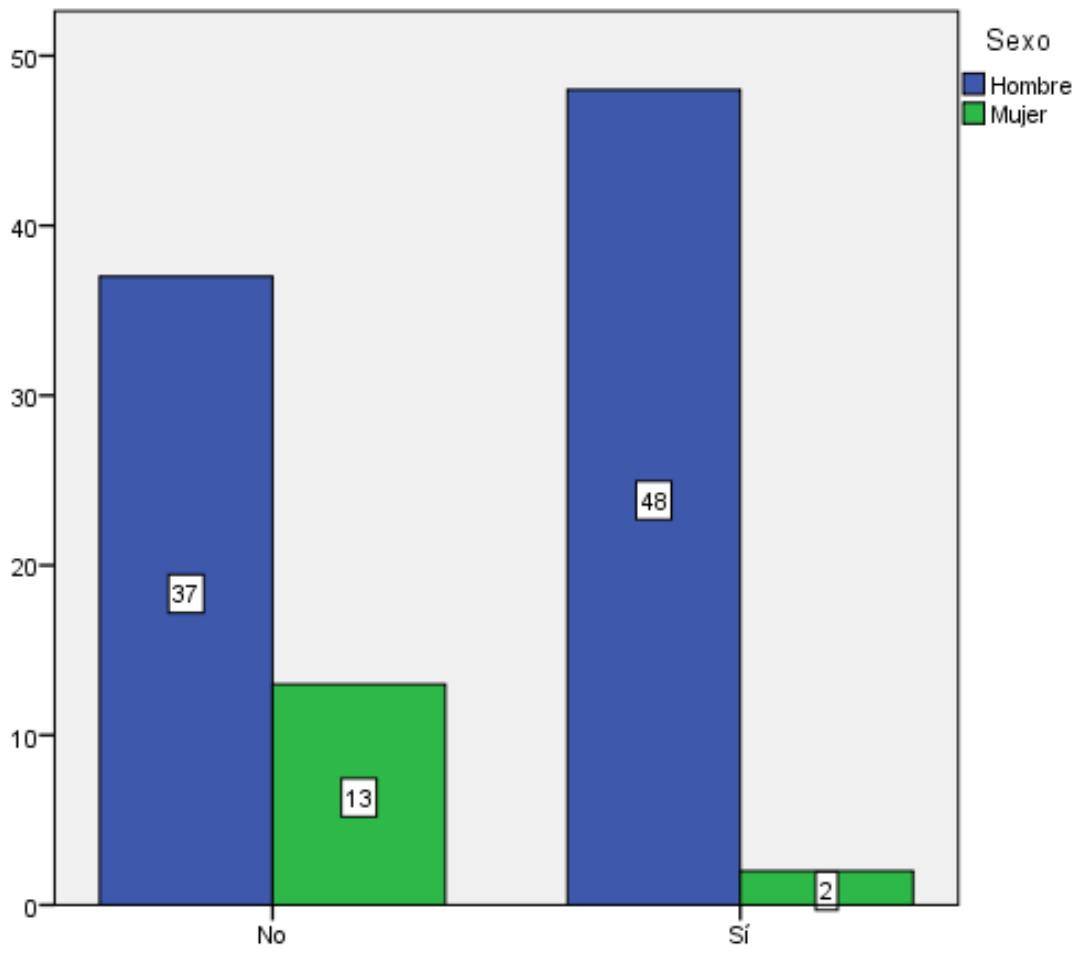

Relaciones Sexuales con las Víctimas Ante Mortem

Figura 66. Gráfico de barras agrupadas de las variables relaciones sexuales con las víctimas ante-mortem y el sexo de los asesinos en serie.

En tercer lugar, en la muestra de 100 asesinos en serie que conforman la muestra de este estudio, 41 proceden de Europa, de los cuales un 30\% (30 casos) no sufrió algún tipo de maltrato en la infancia, frente a un $11 \%$ (11 casos) que sí lo sufrió. Del total de la muestra, 55 proceden de América, de los cuales un 24\% (24 casos) no sufrió algún tipo de maltrato en la infancia, frente a un 31\% (31 casos) que sí lo sufrió. Finalmente, 4 asesinos en serie incluidos en la muestra proceden de Asia, de los cuales un 3\% (3 casos) no sufrió algún tipo de maltrato en la infancia, frente a un 1\% (1 caso) que sí lo sufrió. Con $\mathrm{p}<, 05$ se observó una correlación estadísticamente significativa $\left(\mathrm{G}^{2}=9,124\right.$; $\mathrm{gl}=2 ; \mathrm{n}=100 ; \mathrm{p}<, 010)$ que apoya la suposición inicial de que sí existe relación entre haber sufrido algún tipo de maltrato y el continente de procedencia de los asesinos seriales; siendo el tamaño del efecto moderado $(C=, 286)$. Según el análisis de los resultados tipificados corregidos, se puede indicar que es probable que los asesinos en serie que procedan de Europa no hayan sufrido algún tipo de maltrato en la infancia, mientras que aquellos que procedan de América sí lo hayan sufrido. (Tablas 125, 126 y 127 y Figura 67). 
Tabla 125. Distribución de frecuencias de las variables haber sufrido algún tipo de maltrato en la infancia y el continente de procedencia de los asesinos en serie.

\begin{tabular}{|c|c|c|c|c|c|c|}
\hline & & & \multicolumn{3}{|c|}{ Continente de Procedencia } & \multirow[b]{2}{*}{ Total } \\
\hline & & & Europa & América & Asia & \\
\hline \multirow{6}{*}{$\begin{array}{l}\text { Algún Tipo de Maltrato en la } \\
\text { Infancia }\end{array}$} & $\overline{\text { No }}$ & Recuento & 30 & $\overline{24}$ & 3 & $\overline{57}$ \\
\hline & & $\%$ del total & $30,0 \%$ & $24,0 \%$ & $3,0 \%$ & $57,0 \%$ \\
\hline & & Residuo corregido & 2,7 & $-3,0$ &, 7 & \\
\hline & Sí & Recuento & 11 & 31 & 1 & 43 \\
\hline & & $\%$ del total & $11,0 \%$ & $31,0 \%$ & $1,0 \%$ & $43,0 \%$ \\
\hline & & Residuo corregido & $-2,7$ & 3,0 &,- 7 & \\
\hline \multirow[t]{2}{*}{ Total } & & Recuento & 41 & 55 & 4 & 100 \\
\hline & & $\%$ del total & $41,0 \%$ & $55,0 \%$ & $4,0 \%$ & $100,0 \%$ \\
\hline
\end{tabular}

Tabla 126. Pruebas Chi Cuadrado de las variables haber sufrido algún tipo de maltrato en la infancia y el continente de procedencia de los asesinos en serie.

\begin{tabular}{lcrr}
\hline & Valor & gl & \multicolumn{2}{c}{$\begin{array}{c}\text { Significación } \\
\text { asintótica (bilateral) }\end{array}$} \\
\hline Chi-cuadrado de Pearson & $8,910^{\text {a }}$ & 2 &, 012 \\
Razón de verosimilitud & 9,124 & 2 &, 010 \\
Asociación lineal por lineal & 4,506 & 1 &, 034 \\
N de casos válidos & 100 & & \\
\hline
\end{tabular}

Tabla 127. Coeficiente de contingencia de las variables haber sufrido algún tipo de maltrato en la infancia y el continente de procedencia de los asesinos en serie.

\begin{tabular}{lrrr}
\hline & & Valor & $\begin{array}{c}\text { Significación } \\
\text { aproximada }\end{array}$ \\
\hline Nominal por Nominal & Coeficiente de contingencia &, 286 &, 012 \\
N de casos válidos & 100 & \\
\hline
\end{tabular}




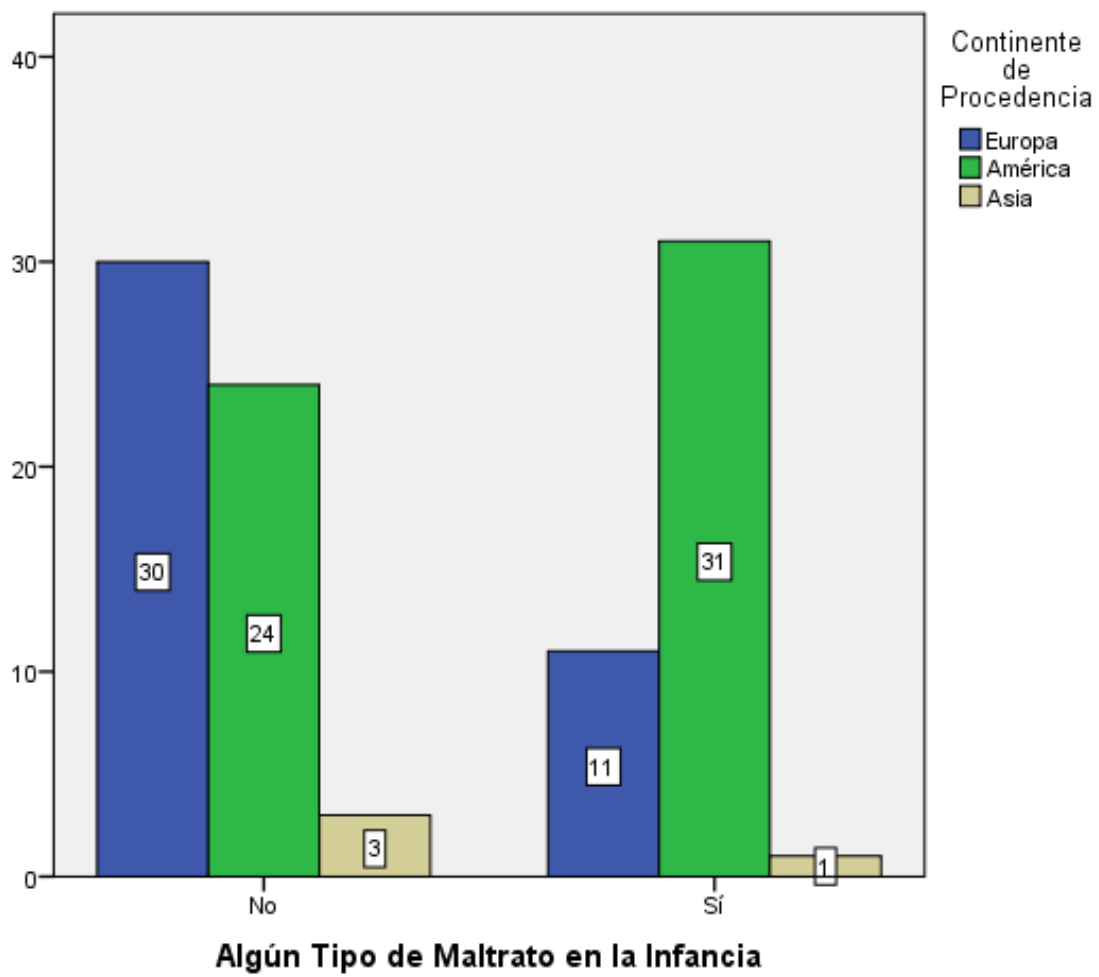

Figura 67. Gráfico de barras agrupadas de las variables haber sufrido algún tipo de maltrato en la infancia y el continente de procedencia de los asesinos en serie.

En cuarto lugar, en la muestra de 100 asesinos en serie incluidos en esta investigación, 57 no sufrieron algún tipo de maltrato en la infancia y un 34\% (34 casos) de ellos no tuvieron relaciones sexuales con las víctimas ante-mortem, frente a un $23 \%$ (23 casos) que sí las tuvieron. Entre los 43 asesinos en serie que sí sufrieron algún tipo de maltrato en la infancia, un 27\% (27 casos) sí mantuvieron relaciones sexuales con las víctimas ante-mortem, frente a un 16\% (16 casos) que no llevaron a cabo esta práctica con sus víctimas. Con $\mathrm{p}<, 05$ se observó una correlación estadísticamente significativa $\left(\chi^{2}=4,937 ; \mathrm{gl}=1 ; \mathrm{n}=100 ; \mathrm{p}<, 026\right)$ que apoya la suposición inicial de que sí existe relación entre mantener relaciones sexuales con las víctimas ante-mortem y haber sufrido algún tipo de maltrato en la infancia; siendo el tamaño del efecto moderado ( $\varphi$ y V=,222). Según el análisis de los residuos tipificados corregidos, se puede indicar que es probable que los asesinos en serie que no hayan sufrido algún tipo de maltrato en la infancia no hayan mantenido relaciones sexuales con las víctimas ante-mortem, mientras que los asesinos seriales que sí lo hayan sufrido sí hayan llevado a cabo este tipo de relaciones con sus víctimas. (Tablas 128, 129 y 130 y Figura 68). 
Tabla 128. Distribución de frecuencias de las variables haber sufrido algún tipo de maltrato en la infancia y mantener relaciones sexuales con las víctimas ante-mortem de los asesinos en serie.

\begin{tabular}{|c|c|c|c|c|c|}
\hline & & & \multicolumn{2}{|c|}{ Algún Tipo de Maltrato en Ia Infancia } & \multirow[b]{2}{*}{ Total } \\
\hline & & & No & Sí & \\
\hline \multirow{6}{*}{$\begin{array}{l}\text { Relaciones Sexuales con las } \\
\text { Victimas Ante Mortem }\end{array}$} & No & Recuento & 34 & 16 & 50 \\
\hline & & $\%$ del total & $34,0 \%$ & $16,0 \%$ & $50,0 \%$ \\
\hline & & Residuo corregido & 2,2 & $-2,2$ & \\
\hline & Sí & Recuento & 23 & 27 & 50 \\
\hline & & $\%$ del total & $23,0 \%$ & $27,0 \%$ & $50,0 \%$ \\
\hline & & Residuo corregido & $-2,2$ & 2,2 & \\
\hline \multirow[t]{2}{*}{ Total } & & Recuento & 57 & 43 & 100 \\
\hline & & $\%$ del total & $57,0 \%$ & $43,0 \%$ & $100,0 \%$ \\
\hline
\end{tabular}

Tabla 129. Pruebas de Chi Cuadrado de las variables haber sufrido algún tipo de maltrato en la infancia y mantener relaciones sexuales con las víctimas ante-mortem de los asesinos en serie.

\begin{tabular}{|c|c|c|c|c|c|}
\hline & Valor & $\mathrm{gl}$ & $\begin{array}{c}\text { Significación } \\
\text { asintótica (bilateral) }\end{array}$ & $\begin{array}{l}\text { Significación exacta } \\
\text { (bilateral) }\end{array}$ & $\begin{array}{c}\text { Significación exacta } \\
\text { (unilateral) }\end{array}$ \\
\hline Chi-cuadrado de Pearson & $4,937^{\text {a }}$ & 1 &, 026 & & \\
\hline Corrección de continuidad ${ }^{\mathrm{b}}$ & 4,080 & 1 &, 043 & & \\
\hline Razón de verosimilitud & 4,982 & 1 &, 026 & & \\
\hline Prueba exacta de Fisher & & & &, 043 &, 021 \\
\hline Asociación lineal por lineal & 4,887 & 1 &, 027 & & \\
\hline $\mathrm{N}$ de casos válidos & 100 & & & & \\
\hline
\end{tabular}

Tabla 130. Coeficientes de contingencia de las variables haber sufrido algún tipo de maltrato en la infancia y mantener relaciones sexuales con las víctimas ante-mortem de los asesinos en serie.

\begin{tabular}{llrr}
\hline & & \multicolumn{2}{c}{$\begin{array}{c}\text { Significación } \\
\text { aproximada }\end{array}$} \\
\hline Nominal por Nominal & Phi &, 222 &, 026 \\
& V de Cramer &, 222 &, 026 \\
N de casos válidos & & 100 & \\
\hline
\end{tabular}




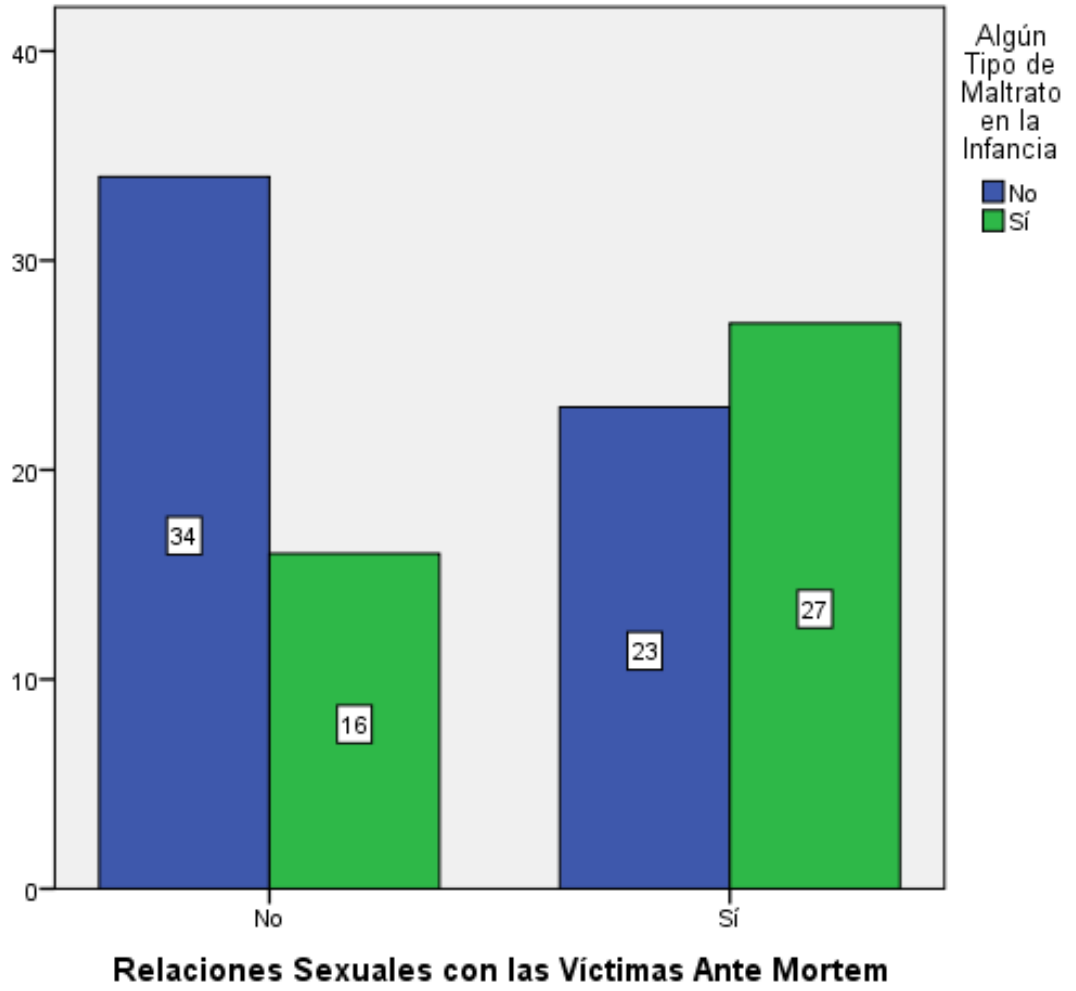

Figura 68. Gráfico de barras agrupadas de las variables haber sufrido algún tipo de maltrato en la infancia y mantener relaciones sexuales con las víctimas ante-mortem de los asesinos en serie.

En último lugar, en la muestra de 100 asesinos en serie que conforman este estudio, 48 son asesinos seriales de tipo organizado, de los cuales un 2\% (2 casos) tienen un nivel de planificación bajo, un 19,2\% (19 casos) lo tienen medio y un 27,3\% (23 casos) lo tienen alto. Entre los 14 asesinos en serie que son de tipo desorganizado, un $4 \%$ ( 4 casos) tienen un nivel de planificación nulo, un 7,1\% (7 casos) lo tienen bajo y un 3\% (3 casos) lo tienen medio. Finalmente, de los 37 asesinos en serie de tipo mixto, un 16,2\% (16 casos) tienen un nivel de planificación bajo, un 17,2\% (17 casos) lo tienen medio y un $4 \%$ (4 casos) lo tienen alto. Con $\mathrm{p}<0,05$ se observó una correlación estadísticamente significativa $\left(\mathrm{G}^{2}=60,101 ; \mathrm{gl}=6 ; \mathrm{n}=100 ; \mathrm{p}<, 000\right)$ que apoya la 
suposición inicial de que sí existe relación entre el nivel de planificación de los asesinos en serie y la clasificación del FBI; siendo el tamaño del efecto elevado $(\mathrm{C}=, 618)$. Según el análisis de los residuos tipificados corregidos, se puede indicar que es probable que los asesinos en serie que sean de tipo organizado hayan tenido un nivel de planificación alto, que los que sean de tipo desorganizado hayan tenido un nivel de planificación nulo o bajo, mientras que los que sean de tipo mixto hayan tenido un nivel de planificación bajo. (Tablas 131, 132 y 133 y Figura 69)

Tabla 131. Distribución de frecuencias de las variables nivel de planificación y tipo I (FBI) de los asesinos en serie.

\begin{tabular}{|c|c|c|c|c|c|c|}
\hline & & & \multicolumn{3}{|c|}{ Tipología FBI } & \multirow[b]{2}{*}{ Total } \\
\hline & & & Organizado & Desorganizado & Mixto & \\
\hline \multirow[t]{12}{*}{ Nivel de Planificación } & Nulo & Recuento & 0 & 4 & 0 & $\overline{4}$ \\
\hline & & $\%$ del total & $0,0 \%$ & $4,0 \%$ & $0,0 \%$ & $4,0 \%$ \\
\hline & & Residuo corregido & $-2,0$ & 5,1 & $-1,6$ & \\
\hline & Bajo & Recuento & 2 & 7 & 16 & 25 \\
\hline & & $\%$ del total & $2,0 \%$ & $7,0 \%$ & $16,0 \%$ & $25,0 \%$ \\
\hline & & Residuo corregido & $-4,7$ & 2,3 & 3,2 & \\
\hline & Medio & Recuento & 20 & 3 & 17 & 40 \\
\hline & & $\%$ del total & $20,0 \%$ & $3,0 \%$ & $17,0 \%$ & $40,0 \%$ \\
\hline & & Residuo corregido &, 2 & $-1,5$ &, 9 & \\
\hline & Alto & Recuento & 27 & 0 & 4 & 31 \\
\hline & & $\%$ del total & $27,0 \%$ & $0,0 \%$ & $4,0 \%$ & $31,0 \%$ \\
\hline & & Residuo corregido & 5,1 & $-2,7$ & $-3,3$ & \\
\hline \multirow[t]{2}{*}{ Total } & & Recuento & 49 & 14 & 37 & 100 \\
\hline & & $\%$ del total & $49,0 \%$ & $14,0 \%$ & $37,0 \%$ & $100,0 \%$ \\
\hline
\end{tabular}

Tabla 132. Pruebas Chi Cuadrado de las variables nivel de planificación y tipo I (FBI) de los asesinos en serie.

\begin{tabular}{lccr}
\hline & Valor & gl & \multicolumn{2}{c}{$\begin{array}{c}\text { Significación } \\
\text { asintótica (bilateral) }\end{array}$} \\
\hline Chi-cuadrado de Pearson & $61,503^{\text {a }}$ & 6 &, 000 \\
Razón de verosimilitud & 60,127 & 6 &, 000 \\
Asociación lineal por lineal & 22,563 & 1 &, 000 \\
N de casos válidos & 100 & & \\
\hline
\end{tabular}

Tabla 133. Coeficiente de contingencia de las variables nivel de planificación y tipo I (FBI) de los asesinos en serie.

\begin{tabular}{lrrr}
\hline & Valor & $\begin{array}{c}\text { Significación } \\
\text { aproximada }\end{array}$ \\
\hline Nominal por Nominal & Coeficiente de contingencia &, 617 &, 000 \\
N de casos válidos & 100 &, \\
\hline
\end{tabular}




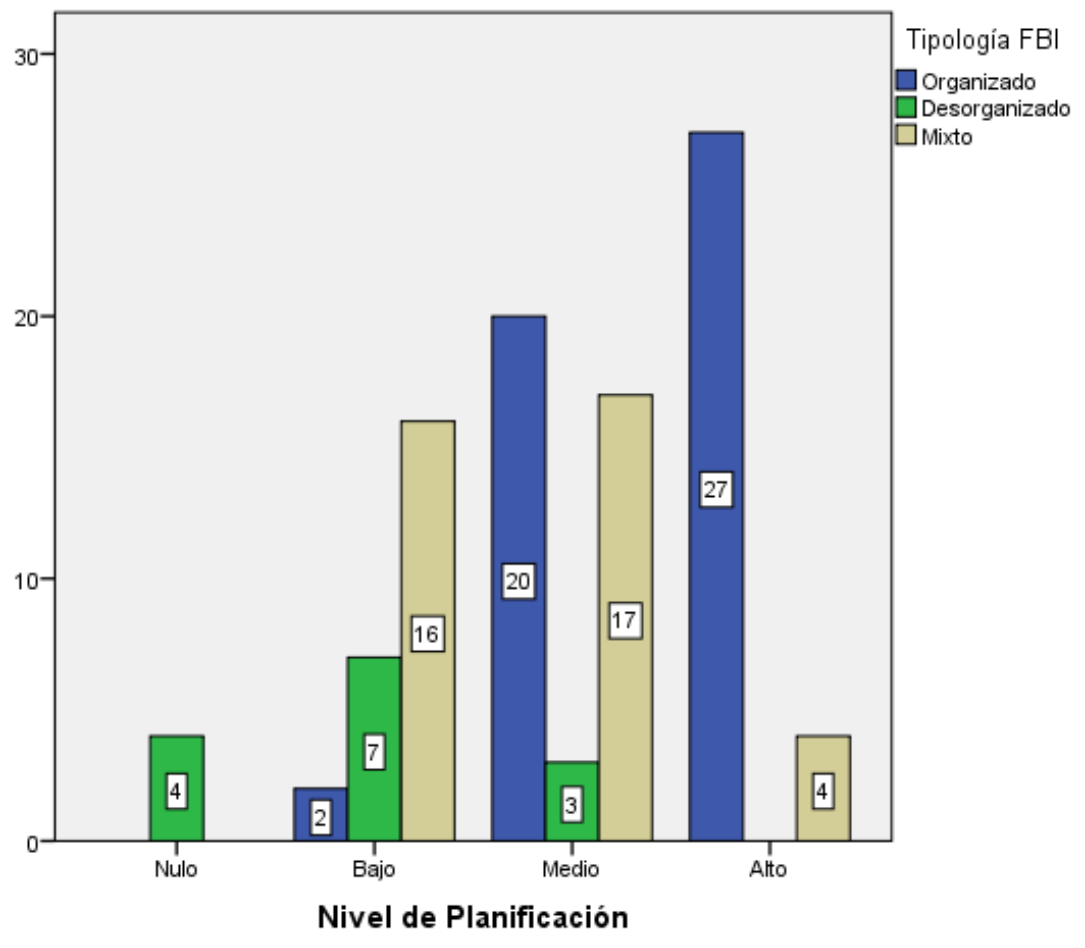

Figura 69. Gráfico de barras agrupadas de las variables nivel de planificación y tipo I (FBI) de los asesinos en serie.

\subsection{CONCLUSIONES}

A lo largo del presente capítulo nos hemos centrado en analizar qué variables influyen en el comportamiento criminal de los asesinos en serie que conforman la muestra internacional, cómo influyen esas variables y conocer las diferencias existentes entre las mismas.

A la luz de los resultados obtenidos en este capítulo, podemos confirmar la primera hipótesis, según la cual existe relación entre las variables nivel de planificación y el sexo de los asesinos en serie que componen la muestra. Se observó que un mayor porcentaje de asesinos en serie varones tienen un nivel de planificación bajo y medio, del mismo modo que se ha observado que un mayor porcentaje de asesinos mujeres lo tienen alto; por lo que es más probable que los asesinos en serie que sean hombres tengan un nivel de planificación medio o bajo, mientras que es probable que los 
asesinos en serie que sean mujeres tengan un nivel de planificación alto. Este resultado apoya las investigaciones de Pérez (2000) en las que afirma que "los hombres matan más, pero las mujeres matan mejor" (citado en Abeijón, 2005, p.98). Además Abeijón (2005), sugiere que el motivo es que las mujeres asesinas en serie son menos violentas y rara vez llevarán a cabo un homicidio de carácter sexual, ya que prefieren utilizar métodos más silenciosos y discretos, lo que apoya también el resultado de la segunda hipótesis.

Podemos confirmar también la segunda hipótesis, según la cual existe relación entre haber mantenido relaciones sexuales con las víctimas ante-mortem y el sexo de los asesinos seriales pertenecientes a la muestra. Se ha observado que un mayor porcentaje de asesinos en serie varones mantienen relaciones sexuales con las víctimas ante-mortem, del mismo modo que se ha observado que un mayor porcentaje de asesinos en serie mujeres no las mantuvieron. Por lo tanto, existirá una tendencia a que los asesinos seriales varones mantengan relaciones sexuales con las víctimas antemortem, así como los asesinos en serie mujeres no las mantengan.

Confirmamos también la tercera hipótesis, según la cual existe relación entre haber sufrido algún tipo de maltrato en la infancia y el continente de procedencia de los asesinos en serie que conforman la muestra. Se ha observado que un mayor porcentaje de asesinos en serie cuyo continente de procedencia es América sí han sufrido algún tipo de maltrato en la infancia, del mismo modo que se ha observado que un mayor porcentaje de asesinos en serie europeos no han sufrido algún tipo de maltrato en la infancia. Por lo tanto, es más probable que los asesinos en serie americanos hayan sufrido algún tipo de maltrato en la infancia; así como los europeos no lo hayan sufrido.

Hemos confirmado la cuarta hipótesis, que plantea una relación entre haber sufrido algún tipo de maltrato en la infancia y haber mantenido relaciones sexuales con las víctimas ante-mortem. Se ha observado que un mayor porcentaje de asesinos en serie que han sufrido algún tipo de maltrato en la infancia, han mantenido relaciones sexuales con las víctimas ante-mortem, del mismo modo que se ha observado un mayor porcentaje de asesinos en serie que no han sufrido algún tipo de maltrato en la infancia, no las han mantenido. Por lo tanto, es probable que los asesinos en serie que hayan sufrido algún tipo de maltrato en la infancia mantengan relaciones sexuales con las 
víctimas ante-mortem, mientras que aquellos que no lo han sufrido no mantengan este tipo de relaciones sexuales con las víctimas. Este resultado corrobora las investigaciones de Antuña et al. (2007), en las que explican que "uno de los principales factores considerados como detonantes de los asesinos en serie, es el hecho de haber padecido una infancia traumática” (Ibíd, 2007, p.33). Además Ressler, Burgess y Douglas (1988) apuntan que tras una infancia fallida, el sujeto crece acompañado de fantasías de control y dominación, sin experimentar empatía por los demás, reduciéndolos a un mero objeto que puede manipular. Igualmente, Norris (1988) describe los ciclos de violencia como generacionales: "los padres que abusan de sus hijos tanto física, como psicológicamente, instalan en ellos instintos de violencia, recurso al cual acudirán en primer lugar para resolver sus retos y problemas personales" (citado en Antuña et al., 2007).

Por último, confirmamos también la quinta hipótesis según la cual existe relación entre el nivel de planificación y la clasificación del FBI (organizado, desorganizado y mixto) de los asesinos seriales pertenecientes a la muestra. Se ha observado que un mayor porcentaje de asesinos en serie de tipo organizado tienen un nivel de planificación alto, del mismo modo se ha observado que un mayor porcentaje de asesinos seriales de tipo desorganizado presentan un nivel de planificación nulo o bajo, y por último los asesinos en serie de tipo mixto tienen un nivel de planificación bajo. Por lo tanto, es probable que los asesinos en serie de tipo organizado presenten un nivel de planificación alto, los de tipo desorganizado lo tengan bajo o nulo y los asesinos seriales de tipo mixto tengan un nivel de planificación bajo. 


\section{DISCUSIÓN Y CONCLUSIONES FINALES}

Como se ha presentado a lo largo del trabajo de investigación, nuestro objetivo ha sido profundizar en el estudio de la psicopatía a través de la comparación entre asesinos en serie nacionales e internacionales. Para ello se ha seleccionado una muestra de asesinos seriales españoles con estadounidense, así como una muestra variada de asesinos en serie internacionales.

Para la selección de las variables que intervienen en el comportamiento criminal de los asesinos en serie se realizó un análisis interjueces con los miembros de la Unidad de Análisis de la Conducta Criminal: UACC de la Universidad de Salamanca. Hemos seleccionado las siguientes variables: nivel intelectual, presencia de psicopatología, haber sufrido algún tipo de maltrato en la infancia, modo de interacción con las víctimas, sadismo empleado en los asesinatos, llevar a cabo mutilación con las víctimas, mantener relaciones sexuales post-mortem, la tipología del FBI a la que pertenecen, el sexo, mantener relaciones sexuales ante-mortem y el nivel de planificación.

Los resultados hallados en esta investigación muestran que el asesinato serial es un fenómeno fundamentalmente americano, corroborando los resultados de las investigaciones de Macía (2011) en los que apunta que tres de cada cuatro asesinatos seriales ocurren en Estados Unidos, pues encontramos que, respecto al número de asesinos seriales y lapso temporal, es decir número de nuevos asesinos por año, es muy elevada en comparación con otros continentes y/o países puesto que, en otras zonas del mundo, pueden tener también una muestra elevada de asesinos seriales pero mucho más dilatada en el tiempo.

Esta comparación de asesinos en serie se ha llevado a cabo en dos fases:

En nuestro primer estudio, donde comparamos una muestra de asesinos en serie que actuaron en EEUU con una muestra de asesinos seriales que actuaron en España, percibimos el fenómeno anteriormente comentado ya que la muestra de asesinos en serie que actuaron en EEUU es ingente mientras que la de asesinos seriales que actuaron en nuestro país es, por suerte, bastante más pequeña (120 vs. 24).

Además, encontramos que en EEUU los asesinos en serie generan cierta admiración debido a las numerosas series y películas existentes basadas en casos de 
asesinos reales. Esta admiración queda patente en el fenómeno Copy Cat o Efecto Werther (Philips, 1974) o Imitación Criminal, en el que los observadores intentan imitar el modus operandi del crimen y del asesino al que admiran. En cambio, en España, las películas o series basadas en asesinos no han sido comercializadas o son escasas por lo que nos lleva a pensar que los medios de comunicación y el Sistema Penal español presentan un mayor respeto por las víctimas al no proporcionar tanto protagonismo al asesino. Este hecho es observable en la fase de recogida de datos donde la información de los asesinos en serie cuya zona de actuación fue América del Norte nos resultó de muy fácil acceso porque existe numerosa información al respecto (bibliografía, congresos, publicaciones no científicas, series y películas...), al contrario de la muestra de asesinos seriales que actuaron en el territorio español, para la que tuvimos que recurrir a expedientes facilitados por las Fuerzas de Seguridad del Estado y a profesionales expertos en esta materia.

En relación a la interacción verbal con las víctimas, encontramos que los asesinos seriales que actuaron en EEUU -en comparación con los asesinos en serie que actuaron en España- es probable que sean más agresivos al interactuar con las víctimas verbalmente y más sangrientos y sádicos a la hora de llevar a cabo el crimen. Este hecho se asocia a las infancias traumáticas sufridas por estos sujetos (abusos y maltrato...) y/o no tenían un ambiente familiar contenedor y funcional, que en el caso de nuestro estudio, los sujetos que llevaron a cabo sus crímenes en territorio estadounidense habían sufrido mayor maltrato en la infancia que los sujetos que llevaron a cabo sus asesinatos en España. Este resultado corrobora las teorías que afirman que una infancia y un ambiente familiar disfuncional puede ser un factor predisponente a la hora de desarrollar psicopatía. (Gil, 1994; Dor, 1996; Abeijón, 2005; Ressler, 2010).

Así, y siguiendo con las diferencias halladas entre las muestras de asesinos que actuaron en EEUU en comparación con los que actuaron en España, encontramos que los sujetos que llevaron a cabo sus crímenes en EEUU presentan mayor nivel de psicopatología manifiesta que los que actuaron en España, es decir, tenían peor salud mental. El porqué de este hecho puede ir unido a la explicación que aportan las teorías anteriormente expuestas respecto a la infancia disfuncional (Ressler, 2010), al estilo de vida (Leyton, 1985), acceso a las armas... y predisposición a desarrollar una patología mental como mecanismo de defensa ante la cruda realidad que sufrieron años atrás (Dor, 1987). Este mayor nivel de gravedad en la psicopatología del asesino en serie, 
lleva a explicar las conductas más aberrantes y bizarras en el hecho criminal como la mutilación y las relaciones sexuales post-mortem. Este comportamiento es más frecuente en los asesinos seriales que perpetraron sus crímenes en EEUU que los que actuaron en España pues son muy difíciles de encontrar. Por todo ello, podríamos pensar si la atención a la salud mental -de carácter privado y no accesible para todos- y el sistema educativo estadounidense son suficientemente adecuados.

En este sentido, los resultados reflejan que los asesinos seriales cuya zona de actuación fue EEUU pertenecen a la tipología propuesta por el FBI de tipo mixto, mientras que los que tuvieron como zona de actuación España son de tipo organizado. Este hecho, también está relacionado con el mayor índice de psicopatología e infancia traumática, lo que hace que a la hora de planificar y llevar a cabo sus crímenes sean menos organizados que los que actuaron en España con menos problemas psicológicos. No obstante, el nivel intelectual -mayor en los asesinos seriales que actuaron en EEUU no explica el tipo mixto u organizado del criminal.

Respecto al segundo estudio aplicado a la muestra de asesinos en serie internacional y general encontramos que:

Las mujeres planifican más los crímenes que los hombres reafirmando el estudio de Abeijón (2005) quien expone que el paso al acto de asesinar de las mujeres homicidas seriales se hace distinto al de los hombres, ya que rara vez actuarán de forma impulsiva, fantaseando sobre la víctima y la forma en que llevarán a cabo el asesinato hasta que la perciben de forma perfecta en su mente.

Los hombres llevan a cabo mayor número de relaciones sexuales ante-mortem con las víctimas en comparación con las mujeres, ya que los crímenes perpetrados por éstas, rara vez contienen un carácter sexual, ya que las mujeres asesinas seriales corroborando el trabajo de López (2005) quien afirma que pretenden causar dolor de manera paulatina y silenciosa, haciéndose de esta manera su captura, mucho más difícil.

Respecto al maltrato en la infancia -en comparación con el resto de continentesnuestro segundo estudio reafirma que los americanos son quienes más han sufrido algún tipo de maltrato en la infancia $y$, como secuela criminal de este maltrato, tener relaciones sexuales ante-mortem con las víctimas. Es decir, es un ciclo que se repite: el maltrato en la infancia se repite en la adultez como forma de venganza como compulsión a la repetición freudiana (Freud, 1920) apoyando los resultados de nuestra 
investigación respecto al papel primordial de la infancia y ambiente familiar de crianza del niño.

En relación a los resultados referidos al nivel de planificación de los asesinos seriales de la muestra internacional, observamos que los asesinos de tipo organizado según la tipología propuesta por el FBI tienen, obviamente, un mayor nivel de planificación del crimen. Estos sujetos suelen ser meticulosos y hasta obsesivos en los detalles de sus asesinatos, emplean tiempo en prepararlos para que salga tal y como habían planeado en la fantasía, para ello deben utilizar un elevado nivel de planificación.

De lo anteriormente presentado en este capítulo de conclusiones, se puede inferir que el concepto de psicopatía es un "cajón de sastre", ya que encontramos múltiples autores que describen las características de la psicopatía (Cleckley, 1976; Gray y Hutchinson, 1964; Hare, 1978,1984, 1991,1992, 2003) pero todavía no contamos con un marco teórico sólido explicativo de la misma. También observamos que existen diferentes corrientes explicativas -biológica, social y psicológica- que intentan aclarar este fenómeno y que, al hacerlo, lo analizan de forma parcelada sin presentarlo de manera consistente.

En esta misma línea, observamos una dispersión en el diagnóstico de psicopatía, debido a las discrepancias de los criterios clínicos o los criterios forenses, es decir, desde la clínica nos resulta muy difícil aseverar que estos sujetos no tienen algún tipo de psicopatología. La afirmación de ausencia de trastorno mental o psicopatía en una persona que asesina a sus víctimas, las mutila y después ingiere miembros de la misma no es indicativa de salud mental funcional; sin embargo, desde los criterios forenses se condenan a estas personas por entender la ausencia de psicopatología. Por tanto, es necesario unificar los criterios diagnósticos para evitar confusiones.

A la luz de lo expuesto en estas páginas consideramos que esta Tesis Doctoral constituye una aportación novedosa dada la escasez de investigaciones sobre los asesinos seriales en diferentes ámbitos geográficos. Tampoco contamos con numerosos estudios de asesinos seriales españoles que, aunque se asientan en una pequeña muestra, no son menos relevante. En este sentido esta tesis es pionera en el estudio comparativo de los aspectos del comportamiento criminal entre asesinos seriales españoles e internacionales. 


\section{PROSPECTIVA}

Antes de finalizar, deseamos aludir a varias cuestiones que quedan sin responder en la presente investigación y que requerirán ser solventadas en futuros esfuerzos investigadores. Así creemos conveniente seguir investigando como señalamos anteriormente, de manera predictiva para poder dar una explicación consistente a la psicopatía.

Por otro lado, hemos podido observar a través de los resultados, como el fenómeno del asesinato serial es fundamentalmente americano tal y como reseñamos, por lo que se hace necesario investigar las características antropológicas y sociológicas de dicha población, qué es lo que puede ocurrir para que cometan los crímenes más macabros y que hace que la muestra de asesinos seriales sea tan elevada, además del matiz cinematográfico y novelesco que le dan al fenómeno del asesinato serial.

En esta misma línea, y desde los resultados obtenidos en la presente investigación, se hace necesario profundizar en la etapa de los 30 años, ya que es la media de edad que presenta la muestra manejada tanto en el estudio comparativo como en el internacional. Consideramos de importancia investigar a fondo la etapa propuesta por Erickson (2000), de la edad adulta "Generatividad vs. Estancamiento", ya que durante la edad adulta media, que comprende desde los 25 hasta los 60 años aproximadamente, establecemos nuestras carreras, una relación, comenzamos nuestras propias familias y desarrollamos una sensación de ser parte de algo más amplio. De manera que el hecho de no alcanzar satisfactoriamente la etapa de generatividad da lugar a un empobrecimiento personal y a un resentimiento de exclusión social. El individuo puede sentir de forma agresiva que la vida es monótona y vacía, que simplemente transcurre el tiempo y envejece sin cumplir sus expectativas. De manera que resultaría interesante profundizar en la relación entre aburrimiento, monotonía, ciclo vital, fantasías agresivas y el paso al acto de los asesinos seriales. Al mismo tiempo que revisar ciertos aspectos evolutivos, debido a que la infancia se acorta, la adolescencia se alarga, hay poco tiempo para la adultez y la vejez también se alarga, cuestión que rompe los cánones psicoevolutivos clásicos.

Igualmente, a raíz de los resultados observados en la relación existente entre el nivel intelectual de los asesinos seriales y la tipología propuesta por el FBI, 
consideramos necesario profundizar en el estudio de la misma, puesto que los resultados obtenidos muestran un hecho paradójico, es decir, se esperaba observar que los asesinos en serie organizados tuvieran un nivel intelectual mayor, sin embargo, los resultados muestran que los asesinos seriales que actuaron en EEUU, que presentan un nivel intelectual más alto que los que actuaron en España, presentan un nivel de organización menor.

Asimismo, las explicaciones descriptivas existentes hasta ahora se han hecho ex post facto, es decir, una vez ha sucedido el hecho, en el caso que nos ocupa, el crimen, por lo que también resulta conveniente investigar en la predicción, de ahí la importancia que tiene la técnica del Perfil Criminológico

En definitiva, el asesinato serial ofrece un campo novedoso de investigación de gran relevancia y atractivo. Esperamos que la presente Tesis Doctoral suponga también una vía para animar a futuros investigadores a embarcarse en el análisis de esta apasionante temática. 


\section{REFERENCIAS BIBLIOGRÁFICAS}

Abeijón, P. (2005). Asesinos en serie. Madrid: Arcopress.

Abeijón, P. (2006). Perfilación criminal. Revisado en Octubre, 17, 2015 de manuelcarballal.blogspot.com/20006/2/ la-perfilacion-criminal.html.

Abellán Pérez, F. (2010) Crimen y criminales Vol. I y II Nowtilus, Madrid.

Abraham, K. (1925). Character-formation on the genital level of the libido. In Selected papers on psychoanalysis. London: Hogarth.

Abrahamsen, D. (1976). La mente asesina. Fondo de Cultura Económica: México.

Abrahamsen, D. (1985) Confession of son of Sam Columbia, University Press, New York.

Adler, F., Adler, H.M., y Levis, H. (1975). Sisters in crime: The rise of the new female criminal. New York: McGraw-Hill.

Agnew, R. (1992). Foundation for a General Strain Theory. Criminology, 30, 47-87.

Agnew, R. y Brezina, T. (1997). Relational Problems with Peers, Gender and Delinquency. Youth Society, 29, 84-111.

Aichhorn, A. (1935). Wayward youth. New York: Viking.

Akers, R.L. (1997). Criminological theories. Los Ángeles: Roxbury Publishing Company.

Alcaraz,J. (2010). Perfil criminológico. Breves aspectos científicos y metodológicos. Recuperado el 16 de Octubre de 2015 en www.seipc.eu/app/downland/5775657392/JFAA1.pdf.

Alcázar-Córcoles, M. A., Bouso-Saiz, J. C., Verdejo-García, A. (2008). La neuropsicología forense ante el reto de la relación entre la cognición y la emoción en psicopatía. Revista Neurología, 47, 607-612. 
Alcázar-Córcoles, M. A., Verdejo-García, A., Bouso-Saiz, J. C., Bezos-Saldaña, L. (2010). Neuropsicología de la agresión impulsiva. Revista Neurología, 50, 291-299.

Alexander, F. (1923). Psychoanalysis of the total personality. New York: Nervous and Mental Disease Publications.

Alexander, F. (1930). The neurotic carácter. International Journal of Psychoanalysis, 11, 292-313.

Alexander, F. (1935). Roots of crime. New York: Knopf.

Alexander, F. y Staub, H. (1935). El delincuente y sus jueces desde el punto de vista psicoanalítico. Madrid: Biblioteca Nueva.

Aliseda, Atocha. (1998) La abducción como cambio epistémico: C. S. Peirce y las teorías epistémicas en inteligencia artificial. Analogía, 12, 125-144.

American Psychiatric Association (2013). DSM-5. Diagnostic and statistical manual of mental disorders ( $5^{\circ}$ Edition). Washington, D.C: Author.

Anderson, S., Bechara, A., Damasio, H., Tranel, D., Damasio, A. (1999). Impairment of social and moral behavior related to early damage in human prefrontal cortex. Nat Neurosci, 2, 1032-6.

Andrews, D.A. y Bonta, J. (1994). The psychology of criminal conduct. Cincinnati: Anderson Publishing Co.

Antuña, M.A. y Rodríguez-Franco, L. (2007). Psicópatas y asesinos en serie. Estudios penales y criminológicos, (27), 7-37.

Aristóteles (2004). Organum. Primeros analíticos. México: Porruá.

Arnett, J. (1997). Conceptions of the transition to adulthood among emerging adults in American ethnic groups. Human Development, 15, 213-240.

Arnold, T. (1806). Observation on the Nature, Kinds, Causes and Prevention of Insanity, Lunacy or Madness. Leicester, England: G. Ireland.

Aulagnier, P., Daumezon, G., Clavreul, J., et al. (2000). La perversión. Barcelona: Azul. 
Babiak, P. (1995) When psychopaths go to work. International Journal of Applied Psychology 44, 171-188.

Bandrés, J., Llavona, R. y Campos, J. (1996). Luis Simarro. En M.Sáiz y D. Sáiz, Personajes para una historia de la Psicología en España, (p.185-199). Madrid: Pirámide.

Bandura, A. (1982). Teoría del aprendizaje social. Madrid: Espasa Calpe.

Barkataki, I., Kumari. V., Das, M., Taylor, P., y Sharma, T. (2006). Volumetric structural brain abnormalities in men with schizophrenia or antisocial personality disorder. Behavioural Brain Research, 169, 239-247.

Bartol, R. C. y Bartol, A.M. (1999). Historia de la Psicología Forense. En Alley, K.; Hess y Weiner, I.B. (eds). The handbook of forensic psychology, Nueva York, Wiley and Sons, pp.3-47.

Bench, C. J., Frith, C. D., Grasby, P. M., Friston, K. J. (1993). Investigations of the functional anatomy of attention using the Stroop test. Neuropsychologia, 31, 90722.

Benjamin, L.S. (1974). Structural analysis of social behavior. Psychological Review, $81,392-425$.

Benson, D. (1993). Prefrontal abilities. Behav Neurol, 6, 75-81.

Berrios, G. (2008). Historia de los sintomas de los trastornos mentales: la psicopatología descriptiva del siglo XIX. México: Fondo de Cultura Económica.

Binet, A. (1900). La suggestibilité, París, Scheleicher.

Birbaumer, N., Veit, R., Lotze, M., Erb, M., Hermann, C., Grodd, W. y Flor, H. (2005). Deficient fear conditioning in psychopathy: A functional magnetic resonance imaging study. Archives of General Psychiatry, 62, 799-805.

Bismarck, P (2002) Emoción, cognición y relaciones interpersonales en la psicopatía primaria de Likken Universidad Católica Boliviana Vol. 1 año 1, pp.

Blackburn, R. (1975). An empirical classification of Psychopathic personality. British Journal of Psychiatry, 127, 456-460. 
Blackburn, R. (1979). Psychopathy and personality: The dimensionality of self report and behavioour rating data in abnormal ofender. British Journal of Social and Clinical Psychology, 18, 111-119.

Blackburn, R. (1986). Patterns of personality deviation among violent offenders. The British Journal of Criminology, 26, 254-269.

Blackburn, R. (1987). Two scales for assessment of personality disorder in antisocial populations. Personality and individual Differences, 8, 81-93.

Blackburn, R. (1992). Conceptions of psychopathy and personality disorder: The Origins of Confusion. En L.Klose (Ed), Proceeding of the Forth Symposium of Violence and Agression (pp.53-67). Saskatoon: University of Saskatchenwan and Regional Psychiatric Centre.

Blackburn, R. (1992). Criminal behavior, personality disorder and mental illnes: The origins of confusión. Criminal Behavior and Mental Health, 2, 66-77.

Blackburn, R. (1993). Psychopathic disorder, personality disorder and agression. En C. Thomson y P. Power (Eds), Violence, Basic and Clinical Science. Oxford: Butherworth-Heinemann.

Blackburn, R. (1996) Replicated personality disorder clusters among mentally disordered offenders and their relation to dimensions of personality. Journal of Personality Disorders, 10, 68-81.

Blair, R. (2004). The roles of orbital frontal cortex in the modulation of antisocial behavior. Brain and Cognition, 55, 198-208.

Blair, R. (2010). Neuroimaging of Psychopathy and Antisocial Behavior: A Targeted Review. Current Psychyatry Reports, 12, 76-82.

Boll, T. J. (1981). Assessment of neuropshychological disorders. Nueva York: Guilford Press.

Borrás Roca, L. (2002) Asesinos en serie españoles. Barcelona: Bosch

Brickner, R. M. (1936). The intelectual functions of the frontal-lobes: study based upon observation of a man after partial bilateral frontal-lobectomy. Nueva York: MacMillan. 
Brussel, J. (1968). Caebook of a crime psychiatrist. Nueva York: Dell Publishing.

Bundy, A. (1990) Catalogue of Artificial Intelligence Techniques. New York : Springer-Verlag.

Burgess, A., y Holmstrom, L. (1979). Rapist's talk: Linguistic strategies to control the victim. Deviant Behavior, vol.1. Washington: Hemisphere.

Burón, J. Psicología Médico-Forense: la investigación del delito. Desclée de Brouwe: Bilbao.

Bursten, B. (1972). The manipulative personality. Archives of Genaeral Psychiatry, 26, 318-321.

Buss, A.H. (1966). Psychopatology. New York: Willey.

Canter y Fritzon, K. (1998), "Diferenctiating arsonist: a model of firesetting and characteristics". Legal and Criminological Psychology, 3, 73-96.

Canter, D. (1993). Criminal Shadows. The Inner Narratives of Evil. Londres: Authorlink Press.

Canter, D. (2000). Criminal Shadows. Londres: HarperCollins.

Canter, D. (2003). Maping Murder. The secrets of geographical profiling. London: Virgin Books.

Canter, D. y Alison, L. (2000). Profiling Poperty Crimes. En D. Canter y L. Alison (eds), Profiling Poperty Crimes. Aldershot: Ashgate Publishing.

Canter, D., Alison, L., Alison, E. y Wentink, N. (2004). The Organized and Desorganized Typology of Serial Murder: Myth or Model? Psychology, Public Policy and Law, 10 (3): 293-320.

Caparrós, N. La construcción de la personalidad: las psicopatías. Madrid: Editorial Fundamentos.

Carpintero, H. (2006). Breve Historia de la Psicología Jurídica. En Garrido, E.; Massip, J. y Herrero, M.C. (eds). Psicología Jurídica, Madrid, Pearson/Prentice Hall, pp. 43-75. 
Carpintero, H. y Rechea, C. (1995). La Psicología Jurídica en España: su evolución. En M. Clemente, Fundamentos de Psicología Jurídica. Madrid: Pirámide.

Castaño, D. y Londoño, P. (2012). De la diferencia en los mecanismos estructurales de la neurosis, la psicosis y la perversión. Revista de Psicología GEPU, 3 (1), 127 147.

Cebrián, J. (2007). Psicokillers. Madrid:Nowtilus.

Cima, M., y Raine, A. (2009). Distinct characteristics of psychopathy relate to different subtypes of aggression. Personality and Individual Differences, 47 (8), 835-840.

Cima, M., y Raine, A. (2009). Distinct characteristics of psychopathy relate to different subtypes of aggression. Personality and Individual Differences, 47 (8), 835-840.

Cleckley, H. M. (1976). The mask of sanity: an attempt to clarify the so-called psychopathic personality, 5 ed. St. Louis: Mosby.

Clemente, M. y Espinosa, P. (2001). La mente criminal: teorías explicativas del delito desde la Psicología Jurídica. Madrid: Dykinson.

Cohen, D. (1955). Delinquent boys: The culture of the Gang. New York: The Free Press.

Cohen, L.E. y Felson, M. (1979). Social change and Crime rate Trends: A routine activities approach. American Sociological Review 44, pp.588-608.

Congreso $12^{\circ}$ de las Naciones Unidas sobre Prevención del Delito y Justicia Penal. Brasil, Salvador: 12-19 abril de 2010.

Cooke, D.J., y Michie, C. (2001) Refining the construct of psychopatly: Towards a hierar chical mode. Psychological Assessment, 13, 171-188.

Craft, M. (1965). The Studies into Psychopatic Personality. Briston: John Wright.

Cronwell, P. (2002). Retrato de un asesino: Jack el destripador, caso cerrado. Madrid: Brosmac.

Crown, S. (1952). An experimental study of psychological changes following prefrontal lobotomy. J Gen Psychol, 47, 3-41. 
Cullen, T. (1993). Otoño de terror. Barcelona: Ultramar.

Damasio, A. R. (1994). Descartes' Error: Emotion, Reason and the Human Brain. Nueva York: Putnam.

De Santiago Herrero, F-J (2007) Los casos clínicos de Freud, Amarú, Salamanca De Santiago Herrero, F-J. de la Fuente Torre, M y Muriel Salas, R. (2014) Construcción y validación del cuestionario de psicopatía latente relacionado con los factores implicados en el pensamiento criminal en una muestra de estudiantes universitarios En Actas del X Congreso Español de Criminologia, Granada

De Santiago Herrero, F-J y Gil Sánchez, L.M. (2016) Diccionario del perfiles criminales (En prensa).

De Santiago Herrero, F-J. (2005) Evaluación de las funciones del yo en población reclusa y no reclusa mediante el método EFY de L. Bellak Tesis Doctoral, Universidad Pontificia de Salamanca.

De Santiago Herrero, F-J. (2008) Aportaciones psicoanalíticas a las ciencias jurídicas En Revista de Psicoanálisis, Psicoterapia y Salud Mental Vol. 1 no 3. http://psi.usal.es/rppsm/pdfn3edicionespecial/PSICOANALISIS\%20APLICADO\%20Y\%20 PSICOLOGIA\%20JURIDICA.doc\%20.pdf

De Waelhens, A. (1985). La psicosis. Madrid, España: Morata.

Decety, J., Michalska, K. J., Akitsuki, Y., y Lahey, B. B. (2009). Atypical empathic responses in adolescents with aggressive conduct disorder: A functional MRI investigation. Biological Psychology, 80, 203-2011.

Díaz Galván, K. X., Ostrosky Shejet, F., Romero Rebollar, C., Pérez López, M. L. (2013). Desempeño neuropsicológico orbitomedial en psicópatas. Revista Neuropsicología, Neuropsiquiatría y Neurociencias, 13, 43-58.

Dietz, D.E. (1986). Mass, serial and sensational homicides. Bulletin of the New York Academic of Medicine, 62, 5, 477-491.

Dinn, W. y Harris, C. (2000). Neurocognitive function in antisocial personality disorder. Psychiatry Research, 97, 173-190.

Dor, J. (1984). Introducción a la lectura de Lacan. Barcelona, España: Editorial Gedisa, S.A. 
Dor, J. (1995). Estructura y perversiones. Barcelona, España: Editorial Gedisa, S.A.

Dor, J. (1996). Clínica psicoanalítica: enseñanza conducción de la cura, estudios clínicos. Barcelona, España: Editorial Gedisa, S.A.

Douglas, J., Ressler, R., Burgess, A. y Hartman, C. (1986). Criminal Profiling From Crime Scene Analysis. Behavioral Sciences and the Law, 4 (4): 401-421.

Douglas, J., y Olshaker, M. Mindhunter. Nueva York: Scribner.

Doval, G. (2012) Los grandes asesinos de la historia Albor, Madrid.

Drewe, E. A. (1974). The effect of type and area of brain lesion on Wisconsin card sorting test performance. Cortex, 10, 159-70.

Echeburúa, E., \& Corral, P. D. (2006). Secuelas emocionales en víctimas de abuso sexual en la infancia. Cuadernos de Medicina Forense, (43-44), 75-82.

Echeburúa, E., Salaberría, K., \& Cruz-Sáez, M. (2014). Aportaciones y limitaciones del DSM-5 desde la Psicología Clínica. Terapia psicológica, 32(1), 65-74.

Erickson, E. (2000). El ciclo vital completado. Barcelona: Paidós.

España, E.G., Repollés, J.L.D.; Jiménez, F.P.; Jiménez, M.J.B. y Domínguez, A.I.C. (2010). Evolución de la delincuencia en España: Análisis longitudinal con encuestas de victimización. Revista Española de Investigación Criminológica: REIC, (8), 6.

Espinoza, A. (1997). Criminología. Panorama contemporáneo. Lima: Intercopy.

Esquirol, J.E. (1847) Tratado completo de las enajenaciones mentales Maxtor, Valladolid, 2011

Ey, H. (2008). Estudios psiquiátricos, Vol.1. Buenos Aires: Polemos.

Farrington, D. (2005). Childhood origins of antisocial behavior. Clinical Psychology and Psychoterapy, 12:177-190.

Fattah, E.A. (2014). Victimología: pasado, presente y futuro. Revista electrónica de ciencia penal y criminología, 16 (3), 17-46.

Fecteau, S., Pascual-Leone, A., y Théoret, H. (2008). Psychopathy and the mirror neuron system: Preliminary findings from a nonpsychiatric simple. Psychiatry Research, 160, 137-144. 
Felson, M. (2006). Crime and nature. Thausand Oaks (EEUU, California): Sage.

Fenichel, O. (1945). Teoría psicoanalítica de las neurosis. Barcelona: Paidós.

Fernández Guinea, S., Muñoz García, J. J. y Navas Collado, E. (2003). Evidencias de alteraciones cerebrales cognitivas y emocionales en los "psicópatas". Psicopatología Clínica, Legal y Forense, 3 (3), 59-84.

Fink, B. (2007). Introducción clínica al psicoanálisis lacaniano. Barcelona, España: Editorial Gedisa, S.A.

Forth, A.E., Brown, S.D. (1996) The assesment of psychopathy in male and female noncriminals: Reliability and validity. Personality and Individual Differences, 20 (5), 531-543.

Foulds, G.A. (1965). Personality and Personal Illnes. London: Taviskow.

Fox, J.A., y Levin, J. Mass murder. En Eric Hickey (Ed.), Encyclopedia of murder and violent crime (pp. 296-299). Tousand Oaks, CA: Sage.

Freud, S. (1895) Proyecto de una psicología para neurólogos En Obras completas, Tomo I, Madrid, España: Biblioteca Nueva.

Freud, S. (1894/1981). Obsesiones y fobias. . En Obras completas, Tomo I. Madrid, España: Biblioteca Nueva.

Freud, S. (1915/1925). Some carácter types in psychoanalytic work. Vol.4. London: Hogarth.

Freud, S. (1915/1981). La represión. En Obras completas, Tomo II. Madrid, España: Biblioteca Nueva.

Freud, S. (1916). El delincuente y el sentimiento de culpa. En Obras Completas, Tomo II. Madrid, España: Biblioteca Nueva.

Freud, S. (1920). Más allá del principio del placer. En Obras Completas, Tomo III. Madrid, España: Bbiblioteca Nueva.

Freud, S. (1927/1981). Fetichismo. En Obras completas, Tomo III. Madrid, España: Biblioteca Nueva. 
Frick, P.J y Hare, R.D. (2001) The Antisocial Process Screnning Device (APSD), Toronto: Multi- Health Systems.

Frick, P.J., Lilienfeld, S.O., Ellis, M., Loney, B. y Silverthorn, P. (1999). The Association between anxiety and psychopaty dimensions in children. Journal of abnormal Child Psychology, 27, 383-392.

Friedlander, K. (1945). Formation of the antisocial carácter. Psychoanalytic Study of the Child, 1, 189-203.

Fritzon, K, Canter, D, Wilton Z. (2001). The aplication of the action system model to destructive behavior: The examples of arson and terrorism. Behavioral Sciences Law, 19: 657-690.

Fu, Q., Heath, A. C., Bucholz, K. K., Nelson, E., Goldberg, J., Tsuang, M. T. y Eisen, S. A. (2002). Shared genetic risk of major depression, alcohol dependence, and marijuana depedence: contribution of antisocial personality disorder in men. Archives of General Psychiatry, 59, 1125-32.

Fuster, J. M. (1999). Synopsis of function and dysfunction of the frontal lobe. Acta Psychiatry Scand, 99, 51-57.

Gao, Y., Glenn, A. L., Schug, R. A., Yang, Y., y Raine, A. (2009). The neurobiology of psychopathy: A neurodevelopmental perspective. Canadian Journal of Psychiatry, 54, 313-823.

García- Pablos, A. (2007). Criminología. Una introducción a sus fundamentos teóricos. Valencia: Tirant to Blanch.

García-Molina, A. (2008). Aproximación histórica a las alteraciones comportamentales por lesiones del córtex prefrontal: de Phineas Gage a Luria. Rev. Neurología, 46, 175-181.

Garrido, E. y Herrero, M.C. (2006). Relaciones entre la psicología y la ley. En E. Garrido, J. Massip y M.C. Herrero (eds). Psicología Jurídica, Madrid, Pearson/ Prentice Hall, 3-42.

Garrido, V. (2000). El perfil psicológico aplicado a la captura de asesinos en serie. El caso de J.F. Armario de Psicología Jurídica, 10: 25-47. 
Garrido, V. (2005). Manual de Psicología Jurídica e Investigación Criminal. Madrid: Pirámide.

Garrido, V. (2012). Perfiles criminales. Barcelona: Ariel.

Garrido, V. y Sobral, J. (2008). La investigación criminal: psicología aplicada al descubrimiento, captura y condena de los criminales. Barcelona: Nabla Ediciones.

Garrido, V., Stangeland, P. y Redondo, S. (2006). Principios de criminología ( $3^{\circ}$ ed.). Valencia: Tirant to Blanch.

Garzon, A. (1989). Perspectiva Histórica de la Psicología Judicial. Valencia: Promolibro.

Geberth, V. (1981). Psychological profiling. Law and Order, 29: 46-49.

Gil, E. (1994). Animals and Children: A Clinician`s View. Animals Agenda, V.14, 2, p.20.

Giner, S. (1993). Sociología. Barcelona: Ediciones Península.

Giraldo, E. (2006). Perfiles criminales: Un resultado ético. Fundación colombiana de publicaciones y orientaciones jurídicas y forenses. Revisado en Octubre, 17, 2015.

Glenn, A. L., y Raine, A. (2009). Psychopathy and instrumental aggression: Evolutionary, neurobiological, and legal perspectives. International Journal of Law \& Psychiatry, 32, 253-258.

Godwin, G.M. (2000). Hunting Serial Predators: A multivariate Classification Approach to Profiling Violent Behavior. CRC Press. Nueva York.

Godwin, M y Rosen, F. (2006) El rastreador Alba Oscura, Barcelona

Golden, C.J. (2001). Stroop: Test de colores y palabras ( $3^{\circ}$ edición). Madrid: TEA Ediciones.

Goleman, D. (2006). Inteligencia social: La nueva ciencia de las relaciones humanas. Barcelona: Kairós. 
González, H; Pérez, M.A. y Soto, J.E. (2014). La investigación psicológica de los delitos violentos. El método VERA. Psicopatología Clínica, Legal y Forense. Vol.14 (pp.51-78)

Goodglass, H., Kaplan, E. (1979). Assessment of cognitive deficit in the brain injured patient. Nueva York: Plenum Press.

Goodglass, H.; Kaplam, E. y Barresi, B. (2005). Test de Boston para el diagnóstico de afasia. Médica Panamericana.

Gorenstein, E. E. (1982). Frontal lobe functions in psychopaths. J Abnorm Psychol, 91, 368-79.

Gorenstein, E.E. y Newman, J.P. (1980) Dishinhibitory psychopathology: A new perspective and model for research. Psychological Review, 87,301-305.

Gottfredson, M.R., y Hirschi, T. (1990). A general theory of crime. Stanford (EEUU): Stanford University Press.

Goyer, P. F., Cohen, R. M., Andreason, P. J. (2004). Positron-emission tomography and personality disorders. Neuropsychopharmacology, 10, 21-28.

Green, A. (2010). El pensamiento clínico. Buenos Aires, Argentina: Amorrortu.

Gutiérrez, A. y Carpintero, H. (2004). La Psicología del testimonio. La contribución de Francisco Santamaría. Revista de Historia de la Psicología, 25, (4), 59-66.

Halty, L y Prieto-Ursúa, M. (2015) Psicopatía inafnto-juvenil: Evaluación y Tratamiento. Papeles del Psicólogo Vol. 36 (2) pp. 117-124.

Hare, R. D. (1991). The Hare Psychopathy Checklist-Revised. Toronto: MultiHealth Systems.

Hare, R. D., Cox, D. N. (1978). Clinical and empirical conceptions of psychopathy and the selection of subjects for research. Nueva York: Wiley.

Hare, R.D. (1978) Electrodermal and cardiovascular correlates of psychopaty. En R,D. Hare y D. Schalling (Eds). Psychopatic Behavior; Approaches to research (pp. 107-144) New York: Wiley.

Hare, R.D. (2003). The Hare Psychopathy Checklist-Revised. ( $2^{\circ}$ ed.) Toronto, ON: Multihealth Systems 
Hare, R.D., McPherson, L.M. (1984) Violent and aggressive behavior by criminal psychopaths. International Journal of Law and Psychiatry, 7, 35-50-

Hare, R.D.; Forth, A,E. y Strachan, K. (1992) Psychopathy and crime across the lifespan. En P. Peters y V. Quinsey (Eds) Aggression and Violence Across the Lifespan (p.p. 285-300) .New York: Sage.

Hare, R.D.; Hart, S.D y Harpur, T.J. (1991) Psychopathy and the DSM-IV criteria for antisocial personality disorder. Journal of Abnormal Psychology, 100, 391-398.

Harper, T.J., Hare, R. y Haskstian, A. (1989). Two-factor conceptualization of psychopathy: Construct validity and assessment implications. Psychological Assessment: A Journal of Consulting and Clinical Psychology, 1, 6-17.

Harpur, T.J y Hare, R.D. (1994) The assessment of psychopathic as a function of age. Journal of Abnormal Psychology 103, 604-609

Hazelwood, R. (1995). Analyzing the rape and profiling the offender. En A. Burgess y R. Hazelwood (Eds)., Practical aspects of rape investigations: a multidisciplinary approach (pp.115-126). Nueva York: CRP Press.

Hazelwood, R., y Warren, J. (2003). Linkage analysis: Modus operandi, ritual and signature in serial sexual crime. Aggression and Violent Behavior, 8, 587-598.

Hazelwood, R.R. y Burgess, A.W. (1995). Practical rape investigation: A multidisciplinary approach, $2^{\circ}$. Ed. Boca Ratón (Florida): CRC Press.

Heaton, R.K. (1981). Wisconsin Card Sorting Test Manual. Odessa (FL). Psychological Assessment Resource Inc.

Henderson, L. (1985). The wrong of victim's rights. Stanford: L.R.

Hernández Sampieri, R., Fernández Collado, C. y Baptista, P. (2010). Metodología de la Investigación. México, D.F.: Mc Graw Hill.

Hernández, J. (2010). Psicología de la Salud. Alicante: Aniorte.

Hesnard, A (1963) Psicología del crimen. Barcelona: Zeus.

Hickey, E.W. (1997). Serial murderers and their victims. Belmont, CA: Wadsworth Publishing Company. 
Hikal, W. (2007). Introducción al estudio de la Criminología. México: Elsa G.D.

Hikal, W. (2009). Introducción al estudio de la Criminología y a su metodología. Porrúa: México.

Hill, C., Neumann, C.S. y Rogers, S. (2004) Confirmatory factor analysis of the Psychopathy Checklist: Screening Version (PCL-SV) in offenders with Axis I disorders. Psychological Assessment, 16, 90-95.

Holmes, R. y Holmes, S. (1992). Understanding mass murder: a starting point, Federal Probation, 49, 29-34.

Holmes, R. y Holmes, S. (2002). Profiling violent crimes. Thousand Oaks: Sage.

Holmes, R.M. y De Burguer, J. (1985). Profiles in terror: the serial murderer. Federal Probation, 39, 29-34.

Holmes, R.M. y De Burguer, J. (1988). Serial murder. Newbury Park: SAGE Publications.

Holms, J. (2013) Antisociales y psicópatas Bosch, Barcelona

Hood, R. y Sparks, R. (1970). Problemas clave en criminología. Madrid: Guadarrama S.A.

Hooper, H. E. (1958). The Hooper visual organization test. Los Ángeles: Western Psychological Services.

Huertas-Díaz, O. (2010). Anomia, normalidad y función del crimen desde la perspectiva de Robert Merton y su incidencia en la criminología. Revista Criminalidad, 52, (1) 365-376.

Hume, D. (1739-1940). Tratado sobre la naturaleza humana: un intento de introducir el método de razonamiento experimental en las cuestiones morales. Madrid: Tecnos.

Ibáñez, T. (1987). Por una psicología social del derecho. En Boletín de Psicología, $15,13-21$.

Illescas, S. y Pueyo, A. (2007). La Psicología de la delincuencia. Papeles del Psicólogo, 28 (3), 147-156. 
INE (Notas de prensa) (2014) Estadística de condenados adultos.

Intrator, J., Hare, R., Stritzke, P., Brichtwein, K., Dorfman, D., Harpur, T., et al. (1997). A brain imaging (single photon emission computerized tomography) study of semantic and effective processing in psychopaths. Biol Psychiatry, 42, 96-103.

Jasper, K. (1913) Psicopatología general EFC, México 2014.

Jiménez, J. (2012). Manual Práctico del Perfil Criminológico. Valladolid: Lex Nova.

Jiménez, J. (2014). Asesinos en serie: definición, tipologías y estudios sobre esta temática. Gaceta internacional de ciencias forenses, (10), 4-12.

Jiménez, J. (2015). Psicología e Investigación Criminal. Psicología Criminalista. Navarra: Lex Nova.

Jiménez, M.P., Ramos, F. y Sanchís, M.C. (2008). Las esquizofrenias: aspectos clínicos. En Manual de Psicopatología. Madrid: McGraw Hill.

Johns JH, Quay HC (1962). The effect of social reward on verbal conditioning in psychopathic and neurotic military offenders. J Consult Psychol. ;36:217-220.

Jones, D. N. y Paulhus, D. L. (2009). Machiavellianism. En M. R. Leary y R. H. Hoyle (eds.), Handbook of individual differences in social behavior (pp. 93-108). New York, NY: Guilford Press

Jones-Gotman, M., Zatorre, R. J., (1988). Olfactory identification deficits in patients with focal cerebral excision. Neuropsychologia, 26, 387-400.

Julien, P. (2012). Psicosis, perversión, neurosis: la lectura de Jaques Lacan. Buenos Aires: Amorrortu, 2012.

Karmen, A. (2007). Crime and victims: An introduction to victimology. $6^{\mathrm{a}} \mathrm{ed}$. Belmont 5, pp.388-394.

Karpman, B. (1941). On the need for separating psychopathy into two distict types: Symptomatic and idiopathic. Journal of Clinical Psychopathology, 3, 112-137.

Keppel, R.D y Birnes, W.J. (1997). Signature Killers: Interpreting the calling cards of serial murderers. Nueva York: Pocket Books. 
Ki moon, B. (2010). Congreso de las Naciones Unidas sobre Prevención del Delito y Justicia Penal, Salvador, abril 2010. Salvador: Naciones Unidas.

Kiehl, K. A., Laurens, K. R., Bates, A. T., Liddle, P.F. (2006). Psychopathy and semantic processing: An examination of the N400. Personality and Individual Differences, 40, 293-304.

King, M. (1984). Understanding the legal system: A job for psychologist? En D.J. Müller, D.E. Blackman y A.J. Chapman (eds), Psychology and law, Chichester, John Wiley and Sons, pp.67-82.

Kirby, M.D. (1978). Psychology and law: A minuet, Australian Psychologist, 13, 339-356.

Klein, M. (1949) Sobre la teoría de la ansiedad y la culpa O.C.II, Horme, Buenos Aires.

Kosson, D.S. , Smith, S.S y Newman, J.P. (1990) Evaluating the construct validity of psychopathic in black and white male inmates: Three preliminary studies. Journal of Abnormal Psychology, 95, 250-259.

Kraemer, G., Wayne, D. y Heilbrun, K. (2004). Comparing single and serial homicide offenders. Behavioral Sciences and the Law, 22, 325-343.

Kraepelin, E. (1896). Psychiatrie; ein Lehrbuch für Studierenden und Aertzen. Leipzig: Barth.

Kraepelin, E. (1904). Lectures on clinical psychiatry. New York: Wood.

Kretschmer, E. (1921). Korperbau und carácter Untersuchungen Zum Konstitutions-Problem Und Zur Lehre Von Den Temperamenten. Berlín: Verlag Von Julios Springer.

Kretschmer, E. (1997). Constitución y carácter. Madrid: Ed. Labor.

Kuruoglu, P., Fitzgeral, W. J., y Rayner, P. (1996). Near optimal detection of signals in impulsive noise modeled with a symmetric a-stable distribution. IEEE Communications Letters, 2, 282-284. 
Kuruoglu, P., Fitzgeral, W. J., y Rayner, P. (1996). Near optimal detection of signals in impulsive noise modeled with a symmetric a-stable distribution. IEEE Communications Letters, 2, 282-284.

Laakso, M. P., Hodgins, S., Testa, C., Pérez, J., Vaurio, O., Aronen, H. J., y Frisoni, G. B. (2008). Brain anatomy of persistent violent offenders: more rather than less. Psychiatry Research: Neuroimaging, 163, 201-212.

Lacan (1954/1990). Seminario I, Los escritos técnicos de Freud. Buenos Aires, Argentina: Paidós.

Lacan, J. (1956/2004). Seminario 3, Las psicosis. Buenos Aires, Argentina: Paidós.

Lacan, J. (1964/1989): Seminario libro 11. Los cuatro conceptos fundamentales del psicoanálisis. Paidós: Argentina.

Lagache, D. (1950) Psicología criminal Paidós, Buenos Aires.

Lang, P.J. (1994) The motivacional organization of emotion; Affect.Reflex connections. En S.H.M. Van Gozen, N. Van Poll y J.A. Sergeant (Eds) Emotions. Essays on emotion therory (pp. 61-93) Hillsdale: Lawrence Erlbaum Associates.

Lang, P.J. (1995) The emotion probe. Studies of motivación and attention. American Psychologist, 50, 372.385-

Lapierre, D., Braun, C. M., Hodgins, S. (1995). Ventral frontal deficits in psychopathy: neuropshycological test finding. Neuropsychol, 33, 139-55.

Learly, T. (1957). Interpersonal diagnosis of personality. New York: Ronald.

Levin, H. S., Culhane, K. A., Hartman, J. (1991). Developmental changes in performance on tests of purported frontal lobe functioning. Dev Neuropsuchol, 7, 377-95.

Ley Orgánica 10/1995, de 23 de noviembre, del Código Penal.

Leyton, E. (1984) Cazadores de humanos Alba oscura, Barcelona, 2005

Leyton, E. (2005) Cazadores de humanos. El auge del asesino en múltiple moderno Alba Oscura, Barcelona.

Lezak, M. D. (1983). Neuropsychological assessment. 2 ed. Nueva York: Oxford University Press. 
Lidberg, L., Levander, S. E., Schalling, D., Lidberg, Y. (1978). Necker cube reversals, arousal and psychopathy. Br J Soc Clin Psychol, 17, 355-61.

Liddle, P. F., Smith, A. M., Kiehl, K. A., Mendrek, A., Hare, R. D. (1999). Response inhibition in schizophrenia and psychopathy: similarities and differences. International Congress of Schizophrenia Research. Santa Fe, California.

Łobaczewski, A. (2006) Political Ponerology: A Science on the Nature of Evil Adjusted for Political Purposes, Grande Prairie: Red Pill Press, p. 22.

Lombroso, C. (2006), El atlas criminal. Valladolid: Ed. Facsímil.

López, A. (2013). Las mujeres también matamos. Derecho y cambio social, 1-7.

López, M. (2005). Ficción y Serial Killer, cuando las mujeres recurren a la violencia. Lectora: revista de dones i textualitat, (11), 0131-141.

López, P. y Gómez, P. (2000). Investigación criminal y criminalística. Bogotá, D.C.:Termis.

López, V. (2008). El perfil criminológico. Revisado en Octubre, 17, 2015. www.grupolugar.com / Documentos/Imputabilidad \%20 y \%20Psiquiatria \%20 Forense.pp.

Luengo, M.A. y Carrillo, M.T. (2008). La psicopatía. En Manual de Psicopatología. Madrid: McGraw Hill.

Lykken, D. T. (1957). A study of anxiety in the sociopathic personality. Nuerol, 6, 15-20.

Lykken, D.T. (2000) Las personalidades antisociales. Barcelona: Herder.

Lynam, D.R. (1996). The early identification of chronic offenders: Who is the fledling psychopath? Psychological Bulletin, 120, 209-234.

Lynam, D.R. (1997) Pursuing the psychopath: Capturing the fledgling psychopath in a monological net. Journal of Abnormal Psychology, 106 (3), 425-438.

Macía, R. (2011). Los asesinos en serie. Revista General de Derecho Penal (16), 125. 
Magnani, L (1998) Abduction and Hypothesis Withdrawal in Science. Twentieth World Congress of Philosopy. Boston, MA.

Munné, F. (1987). La investigación y la intervención psicológicas en el sistema jurídico. Papeles del Psicólogo. Colegio Oficial de Psicólogos. V.3, 5-9.

Muñoz Sabaté, Ll (1980) Método y elementos para una Psicología Jurírica. En Ll. Muñoz Sabaté, R. Bayes y F. Munne Introducción a la Psicología Jurídica México, Trillas

Marina, J.A. (1995). La inteligencia fracasada. Madrid: Anagrama.

Martín, A.L. (2013). Las mujeres también matamos. XXXXX

McCord, W. y McCord, J. (1964). The psychopath: An easy on the criminal mind. New York: Van Nostrand.

Mednik, C. A., Volavka, J., Gabriellik, W. F. (1982). EEG as a predictor of antisocial behavior. Criminology, 19, 219-31.

Miller, J.A. (1997). Introducción al método psicoanalítico. Buenos Aires, Argentina: Paidós.

Millon, T. (1998). Trastornos de la personalidad. Más allá del DSM-IV. Barcelona: Masson, S.A.

Ministerio del Interior: Balance de Criminalidad correspondiente al primer trimestre de 2015.

Moffit, T.E. (2006). A review of research on the taxonomy of life-course persistent versus adolescence-limited antisocial behavior. En F.T. Cullen, J.P. Wright y K.R. Blevins (Eds. De la serie). Taking stock: The status of criminological theory, Vol.15 (pp.277-311). New Brunswick, New Jersey, EEUU: Transaction.

Moll, A. (2000). Psychopathia sexualis. Valencia: La Máscara.

Moniz, E. (1937). Prefrontal leucotomy in the treatment of mental disorders. Am J Psychiatry, 93, 1379-85.

Morales, L. A., Muñoz-Delgado, J., Santillán, A. M., Arenas, R., \& de León, F. C. P. (2007). Perfiles criminológicos: el arte de Sherlock Holmes. Salud mental, 30(3), 68-75. 
Morales, L.A. (2003). La técnica del perfil en la investigación criminal. En V. Garrido. Psicópatas y otros asesinos violentos (pp.305-368). Valencia: Tirant to Blanch.

Moreno, M. (1974). El petiso orejudo. (Vol.4). Planeta.

Muci-Mendoza, R. (2007). Colección Razetti. Caracas: Ateproca.

Münsterberg, H. (1908). On the witness stand, Nueva York, Doubleday.

Muñoz García, J. J. y Navas Collado, E. (2004). El síndrome disejecutivo en la psicopatía. Revista neurología, 38, 582-590.

Muñoz, J.J., Navas, E. y Fernández, S. (2003). Evidencias de alteraciones cerebrales, cognitivas y emocionales en los psicópatas. Psicopatología Clínica, Legal y Forense, 3, 59-84.

Muñoz, J.M. (2011). La psicopatía y su Repercusión Criminológica: Un modelo Comprehensivo de la Dinámica de Personalidad Psicopática. Anuario de Psicología Jurídica, 21, 57-68.

Murrie, D.C. y Cornell, D.G. (2000) The Millon Adolescent Clinical Inventory and psychopathy. Journal of Personality Assesment 75, 110-125.

Nasio, J.D. (1991). El dolor de la histeria. Buenos Aires, Argentina: Paidós.

Nasio, J.D. (1993). Cinco lecciones sobre la teoría de Jaques Lacan. Barcelona, España, Editorial Gedisa, S.A.

Nasio, J.D. (1996). Enseñanza de siete conceptos cruciales del psicoanálisis. Barcelona, España: Editorial Gedisa, S.A.

Neumann, C., Kosson, D., Forth, A., y Hare, R. (2004). Factor structure of the Hare Psychopathy Checklist: Youth Version in inacerated adolescent. Manuscript submitted for publication.

Norza, C., Morales, Q., Merchán, R. y Meléndez, C. (2013). Perfilación criminológica: una revisión de la literatura y su aplicación en la investigación criminal en Colombia. Revista Criminalidad, 55 (3): 309-336. 
Organización Mundial de la Salud. CIE 10. Décima Revisión de la Clasificación Internacional de Las Enfermedades. Trastornos Mentales y del Comportamiento: Descripciones Clínicas y pautas para el Diagnóstico. Madrid: Meditor; 1992.

Otín del Castillo, J.M (2013) Psicología criminal. Técnicas aplicadas de interveción e investigación policial Lex Nova, Valladolid.

Ovejero, A. (2009). Fundamentos de psicología jurídica e investigación criminal. Salamanca: Ediciones Universidad.

Papakostas, Y., Eftychiadis, A., Papakostas, G. y Christodoulou, G.N. (2003). A historical inquirí into the appropriateness of the term "panic disorder". History of Psychiatry, 14 (2), 195-204.

Partidge, G. (1930). Currents conceptions of psychopathic personality. American Journal of psichiatry, 10, 53-99.

Pastor Ramos, G. (1988) Conducta interpersonal. Ensayo de Psicología Social sistemática UPS, Salamanca.

Pastor Verchili, M.C. (1999) Modulación del reflejo de sobresalto y medidas anatómicas en psicópatas encarcelados Tesis Doctoral, Universitat Jaume I de Castelló. Facultat de Ciénces Humanes I Socials.

Patrick, C.J. (1994) Emotion and psuchopathy: Starling new insight. Psychophysiology, 31, 319-330.

Patrick, C.J. (1994). Emotion and Psychopaty. Psychophysiology, 31, 319-330.

Patrick, C.J. y Lang, A.R. (1999) Psychopathic traits and intoxicated states; Affective concomitants and conceptual links. En M. E. Dawson, A.M. Schell y A. .H. Böhmelt (Eds) Startle modification; Implications for neuroscience, cognitive science, and clinical science (pp. 209-230) .Cambridge: Cambridge University Press.

Paulhus, D. L. y Williams, K. M. (2002). The dark triad of personality: Narcissism, Machiavellianism, and psychopathy. Journal of Research in Personality, 36, 556563.

Peirce, C.S. (1906). Prolegomena to an apology for pragmatisms. The Monist, 492546. 
Peirce, C.S. (1968). Escritos lógicos. Madrid: Alianza Universidad.

Petherick, W.A. (2006). Serial crime: Theoretical and practical Issues in behavioral profiling. California: Elsevier.

Phelps, E. A., Hyder, F., Blamire, A. M., Shulman, R. (1997). FMRI of the prefrontal cortex during verbal fluency. Neuroreport, 8, 561-5.

Phillips, D. P. (1974). The Influence of Suggestion on Suicide: Substantive and theoretical Implications of the Werther Effect. American Sociological Review. Vol. $39,340-354$.

Pinel, P. (1809). Traité médico-philosophique de l'aliènation mentale Paris: Brosson.

Pombo, G. (2008). Jack el Destripador. La leyenda continúa. Montevideo: Artemisa.

Porteus, S.D. (2006). Laberintos de Porteus (4 ${ }^{o}$ edición revisada). Madrid: TEA Ediciones.

Pribram, K. H. (1973). The primate frontal cortex -executive of the brain. Psychophysiology of the frontal lobes. Nueva York: Academic Press.

Prichard (1835) Treatise on insanity and other disorders affecting the mind, London.

Prichard, J. (1835). A treatise or insanity. London: Sherwood, Gilbert and Piper.

Prichard, J. (1895). Treatise on Insanity and Other Disorders Affecting the Mind. London: Sherwood, Gilbert and Piper.

Psicologíaforense2009.blogspot.com.es/2011/01/perfil-criminal-modelo-del-fbivs.html.

Purcell, C. (2003). Paraphilia. En Eric Hickey (Ed), Encyclopedia of murder and violent crime (pp. 345-347). Tousand Oaks, CA: Sage.

Raine, A. (2008). From genes to brain to antisocial behavior. Current Directions in Psychological Science, 17 (5), 323-328.

Raine, A. y Sanmartín, J. (2006). Violencia y Psicopatía. Barcelona: Ariel. 
Raine, A., Buchsbaum, M., Stanley, J., Lottenberg, S., Abel, L., Stoddard, J. (1994). Selective reductions in prefrontal glucose metabolism in murderers. Biol Psychiatry, $36,365-73$.

Raine, A., Lencz, T., Bihrle, S., LaCasse, L. B., Colletti, P. (2000). Reduced prefrontal gray matter volumen and reduced autonomic activity in antisocial personality disorder. Arch Gen Psychiatry, 57, 119-27.

Raine, A., Lencz, T., Taylor, K., Hellige, J. B., Bihrle, S., Lacasse, L., Lee, M., Ishkawa, S., y Coletti, P. (2003). Corpus callosum abnormalities in psychopathic antisocial individuals. Archives of General Psychiatry, 60, 1134-1142.

Ray, J.J. y Ray J.A.B. (1982) Some Apparent Advantages of Subclinical Psychopaty. Journal of Social Psychology 117: 135-142.

Rappaport, R. (1998). The serial and mass murderer: patterns, differentiation, pathology, American Journal of Forensic Psychiatry, 9, 39-48.

Real Academia Española (2009). Diccionario de la Lengua Española, $23^{\mathrm{a}}$ Ed. Consultado en http://w.w.w. rae.es/drae/.

Reckless, W. (1961). The Crime Problem. New York: Appleton-Century-Crofts, INC.

Redondo, S y Garrido, V. (2013). Principios de Criminología. Valencia: Tirant to Blanch.

Reich, W. (1925). Der triebhafie charakter. Leipzig: Internationaler Psychoanalytischer Verlag.

Ressler, R. (2010). Dentro del monstruo: un intento de comprender a los asesinos en serie. Ed. Aba Minus: Barcelona.

Ressler, R. y Shachtman, T. (2005). Asesinos en serie. Ed. Ariel: Barcelona.

Ressler, R. y Shachtman, T. (2010). Dentro del monstruo: un intento de comprender a los asesinos en serie. Barcelona: Aba Minus.

Ressler, R.K., Burguess, A.W. y Douglas, J.E. (1988). Sexual homicide: Patterns and motives. Lexington, MA: Lexington Books. 
Ressler, R.K., Burguess, A.W., D’Agostino, R.B. y Douglas, J.E. (1984). Serial murder: A new phenomenon of homicide. Paper presented at the anual meeting of the International Association of Forensic Sciences, Oxford, England.

Rhee, S. H. y Waldman, I. D. (2002). Genetic and environmental influences on antisocial behavior: a meta-analysis of twin and adoption studies. Psychological Bulletin. 128, 490- 529.

Rilling, J. K., Glenn, A. L., Jairam, M. R., Pagnoni, G., Goldsmith, D. R., Elfenbein, H. A., y Lilienfeld, S. O. (2007). Neural correlates of social cooperation and noncooperation as a function of psychopathy. Biological Psychiatry, 61, 1260-1271.

Ripollés, J.L.D. (2006). Algunos rasgos de la delincuencia en España a comienzos del siglo XXI. Revista Española de Investigación Criminológica: REIC, (4), 1.

Rivera, J.L., Munillo, J.A., y Sierra, M.A. (2007). El concepto de neurosis de William Cullen como revolución científica. Enseñanza e Investigación en Psicología, 12 (1), 157-158.

Rizzolatti, G. y Craighero, L. (2004). The mirror-neuron system. Annual Review of Neuroscience, 27, 169-192.

Robins, L. (1966). Deviant children grow up. Baltimore: Williams and Wilkins.

Robins, L. (1978). Sturdy predictors of adult antisocial behavior: Replications from longitudinal studies. Psychological Medicine, 8, 611-622.

Robinson, M.B. y Beaver, K.M. (2009). Why crime? An interdisciplinary approach to explaining criminal behavior. Durham, N.C: Carolina Academic Press.

Rodríguez, R. J. R. (2005). Abducción en el contexto del descubrimiento científico. Revista de Filosofía de la Universidad de Costa Rica.

Romano, A. (s.f.). Destripadores y asesinos de trabajadoras sexuales: entre Eros y Tánatos. Recuperado en Octubre, 16 de 2015 en Www.forenselatina.com/edicionesanteriores/edicion12/documentos/artículos/descarg able/artículo/Destripadores-y-asesinos-de-trabajadoras-sexuales-entre-eros-ytanatos. 
Rossmo, D.K. (1995). Geographic Profiling: Target patterns of serial murderers. Simon Fraser University: Vancouver.

Rossmo, D.K. (2000). Geographic profiling. Boca Raton, FL: CRC Press.

Roussy, S., Toupin, J. (2000). Behavioral Inhibition deficits in juvenile psychopaths. Aggressive Behav, 26, 423-24.

Ruff, R., Light, R. y Evans, R. (1987). The Ruff Fluency Test: A normative study with adults. Developmental Neuropsychology, 3, 37-51.

Rush, B. (1786). An inquiry into influence of physical causes upon the moral faculty. Philadelphia: Charles Cist.

Rush, B. (1812). Medical inquiries and observations upon the diseases of the mind. Philadelphia: Kimber and Richardson.

Safalti, G., y Canter, D. (1999). Differentiating Stranger Murders: Profiling Offender Characteristics form Behavioral Styles. Behavior Sciences and Law; 17, 391-406.

Safarik, M.; Quiñones, M. (2011). Piquerismo. Identificando la conducta parafílica en la escena del crimen violento. En: Revista de la Policía Federal Argentina. Policía y Criminalística, Número 24, Volumen 383.

Sáiz, D.; Baqués, J. y Sáiz, M. (2006). Psicología del testigo: conceptos fundamentales. En Psicología Criminal, Madrid, Pearson/Prentice Hall, pp.125-162.

Saleskin, R.T., Neumann, C.S., Letistico, A.M. y DiCicco, T.M. (2004) Construct validity of psychopaty in a youth ofender simple: Taking a closer look at psychopathy's potencial important over disruptive behavior disorders. Journal of Abnormal Psychology, 113, 416-427.

Salfati, C. y Canter, D. (1999). Differentiating stranger murders: profiling ofender characteristics from behavioral styles. Behaw Sci Law, 17: 391-406.

Sandín, B. y Chorot, P. (2008). Concepto y categorización de los trastornos de ansiedad. Manual de Psicopatología. Madrid: McGraw Hill 
Santtila, P., Runtti, M., Mokros, A. (2004). Predicting Presence of Offender's Criminal Record From Antisocial Lifestyle Indicators of Homicide Victims. $J$. Interpers Violence, 19 (5): 541.557.

Sarundiansky, M. (2013). Ansiedad, angustia y neurosis. Antecedentes conceptuales e históricos. Psicología Iberoamericana, 21 (2) 19-28.

Schafer, S. (1977). Victimology: the victims and his criminal. Reston: Reston Publishing.

Schlesinger, L.B. (2000). Serial homicide: Sadism, fantasy and compulsión to kill. En L.B. Schlesinger (Ed.), Serial offenders: Current thoughts, recent findings (pp. 3-22). Boca Raton, FL: CRC Press.

Schmitt, S. y Neumann, J.P. (1999). Alcohol and drugs abuse-dependence disorders in psychopathic and nonpsychopathics criminal offenders. Journal of Abnormal Psychology, 113, 416-427.

Schneider, K. (1923). Las personalidades psicopáticas. Madrid: Morata.

Sebeck, T.A. y Uniker-Sebeck, J. (1994). Sherlock Holmes y Charles S. Peirce. El método de la investigación. Barcelona: Paidós Comunicación.

Seidenwurn, D. J., McDonell, C. H., Raghavan, N., y Breslau, J. (1996). Cost utility analysis of radiographic screening for an orbital foreign body vefore MR imaging. Am J Neuroradiol, 21, 426.

Seo, D., Patrick, C. J., y Ken, P. J. (2008). Role of serotonin and dopamine system interactions in the neurobiology of impulsive aggression and its comorbidity with other clinical disorders. Aggression and Violent Behavior, 13, 383-395.

Serin, R.C. (1996) Violent recidivism in criminal psychopaths Law and Human Behavior, 20, 207-217.

Serrano, J.J. (2014). Asesinos en serie: definición, tipologías y estudios sobre esta temática. Gaceta Internacional de ciencias forenses, (10), 4-12.

Shapiro, D. (1965). Neurotic styles. New York: Basic Books.

Shrerie, W. Harpur, T.J y Hare, R.D. (1991) Abnormal Processing of Affective Words by Psychopathic Psychophysiology, 28, $n^{o} 3: 260-73$ 
Simon, H.A. (1975). The functional equivalence of problem solving skills. Cognitive Psychology, 7, (2) 68-288.

Simon, R.J. (1975). Women and crime. Lexington, MA: Lexington Books.

Small, M.A. (1993). Legal psychology and therapeutic jurisprudence. En Saint Louis University Law Journal, 37, 675-700.

Smith, M. L., Kates, M. J., Vriezan, E. R. (1992). The development of frontal-lobe functions. Amsterdam: Elsevier.

Soderstrom, H., Blennow, K., y Manhem, A. (2003). CSF Studies in violent offenders. 5-HIAA as a negative and HVA as a positive predictor of psychopathy. $J$ Neural Transm, 108, 869-878.

Soria, M.A. (1998). Psicología y Práctica Jurídica. Barcelona: Ariel.

Soria, M.A. y Sáiz, D. (2008). Psicología Criminal. Madrid: Prentice Hall.

Soto, J.E. (2014). Manual de Investigación Psicopatológica del delito. El método Vera. Madrid: Pirámide.

Soto, J.E., Ordi, H.G. y Nieto, M.A.P. (2014). La investigación psicológica de los delitos violentos. El método V.E.R.A. Psicopatología Clínica, Legal y Forense, 14: $51-78$.

Spielberg, C.D.; Pollans, C.H.; y Worden, T.J. (1984). Anxiety disorders. En S.M. Turner y M. Hersen (Eds).; Adults psychopathology and diagnosis (pp.263-303). Nueva York: Wiley.

Steffensmeir, D.R.J. (1980). Trends in female delinquency. Criminology, 18 (1), 62 85.

Stockdale, K.C., Olver, M.E. y Wong, S.C.P. (2010) The Psychopathy checklist: Youth versión and adolescent and adult recidivism. Consideration with respect to gender, ethnicity, and age. Psychological Assessment, 22 (4), 768-781.

Thagard, P. (2007). I feel your pain: Mirror neurons, empathy, and moral motivation. Journal of Cognitive Science, 8, 109-136. 
Tranel, D. y Damasio, A. R. (1994). Impaired autonomic reactions to emotional and social stimuli in patients with bilateral orbital damage and acquired sociopathy. Society of Neuroscience, 14, 1288-1298.

Tremblay, R. E., Hartup, W. W., Archer, J. (2005). Developmental origins of aggression. Nueva York: Guilford Press.

Turvey, B. (1998). Deductive Criminal Profiling: Comparing Applied Methodologies between Inductive and Deductive Profiling Techniques. The Basel University Law student's journal.

Turvey, B. (2002). Criminal profiling. Nueva York: Academic Press.

Turvey, B. (2008). Criminal profiling. An introduction to behavioral evidence analysis. California: Elsevier.

Urra, J. (1993). Confluencia entre Psicología y Derecho. En J. Urra y B. Vázquez (Comps.) Manual de Psicología Forense. Madrid: Siglo XXI.

Urra, J. (1997) Violencia. Memoria amarga. Madrid. Siglo XXI

Valencia Laharenas, I. (2010) El homicidio serial de niños en Colombia Universidad Libre Seccional de Cali, Cali.

Vallejo. J. (2002). Introducción a la psicopatología y la psiquiatría, $5^{\mathbf{0}}$ ed. Barcelona: Manson.

Van Hock, J., y Schutter, L. G. (2006). Testosterone shifts the balance between sensitivity for punishment and reward in healthy Young women. Psychoneuroendocrinology, 29, 937-943.

Vargas, N. (2008). La criminología y la investigación criminal. En Calixto (Ed.).Experiencias en investigación criminal. Bogotá, D.C., Escuela de Investigación Criminal: 14-23.

Vazquez Tían, J.A. (2015) Matar no es fácil Espasa Calpe, Madrid.

Verona, E., Patrck, C.J. y Joiner, T.T. (2001). Psychopaty antisocial personality and suicide risk. Journal of Abnormal Psychology, 110, 462-470.

Villavicencio, T. (1997). Introducción a la Criminología. Lima: Grijley. 
Viñas, N.Q. (2001). Congreso sobre Asesinos en serie, Psicópatas y Conducta Antisocial.

Virgolini, J. (2004). Crímenes excelentes. Delitos de cuello blanco, crimen organizado y corrupción. Buenos Aires: Del Puerto.

Vitacco, M.J., Newman, C.S. y Jackson, R.L. (2005) Testing a Tour-factor model of Psychopathy and its Association with ethnicity, gender, intelligence and violence. Journal of Consulting and Clinical Psychology, 73, 466-476.

Volkow, N. D, Ascher, P., y Tancredi. L. (1995). Loss of Dopamine Transporters in Methamphetamine Abusers Recovers with Protacted Abstinence. The Journal of Neuroscience, 21, 897-899.

Von Henting, H. (1964). Estudios de Psicología Criminal, vol.III, La Estafa. Madrid: Espasa Calpe.

Wechsler, D. (1999). Escala de Inteligencia Wechsler para adultos. Madrid: TEA Ediciones.

Weeler, S; Book, A y Costello, K (2008) Psychopathic Traits and the Perception of Victim Vulnerability, Criminal Justice and Behavior, $36 \mathrm{n}^{\circ} 6$

Wenzl, R, Potter, T, Laviana, H y Kelly, L. (2011) BTK (Átalas, tortúralas, mátalás) Alba Oscura, Barcelona

White, K. y Shapiro, K. (1994). The culture of violence. The Animals Agenda, V.14, 2, p.22.

Widiger, T., Corbitt, E. y Millon, T. (1991). Antisocial personality disorders. Review of psyquiatry. Vol.2. Washington, DC: American Psychiatry Press.

Wikström, P. (2004). Crime as alternative: towards a cross - level situational action theory of crime causation. Advances in criminological theory, 13,Beyond empiricism institutions in the study of crime.

Wikström, P. (2006). Personas, entornos y actos delictivos: mecanismos situacionales y explicación del delito. Derecho penal y criminología como fundamento de la Política Criminal. Estudios en homenaje al profesor Alfonso Serrano Gómez. Madrid: Dykinson. 
Wittels, F. (1930). The histerical carácter. Medical Review of Reviews, 36, 186-190. www. aniorte-nic.net

Yang, Y., Raine, A., Lencz, T., Bihrle, S., Lacasse, L., y Coletti, P. (2005). Volume reduction in prefrontal gray matter in unsuccessful criminal psychopaths. Biological Psychiatry, 57, 1103-1108.

Zauberman, R. (1985). Fonts d'information sur les victimes et problems du metodologie. En J.J.M Van Dijk, Researches sur la victimization. Strasbourg: Conseil de 1’Europe. 
ANEXO 1. GUÍA DE CODIFICACIÓN DE LA UNIDAD DE ANÁLISIS DE LA CONDUCTA CRIMINAL (UACC)

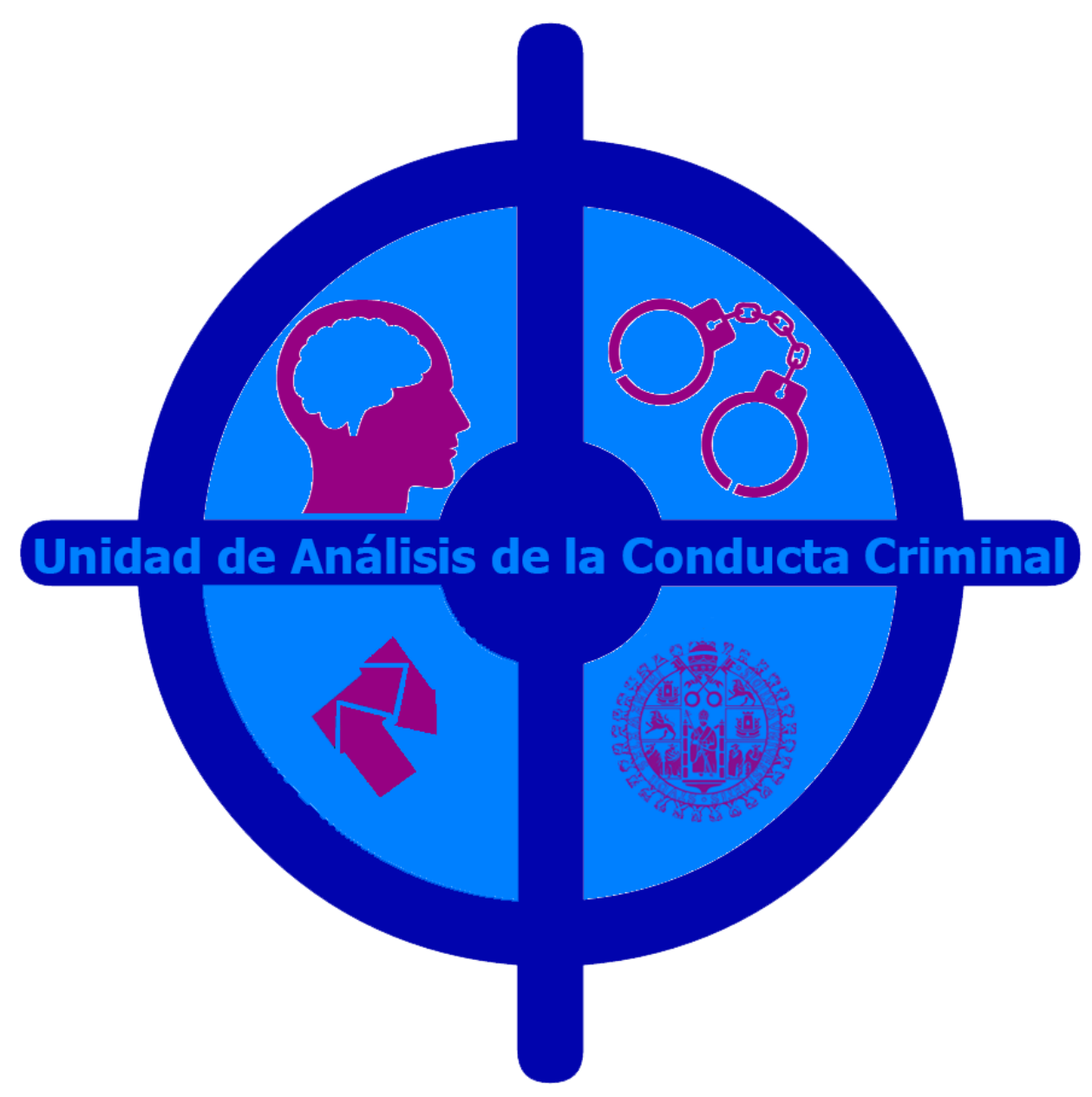

UNIDAD DE ANÁLISIS DE LA CONDUCTA CRIMINAL UNIVERSIDAD DE SALAMANCAC 2016 


\section{ÍNDICE}

I. Aspectos generales 3

II. Aspectos específicos

1. Variables sociodemográficas y físicas 4

2. Variables psicológicas 5

3. Antecedentes infancia y adolescencia $\quad 8$

4. Historial edad adulta 10

5. Antecedentes familiares 11

6. Historial delictivo y de violencia $r$

7. Escena 12

8. Modus operandi 15

9. Ritual 19

10. Comportamiento geográfico 2

11. Victimología 21

12. Tipologías $\quad 23$

13. Fuentes consultadas $\quad 24$

$\begin{array}{lr}\text { III. Fuentes bibliográficas } & 25\end{array}$ 


\section{ASPECTOS GENERALES}

1. La no codificación de una variable significa el desconocimiento de los datos sobre la misma.

2. En caso de información de dudosa credibilidad o datos enfrentados sobre los que no se puede dilucidar, con algo de certeza, la codificación de una variable, deberá optar por su no cumplimentación. Es decir, se opta por el desconocimiento de los datos antes que por la codificación errónea.

3. En la presente guía, en el apartado de "aspectos específicos", tras el nombre de la variable y entre paréntesis, se indica el tipo de variable.

4. Las variables no señaladas explícitamente como de respuesta múltiple, se entienden, automáticamente, como de respuesta única (p. ej. sexo).

5. En las variables de elección múltiple, se seleccionaran todas aquellas opciones que concurran en el caso analizado (p. ej. presencia de parafilias), aunque no sea posible que lo hagan de forma simultánea (p. ej. estado civil) pero sí a lo largo del periodo homicida en cuestión.

6. Cuando en una variable nominal abierta se presenten múltiples respuestas, estas se anotaran separadas por punto y coma (p. ej. alias).

7. En aquellas respuestas en que se pide "especificar", se hace referencia a los datos que argumentan la respuesta y que aportan más información sobre la misma. Siendo, esta cuestión, pormenorizada en los aspectos específicos de cada variable.

8. Las variables cuyas opciones de codificación son "sí", "no" y "se desconoce" requieren anotar en la casilla adyacente de la derecha una cifra que puede hacer referencia a las víctimas o a los crímenes. Debido a ello, en la presente guía, se indicará en cada variable si el recuento debe hacerse en base a los crímenes o a las víctimas. 


\section{ASPECTOS ESPECÍFICOS}

1. VARIABLES SOCIODEMOGRÁFICAS Y FÍSICAS. Grupo de variables que comprende aquellas relativas a aspectos identificativos del sujeto y de su esfera familiar y social.

a. Nombre (nominal abierta). Debe ser tenido en cuenta que, especialmente en el caso de asesinos norteamericanos, no es extraño que el individuo tenga dos nombres. Deben ser reflejados todos los nombres que se conozcan del sujeto, separados por comas.

b. Apellidos (nominal abierta). Hay que considerar que, en muchos casos, el asesino puede tener un solo apellido. Deben ser reflejados todos los apellidos que se conozcan del sujeto, separados por comas.

c. Alias (nominal abierta) Puede presentarse y, en tal caso, existir varios (en este supuesto se deben recoger todos, entrecomillados y separados por comas) o, por el contrario, puede que el asesino no haya sido apodado.

d. Sexo (nominal cerrada). En su determinación se atenderá al sexo biológico del individuo, es decir, al que manifiestan sus órganos sexuales.

e. Estatura (ordinal cerrada). Altura de la persona que debe ser considerada en relación al promedio de la sociedad en que habita, siendo posible diferenciar entre:

Alta: si es superior a la de la media poblacional.

Media: si se encuentra dentro de los parámetros de la media.

Baja: si es inferior a la de la media poblacional.

f. Complexión (ordinal cerrada). Constitución física de una persona, pudiéndose distinguir entre:

Delgada: si es un individuo leptosómico.

Fuerte/atlética: si el sujeto es musculoso o mesomórfico.

Obesa: si es un sujeto pícnico.

g. Fecha de nacimiento (ordinal cerrada). Fecha será recogida en el formato "DD/MM/AAAA" (p. ej. 02/06/1989 codifica a un sujeto que nace el día dos de junio de 1989).

h. Fecha de defunción (ordinal cerrada). Este dato será anotado únicamente en aquel supuesto en que el sujeto halla fallecido, con el formato "DD/MM/AAAA" de no ser así será completado con un guion “-“, entendiéndose la ausencia de ambos como el desconocimiento sobre dicha variable.

i. Fecha inicio asesinatos (ordinal cerrada). Fecha será recogida en el formato "DD/MM/AAAA" (p. ej. 05/04/2010 codifica a un sujeto cuya primera actividad homicida se inicia el día cinco de abril de 2010). 
j. Fecha cese asesinatos (ordinal cerrada). Fecha será recogida en el formato "DD/MM/AAAA" (p. ej. 20/12/2013 codifica a un individuo cuyo último homicidio se culmina el día veinte de diciembre de 2013).

k. Fecha de detención (ordinal cerrada). Fecha será recogida en el formato "DD/MM/AAAA" (p. ej. 12/01/1991 codifica a un criminal que fue detenido por su relación con la actividad homicida el día doce de enero de 1991).

1. Periodo de actuación (numérica cerrada) (elección múltiple). Etapa/s durante la que el agresor desarrolló su actividad homicida.

m. Lugar de nacimiento (nominal abierta). Denominación del municipio o ciudad en el que nace el sujeto.

n. País de procedencia (nominal cerrada). Lugar de nacimiento.

o. Grupo racial (nominal cerrada). Conjunto étnico al que pertenece en función de sus rasgos físicos.

p. Estado civil (nominal cerrada) (elección múltiple). En caso de que varíe durante su periodo de actuación la codificación será múltiple.

q. Orientación sexual (nominal cerrada). En base al sexo biológico del individuo vendrá determinada por sus relaciones sexuales.

r. Número de hermanos (numérica cerrada). Comprende tanto a los hermanos biológicos como a los adoptivos, al igual que los que hayan fallecido antes del periodo homicida o durante el mismo.

s. Número de hijos (numérica cerrada). Engloba tanto a los hijos biológicos como a los adoptivos, así como también los que hayan fallecido antes del periodo homicida o durante su transcurso.

t. Ocupación (nominal semicerrada) (elección múltiple). En los supuestos en que varíe durante el periodo de actuación la codificación será múltiple.

u. Nivel educativo (ordinal cerrada).

Bajo: ausencia de estudios certificados.

Medio: comprende la franja localizada entre el nivel bajo y alto.

Alto: estar en posesión de estudios universitarios.

v. Nivel económico. (ordinal cerrada).

Bajo: si presenta dificultades para satisfacer las necesidades básicas.

Medio: las necesidades básicas están satisfechas e, incluso, pueden llegar a satisfacerse otras secundarias.

Alto: se satisfacen todas las necesidades y se mantiene en una posición económica superior a la de la media de la población de su sociedad, pudiéndose permitir llevar una vida de lujos.

w. Creencia religiosa (nominal semicerrada). Serán inferidas de las conductas y evidencias con las que, el sujeto, las expresa o plasma (p. ej. en las páginas de un diario en que hace referencia a una divinidad, etc.).

x. Ideología política (nominal semicerrada). Debe ser extraída del comportamiento o manifestaciones del sujeto cuando esta no sea explicita (p. ej. de un manifiesto confeccionado por el homicida). 
y. Otros aspectos relevantes (abierta). En ella debe ser recogido cualquier dato sociodemográfico de interés para el caso (p. ej. que el sujeto haya sido criado en adopción).

2. VARIABLES PSICOLOGICAS. Grupo de variables que recogen datos que el agresor manifiesta en el periodo de actuación homicida (incluyendo tanto los actos criminales en todas sus fases, como el posterior enfriamiento emocional). Queda excluida de este grupo la información relativa a otros periodos temporales, ocupándose de ella los grupos de "antecedentes en la infancia y adolescencia" e "historial edad adulta".

a. Coeficiente intelectual (ordinal cerrada). Inferido a través de su conducta o extraído de datos objetivos sobre el mismo.

Bajo: si de sus actos se deducen signos de discapacidad intelectual, su diagnóstico o un nivel inferior a la media.

Medio: comprende a todos aquellos sujetos que se encuentran dentro de la franja media.

Alto: cuando de su conducta se infiere que el individuo puede ser tener superdotación o un nivel superior a la media.

b. Rasgos psicopáticos (nominal cerrada) (elección múltiple). Deberán ser extraídos a través de las conductas manifestadas por el sujeto o informes realizados por profesionales de la Psiquiatría o la Psicología. Los rasgos son los siguientes (Garrido \& Sobral, 2008):

Falta de empatía: incapacidad de ponerse en el lugar de los demás, sobre todo emocionalmente.

Manipulación/mentira: uso de recursos ajenos a la verdad, así como distorsión de la realidad para conseguir sus fines o por el mero placer de hacerlo.

Versatilidad criminal: realización de varios actos delictivos de distinta índole.

Falta de responsabilidad: despreocupación por las obligaciones y los compromisos sociales, laborales, familiares y/o culturales.

Encanto superficial: capacidad para generar en los demás una valoración positiva sobre su persona.

Egocentrismo y elevada autovalía: elevado nivel de narcisismo y arrogancia. Fe ciega en sus capacidades y la superación de obstáculos.

Impulsividad: incapacidad para regular la respuesta conductual y tener una actitud reflexiva.

Falta de culpa: ausencia de preocupación por los efectos de sus actos en los demás.

Estilo de vida parasitario: dependencia económica y/o material buscada y provocada respecto a terceras personas de las cuales se aprovecha,

Promiscuidad sexual: establecimiento de contacto sexual con múltiples personas en distintos momentos sin tener una relación estable o duradera. 
Superficialidad afectiva: imposibilidad de experimentar emociones fuertes, intensas y profundas.

c. Implicación en la vida social (ordinal cerrada). Será inferida de sus hábitos y la práctica de sus relaciones sociales, tanto por el número de las mismas como por el tiempo que invierte en ellas.

Baja: si apenas mantiene relaciones sociales o estas son muy escasas y poco activas.

Media: cuando el sujeto se relaciona con otros miembros de la sociedad de forma normal.

Alta: comprende aquellos supuestos en los que el individuo destaca por una gran actividad social, con un gran número de lazos de amistad, compañerismo, etc.

d. Disfunción sexual (variable nominal cerrada). Señala la presencia de una alteración en la función sexual del individuo.

e. Presencia de parafilias (nominal semicerrada) (elección múltiple). Las parafilias consisten, de acuerdo con el DSM-IV, en «la presencia de repetidas e intensas fantasías sexuales de tipo excitatorio, de impulsos o comportamientos sexuales que, por lo general, engloban objetos no humanos, sufrimiento o humillación de uno mismo o de la pareja, niños $\mathrm{u}$ otras personas que no consienten, con presencia durante al menos 6 meses en la vida del sujeto» (Otín del Castillo, 2009, p. 62). Entre estas se han destacado las siguientes:

- Voyeurismo: se trata de observar a personas que se están desnudando, que están sin ropa o que practican un acto sexual, lo cual generalmente se hará de forma oculta, con el fin de obtener su propio placer sexual

- Fetichismo: consiste en el uso de objetos (denominados fetiches) a fin de lograr la excitación. Un ejemplo prototípico es el empleo de ropa interior femenina por parte de algunos varones para lograr la erección.

- Pedofilia: su rasgo fundamental es la presencia de un deseo sexual o excitación a través de actividades sexuales con niños prepúberes, que aún no manifiestan rasgos adultos.

- Sadismo/masoquismo: consiste en la obtención de placer sexual mediante el sufrimiento propio (masoquismo) o ajeno (sadismo), lo cual lleva en muchos casos implícita su causación.

- Necrofilia: hace referencia a obtener placer y/o atracción sexual con un cuerpo humano sin vida.

- Otra (especificar): existen muchos tipos de parafilias, en este punto se englobarían todos los que no han sido recogidos anteriormente como por ejemplo el travestismo, froteurismo, coprofilia, urofilia, necrofilia, bestialismo, etc.

f. Mantiene relaciones de pareja prolongadas (nominal cerrada). Relación afectiva mantenida durante un tiempo razonable (con un mínimo de varios meses). 
g. Patología mental diagnosticada (nominal semicerrada). Deberá ser inferida a partir de información disponible sobre el sujeto en la que se precise que hay un diagnóstico de la misma.

h. Rasgos de la personalidad (nominal cerrada) (elección múltiple). Para la determinación de la presencia o no de estos rasgos debe atenderse a los criterios diagnósticos establecidos en el DSM-V.

i. Otros rasgos conductuales (nominal semiabierta). Engloba los rasgos no incluidos o que hayan podido ser reflejados en la variable anterior y que sean relevantes en términos psicopatológicos.

j. Recibe tratamiento psicopatológico (nominal semicerrada). Incluye tanto el internamiento en centro psiquiátrico como cualquier otro tipo de tratamiento fuera de él.

k. Abuso de sustancias (nominal semicerrada) (elección múltiple). Se manifiesta cuando un individuo ve perturbado el normal funcionamiento de su vida a causa del consumo de una sustancia.

1. Desencadenante para los actos (nominal semicerrada). Hace referencia a un evento vital del sujeto que precipita el inicio de la actividad homicida. Debe existir contingencia temporal entre el suceso y dicho comienzo.

m. Reconocimiento de los actos (nominal cerrada). Hace referencia a si el agresor reconoce los hechos por los que ha sido condenado o no.

n. Muestra de arrepentimiento (nominal cerrada). Variable relacionada y que debe ser extraída, especialmente, de las declaraciones y los testimonios que presta el agresor, así como de sus conductas.

o. Otros aspectos relevantes (abierta). Relacionadas con las variables psicológicas del agresor y que no hayan podido ser recogidas anteriormente o no quepa la posibilidad de contemplarla en el "historial edad adulta".

3. ANTECENDENTES INFANCIA Y ADOLESCENCIA. Conjunto de variables que agrupan características y circunstancias relacionadas con los primeros años de vida del agresor, a fin de unificar posiciones se entenderá aproximadamente como final de esta etapa y comienzo de la edad adulta los 18 años.

a. Pérdida de alguien muy significativo del entorno (nominal semicerrada). En el caso de concurrir, precisar quién.

b. Negligencia o abandono (nominal semicerrada). En caso de existir, especificar el entorno del que proviene.

c. Abuso sexual (nominal semicerrada). En el caso de existir, especificar el entorno del que proviene.

d. Maltrato físico (nominal semicerrada). En el caso de existir, especificar el entorno del que proviene.

e. Maltrato psicológico (nominal semicerrada). En el caso de existir, especificar el entorno del que proviene. 
f. Otros eventos traumáticos (nominal semicerrada). Recoge aquellos sucesos con potencial traumático en los que el sujeto se haya visto envuelto y hayan podido generar un impacto en el mismo.

g. Conductas disfuncionales (nominal semicerrada). Conductas inapropiadas o socialmente inadecuadas como:

- Enuresis: falta para controlar la micción.

- Crueldad con los animales: maltrato animal.

- Piromanía: provocación intencional de incendios que resulta placentera para el individuo.

- Baja o nula vida social: relaciones pobres o inexistentes con el entorno.

- Fugas: huidas o abandonos inapropiados del hogar.

- Hurtos/robos: sustracción de efectos que no son de su propiedad.

- Amenazas: conductas intimidatorias con finalidad de coaccionar, etc.

- Peleas: reyertas con episodios de agresión física y verbal, que pueden surgir en diferentes entornos.

- Conductas sexuales: comportamientos sexuales inapropiados por el contenido o la inadecuación de los mismos a la edad del individuo.

- Destrucción de la propiedad/vandalismo: violencia sobre bienes materiales, muebles o inmuebles.

- Expulsiones: referido al ámbito escolar, separación temporal o traslado de un centro escolar por problemas de conducta.

- Promiscuidad sexual: establecimiento de relaciones sexuales polígamas.

- Otras (especificar): cualquier otra conducta disfuncional no citada anteriormente.

h. Patología mental (nominal semicerrada). Puede ser inferida a partir de su conducta o porque haya un diagnóstico sobre la misma.

i. Recibe tratamiento psicopatológico (nominal semicerrada). Incluye tanto el internamiento en centro psiquiátrico como cualquier otro tipo de tratamiento fuera de él.

j. Rasgos/conductas alteradas (nominal semiabierta). Presencia de conductas o rasgos que sean atípicos, que salgan de la normalidad.

k. Otros aspectos relevantes (abierta). En este espacio deben ser recogidos aspectos importantes que no hayan sido especificados con anterioridad y referidos a este periodo temporal, como puede ser el abuso de una determinada sustancia psicotrópica o estupefaciente, etc.

4. HISTORIAL EDAD ADULTA. Conjunto de variables que recogen aspectos relativos a la vida adulta del sujeto, entendiéndose como punto de partida de la misma aproximadamente los 18 años y excluyendo el periodo homicida.

a. Pérdida de alguien muy significativo del entorno (nominal semicerrada). En caso de existir, especificar conducta y la persona responsable. 
b. Abuso/agresión sexual (nominal semicerrada). En caso de existir, especificar el entorno del que proviene.

c. Maltrato físico (nominal semicerrada). En caso de existir, especificar el entorno del que proviene.

d. Maltrato psicológico (nominal semicerrada). En caso de existir, especificar el entorno del que proviene.

e. Otros eventos traumáticos (nominal semicerrada). Recoge aquellos sucesos con potencial traumático en los que el sujeto se haya visto envuelto y hayan podido generar un impacto en el mismo.

f. Conductas disfuncionales (nominal semicerrada) (elección múltiple). Engloba aquellos comportamientos desviados o mal vistos socialmente. Estos deberán ser extraídos de la información disponible sobre el sujeto. Entre ellos se han destacado:

- Litigios: en el caso de que el individuo se haya visto envuelto en conflictos de intereses que han llegado a órganos/autoridades jurisdiccionales.

- Otros actos agresivos: exceptuando las acciones de asesinato y lo adyacente al mismo, es posible que el individuo se vea envuelto en actos, aunque estos sean menores, del orden de peleas callejeras, etc.

- Actos temerarios: conductas de riesgo como conducción extrema de vehículo, etc.

- Problemas o inestabilidad laboral/escolar: dependiendo de la edad del individuo estudiado es posible que presente problemas de adaptación escolar, que haya sido expulsado de los centros en repetidas ocasiones o que no logre mantener un trabajo en el tiempo.

- Otros (especificar): en este punto deben ser recogidas otras conductas disfuncionales no reseñadas anteriormente.

g. Patología mental (nominal semicerrada). Puede ser inferida a partir de su conducta o porque haya un diagnóstico sobre la misma.

h. Recibe tratamiento psicopatológico (nominal semicerrada). Incluye tanto el internamiento en centro psiquiátrico como cualquier otro tipo de tratamiento fuera de él.

i. Abuso de sustancias (nominal semicerrada) (elección múltiple). Se manifiesta cuando un individuo ve perturbado el normal funcionamiento de su vida a causa del consumo de una sustancia.

j. Otros aspectos relevantes (abierta). Engloba todos aquellos aspectos a los que no se ha hecho referencia en las variables del grupo y que pueden resultar relevantes para el análisis de la vida adulta agresor.

5. ANTECEDENTES FAMILIARES. Conjunto de variables que contemplan aspectos relativos a la familia en que el agresor se desarrolla y socializa. Generalmente es el entorno en el que vivirá durante su infancia, adolescencia y parte de la juventud, extendiéndose en algunos casos también a la edad adulta. 
a. Antecedentes de patología mental (nominal cerrada) (elección múltiple). Serán extraídos de datos relativos al historial familiar del agresor.

b. Funcionalidad familiar (nominal semiabierta). Referida a si la familia en que se cría el sujeto es apta para un buen desarrollo y socialización, sin que por ello tenga que tener los componentes que se toman como prototípicos (p. ej. una familia monoparental puede resultar ser perfectamente funcional).

c. Nivel socioeconómico (ordinal cerrada). Variable relativa al nivel de ingresos y estatus que la familia ocupa respecto a la sociedad en que habita.

Bajo: si presenta dificultades para satisfacer las necesidades básicas.

Medio: las necesidades básicas están satisfechas e, incluso, pueden llegar a satisfacerse otras secundarias.

Alto: se satisfacen todas las necesidades y se mantiene en una posición económica superior a la de la media de la población de su sociedad, pudiéndose permitir llevar una vida de lujos.

d. Otros problemas (nominal semiabierta). Engloba otros problemas que se manifiestan en la sociedad actual como:

- Hacinamiento: se produce en aquellos casos en que un número excesivamente elevado de personas conviven en un mismo espacio.

- Inmigración: concurre cuando un individuo, familia o grupo se traslada a un país o región distinta a la de procedencia.

- Desempleo: falta de trabajo remunerado.

- Otros (especificar): cualquier otro que no se encuentre entre los recogidos anteriormente.

e. Otros aspectos relevantes (nominal abierta). Comprende aquel conjunto de circunstancias a las que no se ha hecho referencia en las variables precedentes y que pueden ser de relevancia para el estudio de los antecedentes familiares de agresor.

6. HISTORIAL DELICTIVO Y DE VIOLENCIA. Grupo de variables relacionadas con las actividades violentas y criminales del agresor.

a. Episodios previos de violencia (nominal semicerrada). Se refiere a momentos o tiempos anteriores a la actividad homicida en los que el agresor ha podido cometer otro tipo de hechos delictivos o violentos.

b. Antecedentes policiales (nominal cerrada). Historial de sanciones policiales (aunque no hayan llegado a considerarse de tipo penal). En cualquier caso, los antecedentes penales deben ser considerados también policiales, pero no necesariamente a la inversa.

c. Condenas previas (nominal cerrada). Castigos que ha recibido el agresor, para lo cual, generalmente, deberá atravesar un procedimiento judicial que conduzca a la sentencia (condenatoria) del tribunal 
encargado del enjuiciamiento de la causa. En caso de sentencias absolutorias no debe ser tomado en cuenta.

d. Estancia en prisión (numérica de intervalo cerrada). En caso de concurrir, periodo de tiempo que el sujeto ha pasado recluido en un centro penitenciario o institución análoga.

e. Otros aspectos relevantes (abierta). Engloba cualquier cuestión relevante relacionada con el epígrafe y que pueda resultar de importancia.

7. ESCENA. Conjunto de variables que recogen características y elementos relacionados con los escenarios del crimen. Para ello, cabe precisar que entendemos por escena del crimen, de acuerdo con Turvey (2008), el «escenario donde el agresor y la víctima interactúan y donde, según el principio de transferencia de Locard, algo de cada uno de los actores se transferirá al otro dejando una huella que debe ser observada, recogida y analizada» (en Jiménez Serrano, 2010, p. 59). A lo cual cabe añadir «cualquier lugar en el que se encuentran evidencias (tanto físicas como psicológicas) que resultan relevantes para el esclarecimiento del hecho criminal» (Sánchez y Cabezas, 2015).

a. Número de crímenes (numérica abierta). Hace referencia al número de actos (separados por un periodo de enfriamiento emocional). Es decir, recoge los sucesos y no las víctimas derivadas de los mismos, ya que, de un mismo acto, pueden resultar varias víctimas. En esta variable, serán contabilizados tanto los asesinatos/homicidios consumados como las tentativas.

b. Número máximo de escenas por crimen (numérica cerrada). Se refiere al crimen que presenta un mayor número de escenas. Para su determinación no se tendrán presentes las tentativas sino, únicamente, los hechos consumados.

c. Número mínimo de escena por crimen (numérica cerrada). Se refiere al crimen que presenta un menor número de escenas. Para su determinación no se tendrán presentes las tentativas sino, únicamente, los hechos consumados.

d. Ubicación de las escenas (nominal cerrada). Tipo de entorno en el que se ubican las escenas. Distinguiéndose entre:

- Área urbana: si se trata de una ciudad.

- Zona urbana: espacio urbanizado dentro de un gran núcleo urbano (p. ej. una calle, un edificio, etc.).

- Zona no urbana: lugares no edificados encuadrados en un área urbana (p. ej. parques, descampados, etc.).

- Área rural: si se trata de un espació interurbano o una pequeña población.

- Zona urbana: comprende los núcleos urbanos de pequeñas poblaciones encuadradas en un área rural (p. ej. una calle de una aldea, etc.). 
- Zona no urbana: engloba todos aquellos terrenos naturales situados en áreas rurales en los que no se sitúa una zona poblacional (p. ej. un monte, la ribera de un río, etc.).

e. Coincidencia entre punto de contacto y punto de ataque (nominal cerrada) (recuento víctimas). Se entiende por punto de contacto el lugar en el que agresor y víctima confluyen por primera vez. El punto de ataque es el lugar donde el criminal asalta a la víctima.

f. Coincidencia entre escena primaria y escena de abandono del cadáver (nominal cerrada) (recuento víctimas). Se entiende por escena primaria el lugar en el que víctima y agresor mantienen una mayor interacción. Mientras que la escena de abandono del cadáver es aquella en la que el agresor se deshace del cuerpo de la víctima.

g. Tipos de escena (nominal cerrada) (elección múltiple). Se considerará para su determinación los lugares de todos los crímenes (incluidas las tentativas). Según la clasificación de escenas de Turvey (2008) (en Jiménez Serrano, 2010) posteriormente modificada por Sánchez y Cabezas (2015) se distinguen los siguientes tipos de escena:

- Primaria: lugar en el que se produce la mayor interacción (tanto a nivel cualitativo como cuantitativo) entre víctima y agresor.

- Secundaria: toda escena en la que se produce una interacción entre víctima y agresor pero que no es primaria.

- Terciaria: escena relevante para el esclarecimiento del hecho, en la que se presentan efectos intervinientes en el mismo, pero en la que no se ha producido una interacción entre víctima y agresor.

- Intermedia: toda escena ubicada entre dos escenas secundarias, la primaria y una secundaria o viceversa y que sirve, en esencia, para transportar a la víctima o víctimas del crimen de un punto a otro. Es un subtipo de escena secundaria.

h. Tipos de localización (nominal cerrada) (elección múltiple). Se tendrán en cuenta los lugares de todos los crímenes (incluidas las tentativas). De acuerdo a lo establecido por Turvey (2008) (en Jiménez Serrano, 2010) existen los siguientes tipos de localización en base al ambiente en que se ubica la escena:

- Interior: espacios cerrados y cubiertos como un domicilio, un garaje, un centro educativo, etc.

- De vehículo: comprende tanto turismos como otros vehículos (camiones, barcos, trenes, etc.).

- Exterior: lugares abiertos como puede ser la vía pública, espacios naturales, etc.

- Bajo el agua: lugar cubierto por agua como un pantano, un río, un pozo, etc.

- Bajo tierra: espacio cuya característica principal es estar soterrada.

i. Presencia de evidencias físicas en las escenas (nominal semiabierta) (elección múltiple). Vestigios de tipo físico dejados por el autor a consecuencia de la comisión del hecho. Se distingue entre: 
- Indicios lofoscópicos: engloba tanto la presencia impresa como latente de huellas dactilares, palmares, plantares, etc.

- Indicios biológicos: vestigios de materiales de naturaleza biológica, tales como sangre, semen, saliva, sudor, etc. y a partir de los cuales, en muchos casos, es posible extraer un perfil genético.

- Indicios balísiticos: rastros relacionados con el uso o empleo de armas de fuego.

- Indicios de fibras: restos de materiales textiles, que pueden resultar importantes para el esclarecimiento del hecho.

- Otros indicios: cualquier evidencia de otra naturaleza que sea de relevancia para la investigación.

j. Alteración de las escenas (por causas ajenas al agresor) (nominal cerrada) (recuento crímenes). Modificación de los elementos o efectos del escenario criminal por causas ajenas a la voluntad del agresor. La causa más típica es la acción de los agentes meteorológicos. 
8. MODUS OPERANDI. Grupo de variables que reúnen elementos relativos al modus operandi del agresor, entendido como el «conjunto de actos estrictamente necesarios para perpetrar el delito y obtener éxito en su comisión» (Soto, 2014, p. 58):

a. Nivel de planificación (ordinal cerrada). Referida a la proyección que el agresor tiene sobre el acto criminal y que se reflejará en todas las fases del crimen, a partir de las cuales debe ser inferida.

b. Periodo mínimo entre crímenes (ordinal cerrada). Tiempo mínimo que transcurre entre crímenes, que no entre asesinatos (dado que en un mismo crimen puede haber varios asesinatos). Se incluyen las tentativas.

c. Periodo máximo entre crímenes (ordinal cerrada). Tiempo máximo que transcurre entre crímenes. Se incluyen las tentativas.

d. Tiempo mínimo probable empleado en las agresiones (ordinal cerrada). Tiempo mínimo en el que el agresor habrá cometido un crimen. Debido a que es un dato de difícil obtención en gran parte de la casuística, deberá ser inferido a partir de los actos que el criminal realiza con la víctima.

e. Tiempo máximo probable empleado en las agresiones (ordinal cerrada). Tiempo máximo que el agresor habrá invertido en la comisión de un crimen. Debido a que es un dato de difícil obtención, en gran parte de la casuística, deberá ser inferido a partir de los actos que el criminal realiza con la víctima.

f. Implicación de terceras personas en la planificación y/o inducción (nominal semiabierta) (recuento víctimas). Referida al hecho de que terceros, ajenos a la comisión del hecho, hayan participado en la elaboración de un plan de comisión o en el surgimiento de la idea criminal en el delincuente. En algunas ocasiones, es posible encontrar un trasfondo sectario.

g. Implicación de terceras personas en la ejecución (nominal semiabierta) (recuento víctimas). Relativa a la presencia de otros sujetos en la comisión de la agresión. En caso de respuesta afirmativa nos encontraríamos con un caso de pareja o grupo homicida.

h. Toma de contacto con las víctimas (nominal semiabierta) (recuento víctimas). Modo en que el criminal establece conexión directa con la víctima. Puede ser física (p. ej. lugares de ocio nocturno o zonas de prostitución), a través de internet (p. ej. foros o redes sociales virtuales), o de otra forma.

i. Seduce a las víctimas (nominal cerrada) (recuento víctimas). Enfocada a si el agresor utiliza la seducción (no solo sexual) para aproximarse a la víctima y/o ganarse su confianza o no.

j. Método de aproximación (nominal cerrada) (recuento víctimas). Establecido por Turvey (2008) (en Jiménez Serrano, 2010) ampliado por Sánchez y Cabezas (2015) es la estrategia que el agresor emplea para acercarse a la víctima, distinguiéndose entre:

- Explícito: el agresor se acerca a la víctima con la intención clara y manifiesta de efectuar el ataque, siendo esta consciente de ello y teniendo, de este modo, un breve tiempo de reacción. 
- Súbito: el agresor toma contacto con la víctima y, sin dilación, efectúa el ataque.

- Sorpresa: el criminal sorprende a la víctima en un momento en que esta es vulnerable, bien porque está centrada en la ejecución de una tarea, bien porque está distraída, dormida, etc.

- Encubierto: el criminal se aproxima a la víctima sin manifestar ningún tipo actitud hostil de la que pueda inferirse una agresión $\mathrm{y}$, solamente, cuando esta puede ser efectiva realiza el ataque.

- Engaño: el agresor se gana la confianza de la víctima empleando tretas.

- Se desconoce: no hay datos sobre cómo se produce la aproximación del agresor a la víctima.

k. Método de ataque (forma) (nominal cerrada). Establecido por Turvey (2008) (en Jiménez Serrano, 2010) es el mecanismo que el agresor utiliza para sobreponerse inicialmente a la víctima una vez realizado el acercamiento. Se diferencia entre:

- Amenaza verbal: el agresor, tras la aproximación, amenaza a la víctima verbalmente para someterla.

- Uso de la fuerza con o sin arma: el agresor ataca a la víctima con violencia física, pudiendo ser con o sin arma.

- Amenaza verbal y uso de arma: el agresor amenaza a la víctima con agredirla con un arma si no se somete a sus exigencias.

- Se desconoce: no hay constancia de datos sobre el mecanismo con que el agresor se sobrepone a la víctima.

1. Método de ataque (ejecución) (nominal cerrada) (recuento víctimas). Establecido por Sánchez y Cabezas (2015) es el modo en el que se efectúa el ataque. Diferenciando:

- Relámpago: el agresor ataca a la víctima de manera rápida y contundente de forma que no le permite capacidad de reacción.

- Falible: la víctima es agredida pero el ataque no es suficientemente efectivo como para eliminar su capacidad de reacción, y esta tiene oportunidad de defenderse o evitarlo. En estos casos las víctimas suelen presentan heridas defensivas.

- Trampa: el agresor prepara un escenario de ataque donde la víctima no es consciente de que va a ser atacada. Requiere dilación entre que se prepara el escenario y se materializa el ataque. No es necesario que el criminal esté en ese momento en la escena.

- Tóxico: la víctima está siendo atacada por medio de algún tipo de agente tóxico pero no es consciente de ello. Un ejemplo típico es el de envenenamiento prolongado mediante la comida.

- Se desconoce: no hay datos acerca de cómo se produce el ataque a la víctima.

m. Método de control (nominal cerrada) (recuento víctimas). Establecido por Turvey (2008) (en Jiménez Serrano, 2010) como aquellos utilizados para manipular, regular, contener y someter la conducta de la víctima durante la agresión. En el caso de concurrir, se distingue entre: 
- Amenaza verbal: si el criminal amenaza a la víctima con causarle lesiones o realizar algún acto perjudicial para la misma.

- Usando la fuerza: cuando el agresor emplea la violencia física para someter y manejar a la víctima.

- Con presencia de armas: en los casos en que se exhibe un arma, de cualquier tipo, para intimidar y conseguir el control de la víctima.

- Otro (especificar): cuando el método de control no está comprendido en los anteriores.

n. Uso de sustancias con las víctimas (nominal semiabierta) (recuento víctimas). Concurre en aquellos supuestos en los que el criminal emplea sustancias con la víctima o víctimas que favorezcan la comisión de los hechos criminales.

o. Secuestra a las víctimas (nominal cerrada) (recuento víctimas). Para su determinación habrá que tener en cuenta si el agresor retiene a las víctimas en contra de su voluntad durante un periodo de tiempo que va más allá de la comisión del acto homicida y otros que puedan ser adyacentes al mismo (como puede ocurrir en aquellos casos en que el criminal agreda sexualmente a la víctima) o, por el contrario, la retención se limita al acto.

p. Clase de armas y utensilios empleados (nominal cerrada) (elección múltiple). En los casos en que el criminal utilice armas u otros instrumentos, estos pueden ser:

- Armas de oportunidad: objetos que usa el agresor como arma pero son tomados del escenario o de la víctima.

- Armas que porta: instrumentos que lleva el agresor consigo para cometer la acción.

q. Tipo de armas y utensilios empleados (nominal semiabierta) (elección múltiple). Si concurre el uso de estos instrumentos se distingue entre:

- Armas contundentes: objetos de tipo romo (piedras, bastón, etc.).

- Armas blancas: cualquier instrumento punzante, cortante, cortopunzante o corto-contundente.

- Armas de fuego: comprende tanto armas cortas (revólveres y pistolas) como armas largas (escopetas, rifles, etc.).

- Instrumentos de inmovilización: cualquier objeto que sirva para privar a la víctima de libertad de movimientos. Los más típicos son los grilletes, las cuerdas, las bridas, etc.

- Mordazas: instrumentos que, colocados en la boca, impiden la articulación verbal de la víctima.

- Otros (especificar): cualquier otra arma o instrumento empleado que no corresponda a las categorías anteriormente reseñadas.

r. Forma de causar la muerte (nominal semiabierta) (elección múltiple) (recuento víctimas). Se refiere al modo en que el agresor acaba con la vida de la víctima, a pesar de que puedan concurrir múltiples lesiones en esta variable solo deben ser contempladas aquellas que condujeron a la muerte de la víctimas. 
s. Actos de precaución (conciencia forense) (nominal semiabierta) (recuento crímenes). Se entienden como las «acciones que realiza el agresor antes, durante y después del crimen, para ocultar, confundir y despistar a los investigadores respecto a cómo sucedieron los hechos, y principalmente dirigidas a impedir su identificación» (Jiménez Serrano, 2010, p. 128).

t. Conductas de simulación en la escena (nominal semiabierta) (recuento crímenes). También denominada escena amañada. Se da «cuando la evidencia ha sido intencionalmente alterada por el delincuente para confundir a los investigadores y alejar las sospechas de él» (Garrido \& Sobral, 2008, p. 153).

u. Ocultación del cuerpo (nominal cerrada) (recuento víctimas). Se refiere al abandono del cuerpo (con o sin vida) de la víctima, por parte del agresor, en un lugar de difícil acceso o hallazgo.

v. Descuartizamiento para manipulación (nominal cerrada) (recuento víctimas). Relativa a aquellos casos en los que el criminal desmiembra el cuerpo o cuerpos de las víctimas a fin de facilitar su abandono o desaparición.

w. Tipo de vehículo empleado durante el crimen (nominal semiabierta) (elección múltiple) (recuento crímenes). Hace referencia al vehículo que el agresor utiliza en el transcurso de la comisión del crimen, no el que emplea para desplazarse al mismo, aunque en ocasiones este sea coincidente. Por lo tanto, cabe la posibilidad que el criminal emplee un vehículo para llegar al punto de comisión del hecho y para el abandono del mismo, pero si este no fuera empleado para alguna de las fases del crimen (traslado de la víctima, del cadáver o para la comisión del hecho en su interior) no será considerado en esta variable.

x. Franja horaria de comisión de los crímenes (nominal cerrada) (elección múltiple) (recuento crímenes). Se refiere a los momentos en que el criminal desarrolla su acción homicida. A fin de unificar criterios se entenderá:

- Mañana: 06:00-14:00 horas.

- Tarde: 14:00-22:00 horas.

- Noche: 22:00-06:00 horas.

y. Variación del modus operandi (nominal cerrada) (elección múltiple). El modus operandi puede variar o no, diferenciando entre:

- Evoluciona: si el agresor manifiesta mejoras en su forma de actuación, que puede presentarse a través de la asunción de nuevos actos de precaución, formas de captar a las víctimas más efectivas, etc.

- Involuciona-evoluciona: casuística en la que primeramente se produce una etapa de involución $\mathrm{y}$, posteriormente, una de evolución.

- Involuciona: en aquellos casos en que se vea una regresión en la forma o modo en que el criminal comete la acción. En ocasiones la involución llega por un exceso de confianza por parte del 
autor, mientras en otros puede venir precipitada por alguna adicción del sujeto, el curso de una enfermedad, etc.

- Evoluciona-involuciona: supuestos en los que inicialmente el sujeto evoluciona en su modus operandi pero, después, en una etapa posterior involucionar.

- Estático: si no varía a lo largo de los actos.

Cabe precisar que es posible que un criminal evolucione e involucione a lo largo de su ciclo homicida (caso en el que se seleccionarían ambas).

z. Otros aspectos relevantes (abierta). Engloba cualquier circunstancia conductual relacionada con el modus operandi que no haya podido ser recogido en las variables anteriores.

9. RITUAL. Grupo de variables referidas a aquellos aspectos de ritual, entendiendo este como el «patrón distintivo de conductas del agresor que le son características y que satisfacen necesidades psicológicas y emocionales» (Soto, 2014, p. 62).

a. Interacción verbal con las víctimas (nominal cerrada) (recuento víctimas). Relativa a si el agresor habla o no con sus víctimas. En caso de existir la interacción verbal puede catalogarse como agresiva, si emplea violencia verbal, o no agresiva, si no concurre violencia verbal, pudiendo concurrir ambas.

b. Relaciones sexuales con las víctimas ante-mortem (nominal semiabierta) (recuento víctimas). Existe en aquellos casos en que el agresor, antes de causar la muerte a la víctima, práctica sexo con ella.

c. Relaciones sexuales con las víctimas post-mortem (nominal semiabierta) (recuento víctimas). Concurre en los hechos en que el criminal, tras asesinar a la víctima, práctica sexo con ella.

d. Penetración en las relaciones sexuales (nominal cerrada) (recuento víctimas). Precisa si, en el caso de concurrir relaciones sexuales, hay o no penetración y el tipo de esta.

e. Introducción de objetos en órganos sexuales (nominal semiabierta) (recuento víctimas). Relativa a aquellos casos en los que el criminal utiliza algún instrumento, herramienta o fetiche para penetrar a la víctima, distinto a una parte de su cuerpo.

f. Conductas sádicas y de tortura (nominal semiabierta) (recuento víctimas). Concurren en los supuestos en que el agresor pretende provocar un gran sufrimiento en la víctima o víctimas, sufrimiento que trata alargar en el tiempo y a través del cual obtiene placer. Para ello el criminal inflige dolor y causa lesiones en la víctima sin que estas lleguen a provocarle un fallecimiento rápido.

g. Conductas de despersonalización (nominal semiabierta) (recuento víctimas). Relativas a actos efectuados por el criminal y que pretenden la cosificación de la víctima. Un ejemplo paradigmático es abandonar el cuerpo sin vida con el rostro cubierto por una prenda. 
h. Canibalismo (nominal cerrada) (recuento víctimas). Antropofagia. Se produce cuando el individuo ingiere, al menos, alguna parte del cuerpo de sus víctimas (cocinada o cruda).

i. Mutilación (nominal cerrada) (recuento víctimas). Descuartizamiento de la víctima o de alguno de sus miembros con una finalidad distinta a las del modus operandi.

j. Escenificación ritual (nominal cerrada) (recuento crímenes). Teatralización. Modificación o variación de la escena por parte del agresor cuya finalidad no es la de la simulación sino que responde a una necesidad psicológica del sujeto. Esta puede producirse tanto después de la comisión del crimen como en el transcurso del mismo.

k. Contacto con los medios de comunicación/policía (nominal semiabierta). Se entiende por este tanto el contacto directo como el indirecto a través de mensajes u objetos abandonados en la escena del crimen.

1. Toma "trofeos" de sus crímenes (nominal semiabierta) (recuento crímenes). Objetos que el individuo sustrae de las víctimas o de los escenarios del crimen y que «son un símbolo de victoria o de logro»o «recordatorios de una experiencia placentera» (Garrido \& Sobral, 2008, p. 178).

m. Otros aspectos relevantes (abierta). Recoge cualquier tipo de conducta ritual que no haya sido contemplada en las variables precedentes.

\section{COMPORTAMIENTO GEOGRÁFICO}

a. Zona de actuación (nominal semiabierta) (elección múltiple). Continente o zona en que el criminal ha desarrollado su ciclo asesino.

b. País/es de actuación (nominal abierta). Estado/s en los que el agresor ha actuado. Puede darse la circunstancia de que su acción sea trasnacional.

c. Desplazamiento al crimen (nominal cerrada) (elección múltiple). Referida al modo en que el criminal llega al lugar en que comete el hecho delictivo y abandona el mismo.

d. Punto de anclaje (nominal cerrada). Se entiende como «el lugar desde donde se parte para cometer el crimen y al que se regresa, usándose como punto de referencia» (Jiménez, 2010, p. 176).

e. Radio aproximado zona de seguridad (numérica de intervalo cerrada). En caso de existir punto de anclaje, se entiende por zona de seguridad aquella «zona cercana al punto de anclaje donde el agresor no actúa por miedo a ser reconocido» (Rossmo, 2000 en Jiménez, 2010, p. 176).

f. Distancia máxima de desplazamiento (numérica de intervalo cerrada). En caso de existir punto de anclaje, se refiere al espacio que el agresor recorre desde este hasta la escena más alejada del mismo.

g. Otros aspectos relevantes (nominal abierta). Comprende aquellos datos importantes para el análisis geográfico que no han podido ser recogidos con precedencia. 
11. VICTIMOLOGíA. Conjunto de variables relativas a las víctimas del agresor, tanto a la de sus hechos consumados como a las de sus tentativas, siempre y cuando sean hechos probados.

a. Número víctimas total (numérica abierta). Engloba el número de víctimas de sus tentativas y de sus hechos consumados.

b. Número víctimas mortales (numérica abierta). Se refiere, únicamente, a aquellas víctimas de asesinato, no de sus tentativas.

c. Sexo de las víctimas (nominal cerrada) (elección múltiple) (recuento víctimas). En su determinación se atenderá al sexo biológico del individuo, es decir, al que manifiestan sus órganos sexuales.

d. Edad de las víctimas (ordinal cerrada) (elección múltiple) (recuento víctimas). Diferenciándose entre:

Niños: hasta los 12 años.

Adolescentes: 12-17 años.

Adultos: 18-69 años.

Ancianos: a partir de los 70

e. Grupo racial de las víctimas (nominal cerrada) (elección múltiple) (recuento víctimas). Conjunto étnico al que pertenecen en función de sus rasgos físicos.

f. Orientación sexual de las víctimas (nominal cerrada) (elección múltiple) (recuento crímenes). En base al sexo biológico de las víctimas vendrá determinada por sus relaciones sexuales.

g. Relación con las víctimas (nominal semiabierta) (elección múltiple) (recuento víctimas). Para su determinación se atenderá a la pertenencia o no de estas a alguno de los grupos enumerados.

h. Selección de las víctimas (nominal cerrada) (elección múltiple). Para su concreción se emplea la clasificación de Turvey (2008) que precisa que «en la selección de la víctima influyen 6 factores»:

- Posibilidad: se refiere a la accesibilidad de la víctima para el criminal.

- Localización: se refiere al lugar donde se encuentra la víctima.

- Vulnerabilidad: la percepción de la posibilidad de ataque a la víctima sin que el criminal pueda sufrir daños o con peligro.

- Relaciones: la víctima es elegida por la relación que existe con el criminal.

- Simbolismo: la víctima es seleccionada porque tiene un significado para el criminal.

- Fantasía: la víctima es elegida porque puede satisfacer una particular fantasía del criminal.»

(En Jiménez Serrano, 2010, p. 211)

i. Riesgo rasgo de las víctimas (nominal cerrada) (elección múltiple) (recuento víctimas). Nivel de riesgo de victimización que, en una persona, se «suele mantener estable a lo largo de un periodo de tiempo» (Jiménez Serrano, 2010, p. 207). Para su determinación se diferencia entre los siguientes niveles de riesgo: 
- Bajo: «personas que no suelen estar expuestas a riesgos que les lleven a ser probables víctimas. Las conductas que realizan por acción u omisión, les permiten estar alejadas de posibles criminales» (ibíd.).

- Medio: «personas que a veces suelen estar expuestas a algún tipo de riesgo que les hacen ser unas probables víctimas. No todos, pero sí algunos hábitos de vida les hacen ser proclives en algunas ocasiones a convertirse en víctimas» (ibíd.).

- $\underline{\text { Alto: }}$ «personas que de forma rutinaria se ven expuestas a muchos riesgos que hacen que sea muy probable que tarde o temprano se conviertan en víctimas» (ibíd.).

j. Riesgo estado de las víctimas (nominal cerrada) (elección múltiple) (recuento víctimas). Se refiere al riesgo que presenta la víctima ante una determinada situación.

k. Características comunes de las víctimas (nominal abierta). En este espacio deberán ser recogidas características que no hayan podido contemplarse en la variables victimológicas anteriores, que sean compartidas por las víctimas y que, por lo tanto, puedan tener relevancia para el perfil victimológico del agresor.

l. Otros aspectos relevantes (nominal abierta). Recoge la información victimológica de importancia que no haya podido ser contemplada en las variables anteriores. 


\section{TIPOLOGÍAS}

En Jiménez, 2010.

a. Tipo 1 (FBI) (nominal cerrada).

- Organizado:

- Desorganizado:

Agresión planeada

Víctima extraña

Personaliza a la víctima

Agresión espontánea

Controla la conversación

Controla la escena del crimen

Hace sumisa a la víctima

Usa métodos de control

Muchos actos agresivos

Traslada el cadáver

Usa armas

Víctima conocida

Despersonaliza a la víctima

No habla con la víctima o muy poco

La escena del crimen es

caótica

Violencia súbita

No usa métodos de control

Realiza sexo después de la muerte

No traslada el cadáver

No usa armas o son de oportunidad

Deja pocos indicios en la escena

Hay muchos indicios en la escena

- Mixto: no predomina ningún conjunto de características propias de una u otra categoría.

b. Tipo 2 (Canter y Salfati, 1999) (nominal cerrada).

- Instrumental-cognitivo: racional, intencionado, planificador. Su asesinato tiene intencionalidad y persigue un objetivo. Suele planear sus crímenes y no suele haber muchas evidencias forenses debido a la experiencia delictiva del agresor.

- Instrumental-oportunista: también presente la intencionalidad, que obedece a la obtención de algún beneficio con su víctima. La elección de la víctima es oportunista, por estar en un lugar y momento propicios para el agresor. El arma suele ser de oportunidad o las propias manos. Crímenes relacionados con robos o agresiones sexuales.

- Expresivo-impulsivo: actúa como respuesta a un estado emocional intenso. Su crimen es el resultado de la ira o la venganza contra la víctima. El ataque suele producirse de forma repentina, con un ataque fulgurante y explosivo que provoca mucho daño y heridas en la víctima. Sus crímenes no son fríos ni planificados, sino arrebatos de furia contra un tipo concreto de víctima que tiene un significado para el asesino.

c. Tipo 3 (Holmes y DeBerguer, 1988) (nominal cerrada).

- Visionario: es un psicótico que tiene alucinaciones auditivas que le incitan a matar.

- Misionario: no tiene alucinaciones. Elabora una idea delirante en la que tiene la misión de acabar con un determinado colectivo (p. ej. prostitutas, drogadictos, vagabundos...). Se cree un salvador, un redentor. 
- Hedonista: mata por el puro placer que le produce acabar con la vida de otra persona.

- Dominante: mata por la sensación de poder que le produce tener en sus manos la vida y la muerte de otra persona. Busca la sensación de poder y control.

d. Tipo 4 (Fox y Levin) (nominal cerrada).

- Emocional: se mueve por la sensación de experimentar sensaciones fuertes.

- Sádico: se excita con el dolor de la víctima.

- Dominante: necesita experimentar la sensación de dominación y control sobre la víctima.

- Misionario: cree que tiene una misión que cumplir con sus asesinatos.

- Reformista: no tiene alucinaciones.

- Visionario: sí las tiene.

- Por conveniencia: consigue un beneficio con sus víctimas.

- Saca provecho (p. ej. sicario, asesino a sueldo).

- Protector: asesina para eliminar testigos y protegerse.

e. Tipo 5 (Canter, 2005) (nominal cerrada).

- Merodeador: avalan la hipótesis del círculo. Agresores que viajan desde su base o puto de anclaje hasta el lugar del crimen para posteriormente regresar a la base.

- Viajero: no viven dentro del círculo. Viajan desde su base hacia otro lugar y es aquí donde establecen una zona de acción donde cometen sus crímenes.

f. Tipo 6 (Rossmo 1995) (nominal cerrada) (elección múltiple).

- Cazador: busca a sus víctimas en los alrededores de donde vive.

- Cazador furtivo: actúa en un área específica que es distinta a donde vive.

- Pescador: actúa en su zona de actividad rutinaria, donde trabaja, se divierte... buscando la víctima y la situación oportuna.

- Trampero: usa artimañas y situaciones para llevar a la víctima a su punto de anclaje, y es allí donde comete el delito.

13. FUENTES CONSULTADAS. En este apartado abierto se recogerán todas aquellas fuentes consultadas de las que se haya extraído información para la cumplimentación del informe. Para ello se seguirán las normas dictadas por la American Psychological Association (APA). 
ANEXO 2. FICHA DE VARIABLES DEL ESTUDIO COMPARATIVO
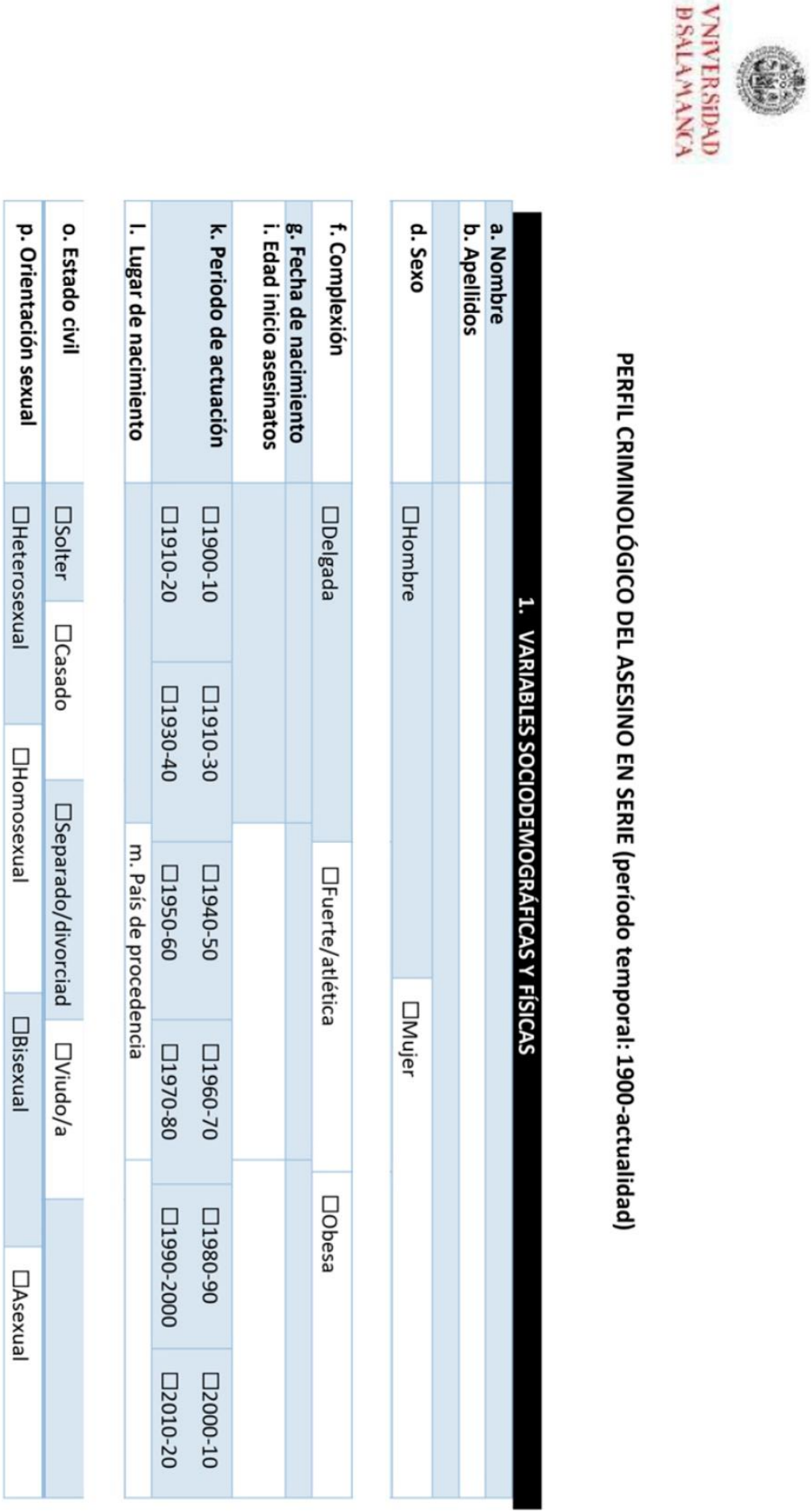

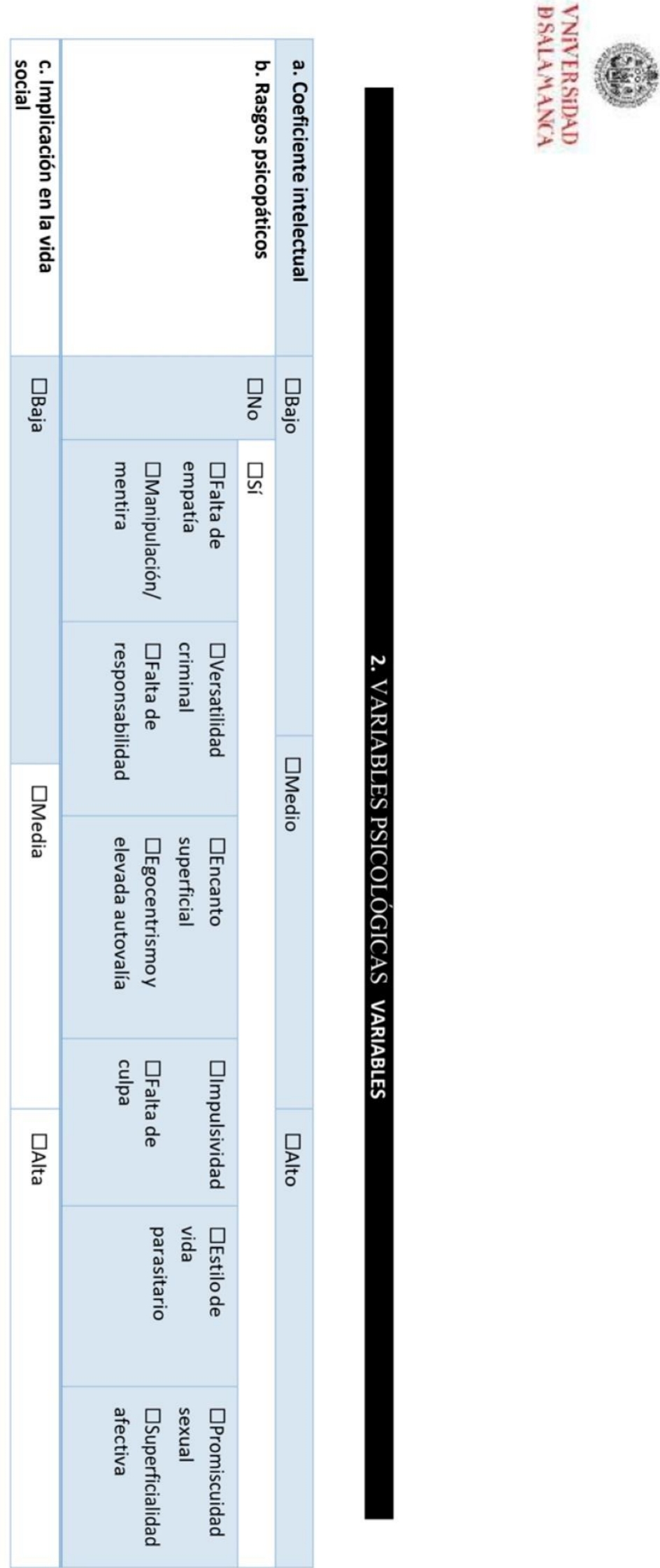


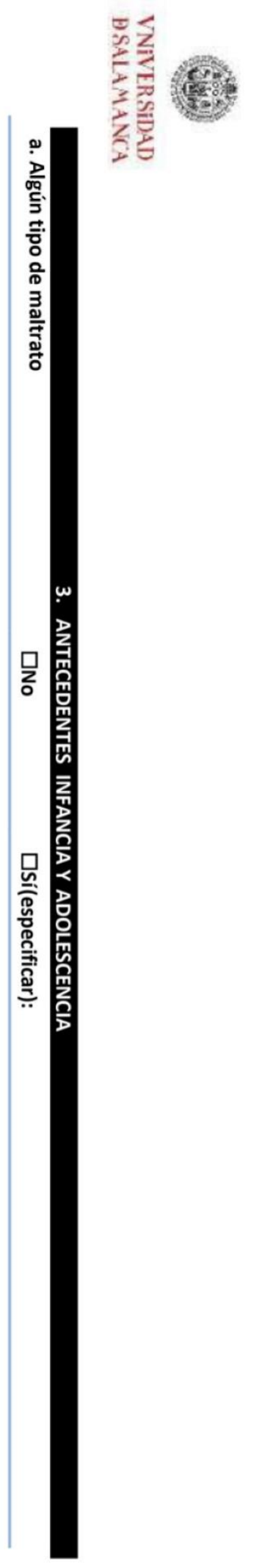




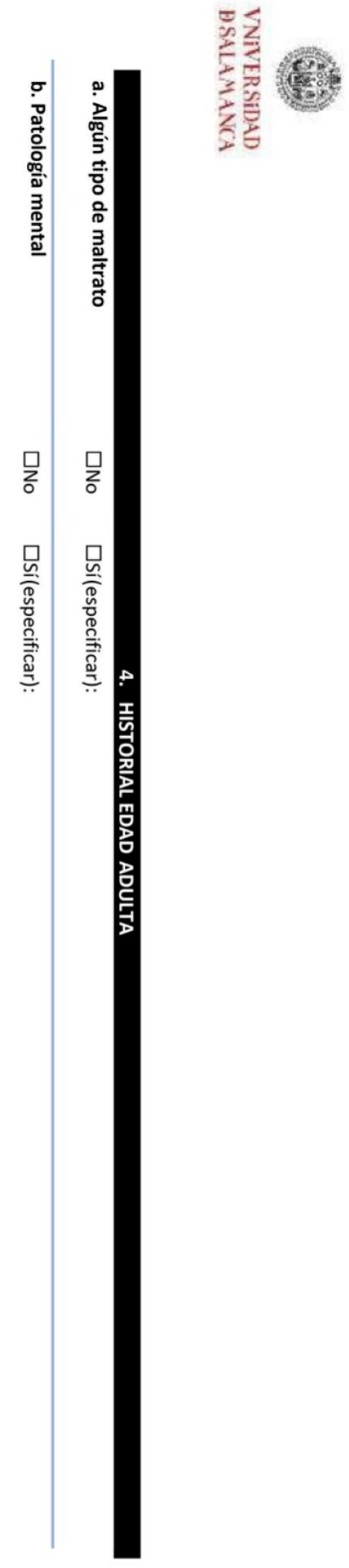




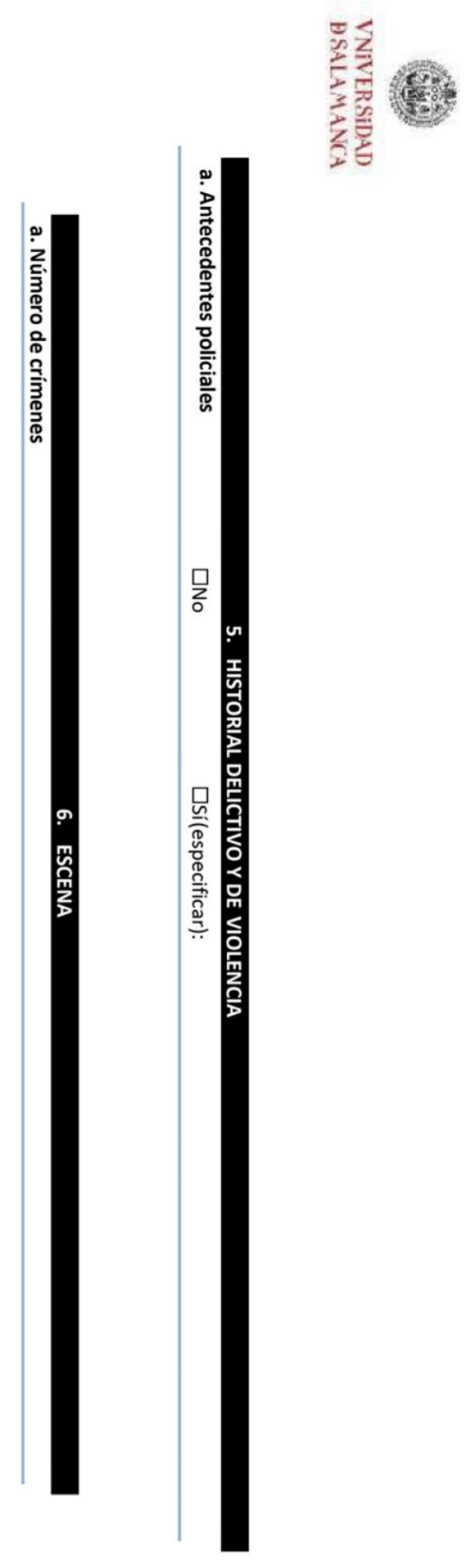




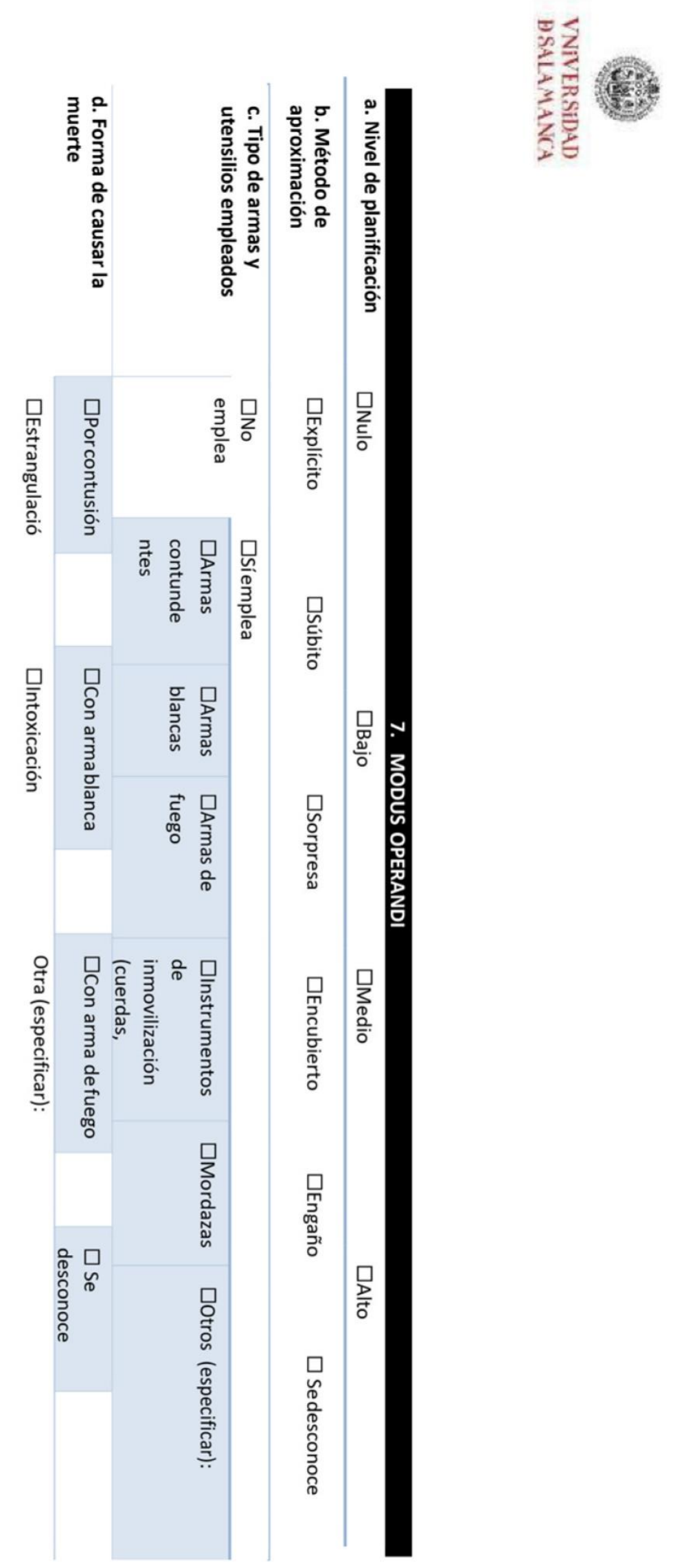




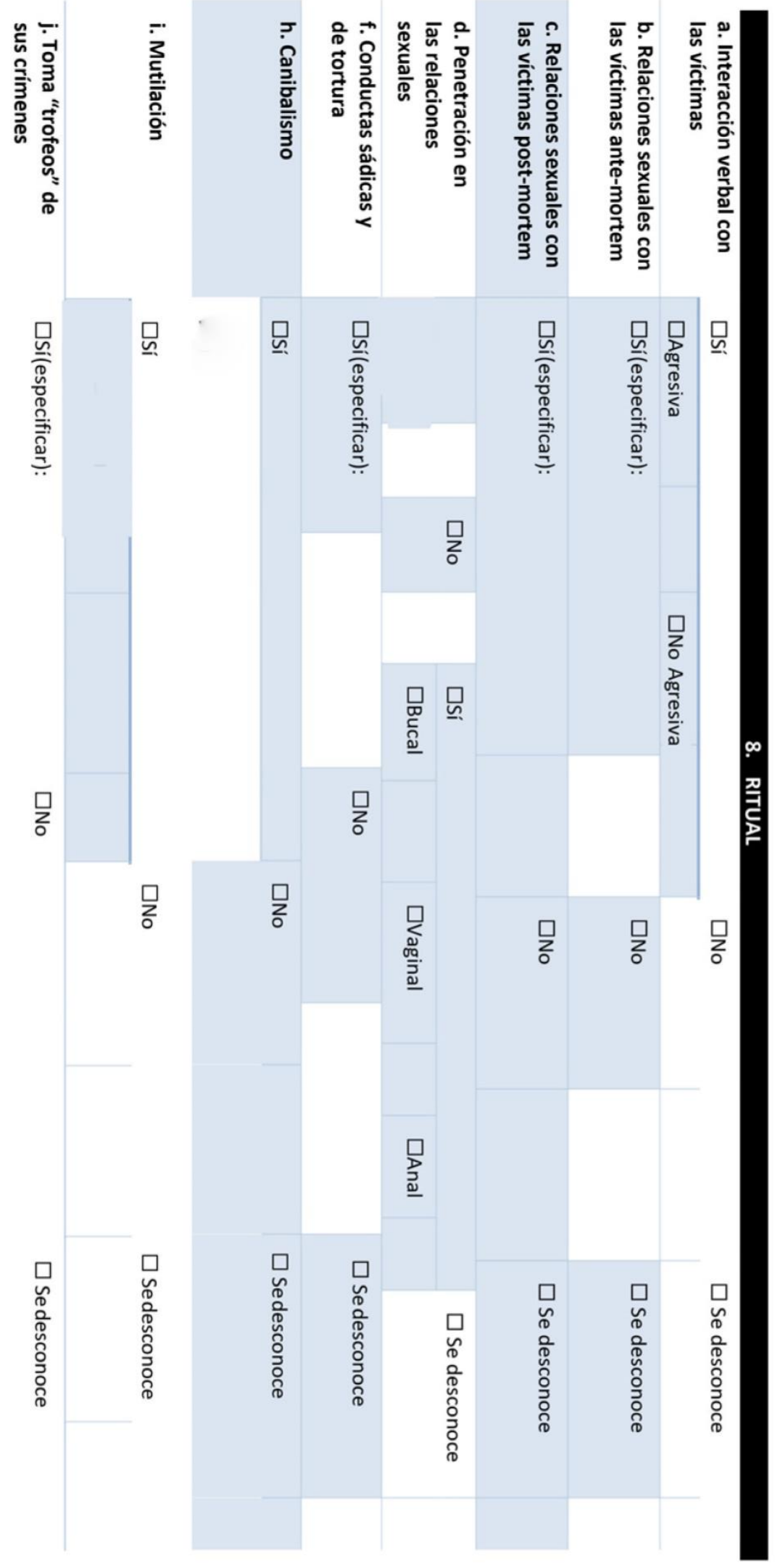




$$
1
$$




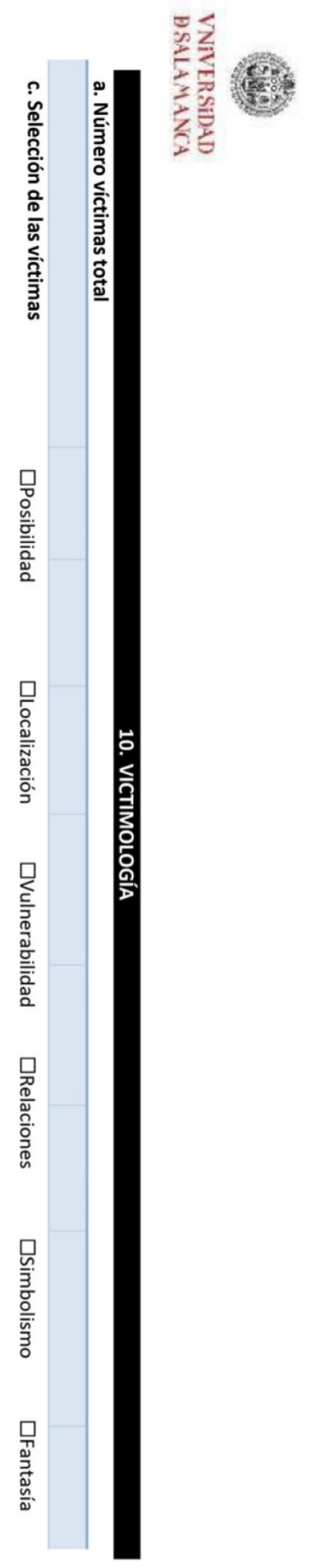




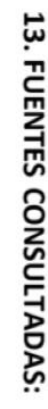

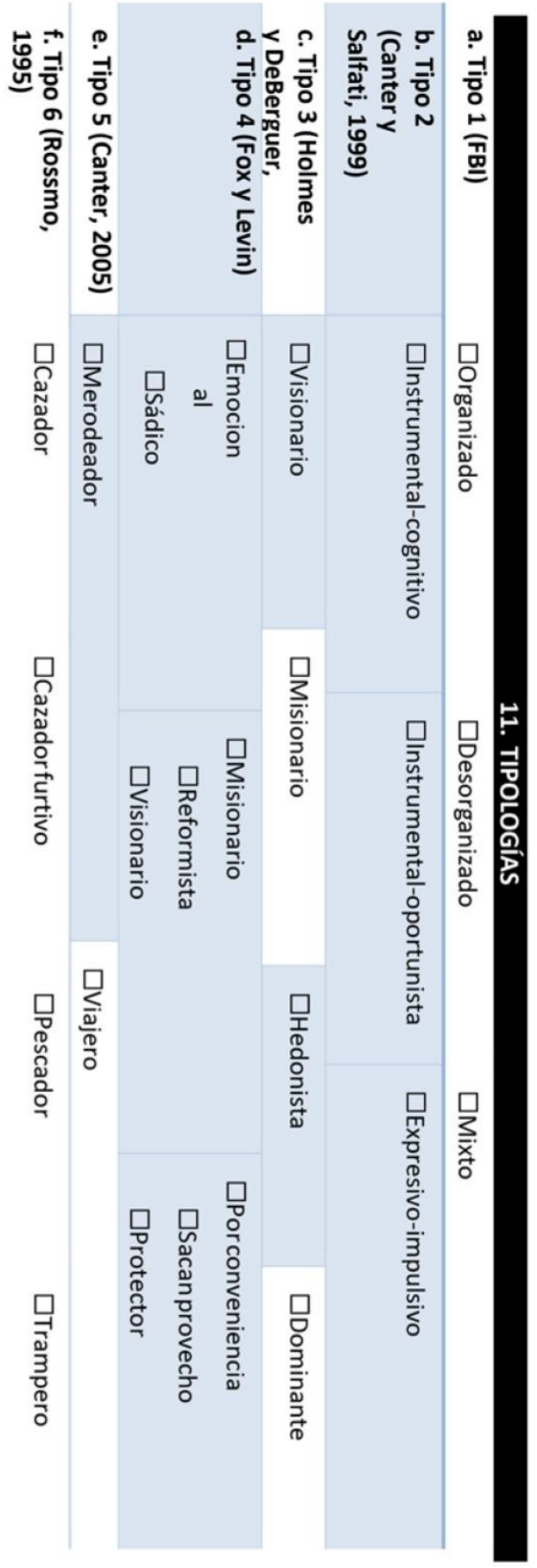




\section{ANEXO 3. FICHA DE VARIABLES PARA EL ESTUDIO INTERNACIONAL}

\section{VARIABLES SOCIODEMOGRÁFICAS Y FÍSICAS}

1. Nombre:

2. Sexo:

3. Edad inicio asesinatos:

4. País de procedencia:

\section{VARIABLES PSICOLÓGICAS}

5. Rasgos psicopáticos:

NO

SI

- $\quad$ Falta de empatía

- Manipulación mentira

- Versatilidad criminal

- $\quad$ Falta de responsabilidad

- $\quad$ Encanto superficial

- $\quad$ Egocentrismo y elevada autovalía

- Impulsividad

- $\quad$ Falta de culpa

- $\quad$ Estilo de vida parasitario

- $\quad$ Promiscuidad sexual

- Superficialidad afectiva 


\section{ANTECEDENTES INFANCIA Y ADOLESCENCIA}

6. Algún tipo de maltrato:

NO

SI

SE DESCONOCE

\section{ESCENA}

7. Número de crímenes:

MODUS OPERANDI

8. Nivel de planificación:

Nulo

Bajo

Medio

Alto

9. Forma de causar la muerte

-Por contusión

- Estrangulación

- Con arma blanca

- Intoxicación

- Con arma de fuego

- Otra

- Se desconoce 
RITUAL

10. Relaciones sexuales con las víctimas ante mortem

SI

NO

SE DESCONOCE

11. Relaciones sexuales con las víctimas post-mortem

SI

NO

SE DESCONOCE

\section{TIPOLOGÍAS}

12. Tipología FBI:

Organizado

Desorganizado

Mixto 